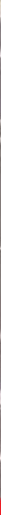

\author{
IntechOpen
}

\title{
Modeling and Optimization of Renewable Energy Systems
}

Edited by Arzu Sencan Sahin
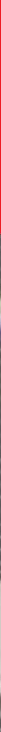



\section{MODELING AND OPTIMIZATION OF RENEWABLE ENERGY SYSTEMS}

Edited by Arzu Şencan Şahin 
Modeling and Optimization of Renewable Energy Systems

http://dx.doi.org/10.5772/2283

Edited by Arzu Sencan Sahin

\section{Contributors}

Ali Baghernejad, Pavel Fuksa, Josef Hakl, Zuzana Hrevušová, Jaromír Šantrůček, Ilona Gerndtová, Jan Habart, Blanca Moreno, Maria Teresa García-Álvarez, Karim Bourouni, Hamidreza Akhondi, Mostafa Saifali, Zhaohong Fang, Marcin Wilk, Thomas Hammons, Laia Ferrer-Marti, Enrique Velo, Rafael Escobar, David Vilar, Bruno Domenech, Feyza Akarslan, Rafic Younes

\section{(c) The Editor(s) and the Author(s) 2012}

The moral rights of the and the author(s) have been asserted.

All rights to the book as a whole are reserved by INTECH. The book as a whole (compilation) cannot be reproduced, distributed or used for commercial or non-commercial purposes without INTECH's written permission.

Enquiries concerning the use of the book should be directed to INTECH rights and permissions department (permissions@intechopen.com).

Violations are liable to prosecution under the governing Copyright Law.

\section{(cc) BY}

Individual chapters of this publication are distributed under the terms of the Creative Commons Attribution 3.0 Unported License which permits commercial use, distribution and reproduction of the individual chapters, provided the original author(s) and source publication are appropriately acknowledged. If so indicated, certain images may not be included under the Creative Commons license. In such cases users will need to obtain permission from the license holder to reproduce the material. More details and guidelines concerning content reuse and adaptation can be foundat http://www.intechopen.com/copyright-policy.html.

\section{Notice}

Statements and opinions expressed in the chapters are these of the individual contributors and not necessarily those of the editors or publisher. No responsibility is accepted for the accuracy of information contained in the published chapters. The publisher assumes no responsibility for any damage or injury to persons or property arising out of the use of any materials, instructions, methods or ideas contained in the book.

First published in Croatia, 2012 by INTECH d.o.o.

eBook (PDF) Published by IN TECH d.o.o.

Place and year of publication of eBook (PDF): Rijeka, 2019.

IntechOpen is the global imprint of IN TECH d.o.o.

Printed in Croatia

Legal deposit, Croatia: National and University Library in Zagreb

Additional hard and PDF copies can be obtained from orders@intechopen.com

Modeling and Optimization of Renewable Energy Systems

Edited by Arzu Sencan Sahin

p. cm.

ISBN 978-953-51-0600-5

eBook (PDF) ISBN 978-953-51-6205-6 


\section{We are IntechOpen, \\ the world's leading publisher of Open Access books}

Built by scientists, for scientists

\section{$4,000+$ \\ Open access books available \\ $116,000+$ \\ International authors and editors

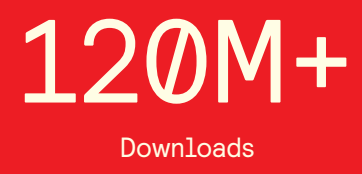

Our authors are among the

151

Countries delivered to

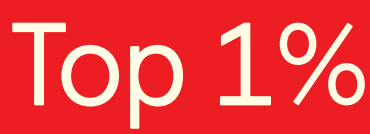

most cited scientists

Contributors from top 500 universities

$12.2 \%$

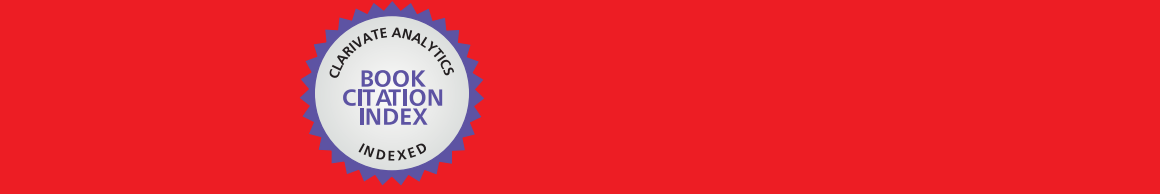

WEB OF SCIENCE ${ }^{\mathrm{M}}$

Selection of our books indexed in the Book Citation Index in Web of Science ${ }^{\mathrm{TM}}$ Core Collection (BKCI)

\section{Interested in publishing with us? \\ Contact book.department@intechopen.com}





\section{Meet the editor}

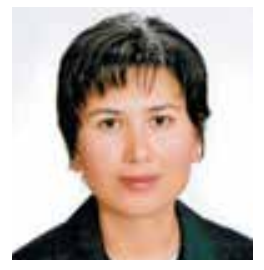

Dr Arzu Şencan Şahin was born in Manisa/TURKEY in 1975. She received his Bachelor's Degree, Master Degree and Ph.D.from Süleyman Demirel University Mechanical Engineering in the years 1996, 1999 and 2004 respectively. Her area of interest is renewable energy, heat transfer, thermodynamic. She has published / presented many research papers in reputed international and national journals and conferences. 



\section{Contents}

Preface XI

Chapter 1 Solar-Energy Drying Systems 1

Feyza Akarslan

Chapter 2 Photovoltaic Systems and Applications 21

Feyza Akarslan

Chapter 3 A New Adaptive Method for Distribution

System Protection Considering Distributed

Generation Units Using Simulated Annealing Method 53

Hamidreza Akhondi and Mostafa Saifali

Chapter 4 Exergoeconomic Analysis and

Optimization of Solar Thermal Power Plants 65

Ali Baghernejad and Mahmood Yaghoubi

Chapter 5 Optimization of

Renewable Energy Systems: The Case of Desalination 89

Karim Bourouni

Chapter 6 Heat Transfer Modeling of

the Ground Heat Exchangers for

the Ground-Coupled Heat Pump Systems 117

Yi Man, Ping Cui and Zhaohong Fang

Chapter 7 Promoting and Improving Renewable

Energy Projects Through Local Capacity Development 147

Rafael Escobar, David Vilar,

Enrique Velo, Laia Ferrer-Martí and

Bruno Domenech

Chapter 8 Utilization of Permanent

Grassland for Biogas Production 171

Pavel Fuksa, Josef Hakl,

Zuzana Hrevušová, Jaromír Šantrůček,

Ilona Gerndtová and Jan Habart 
Chapter 9 Globalization of the Natural Gas Market on Natural Gas Prices in Electric Power Generation and Energy Development 197 Thomas J. Hammons

Chapter 10 An Analysis of the Effect of Renewable Energies on Spanish Electricity Market Efficiency 239

Blanca Moreno and María Teresa García-Álvarez

Chapter 11 Modernization and Intensification of Nitric Acid Plants 259 Marcin Wilk, Andrzej Kruszewski, Marcin Potempa, Romuald Jancewicz, Jacek Mendelewski, Paweł Sławiński, Marek Inger and Jan Nieścioruk

\section{Chapter 12 Optimal Design of an Hybrid Wind-Diesel System with Compressed Air Energy Storage for Canadian Remote Areas 269 \\ Younes Rafic, Basbous Tammam and Ilinca Adrian}




\section{Preface}

Energy needs are continuously increasing and the demand for electrical power continues to grow rapidly. The world energy market has to date depended almost entirely on nonrenewable, but low cost, fossil fuels.

Renewable energy is the inevitable choice for sustainable economic growth, for the harmonious coexistence of human and environment as well as for the sustainable development. As we learn how to economically harness the renewable energy sources, they will get cheaper and cheaper while fossil fuels get more and more expensive. A wind, solar or geothermal power plant may be more expensive to build now than a fossil power plant, but the future cost of fuel will be zero. In addition, the effects of the pollution fossil fuels produce become more and more destructive. The cost of controlling these pollutants is growing every day.

Arzu Şencan Şahin

Süleyman Demirel University, Technology Faculty, Energy System Engineering, Isparta, 



\title{
Solar-Energy Drying Systems
}

\author{
Feyza Akarslan \\ Department of Textile Engineering, Engineering and Architectural Faculty, \\ Süleyman Demirel Univercity, Isparta \\ Turkey
}

\section{Introduction}

Energy is important for the existence and development of humankind and is a key issue in international politics, the economy, military preparedness, and diplomacy. To reduce the impact of conventional energy sources on the environment, much attention should be paid to the development of new energy and renewable energy resources. Solar energy, which is environment friendly, is renewable and can serve as a sustainable energy source. Hence, it will certainly become an important part of the future energy structure with the increasingly drying up of the terrestrial fossil fuel. However, the lower energy density and seasonal doing with geographical dependence are the major challenges in identifying suitable applications using solar energy as the heat source. Consequently, exploring high efficiency solar energy concentration technology is necessary and realistic (Xie et al., 2011).

Solar energy is free, environmentally clean, and therefore is recognized as one of the most promising alternative energy recourses options. In near future, the large-scale introduction of solar energy systems, directly converting solar radiation into heat, can be looked forward. However, solar energy is intermittent by its nature; there is no sun at night. Its total available value is seasonal and is dependent on the meteorological conditions of the location. Unreliability is the biggest retarding factor for extensive solar energy utilization. Of course, reliability of solar energy can be increased by storing its portion when it is in excess of the load and using the stored energy whenever needed. (Bal et al., 2010).

Solar drying is a potential decentralized thermal application of solar energy particularly in developing countries (Sharma et al., 2009). However, so far, there has been very little field penetration of solar drying technology. In the initial phase of dissemination, identification of suitable areas for using solar dryers would be extremely helpful towards their market penetration.

Solar drying is often differentiated from "sun drying" by the use of equipment to collect the sun's radiation in order to harness the radiative energy for drying applications. Sun drying is a common farming and agricultural process in many countries, particularly where the outdoor temperature reaches $30{ }^{\circ} \mathrm{C}$ or higher. In many parts of South East Asia, spice $\mathrm{s}$ and herbs are routinely dried. However, weather conditions often preclude the use of sun drying 
because of spoilage due to rehydration during unexpected rainy days. Furthermore, any direct exposure to the sun during high temperature days might cause case hardening, where a hard shell develops on the outside of the agricultural products, trapping moisture inside. Therefore, the employment of solar dryer taps on the freely available sun energy while ensuring good product quality via judicious control of the radiative heat. Solar energy has been used throughout the world to dry products. Such is the diversity of solar dryers that commonly solar-dried products include grains, fruits, meat, vegetables and fish. A typical solar dryer improves upon the traditional open-air sun system in five important ways (Sharma et al., 2009):

- It is faster. Matetrials can be dried in a shorter period of time. Solar dryers enhance drying times in two ways. Firstly, the translucent, or transparent, glazing over the collection area traps heat inside the dryer, raising the temperature of the air. Secondly, the flexibility of enlarging the solar collection area allows for greater collection of the sun's energy.

- It is more efficient. Since materials can be dried more quickly, less will be lost to spoilage immediately after harvest. This is especially true of products that require immediate drying such as freshly harvested grain with high moisture content. In this way, a larger percentage of product will be available for human consumption. Also, less of the harvest will be lost to marauding animals and insects since the products are in safely enclosed compartments.It is hygienic. Since materials are dried in a controlled environment, they are less likely to be contaminated by pests, and can be stored with less likelihood of the growth of toxic fungi.It is healthier. Drying materials at optimum temperatures and in a shorter amount of time enables them to retain more of their nutritional value such as vitamin C. An added bonus is that products will look better, which enhances their marketability and hence provides better financial returns for the farmers.It is cheap. Using freely available solar energy instead of conventional fuels to dry products, or using a cheap supplementary supply of solar heat, so reducing conventional fuel demand can result in significant cost savings.

\section{Classification of drying systems}

All drying systems can be classifed primarily according to their operating temperature ranges into two main groups of high temperature dryers and low temperature dryers. However, dryers are more commonly classifed broadly according to their heating sources into fossil fuel dryers (more commonly known as conventional dryers) and solar-energy dryers. Strictly, all practically-realised designs of high temperature dryers are fossil fuel powered, while the low temperature dryers are either fossil fuel or solar-energy based systems (Ekechukwu and Norton, 1999).

\subsection{High temperature dryers}

High temperature dryers are necessary when very fast drying is desired. They are usually employed when the products require a short exposure to the drying air. Their operating temperatures are such that, if the drying air remains in contact with the product until equilibrium moisture content is reached, serious over drying will occur. Thus, the products are only dried to the required moisture contents and later cooled. High temperature dryers 
are usually classifed into batch dryers and continuous-flow dryers. In batch dryers, the products are dried in a bin and subsequently moved to storage. Thus, they are usually known as batch-in-bin dryers. Continuous-flow dryers are heated columns through which the product flows under gravity and is exposed to heated air while descending. Because of the temperature ranges prevalent in high temperature dryers, most known designs are electricity or fossil-fuel powered. Only a very few practically-realised designs of high temperature drying systems are solar-energy heated (Ekechukwu and Norton, 1999).

\subsection{Low temperature dryers}

In low temperature drying systems, the moisture content of the product is usually brought in equilibrium with the drying air by constant ventilation. Thus, they do tolerate intermittent or variable heat input. Low temperature drying enables products to be dried in bulk and is most suited also for long term storage systems. Thus, they are usually known as bulk or storage dryers. Their ability to accommodate intermittent heat input makes low temperature drying most appropriate for solar-energy applications. Thus, some conventional dryers and most practically-realised designs of solar-energy dryers are of the low temperature type(Ekechukwu and Norton, 1999).

\section{Types of solar driers}

Solar-energy drying systems are classified primarily according to their heating modes and the manner in which the solar heat is utilised.

In broad terms, they can be classified into two major groups, namely (Ekechukwu and Norton, 1999):

- $\quad$ active solar-energy drying systems (most types of which are often termed hybrid solar dryers); and

- $\quad$ passive solar-energy drying systems (conventionally termed natural-circulation solar drying systems).

Three distinct sub-classes of either the active or passive solar drying systems can be identified which vary mainly in the design arrangement of system components and the mode of utilisation of the solar heat, namely (Ekechukwu and Norton, 1999):

- $\quad$ Direct (integral) type solar dryers;

- Indirect (distributed) type solar dryers.

Direct solar dryers have the material to be dried placed in an enclosure, with a transparent cover on it. Heat is generated by absorption of solar radiation on the product itself as well as on the internal surfaces of the drying chamber. In indirect solar dryers, solar radiation is not directly incident on the material to be dried. Air is heated in a solar collector and then ducted to the drying chamber to dry the product. Specialized dryers are normally designed with a specific product in mind and may include hybrid systems where other forms of energy are also used (Sharma et al., 2009). Although indirect dryers are less compact when compared to direct solar dryers, they are generally more efficient. Hybrid solar systems allow for faster rate of drying by using other sources of heat energy to supplement solar heat. 
The three modes of drying are: (i) open sun, (ii) direct and (iii) indirect in the presence of solar energy. The working principle of these modes mainly depends upon the method of solar-energy collection and its conversion to useful thermal energy.

\subsection{Open sun drying (OSD)}

Fig. 1 shows the working principle of open sun drying by using solar energy. The short wavelength solar energy falls on the uneven product surface. A part of this energy is reflected back and the remaining part is absorbed by the surface. The absorbed radiation is converted into thermal energy and the temperature of product stars increasing. This result in long wavelength radiation loss from the surface of product to ambient air through moist air. In addition to long wavelength radiation loss there is convective heat loss too due to the blowing wind through moist air over the material surface. Evaporation of moisture takes place in the form of evaporative losses and so the material is dried. Further a part of absorbed thermal energy is conducted into the interior of the product. This causes a rise in temperature and formation of water vapor inside the material and then diffuses towards the surface of the and finally losses thermal energy in the and then diffuses towards the surface of the and finally losses the thermal energy in the form of evaporation. In the initial stages, the moisture removal is rapid since the excess moisture on the surface of the product presents a wet surface to the drying air. Subsequently, drying depends upon the rate at which the moisture within the product moves to the surface by a diffusion process depending upon the type of the product (Sodha, 1985).

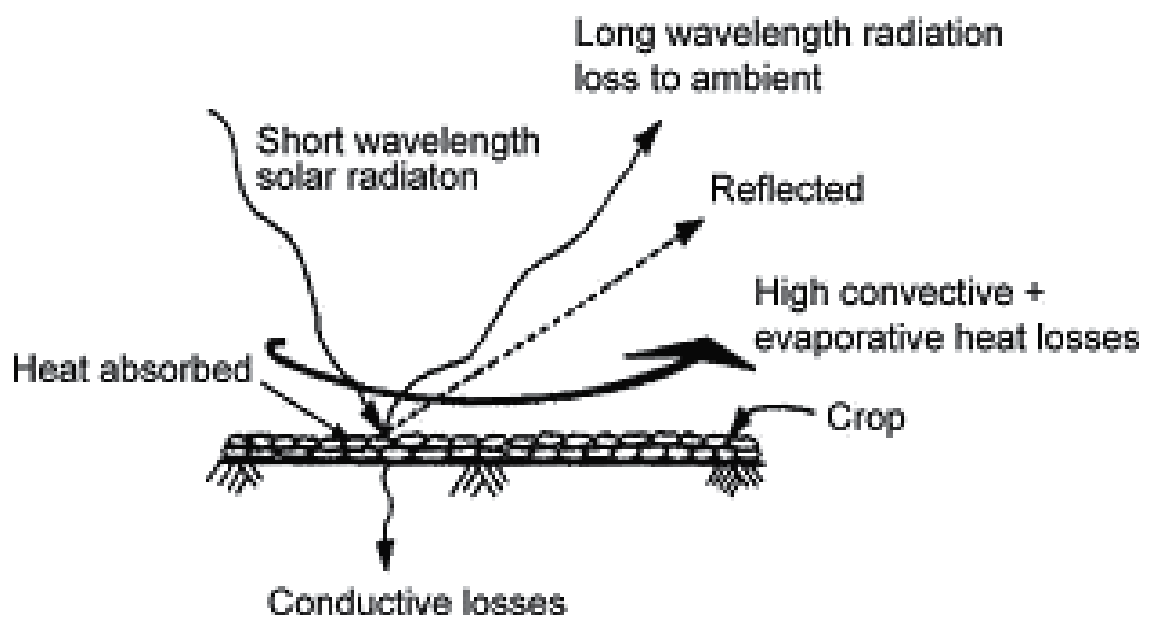

Fig. 1. Working principle of open sun drying.

In open sun drying, there is a considerable loss due to various reasons such as rodents, birds, insects and micro-organisms. The unexpected rain or storm further worsens the situation. Further, over drying, insufficient drying, contamination by foreign material like dust dirt, insects, and micro-organism as well discolouring by UV radiation are characteristic for open sun drying. In general, open sun drying does not fulfill the international quality standards and therefore it cannot be sold in the international market (Sharma et al., 2009). 
With the awareness of inadequacies involved in open sun drying, a more scientific method of solar-energy utilization for drying has emerged termed as controlled drying or solar drying.

The main features of typical designs of the direct an of indirect types solar -energy dryers are illustrated in Table 1.

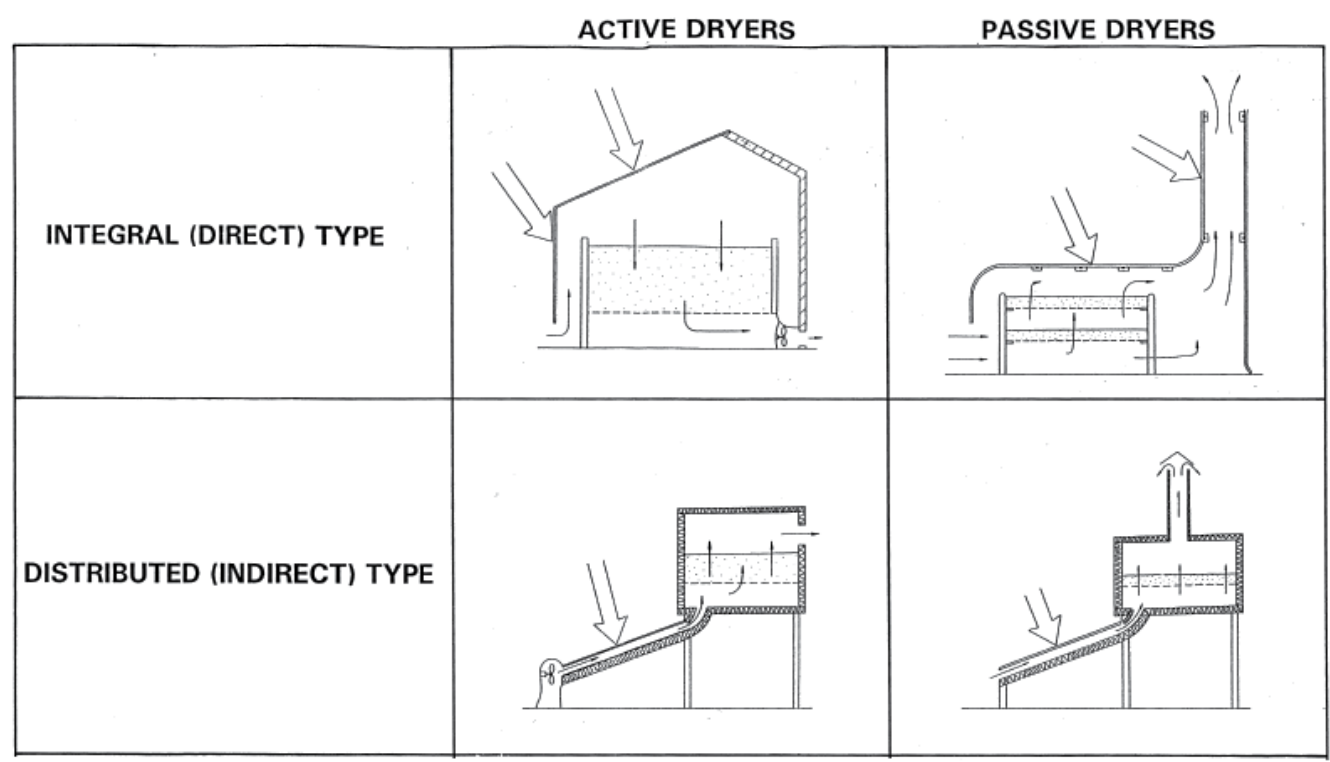

Table 1. Typical solar energy dryer designs (Ekechukwu and Norton, 1999).

\subsection{Direct type solar drying (DSD)}

Direct solar drying is also called natural convection cabinet dryer. Direct solar dryers use only the natural movement of heated air. A part of incidence solar radiation on the glass cover is reflected back to atmosphere and remaining is transmitted inside cabin dryer. Further, a part of transmitted radiation is reflected back from the surface of the product. The remaining part is absorbed by the surface of the material. Due to the absorption of solar radiation, product temperature increase and the material starts emitting long wavelength radiation which is not allowed to escape to atmosphere due to presence of glass cover unlike open sun drying. Thus the temperature above the product inside chamber becomes higher. The glass cover server one more purpose of reducing direct convective losses to the ambient which further become beneficial for rise in product and chamber temperature respectively (Sharma et al., 2009). However, convective and evaporative losses ocur insidethe chamber from the heated material. The moisture is takenaway by the air entering into the chamber from below and escaping through another opening provide at the top as shown in Fig. 2. A direct solar dryer is one in which the material is directly exposed to the sun's rays. This dryer comprises of a drying chamber that is covered by a transparent cover made of glass or plastic. The drying chamber is usually a shallow, insulated box with air-holes in it to allow air to enter and exit the box. The product samples are placed on a perforated tray that allows the air to flow through it and the material. Fig. 2 shows a schematic of a simple direct dryer (Murthy, 2009). Solar radiation passes through the transparent cover and is converted to low-grade heat when it strikes an 
opaque wall. This low-grade heat is then trapped inside the box by what is known as the "greenhouse effect." Simply stated, the short wavelength solar radiation can penetrate the transparent cover. Once converted to low-grade heat, the energy radiates.

Ekechukwu and Norton (1999) reported a modifcation of the typical design. This cabinet dryer (Fig. 3) was equipped with a wooden plenum to guide the air inlet and a long plywood chimney to enhance natural-circulation. This dryer was reported to have accelerated the drying rate about ${ }^{\circledR} v e$ times over open sun drying.

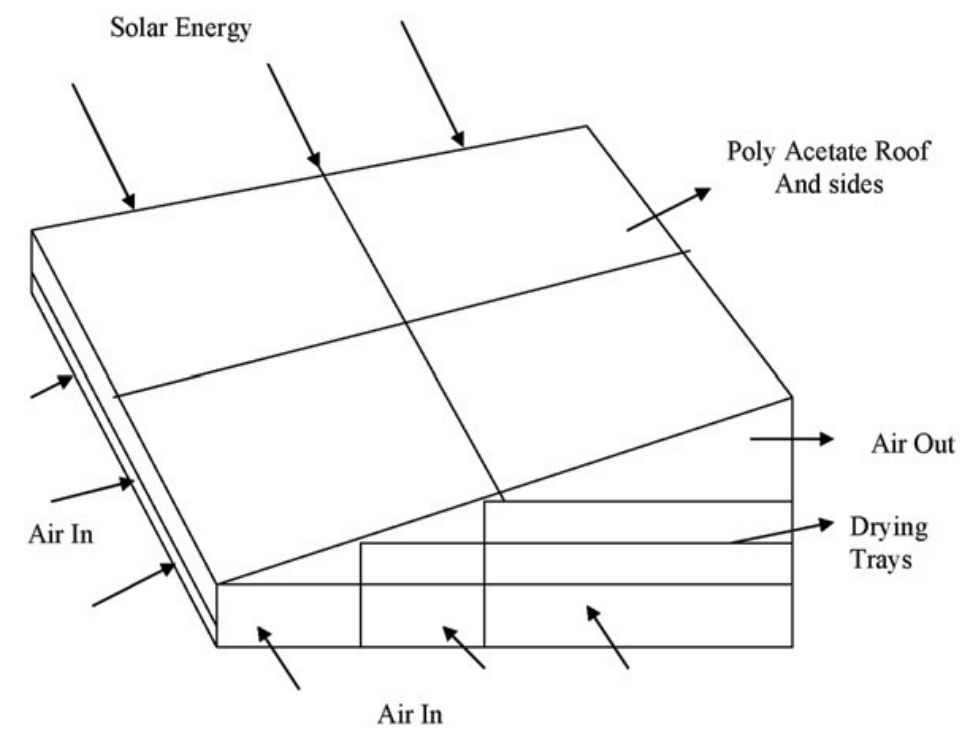

Fig. 2. Direct solar drying (Natural convection type cabinet drier).

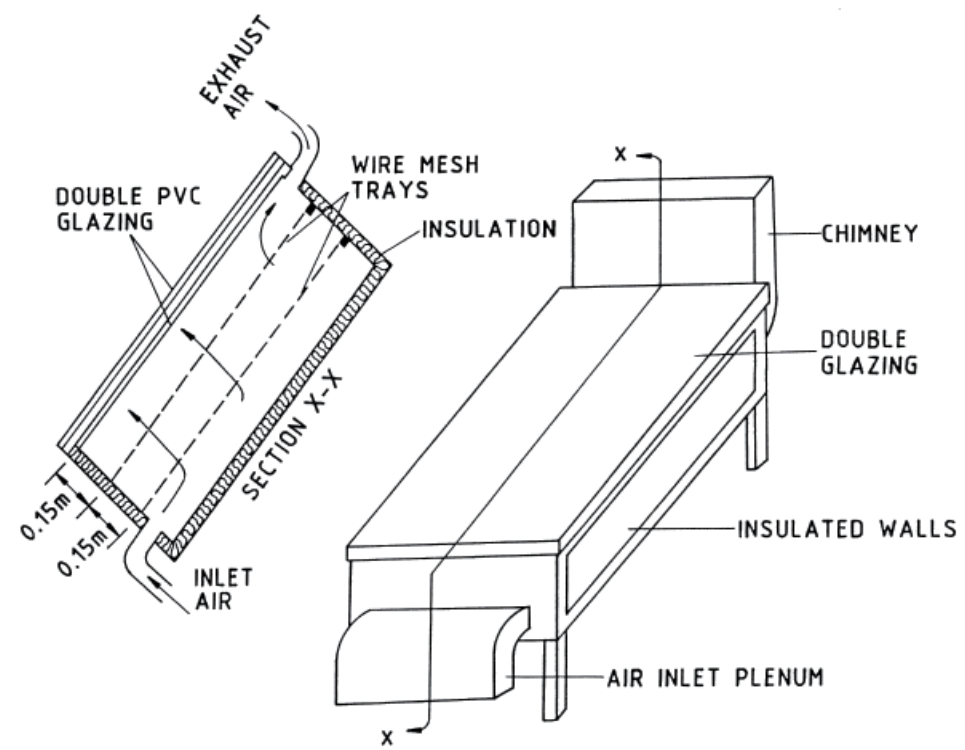

Fig. 3. A modifed natural-circulation solar-energy cabinet dryer. 


\subsection{Indirect type solar drying (ISD)}

The is not directly exposed to solar radiation to minimize discolouration and cracking on the surface of the . Goyal and Tiwari (1999) have proposed and analyzed reverse absorber cabinet dryer (RACD). The schematic view of RACD is shown in Fig. 4. The drying chamber is used for keeping the in wire mesh tray. A downward facing absorber is fixed below the drying chamber at a sufficient distance from the bottom of the drying chamber. A cylindrical reflector is placed under the absorber fitted with the glass cover on its aperture to minimize convective heat losses from the absorber. The absorber can be selectively coated. The inclination of the glass cover is taken as $45^{\circ}$ from horizontal to receive maximum radiation. The area of absorber and glass cover are taken equal to the area of bottom of drying chamber. Solar radiation after passing through the glass cover is reflected by cylindrical reflector toward a absorber. After absorber, a part of this is lost to ambient through a glass cover and remaining is transferred to the flowing air above it by convection. The flowing air is thus heated and passes through the placed in the drying chamber. The is heated and moisture is removed through a vent provided at the top of drying chamber (Sharma et al., 2009).

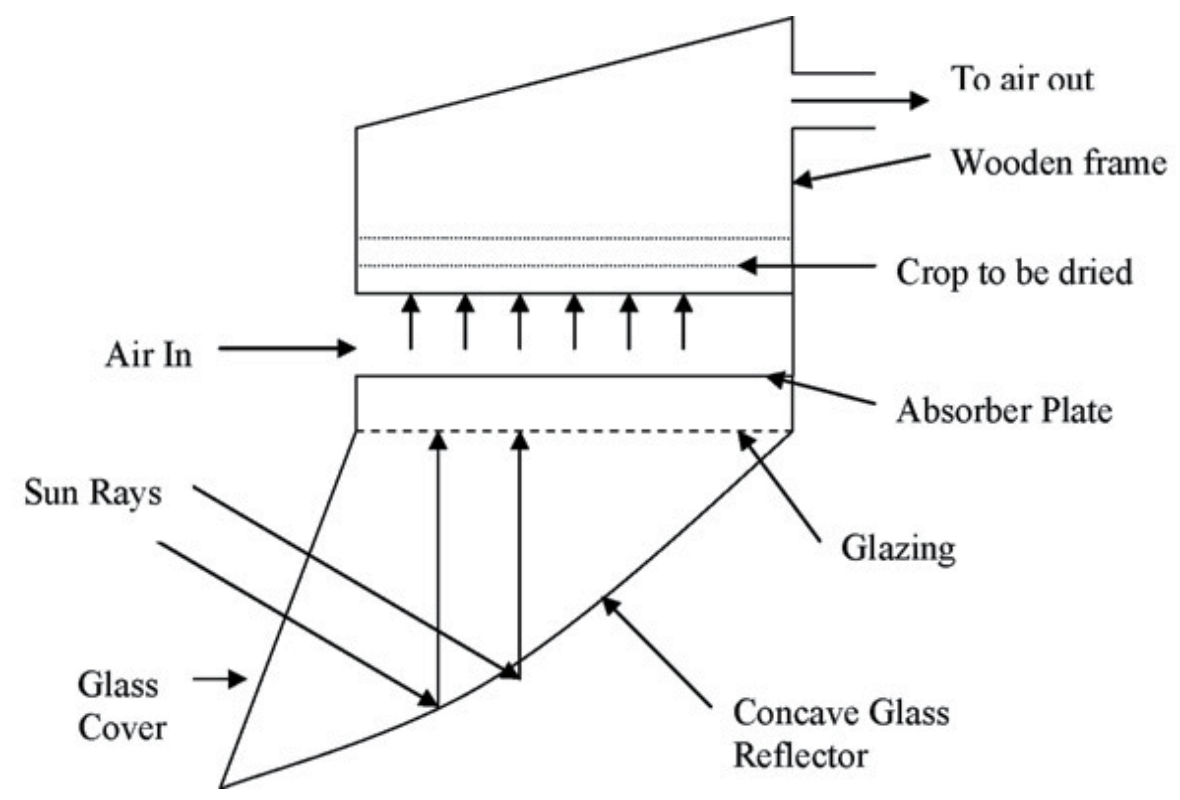

Fig. 4. Reverse absorber cabinet drier.

Fig. 5 describes another principle of indirect solar drying which is generally known as conventional dryer. In this case, a separate unit termed as solar air heater is used for solarenergy collection for heating of entering air into this unit. The air heater is connected to a separate drying chamber where the product is kept. The heated air is allowed to flow through wet material. Here, the heat from moisture evaporation is provided by convective heat transfer between the hot air and the wet material. The drying is basically by the difference in moisture concentration between the drying air and the air in the vicinity of product surface. A better control over drying is achieved in indirect type of solar drying systems and the product obtained is good quality. 


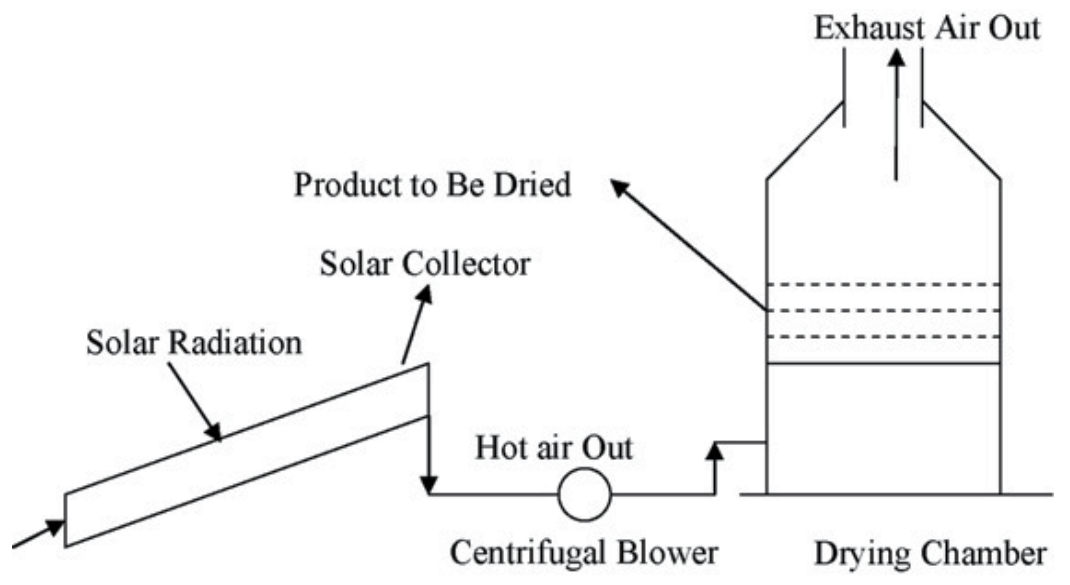

Ambient Air In

Fig. 5. İndirect solar drier ( Forced convection solar drier)

There are several types of driers developed to serve the various purposes of drying products as per local need and available technology. The best potential and popular ones are natural convection cabinet type, forced convection indirect type and green house type. Apart from the above three, as seen from the literature, "Solar tunnel drier" is also found to be popular. These conventional types are shown in Figs 6-7.

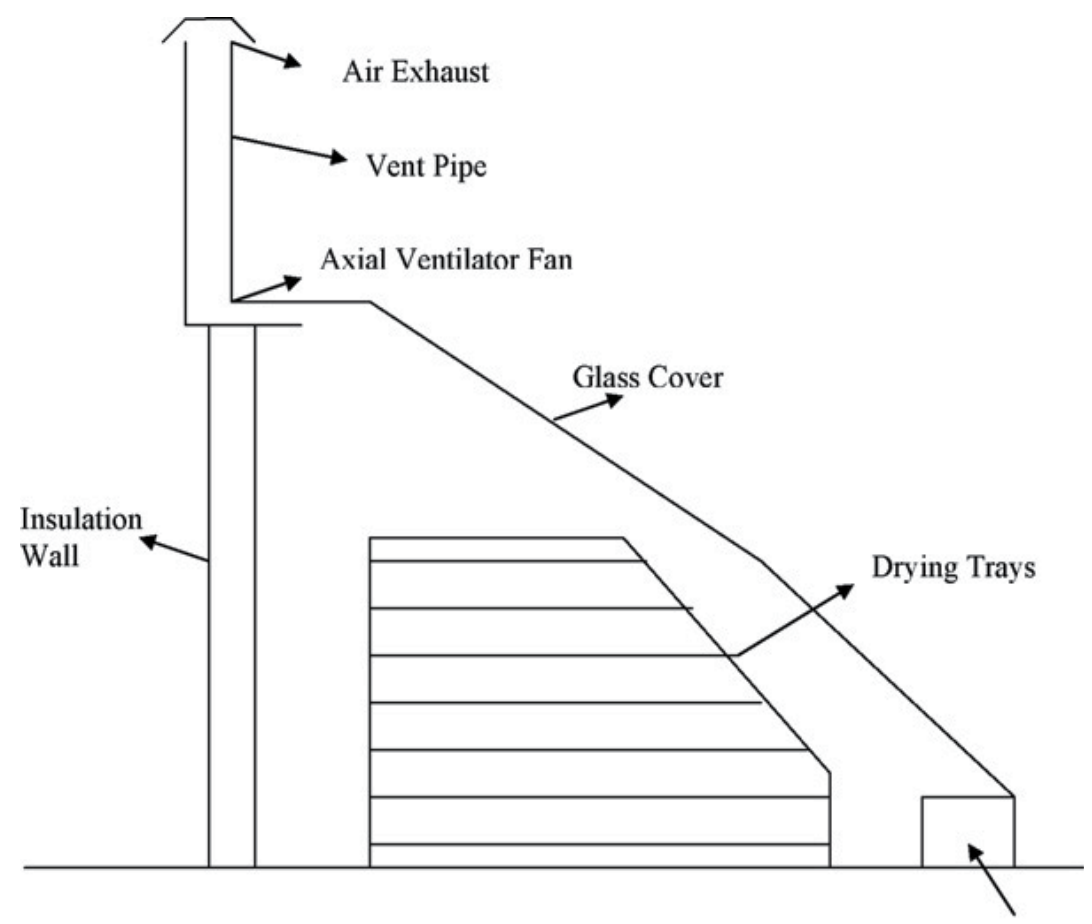

Fresh Air In

Fig. 6. Green house type solar drier. 


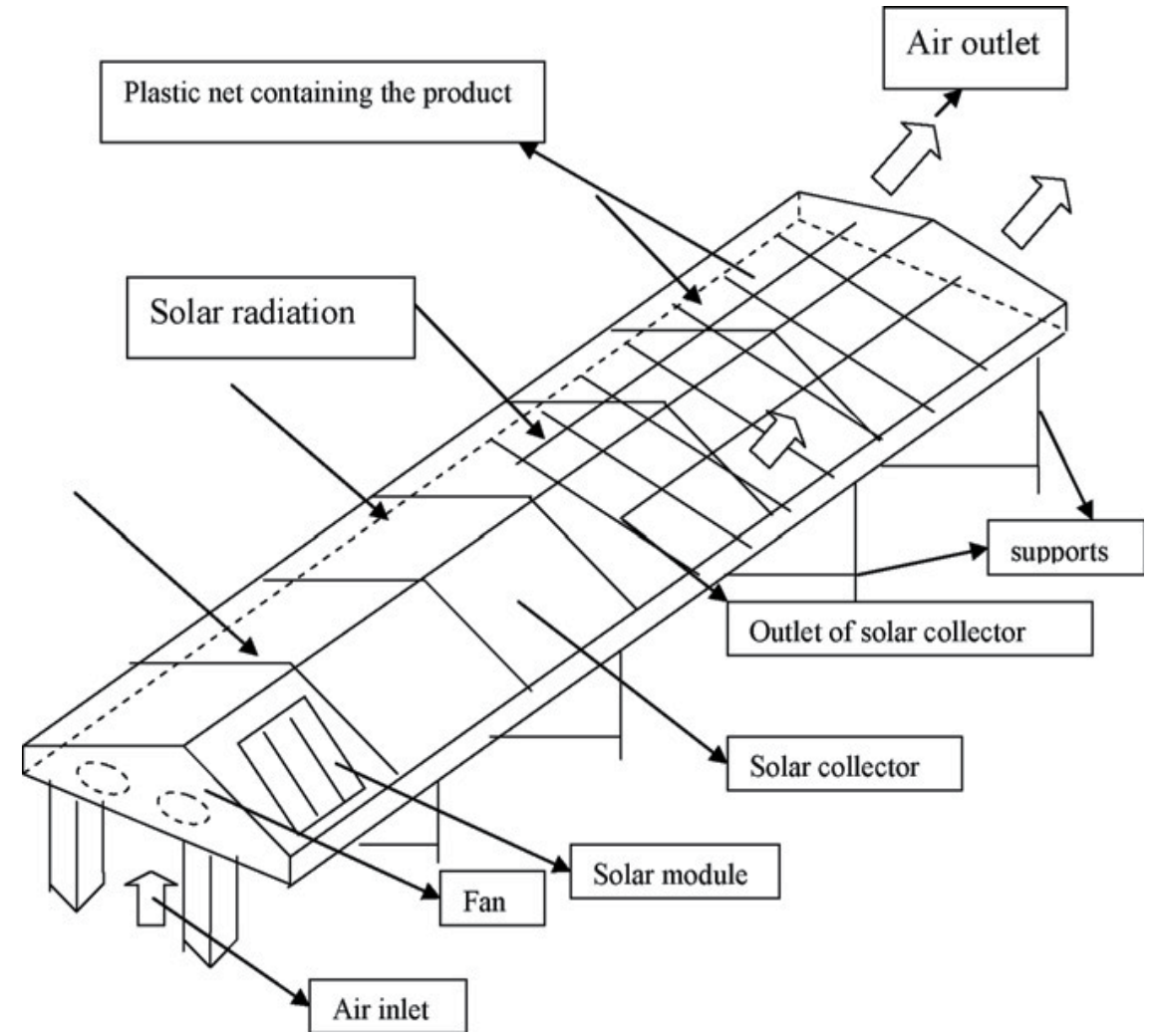

Fig. 7. Solar tunnel drier.

Apart from the obvious advantages of passive solar-energy dryers over the active types (for applications in rural farm locations in developing countries), the advantages of the naturalcirculation solar-energy "ventilated green house dryer" over other passive solar-energy dryer designs include its low cost and its simplicity in both on-the-site construction and operation. Its major drawback is its susceptibility to damage under very high wind speeds. Table 2 gives aconcise comparison of the integral and distributed natural-circulation solarenergy dryers (Ekechukwu and Norton, 1999).

A multi-shelf portable solar dryer (Singh et al., 2004) is developed. It has four main parts, i.e., multi-tray rack, trays, movable glazing and shading plate (see Fig. 8). The ambient air enters from the bottom and moves up through the material loaded in different trays. After passing through the trays, the air leaves from the top. The multirack is inclined depending upon the latitude of the location. Four layers of black HDP sheet are wrapped around the multi-rack such that heat losses are reduced to ambient air from back and sides.

There are seven perforated trays, which are arranged at seven different levels one above the other. The product to be dried is loaded in these trays. To facilitate loading and unloading, a new concept of movable glazing has been developed. It consists of a movable frame (on castor wheels) and UV stabilized plastic sheet. After loading the product, the movable glazing is fixed with the ulti-tray rack so as to avoid any air leakage. 


\begin{tabular}{|c|c|c|}
\hline & \multicolumn{2}{|l|}{ Type } \\
\hline & Integral & Distributed \\
\hline $\begin{array}{l}\text { Principal modes } \\
\text { of heat transfer to } \\
\text { crop }\end{array}$ & $\begin{array}{l}\text { Radiation (ie. By direct absorption of solar } \\
\text { radiation) and convection (ie. from heated } \\
\text { surrounding air). }\end{array}$ & $\begin{array}{l}\text { Convection from pre-heated air in an air- } \\
\text { heating solar-energy collector. }\end{array}$ \\
\hline Components & Glazed drying chamber and chimney. & $\begin{array}{l}\text { Air-heating solar-energy collector, ducting, } \\
\text { drying chamber and chimney. }\end{array}$ \\
\hline Initial cost & Increasing cost $\ldots \ldots$ & $\underset{\mathrm{C}}{\longrightarrow}$ \\
\hline $\begin{array}{l}\text { Construction, } \\
\text { operation and } \\
\text { maintenance }\end{array}$ & $\begin{array}{l}\text { Simplicity in both construction (ie. On-the- } \\
\text { site construction) and operation. Requires } \\
\text { little maintenance. }\end{array}$ & $\begin{array}{l}\text { Consists of comparatively elaborate } \\
\text { structures, thus requires more capital } \\
\text { investment in materials and large running } \\
\text { costs. More operational difficulties of loading } \\
\text { and occasional stirring of the crop (since } \\
\text { crops are usually dried in relatively deep } \\
\text { layers). }\end{array}$ \\
\hline Efficiency & $\begin{array}{l}\text { Little information on comparison of } \\
\text { performance with distributed-type dryers. } \\
\text { Likely to operate at lower efficiencies due to } \\
\text { its simplicity and less controllability of drying } \\
\text { operations. }\end{array}$ & $\begin{array}{l}\text { Have a tendency to higher efficiency since } \\
\text { individual components can be designed to } \\
\text { optimal performance. }\end{array}$ \\
\hline
\end{tabular}

Table 2. Comparisons of natural-circulation solar-energy dryers

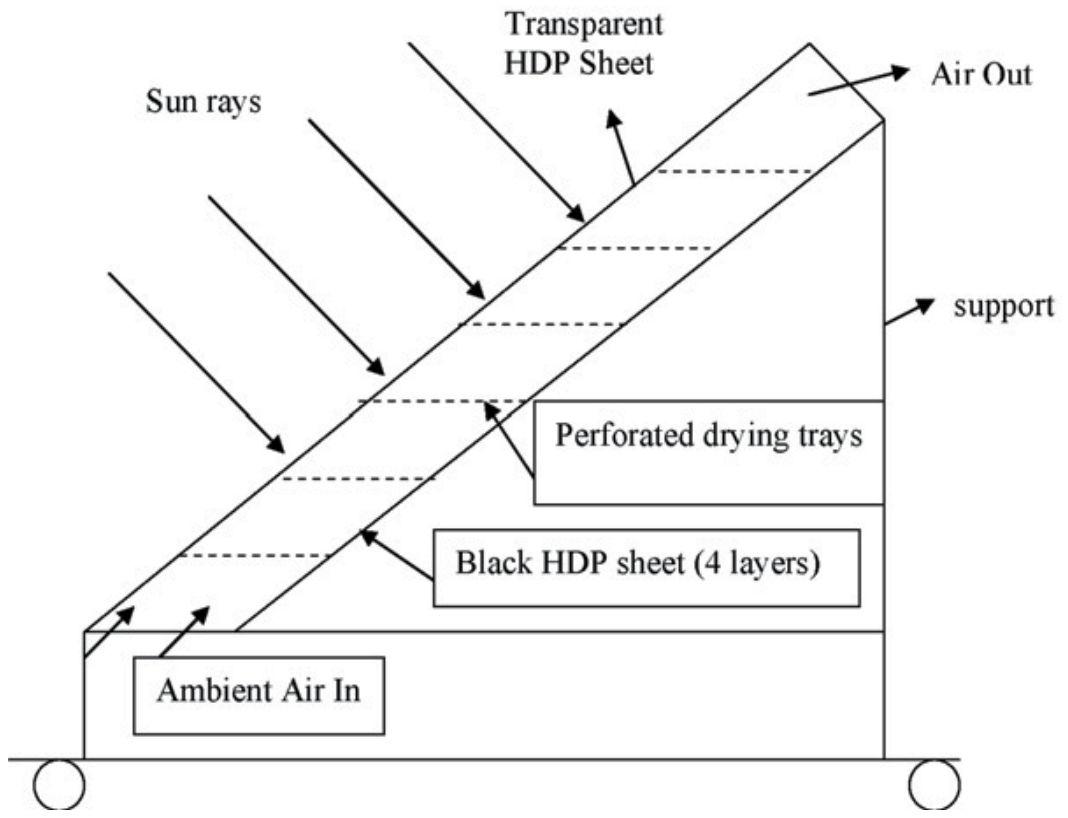

Fig. 8. Multiple-shelf portable solar drier.

A staircase type dryer (Hallak et al., 1996) is developed which is in the shape of a metal staircase with its base and sides covered with doublewalled galvanized metal sheets with a cavity filled with nondegradable thermal insulation (see Fig.9). The upper surface is covered with transparent polycarbon sheet to allow the sun's rays to pass through and be trapped. The upper polycarbon glazed surface is divided into three equal parts which can swing open, to provide access to the three compartment inside the dryer. The base of the dryer has four entry 
points. The partition walls between the compartments also have four port holes for easy air flow. Air moves by natural convection as it enters through the bottom and leaves from the top.

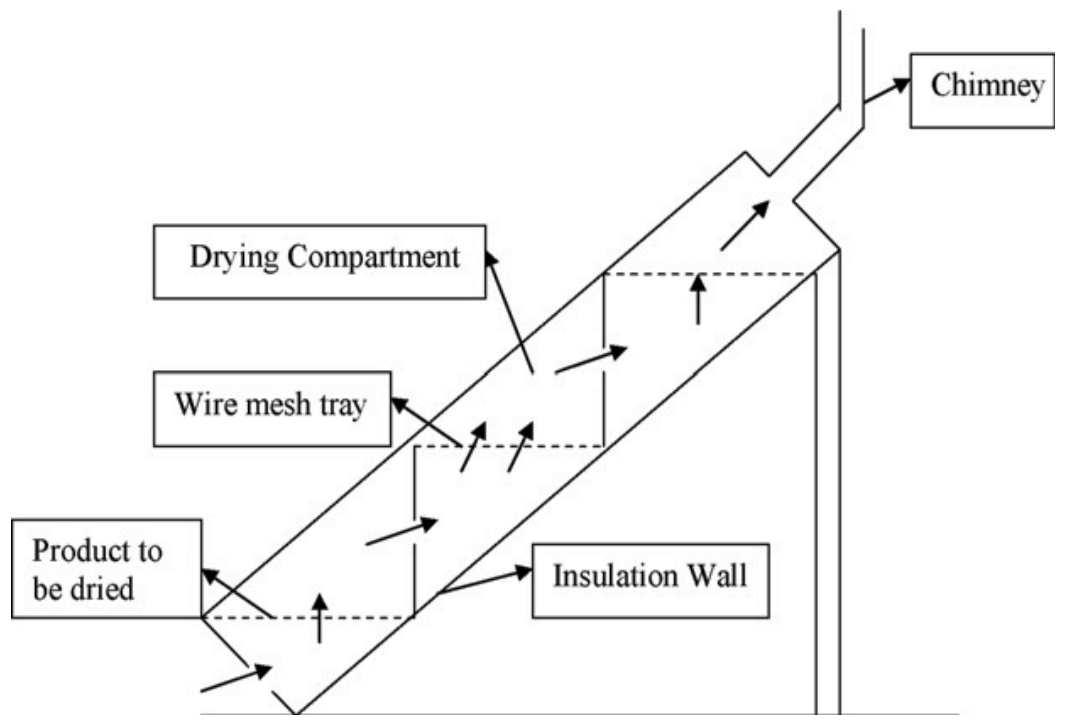

Fig. 9. Staircase solar drier.

Another system called rotary column cylindrical dryer (Sarsilmaz et al., 2000) is developed which contains essentially three parts-air blow region (fan), air heater region (solar collector) and drying region (rotary chamber) (see Fig. 10). A fan with variable speed of air flow rate is connected to the solar collector using a tent fabric. The connection to the dryer or rotary chamber was again through another tent fabric. The dryer is manufactured from wooden plates at the top and bottom and thin ply wood plates at the sides to make cylindrical shape. A rectangular slot is opened on side wall where it faces the solar air heater for the passage of hot air via tent fabric. On the opposite side of this wall a door is provided for loading and unloading of the products. A column is constructed at the center of the rotary chamber to mount the products and the column rotates due to a $12 \mathrm{~V}$ dc motor and a pulley and belt system.

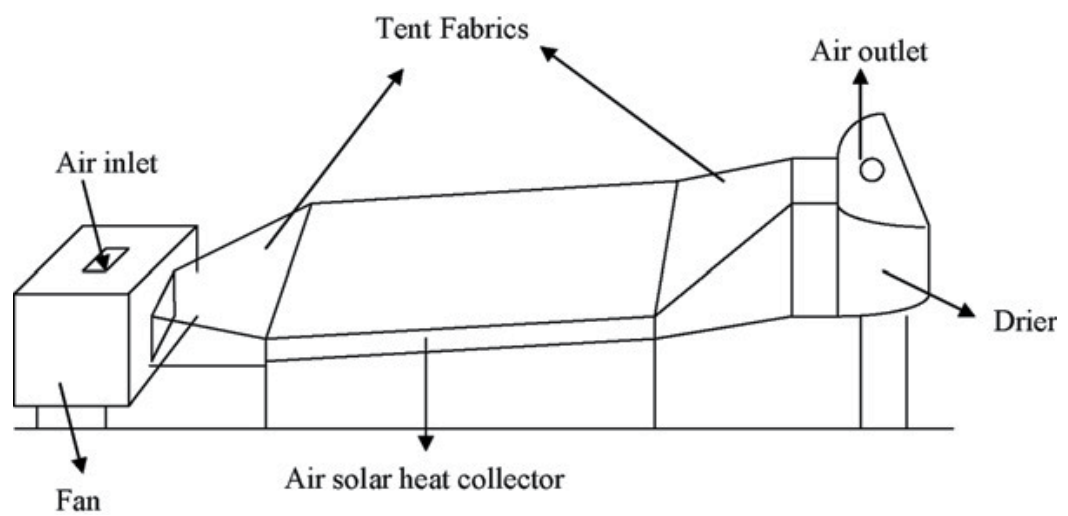

Fig. 10. Rotary column cylindrical drier. 
Other solar assisted drying systems are also developed. The use of V-grooved absorbers improves the heat transfer coefficient between the absorber plate and the air. The present dryer uses collector of the V-groove absorber type (see Fig. 11(a)). A double pass collector is also developed which consists of a porous medium (Othman et al., 2006) in the second pass to store the energy and supply during cloudy weather or in the evenings (see Fig. 11(b)). Some have been improved further by using other methods such as increased convection, etc., which are briefly discussed below.

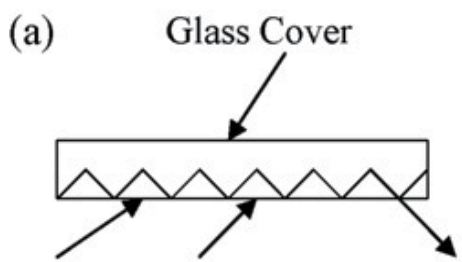

Air inlet V-groove absorber

(b)

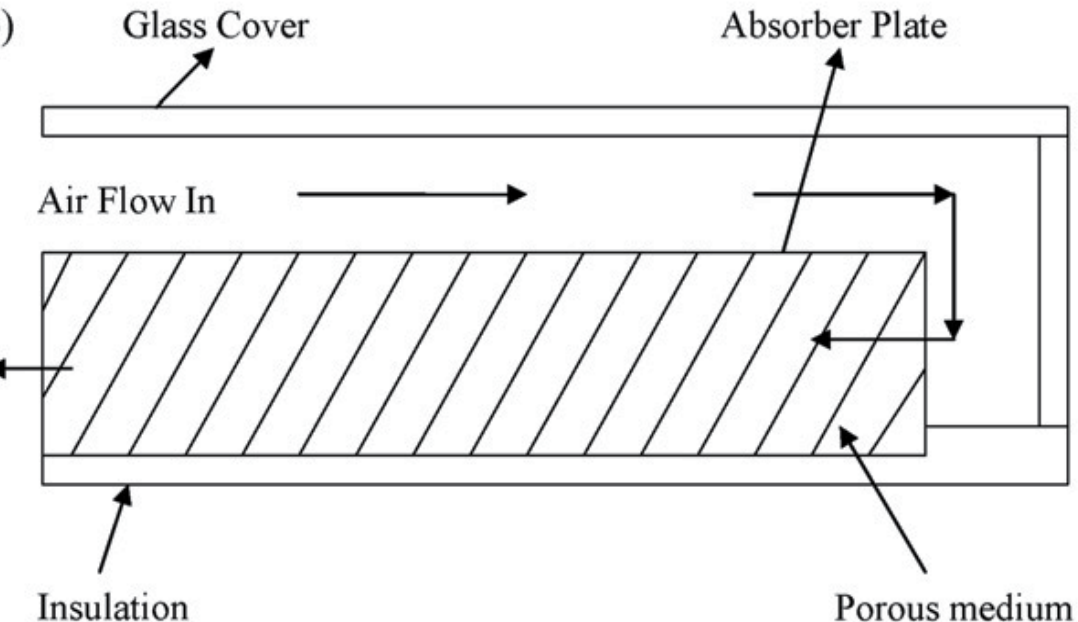

Fig. 11. Solar assisted drying systems.

Since the products need to be spread in a single layer for efficient drying, total tray area available in the dryer for spreading the product is important. In an attempt to acquire the area, the roof top of a farm house has been used as a collector. In extension to this type of drier (Janjai and Tung, 2005), a dual purpose of illuminating the room by providing a low temperature roof integrated solar flat plate air heater is introduced. The heated air is used to dry the product grains spread on perforated plates of aluminum and acrylic, inside the room. The perforation size for groundnut and paddy is calculated. In yet another method, a sun tracking system is used along with a dc driven solar fan (Mumba, 1995) for a controlled heating of the product, as shown in Fig. 12. For example, maize requires to be heated below $60{ }^{\circ} \mathrm{C}$ to avoid overheating and microbial attack. A biomass backup heater is used to supplement the heat required for faster drying process (Bena and Fuller, 2002) 
Six different types of cabinet driers (all natural circulation type) are constructed with same fabrication materials and absorber areas, but different height of air gaps, air pass methods and configurations of absorber plates (Koyuncu, 2006). The air flow rate is maintained constant in all the cases. Out of all, the single covered/glazed and the front pass type with black painted aluminum sheet as absorber plate is found to be most efficient. Also, it is found that, the effect of the shape of the absorbing surface on the performance is considerably less.

In order to make the driers cost effective and comparable to open sun drying, natural convection type green house driers (Koyuncu, 2006) are developed and tested. There are two types of driers (see Figs. 13 and 14). The driers are tested without load-without chimney, with load-without chimney and with load-with chimney. When the driers are loaded (pepper in the present case), the efficiency reduces. It is found that the green house driers are increase the air temperature by $5-9 \circ \mathrm{C}$ and the chimney provides better natural circulation of air.

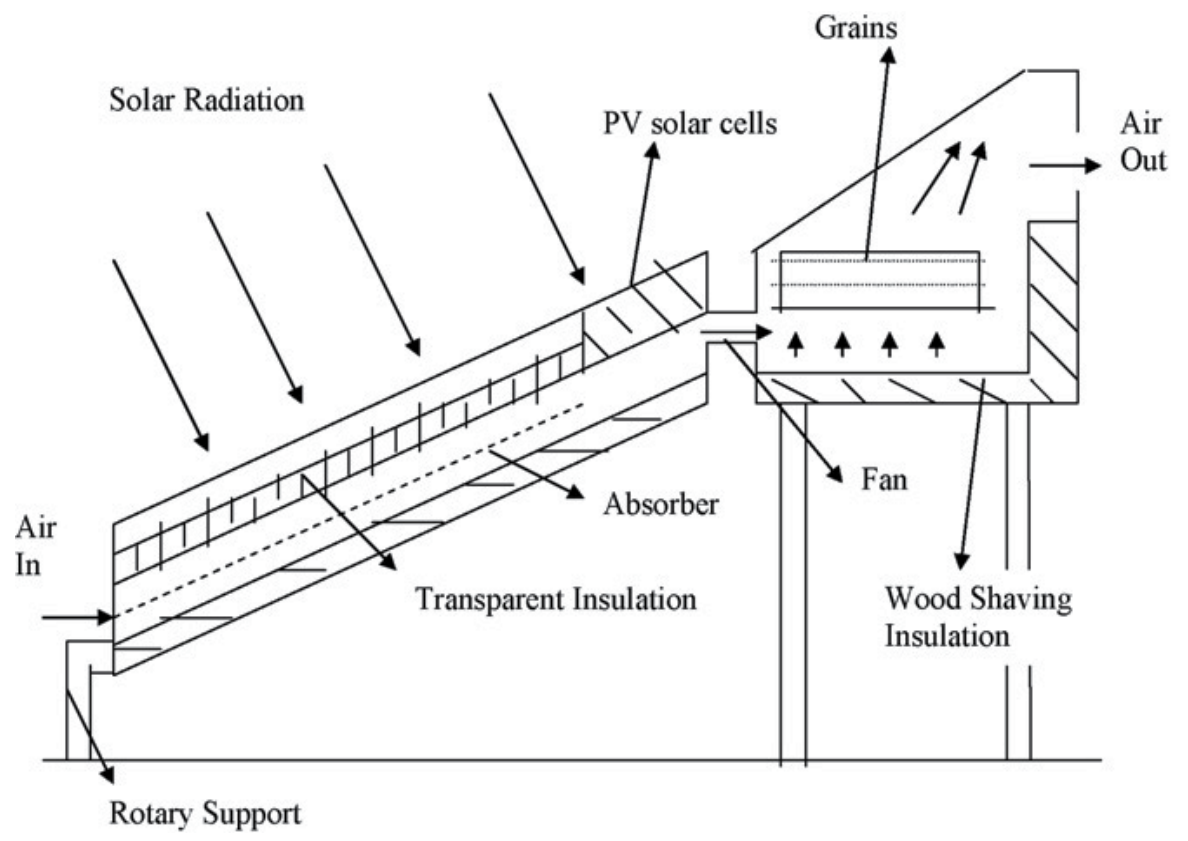

Fig. 12. Solar grain dryer with rotatable indirect air heater and a PV run fan. 

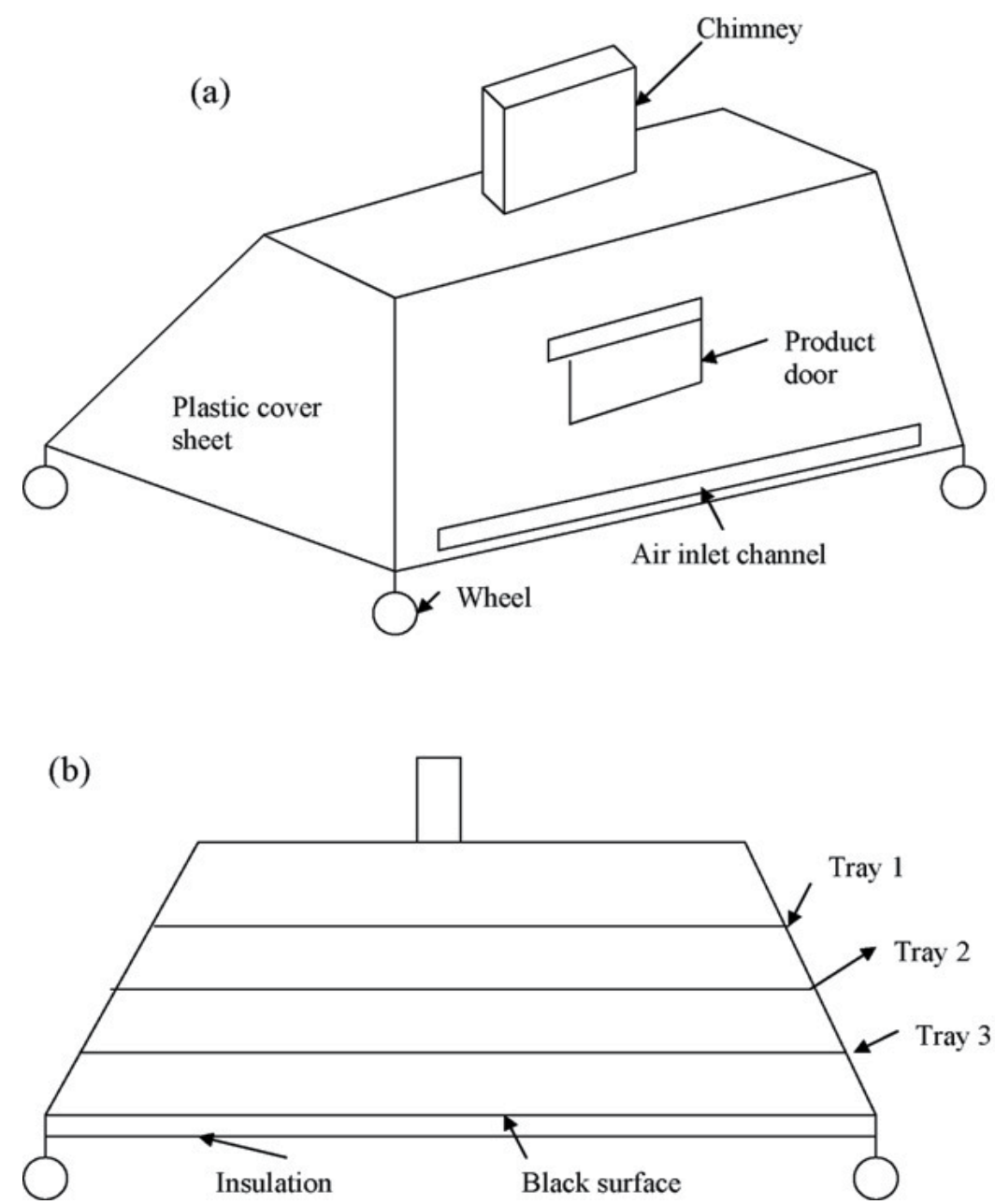

Fig. 13. (a) A simple presentation of first model and (b) side view of first model. 


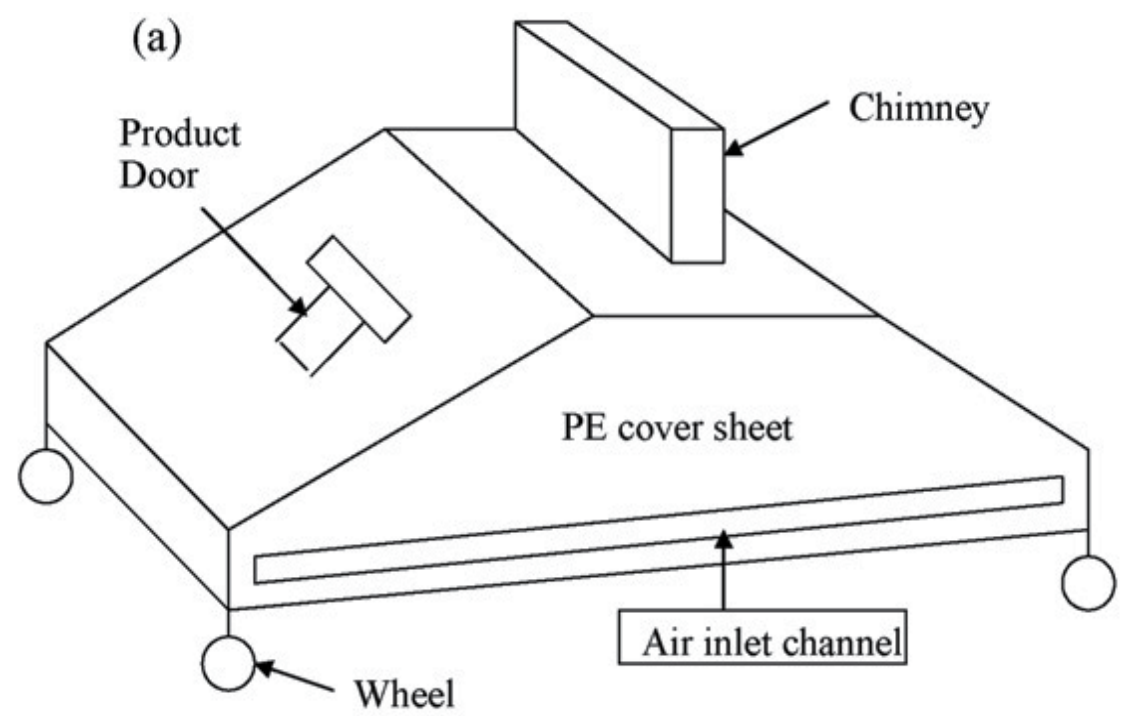

(b)

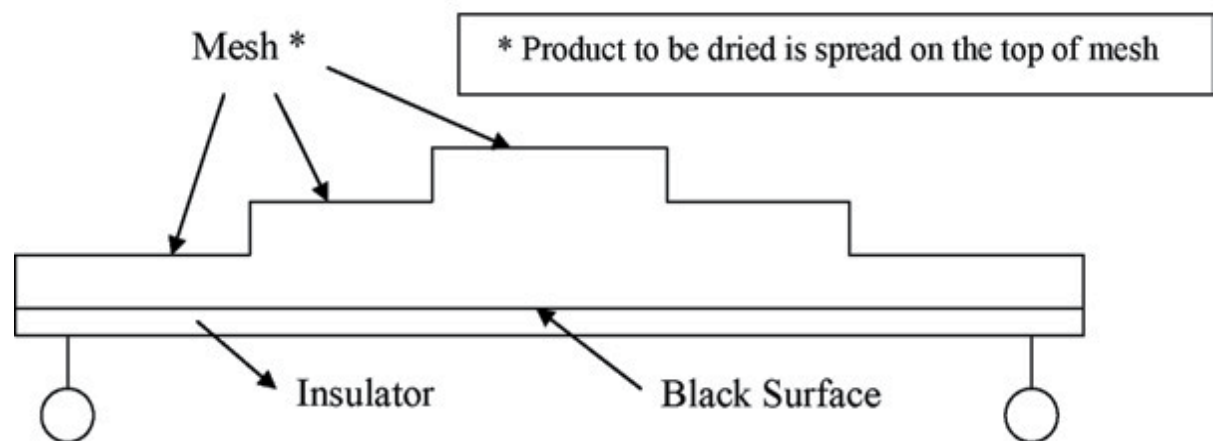

Fig. 14. (a) A simple representation of second model and (b) side view of internal representation of second model.

Totally different methods of drying have been developed which continue to dry the products even in the night times thereby reducing the drying time drastically. The desiccant materials (Shanmugam and Natarajan, 2006) are used which absorb the moisture from the products to be dried. The cost of desiccant materials is high causing the final product cost to be high. Hence, low cost desiccants (Thoruwa et al., 2000) particularly suitable for tropical countries are identified as bentonite-calcium chloride and kaolonite-calcium chloride. Yet another type is the one with thermal storage (sensible) to take care of intermittent incoming solar radiation. The length and width of the air heater, the gap between the absorber plate and glass cover and thickness of the storage material are optimized in this type of drier (Murthy, 2009). The thermal efficiency of the air heater is found to be sufficient for drying of various materials. 
In all the types of driers stated above, the hot air enters the drying chamber and leaves to the atmosphere. But the hot air can be recirculated to save the energy (McDoom et al., 1999). The drying of coconut and cocoa in a scaled down drier of a large scale drier is considered in which the recirculation of hot air yields 31 and $29 \%$ of energy saving, respectively. The recirculation of exhaust/hot air is also applied to hay driers. Lack of uniform drying and inability to accurately predict drying times are some of the existing problems. A new drier is developed which uses forced heated-air circulation through hay stacks. A drying rate difference of $7 \%$ is observed due to recirculation of hot air. By recirculating all of the exhaust air, the previous driers either increased drying time or proved to be uneconomical. So only $30 \%$ of the hot air is recirculated in the present case. The favorable conditions to recirculate the exhaust air are presented (Murthy, 2009).

A drier called FASD (Foldable Agro Solar Dryer) is developed which is a foldable type that can be stored and transported as desired. The performance of the drier is tested to find that the inner temperature is about $8 \circ \mathrm{C}$ higher than ambient and humidity is lesser by $6 \%$ inside. Out of all types, the well known heat pump (Murthy, 2009) principle has been used to dry the products and this has been found to be excellent alternative to the solar drying.

\section{Applications of solar driers}

The drying process has been experimentally studied and analyzed to simulate and design a drier. As drying is a process of removing moisture to a safe level, the equilibrium moisture content is defined as the moisture content in equilibrium with the relative humidity of the environment. The equilibrium moisture content is divided into, static and dynamic. While the static is used for food storage process, dynamic is used for drying process. The drying process is experimentally obtained and presented as moisture content on x-axis and rate of drying on y-axis. A deep bed of food grains is assumed to be composed of thin layers normal to the hot air flow direction. The equations for thin layer were written initially, using empirical, theoretical and semitheoretical equations. The conditions of the grain and air, change with position and time during drying of a deep bed of grains. Logarithmic and partial differential equation models to simulate the deep bed dry modeling are dealt in detail (Murthy, 2009).

A computer program in $\mathrm{C}++$ language is developed for modeling of deep bed drying systems and considers eight different configurations of flow of hot air over absorber plates of solar collectors. The usual parameters such as heat removal factor, overall loss coefficient, top loss coefficient, etc., can be determined. The model prompts for basic data (Murthy, 2009) such as amount of grain to be dried, initial moisture content, number of thin layers and weather data.

In a different direction, the first and second law of thermodynamics (Torres-Reyes et al., 2002) have been used to develop the design methods for a particular application. Semi-empirical formulae are developed to calculate the rise in air temperature as it passes through the heater. NTU (number of transfer units) has been defined analogous to the heat exchangers, as a part of design. Using entropy balance the maximum temperature reached by solar collector is written and then Entropy Generation Number is developed to find the entropy generated during thermal conversion of solar energy. Finally, the drying temperature is established as a function of the maximum limit of temperature the material might support. 
The drying chamber of a drier consists of meshes on which product is spread for drying. Also, the drying chamber (Youcef-Ali et al., 2004) is a wooden cabinet. Hence, the heat loss to the side walls of the drying chamber is considered. As the hot air passes through the mesh, in forced convection driers, turbulence is created. A solar drier without either heat storage or air recycling is considered with a solar collector containing offset plate fins. Experiments are conducted to calculate heat losses (through Nusselt number).

In the above models, the variation of incoming solar radiation is not taken into account. For modeling purpose, a constant artificial flux is adopted to study the drying phenomenon (Hachemi, et al., 1998). A drier with three beds of wool is considered with a solar collector. The drying process in the three zones of the bed is theoretically analyzed. The solar collector is equipped with a flat plate absorber and offset plate fins absorber plate. Under constant incident fluxes, at the same mass flow rate of air, the drying rate and time has been studied to find that offset plate fins collector is better.

The known facts that, the inlet temperature of the air is variable (because of variable incoming solar radiation) and the products shrink as drying process continues are taken into consideration for modeling (Ratti and Mujumdar, 1997). A most common cabinet type drier is considered for the study. A moving co-ordinate is defined to take into account of the shrinkage effects. The experimental data from previous workers is considered for validation of the mathematical model. The carrot cubes are used as product to test the model. It is proposed that the estimation of solar irradiance on the drier is essential to predict the response of the drier (Garg and Kumar, 1998). Considering a semi-cylindrical solar tunnel drier, the irradiance is calculated by taking the geometric quantities, relative motion of sun and optical properties into account.

The change of main variables such as moisture content along the drying tunnel is considered unlike in previous works where uniform distribution is assumed (Condori and Saravia, 2003). This is a study of tunnel green house drier which is continuous type. The conditions for improvement of efficiency are evaluated. A linear relationship between the tunnel output temperature and incident solar radiation is obtained. The drier production is presented by a performance parameter which is defined as the ratio between the energy actually used in the evaporation and the total available energy for the drying process. A non-dimensional variable is also defined, which has all the meteorological information. It is found that, the average moisture content value of the tunnel can be considered to be constant (Murthy, 2009).

The construction and working of solar tunnel drier is explained in detail. Three fans run by a solar module are used to create forced convection. The drying procedure and the instrumentation are also described. The major advantage of solar tunnel drier is that the regulation of the drying temperature is possible. During high insolation periods, more energy is received by the collector, which tends to increase the drying temperature and is compensated by the increase of the air flow rate. The variation of voltage with respect to radiation in a given day and variation of radiation with respect to time of the day are presented. The comparative curves using the tunnel dryer and natural sun drying are presented to show that, the tunnel drying time is less(Murthy, 2009). A substantial increase in the average sugar content is observed. The economics of the drier is worked out to show that, the pay back period is 3 years.

The solar tunnel drier is modified to develop a green house tunnel drier whose working principle and construction is explained in detail. Some additional features of the tunnel drier 
are high lighted such as improvement in the drier efficiency, lowering of the labor cost and ease in installing a conventional heater as an auxiliary heating system for continuous production (Condori et al., 2001). The drier is considered as a solar collector, and its instantaneous efficiency is measured. Products were dried in various configurations, i.e., cut in various ways. The plots of time in a given day vs. moisture content are plotted. The working principle of auxiliary heating system is also presented.

Through out the literature, decrease in drying time has been the main concern. Further, the natural convection type drier is not preferred as low buoyancy forces may cause reverse effect leading to the spoilage of the product. In order to resolve these two issues, an integral type natural convection drier coupled with a biomass stove is developed (Prasad and Vijay, 2005). The constructional details and operation of the drier are presented in detail. Drying time was lowest for solar-biomass method. The uniformity of drying was questionable as there was significant variation in moisture content when samples were tested from trays at top, middle and bottom. Even within a tray, when temperature, relative humidity and velocity of air were measured, variations were observedThe drying efficiency of the drier was evaluated and it is noted that, type of product and its final moisture content level influences the drying efficiency. The final moisture in a product generally requires more energy to extract than the initial moisture and the preparation of the products prior to drying such as slicing, boiling affects the drying efficiency. These factors make it difficult to make comparisons with the drying efficiencies of other solar driers reported in the literature.

\section{Conclusions}

This chapter is focused on the available solar dryer's systems and new technologies. The dependence of the drying on the characteristics of product remains still as a problem, for comparison of drying efficiencies of various driers. Author presented a comprehensive review of the various designs, details of construction and operational principles of the wide variety of practically realized designs of solar-energy drying systems. Two broad groups of solar-energy dryers can be identified, viz., passive or natural-circulation solar-energy dryers and active or forced-convection solar-energy dryers (often called hybrid solar dryers). Three sub-groups of these, which differ mainly on their structural arrangement, can also be identified, viz integral or direct mode solar dryers, distributed or indirect-modes. This classification illustrates clearly how these solar dryer designs can be grouped systematically according to either their operating temperature ranges, heating sources and heating modes, operational modes or structural modes. Though properly designed forced-convection (active) solar dryers are agreed generally to be more effective and more controllable than the natural-circulation (passive) types. This chapter also presents some easy-to-fabricate and easy-to-operate dryers that can be suitably employed at small-scale factories. Such low-cost drying technologies can be readily introduced in rural areas to reduce spoilage, improve product quality and overall processing hygiene.

\section{References}

Bal, L. M., Satya, S., Naik, S.N., Solar dryer with thermal energy storage systems for drying agricultural food products: A review. Renewable and Sustinable Energy Reviews, Vol.14(8), pp. 2298-2314. 
Bena, B., Fuller, R.J., 2002. Natural convection solar dryer with biomass back-up heater. Solar Energy, Vol.72, pp. 75-83.

Condori, M., Echazu, R., Saravia, L., 2001. Solar drying of sweet pepper and garlic using the tunnel greenhouse drier. Renewable Energy, Vol.22, pp. 447-460.

Condori, M., Saravia, L., 2003. Analytical model for the performance of the tunnel-type greenhouse drier. Renewable Energy, Vol.28, pp. 467-485.

Ekechukwu, O.V., Norton, B., 1999. Review of solar-energy drying systems II: an overview of solar drying technology. Energy Conversion \& Management, Vol.40(6), pp. 615-655.

Garg, H.P., Kumar, R., 1998. Studies on semi-cylindrical solar tunnel dryers: estimation of solar irradiance. Renewable Energy, Vol.13, pp. 393-400.

Goyal, R.K., Tiwari, G.N., 1999. Performance of a reverse flat plate absorber cabinet dryer: a new concept. Energy Conversion \& Management, Vol.40(4), pp. 385-392.

Hachemi, A., Abed, B., Asnoun, A., 1998. Theoretical and experimental study of solar dryer. Renewable Energy, Vol.13, pp. 439-451.

Hallak, H., Hilal, J., Hilal, F., Rahhal, R., 1996. The staircase solar dryer: design and characteristics. Renewable Energy, Vol.7, pp. 177-183.

Janjai, S., Tung, P., 2005. Performance of a solar dryer using hot air from roof-integrated solar collectors for drying herbs and spices. Renewable Energy, Vol.30, pp. 20852095.

Koyuncu, T., 2006. Performance of various design of solar air heaters for drying applications. Renewable Energy, Vol.31, pp. 1073-1088.

Koyuncu, T., 2006. An investigation on the performance improvement of green house type agricultural dryers. Renewable Energy, Vol.31, pp. 1055-1071.

McDoom, I.A., Ramsaroop, R., Saunders, R., Tang Kai, A., 1999. Optimization of solar drying. Renewable Energy, Vol.16, pp. 749-752.

Mumba, J., 1995. Development of a photovoltaic powered forced circulation grain dryer for use in the tropics. Renewable Energy, Vol. 6(7), pp.855-862.

Murthy, R. 2009. A review of new technologies, models and experimental investigations of solar driers. Renewable and Sustinable Energy Reviews, Vol.13, pp. 835-844.

Othman, M.Y.H, Sopian, K., Yatim, B., Daud, W.RW., 2006. Development of advanced solar assisted drying systems. Renewable Energy, Vol.31, pp. 703-709.

Prasad, J., Vijay, V.K., 2005. Experimental studies on drying of Zingiber officinale, Curcuma longa and Tinospora cordifolia in solar-biomass hybrid drier. Renewable Energy, Vol.30, pp. 2097-2109.

Ratti, C., Mujumdar, A.S., 1997. Solar drying of foods: modeling and numerical simulation. Solar Energy, Vol.60, pp. 151-157.

Sarsilmaz, C., Yildiz, C., Pehlivan, D., 2000. Drying of apricots in a rotary column cylindrical dryer (RCCD) supported with solar energy. Renewable Energy, Vol.21, pp. 117-127.

Singh, S., Singh, P.P., Dhaliwal, S.S,. 2004. Multi-shelf portable solar dryer. Renewable Energy, Vol.29, pp. 753-765.

Shanmugam, V., Natarajan, E., 2006. Experimental investigation of forced convection and desiccant integrated solar dryer. Renewable Energy, Vol.31, pp. 1239-1251.

Sharma, A., Chen, C. R., Vu Lan, N., 2009. Solar- energy drying systems:A review. Renewable and Sustinable Energy Reviews, Vol.13, pp. 1185-1210. 
Sodha, M.S., Dang, A., Bansal, P.K., Sharma, S.B., 1985. An analytical and experimental study of open sun drying and a cabinet type drier. Energy Conversion $\mathcal{E}$ Management,, Vol.25(3), pp. 263-271.

Thoruwa, T.F.N., Johnstone, M.C., Grant, A.D., Smith, J.E., 2000. Novel, low cost CaCl2 based desiccants for solar crop drying applications. Renewable Energy, Vol.19, pp. 513-520.

Xie, W.T., Dai Y.J., Wang, R.Z., Sumathy, K., 2011. Concentrated solar energy applications using Fresnel lenses: A review Renewable E Sustanable Energy Revıews, Vol. 15(6), pp. $2588-2606$.

Torres-Reyes, E., Gonzalez, N.J.J., Ibarra-Salazar, B.A., 2002. Thermodynamic method for designing dryers operated by flat plate solar collectors. Renewable Energy, Vol.26. pp. 649-660.

Youcef-Ali, S., Desmons, J.Y., 2004. Daguenet M. The turbulence effect of the airflow on the calorific losses in foodstuff dryers. Renewable Energy, Vol.29, pp.661-674. 


\title{
Photovoltaic Systems and Applications
}

\author{
Feyza Akarslan \\ Department of Textile Engineering, Engineering and Architectural Faculty, \\ Süleyman Demirel University, Isparta \\ Turkey
}

\section{Introduction}

Improvements in quality of life and rapid industrialization in many countries are increasing energy demand significantly, and the potential future gap between energy supply and demand is predicted to be large. Interest in sustainable development and growth has also grown in recent years, motivating the development of environmental benign energy technologies. Research on applications of solar energy technologies have as a consequence expanded rapidly, exploiting the abundant, free and environmentally characteristics of solar energy. However, widespread acceptance of solar energy technology depends on its competitiveness, considering factors such as efficiency, cost-effectiveness, reliability and availability (Kumar and Rosen, 2011).

Renewable energy sources can be defined as "energy obtained from the continuous or repetitive currents on energy recurring in the natural environment" or as "energy flows which are replenished at the same rate as they are used". All the earth's renewable energy sources are generated from solar radiation, which can be converted directly or indirectly to energy using various technologies. This radiation is perceived as white light since it spans over a wide spectrum of wavelengths, from the short-wave infrared to ultraviolet. Such radiation plays a major role in generating electricity either producing high temperature heat to power an engine mechanical energy which in turn drives an electrical generator or by directly converting it to electricity by means of the photovoltaic

(PV) effect. It is well known that PV is the simplest technology to design and install, however it is still one of the most expensive renewable technologies. But its advantage will always lie in the fact it is environmentally friendly and a non-pollutant low maintenance energy source (Chaar et. al., 2011).

Some solar thermal systems, such as solar water heaters, air heaters, dryers and distillation devices, have advance notably in decades in terms of efficiency and reliability. Efficiencies of these devices typically range from about $40 \%$ to $60 \%$ for low- and medium-temperature applications (Thirugnanasambandam et al., 2010). Also, the direct conversion of solar energy to electricity has advanced markedly over the last two decades, leading to significantly reduced prices of photovoltaic modules, and applications have increased especially due to the availability of incentives in many parts of the world (Branker and Pearce, 2010). However, the efficiency of mono crystalline silicon based module is still 
around $20 \%$ and the cost of production of PV power remains considerably higher than the cost of generating solar thermal heat (Liou, 2010). The efficiency of photovoltaic cells or modules is measured under controlled conditions (solar irradiance $1000 \mathrm{~W} / \mathrm{m}^{2}$, cell temperature $25^{\circ} \mathrm{C}$, air mass 1.5 ), although the nominal operating cell temperature (NOCT) in actual applications is much higher than the reference cell temperature $25{ }^{\circ} \mathrm{C}$; the higher NOCT is considered a major cause of reduced efficiency and electrical power output of photovoltaic modules (Garcia and Balenzategui, 2004). To enhance and possibly maximize the output of photovoltaic modules, the heat generated in the module can be extracted by passing a heat recovery fluid (water, oil, glycol, air) under and/or over the module (Tonui and Tripanagnostopoulos, 2007).

Photovoltaic conversion is the direct conversion of sunlight into electricity without any heat engine to interfere. Photovoltaic devices are rugged and simple in design requiring very little maintenance and their biggest advantage being their construction as stand-alone systems to give outputs from microwatts to megawatts. Hence they are used for power source, water pumping, remote buildings, solar home systems, communications, satellites and space vehicles, reverse osmosis plants, and for even megawatt scale power plants. With such a vast array of applications, the demand for photovoltaics is increasing every year (Parida et al., 2011)

PV history starts in 1839, when Alexandre-Edmund Becquerel observed that "electrical currents arose from certain light induced chemical reactions" and similar effects were observed by other scientists in a solid (selenium) several decades later. But it was not till the late 1940s when the development of the first solid state devices paved the way in the industry for the first silicon solar cell to be developed with an efficiency of $6 \%$. The development of the first silicon solar cell was fundamental in the initiation of solar technologies as it represented the power conversion unit of a PV system but with practical implications. These Si cells are not used separately rather they are assembled into modules. Presently, various types of solar cells on industrially available, however, the strive for research and development is continuing to expand and improve this energy collector (Chaar et al., 2011).

The growth of such technology depends on materials and structure development; however the goal will always be maximum power at minimum cost. In any structure, solar cells, which are connected in series and in parallel in order to form the desired voltage and current levels, remain the basic semiconductor components of a PV panel. To maximize the power rating of a solar cell which ensures the highest efficiency, hence designed to raise the desired absorption and absorption after reflection (Fig. 1).

This chapter will briefly describe the principles and history of photovoltaic (PV) energy systems and will explore in details the various available technologies while reflecting on the advancement of each technology and its advantages and disadvantages and photovoltaic applications. Included are discussions of the status, development and applications of various $\mathrm{PV}$ and solar thermal technologies. This chapter is a full review on the development of existing photovoltaic (PV) technology. It highlights the four major current types of PV: crystalline, thin film, compound and nanotechnology. The aim of continuous development of PV technology is not only to improve the efficiency of the cells but also to reduce production cost of the modules, hence make it more feasible for various applications. 
Moreover, such variety in technology is needed to enhance the deployment of solar energy for a greener and cleaner environment. Devices such as space PV cell technology were also described and the progress in this field is expanding. In addition, the applications of PV installations are described.

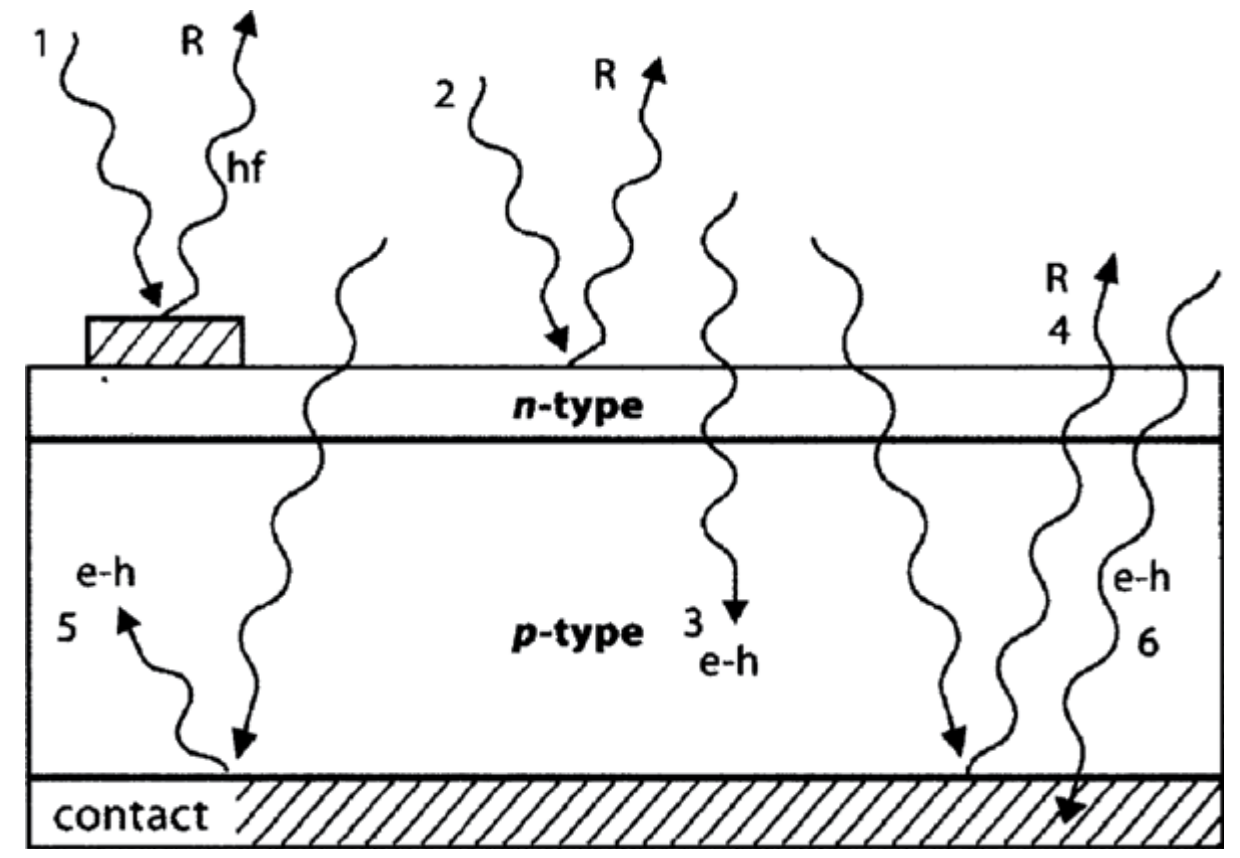

Fig. 1. Behavior of light shining on a solar cell: (1) Reflection and absorption at top contact. (2) Reflection at cell surface. (3) Desired absorption. (4) Reflection from rear out of cell. (5) Absorption after reflection. (6) Absorption in rear contact (Chaar et al., 2011).

\section{Photovoltaic systems}

The photovoltaic phenomenon has been recognized since 1839, when French physicist Edmond Becquerel was able to generate electricity by illuminating a metal electrode in a weak electrolyte solution. The photovoltaic effect in solids was first studied in 1876 by Adam and Day, who made a solar cell from selenium that had an efficiency of $1-2 \%$. The photovoltaic effect was explained by Albert Einstein in 1904 via his photon theory. A significant breakthrough related to modern electronics was the discovery of a process to produce pure crystalline silicon by Polish scientist Jan Czochralski in 1916. The efficiency of first generation silicon cells was about $6 \%$, which is considerable lower than that of contemporary solar cells (about 14-20\%). Early efforts to make photovoltaic cells a viable method of electricity generation for terrestrial applications were unsuccessful due to the high device costs. The "energy crises" of 1970s spurred a new found of initiatives in many countries to make photovoltaic systems affordable, especially for off-grid applications. The significant reductions in the prices of photovoltaic cells in more recent years has rejuvenated interest in the technology, e.g., the annual growth since 2000 in the production of PV system has exceeded $40 \%$ and present total installed capacity worldwide has reached about $22 \mathrm{GW}$ (Kumar and Rosen, 2011). 


\section{Types of photovoltaic installations and technology}

Four main types of PV installations exist: grid-tied centralized (large power plants); gridtied distributed (roof/ground mounted small installations); off-grid commercial (power plants and industrial installations in remote areas); and off-grid (mainly stand alone roof/ground based systems for houses and isolated applications). The balance-of-system requirements of each installation differ significantly. For example, off-grid stand alone applications often require a battery bank or alternative electrical storage capacity (Kumar and Rosen, 2011).

Photovoltaic systems can be further distinguished based on the solar cell technology (Fig. 2). Silicon ( $\mathrm{Si}$ ) based technologies can be categorized as a crystalline silicon and amorphous silicon or thin film, and are considered the most mature. Crystalline silicon cells can have different crystalline structures: mono-crystalline (mono- crystalline) silicon, multi-crystalline silicon and ribbon cast multi-crystalline silicon (Kumar and Rosen, 2011).

A key feature of photovoltaic systems is their ability to provide direct and instantaneous conversion of solar energy into electricity without complicated mechanical parts or integration (Phuangpornpitak and Kumar, 2011).

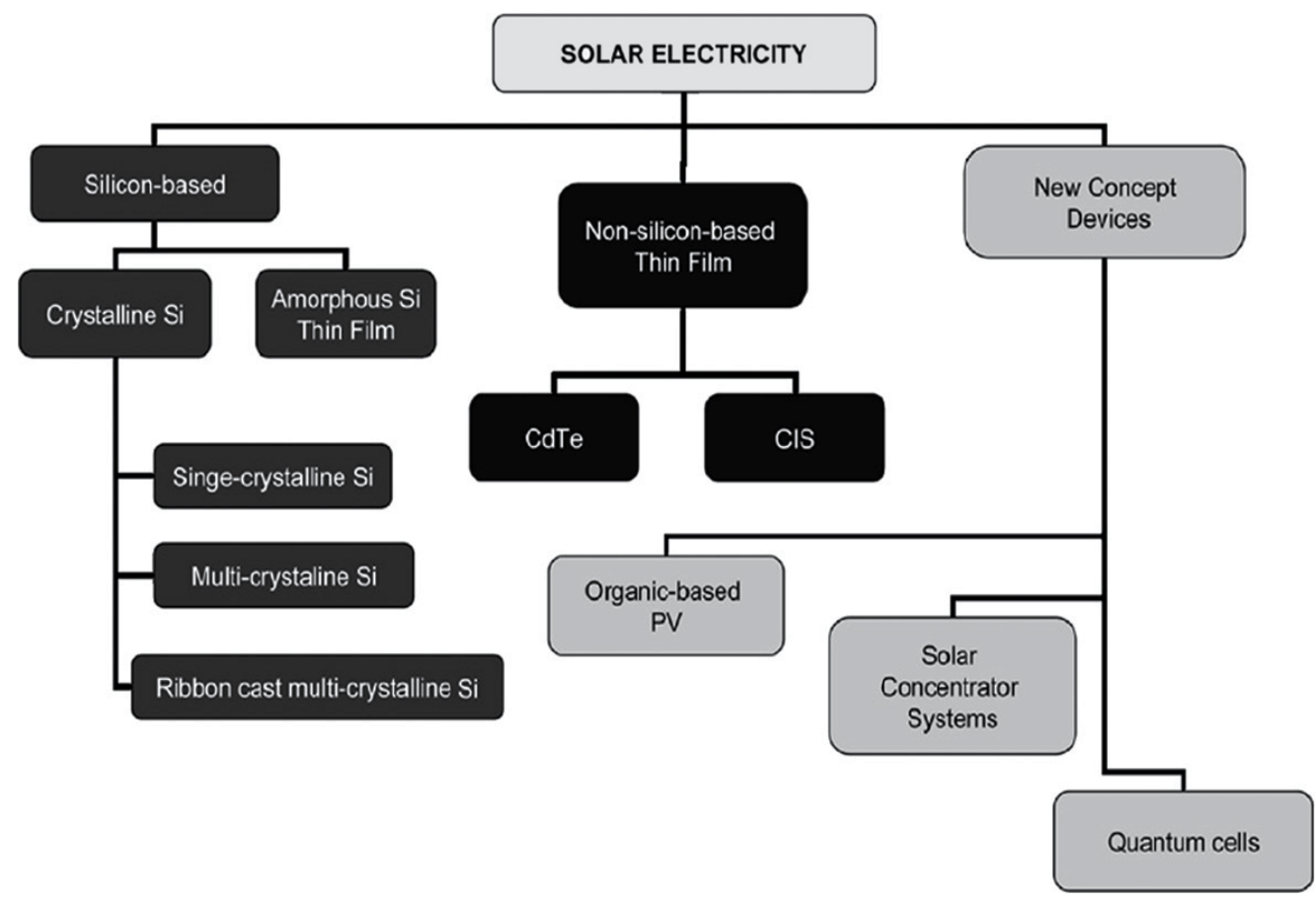

Fig. 2. Various PV technologies.

Most photovoltaic cells produced are currently deployed for large scale power generation either in centralized power stations or in the form of 'building integrated photovoltaics' (BIPV). BIPV is receiving much attention, as using photovoltaic cells in this way minimizes land use and offsets the high cost of manufacture by the cells (or panels of cells) acting as building materials. Although crystalline Si solar cells were the dominant cell type used 
through most of the latter half of the last century, other cell types have been developed that compete either in terms of reduced cost of production (solar cells based on the use of multicrystalline $\mathrm{Si}$ or $\mathrm{Si}$ ribbon, and the thin-film cells based on the use of amorphous $\mathrm{Si}$, CdTe, or CIGS) or in terms of improved efficiencies (solar cells based on the use of the III-V compounds). The market share of the different cell types during 2006 are given in Fig. 3.

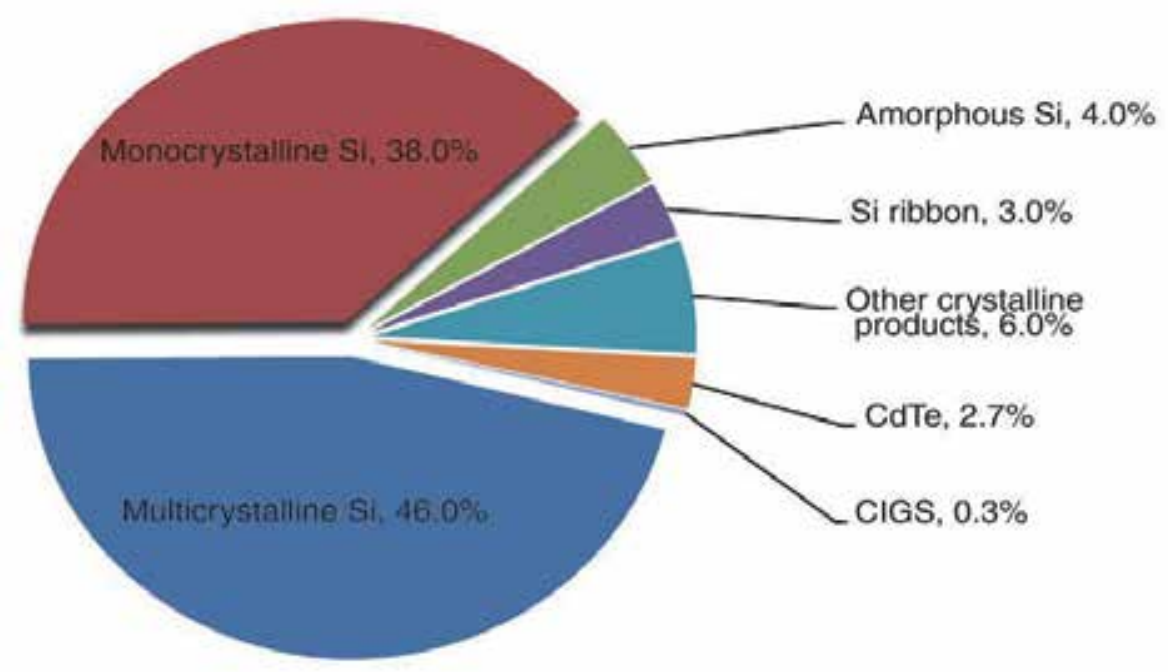

Fig. 3. Market share for various photovoltaic cell technologies in 2006.

\subsection{Silicon crystalline structure}

The first generation of PV technologies is made of crystalline structure which uses silicon (Si) to produce the solar cells that are combined to make PV modules. However, this technology is not obsolete rather it is constantly being developed to improve its capability and efficiency. Mono-crystalline, multi-crystalline, and emitter wrap through (EWT) are cells under the umbrella of silicon crystalline structures and are discussed in the following sections.

\subsubsection{Mono (single)-crystalline photovoltaic cells/panels}

This type of cell is the most commonly used, constitutes about $80 \%$ of the market recently and will continue to the leader until amore efficient and cost effective PV technology is developed. It essentially uses crystalline $\mathrm{Si}$ p-n junctions. Due to the silicon material, currently attempts to enhance the efficiency are limited by the amount of energy produced by the photons since it decreases at higher wavelengths. Moreover, radiation with longer wavelengths leads to thermal dissipation and essentially causes the cell to heat up hence reducing its efficiency. The maximum efficiency of mono-crystalline silicon solar cell has reached around $23 \%$ under STC, but the highest recorded was $24.7 \%$ (under STC). Due to combination of solar cell resistance, solar radiation reflection and metal contacts available on the top side, self losses are generated. After Si ingot is manufactured to a diameter between 10 to $15 \mathrm{~cm}$, it is then cut in wafers of $0.3 \mathrm{~mm}$ thick to form a solar cell of approximately $35 \mathrm{~mA}$ of current per $\mathrm{cm}^{2}$ area with a voltage of $0.55 \mathrm{~V}$ at full illumination. For some other 
semi-conductor materials with different wavelengths, it can reach 30\% (under STC). However module efficiencies always tend to be lower than the actual cell and Sun power recently announced a $20.4 \%$ full panel efficiency. This panel is expected to have better life, and its price is well compatible with other existing sources. Solar silicon processing technology has many points in common with the microelectronics industry, and the benefits of the huge improvements in $\mathrm{Si}$ wafer processing technologies used in microelectronic applications are to improve the performance of laboratory cells, hence made this technology most favorable (Chaar et. al., 2011).

Current PV production is dominated by mono-junction solar cells based on silicon wafers including mono crystal(c-Si) and multi-crystalline silicon (mc-Si). These types of monojunction, silicon-wafer devices are now commonly referred to as the first- generation (1G) technology, the majority of which is based on a screen printing-based device similar to that shown in Fig. 4. (Bagnall and Boreland, 2008)

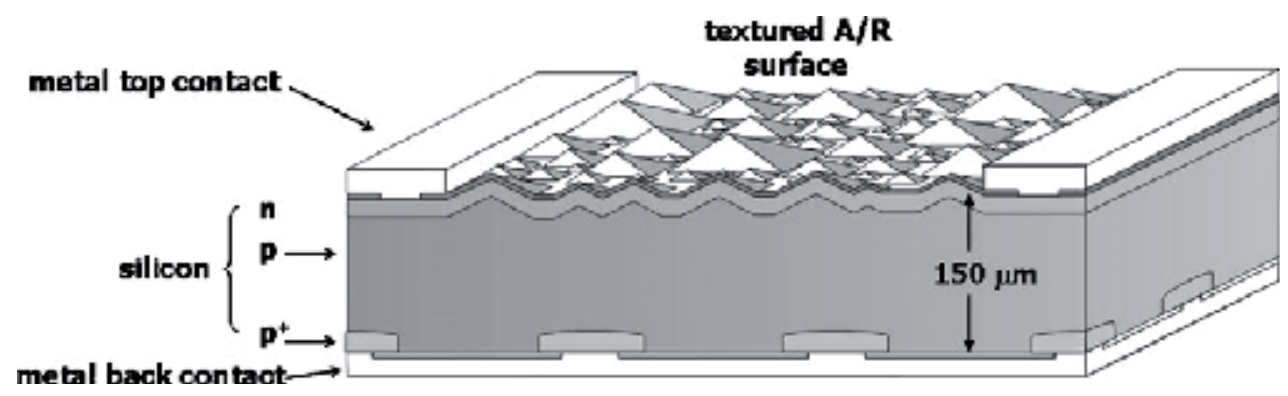

Fig. 4. Schematic of a mono-crystal solar cell. (Bagnall and Boreland, 2008)

\subsubsection{Multi (poly)-crystalline photovoltaic cells/panels}

The efforts of the photovoltaic industry to reduce costs and increase production throughput have led to the development of new crystallization techniques. Initially, multi-crystalline was the dominant solar industry while the cost of $\mathrm{Si}$ was $\$ 340 / \mathrm{kg}$. However, even with a silicon price reduction to $\$ 50 / \mathrm{kg}$, such technology is becoming more attractive because manufacturing cost is lower even though these cells are slightly less efficient (15\%) than monocrystalline. The advantage of converting the production of crystalline solar cells from monosilicon to multi-silicon is to decrease the flaws in metal contamination and crystal structure. Multi-crystalline cell manufacturing is initiated by melting silicon and solidifying it to orient crystals in a fixed direction producing rectangular ingot of multi-crystalline silicon to be sliced into blocks and finally into thin wafers. However, this final step can be abolished by cultivating wafer thin ribbons of multi-crystalline silicon. This technology was developed by Evergreen Solar uses (Chaar et al., 2011). A photograph of a cell is given in Fig. 5.

\subsubsection{Emitter wrap-though cells}

Emitter wrap-through (EWT) cells (Fig. 6) have allowed an increase in efficiency through better cell design rather than material improvements in this technology, small laser drilled holes are used to connect the rear n-type contact with the opposite side emitter. The removal of front contacts allows the full surface area of the cell to absorb solar radiation because masking by the metal lines is no longer present. Several tests showed that (Chaar et al., 2011) 
there are manufacturing gains by putting the contacts on the backs of the cell. One major disadvantage of such a technology is evident on large area EWT cells where this technology suffers from high series resistance which limits the fill factor.

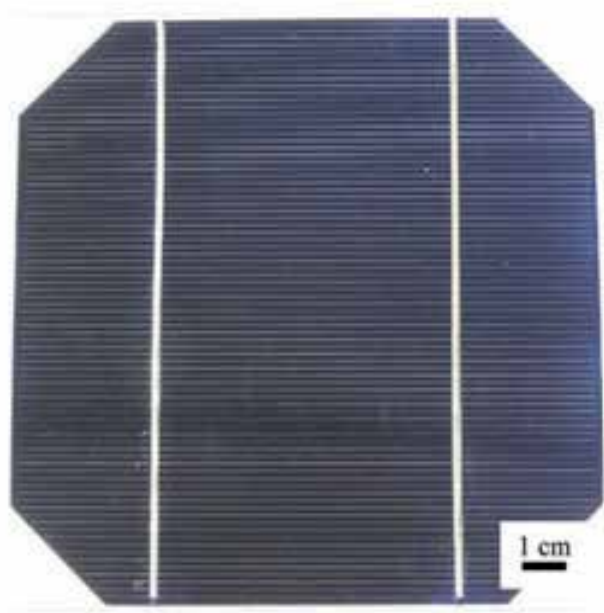

(a)

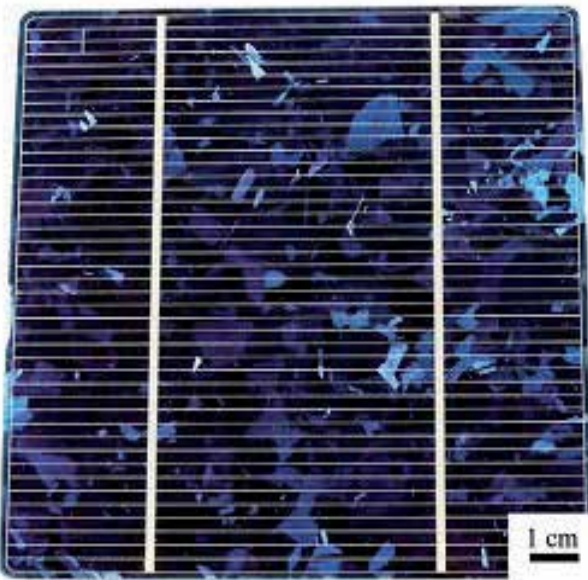

(b)

Fig. 5. Photographs of (a) crystalline Si, and (b) multicrystalline Si solar cells.

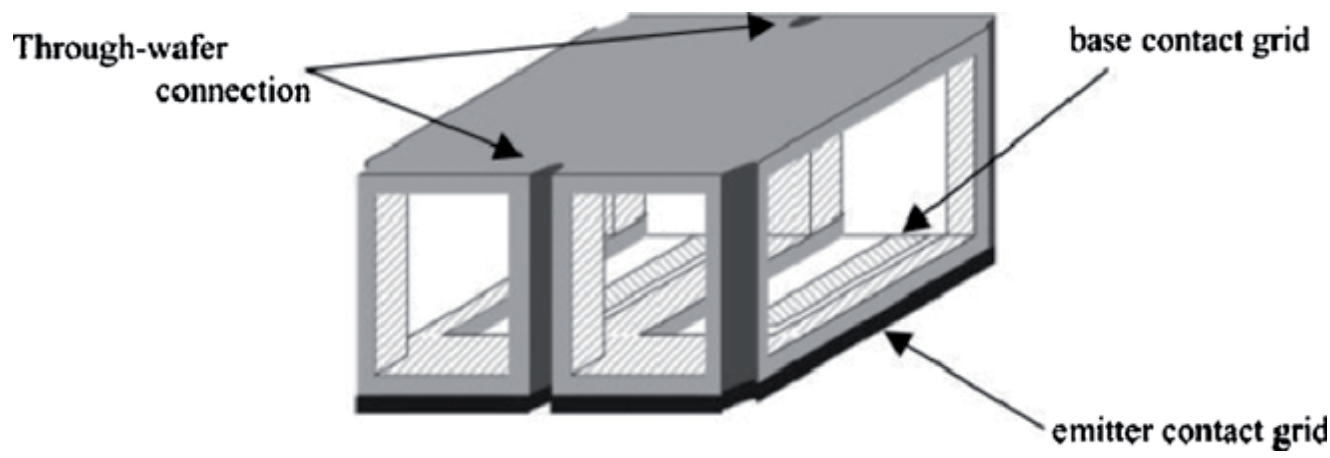

Fig. 6. Schematic representation of an emitter wrap-through solar cell (Chaar et al., 2011).

\subsubsection{Silicon crystalline investment}

Photovoltaic systems have large initial capital costs but small recurrent costs for operation and maintenance. The price of delivered energy varies inversely as the lifetime of the system. The above described silicon based technology modules exhibit lifetimes of 20-30 years. In most systems unless there are extremely aggressive government incentives the payback periods remain long. For that reason, several groups have been researching ways of lowering the initial capital investment, therefore shortening payback periods and as a result making photovoltaics a viable technology that can stand on its own without heavy government subsidies. The need to reduce the manufacturing, and therefore module cost, is the main reason behind the move toward thin film solar cells. The ultimate goal being the achievement of "grid parity", which would make the cost of the kWh delivered by PV 
technologies on par with the $\mathrm{kWh}$ delivered by traditional means. A goal that remains elusive to this day, although improvements in the technologies have allowed in impressive drop in the cost per watt (Chaar et al., 2011).

\subsection{Thin film technology}

Thin-film solar cells are basically thin layers of semiconductor materials applied to a solid backing material. Thin films greatly reduce the amount of semiconductor material required for each cell when compared to silicon wafers and hence lowers the cost of production of photovoltaic cells. Gallium arsenide (GaAs), copper, cadmium telluride (CdTe) indium diselenide $\left(\mathrm{CuInSe}_{2}\right)$ and titanium dioxide $\left(\mathrm{TiO}_{2}\right)$ are materials that have been mostly used for thin film PV cells (Parida et al.,2011).

In comparison with crystalline silicon cells, thin film technology holds the promise of reducing the cost of PV array by lowering material and manufacturing without jeopardizing the cells' lifetime as well as any hazard to the environment. Unlike crystalline forms of solar cells, where pieces of semiconductors are sandwiched between glass panels to create the modules, thin film panels are created by depositing thin layers of certain materials on glass or stainless steel (SS) substrates, using sputtering tools. The advantage of this methodology lies in the fact that the thickness of the deposited layers which are barely a few micron (smaller than $10 \mu \mathrm{m}$ ) thick compared to crystalline wafers which tend to be several hundred micron thick, in addition to the possible films deposited on SS sheets which allows the creation of flexible PV modules. The resulting advantage is a lowering in manufacturing cost due to the high throughput deposition process as well as the lower cost of materials. Technically, the fact that the layers are much thinner, results in less photovoltaic material to absorb incoming solar radiation, hence the efficiencies of thin film solar modules are lower than crystalline, although the ability to deposit many different materials and alloys has allowed tremendous improvement in efficiencies (Chaar et al., 2011).

Four kinds of thin film cells have emerged as commercially important: the amorphous silicon cell (multiple-junction structure), thin multi-crystalline silicon on a low cost substrate, the copper indium diselenide/cadmium sulphide hetero-junction cell, and the cadmium telluride/cadmium sulphide hetero-junction cell (Chaar et al., 2011).

\subsubsection{Amorphous silicon}

Amorphous (uncrystallized) silicon is the most popular thin film technology with cell efficiencies of $5-7 \%$ and double- and triple-junction designs raising it to $8-10 \%$. But it is prone to degradation. Some of the varieties of amorphous silicon are (Parida et al., 2011) amorphous silicon carbide (a-SiC), amorphous silicon germanium (a-SiGe), microcrystalline silicon ( $\mu \mathrm{c}-\mathrm{Si})$, and amorphous silicon-nitride (a- $\mathrm{SiN})$.

Amorphous silicon (a-Si) is one of the earliest thin film Technologies developed. This technology diverges from crystalline silicon in the fact that silicon atoms are randomly located from each other. This randomness in the atomic structure has a major effect on the electronic properties of the material causing a higher band-gap $(1.7 \mathrm{eV})$ than crystalline silicon $(1.1 \mathrm{eV})$. The larger band gap allows a-Si cells to absorb the visible part of the solar spectrum more strongly than the infrared portion of the spectrum. There are several 
variations in this technology where substrates can be glass or flexible SS, tandem junction, double and triple junctions, and each one has a different performance.

\subsubsection{Amorphous-Si, double or triple junctions}

Since a-Si cells have lower efficiency than the mono- and multi-crystalline silicon counterparts. With the maximum efficiency achieved in laboratory currently at approximately $12 \%$, mono junction a-Si modules degrades after being exposed to sunlight and stabilizing at around $4-8 \%$. This reduction is due to the Staebler-Wronski effect which causes the changes in the properties of hydrogenated amorphous $\mathrm{Si}$. To improve the efficiency and solve the degradation problems, approaches such as developing multiplejunction a-Si devices have been attempted and are shown in the graph (Fig. 7). This improvement is linked to the design structure of such cells where different wavelengths from solar irradiation (from short to long wavelength) are captured. The STC rated efficiencies of such technologies are around 6-7\%.

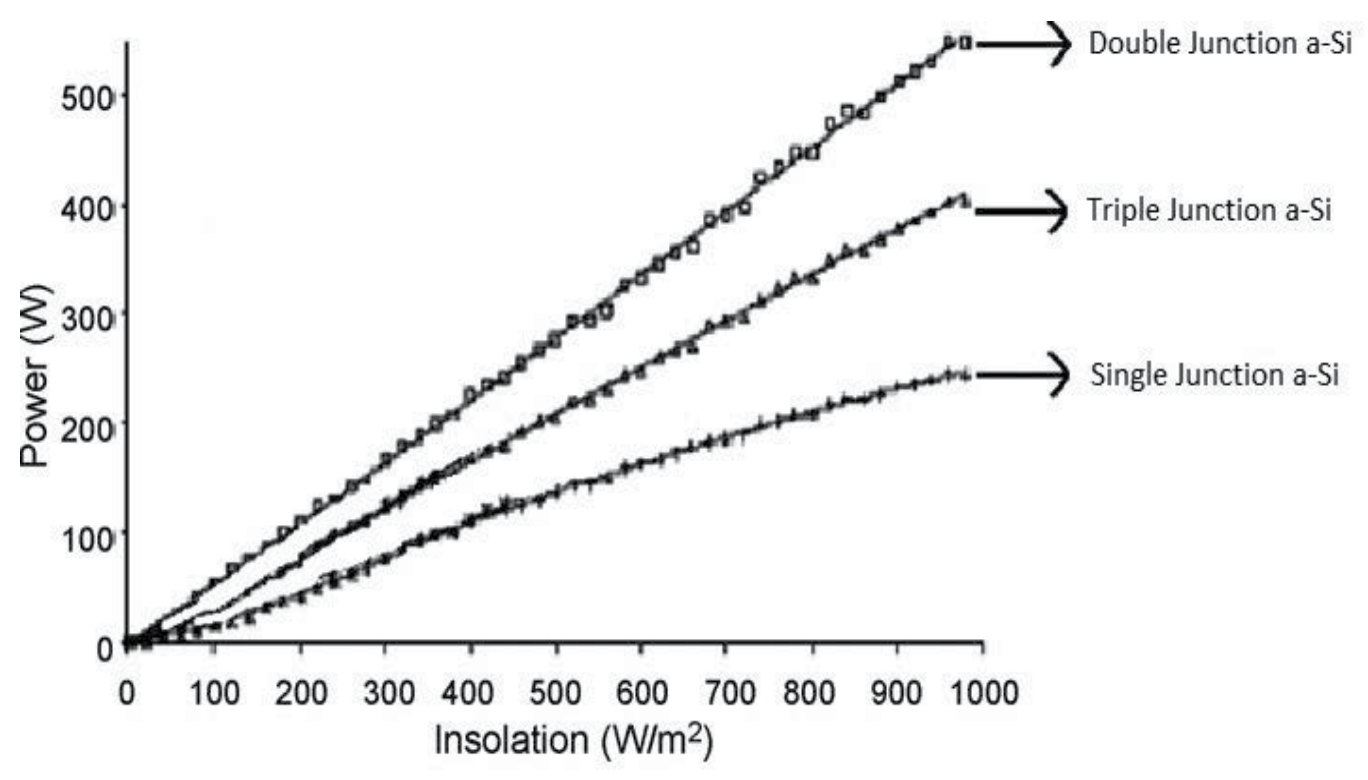

Fig. 7. Variation of output with insolation for representative sub-arrays.

\subsubsection{Tandem amorphous-Si and multi-crystalline-Si}

Another method to enhance the efficiency of PV cells and modules is the "stacked" or multicrystalline (mc) junctions, also called micro morph thin film. In this approach two or more PV junctions are layered one on top of the other where the top layer is constructed of an ultra thin layer of a-Si which converts the shorter wavelengths of the visible solar spectrum. However, at longer wavelength, microcrystalline silicon is most effective in addition to some of the infrared range. This results in higher efficiencies than amorphous Si cells of about 8-9\% depending on the cell structure and layer thicknesses. 


\subsubsection{Cadmium telluride or cadmium sulphide}

Cadmium telluride (CdTe) has long been known to have the ideal band-gap (1.45 eV) with a high direct absorption coefficient for a solar absorber material and recognized as a promising photovoltaic material for thin-film solar cells. Small-area CdTe cells with efficiencies of greater than $15 \%$ and CdTe modules with efficiencies of greater than $9 \%$ have been demonstrated. CdTe, unlike the other thin film technology, is easier to deposit and more apt for large-scale. The other potential issue is the availability of Te which might cause some raw material constraints that will then affect the cost of the modules (Chaar, 2011).

Ferekides et al. (2000) presented work carried out on CdTe/CdS solar cells fabricated using the close spaced sublimation (CSS) process that has attractive features for large area applications such as high deposition rates and efficient material utilization. Pfisterer (2003) demonstrated the influence of surface treatments of the cells (Cu2S-CdS) and of additional semiconducting or metallic layers of monolayer-range thicknesses at the surface and discussed effects of lattice mismatch on epitaxy as well as wet and drytopotaxy and preconditions for successful application of topotaxy.

\subsubsection{Copper indium diselenide or copper indium gallium diselenide}

Copper indium diselenide (CuInSe2) or copper indium selenide (CIS) as it is sometimes known, are photovoltaic devices that contain semiconductor elements from groups I, III and VI in the periodic table which is beneficial due to their high optical absorption coefficients and electrical characteristics enabling device tuning. Moreover, better uniformity is achieved through the usage of selenide, hence the number of recombination sites in the film is diminished benefiting quantum efficiency and hence the conversion efficiency. CIGS (indium incorporated with gallium - increased band gap) are multi-layered thin-film composites. Unlike basic $\mathrm{p}-\mathrm{n}$ junction silicon cell, these cells are explained by a multifaced hetero-junction model. The best efficiency of a thin-film solar cell is $20 \%$ with CIGS and about $13 \%$ for large area modules. The biggest challenge for CIGS modules has been the limited ability to scale up the process for high throughput, high yield and low cost. Several deposition methods are used: sputtering, "ink" printing and electroplating with each having different throughput and efficiencies. Both glass of stainless steel substrates are used, obviously the stainless steel substrates yield flexible solar cells. The biggest worry of this technology is indium shortage. Indium is heavily used in indium tin oxide (ITO), a transparent oxide that is used for flat screen displays such as TVs, computer screens and many others.

The obvious step in the evolution of PV and reduced $\$ / W$ is to remove the unnecessary material from the cost equation by using thin-film devices. Second-generation (2G) Technologies are mono-junction devices that aim to useless material while maintaining the efficiencies of 1GPV. 2G solar cells use amorphous-Si (a-Si),CuIn(Ga)Se2 (CIGS), $\mathrm{CdTe} / \mathrm{CdS}(\mathrm{CdTe})$ or multicrystalline-Si(p-Si) deposited on low-cost substrates such as glass (Fig. 8). These Technologies work because CdTe,CIGS and a-Si absorb the solar spectrum much more efficiently thanc-Sior mc-Si and use only 1-10 mm of active material. Mean while, invery promising work of the last few years, p-Si has been demonstrated to produce _10\% efficient devices using light-trapping schemes to increase the effective thickness of the silicon layer (Fig. 9) (Green et al.,2004; Bagnall and Boreland, 2008) 
CdTe

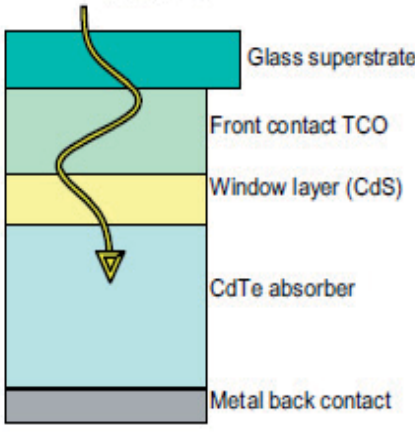

CIGS

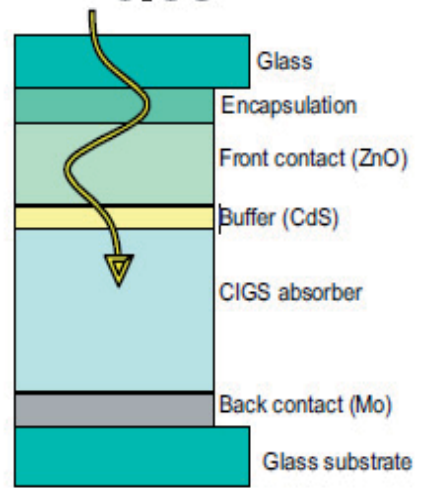

a-Si

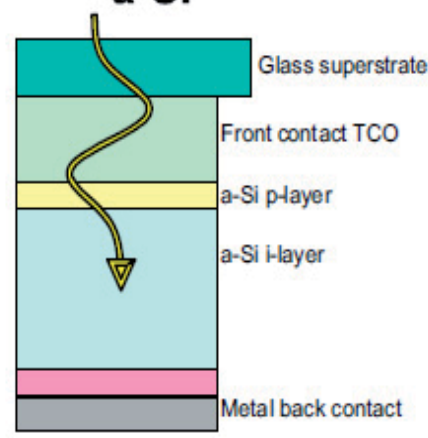

Fig. 8. Schematic diagrams of thin-film CdTe, CIGS and a-Si thin-film PV devices.

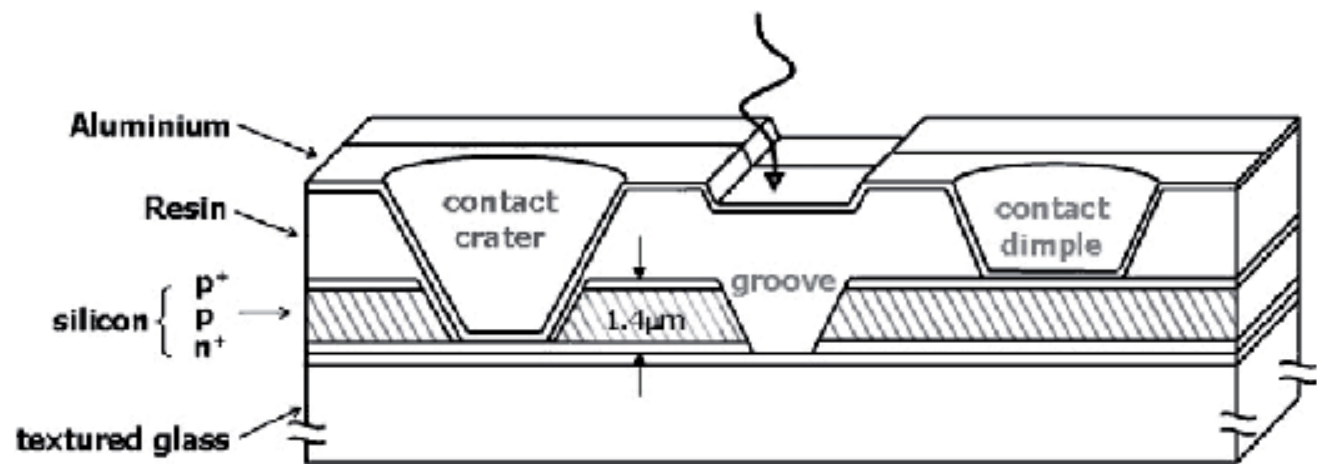

Fig. 9. Key features of the crystalline silicon on glass (CSG) technology . (Bagnall and Boreland, 2008)

\section{Compound semiconductor}

The result is a complicated stack of crystalline layers with different band gaps that are tailored to absorb most of the solar radiation. Also compound semiconductor cells have been shown to be more robust when expose to outer space radiation. Since each type of semiconductor has different characteristic band gap energy which then allows the absorption of light most efficiently, at a certain wavelength, hence absorption of electromagnetic radiation over a portion of the spectrum. These hetero-junction devices layer various cells with different bandgaps which are tuned utilizing the full spectrum. Initially, light strikes a wide band-gap layer producing a high voltage therefore using high energy photons efficiently enabling lower energy photons transfer to narrow bandgap sub-devices which absorb the transmitted infrared photons. Gallium arsenide $(\mathrm{GaAs}) /$ indium gallium phosphide ( $\mathrm{InGaP})$ multi-junction devices have reached the highest efficiency of $39 \%$ with NREL recently announcing a record $40.8 \%$ from a metamorphic triple-junction solar cell. Originally these cells were fabricated on GaAs substrates however, in order to reduce the cost and increase robustness and because it is reasonably lattice-matched to GaAs, germanium $(\mathrm{Ge})$ substrates are being used more 
often. The first cells had a mono junction much like the Si p-n junction solar cells, however because of the ability to introduce ternary and quaternary materials such as InGaP and aluminum indium gallium phosphide (AlInGaP) dual and triple junction devices were grown in order to capture a larger band of the solar spectrum therefore increasing the efficiency of the cells (Chaar, 2011).

\subsection{Space PV cells}

Photovoltaic solar generators have been proven to be the optimal option for providing electrical power to satellites. In 1958, US satellite Vanguard 1 demonstrated the first application. After years of moderate growth of the space PV market, the evolution of large scale applications has increased in the late nineties, where the main applications are dominated by the telecommunication satellites, military satellites, and scientific space probes. Solar cells which are designed for space must ensure that their specifications include apriority space environment condition such as spectral illumination and air mass. Issues of concern with terrestrial PV are their high cost while in space, weight, flexibility, efficiency, temperature, and suitable materials. In the 1950s, Si cells were p-n containing base layers of mono crystal N-Si with boron diffused P-emitters with an efficiency around $6 \%$. In the 1960s, efficiency was improved to $12 \%$ and CdS was investigated because of its flexibility and lightweight, but, its low efficiency and instability left it unfavorable. In the 1970s, although advances in Si growth by float-zoning (Fz) were promising solutions, space cells made from this material suffered additional degradation after radiation exposure. Despite all competitive approaches, Si remains the leader in PV technology for space. In the 1980s similar Technologies to the seventies were used in addition to the deployment in special air force missions indium phosphate (InP) cells which efficiency reached 18\% with high radiation tolerance. In the 1990s, although the high manufacturing cost, GaAs/Ge cells showed significant improvements including reduced area and weight, greater efficiency, and smaller stowage volume per launch. In addition, multijunction cells have shown great promises with efficiencies reaching almost $30 \%$. Due to the expense of the substrate and the growth process, the cost of these cells is extremely high compared to Si cells. For space applications the expense has been acceptable, however for terrestrial/commercial application methods had to be developed to make the cost adequate, and the most successful method of reducing the cost has been to use concentration. Essentially the solar cell wafers are dices into small cells (sometimes as small as $2 \mathrm{~mm} \times 2 \mathrm{~mm}$ ) and then a large lens is placed above the cell in order to concentrate the solar radiation on the small cell. The cell is placed at the focal length of the lens and the solar radiation incident on the lens will get focused on the PV cell. Effectively the cell is exposed to several times the "normal" radiation which is then quantified by using the terms "100 suns" or "300 suns" which concentrates the sun's radiation 100 and 300 times respectively. The technology is called concentrating PV or CPV. Of course with concentration comes the need for tracking as the lens that is concentrating the sun's radiation needs to track the sun to make sure the radiation is then focused on the cell. The concentrating method has used lenses or mirrors, or a combination of both. The mirrors are curved such that the PV cell is placed at the center of the curvature and the solar radiation is concentrated on the cell. 


\subsection{Light absorbing dyes}

Generally these types of cells consist of a semiconductor, such as silicon, and an electrolytic liquid, which is a conducting solution commonly formed by dissolving a salt in a solvent liquid, such as water. The semiconductor and electrolyte work in tandem to split the closely bound electron-hole pairs produced when sunlight hits the cell. The source of the photoinduced charge carriers is a photosensitive dye that gives the solar cells their name: "dyesensitized" (most common dye is iodide). In addition, a nanomaterial, most commonly titanium dioxide $\left(\mathrm{TiO}_{2}\right)$ is also often used to hold the dye molecules in place like a scaffold (Fig. 10). Using dye sensitized cells for photovoltaic application goes back several decades as scientists were trying to emulate chlorophyll action in plants. While the highest efficiency dye-sensitized solar cell ever made is $11 \%$, this technology contains volatile solvents in their electrolytes that can permeate across plastic (i.e. organic compounds) and also present problems for sealing the cells. Cells that contain these solvents are therefore unattractive for outdoor use due to potential environmental hazards. Researchers have developed solar cells that use solvent-free electrolytes, but the cell efficiencies are too low.
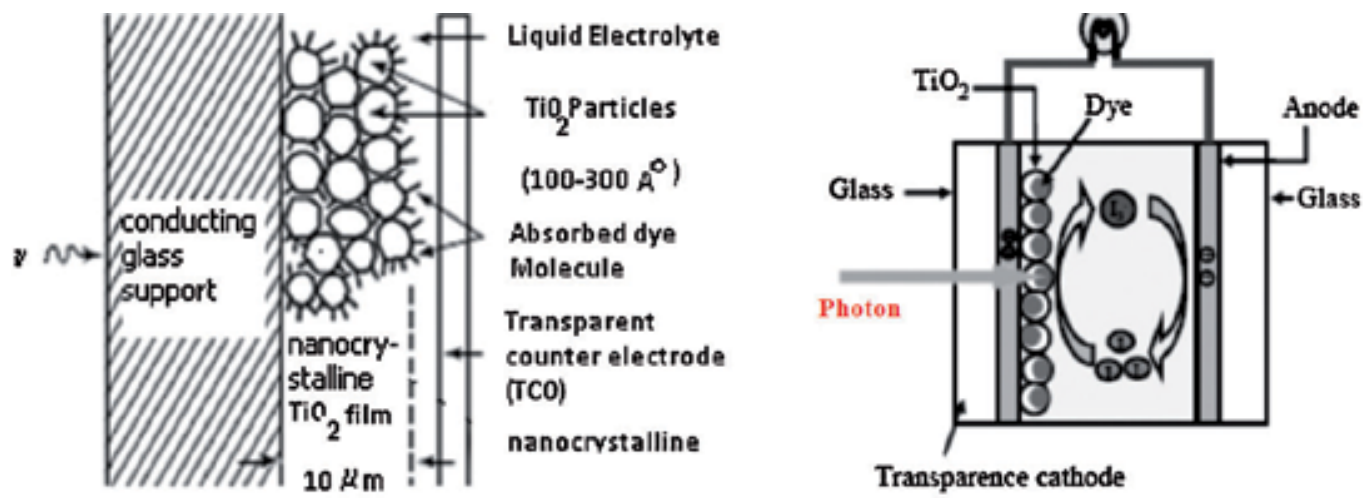

Fig. 10. Cross section of dye-sensitized solar cell (Chaar, 2011).

Lower processing costs along with flexibility of material and type usage achieved by screen printing are the characteristics of dye-sensitized solar cell which depends on a mesoporous layer of nanoparticulate $\mathrm{TiO}_{2}$ to magnify the surface area $\left(200-300 \mathrm{~m}^{2} / \mathrm{g} \mathrm{TiO}\right.$, as compared to approximately $10 \mathrm{~m}^{2} / \mathrm{g}$ of flat mono crystal). However, heat, ultra-violet (UV) light, and the interaction of solvents within the encapsulation of the cell are negative issues with this technology. Despite all the drawbacks and because of the promise of a low cost potential for cells and incorporation in paints among other things, this technology's future must be observed. Most of the current work is on the development of more efficient light absorbing dyes and on the improvement of the reliability, as well as the elimination of solvents from the electrolytes while maintaining a reasonable efficiency. The efficiencies tend to be between 5 and $10 \%$ on a cell level.

\subsection{Organic and polymer PV}

Organic solar cells and polymer solar cells are built from thin films (typically $100 \mathrm{~nm}$ ) of organic semiconductors such as polymers and small-molecule compounds like pentacene, multiphenylene vinylene, copper phthalocyanine (a blue or green organic pigment) and 
carbon fullerenes. $4-5 \%$ is the highest efficiency currently achieved using conductive polymers, however, the interest in this material lies with its mechanical flexibility and disposability. Since they are largely made from plastic opposed to traditional silicon, the manufacturing process is cost effective (lower-cost material, high throughput manufacturing) with limited technical challenges (not require high-temperature or highvacuum conditions). Electron (donor-acceptor) pair forms the basis of organic cell operation where light agitates the donor causing the electron to transfer to the acceptor molecule, hence leaving a hole for the cycle to continue. The photo-generated charges are then transported and collated at the opposite electrodes to be utilized, before they recombine. Typically the cell has a glass front, a transparent indium tin oxide (ITO) contact layer, a conducting polymer, a photoactive polymer and finally the back contact layer ( $\mathrm{Al}$, $\mathrm{Ag}$, etc.). Since ITO is expensive several groups have looked into using carbon nanotube films as the transparent contact layer. A typical cross section of an organic solar cell is shown in Fig. 11. "The year 2007 has been a turning point for PV thin film technology at least for US-based PV manufacturing with US thin film shipments reaching a market share of about $65 \% "$. However, the search for better efficiency and lower cost has never stopped. Nanotechnology seems to support sustainable economic growth by offering low cost but low efficiency PV which although not ideal offers consumers other alternatives.

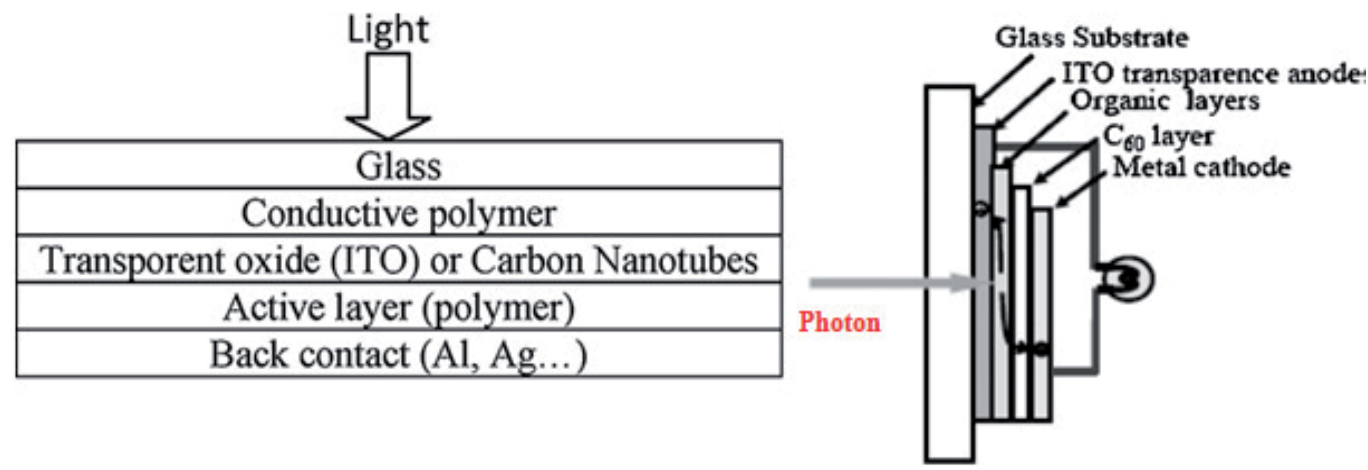

Fig. 11. Organic solar cell.

Organic photovoltaic (OPV) devices are increasingly pursued in view of their low fabrication costs and fairly easy processing. Their light weight, mechanical flexibility and large-scale roll-to-roll production capability are additional advantages compared to traditional Si-based photovoltaics. In a typical OPV device, a blend of conjugated polymer (electron donor) and a fullerene derivative (electron acceptor) is normally used as an active layer sandwiched between the cathode and the anode. The interpenetrating network of donor and acceptor components forms the bulk hetero-junction (BHJ) system for the separation of charge carriers upon illumination and subsequently transports the opposite charge carriers towards the electrodes. Among the various active layers, multi(3-hexylthiophene) (P3HT)/-phenyl-C61-butyric acid methyl ester(PCBM) combination remains the promising system researched till date and shows greater than $5 \%$ power conversion efficiency. The performance of the device, however, critically depends on the nano-scale morphology and phase separation of the blend components (Chang Li et al., 2011). 
Many strategies are employed to optimize the morphology of constituting domains (P3HT or PCBM) in terms of their size, composition, crystallinity and their connectivity to get the best device efficiency. Among them, the use of suitable solvent for both components of the blend, thermal annealing of the films before/after the deposition of electrodes [8,9], slow drying or solvent vapor treatment of blend films, the use of additives, etc., have significant impact on the thin-film morphology and hence the device performance. All these processing conditions essentially contribute to a self organization mechanism in which the P3HT chains initially crystallize as ordered domains and then PCBM molecules diffuse into the polymer chains to grow as aggregates. The characterization of this nano-scale phase separation is usually done by advanced microscopy techniques, X-ray or electron diffraction methods and recently by electron tomography as well. Since the phase segregation is at the nano-scale dimension, the packing order of P3HT and PCBM phases should also manifest in the local mechanical properties. Therefore, we consider it would be more relevant and appropriate to carry out the measurement of the nano-scale mechanical properties of the blend films to identify their correlations with the device performance if any. In this manuscript, the mechanical properties of P3HT:PCBM active layers prepared from different processing conditions are evaluated by nano indentation. We observed the lowest Young's modulus (20.73GPa) and hardness (649MPa) for P3HT:PCBM active layer films that were processed under optimum conditions to show the best power conversion efficiencies as devices. The correlations for the degree of nano-scale phase separation in the P3HT:PCBM blends as well as the device performances with the mechanical properties in the nano dimension could be estimated by nanoindentation. the P3HT:PCBM blends as well as the device performances with the mechanical properties in the nano dimension could be estimated by nanoindentation (Chang Li et al., 2011).

\section{Nanotechnology for PV cell production}

Limitations seen in other PV technologies are lessened by the introduction of nanoscale components due to their ability to control the energy band-gap will provide flexibility and inter-changeability (Serrano et al., 2009) in addition to enhancing the probability of charge recombination.

\subsection{Carbon nanotubes}

Carbon nanotubes (CNT) are constructed of a hexagonal lattice carbon with excellent mechanical and electronic properties. The nanotube structure is a vector consisting of " $\mathrm{n}$ " number line and " $\mathrm{m}$ " number column defining how the grapheme (an individual graphite layer) sheet is rolled up. Nano-tubes can be either metallic or semiconducting and they belong to two categories: mono walled or multi-walled (Fig. 12).

Carbon nanotubes can be used as reasonably efficient photosensitive materials as well as other PV material. PV nanometer-scaletubes when coated by special $\mathrm{p}$ and $\mathrm{n}$ type semiconductor materials, form a $\mathrm{p}-\mathrm{n}$ junction to generate electrical current. Such methodology enhances and increases the surface area available to produce electricity. Recently several articles have reported that "Cornell University researchers have created the basic elements of a solar cell and hope it will lead to much more efficient ways of converting light to electricity than are now used in calculators and on rooftops. The researchers, led by 
Paul McEuen, the Goldwin Smith Professor of Physics, and Jiwoong Park, assistant professor of chemistry and chemical biology fabricated, tested and measured a simple solar cell called a photodiode, formed from an individual carbon nanotube. The researchers describe how their device converts light to electricity in an extremely efficient process that multiplies the amount of electrical current that flows. According to the team, this process could prove important for next-generation high-efficiency solar cells as reported online by Cornell University and published by the group in Science".

Currently nanotubes are used as the transparent electrode for efficient, flexible polymer solar cells. Naphthalocyanine $(\mathrm{NaPc})$ dye-sensitized nanotubes have been developed and resulted in higher short circuit current however the open circuit voltage is reduced (Kyamis and Amaratunga, 2006). There are also several groups working on totally inorganic based nanoparticle solar cells, based on nanoparticles of CdSe, CdTe, CNTs and nanorods made out of the same material. In this case the scientists are trying to get rid of the complications of using a polymer based solar cells. The efficiencies are stil in the $3-4 \%$ range but much research is being conducted in this field.

(a)

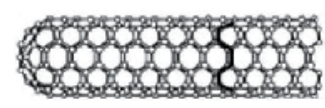

(b)

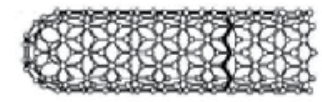

(c)

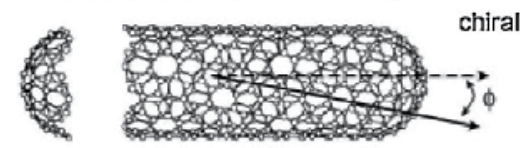

(m)
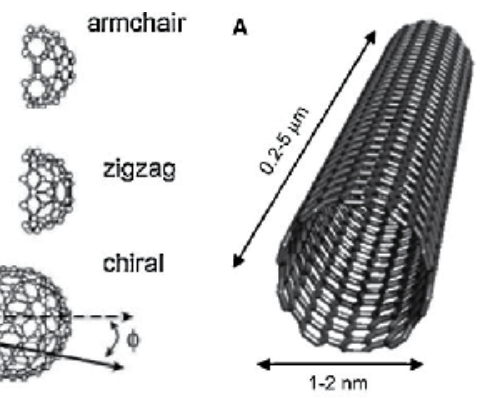

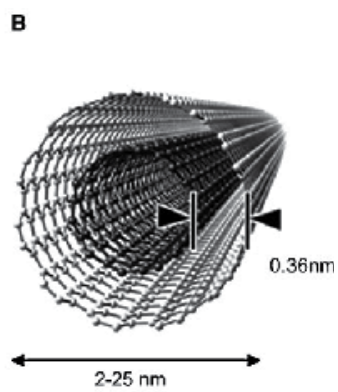

(n)

Fig. 12. (m) Mono walled nanotube and (n) double-walled (Chaar et al., 2011)

\subsection{Quantum dots}

Quantum dot (QD) metamaterials are a special semiconductor system that consists of a combination of periodic groups of materials molded in a variety of different forms. They are on nanometer scale and have an adjustable band-gap of energy levels performing as a special class of semiconductors. The PV cell with larger and wider band-gap absorbs more light hence producing more output voltage, while cells with the smaller band-gap results with larger current but smaller output voltage. The latter includes the band-gap in the red end of solar radiation spectrum. QDs are known to be efficient light emitters with various absorption and emission spectra depending on the particle size. Currently researchers are focusing on increasing the conversion efficiency of PV cells. For this reason, a 3D array design is needed for strong coupling between QDs in order extend the life of excitons for collecting and transporting "hot carriers" to generate electricity at a higher voltage. The principle of QDs has been implemented using several semiconductor materials and has resulted in the following: when GaAs was used, the cell had a high output advantage but was more expensive than $\mathrm{Si}$ semi-conductive designs such as silicon-silicon dioxide ( $\mathrm{Si}$ $\left.\mathrm{SiO}_{2}\right)$, silicon-silicon carbide $(\mathrm{Si}-\mathrm{SiC})$ or silicon-silicon nitrite $\left(\mathrm{Si}_{-}-\mathrm{Si}_{3} \mathrm{~N}_{4}\right)$. Fig. 13 shows the difference in voltage band-gap widths of each of the three Si based technology. 

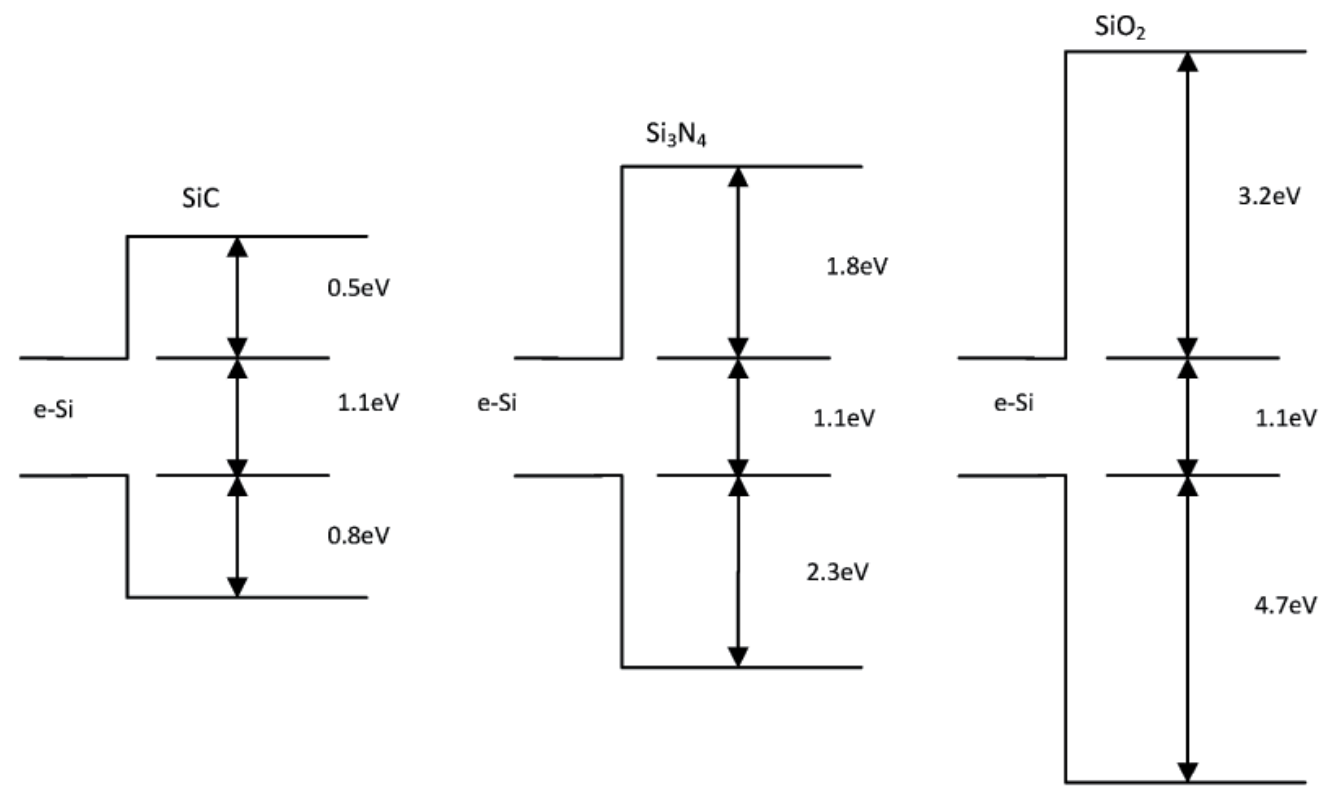

Fig. 13. Bulk band alignments between silicon and its carbide, nitride and oxide.

\subsection{Hot carrier solar cell}

This technique is the most challenging method since it utilizes selective energy contacts to extract light generated by "hot carriers" (HC) (electrons and holes) from semiconductor regions without transforming their extra energies to heat. In other words, "hot carriers" must be collected from the absorber over a very small energy range, with selective energy contacts (Fig. 14). This is the most novel approach for PV cell production and it allows the use of one absorber material that yields to high efficiency under concentration.

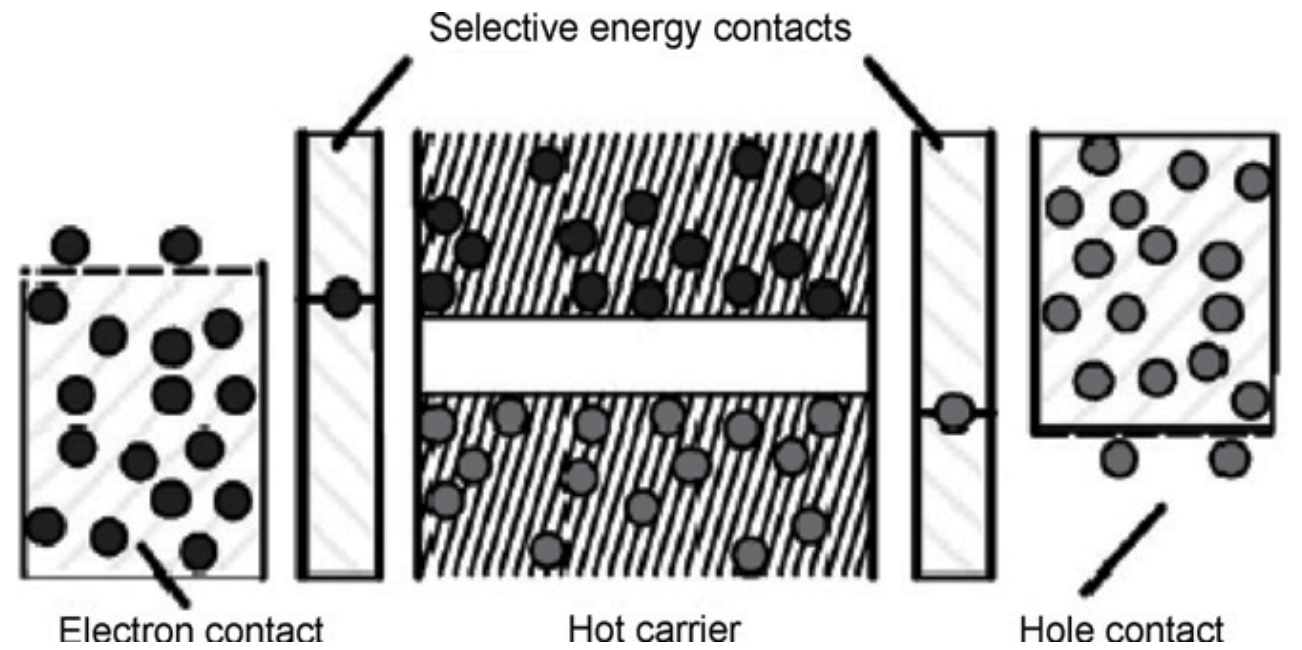

Fig. 14. Schematic and band diagram of an ideal hot carrier solar cell (Chaar et al., 2011) 


\section{Hybrid photovoltaic cell}

Itoh et al. conducted electrical output performances of 'democratic module photovoltaic system' consisting of amorphous-, multicrystalline- and crystalline-silicon-based solar cells that reveal significant differences, mainly with respect to seasonal variation and found that the annual output energy generated by amorphous-Si-based solar cell is about $5 \%$ higher than that of crystalline-Si-based arrays (Itoh et al., 2001). Wu et al. proposed a new technique of maximum power point controller, through which the proposed hybrid PV system could adopt amorphous Si solar cell together with crystalline Si solar cell to realize a PV system with higher ratio of performance to cost (Wu et al., 2005).

\section{Some other solar cells}

Mainz et al. demonstrated that rapid thermal sulphurisation of sputtered $\mathrm{Cu} / \mathrm{In}$ precursor layers is suitable for industrial production of thin film photovoltaic modules. Yoosuf et al. (2005) investigated the effect of sulfurization temperature and time on the growth, structural, electrical and photoelectrical properties of b-In2S3 films. Nishiokaa et al. (2006) evaluated the temperature dependences of the electrical characteristics of $\mathrm{InGaP} / \mathrm{InGaAs} / \mathrm{Ge}$ triple junction solar cells under concentration and found that for these solar cells, conversion efficiency decreased with increasing temperature, and increased with increasing concentration ratio owing to an increase in open-circuit voltage (Nishiokaa et al., 2006). Phani et al. (2001) described the titania solar cells that converts sunlight directly into electricity through a process similar to photosynthesis and has performance advantages over other solar cells, which include the ability to perform well in low light and shade, and to perform consistently well over a wide range of temperatures and low cost.

Some commercial manufacturers use self-organised nanostructured glass surfaces to improve system efficiencies b yaround 10\%. More carefully constructed silicon nanostructure that mimic the eyes of species of moth promise further improvements but are currently too expensive to implement (Bagnall and Boreland, 2008). However, nanoembossing and nano-imprinting technologies are rapidly developing and it is now possible to envisage regular commercial use of nanostructured broad-band antireflective surfaces within the near future, enhancing system efficiencies by more than10\%(Fig.15).

The most promising application fields for the energy conversion domain will be mainly focused on solar energy (mostly PV). Hence to improve the conversion efficiency, structures from nanotechnology products that absorb more sunlight are emphasized: devices such as nanotubes, quantum dots (QDs), and "hot carrier" solar cells.

\section{Performance and reliability}

Researchers and scientists had developed and proposed various methods for evaluation of performance of a photovoltaic system. A brief review of these methods is presented here.

Li et al. (2005) investigated the operational performance and efficiency characteristic of a small PV system installed at the City University of Hong Kong and the amount of solar irradiance data falling on the PV panel was determined using the luminous efficacy approach. Yu et al. (2004) developed a novel two-mode maximum power point tracking (MPPT) control algorithm combining the modified constant voltage control and 
incremental conductance method (IncCond) method to improve the efficiency of the 3 kWPV power generation system at different insolation conditions that provides excellent performance at less than $30 \%$ insolation intensity, covering the whole insolation area without additional hardware circuitry. Huang et al. (2006) proposed a PV system design, called "near-maximum power-point-operation" (nMPPO) that can maintain the performance very close to PV system with MPPT (maximum-power-point tracking) but eliminate the hardware of the MPPT and the long term performance simulation shows that the overall nMPPO efficiency is higher than 93\%. Jaber et al. (2003) developed a computer-simulation model of the behavior of a photovoltaic (PV) gas-turbine hybrid system, with a compressed-air store, to evaluate its performance as well as to predict the total energy-conversion efficiency and found that hybrid plant produces approximately $140 \%$ more power per unit of fuel consumed compared with corresponding conventional gas turbine plants and lower rates of pollutant emissions to the atmosphere per $\mathrm{kWh}$ of electricity generated. Stoppato (2008) presented the results of a life cycle assessment (LCA) of the electric generation by means of photovoltaic panels. Wiemken et al. (2001) studied effects of combined power generation by monitoring data from $100 \mathrm{PV}$ systems that reveals a considerable decrease in power fluctuations compared to an individual system and the energy spectrum of combined power generation showed that produced energy is generated in a range below $65 \%$ of the overall installedpower. Keogh et al. (2004) presented a new tester (commonly used for measuring solar cells and modules) design that is simple, low cost, and reduces transient errors by use of a constant voltage cell-bias circuit and it extracts a family of I-V curves over a decade range of light intensity, which provides comprehensive information on cell performance.

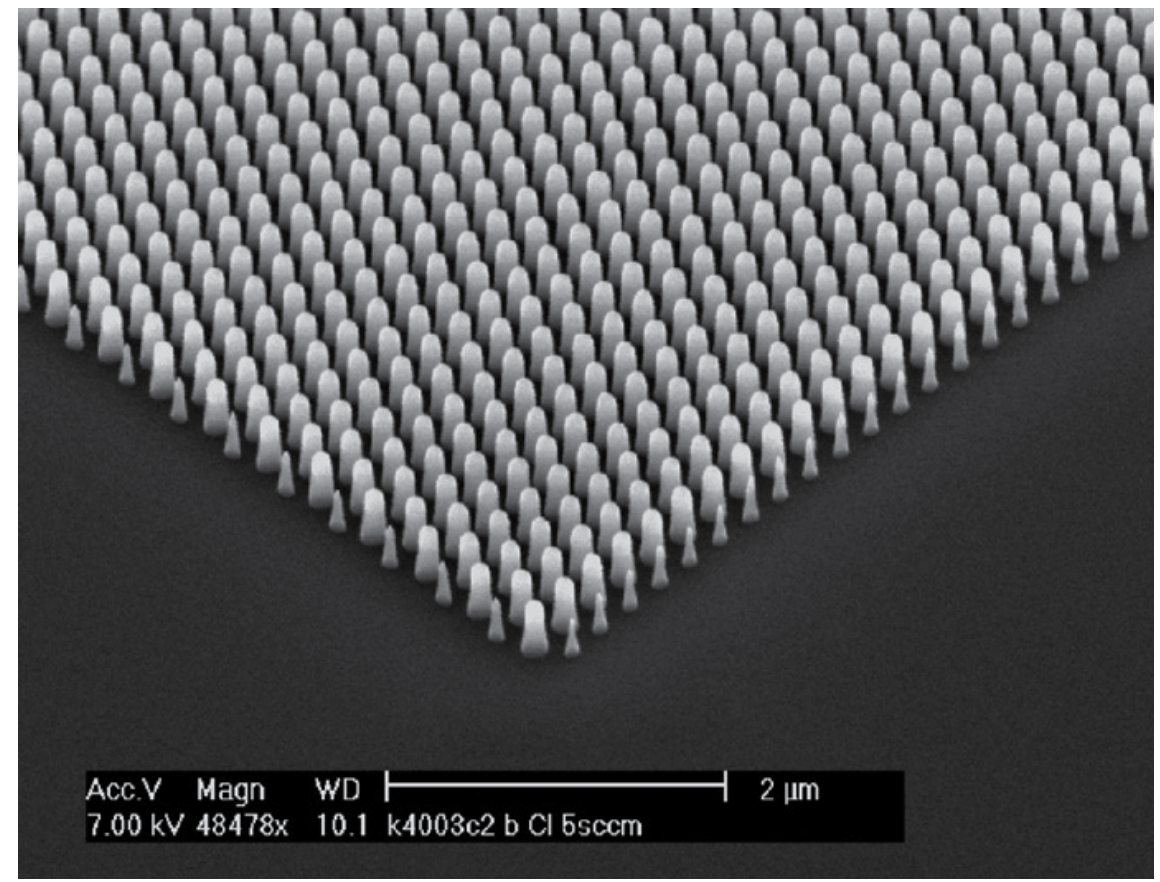

Fig. 15. SEM micrographofasilicon'moth-eye'antireflective surface (Bagnall and Boreland 2008). 


\section{Environmental aspects}

Tezuka et al. (2002) proposed a new method for estimating the amount of CO2-emission reduction in the case where the carbon-tax revenue is used as the subsidy to promote PVsystem installations and concluded that the amount of CO2-emission reduction increases by advertising the PV system with subsidy policy even under the same tax-rate and the CO2payback time of the PV system reduces by half if the GDP is assumed not to change after the introduction of carbon taxation. Krauter et al.(2004) examined a CO2 comprehensive balance within the life-cycle of a photovoltaic energy system and found that the actual effect of the PV system in terms of net reduction of carbon dioxide is the difference between the sum of electrical yield related to the local grid and the value for recycling and the sum of the production requirements and the transport emissions. Fthenakis and Kima (2007) studied solar- and nuclear-electricity-generation technologies' entire lifecycle of energy production; carbon dioxide and other gases emitted during the extraction, processing, and disposal of associated materials and determined the greenhouse gas (GHG) emissions, namely, $\mathrm{CO}$ 2, $\mathrm{CH} 4, \mathrm{~N} 2 \mathrm{O}$, and chlorofluorocarbons due to materials and energy flows throughout all stages of the life of commercial technologies for solar-electric and nuclear-power generation. Kannan et al. (2006) performed life cycle assessment (LCA) and life cycle cost analysis for a distributed 2.7kWpgrid-connected monocrystalline solar PV system operating in Singapore and provided various energy payback time (EPBT) analyses of the solar PV system with reference to a fuel oil-fired steam turbine and their greenhouse gas (GHG) emissions and costs are also compared revealing that GHG emission from electricity generation from the solar PV system is less than one-fourth that from an oil-fired steam turbine plant and onehalf that from a gas-fired combined cycle plant. Tsoutsos et al. (2005) presented an overview of an Environmental Impact Assessment for central solar systems, to estimate the magnitude of potential environmental impacts and proposed appropriate mitigation measures, can play a significant role to proper project design and to a subsequent project public acceptance.

\section{Parametric effects on PV module efficiency}

The electrical efficiency of photovoltaic modules is influenced by module construction and climatic parameters, with the primary parameters being solar irradiance, packing factor and module temperature. PV cell efficiency increases with solar irradiance, as the greater number of photons associated with higher solar irradiance creates more electron-hole pairs and consequently more current in the photovoltaic cell. The packing factor of a PV, defined as the fraction of absorber area occupied by the photovoltaic cells, significantly affects electrical output. A higher packing factor increases the electrical output per unit collector area, but also increases the module temperature. PV efficiency decreases as PV temperature increases, mainly because a higher cell temperature decreases the voltage significantly (even though it increases current by a very small amount).

Many correlations have been developed for the cell temperature $\left(\mathrm{T}_{\mathrm{c}}\right)$ as a function of climatic parameters (solar radiation, ambient air temperature, wind speed, etc.). Also, numerous correlations are available to calculate the influence of cell temperature on the efficiency of a PV cell $\left(\eta_{c}\right)$, but in most practical applications the following linear relation for the cell efficiency can be used without incurring significant loss in accuracy (Skoplaki and Palyvos, 2009): 


$$
\eta_{c}=\eta_{\text {ref }}\left[1-\beta_{\text {ref }}\left(T_{c}-T_{\text {ref }}\right)\right]
$$

where $\eta_{\text {ref }}$ is the efficiency of the photovoltaic cell at temperature $\mathrm{T}_{\text {ref. }}$. The temperature coefficient $\beta_{\text {ref }}$ is mainly determined by the cell material, which usually is provided by the manufacturer, and on the $\mathrm{T}_{\text {ref, }}$ and can be written as (Agarwal and Garg, 1994):

$$
\beta_{r e f}=\frac{1}{\left(T_{0}-T_{r e f}\right)}
$$

Here $T_{o}$ is the maximum temperature at which the efficiency of the PV cells decreases to zero. For a crystalline Si cell this temperature is about $270^{\circ} \mathrm{C}$ (Kumar and Rosen, 2011). A range of values of $\beta_{\text {ref }}$ are suggested for silicon based PV technologies.

\begin{tabular}{l|l}
\hline PV cell type & Temperature coefficient a $, \beta_{\text {ref }},\left({ }^{\circ} \mathrm{C}^{-1}\right)$ \\
\hline Mono c-Si & $0.003-0.005$ \\
Multi c-Si & 0.004 \\
a-Si & $0.0011-0.0026$ \\
PV/Thermal & $0.00375-0.0063$ \\
\hline
\end{tabular}

aThe reference temperature for each case is $25^{\circ} \mathrm{C}$.

Table 1. Temperature coefficients for various PV Technologies.

\section{Applications}

The increasing efficiency, lowering cost and minimal pollution are the boons of the photovoltaic systems that have led to a wide range of their application.

\subsection{Building integrated photovoltaic systems}

The PV system is composed of a number of individual PV modules that can be connected either in series (to increase the dc output voltage up to the desired value) to form a string. Then, multiple strings are connected in parallel to increase the output current. The possibility of using multiple strings ensures the PV system modularity, which is one of the most important features of the PV technology. The arrangement of the PV modules in strings also allows for using different solutions for the dc/ac conversion. Available solutions include the centralised inverter, collecting the dc output from the whole array of PV modules, string inverters (with one inverter for each string) or module-integrated inverters (with a mono inverter for each PV module). The centralised inverter is a solution most suitable for PV systems with rated power indicatively above $20 \mathrm{~kW}$, connected to the supply system through a three-phase inverter. The other solutions are typical of residential installations, where the power is usually not higher than $5-10 \mathrm{~kW}$ and the inverters are mono-phase. The adoption of module-integrated inverters requires the installation of a relatively high number of inverters, each one with its protections, directly on the field, paying attention to the fact that the inverters have to withstand different climatic conditions. Yet, the adoption of module-integrated inverters allows for individual and independent control of the mono inverters, with possibility of minimising the losses due to different 
electrical behavior of the modules (that is, the mismatching of the current/voltage characteristics) and may bring some benefits in increasing the system availability, since the occurrence of an inverter failure affects only a mono module and the relatively low failure rate of the inverter may prevail over the increase of the number of inverters installed with respect to the other solutions (Andrei et al., 2007).

Building-integrated photovoltaic (BIPV) systems incorporate photovoltaic properties into building materials such as roofing, siding, and glass and thus offer advantages in cost and appearance as they are substituted for conventional materials in new construction. Moreover the BIPV installations are architecturally more appealing than roof-mounted PV structures. Yoo et al. (2002) proposed a building design to have the PV modules shade the building in summer, so as to reduce cooling loads, while at the same time allowing solar energy to enter the building during the heating season to provide daylight and conducted an analysis of the system performance, evaluation of the system efficiency and the power output. Bakos et al. (2003) described the installation, technical characteristics, operation and economic evaluation of a grid-connected building integrated photovoltaic system (BIPV) and the technical and economical factors were examined using a computerized renewable energy technologies (RETs) assessment tool. Xu et al. (2008) developed and evaluated the performance of an Active Building Envelope (ABE) systems, a new enclosure technology with the ability to regulate their temperature (cooling or heating) by interacting with the sun which integrates photovoltaic (PV) and thermoelectric (TE) Technologies. Chow et al. (2003) described effectiveness of cooling by means of a natural ventilating air stream numerically based on two cooling options with an air gap between the PV panels and the external facade: (i) an open air gap with mixed convective heat transfer, and (ii) a solar chimney with buoyancy induced vertical flow and found that effective cooling of a PV panel can increase the electricity output of the solar cells. Wong et al. (2008) proposed semi-transparent PV top light material for residential application with 50\% radiation transmission rate contributing to a maximum of $5.3 \%$ reduction in heating and cooling energy consumption when compared with a standard BIPV roof. Cheng et al. (2005) developed an empirical approach for evaluating the annual solar tilted planes irradiation with inclinations from 0 to $90^{\circ}$ and azimuths from 0 to $90^{\circ}$ on building envelopes for BIPV applications in Taiwan. Ruther et al. (2008) studied the behavior of grid connected, building integrated photovoltaic(BIPV) solar energy conversion in the urban environment of a metropolitan area in a Brazilian state capital, aiming at maximizing the benefits of the distributed nature of PV generation. Jardim et al. (2008) Studied the behaviour of grid-connected, building integrated photovoltaic solar energy conversion in the built environment of ametropolitan area in Brazilian state capital, aiming at maximising the benefits of the distributed nature of PV generation.

\subsection{Desalination plant}

Lamei et al. (2008) discussed electricity price at which solar energy can be considered economical to be used for RO (Reverse Osmosis) desalination that is independent of RO plant capacity and proposed an equation to estimate the unit production costs of $\mathrm{RO}$ desalination plants that can be used to calculate unit production costs for desalinated water using photovoltaic (PV) solar energy based on current and future PV module prices. A simple mono-effect solar still plant with a capacity of $5.8 \mathrm{~m} 3$ per day for the treatment of reject brine obtained from Sadous PV-powered RO desalination plant that can be configured 
as a $100 \%$ solar powered desalination system for any location and quality of brackish water and found that the mono effect solar stills for small scale plants is more viable to use in remote area, where the land value is negligible as solar stills are easy to install and maintained and can be fabricated with locally available materials (Parida et al., 2011). ElSayed modeled desalination by spiral-wound $\mathrm{RO}$ membrane modules driven by solar to power photovoltaic converter panels with the purpose of revealing the economic potential of the combination. Weiner et al. (2001) presented the designing, erection and operation process of a stand-alone desalination plant powered by both solar photovoltaic and wind energy.

\subsection{Space}

A trade-off study in the field of space solar arrays and concentration that defines the parameters to evaluate whether a given concept (cell type, concentrator) becomes appropriate as two different trough concentrators, and a linear Fresnel lens concentrator are compared to rigid arrays and thermal and optical behaviors are analysed. Seboldt et al. a developed a new design for an Earth-orbiting Solar Power Satellite (SPS) called "European Sail Tower SPS" featuring an extremely lightweight and large tower-like orbital system with the capability to supply Europe with significant amounts of electrical power generated by photovoltaic cells and subsequently transmitted to Earth via microwaves (Parida et al., 2011). Girish (2006) studied the possibility of nighttime photovoltaic power generation in planetary bodies like moon using reflected light energy flux from nearby planetary objects based on latest low-intensity low-illumination (LILT) solar cell technology.

\subsection{Solar home systems}

Bond et al. (2007) described current experience and trials in East Timor with solar photovoltaic (PV) technology by introduction of solar home systems (SHS). Posorski et al. (2003) proposed SolarHomeSystems (SHS) that are commercially disseminated and used them cost efficiently to substitute kerosene and dry cell batteries to reduce

GHG emissions and thus make a significant contribution to climate protection.

\subsection{Pumps}

Pande et al. (2003) designed and developed a Solar Photovoltaic operated (PV) pump drip irrigation system for growing orchards in arid region considering different design parameters like pump size, water requirements, the diurnal variation in the pressure of the pump due to change in irradiance and pressure compensation in the drippers. Meah et al. (2008) discussed some policies to make solar photovoltaic water pumping (SPVWP) system an appropriate technology for the respective application region as it has proved its aspects technically, economically, and environmentally in developed countries. Short et al. (2003) investigated some of the issues involved in solar water pumping projects, described the positive and negative effects that they can have on the community and proposed an entirely new type of pump, considering the steps that could be taken to ensure future sustainability. Badescu (2003) analyzed the operation of a complex time dependent solar water pumping system consisting of four basic units: a PV array, a battery, a DC motor, and a centrifugal pump. 


\subsection{Photovoltaic and thermal (PV/T) collector technology}

Chow et al. (2007) described an experimental study of a centralized photovoltaic and hot water collector wall system that can serve as a water pre-heating system using collectors mounted at vertical facades preferring natural water circulation over forced circulation and the thermal efficiency was found $38.9 \%$ at zero reduced temperature, and the corresponding electricity conversion efficiency was $8.56 \%$. He et al. (2006) proposed the hybrid photovoltaic and thermal (PV/T) collector technology using water as the coolant as a solution for improving the energy performance. Vokas et al. (2006) studied a photovoltaicthermal system for domestic heating and cooling concluding that the system can cover a remarkable percentage of the domestic heating and cooling demands. Chow et al. (2006) presented a photovoltaic-thermosyphon collector for residential applications with rectangular flow channels and discussed the energy performance.

The merits of photovoltaic technology relative to other power generation technologies include noiseless, relatively environmentally benign, proven, long life (e.g., 20-30 years for crystalline silicon modules) and low maintenance. However, several factors limit the efficiency of photovoltaic module, e.g., $20 \%$ or less for crystalline Si and $12 \%$ or less for amorphous Si. In particular, the efficiency of PV devices decreases as temperature increases and PV cells utilize only a part of solar spectrum (less than $1.11 \mu \mathrm{m}$ for c-Si) for electricity generation. Even the total energy collected in the solar spectrum less than $1.11 \mu \mathrm{m}$ is not converted into electricity, due to the band gap restriction of silicon $(1.12 \mathrm{eV})$ (Helden et al., 2004). Therefore, much of the collected solar energy in a PV module elevates the temperature of its cells. This absorbed heat needs to be extracted to maintain a high electrical output. This requirement creates an opportunity, as the extracted heat can be utilized for many low- and medium-temperature applications.

The concept of photovoltaic-thermal collectors (PV/T) began in the 1970s and now some companies are marketing such collectors. In PV/T collectors, the photovoltaic cells are integral part of the absorber surface. These collectors are known as hybrid solar collectors due to their inherent ability to generate electricity and heat simultaneously. The working principle of these collectors is similar to flat plate solar collectors, except part of the incident solar radiation is converted into electricity. If the heat transfer fluid (air) is flowing through the flow passage attached with the absorber surface, collectors are categorized as a photovoltaic- thermal air collectors or simply PV/T air heaters (Chow, 2010).

The potential of PV/T collectors has been recognized since 1970 and has received increased attention in the past decade. Compared to using separate solar technologies for heat and electricity, the production of heat and electricity from the same collector surface is often considered more cost effective, requires less space and exhibits significantly lower balanceof-system costs (Zondaga, 2003). The potential of PV/T collectors is large, as many potential users have simultaneous requirements for heat and electricity.

\subsection{PV/T air heating collectors}

Significant research has been performed on PV/T collectors over the last four decades, on such topics as design development, numerical simulation, prototype design, experimental testing and testing methodologies for PV/T collectors. In the subsequent sections we describe major investigations on PV/T solar air collectors. 
Hegazy (2000) compared the performances of four commonly used PV/T air collector configurations (Fig. 16). In the four designs, the air flow passage is located above the absorber (model I), below the absorber (model II) and on both sides of the absorber, in a mono- pass (model III) or double-pass (model IV) mode. Numerical solutions of the energy balances indicate that the electrical and thermal outputs for models II-IV are similar and superior to that for model I, and that the pumping power needed is lowest for model III and second lowest for model IV.

Tonui and Tripanagnostopoulos (2007) improved PV/T air collectors by enhancing heat extraction. They addressed some inherent shortcomings of PV/T air collectors, such as the low density, volumetric heat capacity and thermal conductivity of air, by using a thin suspended flat metallic sheet between the absorber surface and back plate and/or by using fins on the back plate of the air duct (Fig. 17). They report energy efficiencies of $30 \%, 28 \%$ and $25 \%$, respectively, for finned, suspended metallic plate and normal air heaters. The choice of particular design depends on location, especially latitude. The use of finned systems is advantageous for higher latitudes where higher heat gains are needed in winter, whereas the PV/T system with a suspended metallic sheet is usually preferable for low latitude or tropical countries.

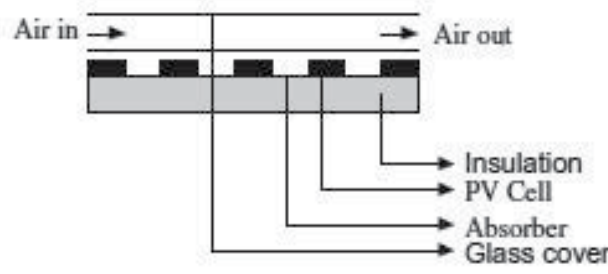

Model I

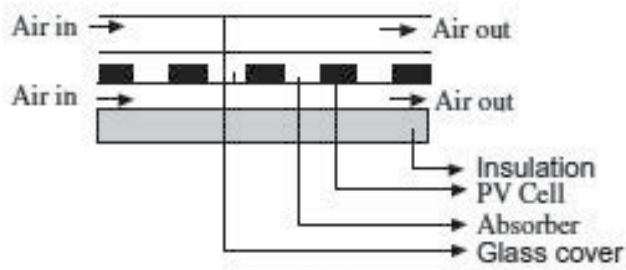

Model III

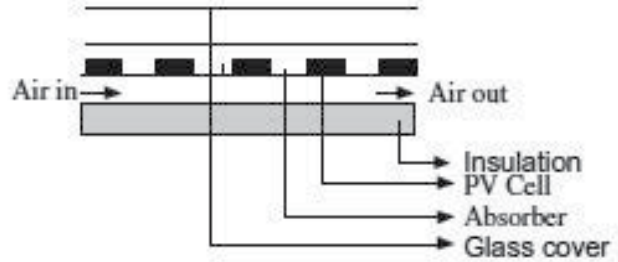

Model II

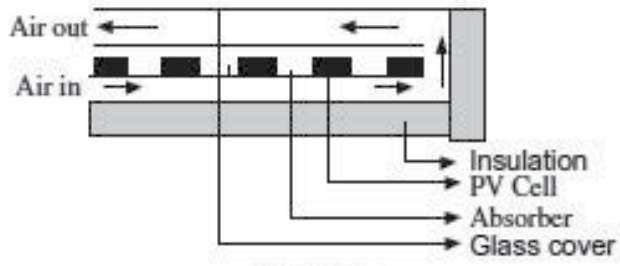

Model IV

Fig. 16. Various PV/T models (Hegazy, 2000). 
(a)

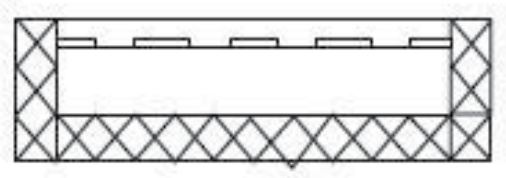

(b)

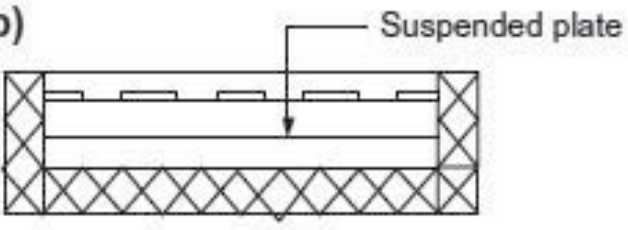

(c)

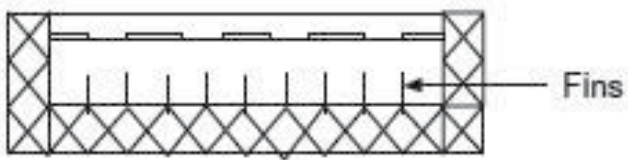

Fig. 17. Cross-sections of (a) a typical PV/T air collector, (b) a PV/T air collector with a suspended plate, and (c) a PV/T air collector with fins. Air flow is perpendicular to the page in all cases. (Tonui and Tripanagnostopoulos, 2007)

The use of a CPC with a double-pass PV/T air heater was examined by Othman et al. (2005). In the considered design, the bottom surface of the absorber has vertical fins (Fig. 18). Electricity production from the PV/T air collector was observed to depend significantly on the air flow rate and to decreases with increasing air temperature. The latter result implies that the air temperature should be maintained at a lower value to generate more electrical energy. These observations are in line with the results reported by Garg and Adhikari (1999) for PV/T air collectors using CPCs.

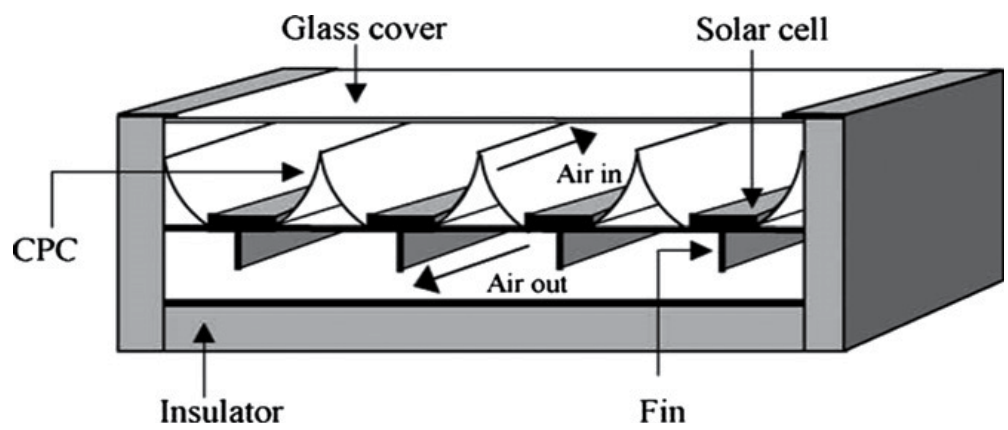

Fig. 18. Double pass PV/T air heater with CPC and fins (Othman et al., 2005).

\subsection{Other applications}

Mpagalile et al. (2006) fabricated a novel, batch operated oil press, powered by solar PV system designed to suit small-scale oil processors in developing countries with the press providing an opportunity for the processor to use different oilseeds and volumes of the materials being processed by either changing the size of the chamber or adjusting the screw rod to reduce the volume of the upper chamber and for pressing the materials at low or high pressure depending on the expression efficiency required. Xi et al. (2007) presented the development and applications of two solar-driven thermoelectric technologies (i.e., solar-driven refrigeration and solar-driven thermoelectric power generation) and the currently existing drawbacks of the solar-based thermoelectric technology as well as methods to improve and evaluate the performance of the solar- 
driven thermoelectric devices. Takigawa et al. (2003) developed a new concept of "smart power conditioner" with small storage battery for value-added PV application that has a smoothing function to reduce PV output variation and customer's load fluctuation, and also has the additional function to compensate for the harmonics current and reactive power caused by customer's load. Bechinger et al. (1998) developed self-powered electrochromic windows where a semi-transparent photovoltaic (PV) cell provides the power to activate an electrochromic system deposited on top of the solar cell and showed that dye-sensitized solar cells and EC (electrochromic) cells can be easily combined. Chow et al. (2007) developed an energy model of a PV ventilated window system and conducted the overall performance analysis for different window orientations. Ji et al. (2009) presented a novel photovoltaic/thermal solar-assisted heat pump (PV/TSAHP) system, which can generate electricity and heat energy simultaneously and introduced a mathematical model based on the distributed parameter technique for predicting the dynamic system behavior. Ahmad et al. (2006) presented a small PV power system for hydrogen production using the photovoltaic module connected to the hydrogen electrolyzer with and without maximum power point tracker .

\section{Conclusion}

Electricity produced from photovoltaic (PV) systems has a far smaller impact on the environment than traditional methods of electrical generation. During their operation, PV cells need no fuel, give off no atmospheric or water pollutants and require no cooling water. Unlike fossil fuel (coal, oil, and natural gas) fired power plants, PV systems do not contribute to global warming or acid rain. The use of PV systems is not constrained by material or land shortages and the sun is a virtually endless energy source. The cost of PV systems has decreased more than twenty times since the early 1970's, and research continues on several different technologies in an effort to reduce costs to levels acceptable for wide scale use. Current PV cells are reliable and already cost effective in certain applications such as remote power, with stand-alone PV plants built in regions not reached by the utility networks. Besides that, integration of PV systems into buildings in residential areas, where the PV system is also connected to the electricity grid to provide an alternative supply source to the load, is becoming even more attractive. Various alternatives have been designed for building-integrated PV systems, including roof-top, facade and sun-shield systems. Early solutions were aimed at superposing the PV modules onto the building structures. Yet, nowadays an increasing attention is paid to the integration of the PV modules into the structural elements that form the building architecture. Although at present the costs of the PV solutions are still not competitive in comparison to other energy sources, the adoption of buildingintegrated solutions and some incentives provided by national regulations and installation programs could make the investment on PV systems affordable. The future extent of using PV systems will strongly depend upon research to reduce costs and on the value societies place on the negative environmental impacts associated to other forms of electricity generation.

The PV module technology and the type of installation affect significantly the performance of the PV systems. Experimental studies aimed at characterizing the electrical behavior of the PV systems are then essential to understand the peculiarities of 
the different solutions and to provide operators and customers with unbiased information on the potentials of purchasing and operating a PV system. This paper deals with presenting various aspects concerning the experimental analysis of grid-connected PV systems integrated into the buildings, with the focus on technical aspects related to data acquisition, monitoring and connection to the grid. The use of "virtual instruments" for monitoring the electrical quantities, the power quality assessment and the need for excluding the PV system from operation in case of lack of supply from the grid are specifically addressed, showing examples of applications taken from two real PV systems in operation for some years. Some cases with uncommon behavior of the PV system are highlighted and discussed.

A review of major solar photovoltaic technologies comprising of photovoltaic systems, performance and reliability of PV system, environmental aspects and PV applications is presented. The different applications of solar PV system such as building integrated system, desalination plant, space, solar home systems, photovoltaic and thermal( PV/T) collectors, $\mathrm{PV} / \mathrm{T}$ air heating collectors, pumps are also presented.

\section{References}

Ahmad, G.E., El Shenawy, E.T., 2006. Optimized photovoltaic system for hydrogen production. Renewable Energy, Vol. 31, pp.1043-1054.

Andrei, H., Dogaru-Ulieru, V., Chicco, G., Cepisca, C., Spertino, F., 2007. Photovoltaic applications. Journal of Materials Processing Technology, Vol. 181, pp. 267-273.

Badescu, V., 2003. Time dependent model of a complex PV water pumping system. Renewable Energ, Vol.;28, pp.543-560.

Bagnall, D.M., Boreland, M., 2008. Photovoltaic Technologies. Energy Policy, Vol.36, pp. 4390-4396.

Bakos, G.C., Soursos, M., Tsagas, N.F., 2003. Technoeconomic assessment of a building integrated PV system for electrical energy saving in residential sector. Energy and Buildings, Vol.35, pp.757-762.

Bechinger, C., Gregg, B.A., 1998. Development of a new self-powered electrochromic device for light modulation without external power supply. Solar Energy Materials and Solar Cell, Vol.54, pp.405-410.

Bond, M., Fuller, R.J., Aye, L., 2007. A policy proposal for the introduction of solar home systems in East Timor. Energy Policy,Vol.35, pp.6535-6545.

Chaar, L.E., Iamont, L.A., Zein, N.E., 2011. Review of photovoltaic Technologies. Renewable and Sustainable Energy Reviews, Vol.15, pp. 2165-2175.

Cheng, C.L., Chan, C.Y., Chen, C.L., 2005. Empirical approach to BIPV evaluation of solar irradiation for building applications. Renewable Energy, Vol.30, pp.10551074.

Chow, T.T., Hand, J.W., Strachan PA. 2003. Building-integrated photovoltaic and thermal applications in a subtropical hotel building. Applied Thermal Engineering, Vol.23,pp.2035-2049.

Chow, T.T., He, W., Ji, J., 2006. Hybrid photovoltaic-thermosyphon water heating system for residential application. Solar Energy, Vol.80, pp.298-306. 
Chow, T.T., He, W., Ji, J., 2007. An experimental study of facade-integrated photovoltaic/water-heating system. Applied Thermal Engineering, Vol.27, pp.3745.

Chow, T.T., Fong, K.F., He, W., Lin, Z., Chan, L.S., 2007. Performance evaluation of a PV ventilatedwindowapplying to office building of Hong Kong. Energy and Buildings, Vol. 39, pp.643-650.

Chow, T.T., 2010. A review on photovoltaic/thermal hybrid solar technology. Applied Energy, Vol.87(2), pp.365-379.

Ferekides, C.S., Marinskiy, D., Viswanathan, V., Tetali, B., Palekis, V., Selvaraj, P., Morel, D.L., 2000. High efficiency CSS CdTe solar cells. Thin Solid Films, Vol.361, pp.520526.

Fthenakisa, V.M., Kima, H.C., 2007. Greenhouse-gas emissions from solar electric- and nuclear power: A life-cycle study. Energy Policy, Vol.35, pp.2549-2557.

He, W., Chow, T.T., Ji, J., Lu, J., Pei, G., Chan, L.S., 2006. Hybrid photovoltaic and thermal solar-collector designed for natural circulation of water. Applied Energy, Vol. 83, pp.199-210.

Hegazy, A., 2000. Comparative study of the performances of four photovoltaic/thermal solar air collectors. Energy Conversion \& Management, Vol.41, pp.861-881.

Helden W.G.J., Zolingen R.J.C., Zondag, H.A., 2004. PV thermal systems: PV panels supplying renewable electricity and heat. Progress in Photovoltaics: Research and Applications, Vol.12, pp.415-426.

Huang, B.J., Sun, F.S., Ho, R.W., 2006. Near-maximum-power-point-operation (nMPPO) design of photovoltaic power generation system. Solar Energy, Vol.80, pp.10031020.

Garg, H.P., Adhikari, R.S., 1999. System performance studies on photovoltaic/thermal solar air heating collector. Renew Energy, Vol.16, pp.725-730.

Girish, T.E., 2006. Nighttime operation of photovoltaic systems in planetary bodies. Solar Energy Materials \& Solar Cells, Vol.90, pp.825-831.

Green, M.A., 2006. Third-Generation Photovoltaics: Advanced Solar Energy Conversion. Springer, Berlin.

Itoh, M., Takahashi, H., Fujii, T., Takakura, H., Hamakawa, Y., Matsumoto, Y., 2001. Evaluation of electric energy performance by democratic module PV system field test. Solar Energy Materials \& Solar Cells, Vol.67, pp.435-440.

Jaber, J.O., Odeh, S.D., Probert, S.D., 2003. Integrated PV and gas-turbine system for satisfying peak-demands. Applied Energy, Vol.76, pp.305-319.

Jardim, S.C., Ruther, R., Salamoni, I.T., Viana S.T., Rebechi, S.H., Knob, P.J., 2008. The strategic sitting and the roofing area requirements of building-integrated photovoltaic solar energy generators in urban areas in Brazil. Energy and Buildings, Vol.40, pp.365-370.

Ji, .J, He, H., Chow T.T., Pei, G., He, W., Liu, K., 2009. Distributed dynamic modeling and experimental study of $\mathrm{PV}$ evaporator in a PV/T solar-assisted heat pump. International Journal of Heat and Mass Transfer, Vol.52, pp.1365-1373. 
Kannan, R., Leong, K.C., Osman, R., Ho, H.K., Tso, C.P., 2006. Life cycle assessment study of solar PV systems: An example of a $2.7 \mathrm{kWp}$ distributed solar PV system in Singapore. Solar Energy, Vol.80, pp.555-563.

Keogh, W.M., Blakers, A.W., Cuevas, A., 2004. Constant voltage I-V curve flash tester for solar cells. Solar Energy Materials \& Solar Cells, Vol.81, pp.183-196.

Krauter, S., Ruther, R., 2004. Considerations for the calculation of greenhouse gas reduction by photovoltaic solar energy. Renewable Energy, Vol.29, pp.345-355.

Kumar, R., Rosen, M.A., 2011. A critical review of photovoltaic-thermal solar collectors for air heating. Applied Energy, Vol.88, pp. 3603-3614.

Kyamis, E., Amaratunga, G.A.J., 2006. Electrical properties of mono-wall carbon nanotubepolymer composite films. Journal of Applied Physics, Vol.80, 465-72.

Li, D.H.W., Cheung, G.H.W., Joseph, C.L., 2005. Analysis of the operational performance and efficiency characteristic for photovoltaic system in Hong Kong. Energy Conversion and Management, Vol.46, pp.1107-1118.

Meah, K., Ula, S., Barrett, S., 2008. Solar photovoltaic water pumping opportunities and challenges. Renewable and Sustainable Energy Reviews, Vol.12, pp.1162-1175.

Mpagalilea, J.J., Hannab, M.A.,Weber, R., 2006. Design and testing of a solar photovoltaic operated multi-seeds oil press. Renewable Energy, Vol.31, pp.1855-1866.

Nishiokaa, K., Takamotob, T., Aguib, T,, Kaneiwab, M., Uraokaa, Y., Fuyuki, T., 2006. Annual output estimation of concentrator photovoltaic systems using highefficiency InGaP/InGaAs/Ge triple-junction solar cells based on experimental solar cell's characteristics and field-test meteorological data. Solar Energy Materials $\mathcal{E}$ Solar Cells, Vol.90, pp.57-67.

Othman, M.Y., Yatim, B., Sopian, K., Bakara, M.N.A., 2005. Performance analysis of a double-pass photovoltaic/thermal (PV/T) solar collector with CPC and fins. Renewable Energy, Vol.30, pp.2005-2017.

Othman, M.Y., Yatim, B., Sopian, K., Bakara, M.N.A., 2007. Performance studies on a finned double-pass photovoltaic-thermal (PV/T) solar collector. Desalination, Vol.209, pp.43-49.

Pande, P.C., Singh, A.K., Ansari, S., Vyas, S.K., Dave, B.K., 2003. Design development and testing of a solar PV pump based drip system for orchards. Renewable Energy, Vol.28, pp.385-396.

Parida, B., Iniyan, S., Goic, R., 2011. A review of solar photovoltaic technologies. Renewable and Sustainable Energy Reviews, Vol.15, pp.1625-1636.

Pfisterer, F., 2003. The wet-topotaxial process of junction formation and surface treatments of $\mathrm{Cu}$ S-CdS 2 thin-film solar cells. Thin Solid Films, Vol.431-432:470-6.

Phani, G., Tulloch, G., Vittorio, D., Skryabin, I., 2001. Titania solar cells: new photovoltaic technology. Renewable Energy, Vol.22, pp.303-309.

Posorski, R., Bussmann, M., Menke, C., 2003. Does the use of Solar Home Systems (SHS) contribute to climate protection? Renewable Energy, Vol.28, 10, pp.61-80.

Ruther, R., Knob, P.J., Jardim, S.C., Rebechi, S.H., 2008. Potential of building integrated photovoltaic solar energy generators in assisting daytime peaking feeders in urban areas in Brazil. Energy Conversion and Management, Vol.49, pp.1074-1079. 
Serrano, E., Rus, G., Garcia-Martinez, J., 2009. Nanotechnology for sustainable energy. Renewable and Sustainable Energy Reviews,Vol.13, pp.2372-2384.

Short, T.D., Thompson, P., 2003. Breaking the mould: solar water pumping - the challenges and the reality. Solar EnergyVol., 75, pp.1-9.

Stoppato, A., 2008. Life cycle assessment of photovoltaic electricity generation. Energy, Vol.33, pp.224-32.

Takigawaa, K., Okadaa, N., Kuwabaraa, N., Kitamurab, A., Yamamoto, F., 2003. Development and performance test of smart power conditioner for value-added PV application. Solar Energy Materials \& Solar Cells, Vol.75, pp.547-555.

Tezuka, T., Okushima, K., Sawa, T., 2002. Carbon tax for subsidizing photovoltaic power generation systems and its effect on carbon dioxide emissions. Applied Energy, Vol.72, pp.677-688.

Tonui, J.K., Tripanagnostopoulos, Y., 2007. Air-cooled PV/T solar collectors with low cost performance improvements. Solar Energy, Vol.81, pp.498-511.

Tonui, J.K., Tripanagnostopoulos, Y., 2007. Improved PV/T solar collectors with heat extraction by forced or natural air circulation. Renewable Energy, Vol.32,pp. 623637.

Tsoutsos, T., Frantzeskaki, N., Gekas, V., 2005. Environmental impacts from the solar energy technologies. Energy Policy, Vol.33, pp.289-296.

Vokas, G., Christandonis, N., Skittides, F., 2006. Hybrid photovoltaic-thermal systems for domestic heating and cooling-A theoretical approach. Solar Energy, Vol.80,pp.607615.

Weiner, D., Fisher, D., Moses, E.J., Katz, B., Meron, G., 2001. Operation experience of a solarand wind-powered desalination demonstration plant. Desalination, Vol.137, pp.713.

Wiemken, E.H., Beyer, G., Heydenreich, W., Kiefer, K., 2001. Power characteristics of PV ensembles: Experiences from the combined power production of 100 grid connected PV systems distributed over the area of Germany. Solar Energy, Vol.70, pp.513-518.

Wong, P.W., Shimoda, Y., Nonaka, M., Inoue, M., Mizuno, M., 2008. Semi-transparent PV: Thermal performance, power generation, daylight modelling and energy saving potential in a residential application. Renewable Energy, Vol.33, pp.10241036.

Wu, L., Tian, W., Jiang, X., 2005. Silicon-based solar cell system with a hybrid PV module. Solar Energy Materials \& Solar Cells, Vol.87, pp.637-645.

Xi, H., Luo, L., Fraisse, G., 2007. Development and applications of solar-based thermoelectric technologies. Renewable and Sustainable Energy Reviews, Vol.11,pp.911- 923.

$\mathrm{Xu}, \mathrm{X}$., Dessel, S., 2008. Evaluation of an active building envelope window-system. Energy and Buildings, Vol.40, pp.168-174.

Yoo, S.H., Lee, E.T., 2002. Efficiency characteristic of building integrated photovoltaics as a shading device. Building and Environment, Vol.37, pp.615- 623.

Yoosuf, R., Jayaraj, M.K., 2005. Optical and photoelectrical properties of b-In2S3 thin films prepared by two-stage process. Solar Energy Materials \& Solar Cells, Vol.89, pp.8594. 
Yu, G.J., Jung, Y.S., Choi, J.Y., Kim, G.S., 2004. A novel two-mode MPPT control algorithm based on comparative study of existing algorithms. Solar Energy, Vol.76, pp.455463.

Zondaga, H.A., Vries, D.W., Helden, W.G.J., Zolingen, R.J.C., Steenhoven, A.A., 2003. The yield of different combined PV-thermal collector designs. Solar Energy, Vol.74, pp.253-269. 


\title{
A New Adaptive Method for Distribution System Protection Considering Distributed Generation Units Using Simulated Annealing Method
}

\author{
Hamidreza Akhondi and Mostafa Saifali \\ Sadra Institute of Higher Education
}

Iran

\section{Introduction}

Distribution systems usually have radial configuration and have unbalanced operation. Distribution system protection is based on a time over current method. This method includes selection of equipment and settings, placement of equipment, and coordination of devices to clear faults with as little impact on customers as possible. Equipment in distribution protection consists of fuses, reclosers and sectionalizers. Also an over current time inverse relay usually exists inside the distribution substation at feeder outset. In distribution system, the main priorities are to prevent further damage to utility equipment, reliability and power quality (Barker \& De Mello, 2003).

The installation of small distributed generation (DG) units at distribution system has many advantages such as energy efficiency, environmental considerations and voltage support. A wide range of power generation technologies are currently in use or under development, these technologies includes: small combustion turbines and micro turbines, small steam turbines, fuel cells, small-scale hydroelectric power, photovoltaic, solar energy, wind turbines and energy storage technologies. Also, Insertion of DG in distribution systems may create technical and safety problems (Brahma, 2001). DG may contribute to increased fault currents, cause in voltage oscillations, decrease or increase losses and interfere in voltage control processes. On the other sides the distribution systems are well designed which could handle the addition of DG if proper grounding, transformers and protection is provided. In fact, all analysis about distribution system occurrence should be reanalyzed as the DG impacts are significant for both planning and operation of distribution networks. The problems associated with protection devices operation and coordination requires special review since they may affect the system security and dependability (Brahma, 2004).

A sample distribution system with DG is shown in Figure 1. In such system DG feed adjacent loads and the system doesn't have radial property. So protection devices must have directional sensitivity in systems with several sources. Fuses, reclosers and sectionalizers don't have directional property while over current relays can equipped with directional element. But displacement of fuses and reclosers with directional over current relays is impossible because of economic considerations. So we need a generalized analysis to distinguish coordination problems of fuse-fuse and fuse-recloser in presence of DG. 


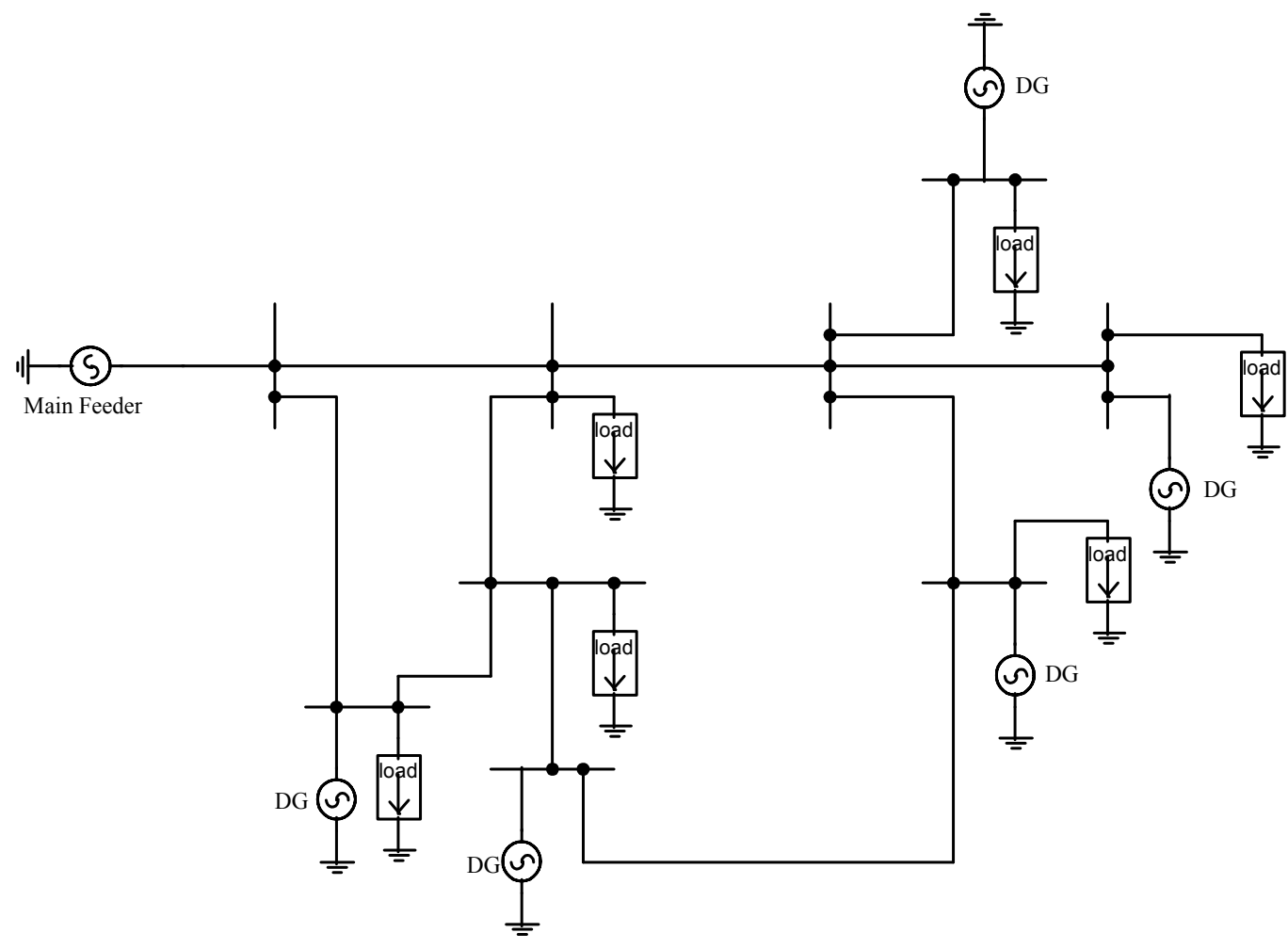

Fig. 1. Sample Distribution System with DG

In this paper, the effect of DG insertion into a distribution network on protection system operation is evaluated by means of short circuit analysis and protective device coordination. In the other words, this paper describes the characteristics of distribution feeder protection and DG interconnection protection, respectively. A new adaptive method is presented based on simulated annealing optimization method for distribution protection considering DG. Simulation results show the effectiveness of the proposed method.

\section{Proposed methodology}

As it mentioned in previous section, distribution system misses its radial nature in presence of distributed generations. So the protective devices may lose their coordination and proper operation. To keep the coordination of protective devices, it is necessary to separate distributed generations after each fault even for transient fault. The ideal for each protection scheme is that only the faulted section is separated form system and other parts maintain their operations. It should be noted that the coordination of fuse-fuse, fuse-recloser, fuserelay and relay-recloser diminish considering the loss of radial nature of distribution network after DG insertion. So the best approach is to divide the distribution system into several zones as shown in Figure 2. These zones should be separated by circuit breakers. The breakers must have the ability of system synchronization and frequent switching because of receiving a signal from main relay located in the substation. 


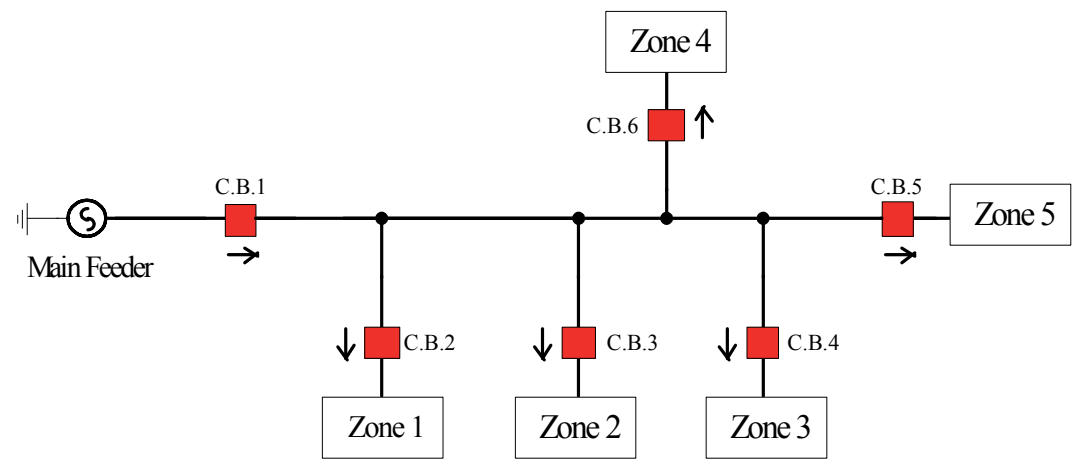

Fig. 2. Distribution system divided into several zones

Outline of proposed adaptive protection method is that first, adaptive relay detects the fault in the system and the fault in DG. If the fault occurred in DG, adaptive relay waits until DG protection system detects the fault and isolates DG from distribution system. Then DG circuit breaker sends a signal to adaptive relay so the adaptive relay will do required analysis for new condition of system. If fault is on the system bus bars, adaptive relay performs online short circuit analysis, detects the fault location and faulted zone and sends a trip command to faulted zone circuit breaker and faulted DG circuit breakers. So only the faulted zone is separated from network and other zones continue their normal operations.

\section{Inputs and online calculations}

The following measurements are used for the proposed algorithm:

- $\quad$ RMS value of three phase current in each DG and main source.

- A signal indicating the current flow direction in each zone circuit breaker and each DG circuit breaker (Chowdhury \& Crossley 2009).

The current indicating signal reports the status of circuit breakers in each zone and DG to the mail relay so the relay run the adaptive algorithm based on the network situation.

The main priciples of proposed adaptive algorithm are that first the distribution system data such as loads, line specifications, generator data, transformer data, busbar voltages, circuit beakers status and measured currents are collected and the following online steps are performed in order to specify the fault type and fault location occurred in DG or system busbars. Then a trip command is issued to separate the faulted zone from the network.

\section{Short circuit analysis}

This adaptive method is based on short circuit analysis for all types of occurred faults in different phases. Also the contribution of main feeder and each DG for various fault current in each bus must be determined. Short circuit analysis calculations have to be changed and updated after major changes in load, DG or system configuration. So after each change, short circuit analysis is performed online and required information will be send to adaptive relay in order to analysis and Prescription (Sukumar ,2001). 
In case of normal operation, total flow of all sources (main source and all DG's) is equal to load current. In case of short circuit conditions the current balance equation is written as following:

$$
\mathrm{I}_{\mathrm{F}}=\sum_{\mathrm{i}=1}^{\mathrm{N}} \mathrm{I}_{\mathrm{F}_{\mathrm{i}}}
$$

Where: $\mathrm{I}_{\mathrm{F}}$ is total fault current, $\mathrm{I}_{\mathrm{Fi}}$ is the contribution of each DG in fault current and $\mathrm{N}$ is the number of DG's.

In the proposed protective method, if a fault occurs in DG, total source currents are approximately equal to load current according to (1). With the difference that all source currents increased significantly. In this case the protection system of faulted DG sense the fault current and send the trip command to DG's circuit breakers and related zone circuit breaker. But if fault occurs in each part of system, total short circuit currents become significantly higher than load current. Thus the fault in DG is detected from fault in system. If the system fault is transient, first the trip command is sent to DG circuit breaker in faulted zone. This DG's never connected to system until the fault is removed from system. Also adaptive relay performs short circuit analysis and load flow immediately according to new network configuration (without DG's in faulted zone). After about 20 cycles, a reclosing command is sent to faulty zone circuit breaker. In this stage if the transient fault is removed, the adaptive relay send a command to DG circuit breaker after about $2 \mathrm{~s}$ and after the synchronism operation DG connected to system. After this step, adaptive relay perform the short circuit analysis for going situation. If the transient fault is unresolved in first stage of reclosing, relay sent trip command to zone circuit breaker immediately and the reclosing operation is done until three stages.

\section{Fault location determination}

In the proposed Adaptive method, a fast detection method is needed for faulted zone diagnosis. So the adaptive relay can send the trip command to each zone and faulted zone circuit breakers. It is necessary to note that faulted zone identification is enough for operation of this method. However if the faulted zone is not specified as precise as possible, much effort will be imposed to maintenance personnel to fault location determination. In order to precise fault location determination, least square method is used. This method is one of the most famous and the most practical methods in system identification theory. There is always a difference between intended structure for modeled system and actual system. Because of nonlinear specification of actual system that be considered linear in modeled system. So there is a difference $e_{t}$ between measured output and model output at any moment. The objective in the least square method is to minimize the sum of the squared errors $\left(\sum \mathrm{e}_{\mathrm{t}}^{2}\right)$.

In the presented adaptive scheme for distribution system, there is always a difference between measured current and obtained current from short circuit analysis. Since the contribution of measured currents from measurement devices and short circuit analysis of each source is available online, the adaptive method can use these currents for placement in least square method. For this purpose, a look-up table as shown in Table 1 according to short circuit analysis for each bus in each zone is formed (Dugan \& McDermott, 2002). 


\begin{tabular}{|c|c|c|}
\hline zone & & \\
\hline Bus & & \\
\hline \multirow{3}{*}{ IDG1 - Calculated } & Phase 1 & \\
\hline & Phase 2 & \\
\hline & Phase 3 & \\
\hline \multirow{3}{*}{ IDG2 - Calculated } & Phase 1 & \\
\hline & Phase 2 & \\
\hline & Phase 3 & \\
\hline \multirow{3}{*}{ ISource - Calculated } & Phase 1 & \\
\hline & Phase 2 & \\
\hline & Phase 3 & \\
\hline
\end{tabular}

Table 1. A look-up table for fault location determination

After the fault is occurred in distribution system, the adaptive relay synthesizes Table 2 with Table 1. In this table the measured currents for sources (DG's and main source) and measurement error for each source according to (2)-(3) are placed (Kotamarty et al., 2008).

\begin{tabular}{|c|c|c|}
\hline zone & & \\
\hline Bus & & \\
\hline \multirow{3}{*}{ IDG1 - measured } & Phase 1 & \\
\hline & Phase 2 & \\
\hline & Phase 3 & \\
\hline \multirow{3}{*}{ I } & Phase 1 & \\
\hline & Phase 2 & \\
\hline & Phase 3 & \\
\hline \multirow{3}{*}{ ISource - measured } & Phase 1 & \\
\hline & Phase 2 & \\
\hline & Phase 3 & \\
\hline \multicolumn{3}{|l|}{$\mathrm{E}_{\mathrm{DG} 1}$} \\
\hline \multicolumn{3}{|l|}{$E_{D G 2}$} \\
\hline ESource $_{\text {S }}$ & & \\
\hline
\end{tabular}

Table 2. Synthesized table in adaptive relay

$$
\begin{aligned}
\mathrm{E}_{\mathrm{DG}} & =\sum_{\mathrm{i}=1}^{3}\left[\left(\mathrm{I}_{\mathrm{i}}\right)_{\text {DG-Calculated }}-\left(\mathrm{I}_{\mathrm{i}}\right)_{\text {DG-measured }}\right]^{2} \\
\mathrm{E}_{\text {Source }} & =\sum_{\mathrm{i}=1}^{3}\left[\left(\mathrm{I}_{\mathrm{i}}\right)_{\text {Source-Calculated }}-\left(\mathrm{I}_{\mathrm{i}}\right)_{\text {Source-measured }}\right]^{2}
\end{aligned}
$$

When a fault is sensed in distribution system, adaptive relay forms the Table 2 immediately according to short circuit analysis and direct measurements for all system buses and calculates the error for each bus. The minimum value of error is obtained from the calculated error so the faulted bus is determined. The adaptive relay sends the trip command to faulted zone circuit breaker and prepares Table 2 for new conditions. 


\section{Proposed adaptive protection scheme algorithm}

The proposed method for adaptive protection of distribution system is shown in figure 3 . The adaptive relay receives source currents from measurement devices and compares the sum of source currents with load current. If the total current is approximately equal with load current and a fault occurs in a DG, adaptive relay waits until DG local protection system operates. If the total current be more than load current significantly, adaptive relay determines fault location and recalls the look-up table obtained from short circuit analysis. Then calculates the error of calculated current and measured current for each bus of system, considers the minimum error and determines the faulted zone. As it shown in figure 3, if there is a transient or permanent fault in system, sends the trip command to DG circuit breaker that equipped with synchronization system immediately. Then reclosing operation is done on DG circuit breaker in three stages for $t_{1}, t_{2}$ and $t_{3}$ duration time.

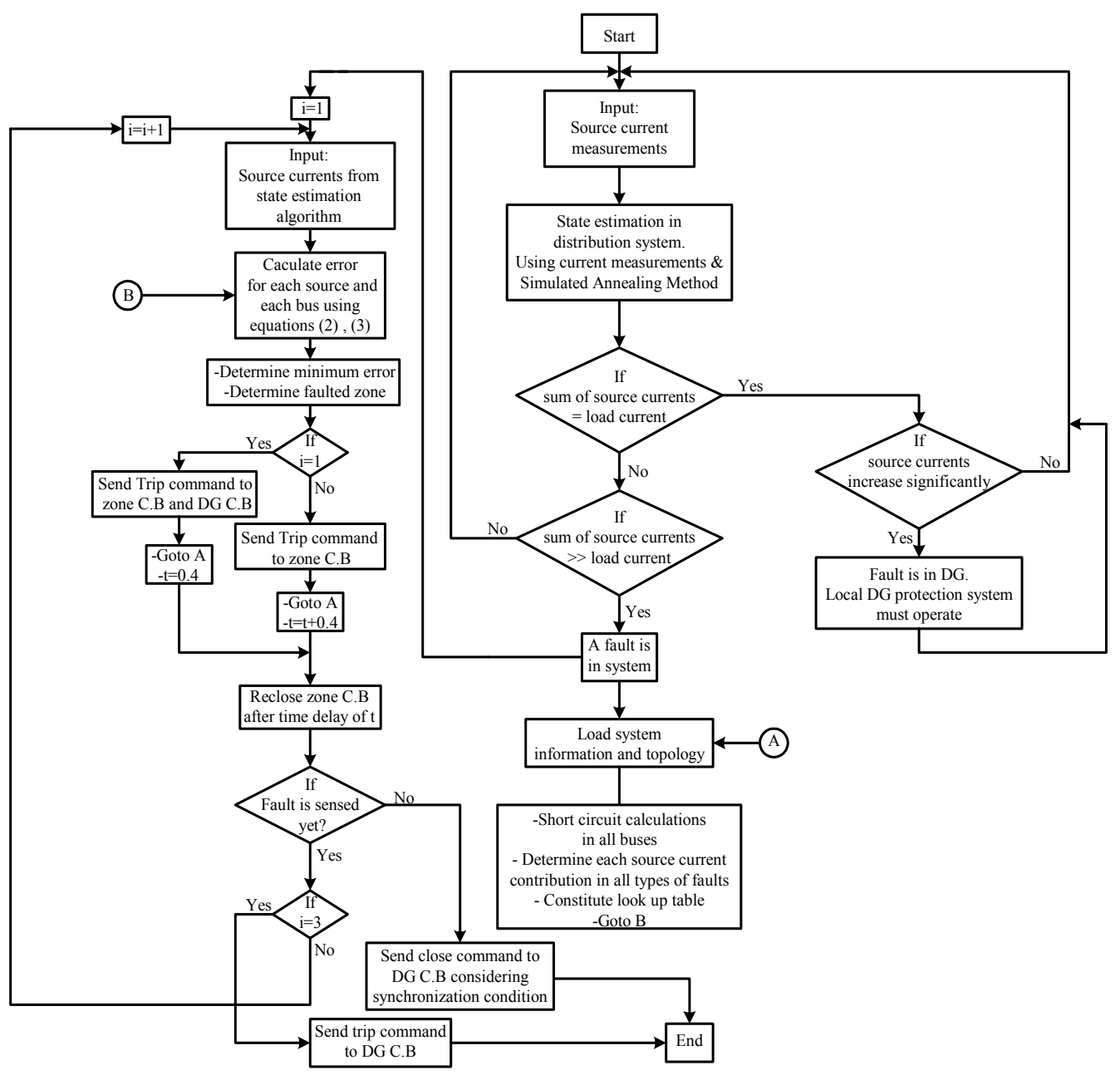

Fig. 3. Proposed adaptive protection scheme for distribution system 


\section{State estimation and simulated annealing method}

The basic idea of the state estimation method proposed in this paper is quite simple (Mori \& Saito, 2006). Besides real-time measurements, there exists other information which does not need to be measured. For sub-transmission networks, active power is always drawn from buses connected to the distribution side via transformers. On the other hand, active power taken from the transmission level is injected into a few buses of the sub-transmission portion. In general, it is possible to assert whether the specified real power for each node is less, greater than or equal to zero. This knowledge can be incorporated into the estimation process in the form of inequality constraints. The estimation problem thus becomes that of minimizing a non-linear function subject to non-linear inequality constraints. Mathematically stated:

For a given set of bus-voltage and line-current magnitude measurements, $z$, related to the vectors of state variables, $x$, and measurement error, $v$, by the following equation,

$$
z=f(x)+v
$$

The estimate $\hat{x}$ is the one which minimizes the scalar

$$
\begin{aligned}
& J(x)=[z-f(x)]^{T} R[z-f(x)]=v^{T} R v \\
& \text { Subject to } \\
& \qquad C_{i}(x) \geq 0 \quad i=1,2, \ldots, N
\end{aligned}
$$

In equation (4) the rows corresponding to a voltage measurement are trivial. For a current measurement between nodes $i$ and $j$ the following equation is used,

$$
\begin{aligned}
I_{i j}=\sqrt{A V_{i}^{2}+B V_{j}^{2}-2 V_{i} V_{j}\left(C \cos \theta_{i j}-D \sin \theta_{i j}\right)} \\
A=g_{i j}^{2}+\left(b_{i j}+b_{s h} / 2\right)^{2} \\
B=g_{i j}^{2}+b_{i j}^{2} \\
C=g_{i j}^{2}+b_{i j}\left(b_{i j}+b_{s h} / 2\right) \\
D=g_{i j} b_{s h} / 2
\end{aligned}
$$

Where $g_{i j}, b_{i j}$ and $b_{s h}$ are the $\pi$-equivalent line parameters.

Matrix $\mathrm{R}$ in equation (5) is the inverse of the measurement covariance matrix. Inequalities are the real components of the well-known Power Flow equations,

$$
C_{i}(x)= \pm \sum_{j=1}^{N} V_{i} V_{j}\left(G_{i j} \cos \theta_{i j}+B_{i j} \sin \theta_{i j}\right)
$$

Where, for load buses, the minus sign must be used. Although zero injection buses may be indistinctly regarded as loads or generators, it is advantageous, for accuracy improvement, to treat them as equality constraints. A clear advantage of current and voltage magnitude measurements is the simplicity for a pre filtering to be implemented. Voltage magnitudes 
differ more than a certain threshold from 1 p.u. should be discarded. Similarly, ampere measurements at both line ends should be almost equal for lines with negligible shunt susceptance.

In this paper the Simulated Annealing Method (SA) is used in optimization part. Simulated annealing is a method for solving unconstrained and bound-constrained optimization problems (Ingber, 1993). The method models the physical process of heating a material and then slowly lowering the temperature to decrease defects, thus minimizing the system energy. In iterations of simulated annealing algorithm, a new point is randomly generated. The distance of the new point from the current point, or the extent of the search, is based on a probability distribution with a scale proportional to the temperature. The algorithm accepts all new points that lower the objective, but also, with a certain probability, points that raise the objective. By accepting points that raise the objective, the algorithm avoids being trapped in local minima, and is able to explore globally for more possible solutions. An annealing schedule is selected to systematically decrease the temperature as the algorithm proceeds. As the temperature decreases, the algorithm reduces the extent of its search to converge to a minimum. Many standard optimization algorithms get stuck in local minima. Because the simulated annealing algorithm performs a wide random search, the chance of being trapped in local minima is decreased.

\section{Simulation results}

As it mentioned previous, proposed protective scheme is simulated for a sample distribution network. Short circuit analysis and adaptive protection algorithm must be examined simultaneously and online. PSCAD is used for adaptive algorithm and distribution system simulation and MATLAB is used for short circuit analysis and state estimation using simulated annealing method. After changes in system topology, short circuit analysis results vary. So the short circuit analysis must be shared to adaptive algorithm online and a data transfer link is needed between PSCAD and MATLAB software.

Figure 4 shows the system single line diagram, load specification, fuses and reclosers situation and distributed generations. Total load of system is 2.2 MVA and the system voltage is $20 \mathrm{kV}$. DG's characteristics are shown in table 3. DG's are modeled as a source and internal impedance and Transformers connection is D/YG 11.

For implementation of proposed method, the network is divided to four zones. Zone 1 clarifies with C.B zone1 circuit breaker and consists of main source and DG2. Zone 2 clarifies with C.B zone2 circuit breaker and consists of DG1. Zone 3 clarifies with C.B zone3 circuit breaker and consists of DG3. Finally Zone 4 clarifies with C.B zone4 circuit breaker and consists of DG4 and DG5.

\begin{tabular}{|c|c|c|c|c|c|}
\hline DG & DG1 & DG2 & DG3 & DG4 & DG5 \\
\hline S (kVA) & 400 & 150 & 400 & 200 & 150 \\
\hline R (p.u.) & 0.0476 & 0.0935 & 0.0714 & 0.0914 & 0.0429 \\
\hline X (p.u.) & 0.4846 & 0.6120 & 0.5244 & 0.7608 & 0.5389 \\
\hline
\end{tabular}

Table 3. DG's and transformers characteristics 


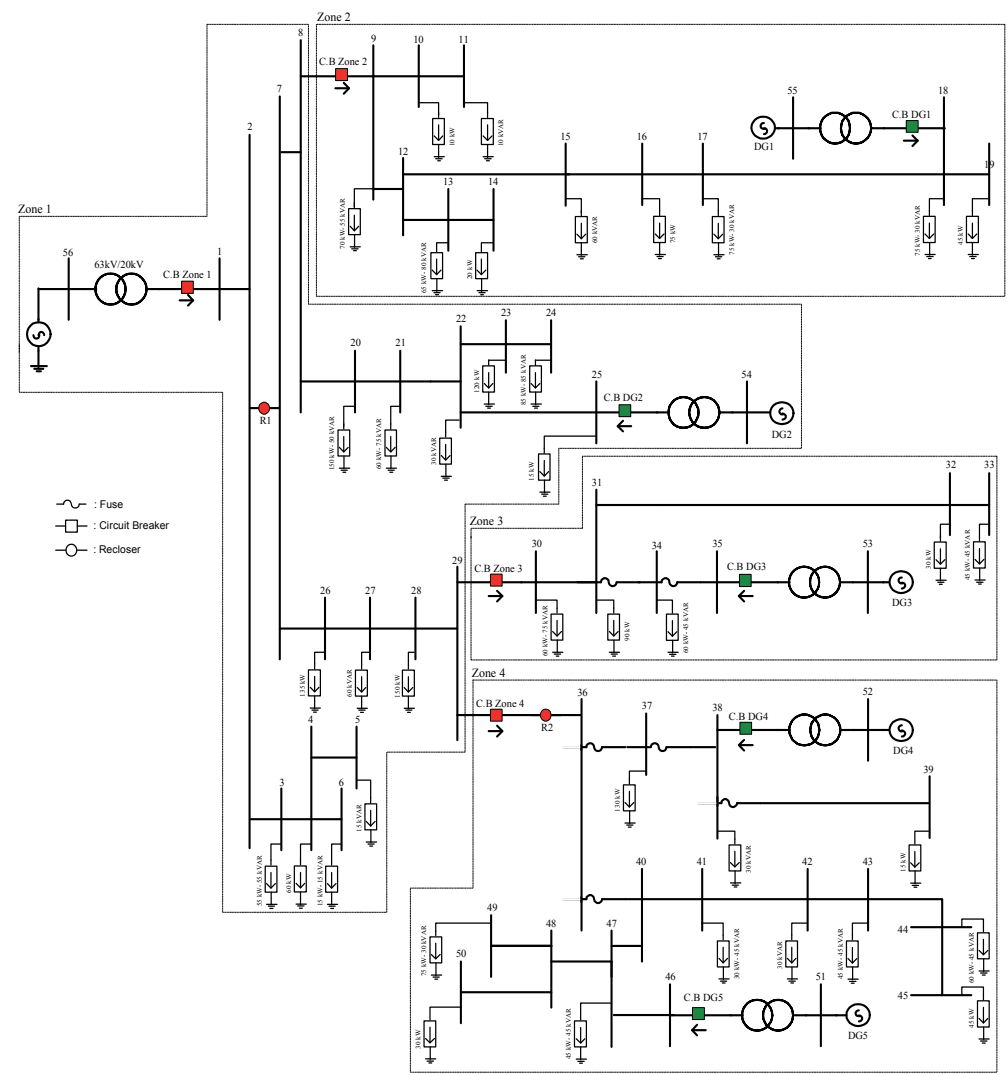

Fig. 4. Proposed adaptive protection scheme for distribution system

The adaptive algorithm is tested under different conditions and faults to ensure of proper performance. These conditions are fault in DG, permanent and transient fault in system buses. The performance of adaptive relay has been studied for some of these faults.

In case of fault occurred in DG, Adaptive relay waits until DG protection system operates and issues the trip command. As it seen in figure 5, while a fault occurs in DG1, current comparator in adaptive relay permits that DG over current relay operates. While a fault occurs in a DG, only the faulted DG must be disconnected from network and the other parts must continue their normal operations as it seen in figure 5 .

In case of studying permanent faults in a system bus, it is assumed that a fault occurs in bus 41 in zone 4 . This fault occurs at $t=2 \mathrm{~s}$ and the fault duration is $3 \mathrm{~s}$. Figures 6 shows that the adaptive relay sends a trip command to DG4, DG5 and zone 4 circuit breaker immediately. As the fault is permanent, adaptive relays doesn't allow DG's to connect on network, even after clearing the fault. After disconnecting DG4 and DG5, the adaptive relay does a reclosing operation on zone 4 circuit breaker. First reclosing is done on the circuit breaker at $0.4 \mathrm{~s}$ after fault occurrence. Second and third reclosing are done $1.2 \mathrm{~s}$ and $2.4 \mathrm{~s}$ after fault occurrence. This is shown in figure 6 . Since the fault is permanent, in each reclosing stage, the adaptive relay senses the fault and sends trip command. After the third reclosing, trip command is sent to zone 4 circuit breaker and zone 4 is disconnected from network. 


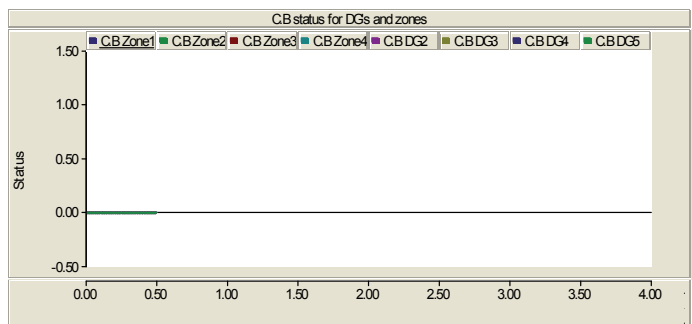

(b)

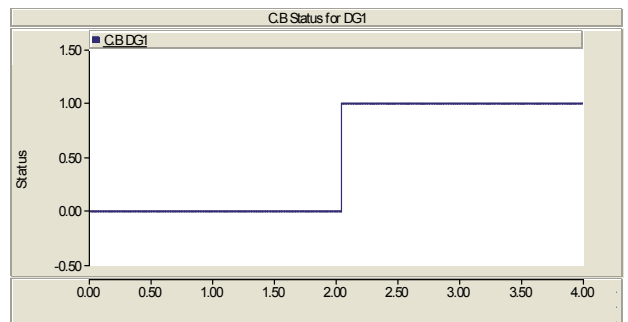

(a)

Fig. 5. Fault occurs in DG1. (a) DG1 C.B status. (b) Other DG's and zones C.B status.

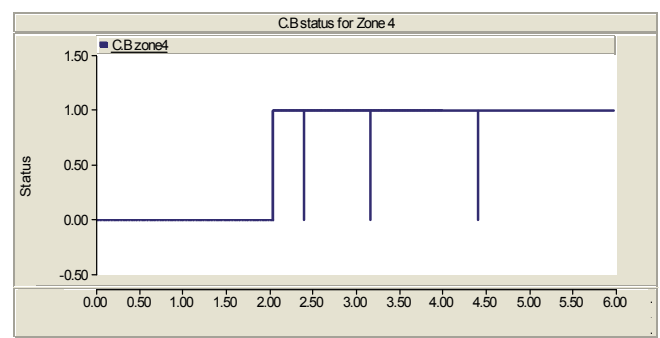

(b)

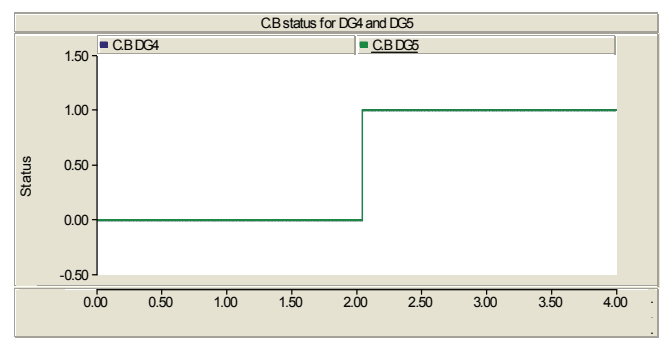

(a)

Fig. 6. Fault occurs in zone 4. (a) DG4 and DG5 C.B status. (b) Reclosing on zone4 C.B.

In the proposed method, only the faulted zone and DG's in that zone are disconnected from network and therefore the other zones can continue their normal operation. In order that the faulted zone returns to network as soon as possible, it must been detected precisely so that the fault could be cleared from the zone. Figure 7 shows the adaptive relay operation in precise fault location determination.

Finally, adaptive relay operation in case of transient fault in system has been investigated. The fault duration is considered in three cases so that we can study the adaptive relay operation at three stages of reclosing. In this simulation, first stage of reclosing is done $0.4 \mathrm{~s}$ after the fault occurrence, second stage of reclosing in done $0.8 \mathrm{~s}$ after the first reclosing and third stage of reclosing in done $1.2 \mathrm{~s}$ after the second reclosing.

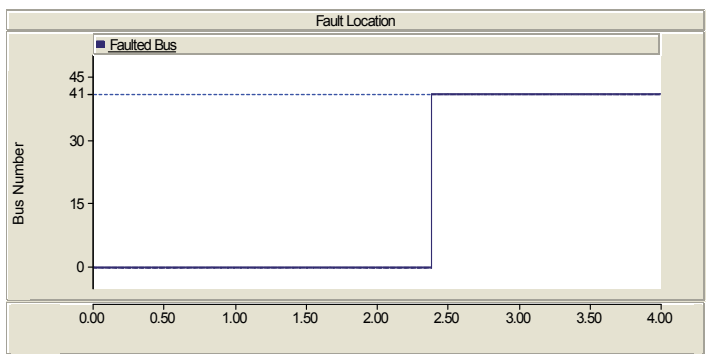

Fig. 7. Fault location determination in case of permanent fault

The fault location is in bus 32 in zone 3 , fault duration is $0.3 \mathrm{~s}$, time to apply fault is $\mathrm{t}=2 \mathrm{~s}$.

As it seen in figure 8, adaptive relay sends the trip command to zone 3 and DG3 circuit breakers. After $0.4 \mathrm{~s}$, a reclosing operation is done on zone 3 circuit breaker. As the fault duration is $0.3 \mathrm{~s}$, after the first reclosing, adaptive relay doesn't sense the short circuit 
current in the network and since a close command is sent to zone 3 circuit breaker. It is needed that DG be connected to network after fault clearing. So that synchronization operation must be done on DG3 circuit breaker. As it seen in figure 8 , adaptive relay permits DG3 circuit breaker to close after $3 \mathrm{~s}$, so that synchronization could be done.

It must be noticed that adaptive relay does reclosing operation only in faulted zone and other zones can continue their normal operation.

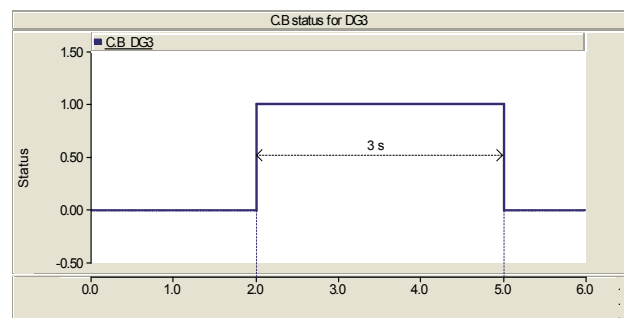

(b)

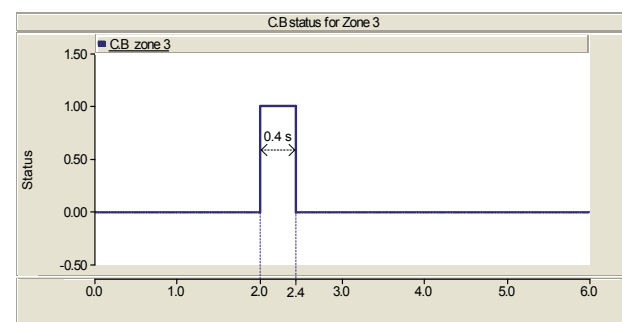

(a)

Fig. 8. Adaptive relay operation while clearing fault before first reclosing. (a) Zone 3 C.B status. (b) DG3 C.B status.

The fault location is in bus 34 in zone 3 , fault duration is $0.6 \mathrm{~s}$, time to apply fault is $\mathrm{t}=2 \mathrm{~s}$.

In this case, after the fault is sensed with adaptive relay in network, the trip command is sent to DG3 and zone 3 circuit breakers immediately. As it seen in figure 9, does the first reclosing on zone 3 circuit breaker. According to the fault time that is more than $0.4 \mathrm{~s}$, relay senses the fault in first reclosing and sends trip command to zone 3 circuit breaker instantaneously. Adaptive relay send a close command to zone 3 circuit breaker $0.8 \mathrm{~s}$ after the first reclosing. Since the fault time is $0.6 \mathrm{~s}$, relay doesn't sense the fault in second reclosing and permits zone 3 circuit breaker to close. Moreover adaptive relay permits DG3 circuit breaker to close $2 \mathrm{~s}$ after second reclosing by the synchronization operation. In the explained situation, other zones should operate normally in network.

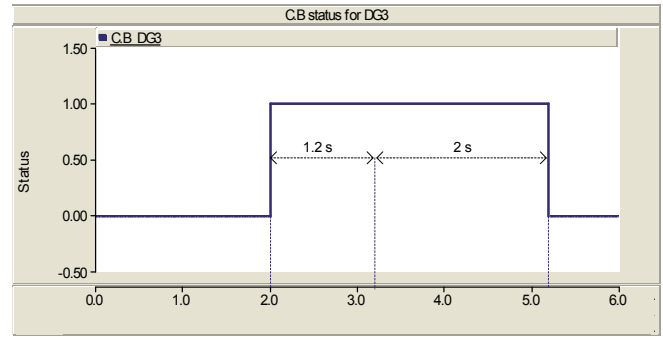

(b)

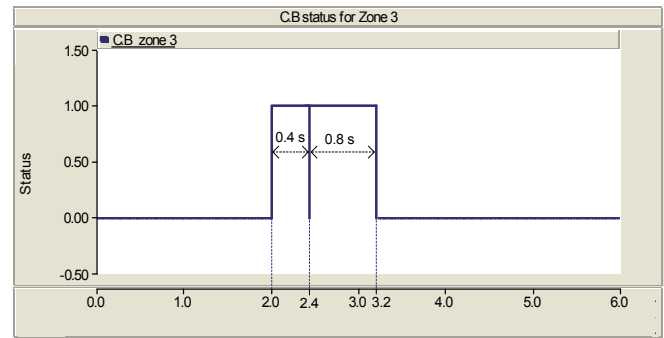

(a)

Fig. 9. Adaptive relay operation while clearing fault before second reclosing. (a) Zone 3 C.B status. (b) DG3 C.B status.

\section{Conclusion}

Distributed generations have possible characteristics for system operation enhancement. Using DG's in distribution systems has many benefits such as system reliability improvement, power loss reduction, development costs decrease, power quality 
improvement and load peak clipping. Also using DG's in systems has disadvantages such as interaction with protective systems, voltage control problems and DG islanding.

While a DG is inserted in distribution system, some parts of system lose their radial characteristics and protective devices coordination is lost. If the influence of DG be intensive, then coordination of protective devices with usual method is impossible. The proposed adaptive protection scheme does short circuit analysis online and whenever system configuration varies, this analysis execution is done and a look up table is conformed. The adaptive scheme diagnoses fault location, faulted bus and faulted zone by the discussed method.

If the fault is permanent, adaptive relay disconnected only the faulted zone and DG's in that zone and other zones continue their normal operation. If the fault is transient, adaptive relay sends trip command to faulted zone and its DG's circuit breakers and then does a reclosing operation in three time stage. If the fault be cleared in each stage, relay sends close command to zone circuit breaker and sends close command to DG circuit breaker after $2 \mathrm{~s}$ or $3 \mathrm{~s}$ for synchronization operation. Adaptive relay disconnects DG's in faulted zone wether the fault is permanent or transient.

\section{References}

Barker P. and De Mello R. (2003). Determining the Impact of Distributed Generation on Power Systems: Part 1-Radial power systems. Proceeding of IEEE Power Engineering Society. Summer Power Meeting, (2003), pp. 1645-1658.

Brahma S. (2001). Effect of Distributed Generation on Protective Device Coordination in Distribution System. Proceeding of Large Engineering Systems Conference on Power Engineering, Halifax, Canada, (2001), pp. 115-119.

Brahma S. (2004). Development of Adaptive Protection Scheme for Distribution Systems with High Penetration of Distributed Generation. IEEE Transactions on Power Delivery. Vol. 19, No. 1, (January 2004). pp. 56-63.

Chowdhury S. and Crossley P. (2009). Islanding Protection of Active Distribution Networks with Renewable Distributed Generators: A comprehensive survey. ELSEVIER Electric Power Systems Research. Volume 79, Issue 6, (June 2009), Pages 984-992.

Dugan R. and McDermott T. (2002). Operating conflicts for Distributed Generation interconnected with Utility Distribution Systems. IEEE Industry Applications Magazine, 19-25, (March/April 2002).

Ingber L. (1993). Simulated annealing: practice versus theory. Mathematical and Computer Modeling, vol.18, (1993), pp.29-57.

Kotamarty S., Khushalani S. and Schulz N. (2008). Impact of Distributed Generation on Distribution Contingency Analysis Electric. ELSEVIER Power Systems Research, Volume 78, Issue 9, (September 2008), Pages 1537-1545.

Mori H. and Saito S. (2006). A Power System State Estimation Technique in Consideration of Network Topology. IEEE International Conference on Systems, Cybernetics, 2006.

Sukumar M. (2001). Development of Adaptive Protection Scheme for Distribution Systems with High Penetration of Distributed Generation. IEEE Transactions on Power Delivery, Vol. 19, No. 1, (January 2004), pp. 56-63. 


\title{
Exergoeconomic Analysis and Optimization of Solar Thermal Power Plants
}

\author{
Ali Baghernejad and Mahmood Yaghoubi \\ Mechanical Engineering School, Mechanical Engineering School, Shiraz University, \\ Iran
}

\section{Introduction}

There is a growing demand for electricity in the developing countries. The conventional approaches to meet this need are through the construction of fossil-fuel power plants. The operation of these plants, however, releases carbon dioxide and contributes to the problem of climate change. Furthermore, many of these countries rely on imports for their energy needs and the purchase of fossil fuel weakens their financial potential. Unlike hydrocarbon energies, renewable energy can be developed from resources which are constantly replenished and will never run out. These energies include:

- Solar Power which utilizes the energy from sunlight either indirectly or directly. It can be used for heating and cooling, generating electricity, lighting, water desalination, and many other commercial and industrial uses.

- Wind Power which captures the energy of the wind through wind turbines.

- Biomass Energy which uses the energy from plants and plant-derived materials, such as wood, food crops, grassy and woody plants, residues from agriculture or forestry, and the organic component of municipal and industrial wastes.

- Geothermal Energy which utilizes the heat from the earth, drawn from hot water or steam reservoirs in the earth's mantle located near the earth's surface.

- Ocean Energy which traps thermal energy from the sun's heat and mechanical energy from the tides, underwater currents and waves.

- Hydropower which captures the energy from flowing water to power machinery and produce electricity

Many developing countries have an abundance of a natural energy source: solar radiation. Operation of solar thermal power plants (STPP) would reduce their reliance on fossil fuels. Regions that could make use of these systems include Southern Africa, Middle East and North Africa (MENA) India, Northern Mexico and parts of South America. The developed regions of Southwest U.S. and Australia could also benefit from this technology.

In this chapter attempt is made to have a brief introduction of solar thermal power plant (STPP) systems and cycles. To develop new approaches to exergoeconomic analysis of such plants, the main elements of exergy and economic analysis are explained. Various methods of optimization from single objective to multi objectives applicable to STPP are developed. Finally application of the developed optimization methods for a sample integrated solar 
combined cycle system (ISCCS) are illustrated. It has been shown that the new optimization schemes are strong tools which can be used to find optimum operating condition based on the main objectives of any thermal plant.

\section{Solar parabolic trough systems}

Solar thermal power plants (STPP) are one of the promising options for electricity supply as demonstrated in some countries during the past decades (Singh \& Kaushik, 1994). These plants with parabolic trough type of solar collectors featuring gas burners and Rankine steam cycles have been successfully demonstrated by California's Solar Electric Generating Systems (SEGS).

Trough systems use linear concentrators of parabolic shape with highly reflective surfaces, which can be turned in angular movements towards the sun position and concentrate the radiation onto a long-line receiving absorber tube. The absorbed solar energy is transferred by a working fluid, which is then piped to a conventional power conversion system. The used power conversion systems are based on two technologies:

- $\quad$ Rankine-Cycle STPP

- Integrated Solar Combined-Cycle Systems (ISCCS) and other hybrid systems.

Rankine-cycle plants are a mature technology that offers a high solar contribution. Recently, integrating the solar collector system with a gas-fired combined-cycle system has been proposed as a lower cost alternative for generating solar-powered electricity.

\subsection{Rankine-cycle systems}

The Rankine-cycle STPP is a steam-based power plant with solar energy as the heat source. The system is a typical Rankine cycle (see Figure 1). The hot collector heat transfer fluid transfers its heat in the heat exchanger to the water/steam. The steam drives the turbine to produce electricity. The spent steam is condensed into water in the condenser. The water is reheated in the heat exchanger and the cycle repeats. Because of the seasonal and daily variation in solar radiation, a Rankine-cycle system can only be expected to operate at full load for approximately 2400 hours annually (25\% capacity factor) without the use of thermal storage. In most cases, it makes sense to add a fossil-fuel heater so that the system can operate at full load for more hours. Back-up fuels can be coal, oil, naphtha and natural gas. The number of hours that such plant can operates depends on the local conditions. In most cases, however, it makes sense to operate this type of plant to meet the daily periods of high demand for electricity (10 to 12 hours per day). However, Rankine-cycle systems suffer from relatively low efficiencies (whether solar or fossil-fuel powered). The conversion of heat to electricity has an efficiency of about $40 \%$. If the conversion efficiency from fossil fuel to heat is included, the plant efficiency drops to approximately 35\% (Status Report on Solar Thermal Power Plants, 1996).

\subsection{Integrated solar combined cycle systems}

Between 1984 and 1990, Luz International Limited developed, built, and sold nine parabolic trough solar power plants in the California Mojave Desert. These plants, called Solar Electric Generating Stations and referred to as SEGS I- IX, range in size from 14 MWe to $80 \mathrm{MWe}$ and make up a total of $354 \mathrm{MWe}$ of installed generating capacity. The details of these plants are summarized in Table 1 (www.greenpeace.org, 2005). 


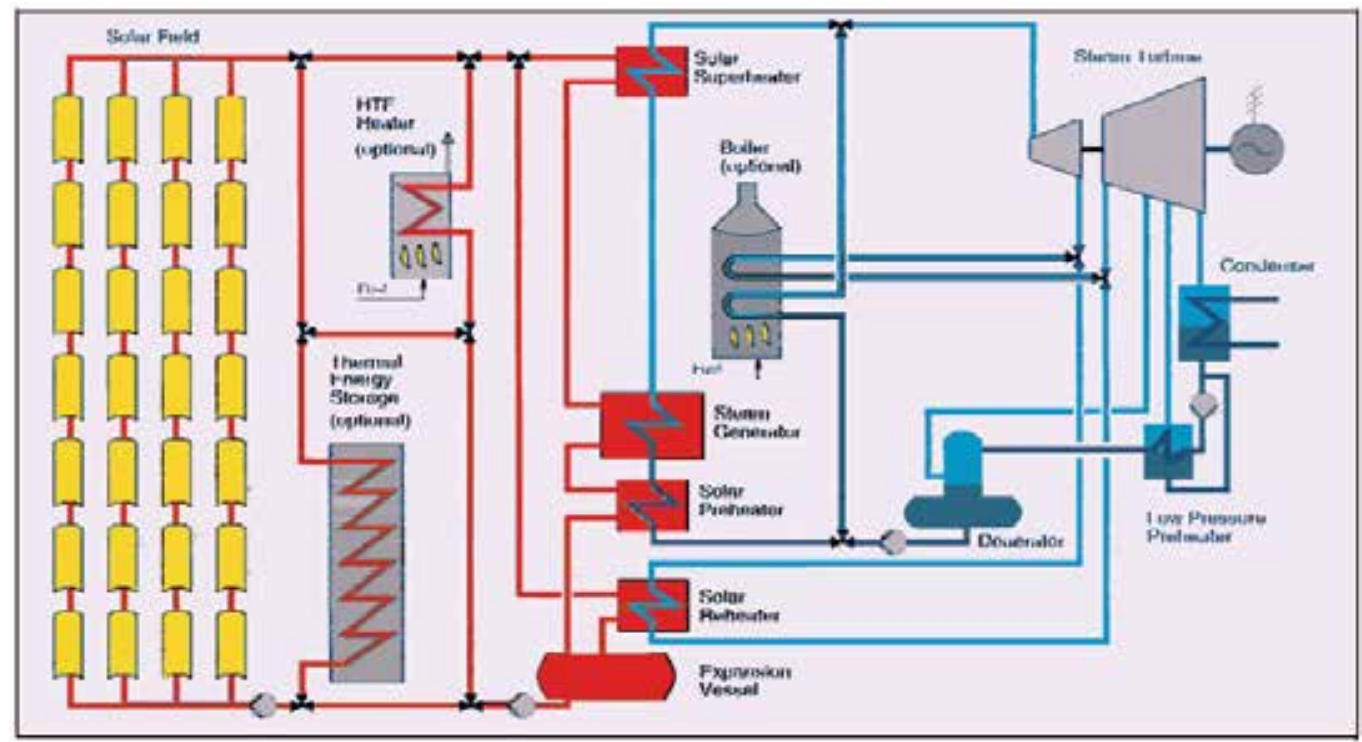

Fig. 1. Schematic diagram of a Rankine- Cycle STTP

The SEGS plants in California utilized a solar steam system to provide inlet steam for a conventional (Rankine) cycle steam turbine power plant. In addition to the standard SEGS configuration, Luz International Limited conceived a system configuration for a solar field integrated with a gas-fired combined cycle plant. This concept, known as the Integrated Solar Combined Cycle System (ISCCS), is derived from a conventional combined cycle design in which the exhaust heat from the combustion turbine generates steam in a heat recovery steam generator (HRSG) to drive a steam turbine connected to a generator, with supplemental heat input from the solar field to increase the steam to the steam turbine (Baghernejad \& Yaghoubi, 2010). This approach offers a potentially more cost effective and thermodynamically efficient method to utilize solar thermal energy to produce electricity compared to the use of solar energy with a conventional boiler fired (Rankine) cycle plant. In comparison to existing Rankine cycle power plants with parabolic trough technology (SEGS), ISCCS plants offer three principal advantages: First, solar energy can be converted to electric energy at a higher efficiency. Second, the incremental costs for a larger steam turbine are less than the overall unit cost in a solar-only plant. Third, an integrated plant does not suffer from the thermal inefficiencies associated with the daily start-up and shutdown of the steam turbine. Crucial issues in the effective utilization of parabolic trough solar fields in combination with combined cycle plants are the ability to achieve a significant reduction in global emissions, the effective annual heat rate of the combined system, and the cost impact on the plant output (Baghernejad \& Yaghoubi, 2011a). 


\begin{tabular}{|l|c|c|c|c|c|c|c|c|c|}
\hline \multicolumn{1}{|c|}{ Unit } & I & II & III & IV & V & VI & VII & VII & IX \\
\hline Capacity (MW) & 13.8 & 30 & 30 & 30 & 30 & 30 & 30 & 80 & 80 \\
\hline Land Area (ha) & 29 & 67 & 80 & 80 & 87 & 66 & 68 & 162 & 169 \\
\hline $\begin{array}{l}\text { Solar field } \\
\text { aperture area (ha) }\end{array}$ & 8.3 & 19 & 23 & 23 & 25.1 & 18.8 & 19.4 & 46.4 & 48.4 \\
\hline $\begin{array}{l}\text { Solar field outlet } \\
\text { temperature (0C) }\end{array}$ & 307 & 321 & 349 & 349 & 349 & 391 & 391 & 391 & 391 \\
\hline \multicolumn{7}{|c|}{ Annual Performance (Design value) } & & & \\
\hline $\begin{array}{l}\text { Solar field } \\
\text { thermal } \\
\text { efficiency (\%) }\end{array}$ & 35 & 43 & 53 & 53 & 53 & 53 & 53 & 53 & 50 \\
\hline $\begin{array}{l}\text { Solar to net } \\
\text { electrical } \\
\text { efficiency (\%) }\end{array}$ & 9.3 & 10.7 & 10.2 & 10.2 & 10.2 & 12.4 & 12.3 & 14 & 13.6 \\
\hline $\begin{array}{l}\text { Net electricity } \\
\text { production } \\
\text { (GWh/yr) }\end{array}$ & 30.1 & 80.5 & 91.3 & 91.3 & 99.2 & 90.9 & 92.6 & 252.8 & 256.1 \\
\hline Unit cost (\$/kW) & 4490 & 3200 & 3600 & 3730 & 4130 & 3870 & 3870 & 2890 & 3440 \\
\hline
\end{tabular}

Table 1. Characteristics of Luz SEGS plants (www.greenpeace.org, 2005)

\section{Exergy analysis}

Exergy is defined as the maximum possible reversible work obtainable in bringing the state of a system to equilibrium with that of environment (Bejan et al., 1996). The physical exergy component is associated with the work obtainable in bringing a stream of matter from its initial state to a state that is in thermal and mechanical equilibrium with the environment. The chemical exergy component is associated with the work obtainable in bringing a stream of matter from the state that is in thermal and mechanical equilibrium with the environment to a state that is in the most stable configuration in equilibrium with the environment. Therefore the exergy of any state of system is:

$$
\dot{E}=\dot{E}_{P H}+\dot{E}_{C H}
$$

The physical exergy component is calculated using the following relation:

$$
\dot{E}_{P H}=\dot{m}\left[\left(h-h_{0}\right)-T_{0}\left(s-s_{0}\right)\right]
$$

The exergy of the air and gas streams per unit mass are defined by (Moran \& Sciubba, 1994):

$$
e_{i}=C_{p, A i r(G a s)}\left[T_{i}-T_{0}-T_{0} \ln \left(\frac{T_{i}}{T_{0}}\right)\right]+R_{\text {Air }(\text { Gas })} T_{0} \ln \left(\frac{P_{i}}{P_{0}}\right)
$$

Energy and exergy analyses for a solar collector-receiver subsystem, Fig. 2 have been carried in Baghernejad and Yaghoubi (2010). 


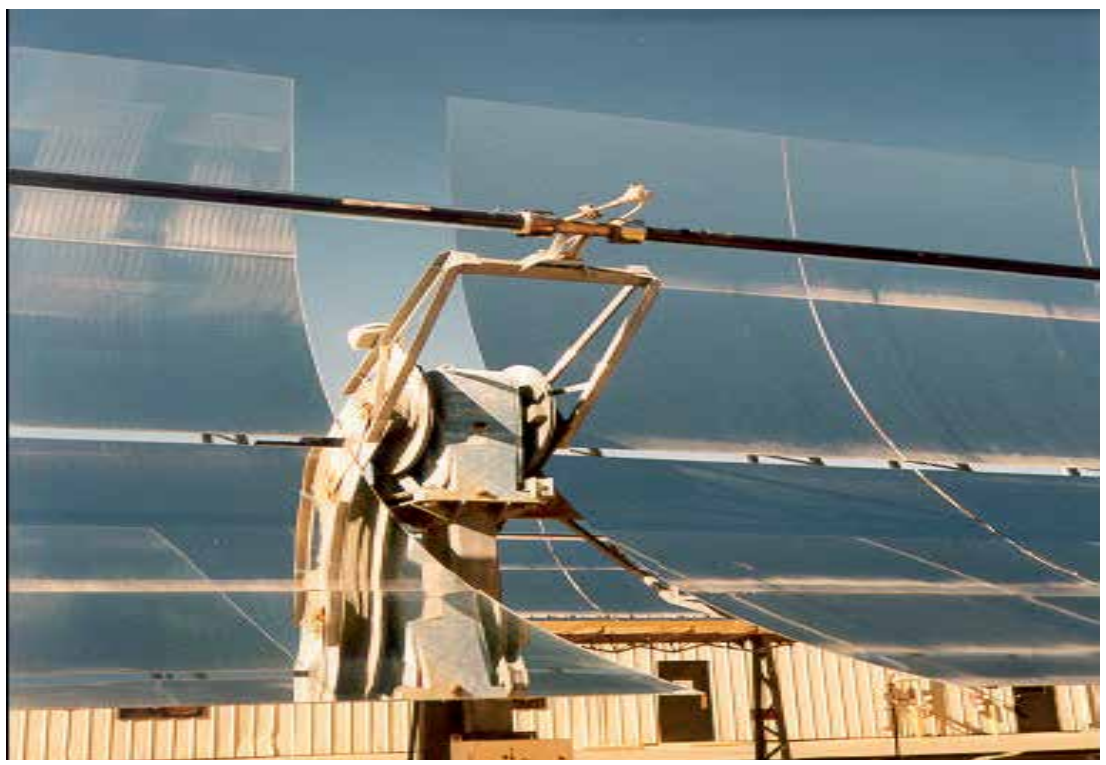

Fig. 2. Typical solar collector-receiver subsystem

\section{Economic model}

The economic model takes into account the cost of the components, including amortization and maintenance, and the cost of fuel consumption. In order to define a cost function which depends on the optimization parameters of interest, component costs have to be expressed as functions of thermodynamic variables (Baghernejad \& Yaghoubi, 2011a, 2011b). These relationships can be obtained by the statistical correlations between costs and the main thermodynamic parameters of the component performed on real data series. The expressions of purchase components costs and amortization factor are accepted here similar to (Schwarzenbach \& Wunsch, 1989). Its format is widely used by various authors but some coefficients were adapted to quotation made by manufacturers. The new coefficients also taken into account the installation, electrical equipment, control system, piping and local assembly.

\section{Exergoeconomic principles}

In the analysis and design of energy systems, the techniques which combine scientific disciplines with economic disciplines to achieve optimum design are growing in the energy industries (Valero, 2004). Exergoeconomic analysis as a powerful scheme is such a method that combines exergy analysis with economic studies. This method provides a technique to evaluate the cost of inefficiencies or cost of individual process streams, including intermediate and final products of any system. These costs are applicable in feasibility studies, for investment decisions, on comparing alternative techniques and operating conditions, in a cost-effective section of equipments during an installation, and an exchange or expansion of an energy system (Johansson, 2002; Verda, 2004). Also it can be utilized in optimization of thermodynamic systems, in which the task is usually focused on minimizing the unit cost of the system product. 
The prerequisite for the exergoeconomic analysis is a proper 'fuel-product-loss' (F-P-L) definition of the system to show the real production purpose of its subsystems by attributing a well defined role, i.e. fuel, product or loss, to each physical flow entering or leaving the subsystems. The fuel represents the resources needed to generate the product and it is not necessarily restricted to being an actual fuel such as natural gas, oil, and coal. The product represents the desired result produced by the system. Both the fuel and the product are expressed in terms of exergy. The losses represent the exergy loss from the system. Once the FP-L of a system is defined according to (Baghernejad \& Yaghoubi, 2011a; Lozano \& Valero, 1993), appropriate cost can be allocated to the products, fuels and losses occurring in the system. A detailed exergy analysis includes calculation of exergy destruction, exergy loss, exergetic efficiency and exergy destruction ratio in each component of the system along with the overall system. Mathematically, these are expressed as follows (Tsatsaronis \& Pisa, 1994):

$$
\begin{gathered}
\dot{E}_{D, k}=\dot{E}_{F, k}-\dot{E}_{P, k}-\dot{E}_{L, k} \\
\varepsilon=\frac{\dot{E}_{P}}{\dot{E}_{F}}=1-\frac{\dot{E}_{D}+\dot{E}_{L}}{\dot{E}_{F}} \\
\chi_{k}=\frac{\left(\dot{E}_{D}\right)_{k}}{\left(\dot{E}_{D}\right)_{T o t}}
\end{gathered}
$$

Exergy costing involves cost balances formulated for each system component separately. A cost balance applied to the $\mathrm{k}^{\text {th }}$ component shows that the sum of cost rates associated with all exiting exergy streams equals the sum of cost rates of all entering exergy streams plus the appropriate charges (cost rate) due to capital investment and operating and maintenance expenses. The sum of the last two terms is denoted by $\dot{Z}$. Accordingly, for a $\mathrm{k}^{\text {th }}$ component:

$$
\sum_{e}^{N}\left(c_{e} \dot{E}_{e}\right)+c_{w, k} \dot{W}_{k}=c_{q, k} \dot{E}_{q, k}+\sum_{i}^{N}\left(c_{i} \dot{E}_{i}\right)_{k}+\dot{Z}_{k}
$$

In the above equation $\dot{Z}_{k}=\frac{f I_{k} \varphi}{H}$, where $f$ and $I_{k}$ are the annuity factor and investment cost which are calculated from those given in (Bejan et al., 1996). $\varphi$ is maintenance factor and $H$ is operation period. In general, if there are $N_{e}$ exergy streams exiting the component being considered, we have $N_{e}$ unknowns and only one equation, the cost balance. Therefore, we need to formulate $N_{e}-1$ auxiliary equations. This is accomplished with the aid of the $\mathrm{F}$ and $\mathrm{P}$ principles in the SPECO approach (Lazzaretto \& Tsatsaronis, 2006).

Developing Eq. (7) for each component of a plant along with auxiliary costing equations (according to $\mathrm{P}$ and $\mathrm{F}$ rules) leads to a system of $N_{e}$ equations. By solving this system of equations, the costs of unknown streams of the system will be obtained. These are the average unit cost of fuel $\left(c_{f, k}\right)$, average unit cost of product $\left(c_{p, k}\right)$, cost rate of exergy destruction $\left(\dot{C}_{D, k}\right)$, cost rate of exergy loss $\left(\dot{C}_{L, k}\right)$, and the exergoeconomic factor $\left(f_{k}\right)$. Mathematically, these are expressed as (Tsatsaronis \& Pisa, 1994): 


$$
\begin{gathered}
c_{f, k}=\dot{C}_{f, k} / \dot{E}_{f, k} \\
c_{p, k}=\dot{C}_{p, k} / \dot{E}_{p, k} \\
\dot{C}_{D, k}=c_{f, k} \dot{E}_{D, k} \\
\dot{C}_{L, k}=c_{f, k} \dot{E}_{L, k} \\
f_{k}=\frac{\dot{Z}_{k}}{\dot{Z}_{k}+\dot{C}_{D, k}+\dot{C}_{L, k}}
\end{gathered}
$$

\section{Optimization problem}

A function optimization problem may be of different types, depending on the desired goal of the optimization task. The optimization problem may have only one objective function (known as a single-objective optimization problem), or it may have multiple conflicting objective functions (known as a multi-objective optimization problem). Some problems may have only one local optimum, thereby requiring the task of finding the sole optimum of the function. Other problems may contain more than one local optima in the search space, thereby requiring the task of finding multiple such locally optimal solutions.

Mathematically, a multi-objective optimization problem (Rao, 1996) having $m$ objectives and $n$ decision variables requires the minimization of the components of the vector $F(x)=F\left(f_{1}(x), f_{2}(x), \ldots, f_{\mathrm{m}}(x)\right)$, where $F$ is the evaluation function that maps the points of the decision variable space, such as $x=x\left(x_{1}, \ldots, x_{\mathrm{n}}\right)$, to the points of the objective function space.

$$
\begin{array}{ll}
\text { Minimize } & \left(f_{1}(x), f_{2}(x), \ldots, f_{m}(x)\right) \\
\text { Subject to } & g_{j}(x) \geq 0, \quad j=1,2, \ldots, J \\
& h_{k}(x)=0, \quad k=1,2, \ldots, K \\
& x_{i}^{(L)} \leq x_{i} \leq x_{i}^{(U)}, \quad i=1,2, \ldots, n
\end{array}
$$

A multi-objective optimization problem requires the simultaneous satisfaction of a number of different and often conflicting objectives. These objectives are characterized by distinct measures of performance that may be (in) dependent and/or incommensurable. A global optimal solution to a multi-objective optimization problem is unlikely to exist: this means that there is no combination of decision variables values that minimizes all the components of vector $F$ simultaneously. Multi-objective optimization problems generally show a possibly uncountable set of solutions, whose evaluated vectors represent the best possible trade-offs in the objective function space. The Pareto approach to multi-objective optimization (Pareto, 1896) is the key concept to establish optimal set of design variables, since the concepts of Pareto dominance and optimality are straightforward tools for determining the best trade-off solutions among conflicting objectives. An evolutionary algorithm is then chosen to carry out the search for the Pareto optimal solution because evolutionary optimization techniques already deal with a set of solutions (a population) to pursue their task, so a multi-objective Pareto-based evolutionary algorithm is able to make the population converge to the entire set of optimal solutions in a single run. 


\section{Evolutionary algorithms for optimization}

The evolutionary algorithm is a method for solving both constrained and unconstrained optimization problems that is based on natural selection, the process that drives biological evolution (Rezende et al., 2008). As a first step, parent selection is performed with each individual having the same probability of being chosen. Suppose $N_{P}$ is the size of generated population. Then $N_{P}$ numbers of parents enter the reproduction step, generating $N_{P}$ offspring through a crossover strategy in which the decision variable values of the offspring fall in a range defined by the decision variable values of the parents. Some of the offspring are also produced by adding a Gaussian random variable $(N)$ with zero mean and a standard deviation proportional to the scaled cost value of the parent trial solution, i.e,

$$
P_{g, i}^{\prime}=P_{g, i}+N\left(0, \sigma_{i}^{2}\right)
$$

The standard deviation $\sigma_{i}$ indicates the range over which the offspring is created around the parent trial solution and is given by

$$
\sigma_{i}^{2}=\varphi \frac{f\left(\bar{P}_{i}\right)}{f\left(\bar{P}_{\min }\right)}
$$

Where $f\left(\bar{P}_{\text {min }}\right)$ is the minimum value of the objective function among the $N_{P}$ trial solution, $f\left(\bar{P}_{i}\right)$ is the objective function value associated with the trial vector $\bar{P}_{i}$ and $\varphi$ is a scaling factor. These offspring $\bar{P}_{i}^{\prime}, i=1,2, \ldots, N_{P}$ and their parents $\bar{P}_{i}, i=1,2, \ldots, N_{P}$ form a set of $2 N_{P}$ trial solutions and they contend for survival with each other within the competing pool. After competition, the $2 N_{P}$ trial solutions including the parents and the offspring are ranked in descending order of the score. The first $N_{P}$ trial solutions survive and are transcribed along with their objective functions $f\left(\bar{P}_{i}\right)$ into the survivor set as the basis of the next generation. Finally, the number of generations elapsed is compared to the established maximum number of generations. If the termination condition is met, the process stops, otherwise the surviving solutions become the starting population for the next generation (Beghi et al., 2011).

\section{Exergoeconomic optimization}

\subsection{Single objective exergoeconomic optimization}

In general, a thermal system requires two conflicting objectives: one being increase in exergetic efficiency and the other is decrease in product cost, to be satisfied simultaneously. The first objective is governed by thermodynamic requirements and the second by economic constraints. Therefore, objective function should be defined in such a way that the optimization satisfies both requirements. For a single objective optimization, the optimization problem should be formulated as a minimization or maximization problem. The exergoeconomic analysis gives a clear picture about the costs related to the exergy destruction, exergy losses, etc. Thus, the objective function in this optimization becomes a minimization 
problem. Using of this technique for optimizing district heating network-using genetic algorithm (GA) demonstrated by (Cammarata et al., 1998). The objective function for this problem is defined as to minimize the total cost function $\dot{C}_{s y s}$, which can be modeled as:

$$
\dot{C}_{s y s}=\sum_{k} \dot{Z}_{k}+\sum_{k} \dot{C}_{D, k}+\dot{C}_{L, k}
$$

\subsection{Multi objective exergoeconomic optimization}

The two objective functions of this multi-criteria optimization problem are the total exergetic efficiency of the plant (to be maximized) and the total cost rate of product (to be minimized). The mathematical formulation of objective functions is as following (Baghernejad \& Yaghoubi, 2011b):

$$
\begin{gathered}
\varepsilon_{T o t}=\frac{\dot{E}_{W}}{\dot{E}_{F}} \\
\dot{C}_{T o t}=\sum_{k} \dot{Z}_{k}
\end{gathered}
$$

\section{Sensitivity analysis}

Sensitivity analysis is a general concept which aims to quantify the variations of an output parameter of a system regarding to the changes imposed on some input important parameters. A comprehensive sensitivity analysis can be performed to examine the impact of the variation of important factors on electricity costs of any STPP. The most important factors which influence electricity cost of a solar thermal power plant are fuel specific cost, interest rate, plant lifetime, solar field operation period and construction period (Baghernejad \& Yaghoubi, 2011a, 2011b).

\section{Example of application}

\subsection{Integrated solar combined cycle system (ISCCS)}

Fig. 3 shows a schematic diagram of an integrated solar combined cycle system. This power plant contains two $125 \mathrm{MW}$ gas turbines, a $150 \mathrm{MW}$ steam turbine, and a $17 \mathrm{MW}$ solar plant.

In this system a combined cycle unit with the following equipments is used:

- Two V94.2 gas turbine units with natural gas fuel

- Two heat recovery steam generators with two pressure lines. The high and low pressure steam conditions are: 84.8 bar and $506^{\circ} \mathrm{C}$ and 9.1 bar and $231.6^{\circ} \mathrm{C}$ respectively. A design stack temperature of $113{ }^{\circ} \mathrm{C}$ is selected to recover as much energy from the turbine exhaust as possible

- A no reheat two pressure steam turbine

The solar field considered in this site is comprised of 42 loops and for each loop, 6 collectors from type of LS-3 (Kearney, 1999) which are single axis tracking and aligned on a northsouth line, thus tracking the sun from east to west. Various design parameters of these 
collectors are given in Table 2. In this study, numerical results are based on site design condition with ambient temperature of $19^{\circ} \mathrm{C}$ and a relative humidity of 32 percent and wind speed of $3 \mathrm{~m} / \mathrm{s}$. The analysis is carried out on 21 Jun at 12:00 noon (LAT). At this hour, solar radiation intensity at the plant site is about $800 \mathrm{~W} / \mathrm{m}^{2}$. Also, Therminol VP-1 is used as heat transfer fluid (HTF) in the solar field. The state properties and exergies calculated for the system of Fig. 3 are given in Table 3. In this table, states 0,0 and 0 " are the dead states for air, water and oil, respectively. In this model, the variables selected for the optimization are (Baghernejad \& Yaghoubi, 2011a, 2011b):

The compressor pressure ratio $P_{r}\left(=\frac{P_{2}}{P_{1}}\right)$, isentropic efficiency of the compressor $\eta_{A C}$, temperature of the combustion products entering the turbine $T_{3}$, isentropic efficiency of the gas turbine $\eta_{G T}$ in the gas cycle, isentropic efficiency of the oil pump $\eta_{\text {OILP }}$, and oil outlet temperature in the collectors $T_{28}$ in the solar field, temperature and pressure of the steams leaving the heat recovery steam generator $T_{23}, P_{23,17}$, isentropic efficiency of the condensed extraction pump $\eta_{C E P}$ and isentropic efficiency of the boiler feed water pump $\eta_{B F P}$ in the steam cycle. This model is treated as the base case and the following nominal values of the decision variables are selected based on the operation program of the constructed site. $P_{r}=11, \quad \eta_{A C}=0.85, T_{3}=1404.8 \mathrm{~K}, \quad \eta_{\mathrm{GT}}=0.875, \quad \eta_{\mathrm{OILP}}=0.8, \quad \mathrm{~T} 28=666.5 \mathrm{~K}$, $T_{23}=779.15 \mathrm{~K}, P_{23}=84.8 \mathrm{bar}, P_{17}=9.1 \mathrm{bar}, \eta_{S T}=0.85, \eta_{C E P}=0.8, \eta_{B F P}=0.8$

\subsection{Exergoeconomic analysis}

The system used in Fig. 3 consists of 16 components and has 38 streams (32 for mass and 6 for work). Therefore 22 boundary conditions and auxiliary equations are necessary. For example in this system, for steam turbine (ST) and solar heat exchanger (SHE), cost balance and auxiliary costing equations (according to $\mathrm{P}$ and $\mathrm{F}$ rules) are formulated as follow:

Steam turbine:

$$
\begin{gathered}
\dot{C}_{11}+\dot{C}_{38}=2\left(\dot{C}_{17}+\dot{C}_{23}\right)+\dot{Z}_{S T} \\
c_{17}+c_{23}=c_{11} \text { or } \frac{\dot{C}_{17}+\dot{C}_{23}}{\dot{E}_{17}+\dot{E}_{23}}=\frac{\dot{C}_{11}}{\dot{E}_{11}}
\end{gathered}
$$

Solar heat exchanger:

$$
\begin{gathered}
\dot{C}_{25}+\dot{C}_{26}=\dot{C}_{24}+\dot{C}_{28}+\dot{Z}_{S H E} \\
c_{26}=c_{28} \text { or } \frac{\dot{C}_{26}}{\dot{E}_{26}}=\frac{\dot{C}_{28}}{\dot{E}_{28}}
\end{gathered}
$$

In the same way developing cost balance equation for other element of oil, gas and steam cycles along with auxiliary costing equations leads to a system of equations. By solving the system of 38 equations and 38 unknowns, the cost of unknown streams of the system will be obtained. More details of cost balance equations can be seen in (Baghernejad \& Yaghoubi, 2011a, 2011b). 


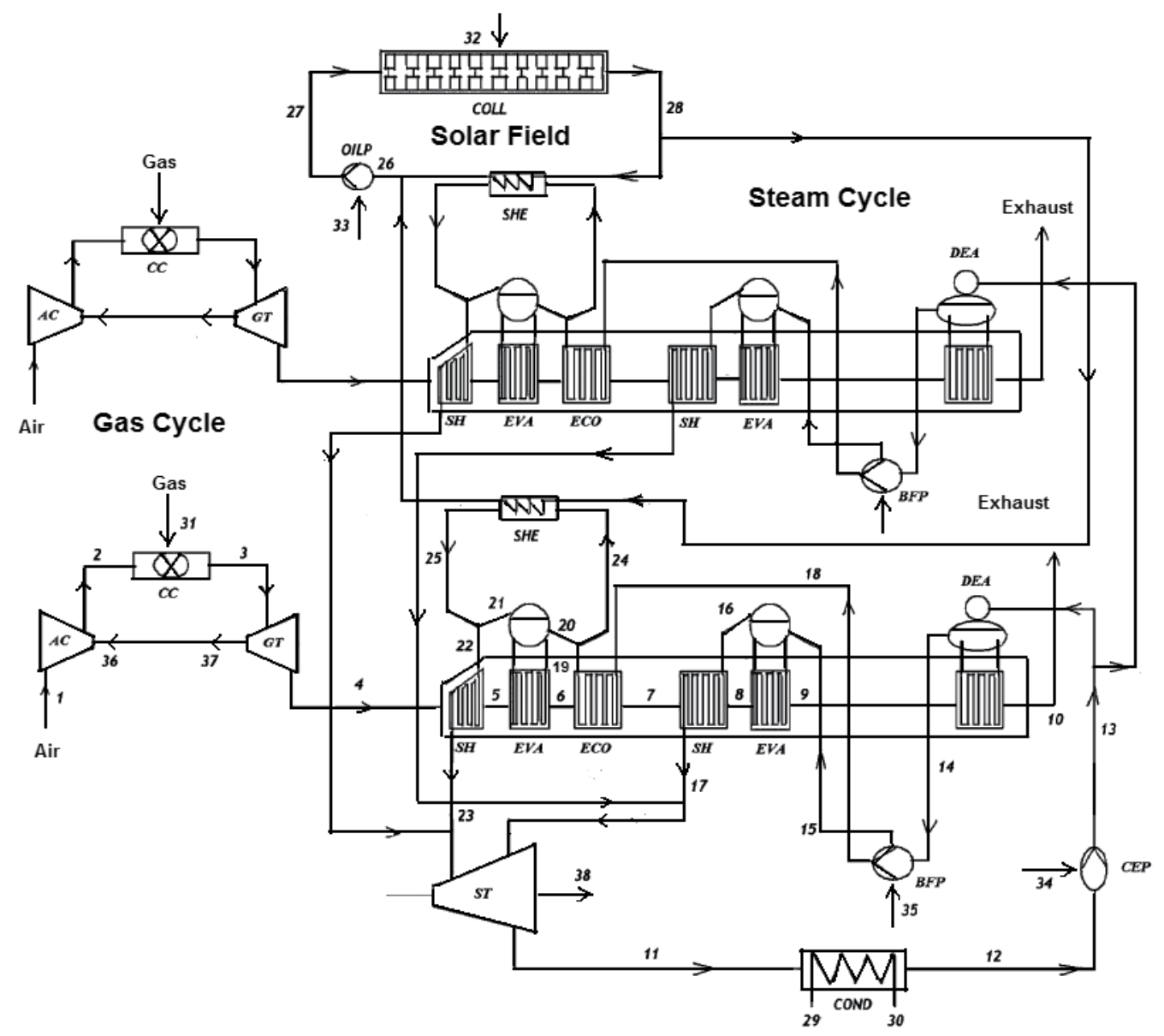

Fig. 3. Schematic diagram of a Integrated Solar Combined Cycle System

\begin{tabular}{|l|c|l|c|}
\hline Aperture Area per SCA $\left(\mathrm{m}^{2}\right)$ & 545 & HCE Transmittance & 0.96 \\
\hline Mirror Segments & 224 & Mirror Reflectivity & 0.94 \\
\hline Aperture (m) & 5.76 & Length & 99 \\
\hline HCE Diameter (m) & 0.07 & Concentration Ratio & 82 \\
\hline Average Focal Distance (m) & 0.94 & Peak Collector Efficiency (\%) & 68 \\
\hline HCE Absorptivity & 0.96 & Annual Thermal Efficiency (\%) & 53 \\
\hline HCE Emittance & 0.17 & Optical Efficiency (\%) & 80 \\
\hline
\end{tabular}

Table 2. LS-3 Collector specifications (Kearney, 1999) 
Modeling and Optimization of Renewable Energy Systems

\begin{tabular}{|c|c|c|c|c|c|}
\hline State & $\begin{array}{c}\dot{m} \\
(\mathrm{~kg} / \mathrm{sec})\end{array}$ & $\begin{array}{c}\mathrm{T} \\
(\mathrm{K}) \\
\end{array}$ & $\begin{array}{c}\mathrm{P} \\
\text { (bar) }\end{array}$ & $\begin{array}{c}\mathrm{h} \\
(\mathrm{kJ} / \mathrm{kg})\end{array}$ & $\begin{array}{c}\dot{E} \\
(\mathrm{MW})\end{array}$ \\
\hline 0 & - & 292.15 & 1.013 & 292.43 & - \\
\hline $0^{\prime}$ & - & 292.15 & 1.013 & 79.82 & - \\
\hline $0^{\prime \prime}$ & - & 292.15 & 1.013 & 12 & - \\
\hline 1 & 421.81 & 292.15 & 1.013 & 292.43 & 0 \\
\hline 2 & 421.81 & 630.35 & 11.14 & 631.8 & 132.86 \\
\hline 3 & 429.56 & 1404.80 & 10.58 & 1409 & 388.29 \\
\hline 4 & 429.56 & 821.46 & 1.05 & 823.6 & 105.8 \\
\hline 5 & 429.56 & 729.67 & 1.07 & 468.15 & 80.24 \\
\hline 6 & 429.56 & 536.86 & 1.04 & 261.64 & 31.75 \\
\hline 7 & 429.56 & 479.67 & 1.04 & 200.65 & 20.59 \\
\hline 8 & 429.56 & 477.12 & 1.02 & 197.92 & 19.39 \\
\hline 9 & 429.56 & 431.1 & 1.02 & 148.67 & 11.87 \\
\hline 10 & 429.56 & 386.15 & 1.013 & 100.58 & 6 \\
\hline 11 & 144.32 & 321.19 & 0.112 & 2304.5 & 28.25 \\
\hline 12 & 144.32 & 321.19 & 0.112 & 201.15 & 0.80 \\
\hline 13 & 144.32 & 321.55 & 25.5 & 204.36 & 1.09 \\
\hline 14 & 72.16 & 390.02 & 1.8 & 490.52 & 4.09 \\
\hline 15 & 9.25 & 390.15 & 9.3 & 491.52 & 0.53 \\
\hline 16 & 9.25 & 449.9 & 9.3 & 2774.3 & 7.82 \\
\hline 17 & 9.25 & 504.74 & 9.1 & 2906 & 8.27 \\
\hline 18 & 62.91 & 391.71 & 119 & 506 & 4.39 \\
\hline 19 & 62.91 & 488.15 & 118 & 923.8 & 13.17 \\
\hline 20 & 53.66 & 488.15 & 118 & 923.8 & 10.22 \\
\hline 21 & 53.66 & 578.66 & 92.77 & 2738.2 & 53.1 \\
\hline 22 & 62.91 & 578.66 & 92.77 & 2738.2 & 68.38 \\
\hline 23 & 62.91 & 779.15 & 84.8 & 3408.6 & 91.22 \\
\hline 24 & 14.06 & 488.15 & 118 & 923.8 & 2.94 \\
\hline 25 & 14.06 & 578.66 & 92.77 & 2738.2 & 15.28 \\
\hline 26 & 218.42 & 571.15 & 11 & 550.34 & 36.54 \\
\hline 27 & 218.42 & 573.82 & 16 & 552.63 & 36.83 \\
\hline 28 & 218.42 & 666.5 & 26 & 790 & 73.16 \\
\hline 29 & 2575 & 292.15 & 1.013 & 79.82 & 0 \\
\hline 30 & 2575 & 320.35 & 1.013 & 197.71 & 13.77 \\
\hline 31 & 7.75 & 292.15 & 20 & 292.43 & 401.89 \\
\hline
\end{tabular}

Table 3. State properties and calculated exergy of the system corresponding to Fig. 3 


\subsection{Result and discussion}

Although the decision variables may be varied in optimization procedure, each decision variable is normally required to be within a given practical range of operation as follow (Baghernejad \& Yaghoubi, 2011a):

$$
\begin{array}{lrrrr}
9 \leq P_{r} \leq 16 \quad 640 \leq T_{28} \leq 670 K & 80 \leq P_{23} \leq 100 \text { bar } & 1350 \leq T_{3} \leq 1500 \mathrm{~K} & 7 \leq P_{17} \leq 10 \text { bar } \\
0.75 \leq \eta_{A C} \leq 0.9 \quad 0.75 \leq \eta_{B F P} \leq 0.9 \quad 0.75 \leq \eta_{S T} \leq 0.9 & 0.75 \leq \eta_{G T} \leq 0.9 & 0.75 \leq \eta_{C E P} \leq 0.9 \\
723.15 \leq T_{23} \leq 823.15 \mathrm{~K} & 0.75 \leq \eta_{\text {OILP }} \leq 0.9 & &
\end{array}
$$

Also, the values of the economic parameters and fixed parameters for the optimization of system are given in Table 4 (Baghernejad \& Yaghoubi, 2011a).

\begin{tabular}{|r|c|r|c|}
\hline$\eta_{\mathrm{CC}}$ & 0.99 & LHV $(\mathrm{kJ} / \mathrm{kg})$ & 47966 \\
\hline$\varphi$ & 1.06 & ri (\%) & 8 \\
\hline in (\%) & 10 & $\mathrm{CP}($ year $)$ & 3 \\
\hline $\mathrm{k}$ (years) & 25 & $\dot{W}_{\text {out }}(\mathrm{MW})$ & 400 \\
\hline H (hour) for solar field & 2000 & H (hour) for Combined cycle & 7500 \\
\hline
\end{tabular}

Table 4. Fixed parameters for the system shown in Fig. 3 (Baghernejad \& Yaghoubi, 2011a)

For a single objective optimization, with the objective function indicated in Eq. (16) in the first generation, 100 vectors $\bar{P}_{i}=\left[P_{r}, \eta_{A C}, T_{3}, \eta_{G T}, \eta_{\text {OILP }}, T_{28}, T_{23}, P_{23}, P_{17}, \eta_{S T}, \eta_{C E P}, \eta_{B F P}\right]$ are randomly generated within the operating range. For each trial, the objective function is evaluated through exergy analysis and exergoeconomic formulations after passing through the system constraints. Performance of the system with each vector is evaluated. The vector having the best system performance is stored for future comparison. The algorithm selects a group of vectors in the current generation, called parents that have better objective function values for the next generation (second generation). These parents are modified using Eq. (14) to generate the offsprings. The performance of the offsprings and the parent vectors are compared to select the best vector in the generation. The process of selecting parents and then generating the offsprings repeats till the specified number of generations.

The structure of the multi objective evolutionary algorithm (MOEA) used in the present work is illustrated in (Schwefwl, 1995). Also, the tuning of MOEA is performed according to the values indicated in Table 5 (Baghernejad \& Yaghoubi, 2011b). Fig. 4 presents the Pareto optimum solutions for the integrated solar combined cycle system with the objective function indicated in Eqs. (17) and (18). As shown in this figure, while the total exergetic efficiency of the plant is increased to about $44 \%$, the total cost rate of products increases very slightly. Increasing the total exergetic efficiency from $44 \%$ to $47 \%$ corresponds to the moderate increase in the cost rate of product. Further increasing of exergetic efficiency from $47 \%$ to the higher value leads to a drastic increasing of the total cost rate.

In multi-objective optimization, a process of decision-making for selection of the final optimal solution from the available solutions is required. The process of decision-making is usually performed with the aid of a hypothetical point in Fig. 5 named as equilibrium point that both objectives have their optimal values independent to the other objective. It 
is clear that it is impossible to have both objectives at their optimum point, simultaneously and as shown in Fig. 5, the equilibrium point is not a solution located on the Pareto frontier. The closest point of Pareto frontier to the equilibrium point might be considered as a desirable final solution. In selection of the final optimum point, it is desired to achieve the better magnitude for each objective than its initial value of the base case problem. On the other hand, the stability of the selected point when one of objective varies is highly important. Therefore a part of Pareto frontier is selected in Fig. 6 for decision-making and coincided with domain between horizontal and vertical lines. A final optimum solution with $45.19 \%$ exergetic efficiency and the total cost rate of product equal to $10920.43 \$ / \mathrm{h}$ as indicated in Fig. 6 is selected. It should be noted that the selection of an optimum solution depends on the preferences and criteria of each decision-maker. Therefore, each decision-maker may select a different point as optimum solution to better suits with his/her desires.

\begin{tabular}{|c|c|}
\hline Turning parameters & Value \\
\hline Population size & 100 \\
\hline Maximum number of generations & 50 \\
\hline$P_{\mathrm{c}}$ (probability of crossover) $(\%)$ & 1 \\
\hline $\mathrm{P}_{\mathrm{m}}$ (probability of mutation) $(\%)$ & Tournament \\
\hline Selection process & 2 \\
\hline Tournament size & 2 \\
\hline
\end{tabular}

Table 5. The turning parameters in MOEA optimization program (Baghernejad \& Yaghoubi, 2011b)

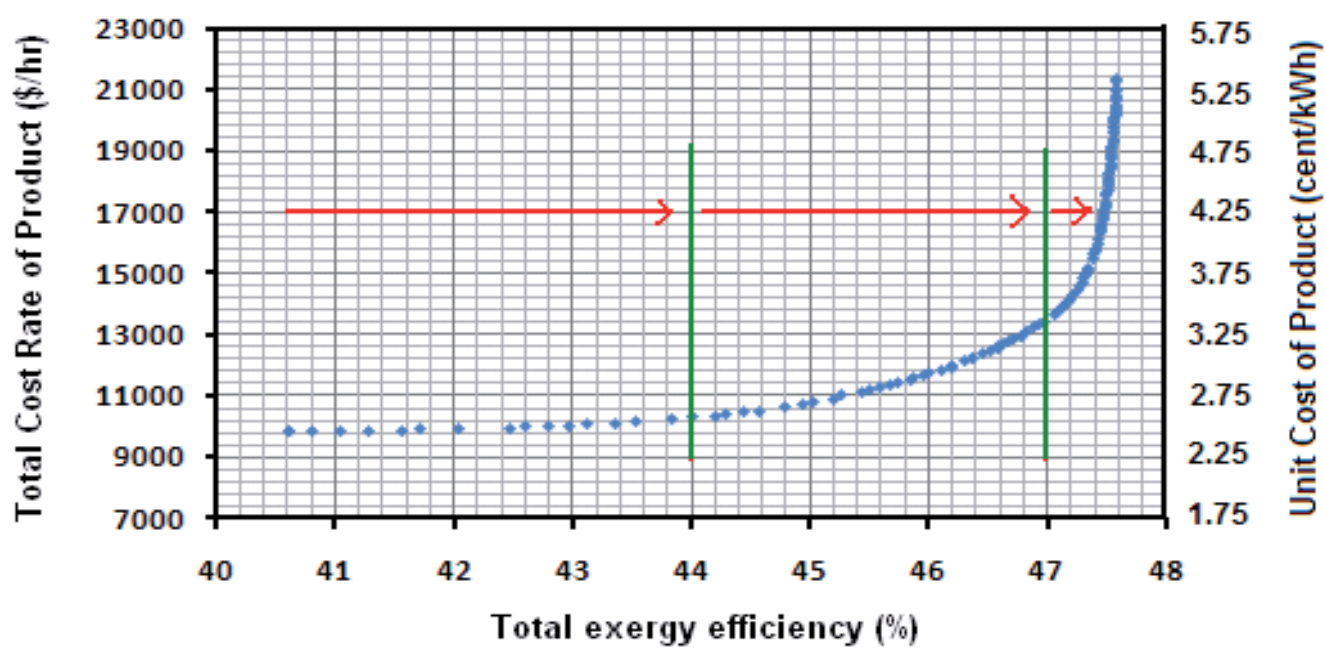

Fig. 4. Pareto optimal solutions for solar combined cycle system shown in Fig. 3 


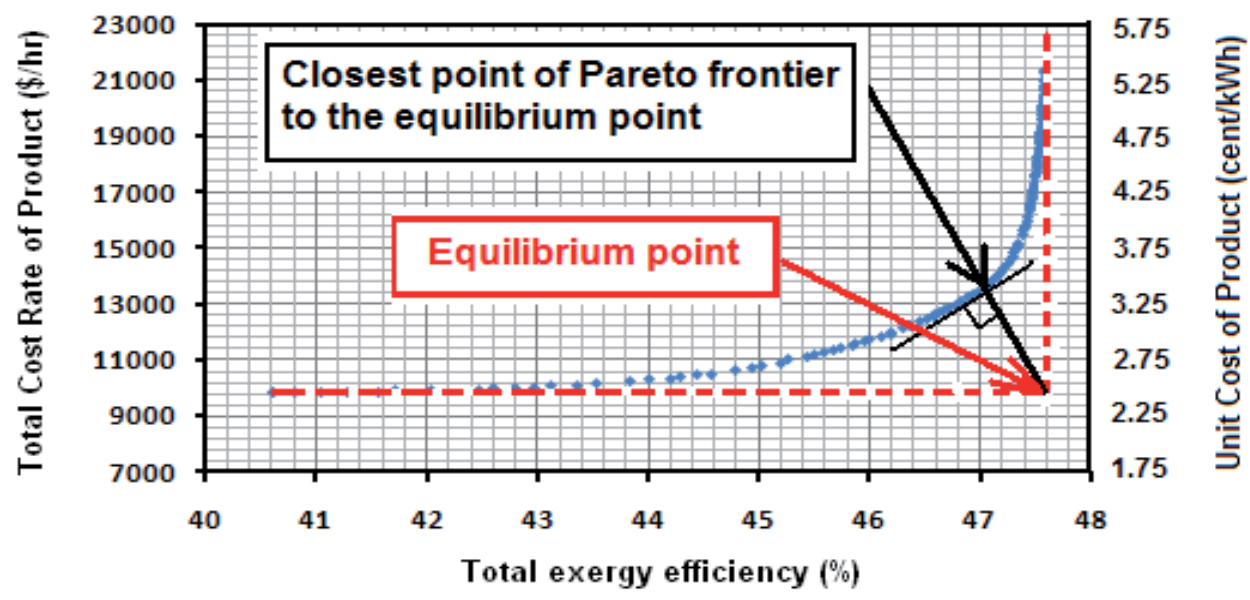

Fig. 5. Pareto frontier: best trade-off values for the objective functions (total exergetic efficiency and total cost rate of products) in the system shown in Fig. 3

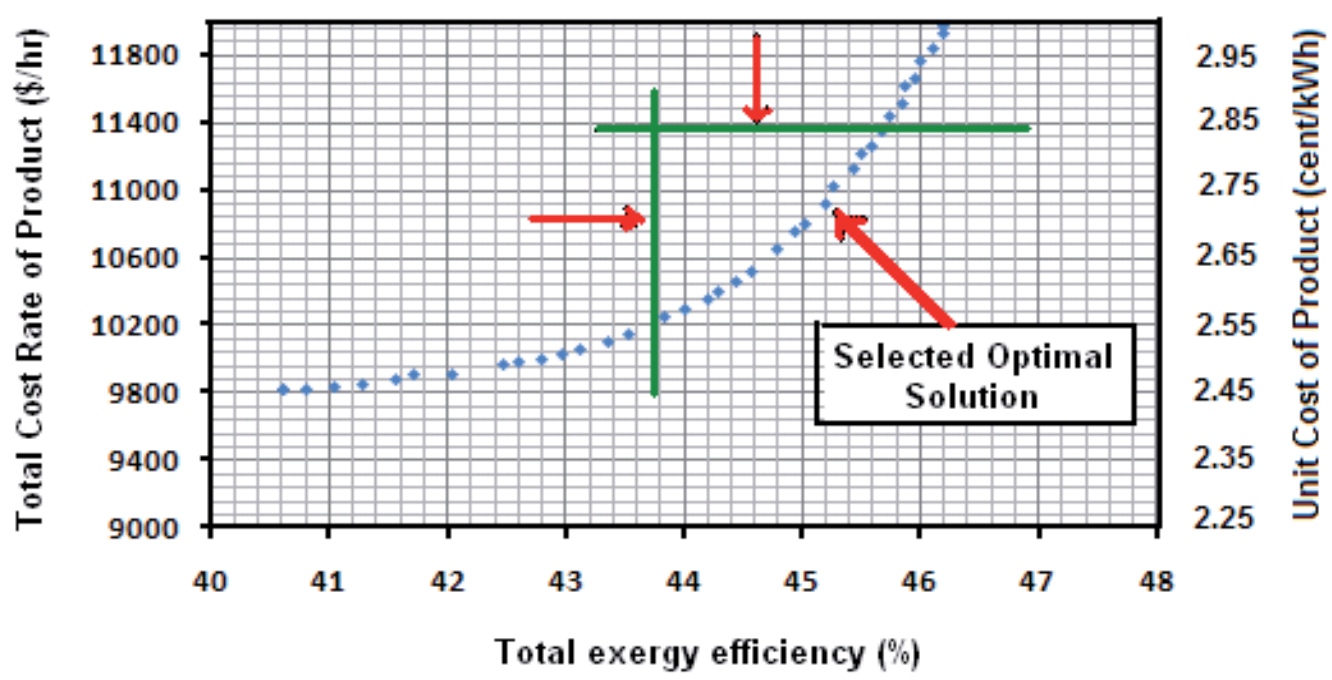

Fig. 6. Selecting procedure for optimal solution from Pareto frontier in the system shown in Fig. 3

The cost of the streams in the base case and optimum cases (single and multi objective optimization) are given in Table 6 . Unit cost of the electricity produced by steam turbine is reduced from 29.57 cents/ $\mathrm{kWh}$ in the base case to 27.47 and 27.63 cents/kWh in the optimum cases respectively.

The related values of decision variables in both optimum cases are given in Table 7. These new parameters obtained in the optimized cases will help the designer to select components, i.e. turbines, compressor, as close to the optimum configuration. 


\begin{tabular}{|c|c|c|c|c|c|c|}
\hline \multirow{2}{*}{$\begin{array}{c}\text { State } \\
\text { points } \\
\text { (Fig. } \\
\text { 2) }\end{array}$} & \multicolumn{2}{|c|}{ Base case } & \multicolumn{2}{|c|}{$\begin{array}{l}\text { Optimum case } \\
\text { (Single objective) }\end{array}$} & \multicolumn{2}{|c|}{$\begin{array}{l}\text { Optimum case } \\
\text { (Multi objective) }\end{array}$} \\
\hline & $\begin{array}{c}c \\
\text { (cents/kWh) }\end{array}$ & C (\$/h) & c (cents/kWh) & C (\$/h) & c (cents/kWh) & $C(\$ / h)$ \\
\hline 1 & 0 & 0 & 0 & 0 & 0 & 0 \\
\hline 2 & 24.44 & 32474 & 24.19 & 29873 & 24.24 & 30219 \\
\hline 3 & 20.88 & 81093 & 20.64 & 74980 & 20.68 & 77156 \\
\hline 4 & 20.88 & 22097 & 20.64 & 19069 & 20.68 & 21474 \\
\hline 5 & 20.88 & 16758 & 20.64 & 13736 & 20.68 & 15675 \\
\hline 6 & 20.88 & 6632 & 20.64 & 5670 & 20.68 & 6337 \\
\hline 7 & 20.88 & 4301 & 20.64 & 3703 & 20.68 & 4091 \\
\hline 8 & 20.88 & 4050 & 20.64 & 3477 & 20.68 & 3856 \\
\hline 9 & 20.88 & 2480 & 20.64 & 2146 & 20.68 & 2337 \\
\hline 10 & 20.88 & 1254 & 20.64 & 1103 & 20.68 & 1159 \\
\hline 11 & 25.99 & 7343 & 25.30 & 6067 & 25.44 & 6798 \\
\hline 12 & 25.99 & 209 & 25.30 & 176 & 25.44 & 198 \\
\hline 13 & 31.49 & 346 & 29.06 & 275 & 30.27 & 321 \\
\hline 14 & 34.77 & 1422 & 34.01 & 1200 & 34.45 & 1361 \\
\hline 15 & 35.59 & 189 & 34.29 & 158 & 35.05 & 180 \\
\hline 16 & 22.98 & 1799 & 22.22 & 1523 & 22.64 & 1736 \\
\hline 17 & 25.07 & 2074 & 24.27 & 1769 & 24.61 & 1994 \\
\hline 18 & 35.59 & 1564 & 34.29 & 1328 & 35.05 & 1517 \\
\hline 19 & 30.07 & 3960 & 29.32 & 3352 & 29.94 & 3826 \\
\hline 20 & 30.07 & 3075 & 29.32 & 2504 & 29.94 & 2879 \\
\hline 21 & 24.99 & 13272 & 24.12 & 10629 & 24.70 & 12281 \\
\hline 22 & 26.88 & 18383 & 26.61 & 15700 & 26.43 & 17465 \\
\hline 23 & 26.07 & 23785 & 25.39 & 21089 & 25.51 & 23325 \\
\hline 24 & 30.07 & 885 & 29.32 & 848 & 29.94 & 947 \\
\hline 25 & 33.44 & 5111 & 33.97 & 5070 & 31.70 & 5184 \\
\hline 26 & 22.92 & 8378 & 23.84 & 9226 & 21.78 & 10234 \\
\hline 27 & 23.14 & 8526 & 24.02 & 9366 & 21.97 & 10399 \\
\hline 28 & 22.92 & 16773 & 23.84 & 17613 & 21.78 & 18647 \\
\hline 29 & 0 & 0 & 0 & 0 & 0 & 0 \\
\hline 30 & 51.90 & 7145 & 50.52 & 5901 & 50.80 & 6611 \\
\hline 31 & 12.09 & 48593 & 12.09 & 45077 & 12.09 & 46908 \\
\hline 32 & 0 & 0 & 0 & 0 & 0 & 0 \\
\hline 33 & 29.57 & 148 & 27.47 & 139 & 27.63 & 165 \\
\hline 34 & 29.57 & 137 & 27.47 & 99 & 27.63 & 124 \\
\hline 35 & 29.57 & 331 & 27.47 & 285 & 27.63 & 337 \\
\hline 36 & 22.18 & 31760 & 21.92 & 28981 & 21.92 & 29754 \\
\hline 37 & 22.18 & 59484 & 21.92 & 57012 & 21.92 & 56214 \\
\hline 38 & 29.57 & 44384 & 27.47 & 39659 & 27.63 & 43850 \\
\hline
\end{tabular}

Table 6. Cost of streams in the system shown in Fig. 3 


\begin{tabular}{|c|c|c|c|}
\hline Decision variables & Base case & $\begin{array}{c}\text { Optimum case } \\
\text { (Single objective) }\end{array}$ & $\begin{array}{c}\text { Optimum case } \\
\text { (Multi objective) }\end{array}$ \\
\hline Compressor efficiency & 85 & 85.98 & 82.98 \\
\hline Compressor pressure ratio & 11 & 11.98 & 10.86 \\
\hline $\begin{array}{c}\text { Inlet temperature of gas } \\
\text { turbine (K) }\end{array}$ & 1404.8 & 1449.9 & 1437.8 \\
\hline Gas turbine efficiency (\%) & 87.5 & 90 & 87.98 \\
\hline Oil outlet temperature (K) & 666.5 & 658.17 & 650.28 \\
\hline $\begin{array}{c}\text { Inlet pressure to HP steam } \\
\text { turbine (bar) }\end{array}$ & 84.8 & 99.91 & 808.66 \\
\hline $\begin{array}{c}\text { Inlet temperature to HP } \\
\text { steam turbine (K) }\end{array}$ & 779.15 & 823.13 & 9.95 \\
\hline $\begin{array}{c}\text { Inlet pressure to LP steam } \\
\text { turbine (bar) }\end{array}$ & 9.1 & 9.97 & 89.99 \\
\hline $\begin{array}{c}\text { Steam turbine efficiency } \\
\text { (\%) }\end{array}$ & 85 & 89.94 & 80 \\
\hline CEP efficiency (\%) & 80 & 88.84 & 77.84 \\
\hline BFP efficiency (\%) & 80 & 84.02 & 86.16 \\
\hline OILP efficiency (\%) & 80 & 83.44 & \\
\hline
\end{tabular}

Table 7. Comparison of the decisions variables for optimum and base cases in the system shown in Fig. 3

The values of objective functions in the base and optimum cases including the total cost of product and the total exergy efficiency are listed in Table 8. This table indicates that the optimization process leads to $10.98 \%$ decrease in the objective function for single objective optimization and 3.2\% increase in the exergetic efficiency and 3.82\% decrease for the rate of product cost in multi objective optimization. Therefore, improvement for all objectives has been achieved using optimization process.

The comparative results of the base case and the optimum cases are presented in Table 9 . According to this table, optimization process improves the total performance of the system in a way that the rate of fuel cost is decreased by 7.23 and $3.46 \%$ in optimum cases. Also exergy destructions is reduced about 12 and $5.7 \%$, the related cost of the system inefficiencies is decreased about 14.8 and $7.32 \%$ and exergetic efficiency is increased from 43.79 to 46.8 and $45.19 \%$ in both optimum cases, although the total owning and operation cost in single objective optimization is increased about $13.3 \%$. Moreover, it can be found from this table that the optimization increases the overall exergoeconomic factor of this system from 12.18 in the base case to 15.51 (27.34\% increases) and 12.56 ( $3.1 \%$ increase) implying that optimization process mostly reduced the associated cost of thermodynamic inefficiencies rather to increase the capital investment and operating and maintenance cost of the system components 


\begin{tabular}{|c|c|ccc|}
\hline $\begin{array}{c}\text { Type of } \\
\text { optimization }\end{array}$ & Objective functions & $\begin{array}{c}\text { Base } \\
\text { case }\end{array}$ & $\begin{array}{c}\text { Optimum } \\
\text { case }\end{array}$ & $\begin{array}{c}\text { Variation } \\
(\%)\end{array}$ \\
\hline $\begin{array}{c}\text { Single objective } \\
\text { optimization }\end{array}$ & Objective optimization $(\$ / \mathrm{h})$ & 93179.46 & 82942.52 & -10.98 \\
\hline $\begin{array}{c}\text { Multi object } \\
\text { optimization }\end{array}$ & $\begin{array}{c}\text { Total cost of product }(\$ / \mathrm{h}) \\
\text { Total exergy efficiency }(\%)\end{array}$ & $\begin{array}{c}11354.02 \\
43.79\end{array}$ & $\begin{array}{c}10920.43 \\
45.19\end{array}$ & -3.82 \\
\hline
\end{tabular}

Table 8. Comparison of the objective functions for optimum and base cases in the system shown in Fig. 3

\begin{tabular}{|l|c|cc|cc|}
\hline & \multirow{2}{*}{$\begin{array}{c}\text { Base } \\
\text { Properties }\end{array}$} & \multicolumn{2}{|c|}{ Single objective } & \multicolumn{2}{c|}{ Multi objective } \\
\cline { 3 - 5 } & & $\begin{array}{c}\text { Optimum } \\
\text { case }\end{array}$ & $\begin{array}{c}\text { Variation } \\
\%\end{array}$ & $\begin{array}{c}\text { Optimum } \\
\text { case }\end{array}$ & $\begin{array}{c}\text { Variation } \\
\%\end{array}$ \\
\hline $\begin{array}{l}\text { Fuel exergy (solar+gas) } \\
(\mathrm{MW})\end{array}$ & 511.02 & 481.94 & -5.69 & 497.07 & -2.73 \\
$\begin{array}{l}\text { Exergy destruction } \\
(\mathrm{MW})\end{array}$ & 456.39 & 401.31 & -12.07 & 430.31 & -5.71 \\
$\begin{array}{l}\text { Fuel cost } \\
(\$ / \mathrm{h})\end{array}$ & 48593 & 45077 & -7.23 & 46908 & -3.46 \\
$\begin{array}{l}\text { Exergy destruction cost } \\
\text { (\$/h) }\end{array}$ & 79255.75 & 67506.68 & -14.82 & 73454.3 & -7.32 \\
$\begin{array}{l}\text { Capital investment cost } \\
(\$ / \mathrm{h})\end{array}$ & 11354.02 & 12866.14 & +13.31 & 10920.43 & -3.82 \\
$\begin{array}{l}\text { Exergy efficiency } \\
(\%)\end{array}$ & 43.79 & 46.80 & +6.87 & 45.19 & +3.2 \\
$\begin{array}{l}\text { Exergoeconomic factor } \\
(\%)\end{array}$ & 12.18 & 15.51 & +27.34 & 12.56 & +3.1 \\
\hline
\end{tabular}

Table 9. Comparative results of the optimum and base cases in the system shown in Fig. 3

\subsection{Sensitivity analysis of the ISCCS}

\subsubsection{Sensitivity analysis for single objective optimization}

Additional runs of the optimization algorithm were performed on the system in order to investigate the influence of the unit cost of fuel, the construction period and solar operation period on the solution. Fig. 7 shows sensitivity with respect to fuel cost which is linear. Fig. 8 illustrates variation of unit cost with increasing solar contribution which is significant (Baghernejad \& Yaghoubi, 2011a).

\subsubsection{Sensitivity analyses for multi objective optimization}

Fig. 9 shows the sensitivity of the Pareto optimal Frontier to the variation of specific fuel cost. A comparison of the Pareto frontiers for the three optimizations shows that the economic minimum at higher unit costs of fuel is shifted upwards as expected. Similar behavior is observed for sensitivity of Pareto optimal solution to the construction period in Figures 10. In fact the exergetic objective has no sensitivity to the economic parameters such as the fuel cost and construction period (Baghernejad \& Yaghoubi, 2011b). 
The final optimal solution that was selected in this system belongs to the region of Pareto frontier with significant sensitivity to the costing parameters. However, the region with the lower sensitivity to the costing parameter is not reasonable for the final optimum solution. Also a small change in exergetic efficiency of the plant (exergetic efficiency from $47 \%$ to the higher value) due to the variation of operating parameters may lead to the danger of increasing the cost rate of product, drastically.

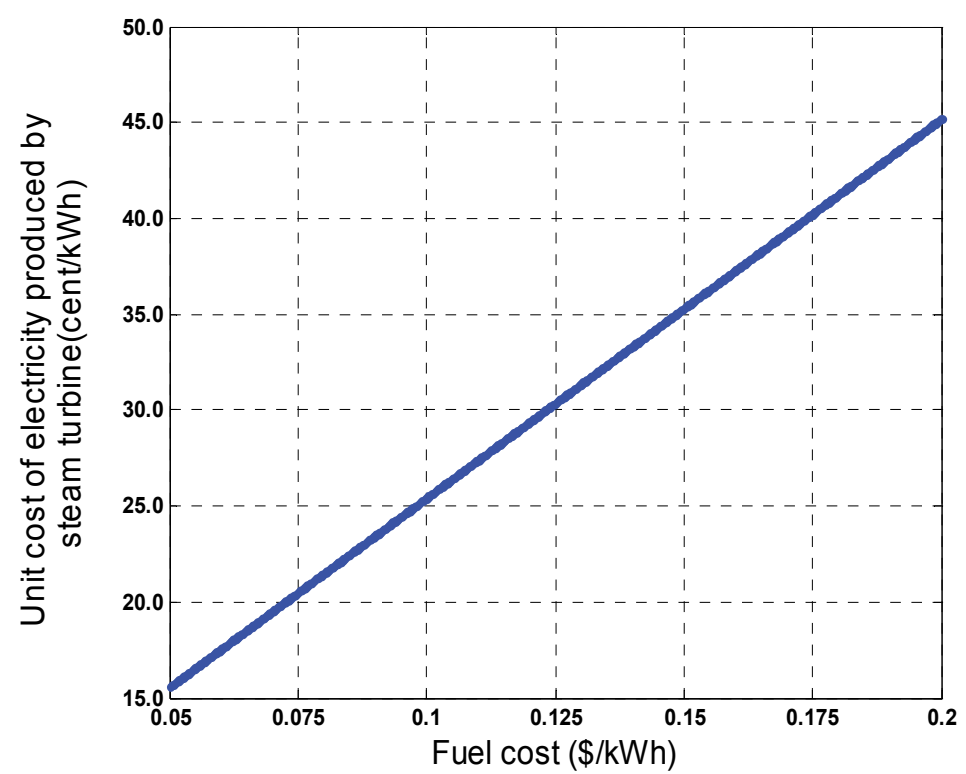

Fig. 7. Sensitivity of unit cost of electricity with specific fuel cost

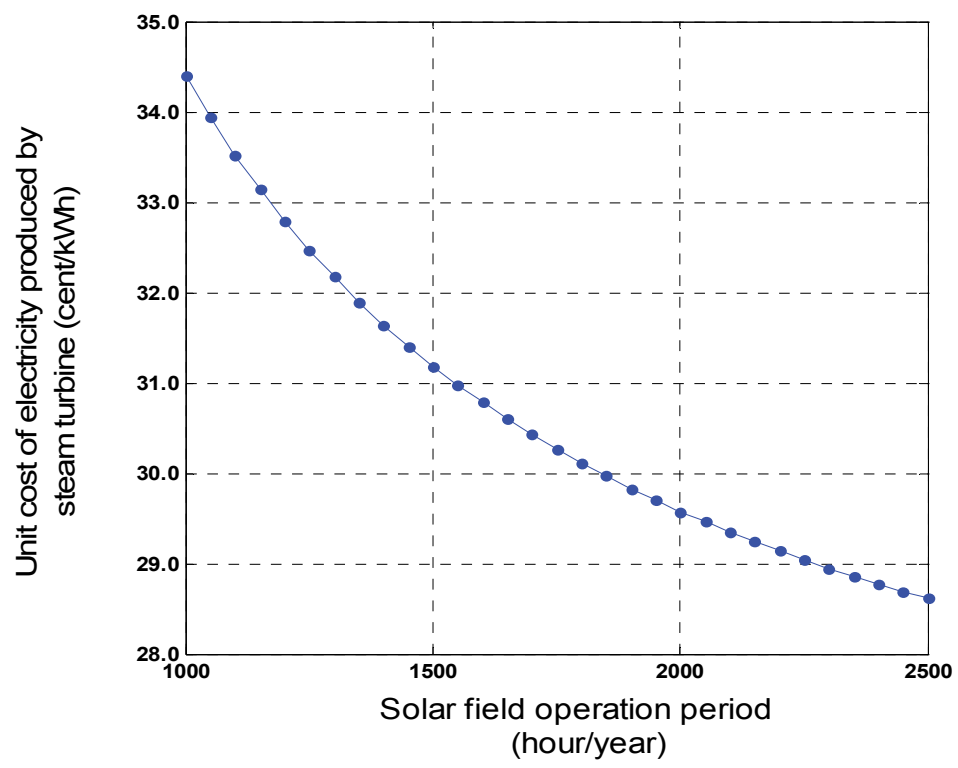

Fig. 8. Sensitivity of unit cost of electricity to the solar field operation periods 


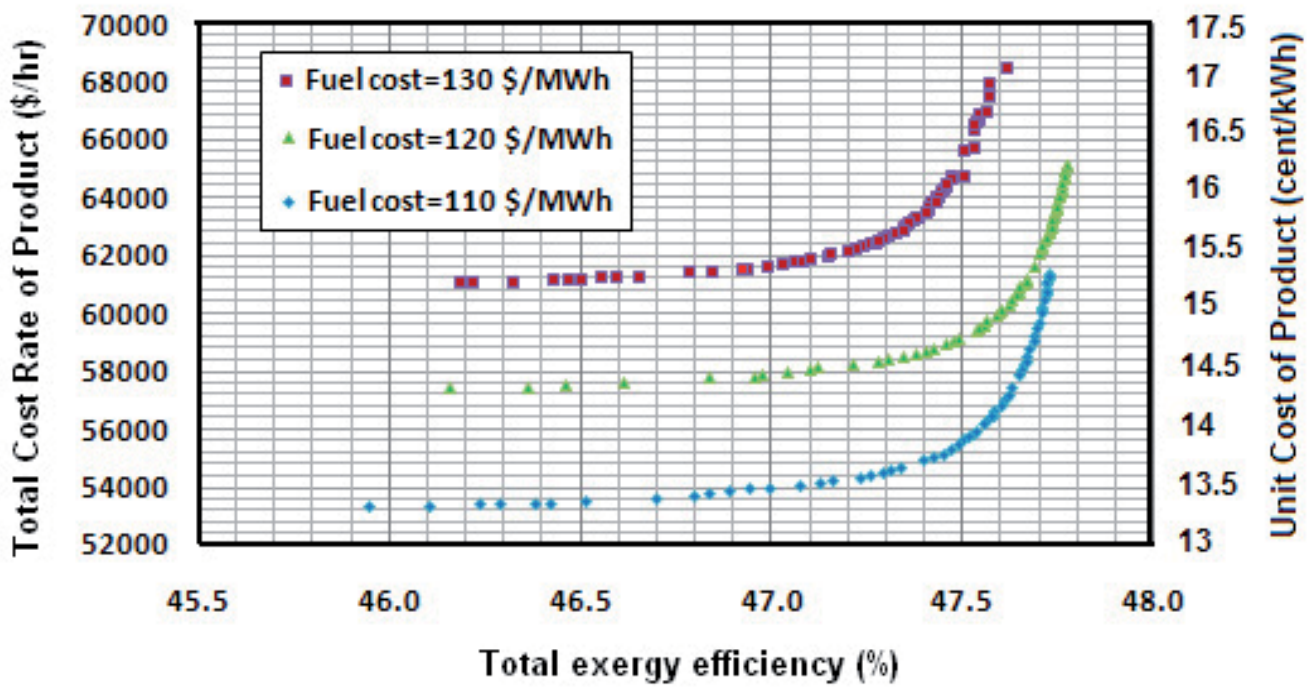

Fig. 9. Sensitivity of Pareto optimum solutions to the specific fuel cost 


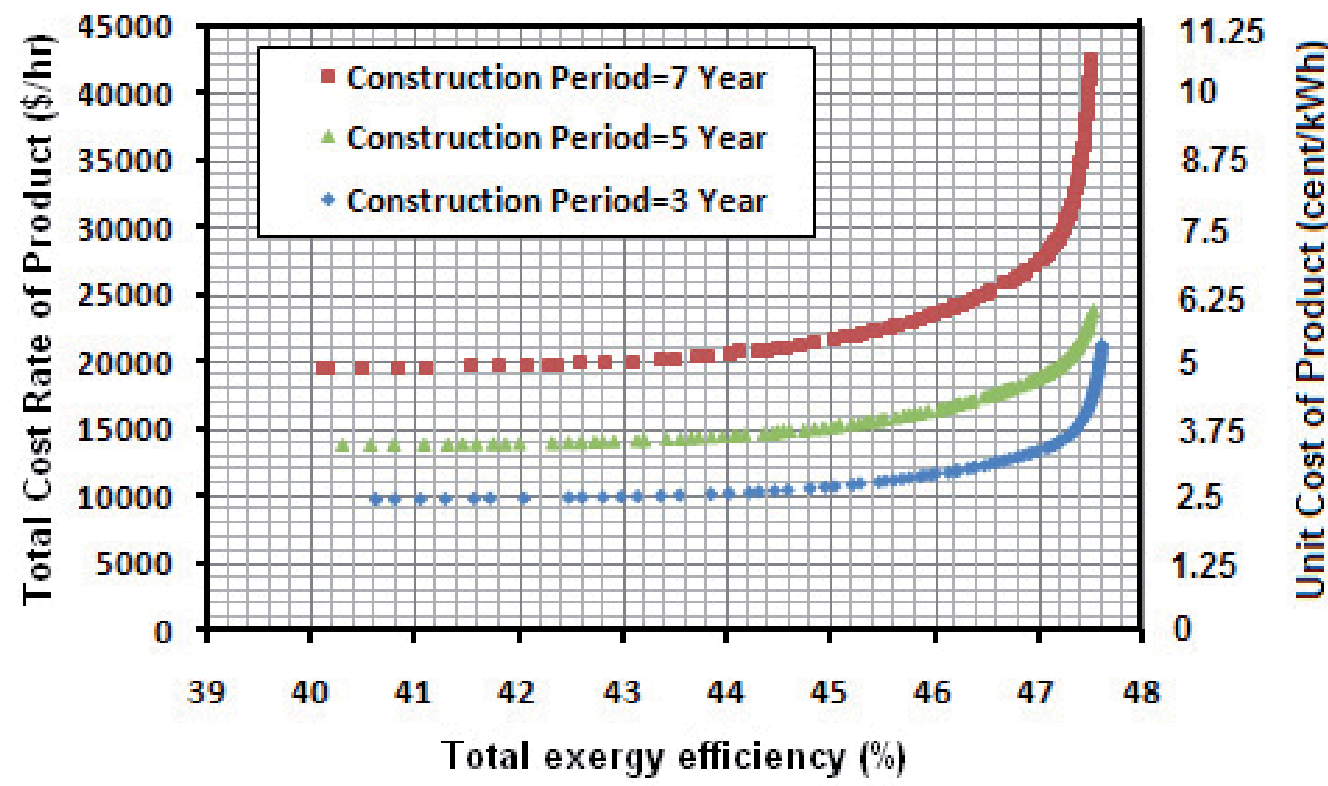

Fig. 10. Sensitivity of Pareto optimum solutions to the construction period

\section{Conclusion}

The presented chapter demonstrates the basic of exergoeconomic modeling of any thermal power plant and application of the exergoeconomic concept to single and multi objective optimization of an Integrated Solar Combined Cycle System (ISCCS). The exergy-costing method is applied to a 400 MW Integrated Solar Combined Cycle System to estimate the unit costs of electricity produced from combined gas and steam turbines.

The application of single objective optimization process shows that exergy and exergoeconomic analysis improved significantly for optimum operation as follows:

1. Objective function decreased by about $11 \%$ and overall exergoeconomic factor of system increased by $27.34 \%$.

2. Unit cost of electricity produced by steam turbine reduced by about $7.1 \%$. This is achieved, however, with $13.3 \%$ increase in the capital investment.

3. Exergy destruction cost reduced by $14.82 \%$ and exergetic efficiency of the system increased from about 43.79 to $46.8 \%$.

Also, it is found that multi-criteria optimization approach, which is a general form of single objective optimization, enables us to consider various and ever competitive objectives for more improvement of any thermal power plant. An example of decision-making process for selection of the final optimal solution from the Pareto frontier in the multi objective optimization is presented. This final optimum solution requires a process of decisionmaking, which depends on the preferences and criteria of each decision-maker. Each decision maker may select different points as optimum solution which better suits with their desires. The final optimum solution for a typical ISCCS is determined and compared to the base case design and discussed. The analysis of the ISCCS shows that: 
1. Optimization process leads to $3.2 \%$ increase in the exergetic efficiency and $3.82 \%$ decrease of the rate of product cost.

2. Optimization leads to the $2.73 \%$ reduction on the fuel exergy, $5.71 \%$ reduction in the total exergy destruction and also $3.46 \%$ and $7.32 \%$ reductions in the fuel cost rate and cost rate relating to the exergy destruction, respectively.

3. It is found that multi-criteria optimization approach, which is a general form of single objective optimization, enables us to consider various and ever competitive objectives.

\section{Nomenclature}

\begin{tabular}{|c|c|c|c|}
\hline $\mathrm{AC}$ & air compressor & $P_{r}$ & pressure ratio \\
\hline BFP & boiler feed pump & ri & rate of inflation \\
\hline $\mathrm{c}$ & cost per exergy unit, $\$ / \mathrm{kWh}$ & $\mathrm{s}$ & specific entropy, $\mathrm{kJ} / \mathrm{kgK}$ \\
\hline$\dot{C}$ & cost rate, $\$ / \mathrm{h}$ & SCA & solar collector assembly \\
\hline $\mathrm{CC}$ & combustion chamber & $\mathrm{SH}$ & superheater \\
\hline CEP & condensate extraction pump & SHE & solar heat exchanger \\
\hline COLL & collector & ST & steam turbine \\
\hline COND & condenser & $\mathrm{T}$ & temperature, $\mathrm{K}$ \\
\hline $\mathrm{CP}$ & construction period, year & $\dot{W}$ & power, MW \\
\hline DEA & dearator & $\dot{Z}$ & investment cost rate, $\$ / h$ \\
\hline$\dot{E}$ & exergy rate, $\mathrm{MW}$ & \multicolumn{2}{|r|}{ Greek symbols } \\
\hline ECO & economizer & $\varepsilon$ & exergetic efficiency \\
\hline EVA & evaporator & $\varphi$ & maintenance factor \\
\hline$f$ & $\begin{array}{l}\text { exergoeconomic factor/ annuity } \\
\text { factor }\end{array}$ & $\eta$ & isentropic efficiency \\
\hline GT & gas turbine & $\chi$ & relative irreversibility \\
\hline $\mathrm{h}$ & specific enthalpy, $\mathrm{kJ} / \mathrm{kg}$ & $\phi$ & scaling factor \\
\hline $\mathrm{H}$ & operation period, hour & $\sigma$ & standard deviation \\
\hline $\mathrm{HCE}$ & heat collection element & \multicolumn{2}{|r|}{ Subscripts } \\
\hline $\mathrm{HP}$ & high pressure & $1,2,3 \ldots, 38$ & state points \\
\hline HRSG & heat recovery steam generator & $\mathrm{CH}$ & chemical exergy \\
\hline HTF & heat transfer fluid & $\mathrm{D}$ & destruction \\
\hline $\mathrm{I}$ & equipment investment, $\$$ & $\mathrm{e}$ & outlet \\
\hline in & interest rate & $\mathrm{i}$ & inlet/ith flow stream \\
\hline $\mathrm{k}$ & plant lifetime, year & $\mathrm{k}$ & $\mathrm{k}^{\text {th }}$ component \\
\hline LHV & lower heating value & $\mathrm{L}$ & loss \\
\hline LP & low pressure & $\mathrm{F}$ & fuel \\
\hline$\dot{m}$ & mass flow rate, $\mathrm{kg} / \mathrm{sec}$ & $\mathrm{P}$ & product \\
\hline OILP & oil pump & $\mathrm{PH}$ & physical exergy \\
\hline $\mathrm{P}$ & pressure, bar & sys & system \\
\hline$P^{\prime}$ & offspring & tot & total \\
\hline
\end{tabular}




\section{References}

Baghernejad, A. Yaghoubi, M. (2010). Exergy Analysis of an Integrated Solar Combined Cycle System. Renewable Energy, Vol.35, No.10, pp. 2157-2164, ISSN 0960-1481

Baghernejad, A. Yaghoubi, M. (2011a). Exergoeconomic Analysis and Optimization of an Integrated Solar Combined Cycle System (ISCCS) Using Genetic Algorithm. Energy conversion and Management, Vol.52, No.5, pp. 2193-2203, ISSN 0196-8904

Baghernejad, A. Yaghoubi, M. (2011b). Multi objective exergoeconomic optimization of an integrated solar combined cycle system using evolutionary algorithms. International Journal of Energy Research, Vol.6, No.7, pp. 601-615

Bejan, A. Tsatsaronis, G \& Moran, M. (1996). Thermal design and optimization, John Wiley and Sons, New York

Beghi, A. Cecchinato, L \& Rampazo, M. (2011). A multi-phase genetic algorithm for the efficient management of multichiller systems, Energy Conversion and Management. Vol.52, No.3, pp. 1650-1661, ISSN 0196-8904

Cammarata, G. Fichera, A \& Marletta, L. (1998). Using genetic algorithms and the exergonomic approach to optimize district heating networks, ASME: Journal of Energy Resource Technology, Vol.120, No.3, pp. 241-246

Concentrated solar thermal power-now. (2005). www.greenpeace.org. Sep. 2005.

Johansson, A. (2002). Entropy and the cost of complexity in industrial production. Exergy an International Journal. Vol.2, No.4, pp. 295-299.

Kearney, D. (1999). Parabolic-Trough Technology Roadmap A Pathway for Sustained Commercial Development and Deployment of Parabolic-Trough Technology. SunLab NREL.

Lazzaretto, A. Tsatsaronis, G. (2006). SPECO: a systematic and general methodology for calculating efficiencies and costs in thermal systems. Energy, Vol.31, No.8, pp. 12571289

Lazzaretto, A. Toffolo, A. (2004). On the thermoeconomic approach to the diagnosis of energy system malfunctions. Indicators to diagnose malfunctions: Application of a new indicator for the location of causes. Int. J. Thermodynamics, Vol.7, No.2, pp. 4149.

Lozano, M. Valero, A. (1993). Theory of the exergetic cost. Energy, Vol.18, No.9, pp. 939-960.

Moran, M. Sciubba, E. (1994). Exergy analysis: principles and practice. Gas Turbines Power, Vol.116, No.2, pp. 285-290

Pareto V. (1896). Cours d'economie politique. Lausanne, Switzerland

Rao SS. (1996). Engineering optimization: theory and practice, John Wiley and Sons, New York

Rezende, M. Costa, C. Costa, A. Maciel, M \& Filho, R. (2008). Optimization of a large scale industrial reactor by genetic algorithms. Chemical Engineering Science. Vol.63. No.2, pp. 330-341

Schwarzenbach, A. Wunsch, AK. (1989). Flexible power generation systems and their planning, ABB Review No.6, pp. 19-26

Schwefel HP. (1995). Evolution and optimum seeking, John Wiley and Sons, New York

Singh, N. Kaushik, SC. (1994). Technology assessment and economic evaluation of solar thermal power generation. IIT, Delhi: CES

Status Report on Solar Thermal Power Plants, Pilkington Solar International: 1996. Report ISBN 3-9804901-0-6. 
Tsatsaronis, G. Pisa, J. (1994). Exergoeconomics evaluation and optimization of energy systems - application to the CGAM problem. Energy, Vol.19, No.3, pp. 287-321

Valero, A. Correas, L. Zaleta, A. Lazzaretto, A. Verda, V. Reini, M \& Rangel, V. (2004). On the thermoeconomic approach to the diagnosis of energy system malfunctions. part 1: the tadeus problem. Energy, Vol.29, No.12-15, pp. 1875-1887.

Verda, V. (2004). Thermoeconomic analysis and diagnosis of energy utility systems. From diagnosis to prognosis. Int. J. Thermodynamics. Vol.7, No.2, pp. 73-83, ISSN 13019724 


\title{
Optimization of Renewable Energy Systems: The Case of Desalination
}

\author{
Karim Bourouni \\ Ecole Nationale d'Ingénieurs de Tunis, \\ Tunisia
}

\section{Introduction}

The application of renewable energies (RE) for driving desalination units (DES) is very promising in isolated areas (i.e. islands, villages in the desert, etc.), where the electricity production is very expensive, potable water resources are inexistent and the potential of renewable energies (solar and wind) is very important (Koroneos et al., 2007; Kalogirou, 2005). The application of renewable energies in the desalination industry does not face the same barriers as in the case of RES for electricity power production (expensive storage systems to compensate the stochastic characteristics of the renewable energies). In the case of RES/DES coupling, the energy is consumed directly for water production, the water can be stored, cheaply in large quantities and for long periods (Koroneos et al., 2007).

The operational performances, the cost and the reliability of RES/DES units depend on the design and calibration of such systems. Optimal use of RES potential is necessary in order to reduce the cost of produced water. In this frame considering hybrid configurations (PV and Wind) is the best way to optimize the use of RE.

On the other hand, the design of such systems is complex because of uncertain renewable energy supplies, load demands and the non-linear characteristics of some components.

Despite the great effort done to improve the efficiency of RES/DES systems the desalinated water cost still relatively high compared to conventional desalination units and more effort should be done to optimize this kind of systems.

In this chapter we present different methods to optimize renewable energy systems driving desalination unit, with a particular interest to the RO driven by hybrid PV/Wind systems. For this last configuration we will present a new methodology based on Genetic Algorithms.

The objective function used in this optimization is the unit cost of desalinated water during the life cycle of the plant (20 years). The presented methodology consists in selecting from available components in the market, the optimal number and the type of each unit (PV panels, wind turbines, membranes, etc.) in such way that the water needs are satisfied and the production cost is minimized. The total water cost for the life cycle of the plant is equal to the sum of the capital and maintenance costs. 
The present methodology has the advantage to take into account all the critical functioning parameters that have an influence on the electricity and desalinated water productions and the investment and operational costs.

The minimization of the function total cost was implemented by using Genetic algorithms (GA), that have the capacity to reach the solution corresponding to the global optimum with a relative simple calculation. The benefit of using Genetic algorithms in the proposed methodology is the calculation of the optimal solution in the global space of feasible solutions of desalination systems (individuals). These later are obtained by different simulation during all over a year.

\section{Desalination technologies}

Future water supply is a major concern in developed and developing countries of the world, such as in Middle East and North Africa (MENA region). In these countries conventional water resources are limited and cannot sustain the growing demand where population growth is increasing dramatically. Hence, since 1970 other non conventional methods have been adopted on a large scale to satisfy this growing demand. One of the most promising technologies is water desalination whom the total world capacity increased from $100.000 \mathrm{~m}^{3}$ / day in 1970 to $6.800 .000 \mathrm{~m}^{3}$ / day in 2007 (GWI, 2010).

By looking at the total desalination plants installed in the world we simply realize that three major desalination technologies are used:

- Multi stage flash process (MSF) - 43.5\% of world production,

- Reverse osmosis (RO) $-43.5 \%$ of world production, and

- Multi effect distillation (MED), which has increased dramatically in the world during the last years.

MED and MSF are classified us thermal desalination technologies, however RO desalination is considered as membrane technology. Besides these technologies other techniques can be used (i.e. Mechanical Vapor Compression, MVC; Electrodialysis, ED; Humidification and Dehumidification of Air, HD; etc.). However their application still limited for specific context.

\subsection{MSF desalination}

An MSF distillation plant consists of several consecutive stages (evaporating chambers) maintained at decreasing pressures from the first stage (hot) to the last stage (cold). The vapor condenses to form fresh water. At vacuum conditions the boiling point of water is low requiring less energy. Before entering the first cell, seawater sweeps all cells from the last one to the first by flowing through the tubes of the heat exchangers where it is warmed by condensation of the vapor produced in each stage (Fig. 1). Its temperature increases from sea temperature to inlet temperature of the brine heater.

The seawater then flows through the brine heater where it receives the heat necessary for the process (generally by condensing steam). At the outlet of the brine heater, when entering the first cell, seawater is overheated exceeding boiling point compared to the temperature and pressure of stage 1 . 
Therefore, it is the abrupt introduction of this sea water into a lower pressure "stage" that makes it boil so quickly as to "flash" into steam to reach equilibrium with stage conditions. The produced vapor is condensed into fresh water on the tubular exchanger at the top of the stage. The process takes place again once the water is introduced into the following stage, and so on until the last and coldest stage. The cumulated fresh water builds up the distillate production which is extracted from the coldest stage. Seawater slightly concentrates from stage to stage and builds up the brine flow which is extracted from the last stage.

Typically a number of units are constructed alongside a combined cycle power plant and utilize low-grade steam (semi waste heat) from the power plant to produce the desalinated water. An MSF plant performance is selected to ensure the overall optimization of the plant power and steam cycles.

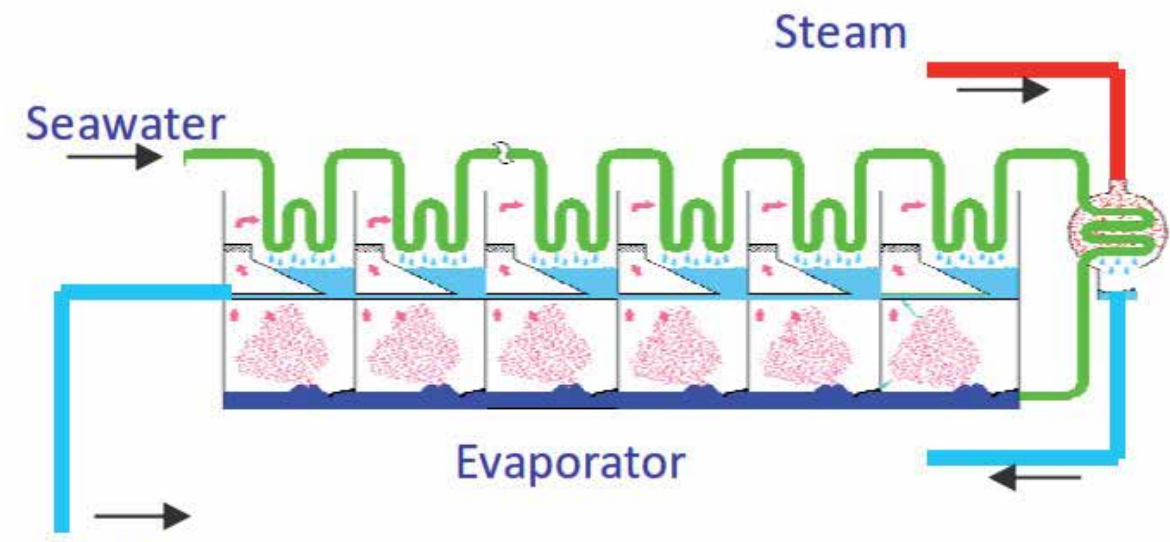

\section{Distillate}

Fig. 1. MSF Desalination Process

\subsection{MED desalination}

MED, like MSF, takes place in successive effects and uses the principle of reducing the ambient pressure in the various effects. This permits the seawater feed to undergo multiple boiling without supplying additional heat after the first effect. In a MED plant, the seawater enters the first effect and is raised to the boiling point after being preheated in tubes. The seawater is either sprayed or distributed onto the surface of evaporator tubes in a thin film to promote rapid boiling and evaporation. The tubes are heated by steam from a boiler or other source, which is condensed on the inside of the tubes. The condensate from the boiler steam is recycled to the boiler for reuse (Fig. 2).

In MED the maximum temperature is now limited to $80^{\circ} \mathrm{C}$ to reduce the scale deposition, which limit the gain output ratio (GOR) to a maximum level of $12 \mathrm{~kg}$ distillate $/ \mathrm{kg}$ of steam. However, with the introduction of a compression technology plant (hybrid) to the MED process the performance has been radically improved to GOR of 15 . The compression is provided by electric compressors or thermo-compressors, which utilize motive steam.

Thermal desalination (MED and MSF) produce very low TDS production (50 mg/l), and does not depend on feed quality, as is the case with the Reverse Osmosis technology. 


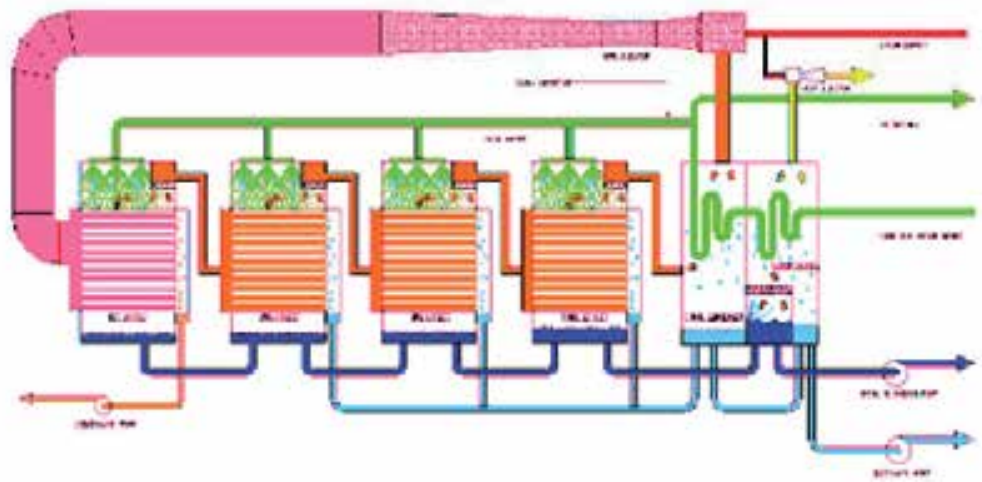

Fig. 2. MED Desalination Process

\subsection{Reverse osmosis (RO)}

$\mathrm{RO}$ is a pressure-driven process that separates two solutions with different concentrations across a semi-permeable membrane. The fresh water flow rate through the membrane is proportional to the pressure differential that exceeds the natural osmotic pressure differential. The membrane itself represents a major pressure differential to the flow of fresh water. For brackish water desalination the operating pressures range from 15 to $30 \mathrm{bar}$, and for seawater desalination from 55 to 70 bar (Abdallah et al., 2005). The initial pressurization of the feed water represents the major energy requirement. As fresh water permeates across the membrane, the feed water becomes more and more concentrated. There is a limit to the amount of fresh water that can be recovered from the feed without causing fouling. Seawater RO plants have recoveries from 25 to $45 \%$, while brackish water RO plants have recovery rates as high as $90 \%$. RO system major components include membrane modules, high-pressure pumps, power plant, and energy recovery devices as needed (Fig 3).

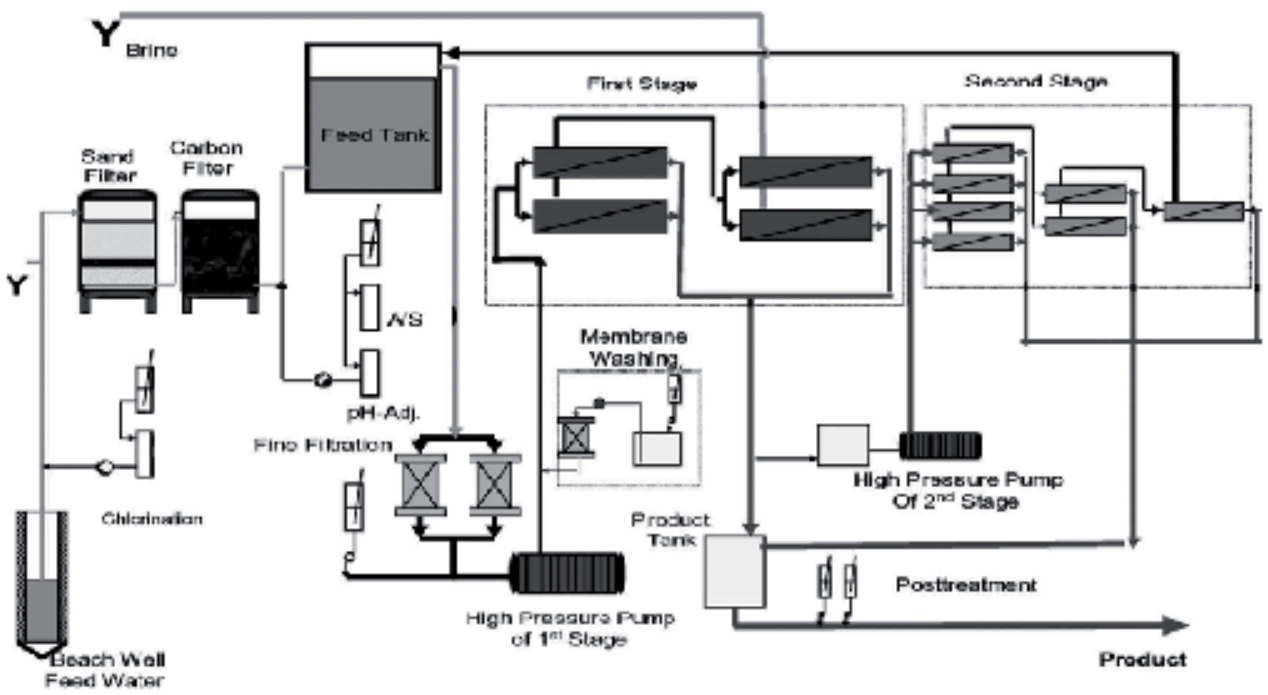

Fig. 3. Schematic diagram of one RO Desalination process with two stages 
Membrane properties and feed water salinity are the two major factors controlling the energy requirements of an $\mathrm{RO}$ system. Higher water salinity requires more energy to overcome the osmotic pressure.

Pre-treatment of seawater feeding $\mathrm{RO}$ membranes is recognized as a key in designing RO desalination plants (Gaid and Treal, 2007). The use of an adapted pre-treatment minimizes the fouling problems and can provide good protection of the membranes and a longer lifetime.

\section{Renewable energy systems for desalination}

Solar and Wind systems can be used to provide heat required to produce steam for the thermal desalination plants and electricity to drive high pressure pumps in RO units and auxiliary components in the different desalination technologies.

\subsection{Solar technologies}

Different solar energy collectors may be used in order to convert solar energy to thermal energy. In most of them, a fluid is heated by the solar radiation as it circulates along the solar collector through an absorber pipe. This heat transfer fluid is usually water or synthetic oil. The fluid heated at the solar collector field may be either stored at an insulated tank or used to heat another thermal storage medium.

The solar collector may be a static or suntracking device. The second ones may have one or two axes of sun tracking. Otherwise, with respect to solar concentration, solar collectors are already commercially available; nevertheless, many collector improvements and advanced solar technologies are being developed. The main solar collectors suitable for seawater distillation are as follow.

\subsubsection{Flat-plate collector}

Flat-plate collectors (FPCs) are used as heat transfer fluid, which circulates through absorber pipes made of either metal or plastic. The absorber selective coatings are used to reduce heat losses and to increase radiation absorption. Thus the thermal efficiency increases although the collector cost also increase.

A typical flat-plate collector is an insulated metal box with a glass or plastic cover and a darkcolored absorber plate. The flow tubes can be routed in parallel or in a serpentine pattern. Flat plate collectors have not been found as a useful technology for desalination (Belessiotis and Delyannis, 2001; Gracia-Rodriguez, 2002). Although they have been used for relatively small desalinated water production volumes, production of large volumes of water would require an additional energy source.

\subsubsection{Parabolic trough collector}

A parabolic trough is a linear collector with a parabolic cross-section. Its reflective surface concentrates sunlight onto a receiver tube located along the trough's focal line, heating the heat transfer fluid in the tube. Parabolic troughs typically have concentration ratios of 10 to 100 , leading to operating temperatures of $100-400^{\circ} \mathrm{C}$.

Parabolic trough collectors (PTCs) require sun tracking along one axis only. In this way, the receiver tube can achieve a much higher temperature than flat-plate or evacuated-tube 
collectors. The parabolic trough collector systems usually include a mechanical control system that keeps the trough reflector pointed at the sun throughout the day. Parabolictrough concentrating systems can provide hot water and steam, and are generally used in commercial and industrial applications.

Due to the high temperatures parabolic troughs are capable of producing high-grade thermal energy that is generally used for electricity generation (Belessiotis and Delyannis, 2001). Parabolic troughs could be a suitable energy supply for most desalination methods, but in practice, they have mainly been used for thermal distillation as these methods can take advantage of both the heat and electricity troughs produce. Parabolic Trough Collectors can also drive RO units by using Rankine Organic Cycle.

\subsubsection{Photovoltaic systems}

Photovoltaic systems consist of a number of PV modules, which convert solar radiation into direct-current (DC) electricity. The voltage and current of the system can be increased by connecting multiple cells in series and parallel, respectively. The other system equipment includes a charge controller, batteries, inverter, and other components needed to provide the output electric power suitable to operate the systems coupled with the PV system. PV is

a rapidly developing technology, with costs falling dramatically with time, and this will lead to its broad application in all types of systems. Today, however, it is clear that PV-RO and PV-ED will initially be most cost-competitive for small-scale systems where other technologies are less competitive.

The electricity form PV systems can be used to drive high-pressure pumps in RO desalination plants. The main advantage of $\mathrm{PV} /$ desalination systems is their ability to develop small size desalination plants. The energy production unit consists of a number of photovoltaic modules, which convert solar radiation into direct electric current (DC). $\mathrm{DC} / \mathrm{AC}$ inverters have to be used because $\mathrm{RO}$ uses alternating current $(\mathrm{AC})$ for the pumps.

Energy storage (batteries) is required for PV output power smoothing or for sustaining system operation when insufficient solar energy is available.

\subsection{Wind systems}

Wind energy and desalination plants can be coupled in various ways (Ma and $\mathrm{Lu}, 2011$ ). Currently, wind energy can power desalination plants directly or indirectly through four types of energy media (Fig. 4): electricity, thermal energy, gravitational potential energy and kinematical power (shaft power).

Electricity is the most commonly used energy form as the interface between wind energy and desalination process. After having converted into electricity, the energy from wind plant can be employed to drive desalination processes such as RO, ED and MVC (Kalogirou, 2005). The wind plant can be on or off the grid. Due to the intermittent characteristic of wind power, usually backup facilities like battery, water tank, flywheel system might be integrated into the system to store or release energy when the wind speed exceeds or cannot achieve the required level. 


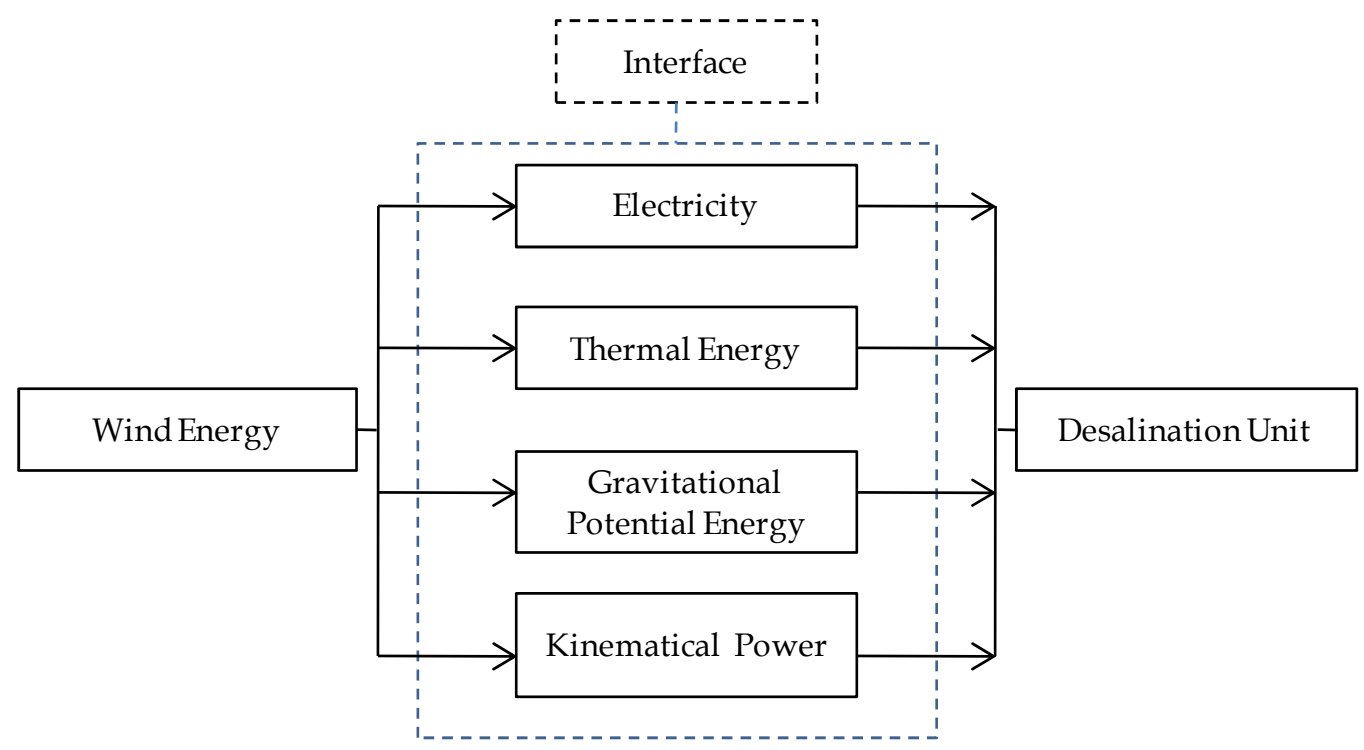

Fig. 4. Existing interfaces between wind energy and desalination unit.

Direct conversion from wind energy to thermal energy to drive thermal desalination units (distiller) has been studied since the efficiency of direct wind-thermal conversion is higher than that of wind-electricity conversion and their structures are simpler (Nakatake and Tanaka, 2005). The proposed distiller could produce $1.5 \mathrm{~kg} / \mathrm{d}$ or more when a $6 \mathrm{~m} / \mathrm{s}$ wind blew steadily all day on a sunny or cloudy day.

To reduce the energy loss caused by the wind-electricity conversion, gravitational energy has also been used as the interface between wind energy and desalination process. Fadigas and Dias (2009) designed an alternative configuration to conventional RO desalination systems by incorporating the use of gravitational potential energy, without using either electricity or fossil fuels. The gravitational potential energy, presented by water stored in a reservoir above a certain height, was converted by wind energy from windmills (or wind turbines).

\section{RE/DES systems}

Many different renewable energy desalination systems are technically feasible (Kalogirou, 2005). Fig.5 presents the possible combinations between desalination processes and RE technologies.

A methodology for selecting the most appropriate combination between desalination technologies and renewable energies for a given site based on different criteria was developed (Setiawan et al., 2009). Desalination systems are energy intensive, and their energy consumption is a driving factor in determining their economic feasibility when they are coupled to RES. Typical energy consumptions for different desalination processes are shown in Table 1. 


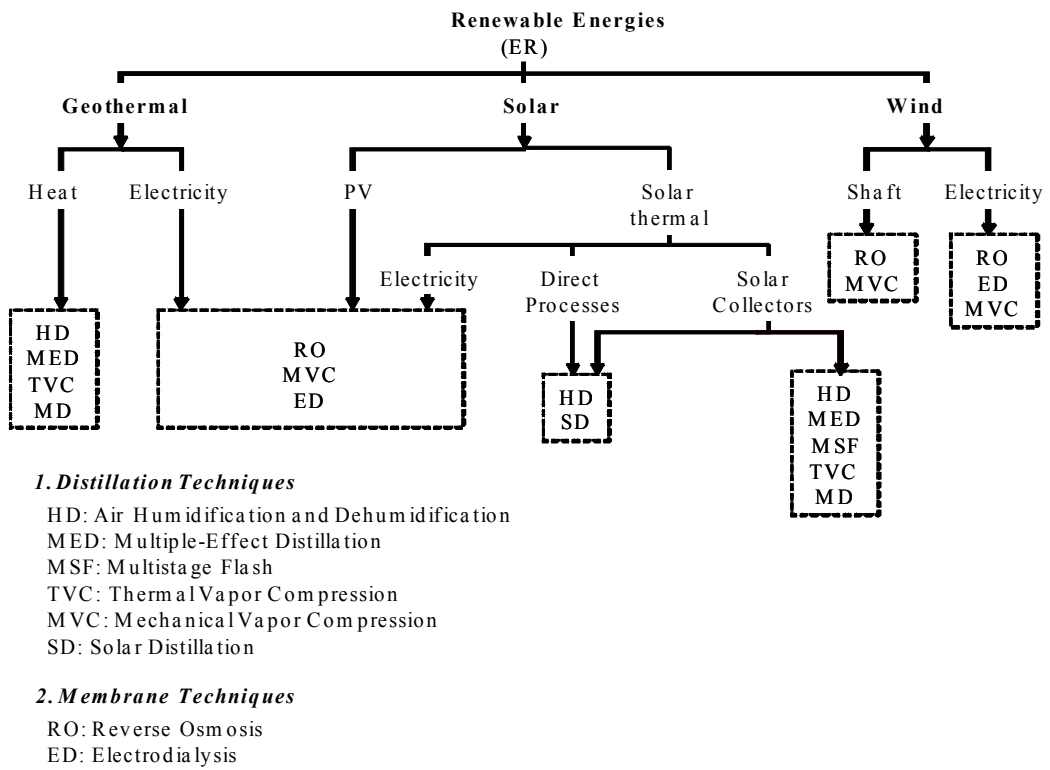

Fig. 5. Technological combinations of the main renewable energies and desalination methods

\begin{tabular}{l|c|c}
\hline \multicolumn{1}{c|}{ Desalination Process } & $\begin{array}{c}\text { Thermal Energy } \\
(\mathrm{kJ} / \mathrm{kg})\end{array}$ & $\begin{array}{c}\text { Electrical Energy } \\
\left(\mathrm{kWh} / \mathrm{m}^{3}\right)\end{array}$ \\
\hline Seawater & $190-290$ & $4-6$ \\
Multi-Stage Flash (MSF) & $150-290$ & $2.5-3$ \\
Multi-Effect Distillation (MED) & - & $8-12$ \\
Vapor Compression (VC) & - & $7-10$ \\
Reverse Osmosis (RO) without Energy Recovery & - & $3-5$ \\
Reverse Osmosis (RO) with Energy Recovery & & \\
Brackish water & & $1-3$ \\
Reverse Osmosis (RO) without Energy Recovery & & $1.5-4$ \\
Reverse Osmosis (RO) with Energy Recovery & & $1.5-4$ \\
Electrodialysis & & \\
\hline
\end{tabular}

Table 1. Energy consumption and electric power cogeneration (Bilton et al., 2011)

In table 1 the energy requirements are separated into thermal energy which is used to heat the seawater and electrical energy which is used to drive pumps, compressors and auxiliary equipment. For seawater desalination, reverse osmosis requires the least amount of overall energy. However, if thermal energy is inexpensive (the case of Middle East), a thermal desalination process like multi-effect distillation can be practical.

Fig.6 illustrates the breakdown of renewable energy powered desalination system technologies implemented worldwide in 2007 (Forstmeier, 2007). It shows that the most used RES/Desalination systems are RES/RO (51\% of the total worldwide installed RES/DES plants). 


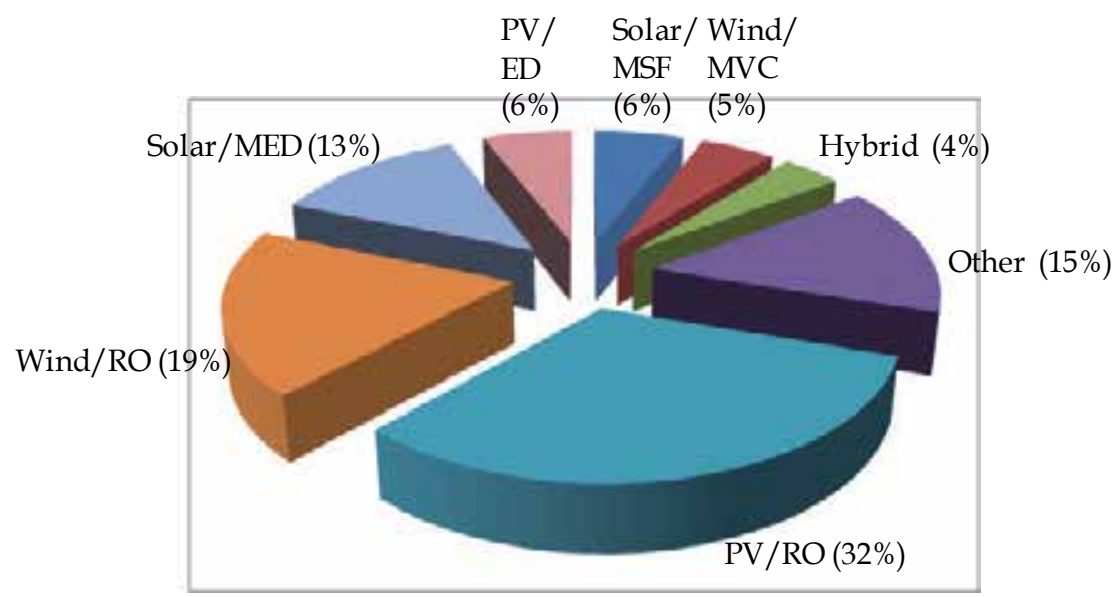

Fig. 6. Breakdown of renewable energy powered desalination system technologies implemented worldwide (Forstmeier, 2007).

Reverse Osmosis (RO) is the desalination process which can be coupled, in reliable and economic way, with RES. The suitability of renewable energy technologies, especially wind turbines and photovoltaics, for RO desalination systems is due to the convenience of $\mathrm{RO}$ for desalinating small quantity of water for remote and isolated areas; it has low energy consumption (Table 1) and little need for maintenance (Weiner et al., 2001).

\subsection{MSF desalination plants driven by solar energy}

Solar-powered MSF plants can produce 6-60 L/ $\mathrm{m}^{2} /$ day, in comparison with the 3-4 $\mathrm{L} / \mathrm{m}^{2} /$ day typical of solar stills (Block, 1989)).

The use of solar troughs for MSF desalination was tested mainly in the USA. In a typical commercial small plant $48 \mathrm{~kW}$ is required to produce $450 \mathrm{~L} /$ day in three stages.

In Szacsvay et al. (1999), a Solar/MSF system using an Atlantis autoflash multistage stage desalination unit is described. Since the standard MSF process is not able to operate coupled to any variable heat source, an adapted MSF system called "Autoflash" was developped. Performance and layout data were obtained both from computer simulation and experimental results with a small-sized Solar/MSF systems in Switzerland. The system had been in operation for 9 years. From these studies it was shown that the cost of distillate could be reduced from $5.48 \$ / \mathrm{m}^{3}$ for small desalination system with a capacity of $15 \mathrm{~m}^{3} /$ day to $2.39 \$ / \mathrm{m}^{3}$ for desalination systems with a capacity of $300 \mathrm{~m}^{3} /$ day.

\subsection{Multiple-effect distillation driven by solar energy}

Several multiple-effect distillation (MED) plants of medium capacity powered by solar energy were built worldwide. One MED-plant designed for a maximum capacity of 120 $\mathrm{m}^{3}$ /day with 18 stack type stages and pre-heaters was analyzed in UAE (El-Nashar and Samad, 1998). Evacuated-tube solar collectors of $1862 \mathrm{~m}^{2}$ were used with water as heat carrying medium. It had a heat accumulator of $300 \mathrm{~m}^{3}$ capacity. Specific heat consumption of the plant was $43.8 \mathrm{kcal} / \mathrm{kg}$ with performance ratio of 12.4 . Due to heat accumulator the 
evaporator could run $24 \mathrm{~h}$ a day during sunny days producing freshwater of $85 \mathrm{~m}^{3} /$ day. The plant was able to desalt seawater of $55,000 \mathrm{ppm}$. The total seawater requirement was $42.5 \mathrm{~m}^{3} / \mathrm{h}$. The major problem was the maintenance of the pumps. It was shown that the acid cleaning and silt removal were extremely necessary for better performance of the plant.

A practical scale desalination system of three effects using only solar energy from solar collectors as the heat source and the electrical power from the PV-cells was investigated by Abu-Jabal et al. (2001). The unit was developed and manufactured by the Ebara Corporation (Tokyo) and tested at the Al Azhar University in Gaza. The average production rate was in the range of $6-13 \mathrm{~L} / \mathrm{m}^{2} /$ day.

Thomas (1997) carried several experiments on MED and MSF units driven by solar energy in Kuwait. He reported several difficulties operating under the variable conditions of solar insulation. Greater success has been found with self-regulating solar MSF plants than solar MED plants.

In Fiorenza et al. (2003) the water production cost for seawater desalination by MED powered by a solar thermal field has been estimated. The results obtained for plants of capacity varying between 500 and $5000 \mathrm{~m}^{3} / \mathrm{d}$ have shown that the cost of water produced can be reduced by increasing the plant capacity; i.e. $3.2 \$ / \mathrm{m}^{3}$ for the $500 \mathrm{~m}^{3} / \mathrm{d}$ plant capacity and $2 \$ / \mathrm{m}^{3}$ for the $5000 \mathrm{~m}^{3} / \mathrm{d}$ plant capacity.

\subsection{Reverse osmosis desalination driven by photovoltaic}

Photovoltaic (PV) powered RO systems have been implemented in different regions, i.e: remote areas of the Tunisia desert, rural areas of Jordan, remote communities in Australia, etc. Several investigations were carried to analyze the cost of $\mathrm{PV} / \mathrm{RO}$ desalination systems (Kalogirou, 2001). If PV connected to a RO system is commercial nowadays, the main problem of this technology is reported to be the high cost of the PV cells. The distance at which the PV energy is competitive with conventional energy depends on the plant capacity, on the distance to the electric grid and on the salt concentration of the feed (GarziaRodriguez, 2002).

In Saudi Arabia, a PV/RO brackish water desalination plant was installed (Hasnain and Alajlan, 1998). It was connected to a solar still with $5 \mathrm{~m}^{3} / \mathrm{d}$ production. The feed water of the water still was the blowdown of the RO unit $\left(10 \mathrm{~m}^{3} / \mathrm{d}\right)$. A detailed cost analysis was also reported.

Bourouni and Chaibi (2009) presented a PV/RO desalination plant, for supplying one village, in southern Tunisia. It uses solar energy to power a reverse osmosis brackish water desalination unit with a capacity of $15 \mathrm{~m}^{3} /$ day. They present an analytical description of the plant components and reports experimental results for a 6-month operating period. Several problems were highlighted such as brine rejection, low efficiencies and high cost.

Several tools were developed to improve the design of $\mathrm{PV} / \mathrm{RO}$ systems by using iterative procedure (Herbert et al., 2007). The size of the RO unit is computed according to the desalinated-water requirements, while the PV system nominal power rating is calculated such that the corresponding energy requirements of the $\mathrm{RO}$ unit are satisfied, taking into account the available solar radiation potential of the installation area. The size of the battery 
incorporated in the system is computed such that the daily variations of the solar radiation are compensated. On the other hand, up to now the design process does not include the optimization of the components' number and type and the minimization of the total system cost.

\subsection{Reverse osmosis driven by wind energy}

Since the coastal areas present a high availability of wind power resources, wind powered desalination represents a promising alternative of renewable energy desalination (GraciaRodriguez et al., 2002). Wind-powered RO plants have been implemented on the islands of the County of Split and Dalmatia (Croatia), on the island Utsira in Norway, and in remote communities in Australia.

A prototype wind-powered $\mathrm{RO}$ desalination system was constructed and tested on Coconut Island off the northern coast of Oahu, Hawaii, for brackish water desalination (Liu et al., 2002). The system has four major subsystems: multivaned windmill/pump, flow/pressure stabilizer, RO module, and control mechanism. It was shown that the flow rate of $13 \mathrm{l} / \mathrm{min}$ could be processed for an average wind speed of $5 \mathrm{~m} / \mathrm{s}$, and a brackish feed water at a total dissolved solids concentration of $3000 \mathrm{mg} / 1$. The average rejection rate and recovery ratio were $97 \%$ and $20 \%$, respectively. Energy efficiency equal to $35 \%$ was shown to be comparable to the typical energy efficiency of well-operated multi-vaned windmills.

A prototype of a fully autonomous wind powered desalination system has been installed on the island of Gran Canaria in the Canarian Archipelago (Carta et al., 2003). The system consists of a wind farm, made up of two wind turbines and a flywheel, which supplies the energy needs of a group of eight RO modules throughout the complete desalination process (from the pumping of seawater to the storage of the product water), as well as the energy requirements of the control subsystems. It was highlighted that this system can be applied to seawater desalination, both on a small and large scale, in coastal regions with a scarcity of water for domestic and/or agricultural use.

The economic feasibility of a wind-powered RO plant was evaluated by mathematical modelling analysis (Forstmeier et al., 2007). It was shown that the costs of a windpowered $\mathrm{RO}$ desalination system are in line with what is expected for a conventional desalination system, proving to be particularly cost-competitive in areas with good wind resources that have high costs of energy. The unit cost of freshwater production by a conventional RO plant can be reduced up to $20 \%$ for regions with an average wind speed of $5 \mathrm{~m} / \mathrm{s}$ or higher.

In order to optimize the design of Wind/RO systems Kiranoudis et al. (1997) considered desalination plants power-supplied by one Wind Generator (W/G). The optimal design objectives are the determination of the optimum size and type of the $\mathrm{W} / \mathrm{G}$ and the optimum structure of the RO desalination unit membranes, such that the system total annual cost is minimized, with respect to certain product quality and quantity demand constraints. This procedure is implemented using a successive quadratic optimization algorithm. The W/Gdesalination systems investigated do not incorporate either electric energy, or produced water storage units. 


\subsection{Reverse osmosis desalination driven by hybrid pv/wind systems}

RO desalination units driven by hybrid PV/Wind power systems have been designed and implemented in different areas of the world (e.g. Sultanate of Oman, Israel, Mexico, Tunisia, etc.). The performances of these units were reported by Weiner et al. (2001), Peterson et al. (1981), Bourouni and Chaibi (2009) and Peterson et al. (1979).

Two RO desalination plants (Germany) using a plate module system supplied by a $6 \mathrm{~kW}$ wind energy converter and a $2.5 \mathrm{~kW}$ solar generator have been designed for remote areas (Peterson et al., 1979). Two of these prototypes were installed in the northern part of Mexico and in a small island on the German coast of the North Sea (Peterson et al., 1981).

The design of a stand-alone, hybrid PV/Wind system, used to power-supply a seawater RO desalination unit, based on a technoeconomic analysis, is proposed by Mohamed and Papadakis (2004). The system contains both a battery bank and a storage tank for the produced water, in order to cover the potable water demand during the days with negligible solar and/or wind energy production. The RO unit is designed to be able to cover the maximum daily water demand, dictating the corresponding maximum total power requirements. In the second step of the proposed methodology the number of PV modules is calculated such that the maximum energy requirements during the year are covered, taking into account the available solar radiation potential. The battery bank capacity is computed such that the electric energy required for two days can be stored. The volume of the water storage tank is calculated in such way that it provides two summer day autonomy. In order to minimize the total system cost, the developed software eliminates a part of the PV modules, determines the corresponding produced daily energy and replaces them by one or more W/G. This calculation is performed for various combinations of PV and W/G contribution percentages to the hybrid system total energy production. The combination achieving the minimum water production cost is selected as the final hybrid system configuration.

Manolakos et al. (2001) discussed the developed and the application a software tool for designing hybrid PV/Wind systems, which are used to cover the electricity and water demands of remote areas. The nominal power rating of the $\mathrm{W} / \mathrm{G}$ and the number of the PV modules are determined through several program runs simulating the system operation, in order to satisfy the electric energy and water needs. The battery bank is sized taking into account several days of energy autonomy of the system, in order to ensure the uninterrupted power-supply during the time periods of low solar radiation and/or low wind speed. The volume of the desalinated-water tank is computed to satisfy the water demand, even during the time periods of low RES potential availability.

Voivontas et al. (2001) developed a computer-aided design tool for the preliminary design of desalination plants driven by RES and the evaluation of the corresponding water production cost. The RES power production capability is determined using an iterative procedure allowing an energy balance between the energy produced by the RES and the auxiliary energy sources (e.g. electric grid, diesel generators etc.) and the energy requirements of the desalination unit. However, this design method does not include the economic optimization of the resulting configurations. The investigations carried on $\mathrm{RO}$ desalination plants driven by hybrid PV/Wind systems showed that this kind of units is the most efficient compared to the other RES/DES technologies. Moreover, this technology can be improved by optimizing 
the design of the overall plant. For these reasons we focus in this chapter on the optimization of this kind of systems.

\section{New methodology of optimization hybrid PV/WIND/RO systems}

The operational performance and the reliability of the desalination systems driven by RES depend on their proper design and sizing. The optimal exploitation of the available RES potential is necessary in order to reduce the cost of the water produced.

The objective of this chapter is to present a new methodology to optimize RO desalination system, which is power-supplied by hybrid Photovoltaic (PV) and Wind-Generator (W/G) energy sources. Compared to the past-proposed methodologies, which have been used in order to design water desalination systems driven by RES, the methodology presented in this chapter has the advantage to take into account all the critical operational parameters that affect both the resulting electric energy and desalinated-water production levels and the system capital and maintenance costs. The block diagram of the PV/Wind/RO system considered in this study is illustrated in Fig.7.

The Battery bank is charged from the respective PV and W/G input power sources by using battery chargers, connected to a common DC bus. The power sources are usually configured in multiple power generation blocks according to the devices nominal power ratings and the redundancy requirements. The battery bank, which is usually of lead-acid type, is used to store the generated electric energy surplus and to supply the $\mathrm{RO}$ desalination units in case of low solar radiation and/or wind speed conditions. DC/AC converters are used to interface the DC battery voltage to the AC requirements of the $\mathrm{RO}$ desalination units. A water tank is used to store the produced desalinated water surplus, which is not directly consumed.

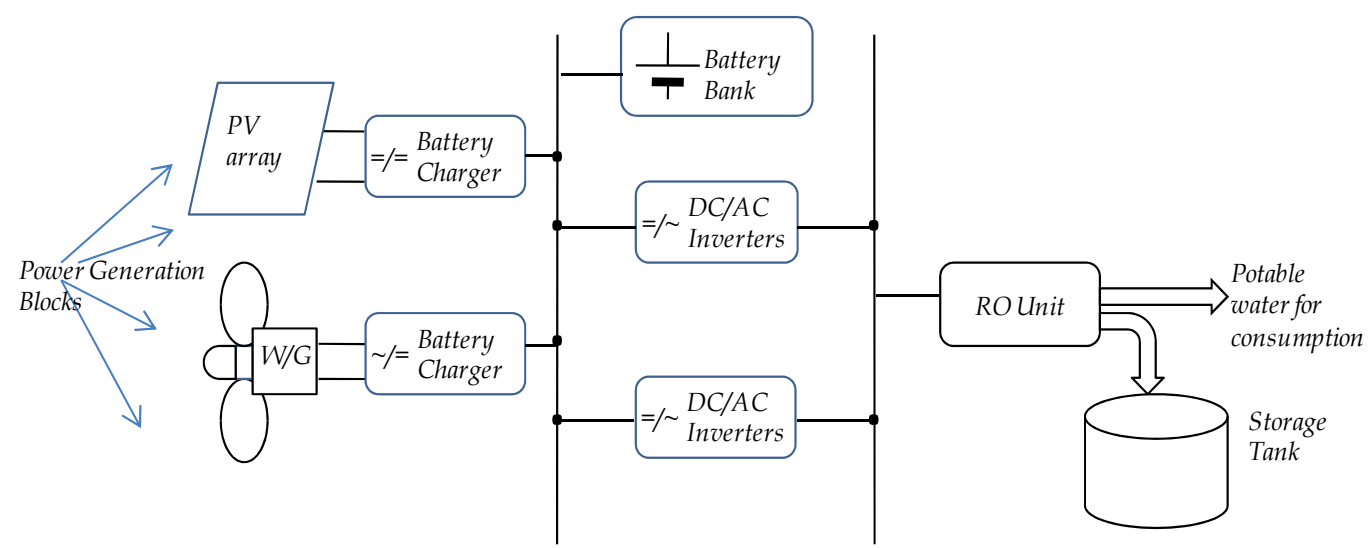

Fig. 7. Block diagram of RO driven by Hybrid PV and W/G energy sources.

The purpose of the proposed methodology is to derive, among a list of commercially available system devices, the optimal number and type of units such that the life time round total system cost $\left(\mathrm{CO}_{\mathrm{Tot}}\right)$ is minimized. At the same time the desalinated-water demand is completely covered. 
$\mathrm{CO}_{\text {Tot }}$ is equal to the sum of the respective components capital and maintenance costs. The decision variables for the optimization are: (i) the number and the type of the membranes, (ii) the number and the type of the PV modules, (iii) the number and the type of the wind turbines, (iv) the batteries charger, (v) the DC/AC converters, (vi) the height of the turbines and the volume of the storage tank.

The minimization of the system total cost function has been implemented using genetic algorithms (GAs), which have the ability to attain the global optimum solution with relative computational simplicity. The scope of the GAs in the proposed methodology is the calculation of the optimum solutions in the overall state space of the desalination system sizing problem.

The block diagram depicted in Fig.8 summarizes the proposed optimization methodology. This methodology uses a database including: (i) the technical characteristics of commercially available system devices, (ii) their associated per unit capital and (iii) their maintenance costs. The input of the model are the: (i) feed and the desalinated water quality specifications (ii) water demand profile, (iii) daily solar irradiation on a horizontal plane, (iv) the hourly mean values of ambient temperature and wind speed.

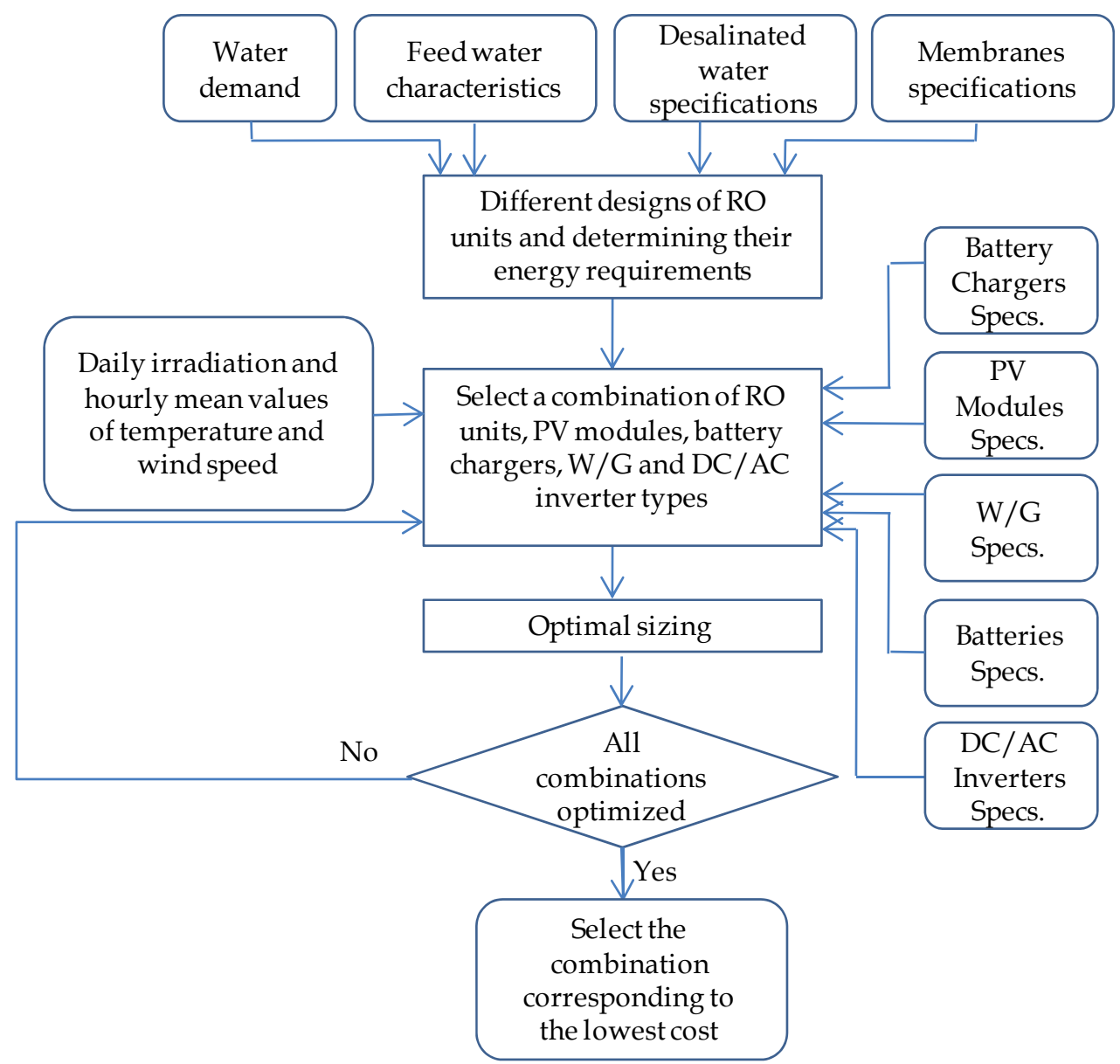

Fig. 8. The flowchart of the proposed optimization methodology. 
At the first step the RO plant is designed and optimized based on water demand, feed water characteristics and desalinated water specifications. One important outcome of this step is the determination of the energy required to operate the pumps and other auxiliaries. In the second step, special attention is paid to the design of energy systems related to the chosen technology and the arrangements of various components that can meet the goal of energy demand. In this step, the structure of the power unit, batteries, water storage and inverters are studied. Several Hybrid PV/Wind combinations are possible to power the designed RO plant. To validate the RES configuration, a simulation of the system operation is performed during the year in order to examine whether it fulfils the desalinated-water requirements.

In the third step, a process employing GAs is executed, in order to dynamically search for the system configuration, which subject to the criterion set in the first step, results in minimum total system cost.

During the application of the proposed methodology, the system operation is simulated for one year with a time step of one hour. The power produced by the PV and W/G sources and the desalinated-water flow rate are assumed to be constant during that time step and they are arithmetically equal to the corresponding energy and water volume, respectively.

\subsection{Modeling of the RO unit}

The equations of flow and salt distribution, used in the model, are similar to those provided by the software for the design of RO membrane "FILMTEC-ROSA" (DOW, 2006).

$\mathrm{RO}$ membranes are selected after checking the feed water characteristics. Hence, the number of membranes $N_{m b}$ which is a function of unit capacity, the stream flow $Q_{p}$ and the membrane surface $S_{\mathrm{mb}}$ is calculated as follows.

$$
\mathrm{N}_{\mathrm{mb}}=\frac{\mathrm{Q}_{\mathrm{p}}}{\mathrm{f} . \mathrm{S}_{\mathrm{mb}}}
$$

Where $\mathrm{f}$ is the pure water transport coefficient.

The number $\mathrm{N}_{\mathrm{tp}}$ of pressure vessels in the system is calculated the following equation:

$$
\mathrm{N}_{\mathrm{tp}}=\frac{\mathrm{N}_{\mathrm{mb}}}{\mathrm{N}_{\mathrm{T}}}
$$

Where $\mathrm{N}_{\mathrm{T}}$ is the total number of membranes per unit.

Equation 3 is used to calculate the water flow rate produced by $\mathrm{RO}$ membranes.

$$
\mathrm{Q}_{\mathrm{p}}=A \cdot S_{m b} \cdot T C F \cdot F \cdot(\Delta P-\Delta \Pi)
$$

$\mathrm{A}$ is the membrane pure water permeability, TCF is the temperature correction factor, $\mathrm{F}$ is the membrane fouling factor $(0.8 \leq \mathrm{F} \leq 1), \Delta \mathrm{P}$ is the applied transmembrane pressure and $\Delta \Pi$ is the transmembrane osmotic pressure.

The osmotic pressure in the different elements of $\mathrm{RO}$ unit is given by equation 4 . 


$$
\Pi=0.002654 .(T+273) \cdot C \cdot \frac{1}{1000-\frac{C}{1000}}
$$

Where $\mathrm{C}$ is the salt concentration.

The average pressure drop $\Delta \mathrm{P}$ between the first and the last element is given by equation 5 .

$$
\Delta P=P_{f}-1 / 2 \Delta P_{f s}
$$

$\Delta \mathrm{P}_{\mathrm{fs}}$ represents the pressure drop between feed and discharge of a single element, it's given as follows:

$$
\Delta P_{f s}=0.01 \cdot \bar{Q}_{f c}^{1.7}
$$

The efficiency $\left(\mathrm{Y}_{\mathrm{k}}\right)$ of the membrane is a function of the overall performance of the RO system $\mathrm{Y}$ and $\mathrm{N}_{\mathrm{mb}}$ in the system (equation 7).

$$
Y_{k}=1-(1-Y)^{1 / N_{m b}}
$$

The product concentration $C_{P}$ is function of recovery rate and salt rejection (equation 8). The brine concentration $\mathrm{C}_{\mathrm{c}}$ of $\mathrm{RO}$ element is calculated from the equation 9.

$$
\begin{gathered}
C_{p}=\left(1-R_{m b}\right) \times C_{f c} \times p_{f} \times T C F \times \frac{S_{m b}}{Q_{p}} \\
Q_{f} \cdot C_{f}=Q_{p} \cdot C_{p}+Q_{c} \cdot C_{c}
\end{gathered}
$$

By applying equations (6), (7) and (8) the: flow rates and concentrations of permeate and concentrated brine in the first element are determined respectively. Thus, product water is collected in the central tube and the brine becomes feed to the second element. This process is repeated for all elements in series. To determine the feed pressure of the system, the model starts from last element for which the applied pressure $\mathrm{P}_{\mathrm{a}}$ is calculated from equation (3).

The total water quantity $\mathrm{Q}_{\mathrm{T}}$ produced by $\mathrm{RO}$ system is given by equation 10 . Where $\mathrm{Q}_{\mathrm{k}}$ is the amount of water produced by the cell $\mathrm{k}$. The desalinated water salinity concentration is deduced from equation 11 .

$$
\begin{gathered}
Q_{T}=\sum_{k=1}^{N_{m b}} Q_{k} \\
C_{T}=\frac{\sum_{k=1}^{N_{m b}} C_{k} \cdot Q_{k}}{Q_{T}}
\end{gathered}
$$


It should be noted that many other parameters are considered in the model including estimation of the water needs, chemical analysis of the feed water and the choice of the membranes. The optimal system design is targeting towards the minimization of the RO energy consumption. In this frame energy recovery systems can be considered.

\subsection{Modeling of the photovoltaic PV panels}

Each PV power generation block shown in Fig. 7, consists of $N_{P}$ PV modules connected in parallel and $N_{S}$ PV modules connected in series. On one day $\mathrm{i}(1 \leq \mathrm{i} \leq 365)$ and at hour $\mathrm{t}$ $(1 \leq t \leq 24)$ the maximum output power of each PV power generation block is determined. This calculation is based on the specifications of the PV module under Standard Test Conditions (STC, cell temperature $=25^{\circ} \mathrm{C}$ and solar irradiance $=1 \mathrm{~kW} / \mathrm{m}^{2}$ ), provided by the manufacturer, as well as the ambient temperature and solar irradiation conditions. The following equations (12-15) are used to design the PV modules:

$$
\begin{gathered}
P_{M}^{i}(t)=N_{s} \cdot N_{p} \cdot V_{O C}^{i}(t) \cdot I_{S C}^{i}(t, \beta) \cdot F F^{i}(t) \\
I_{S C}^{i}(t, \beta)=\left\{I_{S C, S T C}+K_{I}\left[T_{c}^{i}(t)-25^{\circ} C\right]\right\} \cdot \frac{G^{i}(t, \beta)}{1000} \\
V_{O C}^{i}(t)=V_{O C, S T C}-K_{v}\left[T_{c}^{i}(t)-25^{\circ} C\right] \\
T_{c}^{i}(t)=T_{A}^{i}(t)+\frac{N O C T-20^{\circ} C}{800} \cdot G^{i}(t, \beta)
\end{gathered}
$$

Where $P_{M}^{i}(t)$ is the maximum output power of the PV array, $I_{S C}^{i}(t, \beta)$ is the PV module short-circuit current (A), $I_{S C, S T C}$ is the short-circuit current under STC, $G^{i}(t, \beta)$ is the global irradiance $\left(\mathrm{W} / \mathrm{m}^{2}\right)$ incident on the PV module placed at tilt angle $\beta\left({ }^{\circ}\right), \mathrm{K}_{\mathrm{I}}$ is the short-circuit current temperature coefficient $\left(\mathrm{A} /{ }^{\circ} \mathrm{C}\right), V_{O C}^{i}(t)$ is the open-circuit voltage $(\mathrm{V}), V_{O C, S T C}$ is the open-circuit voltage under STC $(\mathrm{V}), K_{v}$ is the open-circuit voltage temperature coefficient $\left(\mathrm{V} /{ }^{\circ} \mathrm{C}\right), T_{A}^{i}(t)$ is the ambient temperature $\left({ }^{\circ} \mathrm{C}\right)$, NOCT is the Nominal Operating Cell Temperature $\left({ }^{\circ} \mathrm{C}\right)$, provided by the manufacturer and $F F^{i}(t)$ is the Fill Factor, (Markvart, 1994).

The number of PV modules connected in series in each PV power generation block, $N_{S}$, is calculated according to the battery charger maximum input voltage, $V_{D C}^{m}$, and the PV modules maximum open-circuit voltage level, $V_{O C}^{m}$ :

$$
N_{s}=\frac{V_{D C}^{m}}{V_{O C}^{m}}
$$

The values of the daily solar irradiation on the horizontal plane are used to calculate the value of $G^{i}(t, \beta)$ according to the methodology analyzed by Lorenzo (1994). 
The battery charger power conversion factor $\mathrm{n}_{\mathrm{s}}$ is defined as follows:

$$
n_{s}=\frac{P_{P V}^{i}(t, \beta)}{P_{M}^{i}(t, \beta)}=n_{1} \cdot n_{2}
$$

Where $P_{P V}^{i}(t, \beta)$ is the PV power really transferred to the battery bank by each PV power generation block, $n_{1}$ is the battery charger power electronic interface efficiency and $n_{2}$ is a conversion factor, which depends on the battery charging algorithm executed during the charger operation and indicates the deviation of the actual PV power generated from the corresponding maximum power.

In case that the battery charger operates according to the Maximum Power Point Tracking (MPPT) principle (Esram and Chapman, 2007), $\mathrm{n}_{2}$ is approximately equal to 1 , otherwise its value is much lower. The values of $n_{1}$ and $n_{2}$ are specified by the battery charger manufacturer.

\subsection{Modeling of wind generator W/G}

The variation of the $W / G$ output power versus the wind speed is provided by the manufacturer. It usually indicates the actual power transferred to the battery bank from the $\mathrm{W} / \mathrm{G}$ source, taking into account the effects of both the battery charger power electronic interface efficiency and the MPPT operation, if available. Thus, in the proposed methodology, the power transferred to the battery bank at hour $t$ of day $i$, from each $W / G$ power generation block, $P_{W G}^{i}(t, h)$, is calculated using the following linear relation:

$$
P_{W G}^{i}(t, h)=P_{1}+\left[v^{i}(t, h)-v_{1}\right] \cdot \frac{P_{2}-P_{1}}{v_{2}-v_{1}}
$$

where $\mathrm{h}(\mathrm{m})$ is the W/G installation height, $v^{i}(t, h)$ is the wind speed $(\mathrm{m} / \mathrm{s})$ at height $\mathrm{h}$ $\left(h_{\text {low }} \leq h \leq h_{\text {high }}\right.$ according to the limits $h_{\text {low }}$ and $h_{\text {high }}$ specified by the $W / G$ manufacturer) and $\left(\mathrm{P}_{1}, \mathrm{v}_{1}\right),\left(\mathrm{P}_{2}, \mathrm{~V}_{2}\right)$ are the $\mathrm{W} / \mathrm{G}$ output power and wind speed pairs.

If the input wind speed data are measured at a different height than the desired $W / G$ installation height, $\mathrm{h}$, thus, $v^{i}(t, h)$ is corrected using the following exponential law:

$$
v^{i}(t, h)=v_{r e f}^{i}(t) \cdot\left(\frac{h}{h_{r e f}}\right)^{\alpha}
$$

where $v_{r e f}^{i}(t)$ is the reference (input) wind speed $(\mathrm{m} / \mathrm{s})$ measured at height $\mathrm{h}_{\text {ref }}(\mathrm{m})$ and the exponent a ranges from $1 / 7$ to $1 / 4$.

\subsection{Modeling of batteries}

The number of batteries connected in series in each of the multiple, parallel-connected battery strings forming the battery bank, $n_{B}^{s}$, depends on the nominal DC bus voltage and the nominal voltage of each individual battery, $V_{B}(\mathrm{~V})$ : 


$$
n_{B}^{s}=\frac{V_{B U S}}{V_{B}}
$$

The value of the battery bank nominal capacity, $\mathrm{C}_{\mathrm{n}}(\mathrm{Ah})$, depends on the total number of batteries, $\mathrm{N}_{\mathrm{BAT}}$, the number of series connected batteries and the nominal capacity of each battery, $\mathrm{C}_{\mathrm{B}}(\mathrm{Ah})$ :

$$
C_{n}=\frac{N_{B A T}}{n_{B}^{S}} \cdot C_{B}
$$

The maximum permissible battery depth of discharge, DOD (\%) is specified by the system designer at the beginning of the optimal sizing procedure and it dictates the value of the minimum permissible battery bank capacity during discharging, $C_{\min }(\mathrm{Ah})$, which is calculated as follows:

$$
C_{\min }=D O D \cdot C_{n}
$$

During the desalination system operation the available battery bank capacity is modified according to the PV and W/G energy production levels and the power requirements of the desalination units. This variation is expressed by the following equation:

$$
\begin{gathered}
C^{i}(t)=C^{i}(t-1)+n_{B} \cdot \frac{P_{B}^{i}(t)}{V_{B U S}} \cdot \Delta t \\
C^{i}(24)=C^{i+1}(0)
\end{gathered}
$$

where $C_{i}(t), C_{i}(t-1)$ is the available battery capacity (Ah) at hour $t$ and $t-1$, respectively, of day $i, n_{B}=80 \%$ is the battery round-trip efficiency during charging and $n_{B}=100 \%$ during discharging (Borowy and Salameh, 1996), $\mathrm{V}_{\mathrm{BUS}}$ is the nominal DC bus voltage $(\mathrm{V}), P_{B}^{i}(t)$ is the battery input/output power $(\mathrm{W})\left(P_{B}^{i}(t)<0\right.$ during discharging and $P_{B}^{i}(t)>0$ during charging) and $\Delta \mathrm{t}$ is the simulation time step $(\Delta \mathrm{t}=1 \mathrm{~h})$.

In order to avoid the battery performance degradation under practical operating conditions the maximum permissible battery bank charging or discharging current has been limited to $\left(C_{n} / 5\right)$ $h$. The initial capacity of the battery bank, $C_{1}(0)$, is calculated using the following equation:

$$
C^{1}(0)=\left(\frac{1-D O D}{2}\right) \cdot C_{n}
$$

\subsection{Modeling of the global RE/DES system}

The PV panels and W/G must be sized such that the produced energy during the year allows to completely satisfy the desalination system energy requirements. Hence, the remaining battery bank capacity at the end of the simulation period must be higher than its initial value:

$$
C^{365}(24) \geq C^{1}(0)
$$


When the necessary power for the RO operation is available, then the desalination process is performed and desalinated water is produced. Otherwise, the operation of the RO units is suspended. In this case, cleaning of each RO unit membranes should be performed, using flushing techniques. The total power produced by the PV and Wind Turbines at hour $t$ of day $i$ is calculated as follows:

$$
P_{R E}^{i}(t)=N_{c h}^{P V} \cdot n_{S} \cdot P_{M}^{i}(t, \beta)+N_{W G} \cdot P_{W G}^{i}(t, h)
$$

where $N_{W G}$ is the total number of W/G power generation blocks incorporated in the desalination system. At the hour $\mathrm{t}$ of the day $\mathrm{i}$ the total $\mathrm{DC}$ power input to the $\mathrm{DC} / \mathrm{AC}$ inverters, $P_{T}^{i}(t)(\mathrm{W})$, is related with the total AC power supplying the desalination units, $P_{R O}^{i}(t)(\mathrm{W})$, according to the following equation:

$$
P_{T}^{i}(t)=\frac{P_{R O}^{i}(t)}{n_{i}}
$$

where $n_{i}(\%)$ is the power conversion efficiency of the DC/AC inverters. The minimum permissible amount of water stored in the tank, $V_{\min }\left(\mathrm{m}^{3}\right)$, should be fixed (generally set equal to $25 \%$ to $30 \%$ of the tank total volume, $\left.\mathrm{V}_{\text {TANK }}\left(\mathrm{m}^{3}\right)\right)$.

The volume of the available water stored in the tank at hour $t$ of day $i, V_{i}(t)\left(m^{3}\right)$, is modified during the desalination system operation, such that:

$$
V_{\min } \leq V^{i}(t) \leq V_{\text {TANK }}
$$

When the desalinated water demand at hour $\mathrm{t}$ of day i $V_{D}^{i}(t),\left(\mathrm{m}^{3}\right)$, is defined then the energy and water flows among the components of the system can be described by the Fig.9.

The developed desalination system model should be used to simulate the system operation on a yearly basis to check the feasibility of the proposed solution. The optimization of the whole system is achieved by using the Genetic Algorithms methods by considering potential solutions.

\subsection{System total cost minimization using gas}

The genetic algorithms (GAs) are used for designing and sizing a, through the calculation of optimum solutions in the overall state space. The role of the GA is to derive the optimal desalination system configuration by selecting chromosomes from the total state space of potential solutions, which minimize the problem's objective function and simultaneously lead to a successful system operation during the whole year.

GAs is an optimum search technique based on the concepts of natural selection and survival of the fittest individuals.

It works with a fixed-size population of possible solutions of a problem, which are evolving in time. A genetic algorithm utilizes three principal genetic operators; selection, crossover andmutation. Compared to conventional optimization methods, such as dynamic programming and gradient techniques, genetic algorithms are able to: (i) handle complex 
problems with linear or non-linear cost functions, both accurately and efficiently and (ii) attain the global optimum solution with relative computational simplicity, without being restricted by local optima (Michalewicz, 1994).

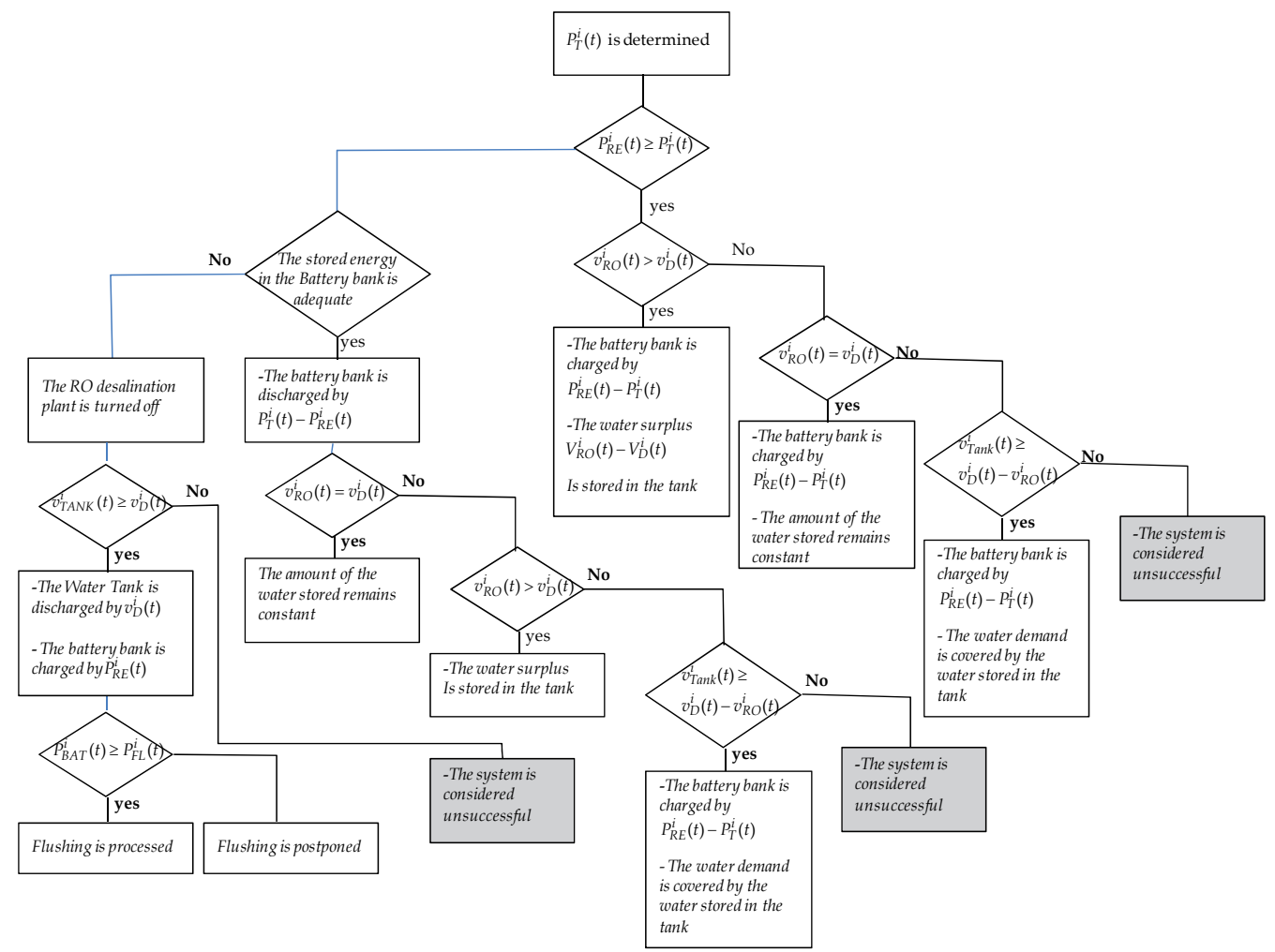

Fig. 9. The flowchart of energy and water flows among the components of the system.

The GA chromosomes are in the form of $X=\left[N_{m b}, N_{P V}, N_{W G}, N_{B A T}, h, \beta, W_{\text {TANK }}\right]$. The objective function to be minimized by the GA is equal to the sum of the capital and maintenance costs evolving during the desalination system lifetime period:

$$
\begin{aligned}
f(x) & =\left[C O_{A q \cdot R O}+20 \cdot C O_{M \cdot R O}+C O_{A q . I N V}\left(\tau_{I N V}+1\right)+C O_{M \cdot I N V} \cdot\left(20-\tau_{I N V}-1\right)\right] \\
& +N_{P V}\left(C O_{A q \cdot P V}+20 \cdot C O_{M \cdot P V}\right)+N_{W G}\left(C O_{A q \cdot W G}+20 \cdot C O_{M \cdot W G}+h \cdot C O_{A q . h}+20 \cdot h \cdot C O_{M \cdot h}\right) \\
& \left.+N_{B A T} \cdot\left[C O_{A q \cdot B A T}+\tau_{B A T} \cdot C O_{A q \cdot B A T}+\left(20-\tau_{B A T}-1\right) \cdot C O_{M \cdot B A T}\right)\right] \\
& +N_{c h}^{P V} \cdot\left[C O_{A q \cdot c h}^{P V}+\left(\tau_{c h}^{P V}+1\right)+C O_{M . c h}^{P V} \cdot\left(20-\tau_{c h}^{P V}-1\right)\right]+V_{T A N K} \cdot\left[C O_{A q \cdot T a n k}+20 \cdot C O_{M \cdot T A N K}\right]
\end{aligned}
$$

with the following constraints :

$$
\begin{aligned}
& \mathrm{N}_{\mathrm{mb}} \geq 1 ; \mathrm{N}_{\mathrm{PV}} \geq 0 ; \mathrm{N}_{\mathrm{WG}} \geq 0 ; N_{B A T} / n_{B}^{\mathrm{s}} \geq 1 ; \mathrm{V}_{\mathrm{TANK}} \geq 0 ; \\
& \mathrm{h}_{\text {low }} \leq \mathrm{h} \leq \mathrm{h}_{\text {high }} ; 0 \leq \beta \leq 90^{\circ} .
\end{aligned}
$$


where $\mathrm{CO}_{A q . R O}, \mathrm{CO}_{A q . P V}, \mathrm{CO}_{A q . W G}, \mathrm{CO}_{A q . B A T}, \mathrm{CO}_{A q . I N V}, \mathrm{CO}_{\text {Aq.ch }}^{P V}, \mathrm{CO}_{\text {Aq.Tank }}$ and $\mathrm{CO}_{\text {Aq.h }}$ are the capital costs of the RO desalination units, PV modules, W/Gs, batteries, DC/AC inverters, PV battery chargers, water storage tank (per $\mathrm{m}^{3}$ ), and $\mathrm{W} / \mathrm{G}$ installation tower (per $\mathrm{m})$, respectively. $\mathrm{CO}_{M . R O}, \mathrm{CO}_{M . P V}, \mathrm{CO}_{M . W G}, \mathrm{CO}_{M . B A T}, \mathrm{CO}_{M . I N V}, \mathrm{CO}_{M . c h}^{P V}, \mathrm{CO}_{M . T A N K}$ and $\mathrm{CO}_{M . h}$ are the annual maintenance costs of the $\mathrm{RO}$ plant, $\mathrm{PV}$ modules, W/Gs, batteries, $\mathrm{DC} / \mathrm{AC}$ inverters, PV battery chargers, water storage tank (per $\mathrm{m}^{3}$ ) and $\mathrm{W} / \mathrm{G}$ installation tower (per $\mathrm{m}$ ), respectively. $\tau_{\mathrm{BAT}}$ is the expected number of battery replacements during the 20-year system operation, because of limited battery lifetime and $\tau_{c h}^{P V}$ and $\tau_{\mathrm{INV}}$ are the expected numbers of PV battery chargers and DC/AC inverters replacements during the system 20-year lifetime period, which are equal to the system lifetime period (20 years) divided by the Mean Time Between Failures (MTBF) of power electronic converters. Each of the capital costs incorporated in Eq. (30) incorporates the market price and the installation cost of the respective device.

Initially, a population of chromosomes is generated randomly and the constraints described by the inequalities (Eq. 30) are evaluated for each chromosome. If any of the initial population chromosomes violates these constraints then it is replaced by a new, randomly generated chromosome, which fulfils these constraints. The first step of the GAbased optimal sizing algorithm iteration is the fitness function evaluation for each chromosome of the extracted population. If any of the resulting fitness function values is lower than the lowest value obtained at the previous iterations then this value is considered to be the optimal solution of the minimization problem and the corresponding chromosome's values are considered to be the desalination system's optimal sizing and operational parameters.

This optimal solution is replaced by better solutions, if any, produced in subsequent GA generations during the program evolution. The selection of the chromosomes which will be subject to the crossover andmutation operations, thus producing the next generation population, is based on the roulette wheel method (Michalewicz, 1994). The crossover mechanism uses the Simple Crossover, Simple Arithmetical Crossover and Whole Arithmetical Crossover operators. Next, the selected chromosomes are subject to the mutation mechanism, which is performed using the Uniform Mutation, Boundary Mutation and Non-Uniform Mutation operators. In case that the application of the crossover or mutation operators results in a chromosome which does not satisfy the optimization problem constraints, then a "repair" procedure is performed and that chromosome is replaced by the corresponding parent. In case of the Simple Crossover operation, where each new chromosome is generated by two parents, then the chromosome is replaced by the parent with the best fitness function value. The GA optimization process described above is repeated until a predefined number of population generations have been evaluated.

\section{Simulation results and discussion}

The proposed methodology, has been applied and tested for the design and optimal sizing of RO desalination systems power-supplied by PV and W/G energy sources, located in the area of Ksar Ghilène Village (300 inhabitants), southern Tunisia at: 
latitude $=33.45^{\circ}$, longitude $=9.02^{\circ}$ and altitude $=64 \mathrm{~m}$ above sea level. The average national water consumption in Tunisia is about $150 \mathrm{l}$ /day/inhabitant. However, the RO unit is designed for primary needs consumption (drinking, cooking, etc.). Hence, a maximum daily water consumption of $50 \mathrm{l}$ /day/inhabitant was assumed; giving $15 \mathrm{~m}^{3} /$ day as maximum total water needs.

To calculate the energy needs of the system, first we calculate the total power requirements for different subsystems, given the maximum operation hours of the RO system. In the present case the total energy demand for the RO plant is $558.03 \mathrm{Wh}$.

In the first iteration of the optimization methodology 20 individuals were generated. This population contains different PV/Wind combinations allowing to provide the water required by the village and the power to drive the $\mathrm{RO}$ plant.

The different characteristics of the components used in these simulations are summarized in table 2 .

\begin{tabular}{|c|c|c|c|}
\hline RO Membranes & Solar Generators & Wind Turbines & Batteries \\
\hline Diameter $=8^{\prime \prime}$ & $\begin{array}{l}\text { Nominal power }= \\
230 \mathrm{~W}\end{array}$ & Rotor diameter $=6.7$ & Nominal capacity $=200 \mathrm{Ah}$ \\
\hline Active surface $=37 \mathrm{~m}^{2}$ & $\operatorname{Imax}=7.2 \mathrm{~mA}$ & Heigh $=18 \sim 43 \mathrm{~m}$ & Nominal voltage $=12 \mathrm{~V}$ \\
\hline Recovery $\sim 15 \%$. & $\begin{array}{l}\text { Module efficiency = } \\
10 \%\end{array}$ & Rated power $=7.5 \sim 10 \mathrm{~kW}$ & $\mathrm{DOD}_{\max }=40 \%$ \\
\hline \multirow[t]{2}{*}{ Salt Reject $=99.5 \%$} & $\begin{array}{l}\text { Module Area }= \\
1.18 \mathrm{~m}^{2}\end{array}$ & & Efficiency $=80 \%$ \\
\hline & $\begin{array}{l}\text { Acquisition cost = } \\
4.7 \text { US } \$ / \mathrm{W}\end{array}$ & & Acquisition cost $=760$ US $\$$ \\
\hline
\end{tabular}

Table 2. Characteristics of the different components used in the model

From the chromosomes generated in the first step a second generation is provided by using selection $(30 \%)$, crossover $(50 \%)$ and mutation $(20 \%)$. We found that the minimum cost of water in the first generation was $3.56 \$ / \mathrm{m}^{3}$. It decreased to $3.12 \$ / \mathrm{m}^{3}$ in the second generation.

The variation of the water cost during the GA-based optimization process evolution is presented in Fig.10.

This figure shows a significant decrease of the objective function $\mathrm{CO}_{\text {Tot }}$ for the first 30 generations and stabilizes around $2.62 \$ / \mathrm{m}^{3}$. This means that the optimal solution is reached.

In the context of Ksar Ghilène Village the minimum cost corresponds to RO desalination plant driven by PV modules only. Fig.11 presents the variation of the charge and discharge state of the batteries during throughout the year.

In the optimal solution no $\mathrm{W} / \mathrm{G}$ is considered since the village of Ksar Ghilène does not have a good potential for wind energy but a very interesting solar potential. 


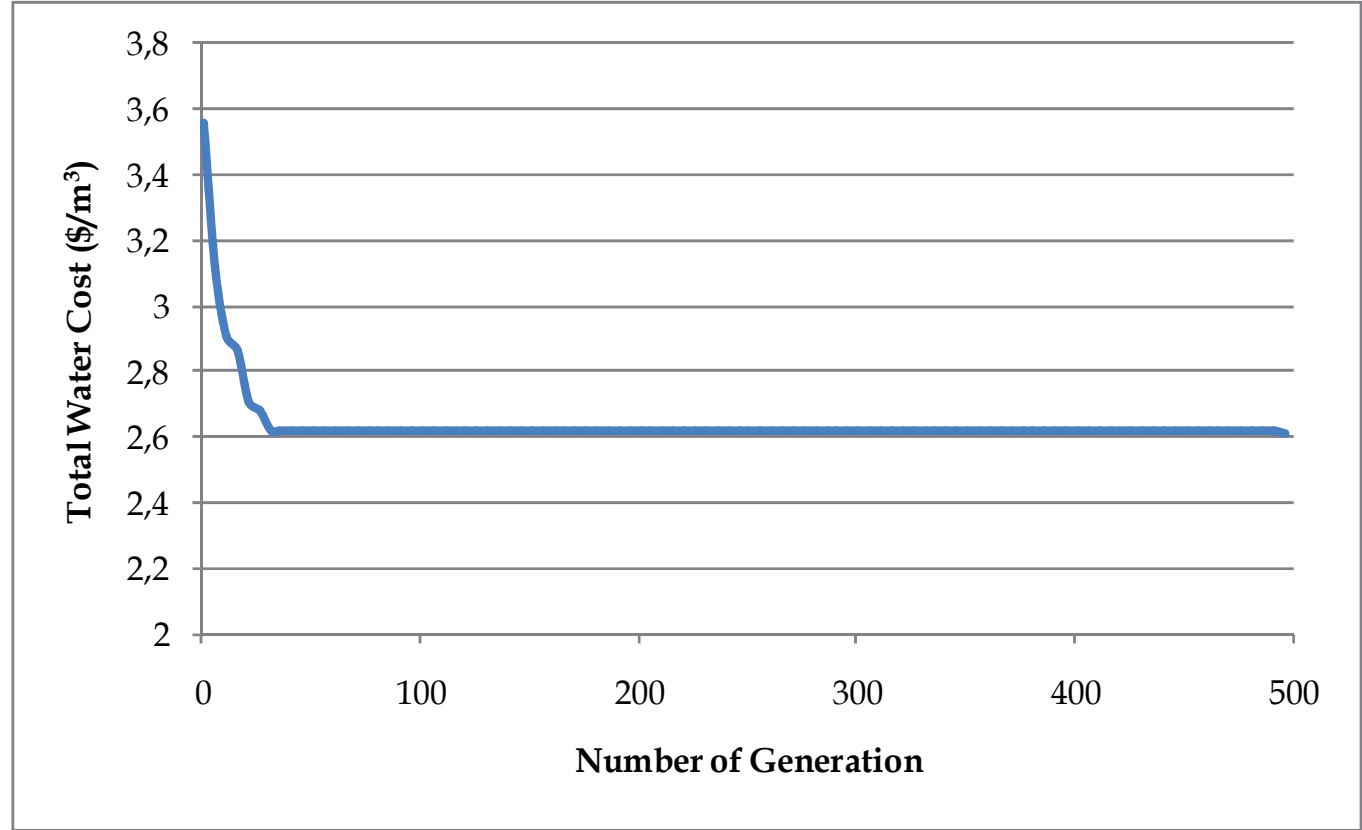

Fig. 10. The variation of the total cost function during the GA-based optimization process 


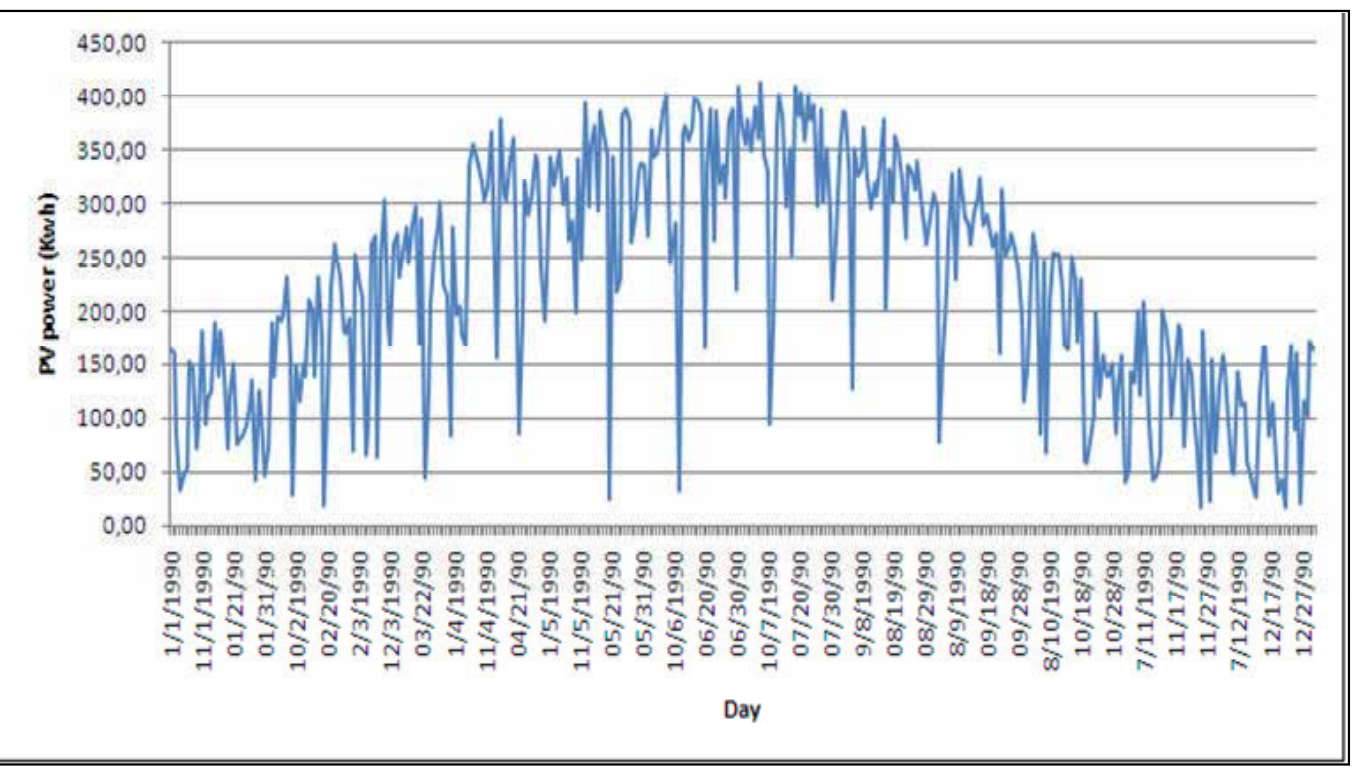

Fig. 11. Variation of the Batteries charges for the optimal solution

\section{Conclusion}

Several combinations for desalination processes driven by renewable energies (RE) can be proposed to provide water and energy in remote areas (Solar/MSF, Solar/MED, $\mathrm{PV} / \mathrm{RO}$, etc.). Reverse Osmosis (RO) is most often chosen as one of the most efficient desalination techniques in terms of energy consumption, flexibility, reliability, simple maintenance, etc.

There are a number of issues that should be taken into consideration while designing RES/RO systems as: the characteristics of water demand, the cost of water and fuel, the availability of renewable energy resources, the initial cost of the project, including the cost of each component required, the life time of the project, the interest rate subsidies, etc. A techno-economic comparison between different scenarios can be carried out to study the feasibility of the project.

In this chapter a new methodology to optimize RO desalination system driven by hybrid PV/Wind systems is presented. The proposed methodology is based on determining, among a list of commercially available system devices, the optimal number and type of units (PV modules, W/G, Batteries, etc.) such that the life time round total system cost is minimized, while simultaneously the desalinated-water demand is completely covered. The minimization of the system total cost function has been implemented using genetic algorithms (GAs) that allows considering a large number of possible configurations.

The proposed method has been applied and tested for the design of a desalination system, which cover the potable water demands of a small community in South Tunisia. The application of this methodology allows to reduce the cost of the produced water from $56 \$ / \mathrm{m}^{3}$ in the first generation to $2.62 \$ / \mathrm{m}^{3}$ for the optimal solution. The fluctuation of the 
different costs during the GA-based optimization process shows that the capital cost of the system varies from $69 \%$ to $82 \%$ of the total cost. In all cases examined, a significant part of the desalination system total capital cost is comprised by the cost of the batteries, which fluctuates between $17 \%$ and $32 \%$ depending on the PV modules types and inclination.

\section{References}

Abdallah, S.; Abu-Hilal, M. \& Mohsen, M.S. (2005). Performance of a photovoltaic powered reverse osmosis system under local climatic conditions. Desalination, vol.183, pp. 95-104.

Abu-Jabal Moh'd, S.; Kamiya, I.; \& Narasaki, Y. (2001). Proving test for a solar-powered desalination system in Gaza-Palestine. Desalination, vol.137, pp 1-6.

Belessiotis, V. \& Delyannis, E. (2001). Water shortage and renewable energies (RE) desalination-possible technological applications. Desalination, vol.139, pp. 133138.

Bilton, A.M.; Wiesman, R.; Arif ., Syed, A.F.M.; Zubair, M. \& Dubowsky S. (2011) On the feasibility of community-scale photovoltaic-powered reverse osmosis desalination systems for remote locations, Renewable Energy, vol. 36, pp. 3246-3256.

Block, D. (1989). Solar Desalination of Water, FSECRR-14-89, Florida Solar Energy Center, Cape Canaveral, February 1989.

Borowy, B.S. \& Salameh, Z.M. (1996). Methodology for optimally sizing the combination of a battery bank and PV array in a wind/PV hybrid system, IEEE Transactions on Energy Conversion, vol. 11, N², pp. 367-373.

Bourouni, K. \& Chaibi, M.T. (2009). Solar Energy for Application to Desalination in Tunisia: Description of a Demonstration Project, Chapter 8, Renewable Energy in the Middle East: Enhancing Security through Regional Cooperation, Springer Science, Berlin.

Carta, J.A., Gonzalez J. \& Subiela V. (2003). Operational analysis of an innovative wind powered reverse osmosis system installed in the Canary Islands, Solar Energy, vol.75, pp. 153-168.

DOW. (2006). Design a reverse osmosis system: design equations and parameters, Technical Manual.

El-Nashar, A. \& Samad, M., (1998). The solar desalination plant in Abu Dhabi: 13 years performance and operation history, Renewable Energy, vol.14, pp. 263-274.

Esram T. \& Chapman P.L. (2007). Comparison of photovoltaic array maximum power point tracking techniques, IEEE Transactions on Energy Conversion, vol.22, N2, pp. 439449.

Fadigas, E.A.F.A. \& Dias J.R. (2009). Desalination of water by reverse osmosis using gravitational potential energy and wind energy, Desalination, vol. 237, pp.140146.

Fiorenza, G.; Sharma, V.K. \& Braccio, G.; (2003). Techno-economic evaluation of a solar powered water desalination plant, Energy Conversion and Management, vol. 44, pp. 2217-2240. 
Forstmeier, M.; Mannerheim F.; D'Amato, F.; Shah, M.; Liu, Y.; Baldea M. \& Stella A. (2007). Feasibility study on wind-powered desalination, Desalination, vol. 203, pp.463-470.

Gaid K. \& Treal Y. (2007). Le dessalement des eaux par osmose inverse: l'expérience de Véolia Water, Desalination, vol.203, pp.1-14.

Gracia-Rodriguez, L. (2002). Seawater desalination driven by renewable energies: a review, Desalination, vol.143, pp. 103-113.

Gracia-Rodriguez, L.; Palmero-Marrero, A. \& Comez-Camacho, C. (2002). Comparison of solar thermal technologies for applications in seawater desalination, Desalination, vol.142, pp. 135-142.

GWI (2010). Water Market Middle East 2010, Global Water Intelligence.

Hasnain, S.M. \& Alajlan, S.A. (1998). Coupling of PVpowered RO brackish water desalinateon plant with solar stills, Desalination, vol.116, pp. 57-64.

Herbert, G.M.; Iniyan, S., Sreevalsan, E. \& Rajapandian, S. (2007). A review of wind energy technologies, Renewable Sustainable Energy Review, vol.11, pp. 1117-1145.

Kalogirou, S.A. (2005). Sewater desalination using renewable energy sources, Progress in energy and combustion science, vol.31, pp. 242-281.

Kalogirou, S.A. (2001). Effect of fuel cost on the price of desalination water: a case for renewables, Desalination, vol.138, pp. 137-144.

Kiranoudis, C.T.; Voros, N.G. \& Maroulis, Z.B. (1997). Wind energy exploitation for reverse osmosis desalination plants, Desalination, vol.109, pp.195-209.

Koroneos, C.; Dompros, A. \& Roumbas, G.(2007). Renewable energy driven desalination systems modelling, Journal of Cleaner Production, vol. 15, pp.449-464.

Liu, C.C.K.; Park, J.W.; Migita, R. and Qin, G. (2002). Experiments of a prototype winddriven reverse osmosis desalination system with feedback control, Desalination, vol. 150, pp. 277-287.

Lorenzo, E. (1994). Solar electricity: engineering of photovoltaic systems, 1st edition, Progensa, Sevilla.

Ma, Q.; Lu, H. (2011). Wind energy technologies integrated with desalination systems: Review and state-of-the-art, Desalination, vol.277, pp. 274-280.

Manolakos, D.; Papadakis, G.; Papantonis, D. \& Kyritsis, S. (2001). A simulationoptimization program for designing hybrid energy systems for supplying electricity and fresh water through desalination to remote areas - case study: the Merssini village, Donoussa island, Aegean Sea, Greece, Energy, vol.26, pp. 679704.

Markvart, T. (1994). Solar electricity, 1st edition, Wiley, Chichester.

Michalewicz, Z. (1994). Genetic algorithms and data structures evolution programs, 2nd edition, Springer-Verlag, New York.

Mohamed, E.S. \& Papadakis, G. (2004). Design, simulation and economic analysis of a stand-alone reverse osmosis desalination unit powered by wind turbines and photovoltaics, Desalination, vol.164, pp.87-97.

Nakatake, Y.; Tanaka, H. (2005). A new maritime life saving distiller driven by wind, Desalination, vol.177, pp. 31-42. 
Petersen, G.; Fries, S.; Mohn, J. \& Müller A.(1981), Wind and solar powered reverse osmosis desalination units - Design, start up, operating experiences, Desalination, vol.39 pp.125-135.

Petersen, G.; Fries, S.; Mohn, J. \& Müller A. (1979). Wind and solar-powered reverse osmosis desalination units-description of two demonstration projects, Desalination, vol.31, pp.501-509.

Setiawan, A. A.; Zhao, Y.; Nayar, C.V. (2009). Design, economic analysis and environmental considerations of mini-grid hybrid power system with reverse osmosis desalination plant for remote areas, Renewable Energy, vol.34, pp.374383 ,

Szacsvay, T.; Hofer-Noser P. \& Posnansky, M. (1999). Technical and economic aspects of small-scale solar pond powered seawater desalination systems, Desalination, vol.122 pp.185-193.

Thomas. K. (1997). Overview of Village Scale, Renewable Energy Powered Desalination, NREL/TP-440-22083, UC Category: 1210 DE 97000240.

Voivontas, D. ; Misirlis, K.; Manoli, E.; Arampatzis, G.; Assimacopoulos, D. \& Zervos, A.(2001). A tool for the design of desalination plants powered by renewable energies, Desalination, vol.133, pp.175-198.

Weiner, D.; Fisher, D.; Moses, E.J.; Katz, B. \& Meron, G. (2001). Operation experience of a solar-and wind-powered desalination demonstration plant, Desalination, vol.137, pp. 7-13. 


\title{
Heat Transfer Modeling of the Ground Heat Exchangers for the Ground-Coupled Heat Pump Systems
}

\author{
Yi Man, Ping Cui and Zhaohong Fang \\ Key Laboratory of Renewable Energy Utilization Technologies in Buildings, \\ Ministry of Education, China; Shandong Jianzhu University, Jinan, Shandong,
}

China

\section{Introduction}

Ground-coupled heat pump (GCHP) systems have been gaining increasing popularity for space air conditioning in buildings due to their reduced energy and maintenance costs. The efficiency of GCHP systems is inherently higher than that of the traditional options because it utilizes the ground which maintains a relatively stable temperature all the year round as a heat source/sink. Compared with traditional air-conditioning systems, the GCHP system features its ground heat exchanger (GHE), whether it is horizontally installed in trenches or as U-tubes in vertical boreholes. The advantages of vertical GHEs are that they require smaller plots of land areas, and can yield the most efficient GCHP system performance. The vertical GHEs are usually constructed by inserting one or two high-density polyethylene Utubes in vertical boreholes, which are referred to as single U-tube or double U-tube GHEs, respectively. The boreholes should be grouted to provide better thermal conductance and prevent groundwater from possible contamination. Borehole depths usually range from 40 to 200 meters with diameter of 100 to 150 millimeters. The schematic diagram of a borehole with U-tubes in vertical GHEs is illustrated in Fig. 1.

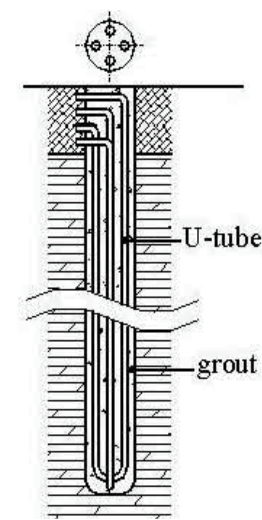

a) double U-tube

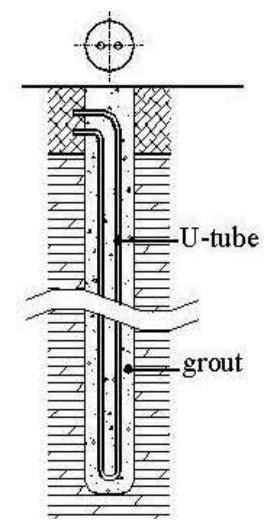

b) single U-tube

Fig. 1. Schematic diagram of boreholes in the vertical GHE exchanger 
However, the commercial growth of the GCHP systems has been hindered by its higher capital cost, of which a significant portion is attributed to the GHE. Besides the structural and geometrical configuration of the exchanger a lot of factors influence the exchanger performance, such as the ground temperature distribution, soil moisture content and its thermal properties, groundwater movement and possible freezing and thawing in soil. Thus, heat transfer between a GHE and its surrounding soil/rock is difficult to model for the purpose of sizing the GHE or simulation of the GCHP systems. In order to assess the thermal behaviour and to optimise the technical as well as economical aspects of GCHP systems, it is crucial to work out appropriate and validated heat transfer models of the GHE.

To determine the heat transfer in the GHEs with adequate accuracy is a crucial task, and has great impact on sizing and simulating GHE. The design goal is to control the temperature rise of the ground and the circulating fluid within acceptable limits over the lifetime of the system. A fundamental task for application of the GCHP technology is to grasp the heat transfer process of a single borehole in the GHE. Heat transfer in a field with multiple boreholes may be analyzed on this basis with the superposition principle.

There are roughly two categories of approaches in dealing with the thermal analysis and design of the GHEs. Empirical or semi-empirical formulations are recommended in textbooks and monographs for GHE design purposes (Bose et al., 1985; Kavanaugh, 1997). These approaches are relatively simple, and may be manipulated easily by design engineers. However, they do not reveal in detail the impacts of complicated factors on the GHE performance. The second kind of approaches involves numerical simulation of the heat transfer in the GHEs (Mei \& Baxter, 1986; Yavuzturk \& Spitler, 1999). While having provided important understandings on GHE heat transfer, these studies of numerical simulation have not yet been suitable to design and/or energy analysis of full scale engineering projects because it takes too substantial computing time.

Theoretical study on the GHE with an analytical approach is presented by some Swedish and American scholars (Eskilson, 1987; Spitler, 2005). Involving a time span of several years, the heat transfer process in the ground around the vertical boreholes is rather complicated, and should be treated, on the whole, as a transient one. Because of all the complications of this problem and its long time scale, the heat transfer process may usually be analyzed in two separated regions. One is the solid soil/rock outside the borehole, where the heat conduction must be treated as a transient process. With the knowledge of the temperature response in the ground, the temperature on the borehole wall can then be determined for any instant on specified operational conditions. Another sector often segregated for analysis is the region inside the borehole, including the grout, the U-tube pipes and the circulating fluid inside the pipes. The main objective of this analysis is to determine the inlet and outlet temperatures of the circulating fluid according to the borehole wall temperature, the thermal resistance inside the borehole and the heat rate of the GHE.

In this approach for GHE analysis a single borehole is investigated in detail experiencing a step heating/cooling. Then, the principle of superimposition is used to deal with the more complicated situation of GHEs with multiple boreholes as well as the variable load. It is more adequate and accurate than the empirical approaches and yet much more convenient for computations than the numerical simulations. In this regard, better understanding of every thermal resistances of the GHE is crucial, and their analytical solutions are especially 
preferred to facilitate the computation. Following such an approach, some important analytical solutions have been derived by our research group (Diao \& Fang, 2006) for heat transfer processes both inside and outside the boreholes, which can be easily incorporated into computer programs for thermal analysis and sizing of the GHEs while providing better insight into influences of various factors on the GHE performance.

In practice, the boreholes of GHEs may penetrate several geologic strata. It is desirable to account for the groundwater flow in the heat transfer model to avoid over-sizing of the GHE. Taking the groundwater advection into account, the combined heat transfer of conduction and advection in the GHE has been solved by an analytical approach, and explicit expressions of the temperature response has been derived (Diao et al., 2004; Nelson et al., 2011).

Recently, a novel configuration of GHE with a spiral coil has been proposed and applied in practical projects due to its distinct thermal and economical advantages especially combined with the foundation piles of buildings. For better simulating the heat transfer of buried spiral coils, our research group have proposed two new kinds of models and resolved their analytical solutions (Cui et al., 2011; Man et al., 2011).

This chapter analyzes in detail every links of the heat transfer process in borehole heat exchangers, including the influence of the groundwater movement. Adequate analytical solutions are suggested for modeling of the GHEs. The superposition procedures for multiple boreholes and variable loads are also discussed to provide an integrated solution of the thermal analysis of the GHEs. This approach can be easily incorporated into computer programs for thermal analysis and sizing of the GHEs while providing better insight into influences of various factors on the GHE performance.

\section{Heat transfer inside boreholes}

\subsection{Overview}

The main objective to analyze the heat transfer inside boreholes is to determine the entering and leaving temperatures of the circulating fluid in the GHE according to the borehole wall temperature and its heat flow. Compared with the infinite ground outside it, both the dimensional scale and thermal mass of the borehole are much smaller. Moreover, the temperature variation inside the borehole is usually slow and minor. Thus, it is a common practice that the heat transfer in this region is approximated as a steady-state process.

It is obvious that the double U-tube configuration provides more heat transfer area between the circulating fluid and the ground than the single U-tube GHE does, and will reduce thermal resistance inside the borehole. On the other hand, however, it might require more pipes and consume more pumping power on operation for a certain project. Thus, analysis on performance and costs of different configurations of the GHEs has been a task for scholars and engineers to study.

A few models of varying complexity have been established to describe the heat transfer inside the GHE boreholes. Models for practical engineering designs are often oversimplified in dealing with the complicated geometry inside the boreholes. One-dimensional (1-D) model (Bose et al., 1985) has been recommended for engineering design, conceiving the U- 
tube pipes as a single "equivalent" pipe. By a different approach Hellstrom (1991) has derived two-dimensional (2-D) analytical solutions of the borehole thermal resistances in the cross-section perpendicular to the borehole. On assumptions of identical temperatures and heat fluxes of all the pipes in it, the borehole resistance was worked out. Exchanging heat with the surrounding ground, however, the fluid circulating through different legs of the Utubes is of varying temperatures. As a result, thermal interference, or thermal "shortcircuiting", among U-tube legs is inevitable, which degrades the effective heat transfer in the GHEs. With the assumption of identical temperature of all the pipes, it is impossible for all the models mentioned above to reveal impact of this thermal interference on GHE performances.

On the other hand, Mei \& Baxter (1986) considered the 2-D model of the radial and longitudinal heat transfer, which was solved with a finite difference scheme. Yavuzturk et al. (1999) employed the 2-D finite element method to analyze the heat conduction in the plane perpendicular to the borehole for short time step responses. Requiring numerical solutions, these models are of limited practical value for use by designers although they may result in more exact solutions for research and parametric analysis of GHEs.

Taking the fluid axial convective heat transfer and thermal "short-circuiting" among U-tube legs into account, a quasi three-dimensional (3-D) model for boreholes in GHEs has been established as an extension of the work of Eskilson (1987) and Hellstrom (1991) to reveal the thermal interference between the U-tube legs. Analytical solutions of the fluid temperature profiles along the borehole depth have been obtained (Zeng et al., 2003). This model takes into account more factors than previous models ever did before, including the geometrical parameters (borehole and pipe sizes and pipe disposal in the borehole) and physical parameters (thermal conductivity of the materials, flow rate and fluid properties) as well as the flow circuit configuration. Its solutions have provided a reliable tool for GHE sizing and performance simulation and a solid basis for technical and economic assessment of different borehole configurations.

\subsection{Quasi 3-D model on heat transfer inside the borehole}

This section focuses on the model of heat transfer inside the borehole taking into account the 2$\mathrm{D}$ heat conduction in the transverse cross-section as well as the convective heat transfer in the axial direction by the fluid inside the U-tubes, which is referred to as the quasi 3-D model. To keep the problem analytically manageable some simplifications are assumed. They are:

1. The heat capacity of the materials inside the borehole is neglected.

2. The heat conduction in the axial direction is negligible, and only the conductive heat flow among the borehole wall and the pipes in the transverse cross-section is counted.

3. The borehole wall temperature, $T_{\mathrm{b}}$, is constant along its depth, but may vary with time.

4. The ground outside the borehole and grout in it are homogeneous, and all the thermal properties involved are independent of temperature.

Number the pipes in the borehole clockwise as shown in Fig. 2. If the temperature on the borehole wall is taken as the reference of the temperature excess, the fluid temperature excess in the pipes may be expressed as the sum of four separate temperature excesses caused by the heat fluxes per unit length, $q_{1}, q_{2}, q_{3}$ and $q_{4}$ from the four legs of the U-tubes. Thus, the following expressions may be obtained 


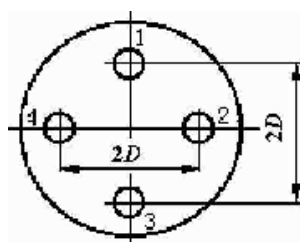

Fig. 2. Cross-section of a borehole with double U-tube

$$
\left.\begin{array}{l}
T_{f 1}-T_{b}=R_{11} q_{1}+R_{12} q_{2}+R_{13} q_{3}+R_{14} q_{4} \\
T_{f 2}-T_{b}=R_{21} q_{1}+R_{22} q_{2}+R_{23} q_{3}+R_{24} q_{4} \\
T_{f 3}-T_{b}=R_{31} q_{1}+R_{32} q_{2}+R_{33} q_{3}+R_{34} q_{4} \\
T_{f 4}-T_{b}=R_{41} q_{1}+R_{42} q_{2}+R_{43} q_{3}+R_{44} q_{4}
\end{array}\right\}
$$

where $R_{\mathrm{ii}}(\mathrm{i}=1,2,3,4)$ is the thermal resistance between the circulating fluid in a certain Utube leg and the borehole wall, and $R_{\mathrm{ij}}(\mathrm{i}, \mathrm{j}=1,2,3,4)$ the resistance between two individual pipes. It is most likely in engineering practice the U-tube legs are disposed in the borehole symmetrically as shown in Fig. 2 . In this case one gets $R_{\mathrm{ij}}=R_{\mathrm{ji}}, R_{\mathrm{ii}}=R_{\mathrm{jj}}(\mathrm{i}, \mathrm{j}=1,2,3,4)$ and $R_{14}=R_{12}$ and so on. Hellstrom (1991) analyzed the steady-state conduction problem in the borehole cross-section in detail with the line-source and multiple approximations. The linesource assumption has resulted in the following solution.

$$
\begin{aligned}
& R_{11}=\frac{1}{2 \pi k_{b}}\left[\ln \left(\frac{r_{b}}{r_{P}}\right)-\frac{k_{b}-k}{k_{b}+k} \ln \left(\frac{r_{b}^{2}-D^{2}}{r_{b}^{2}}\right)\right]+R_{P} \\
& R_{12}=\frac{1}{2 \pi k_{b}}\left[\ln \left(\frac{r_{b}}{\sqrt{2} D}\right)-\frac{k_{b}-k}{2\left(k_{b}+k\right)} \ln \left(\frac{r_{b}^{4}+D^{4}}{r_{b}^{4}}\right)\right] \\
& R_{13}=\frac{1}{2 \pi k_{b}}\left[\ln \left(\frac{r_{b}}{2 D}\right)-\frac{k_{b}-k}{k_{b}+k} \ln \left(\frac{r_{b}^{2}+D^{2}}{r_{b}^{2}}\right)\right]
\end{aligned}
$$

where $k$ denotes the conductivity of soil/rock around the borehole, while $k_{\mathrm{b}}$ the heat conductivity of the grouting material, and $R_{\mathrm{p}}$ the heat transfer resistance from the fluid inside the U-tubes to the pipe outside surface.

A linear transformation of equation (2) leads to:

$$
\left.\begin{array}{l}
q_{1}=\frac{T_{f 1}-T_{b}}{R_{1}^{\Delta}}+\frac{T_{f 1}-T_{f 2}}{R_{12}^{\Delta}}+\frac{T_{f 1}-T_{f 3}}{R_{13}^{\Delta}}+\frac{T_{f 1}-T_{f 4}}{R_{12}^{\Delta}} \\
q_{2}=\frac{T_{f 2}-T_{f 1}}{R_{12}^{\Delta}}+\frac{T_{f 2}-T_{b}}{R_{1}^{\Delta}}+\frac{T_{f 2}-T_{f 3}}{R_{12}^{\Delta}}+\frac{T_{f 2}-T_{f 4}}{R_{13}^{\Delta}} \\
q_{3}=\frac{T_{f 31}-T_{f 1}}{R_{13}^{\Delta}}+\frac{T_{f 3}-T_{f 2}}{R_{12}^{\Delta}}+\frac{T_{f 1}-T_{b}}{R_{1}^{\Delta}}+\frac{T_{f 3}-T_{f 4}}{R_{12}^{\Delta}} \\
q_{4}=\frac{T_{f 4}-T_{f 1}}{R_{12}^{\Delta}}+\frac{T_{f 4}-T_{f 2}}{R_{13}^{\Delta}}+\frac{T_{f 4}-T_{f 3}}{R_{12}^{\Delta}}+\frac{T_{f 4}-T_{b}}{R_{1}^{\Delta}}
\end{array}\right\}
$$


where

$$
\begin{gathered}
R_{1}^{\Delta}=R_{11}+R_{13}+2 R_{12}, R_{12}^{\Delta}=\frac{R_{11}^{2}+R_{13}^{2}+2 R_{11} R_{13}-4 R_{12}^{2}}{R_{12}}, \\
R_{13}^{\Delta}=\frac{\left(R_{11}-R_{13}\right)\left(R_{11}^{2}+R_{13}^{2}+2 R_{11} R_{13}-4 R_{12}^{2}\right)}{R_{13}^{2}+R_{11} R_{13}-2 R_{12}^{2}} .
\end{gathered}
$$

In this model the convective heat flow along the fluid channel is balanced by the conductive heat flows among the fluid channels and borehole wall. According to equation (3) the heat equilibrium of the fluid in individual pipes can be formulated as:

$$
\left.\begin{array}{l} 
\pm M c \frac{d T_{f 1}(z)}{d z}=\frac{T_{f 1}(z)-T_{b}}{R_{1}^{\Delta}}+\frac{T_{f 1}(z)-T_{f 2}(z)}{R_{12}^{\Delta}}+\frac{T_{f 1}(z)-T_{f 3}(z)}{R_{13}^{\Delta}}+\frac{T_{f 1}(z)-T_{f 4}(z)}{R_{12}^{\Delta}} \\
\pm M c \frac{d T_{f 2}(z)}{d z}=\frac{T_{f 2}(z)-T_{f 1}(z)}{R_{12}^{\Delta}}+\frac{T_{f 2}(z)-T_{b}}{R_{1}^{\Delta}}+\frac{T_{f 2}(z)-T_{f 3}(z)}{R_{12}^{\Delta}}+\frac{T_{f 2}(z)-T_{f 4}(z)}{R_{13}^{\Delta}} \\
\pm M c \frac{d T_{f 3}(z)}{d z}=\frac{T_{f 3}(z)-T_{f 1}(z)}{R_{13}^{\Delta}}+\frac{T_{f 3}(z)-T_{f 2}(z)}{R_{12}^{\Delta}}+\frac{T_{f 3}(z)-T_{b}}{R_{1}^{\Delta}}+\frac{T_{f 3}(z)-T_{f 4}(z)}{R_{12}^{\Delta}} \\
\pm M c \frac{d T_{f 4}(z)}{d z}=\frac{T_{f 4}(z)-T_{f 1}(z)}{R_{12}^{\Delta}}+\frac{T_{f 4}(z)-T_{f 2}(z)}{R_{13}^{\Delta}}+\frac{T_{f 4}(z)-T_{f 3}(z)}{R_{12}^{\Delta}}+\frac{T_{f 4}(z)-T_{b}}{R_{1}^{\Delta}}
\end{array}\right\}
$$

Here the signal \pm on the left side of the equations depends on the condition whether the fluid flows in the same direction as the $z$-coordinate, which is designated to be downwards. When the fluid moves downwards, the signal is positive, and vice versa. Combined with certain connecting conditions from the flow circuit arrangement, the energy equilibrium equation can be solved by means of Laplace transformation. Then, the temperature distribution of circulating fluid along the channels can be analytically worked out, and the thermal resistance inside the borehole can be determined more adequately.

\subsection{Fluid temperature profiles along the depth and borehole resistance}

The fluid temperature profiles in the flow channels and, then, the borehole resistance are affected by borehole configuration. As mentioned above, there are single and double U-tube boreholes. The latter can be arranged in series or parallel flow circuits, and each of them includes a few connecting patterns. For the two U-tubes in the borehole connected in parallel circuit, different combinations of circuit arrangement come down to two options that make difference to its heat transfer. They may be represented by notations of $(1-3,2-4)$ and (1-2, 3-4). Here 1-3 denotes that the fluid flows through pipes 1 and 3 as indicated in Fig. 2 , and also through pipes 2 and 4 in parallel. When the fluid circulates through the four legs of the U-tubes in a series circuit, there are quite a few possible layouts. Only three of them, however, bear different impact on the performance of GHE on the assumption of symmetrical disposal of the pipes. The three representative layouts in series are marked as 1-3-2-4, 1-2-3-4 and 1-2-4-3, where the sequence indicates flow succession of the pipes as shown in Fig. 2. 
All these options have been analyzed separately. Analytical expressions of the fluid temperature profiles along the channel have been obtained for all these option. The dimensionless solution of the temperature profile along the borehole depth takes the following form for the single U-tube and the double U-tube in parallel configurations.

$$
\left.\begin{array}{c}
\Theta_{1}(Z)=\cosh (\beta Z)-\frac{\sinh (\beta Z)}{\sqrt{1-P^{2}}}\left[1-P \frac{\cosh (\beta)-\sqrt{\frac{1-P}{1+P}} \sinh (\beta Z)}{\cosh (\beta)+\sqrt{\frac{1-P}{1+P}} \sinh (\beta)}\right] \\
\Theta_{2}(Z)=\frac{\cosh (\beta)-\sqrt{\frac{1-P}{1+P}} \sinh (\beta)}{\cosh (\beta)+\sqrt{\frac{1-P}{1+P}} \sinh (\beta)} \cosh (\beta Z)+\frac{\sinh (\beta Z)}{\sqrt{1-P^{2}}}\left[\frac{\cosh (\beta)-\sqrt{\frac{1-P}{1+P}} \sinh (\beta)}{\cosh (\beta)+\sqrt{\frac{1-P}{1+P}} \sinh (\beta)}-P\right]
\end{array}\right\}
$$

More intricate but less-frequently-used solutions for the double U-tube in series can be found elsewhere (Zeng et al., 2003) together with the definitions of the dimensionless parameters in above equations. Typical temperature profiles along the single and double Utubes in different flow patterns are plotted in Fig. 3.

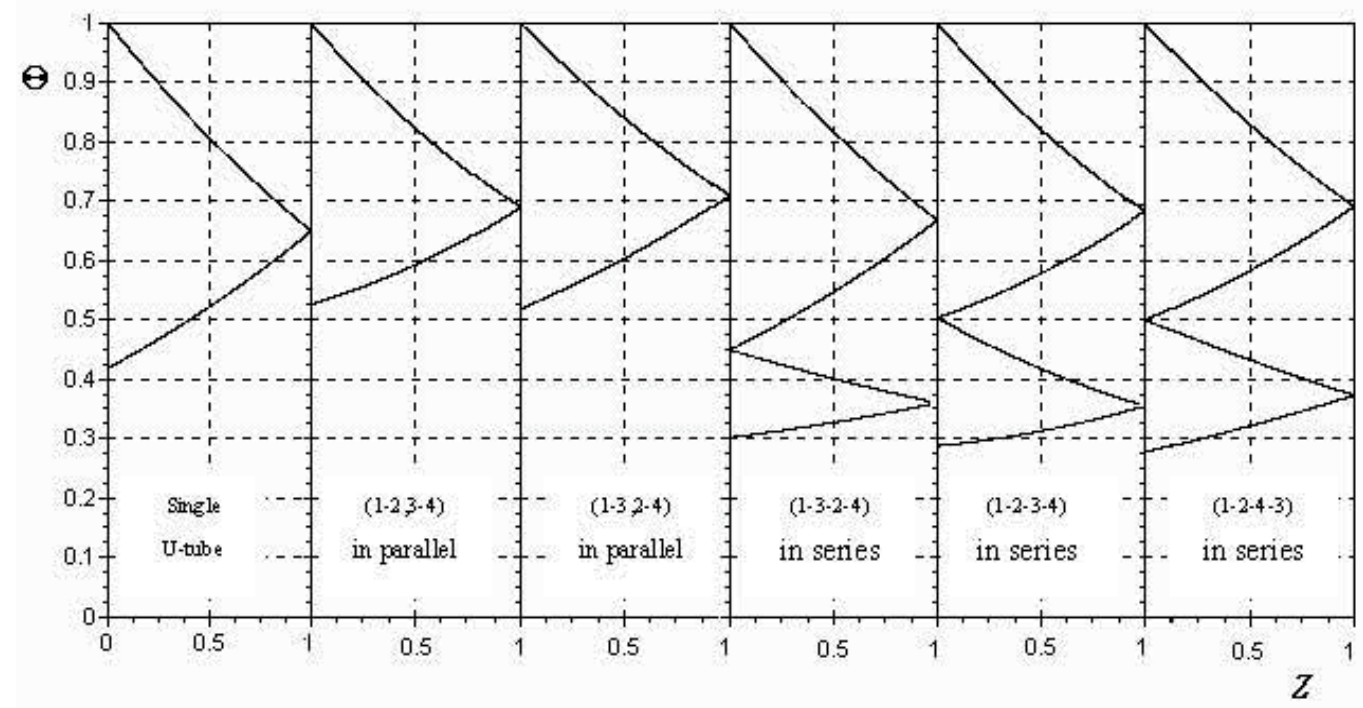

Fig. 3. Temperature profiles along the borehole depth with different U-tube configurations

The effective borehole thermal resistance defines the proportional relationship between the heat flow rate transferred by the borehole and the temperature difference between the circulating fluid and the borehole wall, that is:

$$
R_{b}=\frac{T_{f}-T_{b}}{q_{l}}
$$


where $T_{f}=\left(T_{f}^{\prime}+T_{f}^{\prime \prime}\right) / 2$ denotes the arithmetic mean of the inlet and outlet fluid temperatures. In view of heat balance for the single U-tube and double U-tube in series one also has:

$$
q_{l} H=M c\left(T_{f}^{\prime}-T_{f}^{\prime \prime}\right)
$$

As a result the borehole resistance can be determined according to the analytical solutions of fluid temperature profile in the borehole presented in previous discussion.

Combined with the definition of dimensionless temperature, equations (6) and (7) result in the following expression of borehole resistance for boreholes with the single U-tube and double U-tube in series.

$$
R_{b}=\frac{H}{2 M c} \cdot \frac{1+\Theta_{f}^{\prime \prime}}{1-\Theta_{f}^{\prime \prime}}
$$

In the case of double U-tubes in parallel the fluid mass rate in the borehole is doubled, i.e. $2 M$, thus the borehole thermal resistance can be expressed as:

$$
R_{b}=\frac{H}{4 M c} \cdot \frac{1+\Theta_{f}^{\prime \prime}}{1-\Theta_{f}^{\prime \prime}}
$$

The borehole thermal resistance defined above takes into accounts both the geometrical parameters (borehole and pipe sizes and pipe disposal in the borehole) and physical parameters (thermal conductivity of materials, flow rate and fluid properties). Therefore the concept of effective thermal resistance facilitates heat transfer analysis. Analyses have shown that the single U-tube boreholes yield considerably higher borehole resistance than the double U-tube boreholes do while the other conditions are identical. Practical choice of the U-tube configuration should be taken in accordance with economic consideration in practical engineering.

\section{Heat conduction outside boreholes}

\subsection{Overview}

There have been some classical models for GHE thermal analysis based on analytical 1-D solutions. A most widely used 1-D model for this purpose is Kelven's line source model (Carslaw \& Jeager, 1947). In this model the borehole is replaced by a line heat source with its radial dimension neglected. Another best known 1-D model, referred as the cylindrical heat source model (Carslaw \& Jeager, 1947; Ingersoll \& Zobel, 1954) is an alternative approach to sizing GHEs. Although the radial dimension of the borehole is taken into consideration in this model, the heat capacity of the cylinder is ignored, so the geometrical domain of the model can be regarded as an infinite medium with a cylindrical cavity in it. We refer it to as the "hollow" cylindrical heat source model to distinguish it from the "solid" cylindrical heat source model we are to propose below. Significant simplifications are made in these two classical models, which result in substantial deviations of the temperature response from the actual situation especially in the initial period of the heating pulse. Therefore, neither of these two models is suitable for short time-step analysis of GHEs. 
A progress in the short time-step simulations of the GHEs is the short time-step response factor model developed by Yavuzturk \& Spitler (1999) based on numerical solution by taking the heat capacity of grout and pipe into account. This model is validated to be accurate and has been implemented as part of a component model of the TRNSYS, but its numerical calculation is sophisticated and time-consuming.

Considering the axial heat flow and taking the long-term effect of the limited borehole depth into account, a 2-D finite line source model was established by Zeng et al. (2002) to analyze the heat transfer outside vertical borehole GHE. This 2-D model assumes the ground as a homogeneous semi-infinite medium with a uniform initial temperature, and assumes the borehole as a line source with finite length releasing heat at a constant rate per length. Evolved from the vertical borehole systems, inclined boreholes are considered as a favorable alternative to further reduce the land areas required for the GHEs. Then a 3-D finite line source model for inclined borehole GHE was also proposed by Cui et al. (2006). In order to take characteristics of the pile GHEs into proper consideration and to deal with the short term temperature response, Man et al. (2010) proposed a "solid" cylindrical source model, which suppose that the cylinder is no longer a cavity, but filled with the medium identical to that out of the cylinder, so that the whole infinite domain is composed of a homogeneous medium.

\subsection{Vertical and inclined finite line source model}

As mentioned, the 2-D vertical finite line source model and the 3-D inclined finite line source model are established based on the Green's function method to analyze the heat conduction outside the vertical and inclined boreholes, as shown in Fig. 4. An analytical solution has been derived for the 3-D inclined finite line source model as follows (Cui et al., 2006). Then, the 2-D model of vertical finite line source becomes a special case of the 3-D model with $\alpha=0$.

$$
t-t_{0}=\frac{q_{l}}{4 \pi k} \int_{0}^{H}\left(\frac{\operatorname{erfc}\left(\frac{r_{+}}{2 \sqrt{a \tau}}\right)}{r_{+}}-\frac{\operatorname{erfc}\left(\frac{r_{-}}{2 \sqrt{a \tau}}\right)}{r_{-}}\right) d S
$$

where

$$
\begin{aligned}
& r_{+}=\sqrt{\left(x-x_{0}-s \sin \alpha \cos \beta\right)^{2}+\left(y-y_{0}-s \sin \alpha \sin \beta\right)^{2}+(z-s \cos \alpha)^{2}} \\
& r_{-}=\sqrt{\left(x-x_{0}-s \sin \alpha \cos \beta\right)^{2}+\left(y-y_{0}-s \sin \alpha \sin \beta\right)^{2}+(z+s \cos \alpha)^{2}} .
\end{aligned}
$$

\subsection{Infinite and finite solid cylindrical source model}

For the solid cylindrical source model, a heat source shaped in a cylindrical surface of a radius $r_{0}$ is supposed to be buried in the medium with its axis being coincident with $z$ axis. 


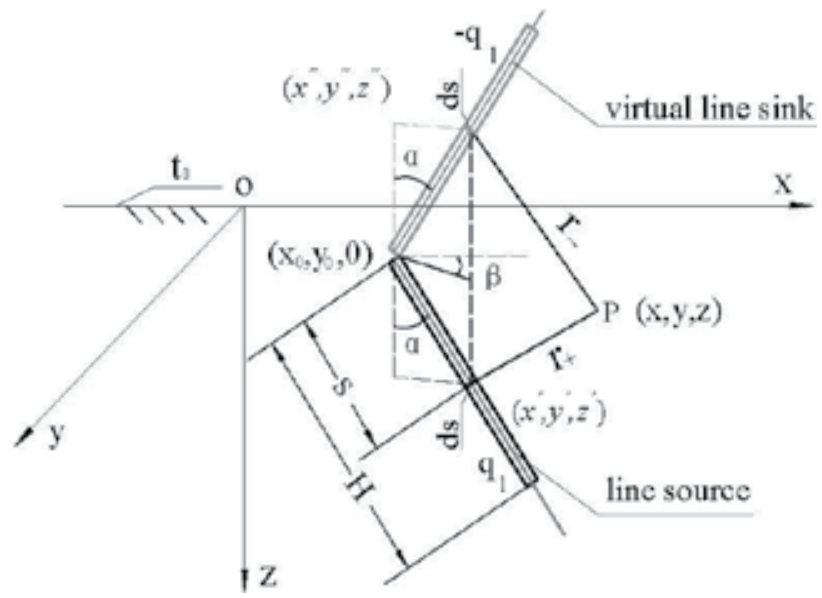

Fig. 4. Schematic diagram of an inclined finite line source in a semi-infinite medium

\subsubsection{The Infinite solid cylindrical source model}

First, the 1-D infinite solid cylindrical source model is studied with the axial heat flow neglected (Man et al., 2010). The analytical solution of this 1-D problem can be obtained directly with the Green's function method. The cylindrical heat source can be regarded as a collection of numerous line sources disposed along a circle of the radius $r_{0}$. The temperature rise at any location with the radial coordinate $r$ should be the sum, or integral, of all the individual temperature rises caused by the corresponding line sources. Then the analytical solution of the infinite solid cylindrical source model can be written as:

$$
\theta_{1}(r, \tau)=-\frac{q_{l}}{4 \pi \mathrm{k}} \int_{0}^{\pi} \frac{1}{\pi} \mathrm{Ei}\left(-\frac{r^{2}+r_{0}^{2}-2 r r_{0} \cos \varphi}{4 a \tau}\right) d \varphi
$$

Alternatively, the cylindrical heat source in this model can be reckoned as a collection of numerous ring line heat sources piled along the axial direction. Induced by a single instant ring line source with radius $r=r_{0}$ which lies on the plane $z=z^{\prime}$ and releases heat at the instant $\tau^{\prime}$, the temperature rise at any location of the coordinate $(r, z)$ and at the instant $\tau$ can be obtained according to the Green's function theory as:

$$
\theta^{*}=\frac{Q}{\rho c} \frac{1}{8\left[\sqrt{\pi a\left(\tau-\tau^{\prime}\right)}\right]^{3}} \exp \left[-\frac{r^{2}+r_{0}^{2}+\left(z-z^{\prime}\right)^{2}}{4 a\left(\tau-\tau^{\prime}\right)}\right] I_{0}\left[\frac{r r_{0}}{2 a\left(\tau-\tau^{\prime}\right)}\right]
$$

Thus, the overall temperature rise caused by the infinite cylindrical heat source at any location should be the sum, or integral, of all the individual temperature rises caused by the corresponding ring sources over the duration from 0 and $\tau$. Then, the solution of the infinite solid cylindrical source model can be written, alternatively, as:

$$
\theta_{1}(r, \tau)=\frac{q_{l}}{\rho c} \int_{0}^{\tau} \int_{-\infty}^{\infty} \frac{1}{8\left[\sqrt{\pi a\left(\tau-\tau^{\prime}\right)}\right]^{3}} \exp \left[-\frac{r^{2}+r_{0}{ }^{2}+z^{\prime 2}}{4 a\left(\tau-\tau^{\prime}\right)}\right] I_{0}\left[\frac{r r_{0}}{2 a\left(\tau-\tau^{\prime}\right)}\right] d z^{\prime} d \tau^{\prime}
$$


This solution is independent of the axial coordinate $z$, and it provides a means to tackle the relevant finite problem.

\subsubsection{The finite solid cylindrical source model}

A 2-D finite solid cylindrical source model has also been presented (Man et al., 2010) in order to consider the influences of the finite length of the cylindrical heat source and the boundary. Similar to the approach for the finite line source problem, a virtual cylindrical sink with the same length but a negative heating rate may be set on symmetry to the boundary. Then, the solution of this problem can be obtained as:

$$
\begin{aligned}
& \theta_{2}(r, z, \tau)=\frac{q_{l}}{\rho c} \int_{0}^{h} d z^{\prime} \int_{0}^{\tau} \frac{1}{8\left[\sqrt{\pi a\left(\tau-\tau^{\prime}\right)}\right]^{3}} I_{0}\left[\frac{r r_{0}}{2 a\left(\tau-\tau^{\prime}\right)}\right] . \\
& \left\{\exp \left[-\frac{r^{2}+r_{0}^{2}+\left(z-z^{\prime}\right)^{2}}{4 a\left(\tau-\tau^{\prime}\right)}\right]-\exp \left[-\frac{r^{2}+r_{0}^{2}+\left(z+z^{\prime}\right)^{2}}{4 a\left(\tau-\tau^{\prime}\right)}\right]\right\} d \tau^{\prime}
\end{aligned}
$$

Temperature response at the half depth of the cylinder surface calculated with the infinite and finite solid cylindrical source models are compared in Fig. 5. Clear distinction can be seen between the responses of these two models. While the temperature response rises continuously with time for the infinite model, the temperatures of those GHEs simulated by the finite model with different finite lengths tend to produce different steady-state temperatures as time approaches infinity. This feature indicates that, it is important to take the finite length effect of heat source into account and to utilize the finite solid cylindrical source model in simulating the long-term operation of the GHE.

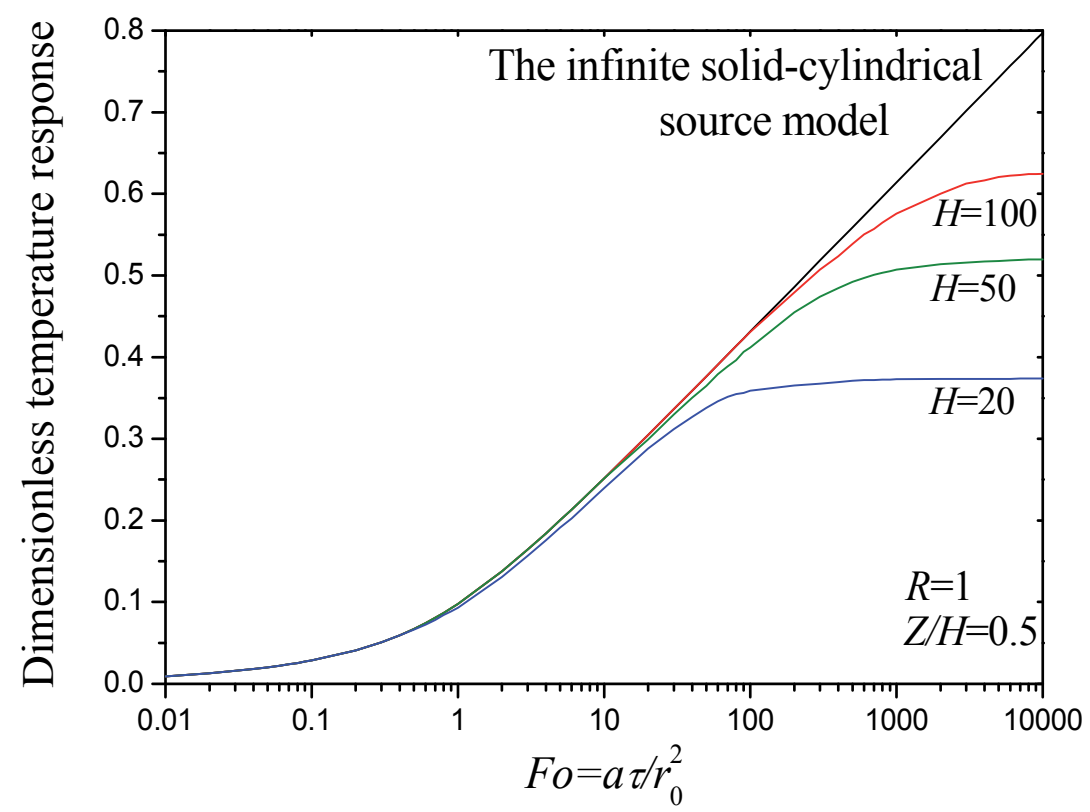

Fig. 5. Temperature response vs. time from infinite and finite solid cylindrical source models 


\section{Heat transfer with groundwater infiltration}

In practice, the boreholes of GHEs may penetrate several geologic strata. Below the water table, water is held and moves between the grains of geologic formations in response to hydraulic gradients. In general, a moderate groundwater advection is expected to make notable difference in alleviating the possible heat buildup around the borehole over time. As a result, it is desirable to account for the groundwater infiltration in the heat transfer model to avoid over-sizing of the GHEs. However, all of the GHE design tools available at present are based simply on principles of heat conduction, and do not consider the implications of groundwater flow in carrying away heat due partly to lack of appropriate analytical tools.

Taking the groundwater advection into account, the combined heat transfer models of conduction and advection in the GHE have been solved with analytical approach. Explicit expressions about temperature response of the moving infinite/finite line source models have been derived (Diao et al., 2004; Nelson et al., 2011). In these studies the ground around the boreholes is assumed to be a homogeneous porous medium saturated by groundwater. The groundwater velocity is uniform in the whole domain concerned and parallel to the ground surface. Heat is transported through the saturated porous medium in a combined mechanism: by conduction through its solid matrix and liquid in its pores as well as by convection of the moving liquid.

\subsection{Moving infinite line-source model}

The partial differential equation for advective and conductive heat transport in porous media can be expressed in a 2-D form ( $x-y$ plane) as follows (Domenico \& Schwartz, 1998):

$$
\rho c \frac{\partial T}{\partial t}+u_{x} \rho_{w} c_{w} \frac{\partial T}{\partial x}-\lambda\left(\frac{\partial^{2} T}{\partial x^{2}}+\frac{\partial^{2} T}{\partial y^{2}}\right)=0
$$

The solution of equation (15) for an infinite porous medium with a uniform initial temperature was given by Sutton et al. (2003) and Diao et al. (2004):

$$
\Delta T_{2}(x, y, t)=\frac{q_{L}}{4 \lambda \pi} \exp \left[\frac{v_{T} x}{2 a}\right] \int_{0}^{v_{T}^{2} t / 4 a} \frac{1}{\psi} \exp \left[-\psi-\frac{v_{T}^{2}\left(x^{2}+y^{2}\right)}{16 a^{2} \psi}\right] d \psi
$$

This analytical solution applies for the response of a constant line source with infinite length along the $z$-direction with a continuous heat flow rate per unit length of the borehole, $q_{L}$. Although a GHE is composed of a buried pipe that commonly is surrounded by grouting material, approximation by a line source is commonly accepted in heat transport models of GCHP systems (Diao et al., 2004; Eskilson, 1987; Sutton et al., 2003). The underground is assumed to be homogeneous with respect to the thermal and hydraulic parameters. For steady state conditions equation (16) becomes:

$$
\Delta T_{2 s}(x, y)=\frac{q_{L}}{2 \pi \lambda} \exp \left[\frac{v_{T} x}{2 a}\right] K_{0}\left[\frac{v_{T} \sqrt{x^{2}+y^{2}}}{2 a}\right]
$$


Introducing the dimensionless variable $P e=v_{T} H / a$ (Peclet number), equations (16) and (17) can be expressed in dimensionless forms:

$$
\begin{gathered}
\Theta_{2}(R, F o, P e)=\exp \left[\frac{P e}{2} R \cos (\varphi)\right] \int_{0}^{P e^{2} F o / 4} \frac{1}{\psi} \exp \left[-\psi-\frac{P e^{2} R^{2}}{16 \psi}\right] d \psi \\
\Theta_{2 s}(R, P e)=2 \exp \left[\frac{P e}{2} R \cos (\varphi)\right] K_{0}\left[\frac{P e}{2} R\right]
\end{gathered}
$$

The isotherms of a GHE field with groundwater advection simulated with the moving infinite line source model are shown in Fig. 6. Analysis on the influence of the groundwater advection on GHE performance may be found in details elsewhere (Diao et al., 2004).

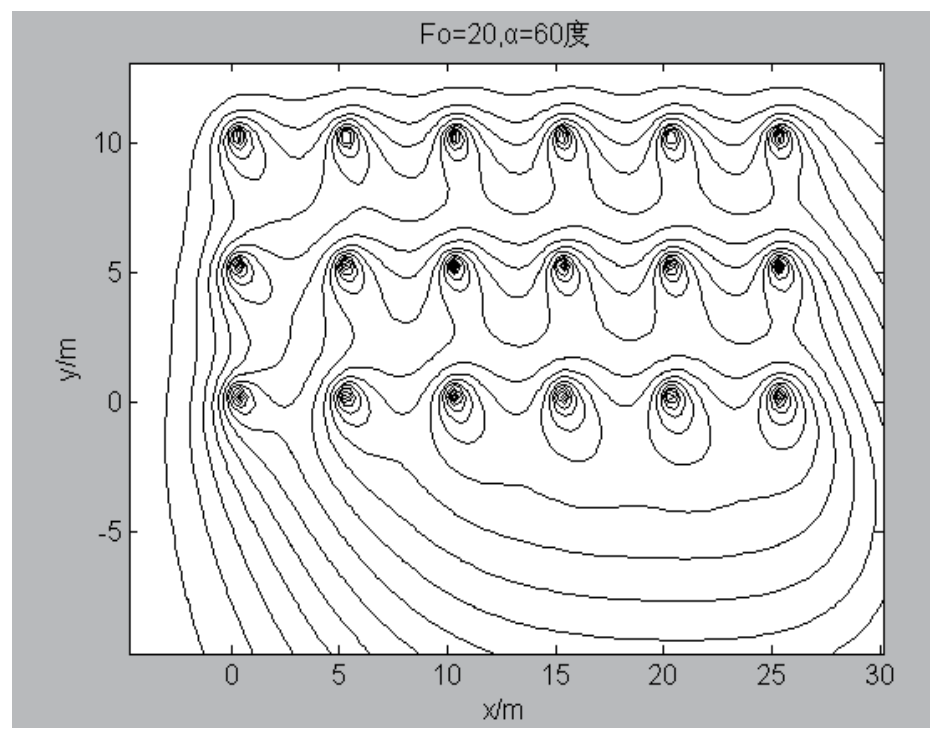

Fig. 6. Isotherms of a GHE field of 18 boreholes with groundwater advection

\subsection{Moving finite line-source model}

For long-term period simulations of the GHEs axial effects become more evident. Therefore, the moving finite line source model has been further established based on the Green's function by applying the method of images (Eskilson, 1987) and the moving source theory (Carslaw \& Jaeger, 1959). The detailed derivation is presented by Nelson et al. (2011). The transient solution reads as:

$$
\begin{gathered}
\Delta T_{3}(x, y, z, t)=\frac{q_{L}}{2 \lambda \pi} \exp \left[\frac{v_{T} x}{2 a}\right]\left[\int_{0}^{H} f(x, y, z, t) d z^{\prime}-\int_{-H}^{0} f(x, y, z, t) d z^{\prime}\right] \\
f(x, y, z, t)=\frac{1}{4 r}\left[\exp \left(-\frac{v_{T} r}{2 a}\right) \operatorname{erfc}\left(\frac{r-v_{T} t}{2 \sqrt{a t}}\right)+\exp \left(\frac{v_{T} r}{2 a}\right) \operatorname{erfc}\left(\frac{r+v_{T} t}{2 \sqrt{a t}}\right)\right]
\end{gathered}
$$


As time approaches infinity, the steady state solution is derived as follows:

$$
\Delta T_{3 s}(x, y, z)=\frac{q_{L}}{4 \lambda \pi} \exp \left[\frac{v_{T} x}{2 a}\right]\left[\int_{0}^{H} \frac{1}{r} \exp \left[-\frac{v_{T} r}{2 a}\right] d z^{\prime}-\int_{-H}^{0} \frac{1}{r} \exp \left[-\frac{v_{T} r}{2 a}\right] d z^{\prime}\right]
$$

Equations (20), (21) and (22) can be expressed in dimensionless forms:

$$
\begin{gathered}
\Theta_{3}(R, Z, F o, P e)=2 \exp \left[\frac{P e}{2} R \cos (\varphi)\right]\left[\int_{0}^{1} f(R, Z, F o, P e) d Z^{\prime}-\int_{-1}^{0} f(R, Z, F o, P e) d Z^{\prime}\right] \\
f(R, Z, F o, P e)=\frac{1}{4 R^{\prime}}\left[\exp \left(-\frac{P e}{2} R^{\prime}\right) \operatorname{erfc}\left(\frac{R^{\prime}-P e F o}{2 \sqrt{F o}}\right)+\exp \left(\frac{P e}{2} R^{\prime}\right) \operatorname{erfc}\left(\frac{R^{\prime}+P e F o}{2 \sqrt{F o}}\right)\right] \\
\Theta_{3 s}(R, Z, P e)=\exp \left[\frac{P e}{2} R \cos (\varphi)\right]\left[\int_{0}^{1} \frac{1}{R^{\prime}} \exp \left[-\frac{P e}{2} R^{\prime}\right] d Z^{\prime}-\int_{-1}^{0} \frac{1}{R^{\prime}} \exp \left[-\frac{P e}{2} R^{\prime}\right] d Z^{\prime}\right]
\end{gathered}
$$

Temperature contours obtained according to the moving finite and infinite line source models with groundwater advection considered are compared in Fig. 7. Note that temperature plumes are shorter for the finite model (Fig. 7a). Axial effects yields lower temperature changes at any given distance from the source due to the vertically dissipated heat. Temperature anomaly created in the vertical direction due to the axial effects can be observed in Fig. $7 \mathrm{~b}$. Obviously the differences between the models are most evident in the vicinity of the borehole ends.
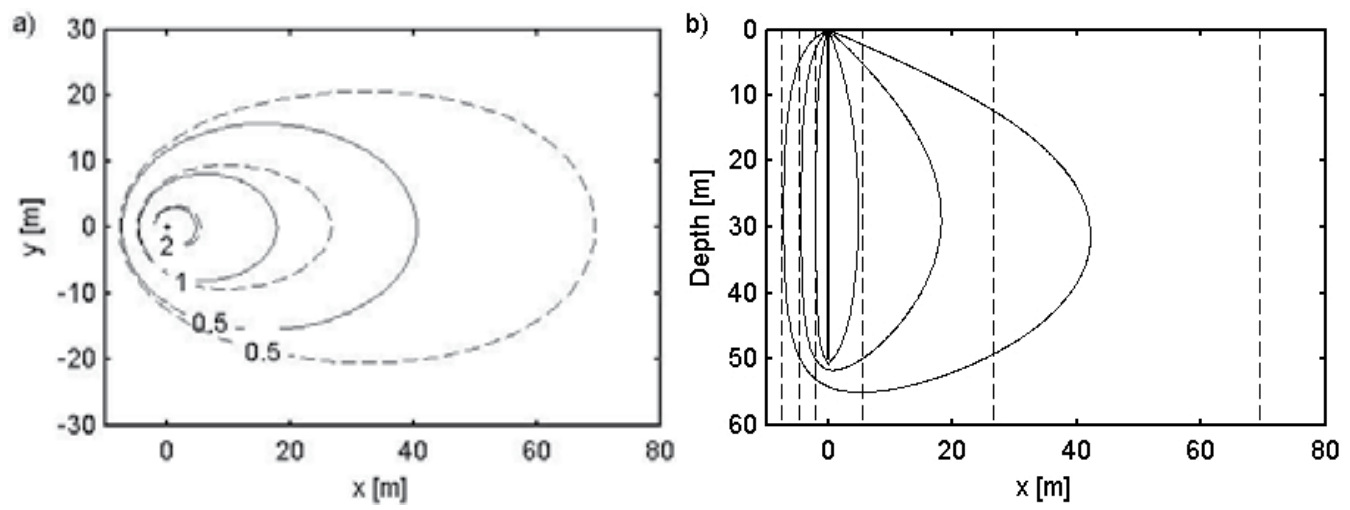

Fig. 7. Temperature contours $\left(\lambda=2.5 \mathrm{Wm}^{-1} \mathrm{~K}^{-1}, q_{l}=20 \mathrm{Wm}^{-1}, q=1.0 \times 10^{-7} \mathrm{~ms}^{-1}, t=20 \mathrm{yrs}\right)$. Solid lines: Moving finite line source model; Dashed lines: Moving infinite line source model. (a) Plan view (b) Vertical cross section.

By comparisons based on the simulation results, the shorter the borehole length is, the larger the discrepancy is between the moving finite and infinite line source models, and the shorter is the time when resulted temperature responses of the moving finite and infinite line source models start to differ. Besides, it is noticeable that the larger the Peclet number the lesser the discrepancy between the moving finite and infinite line source models. 


\section{Heat conduction around a buried spiral coil}

\subsection{Overview}

The GHE with vertical boreholes (Bose et al., 1985) has been the mainstream for the GCHP systems, which is also a major obstacle to apply the GCHP technology because its installation needs a substantial initial cost and requires additional ground area. In recent years foundation piles of buildings start to be utilized as part of the GHEs. These so-called "energy piles" combining the heat exchanger with building foundation piles are a notable progress in the GCHP applications, and its most competitive advantage is that it can reduce the initial cost as well as ground requirement for the borehole field.

Literature review has shown that most of existing studies of pile GHE were based on either experiments or numerical simulations (Morino \& Oka, 1994; Pahud et al., 1996; Pahud et al., 1999; Laloui et al., 2006; Hamada et al., 2007; Sekine et al., 2007). Besides, pipes are buried in concrete piles in configurations of U-tubes in most of such applications. The effective heat transfer area in a certain pile is limited, and air choking may occur in the turning tips of the tubes connected in series. In order to overcome these drawbacks, a novel configuration of the foundation pile GHE with a spiral coil has been proposed (Man et al., 2010). The distinct advantage of this novel GHE is that it can offer higher heat transfer efficiency, reduce pipe connection complexity, and decrease the thermal "short-circuiting" among the feed and return pipes. The schematic diagrams of a conventional single U-tube vertical borehole GHE and the pile GHE with spiral coil are compared in Fig. 8.
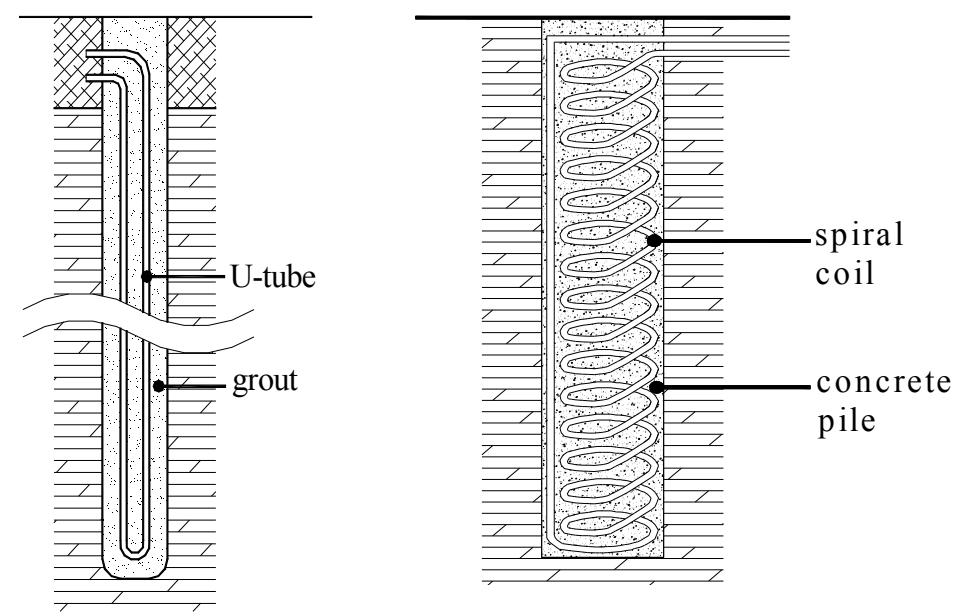

Fig. 8. Schematic diagram of a vertical borehole and a pile with a coil

Piles are much thicker in diameter but shorter in depth than boreholes. Obviously, either the line source models or the "hollow" cylindrical model mentioned in previous sections is no longer valid in this case. Due to its limited application history few analytical models on the buried spiral coils have been seen in literature. In order to better understand and simulate the heat transfer of buried spiral pipes, the authors have proposed two new kinds of models.

The first model is referred as the "ring-coil source model" (Cui et al., 2011), which is developed on the basis of cylindrical source model (Man et al., 2010), as shown in Fig. 9 (a) 
and (b). The ring-coil model further takes into account the discontinuity of the heat source and the impact of the coil pitch by simplifying the buried spiral coil as a set of separated rings located on the cylindrical surface. This model has made big progress from the classical models, however, the ring heat sources is discontinuous and separated with each other, which still deviates from the realistic conditions of the buried spiral coil.

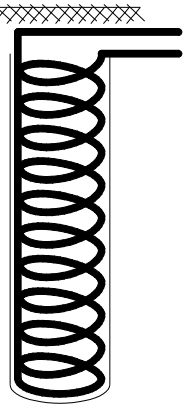

Pile GHE with spiral coil

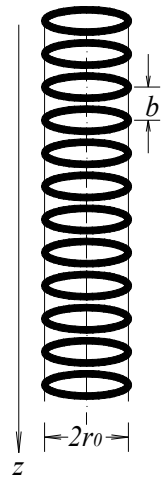

(a) Infinit ring-coil source model

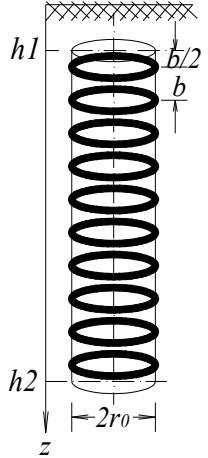

(b) Finit ring-coil source model

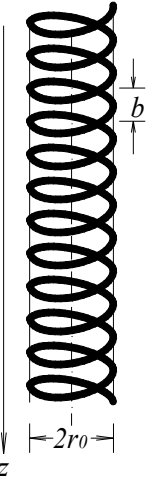

(c) Infinit spiral source model

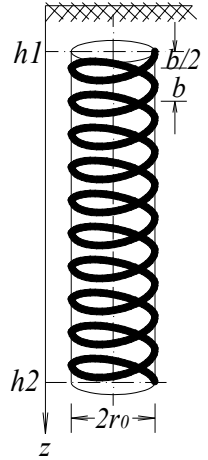

(d) Finit spiral source model

Fig. 9. Established heat source models of the pile GHE

Evolved from the ring-coil source model, the "spiral source model" (Man et al., 2011) is further presented for better analyzing and designing the pile GHE with spiral coils, as shown in Fig. 9 (c) and (d). For this model, the buried spiral coil is approximated by a spiral line heat source. The temperature response of the buried spiral coils can be evaluated according to the analytical solutions of this model.

\subsection{Ring model and spiral model}

\subsubsection{Ring-coil heat source model and solutions}

In the ring-coil heat source model, the buried spiral coil is simplified as a number of separated rings located on the cylindrical surface. In order to analyze the thermal effect of the heat transfer along the axis on the total heat transfer efficiency, both the infinite and finite ring-coil source models are discussed by means of the Green's function method.

To develop the analytical model of the buried spiral coils a basic and simple starting point is to study a single ring-coil heat source. Suppose the ring coil is located on the plane $z=z^{\prime}$ with its axis being coincident with $z$-axis with a continuous heating rate of $q$ since a starting instant, $\tau=\tau^{\prime}$. Based on the governing equation of transient heat conduction along with given boundary and initial conditions, the temperature response at location $(r, z)$ in the medium to such a single ring source can be obtained according to the Green's function theory:

$$
\Theta_{r, s}=\frac{1}{8 \pi^{3 / 2}} \int_{0}^{F o} \frac{1}{\left(F o-F o^{\prime}\right)^{3 / 2}} I_{0}\left[\frac{R}{2\left(F o-F o^{\prime}\right)}\right] \exp \left[-\frac{R^{2}+1}{4\left(F o-F o^{\prime}\right)}\right] \cdot \exp \left[-\frac{\left(Z-Z^{\prime}\right)^{2}}{4\left(F o-F o^{\prime}\right)}\right] d F o^{\prime}
$$




\subsubsection{Infinite ring-coil source model}

The infinite ring-coil source model is first studied, which means the ring-coil source is assumed to be infinite in the longitudinal direction. Define that the $z$-coordinates of the ring coils are $z^{\prime}= \pm(n+0.5) b$, where $n=0,1,2, \ldots,+\infty$. As a consequence, the overall temperature response at a random point in the medium to all the ring sources can be determined as the sum of all the individual temperature rises caused by each ring-coil source:

$$
\begin{gathered}
\Theta_{r, i}(R, Z, F o)=\frac{B}{8 \pi^{3 / 2}} \sum_{n=0}^{\infty} \int_{0}^{F o} \frac{1}{\left(F o-F o^{\prime}\right)^{3 / 2}} I_{0}\left[\frac{R}{2\left(F o-F o^{\prime}\right)}\right] \exp \left[-\frac{R^{2}+1}{4\left(F o-F o^{\prime}\right)}\right] . \\
\left\{\exp \left[-\frac{(Z-n B-0.5 B)^{2}}{4\left(F o-F o^{\prime}\right)}\right]+\exp \left[-\frac{(Z+n B+0.5 B)^{2}}{4\left(F o-F o^{\prime}\right)}\right]\right\} d F o^{\prime}
\end{gathered}
$$

\subsubsection{Finite ring-coil source model}

The infinite model neglects the effects of heat flow through the top and bottom ends of the heat source; therefore it is inadequate for the long-term operation of the GHE made of buried spiral coil. While keeping the ring-coil source simplification, the spiral coil is taken as a finite ring-coil source buried in a semi-infinite medium, stretching from $h_{1}$ to $h_{2}$ from the boundary of the ground surface. The coil is then approximated as $m$ pieces of rings. Again, the images of the ring coils with negative heating rate $-q_{l} b$ are set on symmetry to the boundary in order to keep the constant temperature of the ground surface, and the solution for the finite ring-coil source model is expressed as:

$$
\begin{aligned}
& \Theta_{r, f}(R, Z, F o)=\frac{B}{8 \pi^{3 / 2}} \int_{0}^{F o} \frac{1}{\left(F o-F o^{\prime}\right)^{3 / 2}} I_{0}\left[\frac{R}{2(F o-F o}\right] \exp \left[-\frac{R^{2}+1}{4(F o-F o}\right] \\
& \sum_{n=0}^{m}\left\{\exp \left[-\frac{(Z-H 1-(n+0.5) B)^{2}}{4\left(F o-F o^{\prime}\right)}\right]-\exp \left[-\frac{(Z+H 1+(n+0.5) B)^{2}}{4\left(F o-F o^{\prime}\right)}\right]\right\} d F o^{\prime}
\end{aligned}
$$

\subsubsection{The spiral source model and its analytical solutions}

On the basis of the ring-coil source model, the spiral source model is further developed with increasing sophistication and accuracy to take the 3-D geometrical characteristic of spiral coil into account. In the spiral source model, the buried coil is represented by a spiral line heat source. Both the infinite and finite spiral source models are studied.

For an instantaneous point heat source with intensity of $\rho c$, located at $\left(r^{\prime}, \varphi^{\prime}, z^{\prime}\right)$ and activated at the instant $\tau^{\prime}$, its Green's function in the cylindrical coordinates at point $(r, \varphi, z)$ can be expressed as: 


$$
\begin{aligned}
& G\left(r, \varphi, z, \tau ; r^{\prime}, \varphi^{\prime}, z^{\prime}, \tau^{\prime}\right)=\frac{1}{8\left[\pi a\left(\tau-\tau^{\prime}\right)\right]^{3 / 2}} . \\
& \cdot \exp \left[-\frac{\left(r \cos \varphi-r^{\prime} \cos \varphi^{\prime}\right)^{2}+\left(r \sin \varphi-r^{\prime} \sin \varphi^{\prime}\right)^{2}+\left(z-z^{\prime}\right)^{2}}{4 a\left(\tau-\tau^{\prime}\right)}\right]
\end{aligned}
$$

\subsubsection{Infinite spiral source model}

The infinite spiral source model is discussed with the axial heat flow neglected, as shown in Fig. 9 (c). This spiral heat source can be considered as the sum, or integral, of numerous point heat sources located on the spiral line with the instantaneous intensity of $q_{l} b d \varphi^{\prime} d \tau^{\prime} /(2 \pi)$, which cylindrical coordinates keep $r^{\prime}=r_{0}, z^{\prime}=b \varphi^{\prime} /(2 \pi)$. Then the temperature response in the medium resulted from the step heating of the spiral heat source from the starting instant $\tau^{\prime}=0$ can be deduced according to the Green's function and superimposing theory based on the temperature response to a point heat source:

$$
\Theta_{i, \text { spiral }}=\frac{B}{16 \pi^{5 / 2}} \int_{0}^{F o}\left(\frac{1}{F o-F o^{\prime}}\right)^{3 / 2} \cdot \int_{-\infty}^{\infty} \exp \left[-\frac{R^{2}+1-2 R \cos \left(\varphi-\varphi^{\prime}\right)+\left(Z-B \varphi^{\prime} / 2 \pi\right)^{2}}{4\left(F o-F o^{\prime}\right)}\right] d \varphi^{\prime} d F o^{\prime}
$$

\subsubsection{Finite spiral source model}

In order to take the effects of heat flow through the top and bottom ends of pile into account and investigate the long-term operation performance of the pile GHE, the finite spiral source model is proposed and analyzed. In this model, the coil pipe buried in the pile is considered as a finite-length spiral coil in a semi-infinite medium, as shown in Fig. 9 (d).

With the virtual heat source theory, a virtual spiral heat sink with negative heating rate $-q_{l}$ and of identical physical dimensions is set on symmetry to the boundary. Then the finite spiral heat source and heat sink can be approximated as the sum of numerous point heat sources and heat sinks. Again, the Green's function theory is employed to obtain the temperature response of the medium. For the finite-length spiral source starts at $z^{\prime}=h_{1}$, or $\varphi^{\prime}=2 \pi h_{1} / b$, and ends at $\varphi^{\prime}=2 \pi h_{2} / b$ buried in a semi-infinite medium with a step heating rate per length of the pile, $q_{l}$, the solution may be derived:

$$
\begin{aligned}
& \Theta_{f, \text { spiral }}=\frac{B}{16 \pi^{5 / 2}} \int_{0}^{F o}\left(\frac{1}{F o-F o^{\prime}}\right)^{3 / 2} \cdot \exp \left[-\frac{R^{2}+1}{4\left(F o-F o^{\prime}\right)}\right] \cdot \\
& \int_{2 \pi H_{1} / B}^{2 \pi H_{2} / B} \exp \left[\frac{2 R \cos \left(\varphi-\varphi^{\prime}\right)}{4\left(F o-F o^{\prime}\right)}\right] \cdot\left\{\exp \left[-\frac{\left(Z-B \varphi^{\prime} / 2 \pi\right)^{2}}{4\left(F o-F o^{\prime}\right)}\right]-\exp \left[-\frac{\left(Z+B \varphi^{\prime} / 2 \pi\right)^{2}}{4\left(F o-F o^{\prime}\right)}\right]\right\} d \varphi^{\prime} d F o^{\prime}
\end{aligned}
$$

Take an example of buried spiral source with $B=1, H_{1}=2.0$, and $H_{2}=12.0$, the temperature distributions in the longitudinal profile of pile as well as the ground at the dimensionless time of $F_{o}=1.0$ calculated with infinite and finite spiral source model are compared in Fig. 10. In general, the spiral configuration of the heat source gets well representation. 


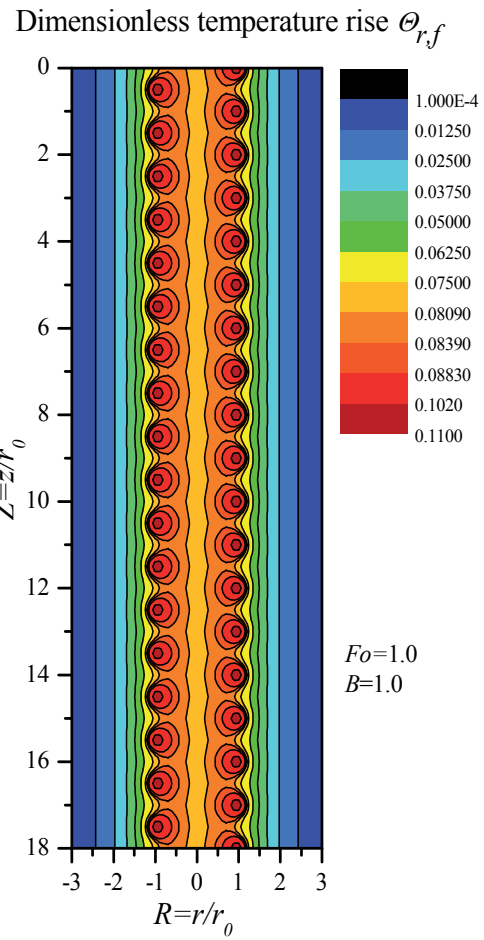

Infinite spiral source model
Dimensionless temperature rise $\Theta_{r, f}$

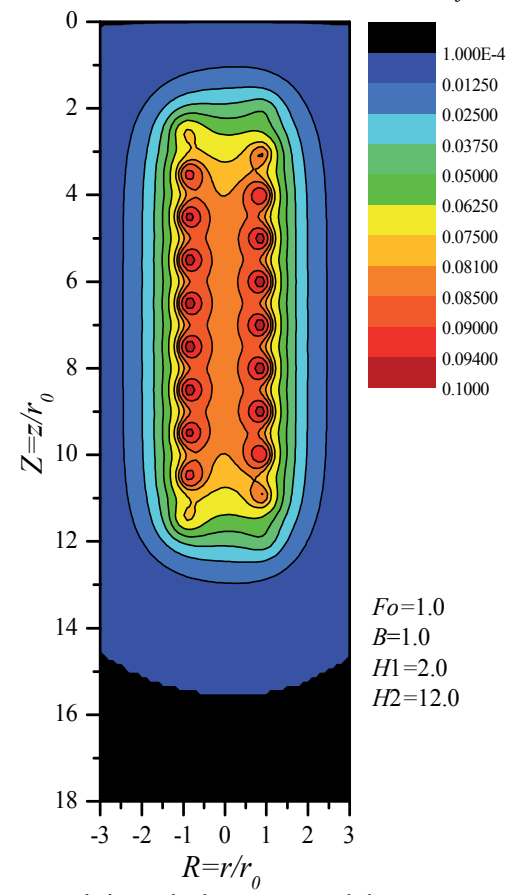

Finite spiral source model

Fig. 10. Temperature response of the infinite and finite spiral source models

The dimensionless temperature response at the midpoint of spiral heat source calculated with infinite and finite spiral source model are further compared in Fig. 11.

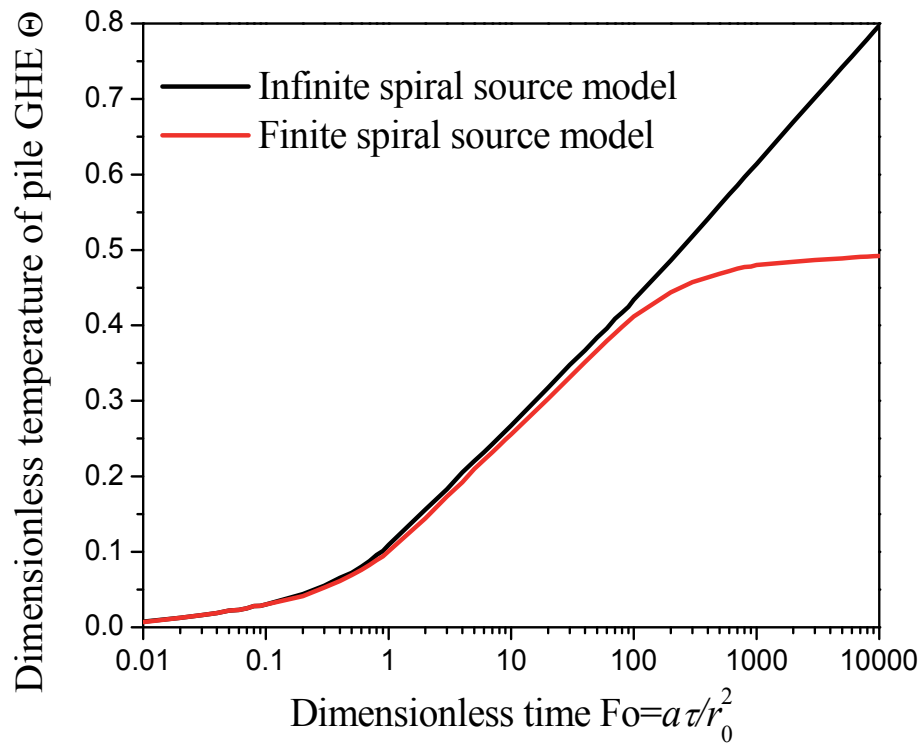

Fig. 11. Dimensionless temperature vs. time from infinite and finite spiral source models 
As shown in Fig. 11, the finite model yields a relatively lower temperature response compared with the infinite model. Temperature rises calculated with these two models are in good agreement for a short period after the start of heating. As time goes on, remarkable discrepancy of the finite model from the infinite one appears since the former takes the heat transfer through the top and bottom ends of the pile into account. While the temperature response rises continuously with time for the infinite model, temperature response for the finite model tends to a steady state as time approaches infinity. This feature indicates the importance to take the finite length effect into account in consideration of the long term operation of the buried spiral heat source. The heat transfer features of the pile GHE can be adequately described by the finite spiral source model, and its analytical solutions have provided a desirable tool for simulating the pile GHE and prompting its applications.

\section{Ground heat exchangers with multiple boreholes}

GHEs in practical GCHP projects usually consist of multiple boreholes. The conduction problems under the assumption of constant properties satisfy the condition of superposition; therefore the temperature rise at a certain location in the GHE with multiple boreholes can be obtained by means of summing up all the individual temperature excesses caused by each of the boreholes at the concerned spot, that is:

$$
\theta_{m}(\tau)=\sum_{i=1}^{N} \theta_{i}(\tau)
$$

According to simulation requirements and conditions the function for the temperature excess, $\theta_{i}(\tau)$, caused by a single borehole may be determined from models discussed in previous sections such as the finite line source model or cylindrical source model.

As mentioned above, while the superposition approach is employed for thermal analysis of GHEs, the domain involved is divided into two separate regions, i.e. the region inside the borehole and that outside it. For the former region the heat transfer is considered as steadystate. For heat transfer outside the borehole, transient heat transfer models should be used. The temperature on the interface of the two regions, i.e. the borehole wall, constitutes a key link of the thermal analyses in the two regions. The mean temperature of the circulating fluid, and, then its inlet and outlet temperatures, varying with time, can be determined with the borehole temperature plus a temperature difference resulted from the borehole resistance. The temperature on borehole wall, however varies along its depth as indicated in previous discussions, and differs from each other among different boreholes. As a consequence, it is desirable to define a representative temperature of the borehole wall for the entire borehole field so as to keep the analysis concise enough for engineering design and thermal analysis purposes.

Normally, the temperature response at the midpoint of borehole in depth-direction is selected to represent the borehole wall temperature response for each individual borehole. Although more sophisticated approaches have been investigated such as taking the integrated average temperature along the borehole depth as the representative one, the study (Zeng et al. 2003) has shown that the simpler choice of the midpoint temperature as the representative one is acceptable for engineering applications. 
On determination of the temperature rise on a certain borehole wall it is important to distinguish the temperature rise caused by the heat source (U-tubes) in the borehole itself, which is usually the most significant, and those caused by thermal interference from other boreholes in the GHE. The spaces between adjacent boreholes are much greater than borehole radius, as a consequence, the minor discrepancy in the temperature rises on the borehole perimeter in the circumferential direction caused by an adjacent borehole can be neglected, and, then, the distance between the two borehole axes is counted. As a result, for calculation of the temperature rise on a borehole wall equation (32) turns to be:

$$
\theta_{m}(\tau)=\theta\left(r_{b}, 0.5 H, \tau\right)+\sum_{j=1}^{N-1} \theta\left(x_{j}, 0.5 H, \tau\right)
$$

where $x_{\mathrm{j}}$ is the distance between the $j$ borehole and the borehole concerned.

In the GHE with multiple boreholes the boreholes experience diversified temperature responses owing to their specific locations in the GHE configuration and, then, different heat transfer conditions. A representative borehole needs to be selected to determine the temperature rise on the borehole wall to avoid too large a workload of computation. It is usually recommended for engineering design to take the least favorable borehole as the representative, i.e. the one with largest temperature rise in the GHE. It is defined as:

$$
\theta_{e}=\operatorname{Max}\left(\theta_{m, i}\right)=\operatorname{Max}\left(\theta_{i}+\sum_{\substack{j=1 \\ j \neq i}}^{N} \theta_{i j}\right)
$$

It is easy to locate the least favorable borehole in most of the GHE configurations for pure conduction models; and this choice is conservative for GHE design. While ensuring safe operation of the GHE, it leads to over-sizing of the GHE and aggravating its cost. In view of fact that larger and larger GHEs are constructed consisting of hundreds boreholes in a single GHE, this choice of the representative borehole can result in too severe deviations. A desirable alternative for the representative borehole would be the one whose temperature rise follows closely the average temperature rise of the GHE. This task is demanding even for the pure conduction models due to the wide diversity of possible configurations of the GHE. Some studies are under the way on this subject, and the borehole locating at the nearest vicinity of the geometric center of a quarter of a matrix configuration of the GHE is considered to be an appropriate choice for the representative one in pure conduction models (Lin, 2010). For the advection models it is even more intricate to find out a proper representative borehole because another factor, the velocity of the groundwater infiltration is incorporated into the model while its direction has added more numerous variations relative to the orientation of the GHE configuration. This seems a problem which needs to be addressed to properly in such an approach.

\section{Temperature response to variable loads}

GCHP systems can provide buildings with heating and cooling in different seasons, so heat can be extracted from or rejected to the ground. As defined, the heat load $q_{1}$ means the heat 
rejected to the ground, so the temperature rise in ground is positive; they both turn to negatives if heat is extracted from the ground.

In order to analyze the intricate heat transfer process in the GHEs effectively and efficiently, a basic and simple model must be established and solved first, and then, more complicated factors are added gradually. The basic problem is the heat transfer of a single borehole under a step heating, which means a constant heating rate starting from a certain instant. All the models for outside boreholes heat transfer discussed in previous sections deal with the primary problem of step heating.

The heat extracted from or rejected to the ground varies with time because the GCHP load usually varies with time. The variable heat flow can be approximated by a pulse train of heating load as shown in Fig. 12. A heating pulse imposed in the time interval $\tau_{i}<\tau<\tau_{i+1}$ can be considered as superposition of two step heating fluxes, as shown in Fig. 13.

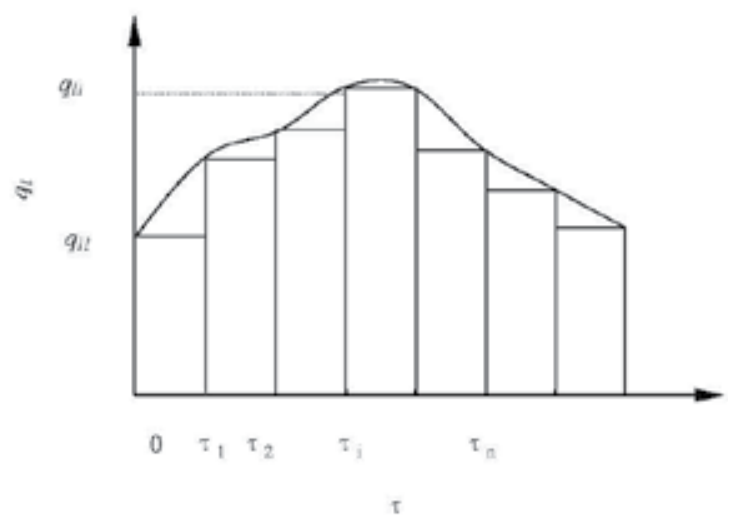

Fig. 12. Continuous heating approximatedby a rectangular pulse train

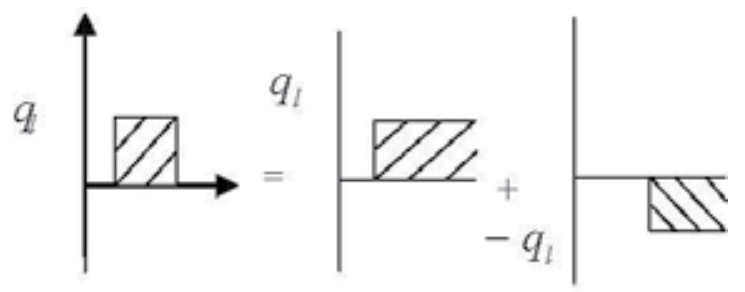

Fig. 13. A pulse heating equals two step heating fluxes

In order to facilitate computation of the temperature response of the GHEs to such sequential heating pulses the concept of so-called $g$-function is usually introduced. The $g$ function represents the non-dimensional temperature response on the representative borehole wall to the step heating for a specific configuration of the GHE, which is defined as

$$
g(\tau)=\frac{2 \pi k \theta_{e}}{q_{l}}
$$


On the assumption of a uniform heating rate $q_{1}$ in all the boreholes of the GHE, the $g$ function is independent of $q_{1}$. The temperature response to the step heating on the representative borehole wall can be determined on basis of the models presented in previous sections together with the superposition procedures such as that of equation (34).

For sequential heating pulses shown in Fig. 12, the borehole wall temperature rise at time $\tau$ can be obtained by superposition as:

$$
\theta=\frac{1}{2 \pi k} \sum_{i=1}^{\infty}\left(q_{l_{i}}-q_{l_{i-1}}\right) \cdot g\left(\tau-\tau_{i}\right), \quad\left(q_{l_{0}}=0\right)
$$

Let's consider a simple case of periodic on-off operation of the GCHP system to demonstrate the impact of discontinuous heating. Assume that the discontinuous GCHP operation is cyclic with a period $T$, of which the on-time is $T_{1}$. Then, $C=T_{1} / T$ denotes the on-time ratio. If the average heating intensity over the operating period is denoted by $\overline{q_{l}}$, the pulse heating intensity is $\overline{q_{l}} / C$, as shown in Fig. 14 (a).

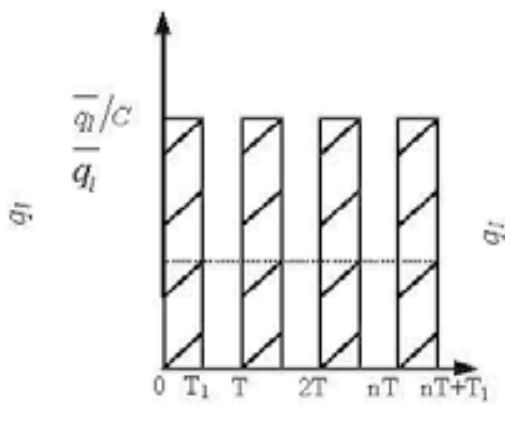

(a)

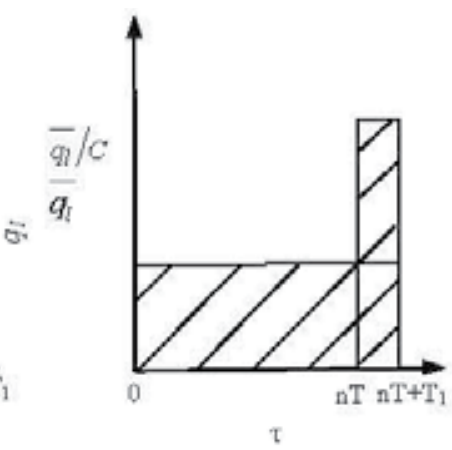

(b)

Fig. 14. A cyclic pulse load and its simplification

The borehole wall temperature response in a single borehole GHE to such cyclic pulse heating is calculated based on the line source model. Fig. 15 shows the borehole wall temperature response with the same average heating intensity but different operating time ratios. Simulations indicate that on such conditions the borehole wall temperature oscillates significantly while rising gradually over cycles. Furthermore, the smaller the operating time ratio is, which corresponds to stronger pulse intensities, the larger temperature swings are resulted in. The maximum temperature rise of the fluid after an operating period is an important criterion in design and thermal analysis of the GHEs. Study has shown that the maximum borehole wall temperature rise due to the periodic on-off heating load can be approximated by superposition of temperature rises caused by a continuous mean load and a single heating pulse as shown in Fig. 14 (b). Fig. 16 shows that the maximum temperature rise obtained from the simplified model is equivalent to that from the exact periodical pulse load model. Thus, this simplification provides an approach to analyze discontinuous loads over long durations. The results also indicate that the maximum temperature rise depends not only on the mean load over the whole duration, but also on the intensity and operating span of a single pulse. 


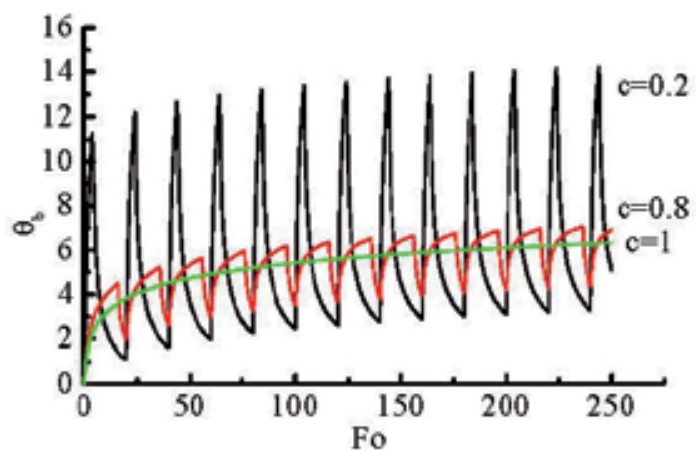

Fig. 15. Borehole wall temperature response to cyclic pulse loads

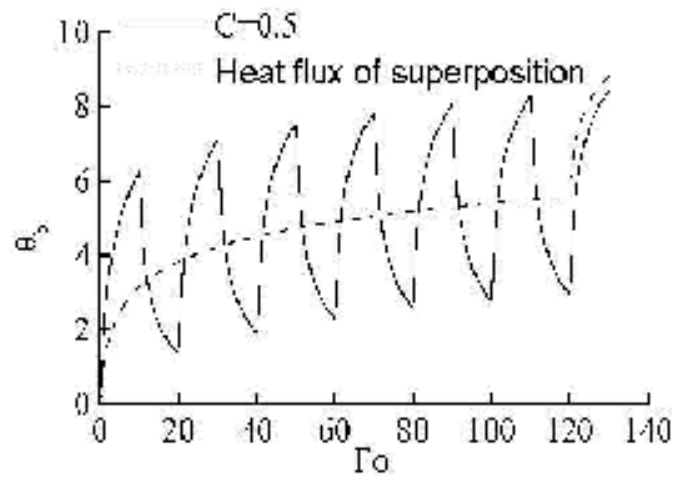

Fig. 16. Temperature response to a cyclic load and its simplification

\section{Design and simulation software for ground heat exchangers}

As mentioned above, the heat transfer process in a GHE involves quite a number of factors. It is necessary to further develop an accurate, reliable and convenient program for GHE design and simulation. In the last decade, a number of GHE models have been developed and they have been combined, directly or indirectly, with models of the building, heat pumps, and other components in various modeling environments such as TRNSYS, EnergyPlus, eQuest, and HVACSIM+. The GHE model used in TRNSYS (Hellström, 1989) is called the Duct Ground Heat Storage model, originally intended for underground thermal storage systems. The model uses numerical solutions for the global heat transfer between the storage volume and the far-field, and for the local problem of the heat transfer around the boreholes. An analytical method is employed to solve the steady-flux problem around the nearest pipe. The three models implemented in HVACSIM+ (Xu \& Spitler, 2006), EnergyPlus (Fisher, 2006) and eQuest (Liu, 2008) have a common heritage, which are based on extensions of Eskilson's model (1987). The programs are based on pre-computed response functions for specific GHE geometries.

On basis of the study on the heat transfer modeling of the GHEs, a software package in Chinese interface named GeoStar has been developed and spread for the design and simulation of the GHEs mainly in China (Fang et al., 2002). This software package is able to size GHEs to meet the user-specified minimum and maximum entering fluid temperatures 
to a heat pump for a given set of design conditions, such as building load, ground thermal properties, borehole configuration, and heat pump operating characteristics. The heat transfer models mentioned above are employed in the software, including the analytical solution of the finite line source model for the thermal resistance outside boreholes and the quasi 3-D model for the thermal resistance inside boreholes. In addition, the modeling procedure uses spatial superimposition for multiple boreholes and sequential temporal superimposition to dealing with the dynamic heating and cooling loads of the systems. The flow chart of the computing procedure for the model implementation is described in Fig. 17. The design process is actually a simulation-based process by means of the trial-and-error method.

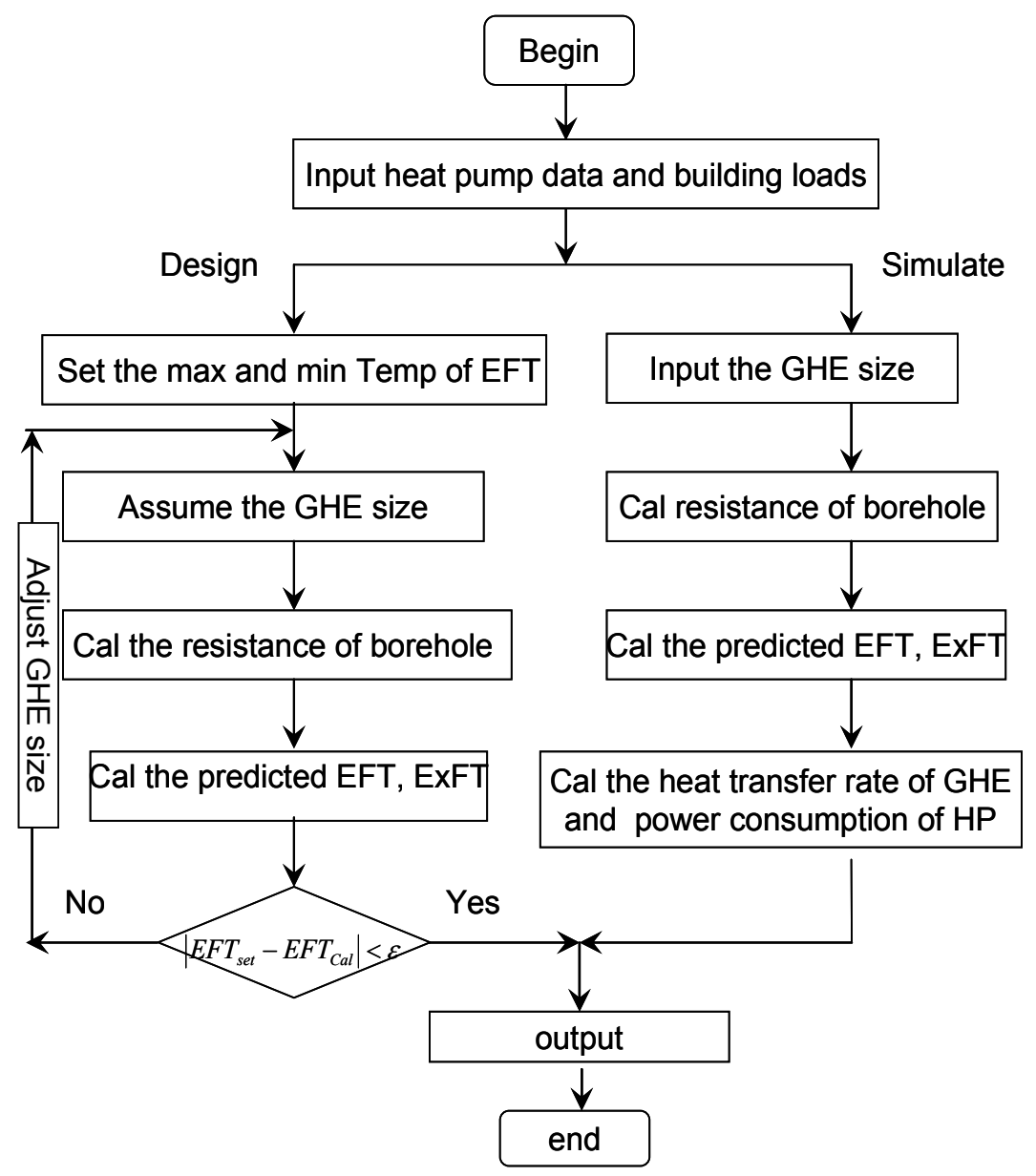

Fig. 17. The flowchart of the GeoStar program

The program with a friendly interface and visual graph has been developed under the Delphi Environment. In the visual interface, all the geometry parameters and inlet conditions can be set up in dialog boxes which can be popped up by clicking the different pages, as shown in Fig. 18. When all the required parameters are set up, the pre-compiled program will begin to simulate or design under the specific conditions. 


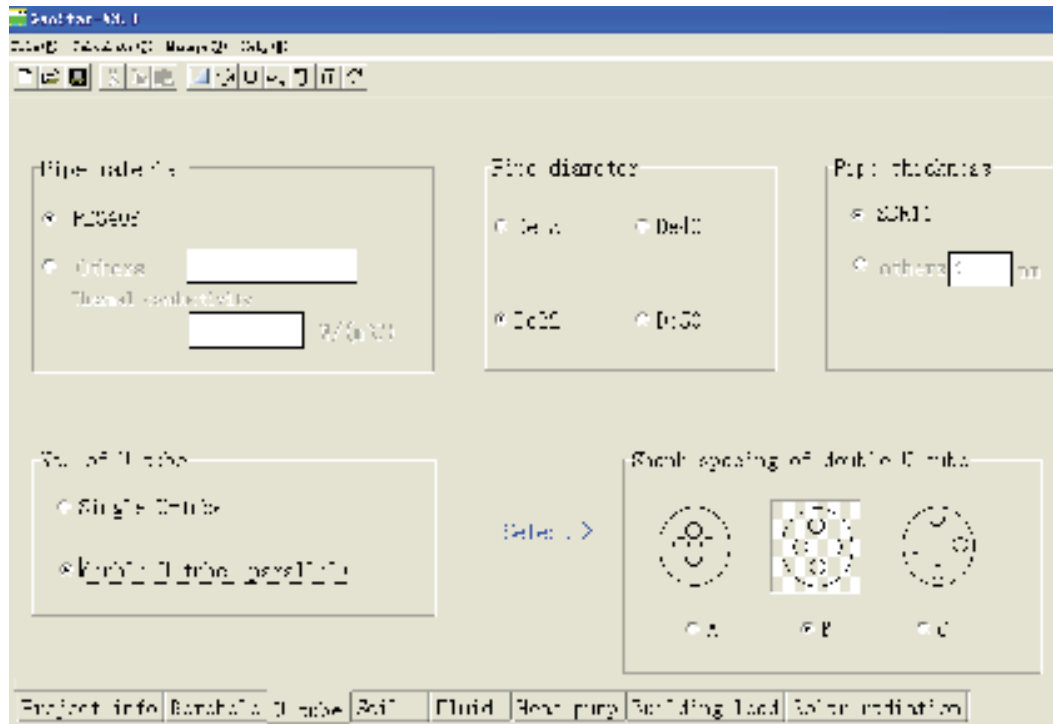

Fig. 18. Wizard user interface

In the past ten years a number of GHE models have been developed for use with various building simulation programs. In view of this, one of the authors together with other researchers conducted a comparison of GHE models developed for use with programs, including GeoStar, TRNSYS, HVACSIM+, GEOEASE II and eQuest (Spitler et al., 2009). The experimental validation was also carried out between the models and the experimental results. One of the research results is described in Fig. 19, which illustrated the predicted monthly average borehole ExFT and the measured data, when the hourly heat transfer rate was specified. It can be seen that all of the models (including GeoStar) predicted the ExFT within $1^{\circ} \mathrm{C}$, except HVACSIM+ which overpredicted a maximum of $2^{\circ} \mathrm{C}$, for the summer cooling months during the first year. For the shoulder seasons and heating months, the errors decreased slightly.

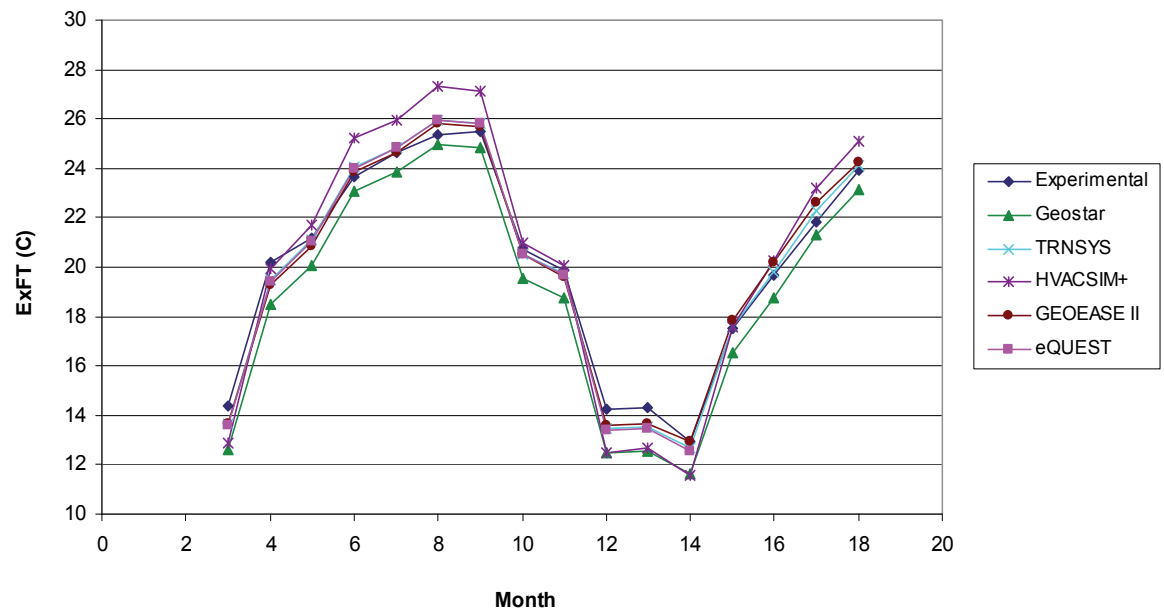

Fig. 19. Comparisons of experimental and predicted monthly average borehole ExFTs 


\section{Conclusion}

This chapter presents a comprehensive review of the study on heat transfer modeling of the ground heat exchangers in ground-coupled heat pump systems by means of superposition principle and analytical solutions. An entire set of techniques are provided to develop computer software for thermal analysis and design of GHEs in practical engineering.

Contributions of our research group to improvement of the GHE heat transfer modeling are expounded in particular, which include mainly

1. A quasi 3-D model for heat transfer inside borehole has been proposed, and its analytical solution derived to account for the borehole geometry and thermal interference among the legs of the U-tube.

2. The explicit analytical solutions of 2-D and 3-D models for vertical and inclined finite line source model for heat transfer outside borehole have been obtained to consider the axial heat flow and take the long-term effect of the limited borehole depth into account.

3. A solid cylindrical source model has been developed which gives a better description of the short-term temperature response for boreholes than the traditional 1-D models do, and may also serve as a tool for the pile GHE thermal analysis.

4. The advection models of infinite and finite line source have been proposed, and their analytical solutions derived to deal with the combined conductive and convective heat transfer in GHEs with groundwater infiltration taken into account.

5. The ring-coil source model and the spiral source model established for the heat transfer of a buried spiral coil to simulate heat transfer in the foundation pile GHE, which having created a new frontier of the GCHP applications.

The entire modeling uses the techniques of spatial superimposition for multiple boreholes and sequential temporal superimposition for arbitrary heating/cooling loads of the systems. The heat transfer models for the borehole GHE have been incorporated into a computer program, developed by our research group for providing a reliable and useful tool to design and simulate the GHE of GCHP systems. These studies on GHE heat transfer modeling in this chapter is expected to provide supports for developing the technique and promoting applications of the GCHP systems.

\section{References}

Bose, J. E.; Parker, J. D. \& McQuiston, F. C. (1985). Design/data manual for closed-loop ground coupled heat pump systems, Oklahoma State University for ASHRAE.

Carslaw, H. S. \& Jeager, J. C. (1947). Conduction of heat in solids, Oxford Press, Oxford.

Carslaw, H. S. \& Jaeger, J. C. (1959). Conduction of Heat in Solids, second ed. Oxford University Press, New York.

Cui, P; Yang, H. X.; \& Fang, Z. H. (2006). Heat transfer analysis of ground heat exchangers with inclined boreholes. Applied Thermal Engineering, 2006, 26: pp. 1169-1175. 
Cui, P.; Li, X.; Man, Y. \& Fang, Z. H. (2011). Heat transfer analysis of pile geothermal heat exchangers with spiral coils, Applied Energy, 2011, 88 : pp. 4113-4119.

Diao, N. R.; Li, Q. Y. \& Fang, Z. H. (2004). Heat Transfer in Ground Heat Exchangers with Groundwater Advection, International Journal of Thermal Sciences, 2004, 43 (12): pp. 1203-1211.

Diao, N. R. \& Fang, Z. H. (2006). Ground-coupled heat pump technology, The Higher Education Press, Beijing.

Domenico, P.A. \& Schwartz, F.W. (1998) Physical and Chemical Hydrogeology, seconded. John Wiley \& Sons Inc, New York.

Eskilson, P. (1987). Thermal analysis of heat extraction boreholes, Doctoral Thesis, University of Lund, Department of mathematical Physics, Lund, Sweden.

Fang, Z. H.; Diao, N. R. \& Cui, P. (2002). Discontinuous operation of geothermal heat exchangers. Tsinghua Science and Technology, 2002, 7(2): pp. 194-197.

Fisher, D. E.; Murugappan, A.; Padhmanabhan, S. K. \& Rees, S. J. (2006). Implementation and Validation of Ground-Source Heat Pump System Models in an Integrated Building and System Simulation Environment. HVAC\&R Research, 2006, 12 (3a): pp. 693-710.

Hamada, Y.; Saitoh, H.; Nakamura, M.; Kubota, H. \& Ochifuji, K. (2007). Field performance of an pile GHE system for space heating, Energy and Buildings, 2007: 39 (5): pp. 517-524.

Hellström, G. (1989). Duct Ground Heat Storage Model, Manual for Computer Code, Department of Mathematical Physics, University of Lund, Sweden.

Hellström, G. (1991). Ground heat storage, Thermal analysis of duct storage systems. Doctoral Thesis, Department of Mathematical Physics, University of Lund, Lund, Sweden.

Ingersoll, L. R. \& Zobel, O. J. (1954). Heat conduction with engineering and geological applications, 2nd edition, McGraw-Hill, New York.

Kavanaugh, S. P. (1997). Ground source heat pumps, Design of geothermal systems for commercial and institutional buildings. American Society of Heating, Refrigerating and Air-Conditioning Engineers (ASHRAE).

Laloui, L.; Nuth, M. \& Vulliet, L. (2006). Experimental and numerical investigations of the behaviour of a heat exchanger pile, International Journal for Numerical and Analytical Methods in Geomechanics, 2006, 30 (8): pp. 763-781.

Lin Y., (2010). Study on heat transfer modeling and design of ground heat exchangers, Master's Thesis, Shandong Jianzhu University, Jinan, China.

Liu, X. (2008). Enhanced design and energy analysis tool for geothermal water loop heat pump systems. Proceedings of 9th International Energy Agency Heat Pump Conference. pp. 20-22, May. Zürich, Switzerland.

Man, Y.; Yang, H. X. \& Fang, Z. H. (2008). Study on hybrid ground-coupled heat pump systems. Energy and Buildings, 2008, 40(11): pp. 2028-2036.

Man, Y.; Yang, H. X.; Diao, N. R.; Liu, J. H. \& Fang, Z. H. (2010). A new model and analytical solutions for borehole and pile ground heat exchangers. International Journal of Heat and Mass Transfer, 2010, 53: pp. 2593-2601. 
Man, Y.; Yang, H. X.; Li, X.; Cui, P.; \& Fang, Z. H. (2011). The spiral heat source model for the pile ground heat exchangers, In press by HVAC\&R Research (2011).

Mei, V. C. \& Baxter, V. D. (1986). Performance of a ground-coupled heat pump with multiple dissimilar U-tube coils in series. ASHRAE Transactions, 1986, 92(2): pp. 22-25.

Morino, K. \& Oka, T. (1994). Study on heat exchanged in soil by circulating water in a steel pile, Energy and Buildings, 1994, 21 (1): pp. 65-78.

Nelson, M. G.; Philipp, B.; Zhu, K.; Bayer, P. \& Fang, Z. H. (2011). A moving finite line source model to simulate borehole heat exchangers with groundwater advection, International Journal of Thermal Sciences, 2011, 50: pp. 2506-2513.

Pahud, D.; Fromentin, A. \& Hadorn, J. C. (1996). The Duct Ground Heat Storage Model (DST) for TRNSYS Used for the Simulation of Heat Exchanger Piles, DGC-LASEN, Lausanne.

Pahud, D.; Fromentin, A. \& Hubbuch, M. (1999). Heat exchanger pile system for heating and cooling at Zurich Airport, IEA Heat Pump Centre Newsletter, 1999, 17 (1): pp. 1516.

Sekine, K.; Ooka, R.; Yokoi, M.; Shiba, Y. \& Hwang, S. (2007). Development of a groundsource heat pump system with ground heat exchanger utilizing the cast-in-place concrete pile foundations of buildings, ASHRAE Transactions, 2007, 113 (1): pp. $558-566$.

Spitler, J. D. (2005). Ground-source heat pump system research - past, present and future. International Journal of HVAC\&R Research, 2005, 11(2): pp. 165-167.

Spitler, J. D.; Cullin, J.; Bernier, M.; Kummert, M.; Cui, P.; Liu, X.; Lee, E. \& Fisher, D. (2009). Preliminary intermodel comparison of ground heat exchanger simulation models. Proceedings of 11th International Conference on Thermal Energy Storage. June 1417. Stockholm, Sweden.

Sutton, M. G.; Nutter, D. W. \& Couvillion, R. J. (2003). A ground resistance for vertical borehole heat exchangers with groundwater flow, J. Energy Resour. ASME, 2003; 125 (3): pp. 183-189.

Xu, X.; Spitler, J. D. (2006). Modeling of Vertical Ground Loop Heat Exchangers with Variable Convective Resistance and Thermal Mass of the Fluid. Proceedings of Ecostock 2006, Pomona, NJ.

Yavuzturk, C. \& Spitler, J. D. (1999). A short time step response factor model for vertical ground loop heat exchangers, ASHRAE Transactions, 1999, 105(2): pp. 475-485.

Yavuzturk, C.; Spitler, J. D.; \& Rees, S. J. (1999). A transient two-dimensional finite volume model for the simulation of vertical U-tube ground heat exchangers, ASHRAE Transactions, 1999, 105 (2): pp. 465-474.

Zeng, H. Y.; Diao, N. R. \& Fang, Z. H. (2002). A finite line-source model for boreholes in geothermal heat exchangers, Heat Transfer-Asian Research, 2002, 31(7): pp. 558567. 
Zeng, H. Y.; Diao, N. R. \& Fang, Z. H. (2003). Heat transfer analysis of boreholes in vertical ground heat exchangers, International Journal of Heat and Mass Transfer, 2003, 46 (23): pp. 4467-4481. 


\title{
Promoting and Improving Renewable Energy Projects Through Local Capacity Development
}

\author{
Rafael Escobar1, David Vilar2, Enrique Velo ${ }^{3}$, \\ Laia Ferrer-Martí ${ }^{3}$ and Bruno Domenech ${ }^{3}$ \\ 1 Practical Action \\ ${ }^{2}$ Engineering Without Borders \\ ${ }^{3}$ Universitat Politècnica de Catalunya-BarcelonaTech, \\ 1 Peru \\ 2,3Spain
}

\section{Introduction}

Early in the $21^{\text {st }}$ century, an estimated one and half billion people lacked access to electricity and three billion people, almost half of the world population, still rely on solid fuels and traditional biomass to meet their cooking needs (WHO, 2009). The important role of energy systems in the design of a sustainable development model has been recognized worldwide (Modi et al, 2006). It is estimated that, to achieve the Millennium Development Goals (MDG), among other goals, it is necessary "To provide access to modern energy services (in the form of mechanical power and electricity) to all rural communities".

Electricity effectively contributes to improve living conditions of people (Chaureya et al, 2004) through services such as night lighting (domestic and public), access to information and communications, drinking water and sanitation, medical assistance and education, and creates opportunities to generate incomes and jobs. Likewise, electricity can contribute efficiently to social empowerment, promoting equity and empowerment of women.

Nowadays, technologies that use renewable sources are considered appropriate for energy supply in isolated rural communities with autonomous systems (Chaureya et al, 2004). However, there are barriers that difficult this process, related to the social, technological, economical, financial, institutional or political context. Although in the countries of the Andean Community of Nations, some institutional and political barriers are starting to be overcome, lack of capacity and high investment costs remain major barriers (Figure 1), which slow down the rural energy development in the region.

In the Andean region, technical teams, municipalities and regional governmental authorities, community leaders and base organizations often have limited knowledge about the potential of renewable sources. Thus, despite belonging to organizations that should promote the development of poorest populations, they do not exploit the benefits of their potential for the implementation of energy systems and the increase of beneficiaries' quality of life. Due to this lack of knowledge and sometimes lack of confidence in renewable energy 
technologies, these organizations usually do not consider renewable sources within their energy options portfolio. On the contrary, they focus on grid extension and the implementation of diesel generators that in most cases increase the indebtedness of countries and communities, and mortgage their development options. In addition, many rural electrification projects implemented with renewable sources in recent decades have collapsed or are in a precarious state, mainly because of lack of proper and complete training of beneficiaries (Vilar et al, 2006), both in operation, maintenance and management models, poor (or nonexistent) identification of their needs, and low (or no) community involvement throughout the process.

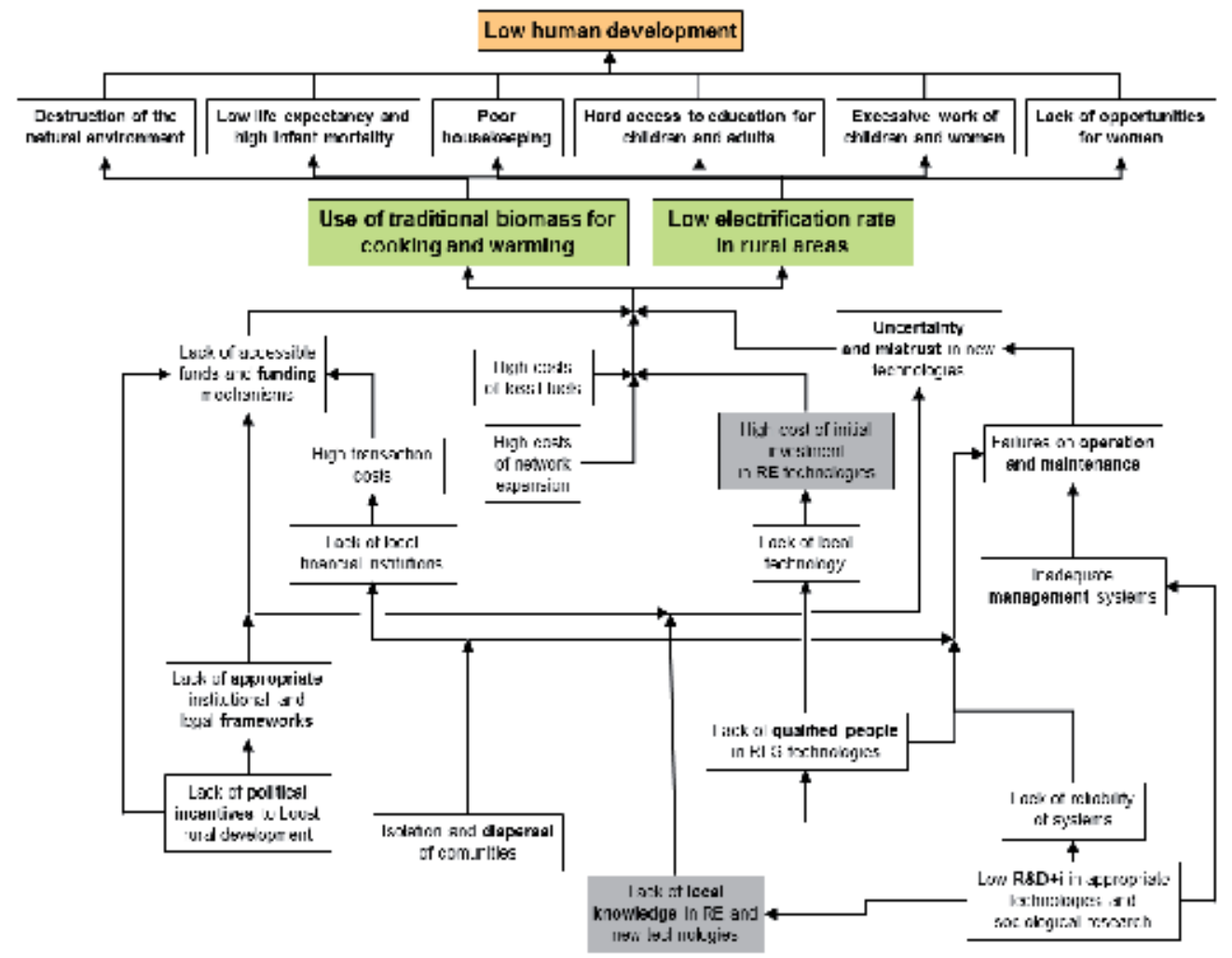

Fig. 1. Barriers that slow down rural energy development

The key factors for sustainability success and reduction of initial and maintenance costs of isolated energy systems (Figure 1) are: community participation, strengthening of community organization, training in management methods and, if possible, training of local manufacturers for the production of equipment and components (PNUD, 2005b). Consequently, capacity development of local and regional leaders, planners as well as technicians training, is an increasingly pressing need.

In this context, Practical Action (Peru), Engineering Without Borders-ISF (Spain), Universitat Politècnica de Catalunya (Spain) and Green Empowerment (USA) developed the project CEDECAP (Demonstration and Training Centre in Appropriate Technologies). Its specific aim is to develop technical and management capacities and offer training in 
the framework of access to energy and use of renewable sources, and to create a knowledge and research network in the Andean zone. One of the most noteworthy innovative aspects of CEDECAP is the creation of new spaces to canalize and share knowledge and create new synergies between different actors of public or private development. The objective goes beyond the simple approach of the punctual impartation of training lessons or technical demonstrations; the purpose is to insert capacity development and networking in the infrastructure and service policies in order to assure the sustainability, improve the projects' impact and promote the role of renewable energies (RE) in rural areas.

The CEDECAP began as a support center for training and design of electrification projects that their promoters, mainly Practical Action, were carrying out in the rural areas. However, the center's scope has been expanding and now has the following action lines: capacity development, research, dissemination and incidence, always maintaining its initial support to the implementation of projects. The following sections present each of these lines. Section 2 presents the overall project, the center, and its installations. Section 3 explains how CEDECAP supports the implementation of the projects. The capacity development and the training offer are summarized in the section 4 . Section 5 introduces the main research activities developed in CEDECAP and section 6 presents the CEDECAP's role as information and advocacy node. Section 7 explains how the developed planning methodologies include the four working activities presented in previous sections, and finally section 8 is devoted to conclusions.

\section{The project CEDECAP}

Initially, Practical Action - ITDG boosted the construction of a training center, promoted through its programs operating in Cajamarca, as part of its institutional proposal of development of local and regional capacities and promotion of renewable energies as an alternative for rural development. After several years of preliminary activities, in 1998, the CEDECAP (Demonstration and Training Centre in Appropriate Technologies) was officially opened, with the main objective of promoting activities aimed at the training human resources and the strengthening of capacities in the field of renewable energy, with preponderance on mini-hydraulics.

Since 2005, through a partnership between the Catalan Association of Engineering Without Borders (ESF) from Spain and Practical Action - ITDG from Peru, a more sustained work was promoted to achieve the consolidation of CEDECAP as a reference in the field of capacity development. The project CEDECAP was part of the Andean Program of Rural Electrification developed by ESF in countries such as Ecuador, Bolivia and Peru. The main purpose of the program was to improve the quality of life of the Andean population, through the universal access to energy in the area, especially through renewable sources. The specific objective was to develop technical and management capacities, and offer proposals for training, creating a network of knowledge and research in the Andean region (mainly Peru, Ecuador and Bolivia) in the context of access to energy and use of renewable sources, under the approach of technology for human development (Fernández-Baldor et al, 2009). Now, Peruvian (Pontificia Universidad Católica de Peru - PUCP) and Spanish (Universitat Politècnica de Catalunya - UPC) universities participate in the advisory body of the center to give support in the definition of courses and in the strategy. 
As detailed below, CEDECAP facilities currently do not only have energy modules but also other thematic areas of rural development, such as information and communication technologies, and water and sanitation. There are also accommodations where students can stay during the courses. In view of coming years and the relevance the center is taking, there are plans to expand the accommodations, build offices and a dining hall, and create a working module in the area of agronomy to strengthen capacities development in the area of production (Figure 2).

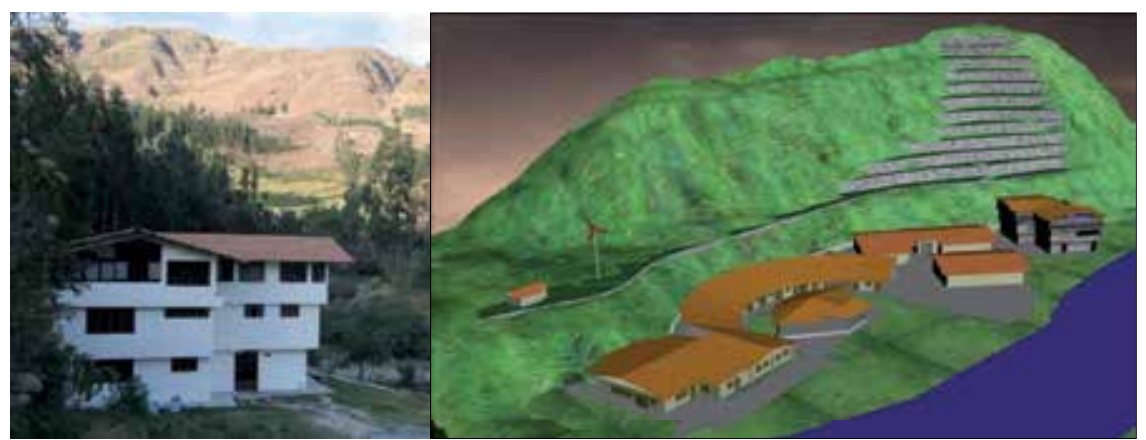

Fig. 2. CEDECAP facilities at present and those planned

At the same time, the CEDECAP aims to enhance networking among different reference groups in the South working on access to energy and defense of rights in the exploitation of natural resources, to facilitate coordination, social connectedness, knowledge sharing and interaction between different actors involved in Education for Sustainable Development (UNESCO). Figure 3 shows a scheme of the continuous process of strengthening and local capacity development, in short and long terms. The strategy of the CEDECAP is formulated under this conceptual process. The objective goes beyond the simple approach of the punctual impartation of training lessons or technical demonstrations; the point is to insert capacity development and networking in the infrastructure and service policies in order to improve the projects' impact and to promote the role of renewable energies in rural areas.

\subsection{Objectives and strategy}

The CEDECAP's vision is to be the leader in capacity development for the implementation and use of appropriate technologies in Latin America. For this purpose, the center has the main objective to strengthen technical and management capacities of leaders, students, manufacturers, technicians, professionals and government's employees for the formulation, implementation and monitoring of appropriate technological systems and to be able to formulate policy proposals, in order to support the development of rural areas.

The CEDECAP's stakeholders are the government (regional and local agencies), civil society (base associations and organizations), under-national and local governments, private companies (local decision-making institutions) and academic institutions (universities and institutes). It is a priority to establish partnerships with the different actors through the development of a capacity offer in order to ensure CEDECAP's sustainability; these partnerships will allow the center to accomplish the mission within the period covered by this strategic proposal. 


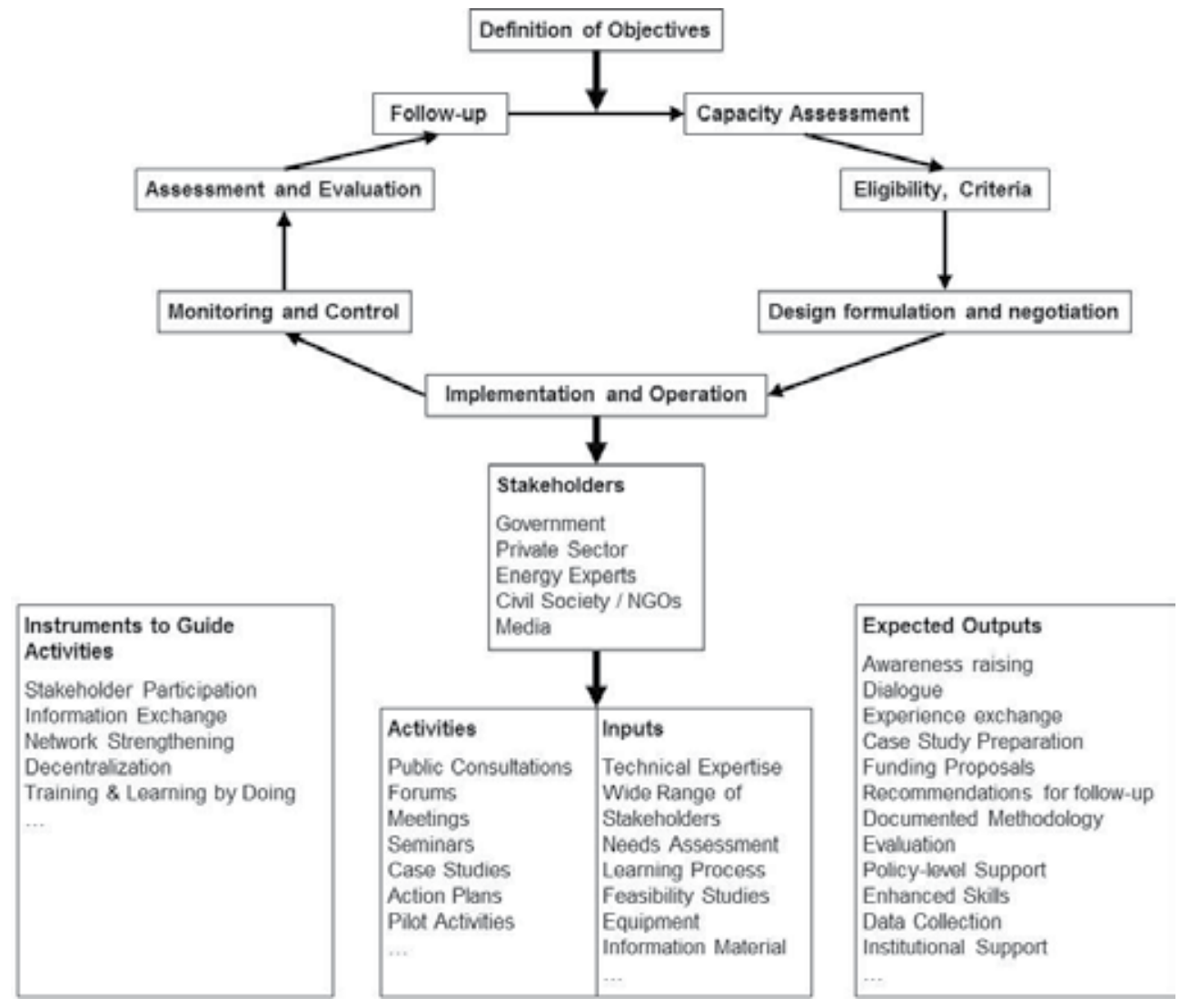

Fig. 3. Interventions on capacities development: planning and implementation cycle [adapted from Bouille and McDade, 2002]

The CEDECAP's initial working area was only energy but, after a while, an information and communication technologies module and water and sanitation area were added. Recently, a still incipient agronomy area has been initiated. None of the thematic areas is independent, they are all interrelated with the others, either by the type of institutions promoting capacities development, or by the type of target audience or by the teaching tools used to accomplish the goals. Although probably the area with higher impact levels is still the energy one, the objective of having a range of beneficiaries trained in the field of appropriate technologies will be accomplished through the intervention in all the thematic areas.

CEDECAP's principles are: a) to generate knowledge through applied research and development and technology transfer; b) to disseminate knowledge through the continuous training proposal that will be developed at the regional level; c) to transform the framework, which can be achieved through the access to information and advocacy. All this will be done through developing and offering a training proposal to meet current and future demands for training in renewable energies and related issues.

The following figure (Figure 4) illustrates CEDECAP's strategy and the tree constructed in order to consolidate it. 


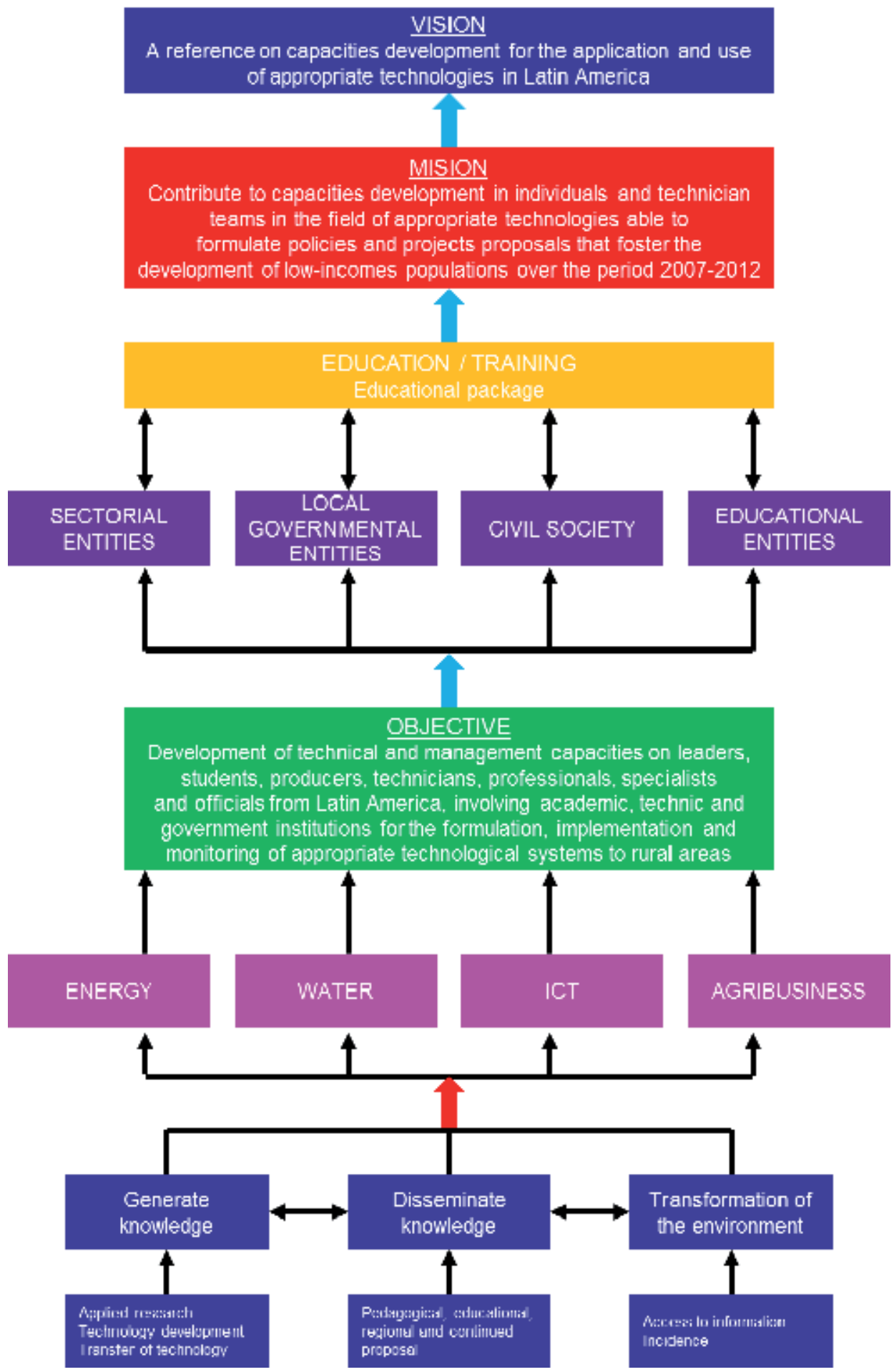

Fig. 4. General strategy of the CEDECAP 
Making a bottom-up description, on the lowest level there is the importance of developing activities in the field of generation, diffusion and transformation in the four areas (energy, information and communication technology, water and sanitation, and agronomy). Then, the key actors (local governmental agencies, civil society and educational institutions) are approached with an offer of full and comprehensive training that contributes to strengthen individuals' and teams' of technical capacities in the field of appropriate technologies, turning the CEDECAP on a reference in capacities development for the implementation and use of appropriate technologies in Latin America.

Although, as it has been mentioned, the CEDECAP has different thematic areas, this work mainly focuses on presenting the energy one, which is the promoter and still the one that is far more developed.

\subsection{Installations}

The CEDECAP is located in Llushcapampa, $20 \mathrm{~km}$ from the city of Cajamarca, and has an area of around $6.000 \mathrm{~m}^{2}$. CEDECAP was built in the area of a former hydroelectric power plant, so it has a loading chamber and the presence of falling water. CEDECAP construction began in 1999 and was held in several stages. The CEDECAP has real-size facilities that are used both for training and for research purposes. The CEDECAP's equipment started in relation to energy, and nowadays there are hydro, photovoltaic, wind and hybrid energy generators. Recently, information and communication technologies module and water and sanitation installations have been added.

\subsubsection{Energy module}

The energy module has facilities in relation to micro hydro, wind and photovoltaic power (Figure 5):

- A micro hydropower module with 3 pico-turbines of 0,8, 1 and $5 \mathrm{~kW}$, plus an electronic control and regulation equipment, banks of electric resistors, and other supplementary equipment.

- A micro wind energy module with 2 micro-wind generators of $100 \mathrm{~W}$ that were designed by Practical Action (Peru). One of them is in use while the other one is taken apart to be used in practical lessons.

- A photovoltaic energy module with solar panels from 50 to $80 \mathrm{~W}$ mountable in workshops.

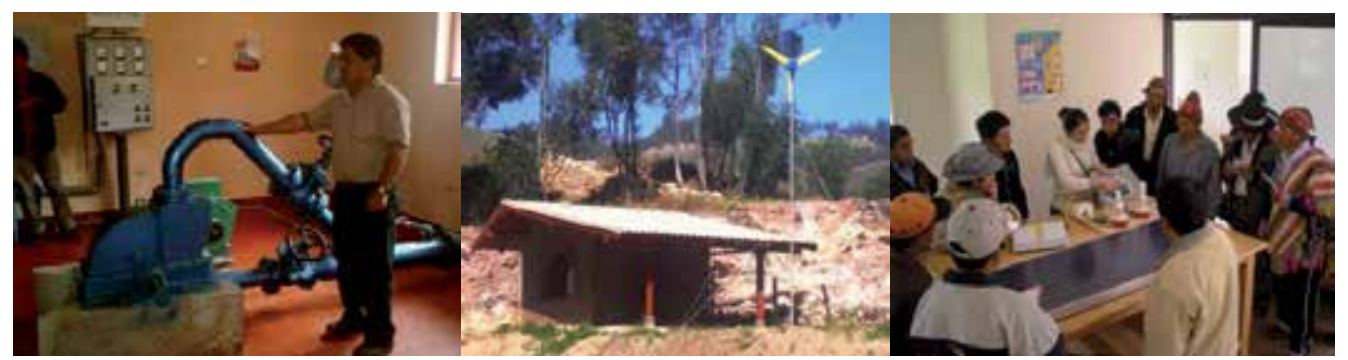

Fig. 5. Micro hydro (left), wind (center) and photovoltaic (right) modules 


\subsubsection{Information and communication technologies module}

The information and communication technologies (ICT) module aims to provide a proposal for training and research in ICT and telecommunications, and to design, to plan and to develop projects related to the use of low-cost ICTs in order to contribute to the development of disadvantaged people. To do this, there are:

- Computer equipment: 2 laptops for training and 2 more for the work team, 9 workstations, 5 spares of network cards, 2 spares of laptop batteries, and a color printer.

- Multimedia equipment: two multimedia projectors, an interactive whiteboard to enhance trainings and an electronic screen with laser pointers.

- Telecommunication equipment: equipment that facilitates the development of workshops and courses in wireless networks (antennas, routers, wireless cards, etc.).

- Video-security system.

\subsubsection{Water and sanitation module}

The water and sanitation module has:

- $\quad$ Different models of bio-filters for the development of practical workshops.

- Break-pressures with PVC pipe.

- A dry ecological toilet, currently under construction.

\section{Support to rural electrification projects}

Access to information, training, work experience, transfer, business management strengthening is needed in order to to ensure that rural electrification projects are carried out with the right technology and can be self-sustaining from its initial design.

The CEDECAP began as a tool for the improvement of projects in social and technical aspects, to ensure the projects' effectiveness and their long-term sustainability. Nowadays, it still maintains this role, among others, and supports the implementation of projects at all stages: from the project identification and design (technical and social aspects) to the implementation and subsequent follow-up and performance monitoring:

1. Identification of the project: Presentation and explanation of the project to the authorities and the community members, in technical and social terms, to confirm their interest in it.

2. Training of the community: In technical terms (use of energy and proper functioning of the systems) and in social terms (rights and obligations of users of the systems).

3. Design of the management model: The scheme of organization that will be responsible of economic management and technical maintenance of the system is designed and decided jointly with the community.

4. Training of candidates to operator-administrator (Vilar et al, 2006): Candidates to be operators and administrators of the system receive a specialized training in technical and economic issues. In the end, the community elects two candidates to be an operator and an administrator, who will receive an extra course in order to strengthen their capabilities for running the systems. 
5. Later follow-up and support in technical and social aspects: The CEDECAP team is responsible for supporting and monitoring technical and social projects, and to respond to specific queries.

\subsection{Training and linkage with the operators-administrators}

The training of some community members in the use and maintenance of the systems (operators) is a first step but, to ensure long-term sustainability, technological training is not enough. In order to keep the system running along its useful lifetime, it is also necessary to develop technical and economic management systems (Figure 1) that make possible to face up with the costs of repairs and periodic replacement of components (preventive maintenance). In this regard, some classical trainings that omitted management issues, have erroneously led the community to think that the systems work by themselves, without creating the awareness of the need to manage sustainably.

In general, beneficiaries of projects and CEDECAP users come from communal practice and reinforce their knowledge to provide a suitable service to their community. Generally, their community would not have electricity in the short and medium term, except by the renewable energy projects. Some farmers have had experience of other projects of Practical Action and are beneficiaries of water training programs, among others. They look for increasing their qualification to specialize in maintenance and operation of renewable energy techniques. Thus, they are involved from the beginning in the process of research and socio-economic diagnosis to establish the access mode to energy. Together with the technical team and the community, they are responsible of the selection of the users to electrify. This implies that the user must have family at scholar age and have participated in the previous processes (meetings, community work), in recognition of its counterpart.

To select a promoter or administrator, the first stage is to call for a meeting with all the community. In each community, eight people are formed to be promoters and administrators through a three to four days training in the CEDECAP, where they learn the operation and management of the renewable technologies to be implemented in the community. In order to improve the selection process, the technical team organizes a mini competition to select the best pairs of administrators and/or technicians basing on work plans presentations. The evaluator committee selects the best couple (operator and administrator), trying to make interdisciplinary teams. Then, the couple receives strengthening capabilities program for the appropriate operation and maintenance of the generating machines and the microgrids.

The installed electrification system passes through a stage of validation. This implies technical support to the facilities and the operators' decisions; this technical assistance helps to correct the problems promptly. However, despite the support, some systems may have different technical difficulties during the pilot test; these situations are in most cases promptly and progressively corrected. The technical support of the project team does not avoid that some operators seek support from other specialists, for example, the leading power generation and energy trading. This aspect is positive because it reflects the interest of the operator to expand his expertise in order to maintain the system properly. In most cases, when the system "reaches the operating point" the operator has already acquired capacities to maintain the system. 


\subsection{Training and participation of the community beneficiaries}

All the community receive training on the mechanisms of installation and maintenance of home systems. Users were trained on both technical and administrative topics, how to operate the household equipment, read the controller, manage battery charging and understand the tariff and late fees. The training program include education for all the inhabitants on the proper use of energy, such as: the use of energy efficient light bulbs and the prohibition of irons or other equipment that would not work with the system. The theoretical lessons take place at the school and the practice is undertaken during the installation of the systems. The implementation of the management model is developed in parallel to the installation of the systems, and promete participation of the entire village. Moreover, many communities now require training to reinforce the one received during the execution of the project, which in fact should always be included in post or impact assessments. Therefore, one of the useful or indispensable tools to ensure sustainability in the medium and long term of the technology-based development programs are Regional Training Centers, to offer continued support to the projects. Additionally, operators have played an important role in promoting the proper use of energy, going door to door to explain the residents the proper use of the systems from the in-door wiring to the mechanisms of saving electricity.

Communities lighting usually consists of two or three $15 \mathrm{~W}$ bulbs and for some families a TV and a DVD player. In some areas not reached by the broadcast TV signal there are also satellite dishes. The energy is used to charge cell phones and even to sell the cell phone charging service to users from other communities who have not energy yet. The CEDECAP has developed complementary and transversal learning on the use and saving of domiciliary electric energy. This issue usually does not receive enough attention by the beneficiaries, as part of the training to the access to electricity. However, in micro hydroelectric facilities where there is normally an excess of energy during the day, people are encouraged to seek new commercial outlets and small businesses by a proportionally lowering rate when increasing consumption.

It is critical to promote the active participation of the beneficiaries, representatives and community leaders in the entire process of project implementation. In the project identification phase, meetings were held with all of the beneficiaries to explain in detail the advantages and limitations of the energy systems as well as their rights and responsibilities so that the energy supply is maintained (Figure 6). These responsibilities include the active participation in the installation of the system and a commitment to pay a monthly tariff to guarantee the maintenance and replacement of the equipment. Finally, gender perspective is an institutional policy and has to be taken into account when formulating and implementing projects. In practical terms, gender perspective allows access to project benefits to a greater number of women, since the existence of gender inequities in rural areas is admitted and considered from the beginning. With this objective, organizations led by women are sought to identify their advances on promoting gender equality in the area. In particular, participation of women in trainings was promoted and monitored to ensure their appropriation of the technology and the project. 

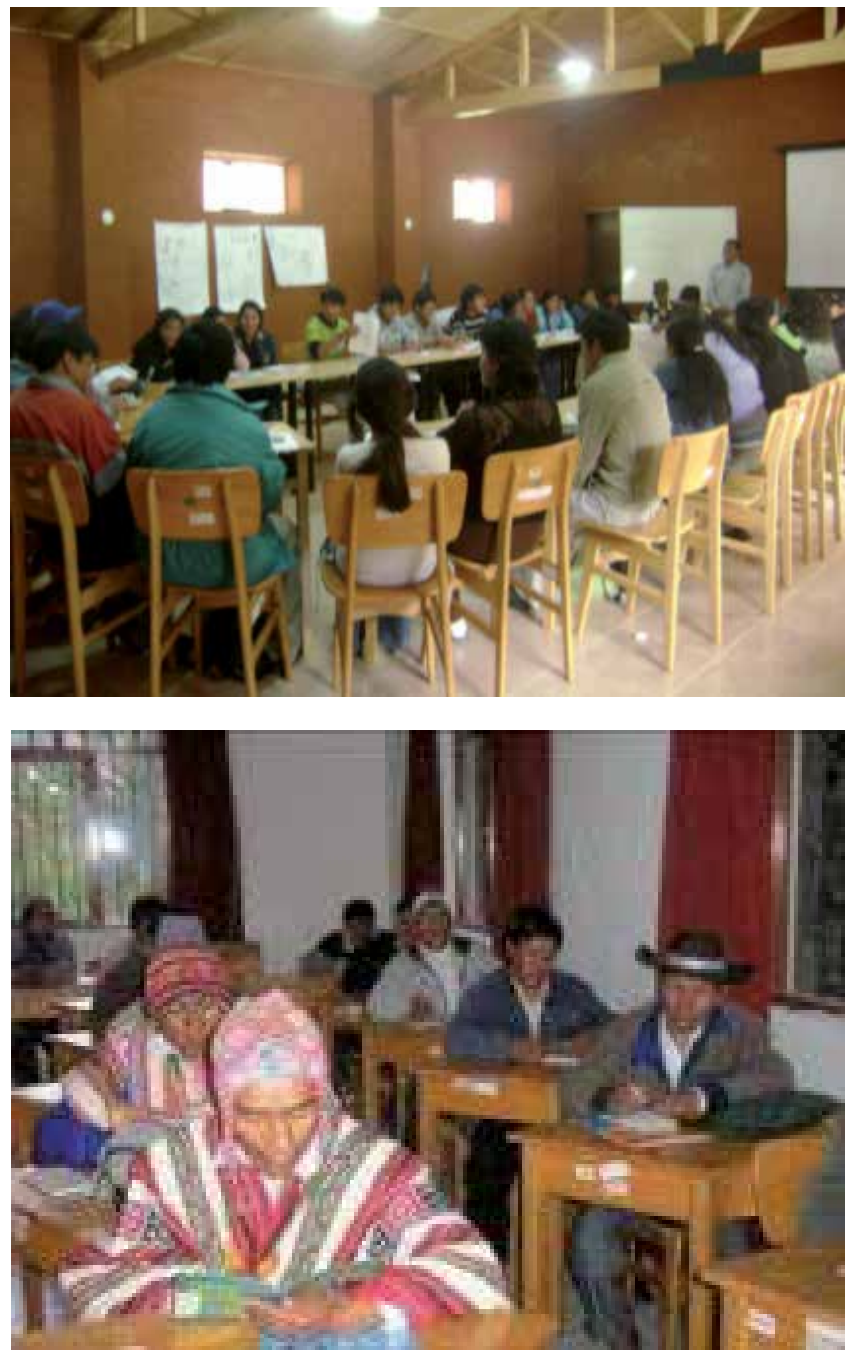

Fig. 6. Training of operators in the CEDECAP

\section{Capacity development program}

In this section, the capacity development program of the CEDECAP is presented in terms of the offered courses, used pedagogical methodologies and their involvement in education programs. Finally, a summary of the realized activities is provided.

\subsection{Training proposal}

The CEDECAP has developed training activities especially designed to meet evident demands at different levels: universities, municipalities, regional governments, technicians, specialists and manufacturers have improved and increased their knowledge. Moreover, these events answer to local, regional and international demands. Table 1 shows the main types of scheduled training activities: 


\begin{tabular}{|c|c|c|}
\hline ACTIVITY & INTRODUCTION & OBJECTIVES \\
\hline $\begin{array}{c}\text { WORKSHOP } \\
\text { TRAINING FOR } \\
\text { RURAL ENERGY } \\
\text { DEVELOPERS } \\
\text { Target audience: } \\
\text { rural promoters. }\end{array}$ & $\begin{array}{l}\text { Traditionally, in the scenario of energy } \\
\text { development work in rural areas, farmers, } \\
\text { who are the main players, have been excluded } \\
\text { from the processes of searching alternatives } \\
\text { and even from the implementation of } \\
\text { technologies and knowledge aimed to solve } \\
\text { their own problems. } \\
\text { Rural development requires a process of } \\
\text { rapprochement between professionals, } \\
\text { technicians and farmers, which achieves on } \\
\text { solutions to the problems of communities, } \\
\text { developing and strengthening local capacities. } \\
\text { This workshop aims to complement the } \\
\text { training of rural promoters, adding the } \\
\text { energy component as one of the main inputs } \\
\text { for the promotion of development in their } \\
\text { environment. }\end{array}$ & $\begin{array}{l}\text { To develop and strengthen } \\
\text { capacities of rural promoters in } \\
\text { order to improve their technical } \\
\text { and social skills in the field of local } \\
\text { development, and to become rural } \\
\text { energy developers. }\end{array}$ \\
\hline $\begin{array}{l}\text { WORKSHOP } \\
\text { POLICIES AND } \\
\text { ENERGY } \\
\text { DEVELOPMENT } \\
\text { Target audience: } \\
\text { leaders, authorities, } \\
\text { officials and } \\
\text { decision makers. }\end{array}$ & $\begin{array}{l}\text { The analysis, reflection and implementation of } \\
\text { energy policies in the field of rural } \\
\text { electrification should be part of the ongoing } \\
\text { tasks of the leaders and institutions that make } \\
\text { decisions to improve access to electricity and } \\
\text { to promote local economic development. } \\
\text { This workshop aims to disseminate } \\
\text { experiences and to generate the discussion on } \\
\text { electrification policies in the country and its } \\
\text { implications for regional and local energy } \\
\text { development. It also aims to promote the } \\
\text { interrelationship of both public and private } \\
\text { institutions in the field of rural electrification. }\end{array}$ & $\begin{array}{l}\text { To promote discusses and analysis } \\
\text { of the rural electrification problems. } \\
\text { To motivate synergies between the } \\
\text { institutions and other actors to } \\
\text { strengthen the work on rural } \\
\text { electrification. }\end{array}$ \\
\hline $\begin{array}{c}\text { MANAGEMENT, } \\
\text { OPERATION AND } \\
\text { MAINTENANCE } \\
\text { OF MICRO- } \\
\text { HYDROELECTRIC } \\
\text { POWER PLANTS } \\
\text { Target audience: } \\
\text { managers and } \\
\text { operators of energy } \\
\text { systems. }\end{array}$ & $\begin{array}{l}\text { Micro hydro energy is a suitable option for } \\
\text { isolated rural areas that have courses and } \\
\text { waterfalls, which enables them to access to } \\
\text { basic energy services and to improve their } \\
\text { living conditions. } \\
\text { To ensure the success and sustainability, } \\
\text { these projects require, the proper } \\
\text { implementation of the technology to the } \\
\text { efficient use of water resources, and the } \\
\text { development of a set of tools for the } \\
\text { management, operation and maintenance of } \\
\text { systems. These tools must ensure the quality } \\
\text { and continuity of the energy service, as well } \\
\text { as the lifespan of equipment and its } \\
\text { accessories, using local human resources as } \\
\text { the main support for system's sustainability. } \\
\text { This course aims strengthen knowledge of } \\
\text { operators and managers of small } \\
\text { hydroelectric systems, both in technical and } \\
\text { organizational and administrative aspects, } \\
\text { which will improve their performance. }\end{array}$ & $\begin{array}{l}\text { To transmit theoretical and } \\
\text { practical knowledge to develop the } \\
\text { capacities of operators and } \\
\text { managers of micro hydroelectric } \\
\text { power plants for identifying and } \\
\text { resolving performance problems in } \\
\text { those facilities, identifying and } \\
\text { using proper tools for a good } \\
\text { management, service control and } \\
\text { decision-making. }\end{array}$ \\
\hline
\end{tabular}




\begin{tabular}{|c|c|c|}
\hline ACTIVITY & INTRODUCTION & OBJECTIVES \\
\hline $\begin{array}{c}\text { COURSE } \\
\text { ASSESSMENT, } \\
\text { DESIGN AND } \\
\text { MANAGEMENT } \\
\text { OF WIND, } \\
\text { PHOTOVOLTAIC } \\
\text { AND HYDRAULIC } \\
\text { LOW-POWER } \\
\text { SYSTEMS } \\
\text { Target audience: } \\
\text { students in the last } \\
\text { cycles of technical } \\
\text { levels and } \\
\text { academics. }\end{array}$ & $\begin{array}{l}\text { In technical degrees, students are formed } \\
\text { about large-scale facilities implementation of } \\
\text { renewable energies. Furthermore, in most } \\
\text { cases, education is theoretical. } \\
\text { This course aims to complement the } \\
\text { education given in these degrees by } \\
\text { providing to students a very practical course } \\
\text { about low-power energy systems for rural } \\
\text { electrification. }\end{array}$ & $\begin{array}{l}\text { To strengthen academic training is } \\
\text { taking place in the higher level } \\
\text { centers of the country through the } \\
\text { creation of new knowledge and } \\
\text { abilities in young students, so they } \\
\text { can harness the potential of } \\
\text { renewable energies in the country. }\end{array}$ \\
\hline $\begin{array}{c}\text { INTERNATIONAL } \\
\text { COURSE } \\
\text { SPECIALIZATION } \\
\text { ON MICRO } \\
\text { HYDROENERGY, } \\
\text { WIND AND } \\
\text { PHOTOVOLTAIC } \\
\text { SYSTEMS } \\
\text { Target audience: } \\
\text { technical specialists } \\
\text { and researchers, } \\
\text { employees and } \\
\text { technical staff from } \\
\text { public administration } \\
\text { and students of the } \\
\text { last cycles of technical } \\
\text { levels and academics. }\end{array}$ & $\begin{array}{l}\text { Technologies based on the use of renewable } \\
\text { energies have proven to be adequate for the } \\
\text { electrification of isolated rural communities } \\
\text { with autonomous systems. In this context, } \\
\text { improvements on the systems are being } \\
\text { developed to increase its potential, both } \\
\text { technically and in the intervention } \\
\text { methodologies. } \\
\text { This course offers a specific training in the } \\
\text { latest advances of these technologies and } \\
\text { creates a space for discussion and } \\
\text { experiences exchange, for those involved in } \\
\text { the implementation of these systems, } \\
\text { counting on professionals and institutions of } \\
\text { international prestige. }\end{array}$ & $\begin{array}{l}\text { Strengthen capacities for planning, } \\
\text { policies implementation and rural } \\
\text { electrification projects of } \\
\text { government employees, } \\
\text { professionals, technicians and } \\
\text { researchers in isolated electrical } \\
\text { power generation through } \\
\text { renewable energies, in order to } \\
\text { show evidences of advances in } \\
\text { developed technological and } \\
\text { experiences on the use of renewable } \\
\text { energies. }\end{array}$ \\
\hline $\begin{array}{l}\text { VIRTUAL COURSE } \\
\text { ENERGY AND } \\
\text { COOPERATION } \\
\text { FOR } \\
\text { DEVELOPMENT } \\
\text { Target audience: } \\
\text { designers and } \\
\text { project managers. }\end{array}$ & $\begin{array}{l}\text { In the framework of cooperation for } \\
\text { development, energy supply for the } \\
\text { implementation of projects is usually seen as } \\
\text { a tool to generate energy. This approach } \\
\text { ignores the role of access to energy for } \\
\text { achieving the Millennium Development } \\
\text { Goals of the UN (PNUD, 2005a,b) and, } \\
\text { consequently, the different dimensions of } \\
\text { energy as a technology for human } \\
\text { development are not considered. } \\
\text { This course aims to make understand energy } \\
\text { and energy technologies as a transversal } \\
\text { approach to projects, to promote sustainable } \\
\text { and human development as a tool of social } \\
\text { transformation of the beneficiary communities. }\end{array}$ & $\begin{array}{l}\text { To identify and to discuss } \\
\text { strategies, programs and projects } \\
\text { that include energy supply for } \\
\text { domestically, communal or } \\
\text { productive uses. } \\
\text { To analyze energy as a tool of social } \\
\text { transformation from the point of } \\
\text { view of sustainable and human } \\
\text { development. }\end{array}$ \\
\hline
\end{tabular}

Table 1. Main courses scheduled in the CEDECAP 
So far courses and workshops offered by CEDECAP have achieved that:

- Students, especially of engineering careers, improve their academic skills and receive new technical and social knowledge.

- Peasant leaders are aware of the natural resources that can be used to promote rural electrification projects. This in turn allows a greater field of negotiation of the leaders with the political authorities that implement strategies at regional and national levels.

- Technicians and professionals refine and expand their expertise and broaden their knowledge in cross issues to their own disciplines, thus allowing professional skills to become more versatile.

- Manufacturers and designers exchange experiences and knowledge about elaboration process, which enables to work respecting technical standards.

- $\quad$ Authorities and politicians are aware of the characteristics of energy demands in rural communities and are able to set some criteria to look for a better implementation of energy policies.

Figure 7 shows some examples of trainings in the different technologies in the CEDECAP facilities.

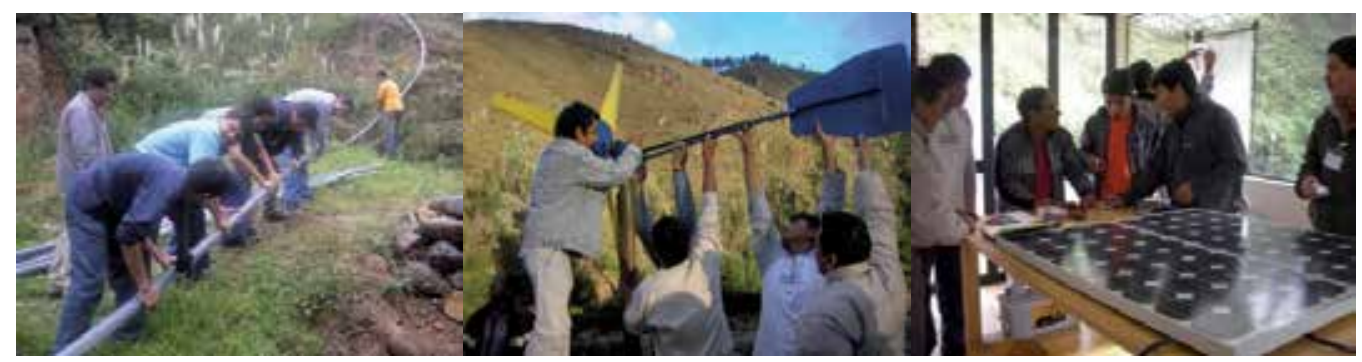

Fig. 7. Examples of trainings in micro hydro (left), wind (center) and PV (right) technologies

\subsection{Teaching methodology}

Although the methodologies used in the areas of training have been diverse, one aspect has been a common priority: the practice. In this sense, one of the most noteworthy aspects of CEDECAP is the availability of real size facilities. Thus, practice lessons were carried out in installations equal to real systems, students could learn exactly how it worked, and how they should be operated once installed in the communities.

CEDECAP's formative approach is based on the concept of "constructivist learning". This approach includes the need of the analysis, the representation and the management of contents and exercises to transmit in a proper, reliable and organized manner. For that reason, the educational methods must be adapted to the sociocultural context of the students. In other words, it is a perspective of training as a way to strengthen the abilities and skills of people and to develop guidelines for strengthening competences. This approach is defined in relation to social actors that it expects to train. Therefore, the beginning is the knowledge of each person.

Extending the range of courses implied improving the courses and trainings from a pedagogic point of view. Training teachers in pedagogic techniques in order to achieve 
better results in the target population was a challenge. In this sense, the role of an educational consultant for the implementation of courses was essential to make the corresponding improvements. Currently, there are educational records of all courses in which objectives, contents, skills and learning expectations are clarified.

\subsection{Formal education}

The development of a competency-based curriculum permitted to link the CEDECAP with formal technical training programs, which now is the main challenge for the future impact and sustainability of the center. The idea was to keep the system and the practical experience alive while developing formal educational organizations (professional training centers, universities) that allow to certify the skills acquired by the students. In this sense, the most notorious result has been the relation of the CEDECAP and the CEFOP, an agricultural training center in Cajamarca. In this regard, in 2008, a cooperation agreement with Fe y Alegría (CEFOP), an organization with the same objective of developing capacities of vulnerable people from rural areas, was signed to contribute to the institutionalization of training activities. Thanks to the alliance with CEDECAP, the possible use of renewable energy for improving production, handling and processing of products has been inserted in the courses of CEFOP.

The CEFOP has been working in Cajamarca since 1998; the work began with a European Union project copying a successful Spanish model that trains and links young people who cannot follow a technical career by themselves. In Cajamarca, there is the vocation to productive livestock activities; as CEFOP centers respond to this productive vocation of each region, their specialties are related to this field. Young people are formed around the labor needs of each region, and besides, the formation of micro and small enterprises is promoted. In 2002, Fe y Alegría assumed CEFOP's management, according to an agreement that defines the management and CEFOP centers coverage expansion nationwide.

The CEFOP identifies three training milestones: first Productive Technician (1 year of training and graduates at the level of a qualified operator), second Higher Technician (2 years of training) and third Professional Technician ( 3 years of training). The feature of this training is that a young person that studies for professional technician, receives the same training modules that a higher or productive technician. Until 2007, the CEFOP had the same level as a CETPRO, but later, the development of higher technological education was authorized. According to the teachers and directives, CEFOP's methodology ensures a very practical training, where $70 \%$ of time is in field or expertise and $30 \%$ in classroom. In this sense, the training methodology starts from the formulation of a productive project, and depending on the needs of the project, young people are trained. This training methodology is being developed in the different organizations where the CEFOP takes part.

The new training modules were worked together with teachers and technical staffs, under the capacities focus. The design of the modules was born from the experience of Practical Action in the field of renewable energies and the Universitat Politècnica de Catalunya for the methodological development of new proposals. This, together with the technical support of human resources from the CEFOP, is a good basis for learning. The construction of the training modules has been developed from workshops realized in the CEFOP, both among the involved organizations and the participation of specialists. The students prepare for the agricultural part but are cross-trained in renewable energies (an average of $10 \%$ of all the training in a year). 
When developing renewable energies modules, Practical Action's technical team participated getting involved as specialist teachers in different subjects. Students have done training to do the maintenance and the conceptual development. Practical lessons were carried out in the CEDECAP's facilities. The courses were conducted with the active participation of students, and at the end of the training, they were able to install or maintain an energy provision system. Another prominent theme of working together has been the construction and operation of a bio-digester in the CEFOP. In this line, the program covered from the background knowledge to the installation of the bio-digester, as well as identified the capacities and abilities for the installation of this tool. This work was carried out under the coordination between students and CEFOP teachers.

\subsection{Summary of the realized activities}

Since 2005 until today, the CEDECAP has allowed the development of many training activities:

- 22 courses have been developed on the subject matter of renewable energies, rural strategic planning and implementation of bio-digesters. 484 people have participated in the courses, among subnational government employees, students and renewable energies promoters. The courses are:

3 international courses and 1 virtual course on renewable energies.

18 regional courses and workshops related to renewable energies.

15 workshops and internships on rural electrification planning.

5 workshops on bio-digesters.

- 22 educational materials have been generated for training programs. These are:

9 presentations.

1 training report.

9 hand-outs.

3 user's manual.

- The CEDECAP supports the electrification projects of Practical Action. For example, since 2005, 5 hydroelectric projects and 3 wind projects have been implemented.

\section{Research and development}

The CEDECAP has real-size facilities that are used both for training and for research purposes. It is especially relevant that real-size equipment allow very applied and practical research. Moreover, improvements and technical developments can be tested in the CEDECAP before moving on to real projects to ensure that their performance in field will be appropriate and reliable. Next, we present the main reach lines that have been developed involving wind electrification systems, household bio-digesters and methodologies for developing rural electrification plans.

\subsection{Wind electrification systems}

It is worth to mention the research carried out in relation to small wind turbines. In 1998, ITDG began a long-term research study focused on taking advantage of small wind energy to generate electricity for poor rural families in three countries: Peru, Sri Lanka and Nepal. Wind turbines were designed under the concept of appropriate technology: they should be 
simple, cheap, reliable, easy to maintain and, above all, achievable through local workshops or microenterprises with a minimum of imported materials and components (Schumacher, 1973). In the case of Peru, the developed turbines were specifically designed to operate at low-moderate wind speeds that predominate in Andean Peru. In August 2006, a meeting between Practical Action (International Programs and Latin America's Office), Engineers Without Borders - Catalonia and the Universitat Politècnica de Catalunya (UPC) was celebrated in Cajamarca (Peru). At that meeting the three entities established and promoted the groundwork for the design of an international program called "Development and Dissemination of Micro Wind Energy Generation Systems in Developing Countries (MicroWEGS)", whose main coordinator was Teodoro Sánchez, the technologies and policies consultant of Practical Action.

Until now, two different models have been developed: the IT-PE-100 operates with wind speeds from $3.5 \mathrm{~m} / \mathrm{s}$ to $12 \mathrm{~m} / \mathrm{s}$, and produces $100 \mathrm{~W}$ at $6.5 \mathrm{~m} / \mathrm{s}$, and the SP-500 that produces $500 \mathrm{~W}$ at $8 \mathrm{~m} / \mathrm{s}$. Both models are furling tail turbines with three fiberglass blades and axial permanent magnet generators. At the same time, a local company was created to manufacture the wind turbines in Lima, thereby stimulating business creation and facilitating repair and parts replacement. So far, these models have already been used in the electrification of three communities in Peru (Ferrer-Martí et al, 2010). Moreover, these designs and technology were transferred to Bolivia. A Peruvian team from Practical Action went to Bolivia to impart theoretical bases of the designs and how to manufacture them in NGOs (Prodener, CINER) and universities (Universidad de San Simon, Universidad de San Antonio Abad). In this sense, research studies continue to improve the mechanical aspects checking the design, materials and manufacturing processes to improve the general performance of the wind turbine from the queue system redesign and to improve its robustness against non-constant winds, trying to influence the vibration's control. In parallel, control systems are being developed to optimize generator's performance (ColetSubirachs et al, 2010) and low-cost monitoring systems, to record and characterize the operation of all the equipment.

Moreover, some research studies are being developed for the optimization of the design of the projects, studying the location of the generators and the use of possible distribution microgrids. Due to the characteristic dispersion between households in the villages, the projects tend to install individual wind turbines at each demand point. However, the projects that combine individual generators and microgrids have proven to be beneficial: this design option considers the use of more powerful turbines, economically advantageous, and does not constraint the energy of a demand point to its location. The objective of these studies is to develop a decision models to design wind electrification projects, taking into account the location of the demand points, the detailed wind resource map and the possible use of micro grids. The wind resource at each point of the village is calculated using specialized software (Ferrer-Martí et al, submitted).

Mixed and integer linear programming (MILP) models have been developed to solve the design of the wind electrification project and gives the location and size or type of the wind turbines systems, the batteries, the charge controllers, the inverters, and the wires to be used in the micro grids (Ferrer-Martí et al, 2011). This type of mathematical formulation is used to model combinatorial problems, and can be solved optimally using specialized software. As input data, we introduce the location, the energy, and the power demand of each point, as 
well as the detailed map of the wind and solar potential of the village and the costs and technical characteristics of the equipment. As constraints, we introduce the technical characteristics and relation between the generation, storage and distribution equipment. Moreover, social constraints to consider social characteristics of the village and to improve the performance of the system from a social point of view are also introduced. Recently, models have been extended to consider hybrid systems with wind and photovoltaic generators (Ranaboldo et al, submitted) and micro hydraulic systems.

\subsection{Household bio-digesters}

Another research line has studied the technological development and performance of household bio-digesters for the use of biogas in the kitchen and the use of biol as an organic fertilizer. Low-cost tubular digesters originally were developed in tropical regions; to work in Andean Plateau designs and operation conditions had to be adapted to the extreme weather conditions of 3000-4000 m above sea level, where average annual temperatures are around $10{ }^{\circ} \mathrm{C}$. Since 2006, more than 30 digesters have been implemented in rural Andean communities of Peru by means of pilot research and development cooperation projects. In these projects, improvements in the design, in the used materials and in the management process where introduced. Moreover, two bio-digesters have been put at the National Institute of Farming Research (INIA) to be able to control and evaluate the biogas production under controlled conditions.

The adaptation of low-cost plastic tubular digesters originally developed for tropical areas to the conditions of the Andean plateau, continues to be a technological challenge. In this sense, research involving the characterization of the performance and the development of adapted and optimized designs has been developed. This information is needed in order to evaluate the performance of the systems, improve their efficiency and reduce capital costs, which would help fulfilling the strong demand for low-cost digesters by families and farmers in the Andes.

First, studies involving the analysis of biogas in such conditions were carried out to characterize the production, its composition and the burners' efficiency (Ferrer et al, 2011). To this end, two pilot plants were monitored and field campaigns were carried out in two representative household digesters of rural communities. In this study, we verified that specific biogas production in household digesters designed for extreme conditions of Andean communities was relatively low in comparison with digesters implemented in tropical areas, but methane content in biogas was high and a maximum burner's efficiency was around $52 \%$. Currently, the biogas produced in household digesters is consumed during 2-3 $\mathrm{h}$ of cooking per day, depending on the location, weather and operation conditions. This accounts for 40-60\% of fuel requirements for cooking.

First, we study the anaerobic digestion of guinea pig manure alone in low-cost unheated tubular digesters, as guinea pig is one of the most common livestock in rural communities of the Andes (Garfi et al, 2011). Two greenhouse designs were compared: in the dome roof digester the temperature and biogas production were significantly higher than in the shed roof digester. In a preliminary fertilization study, the potato yield per hectare was increased by $100 \%$ using the effluent as bio-fertilizer. However, the biogas production rate was low, which is attributed to the low organic loading rate, so results recommend to improve 
manure management techniques, increasing the organic loading rate and co-digesting other substrates to enhance the process. Taking into account the low biogas potential of cow manure compared to other cattle dung, next studies analyses if the process was enhanced by co-digestion with other manure and food or vegetable wastes. Moreover, agricultural reuse of the digestate from low-cost tubular digesters as fertilizer is being analyzed (Garfi et al, in press).

\section{Information and advocacy node}

CEDECAP aims to become a reference node in the Andean region in training in rural electrification and in the rational and efficient use of energy, in terms of disseminating information and promoting networking.

\subsection{Information center}

The CEDECAP has a library, which has technical documents about non-conventional energies and all the material generated in the events and training processes. Recently, the website has been updated to provide technical consulting service in addition to supplying information (documents, papers, reports). CEDECAP's website is independent from Practical Action's website, and until December 2009, 650 people had visited it. However, the website does not allow the user to connect directly to a specialist, but only indirectly.

The international courses on projects and systems design are a meeting place for NGOs, universities (students and teachers) and professional technicians. In addition, workshops that are organized around specific themes are the meeting point for civil society, universities, administration, private sector and government. In this sense, conversations with OLADE (Ecuador), that has 26 countries as partners, were initiated. Together with the organization, a virtual international course in micro hydroelectric power plants (both technical and management) was made using the OLADE platform. The alliance with OLADE allowed the groups to count on support to find demand in Latin America. Virtual courses are taken by OLADE as a success because the interesting and virtually forced subject reaches to 26 countries. For the CEDECAP the link is valuable because the institution has been recognized as a visible organization with expertise in the field of renewable energies. In particular, developing courses in a virtual platform (OLADE, 2008) allows not only training people from very different geographical areas, but also providing opportunities for participatory group learning with people of different cultures and personal and professional experiences.

\subsection{Networking center}

Promoting the CEDECAP means trying to promote networking, social connectivity, exchange and interaction between different actors involved in sustainable development in the region. Moreover, among the innovative aspects of CEDECAP, it is worth to mention the opportunity to break the paradigm that technology transfer is always from north to south. This project strengthens and promotes South-North and South-South transfers. In this sense, the center aims to create new spaces to canalize and share knowledge, and create new synergies between different actors in the public or private development, both South and North. 
The formation of these knowledge networks, which will be promoted with greater emphasis on Latin American countries, will shape new ideas and proposals that contribute to reduce the gap of isolation between academicals, governmental, NGO and private institutions. Strengthening the approach between these institutions will result in, among others, the opportunity to influence public policies related to the technical proposal of the center.

In particular, the CEDECAP is the permanent headquarters of the technical secretariat of the Latin American Network of Hydro energy (HIDRORED), whose framework is the use of renewable energy in rural areas. HIDRORED is made up of public and private organizations, mostly universities, development cooperation organizations and centers that promote renewable energy in Latin America and Europe. The magazines HIDRORED and Energía y Desarrollo offer an information service about the experiences and activities of the organizations working in the field of energy and development. Currently, there is an extensive broadcast coverage: around 50 countries receive the editions of the magazines.

Among the events organized and held in the CEDECAP, for example, must be highlighted the XIII Latin American and Caribbean Meeting on small hydropower exploitation that took place between 20 and 24 July 2009. The event was organized by the Latin American Network of Energy (Hidrored), Practical Action - ITDG, Engineers Without Borders (ESF) and Green Empowerment (GE). The event was divided into 3 parts: 1) a course on evaluation, design, implementation and management of small-scale wind energy systems; 2 ) a conference including specialists, professionals, researchers and interested persons from Latin America; and 3) a meeting of the Latin American Network Hidrored. The target audience was: researchers and professionals interested on spreading their progress and experiences, officials of non-governmental institutions related to the implementation of $\mathrm{PAH}$ in Latin America and the Caribbean, officials of financial institutions, international cooperation agencies, multilateral development agencies, equipment manufacturers, contractors and consultants.

\section{Planning rural electrification systems}

Recently, studies in developing procedures to improve the electrification systems with renewable energies in the broadest sense have been initiated: the development of rural electrification plans as a method for the diagnosis, selection and implementation of projects. The conventional strategy for increasing access to electricity is extending the national electricity grid; however, this option is limited by the complex terrain and dispersed nature of rural villages in some regions. Under these circumstances, stand-alone electrification systems that use renewable energy sources are a suitable alternative. A methodology for evaluating and analyzing the energy needs and potentials is required in order to design a rural electrification plan where each community has its own stand-alone electrification system. Progress has been made on a methodology that: 1) encourages and involves the coordinated participation in all institutional and community levels; 2) obtains proposals of projects and the technological designs from the analysis and comprehensive studies that considers the needs and potentials of the people; and 3) considers and 
includes funding instruments to ensure that the plan successfully translates in implemented projects.

The isolated rural electrification is usually accomplished by means of individual photovoltaic systems- without assessing the demand, needs, energy potentialities or community's organization. This lack of evaluation criteria tends to lead to inadequate solutions that do not meet demand, that install generators in non-priority sites, or that are technologically inappropriate. The omission of these factors implies the risk that the community will not appropriate itself the system, which would lead to inadequate management and maintenance. Consequently, many projects stop working in a few years due to technical or management problems. In most cases, standard solutions are not suitable and the appropriate design of the solutions, unlike what is normally considered, is not simple or easy. Furthermore, in isolated systems that do not have the flexibility to absorb new users or possible changes in the demand or in the demand profile, thus, a detailed project design is even more necessary in order to cover these aspects. In this sense, planning is essential to ensure the appropriate design of these autonomous projects.

It is important to define what Rural Electrification Plan using Renewable Energies means. It is a process aiming to identify needs and energy potentialities from a geographic area, which is not included in the rural electrification plan of the country or a regional government. Furthermore, domestic and productive demand can be met through appropriate technologies at local and regional levels. It is noteworthy that this process is not independent or isolated, but aims to strengthen the work done by the regional energy agencies, providing real information and promoting internal dynamics that may be useful for a more harmonious development of the national energetic sector.

The methodology to implement a plan should consider the particularities of the electrification systems of each of the communities included in the plan. In particular, a rural electrification plan of isolated systems should: 1) encourage and involve the coordinated participation in all institutional and community levels, 2) obtain project proposals from complete analysis and studies that consider needs and potentials of people, and 3) consider and include funding mechanisms that ensure the plan runs successfully, translating in implemented projects. With this information, the CEDECAP coordinates with authorities such as the Ministry of Energy and Mines trying to link them to the energy access proposal from the population.

Thus, the first experiment in regional or local energy planning was carried out in the region of Cajamarca, province of San Pablo, where the rural electrification rate has increased from 13.6 to $19 \%$ in the period from 2007 to 2009 , although it still remains one of the lowest of Peru [HDR, 2009]. The process lasted 10 months, and the projects portfolio was obtained and made funding search possible, both internally (FONCOMUN, Canon) and externally (international cooperation and regional government). The REP of San Pablo cost \$ 4000 and allowed to engage municipalities to invest S/. 4000000 (a quarter has already been spent on the development of isolated rural electrification projects). It is noteworthy the participation of district municipalities with their technical teams 
throughout the development of the plan, as well as community participation, since they are the ones who will ultimately be present at the implementation of the system. Currently, the CEDECAP has the strategy of working with local governments for making an energy planning in each of the districts jointly.

Due to lack of references, CEDECAP's technical team is working to adapt the public investment system to project profiles in renewable energies. Mechanisms and guidelines have been created to support municipalities in the formulation of investment projects; the main idea is to save administrative processes. This guidance will also be delivered to the regional government presidency.

\section{Conclusions}

Electrification systems based on the use of renewable energy sources are suitable for providing electricity to isolated communities autonomously. However, there are barriers that hinder this process and, between them, the major one is lack of local capacities. In this context, Practical Action (Peru), Engineers Without Borders (Spain), Universitat Politècnica de Catalunya (Spain) and Green Empowerment (USA) are promoting the CEDECAP, a capacity development center in Peru that support the implementation of energy projects and trains farmers, community leaders, policy makers and students of technical degrees and universities. In 2006-2009, 22 courses were developed with 484 participants and 22 educational materials.

The future challenge of CEDECAP is to strengthen and to consolidate its role within formal education, both in professional schools and universities, to increase professional's training, upgrade research and keep on working to insert renewable energy projects on the political agenda as a definitive step for promoting and improving their impact.

\section{Acknowledgments}

This paper was supported by the Spanish MICINN project ENE2010-15509 and co-financed by FEDER, the Centre of Cooperation for Development of the Universitat Politècnica de Catalunya (UPC), the Agència Catalana de Cooperació al Desenvolupament (ACCD), the Generalitat de Catalunya, the Ajuntament de Barcelona, the Agencia Española de Cooperación Internacional para el Desarrollo and the Directoraten-Generaal Internationale Samenwerking (DGIS).

\section{References}

Bouille, D. and McDade, S. (2002). Capacity for development. Energy for Sustainable Development. A policy agenda. Johansson and Goldemberg (eds.). UN Development Programme. New York.

Chaureya, A., Ranganathana, M. and Mohanty, P. (2004). Electricity access for geographically disadvantaged rural communities - technology and policy insights. Energy Policy, 32, 1693-1705. 
Colet-Subirachs, A., Gomis-Bellmunt, O., Clos-Costa, D., Martín- Segura, G., Junyent Ferre, A., Villafáfila-Robles. R. and Ferrer-Martí, L. (2010). Electromechanical modelling and control of a micro-wind generation system for isolated low power DC micro grids. EPE Journal, 20 (2), 2943-2959.

Fernández-Baldor, A., Hueso, A. and Boni, A. (2009). Technologies for Freedom: collective agency-oriented technology for development processes. Annual Conference of Human Development and Capability Association at the Pontificia Universidad Católica del Perú.

Ferrer, I., Garfi, M., Uggetti, E., Ferrer-Martí, L., Calderon, A. and Velo, E. (2011). Biogas production in low-cost household digesters at the Peruvian Andes. Biomass \& Bioenergy, 35 (5), 1668-1674.

Ferrer-Martí, L., Garwood, A., Chiroque, J., Escobar, R., Coello, J. and Castro, M. (2010). A community small-scale wind generation project in Peru. Wind Engineering. Special Issue on Small Wind Energy for Developing Countries, 277-288.

Ferrer-Martí, L., Pastor, R., Capó, G.M. and Velo, E. (2011). Optimizing microwind rural electrification projects. A case study in Peru. Journal of Global Optimization, 50 (1), 127-143.

Ferrer-Martí, L., Domenech, B., García-Villoria, A. and Pastor, R. A MILP model to design hybrid-photovoltaic isolated rural electrification projects in developing countries. European Journal of Operational Research (Submitted).

Garfí, M., Ferrer-Martí, L., Villegas, V. and Ferrer, I. (2011). Psychrophilic anaerobic digestion of guinea pig manure in low-cost tubular digesters at high altitude. Bioresource Technology, 102 (10), 6356-6359.

Garfí, M., Gelman, P., Comas, J. and Ferrer, I. Agricultural reuse of the digestate from low-cost tubular digesters in rural Andean communities. Waste Management, (in press).

Modi, V., McDade, S., Lallement, D. and Saghir, J. (2006). Energy and the Millennium Development Goals. New York: Energy Sector Management Assistance Programme, United Nations Development Program.

OLADE Latin American Organization of Energy (2008). Diseño, implementación y gestión de microcentrales hidroeléctricas. From 6 to 29 october 2008 at the IMTA (Instituo Mexicano de Tecnología del Agua), Mexico. Available at:

http:/ / www.imta.gob.mx/index.php?option=com_content\&view=article\&id=260 \&Itemid $=90$

PNUD (2005a). Achieving MDG: the role of energy services.

PNUD-ESMAP (2005b). Energy Services for the Millenium Development Goals. UNDP, UN Millennium Project, World Bank, and ESMAP. New York.

Ranaboldo, M., Ferrer-Martí, L. and Velo, E. Micro-scale wind resource assessment for offgrid electrification projects in rural communities. A case study in Peru. Int. Journal of Green Energy (Submitted).

Schumacher, E.F. (1973). Small is beautiful: Economics as if people mattered. Blond \& Briggs, London, UK. 
Vilar, D., Sneij, J., Marcelo, O. and Martín, G. (2006). Developing peasants' capacity on the operation and maintenance of a photovoltaic system. Experience in a training centre of the Andean region. 21 $1^{\text {st }}$ European Photovoltaic Energy Conference and Exhibition.

World Health Organization (WHO), United Nations Development Programme (UNDP) (2009). The energy access situation in developing countries. Available at [last accessed 3 December, 2010]:

http://www.who.int/indoorair/publications/energyaccesssituation/en/index.html. 


\title{
Utilization of Permanent Grassland for Biogas Production
}

\author{
Pavel Fuksa1, Josef Hakl11, Zuzana Hrevušová1, \\ Jaromír Šantrůček ${ }^{1}$, Ilona Gerndtová ${ }^{2}$ and Jan Habart ${ }^{3}$ \\ ${ }^{1}$ Department of Forage Crops and Grassland Management, \\ Czech University of Life Sciences, Prague \\ ${ }^{2}$ Research Institute of Agricultural Engineering \\ ${ }^{3}$ Department of Agro-Environmental Chemistry and Plant Nutrition, \\ Czech University of Life Sciences, Prague \\ Czech Republic
}

\section{Introduction}

Permanent grasslands represent undoubtedly an inseparable part of landscape, which has historically both agriculture and environmental importance. Considering restricting agriculture-food-processing production, especially in Central and Eastern European countries, the main aim of European policy is to support mainly environmental function of permanent grasslands. To fulfil non-productive function of permanent grasslands, there is the base of their utilization and harvest of biomass. Therefore, agriculture is also focused on non-food processing production where the first place is taken by energy production.

This chapter is dealing with utilization of permanent grasslands for energy production and their energetic balance. The main attention deals with a particular way of production of biogas, which is the most applied method as far as energy production of this vegetation in Europe is concerned. The production of biomass for energy, as well as traditional forage produce, cannot omit functions of permanent grasslands. Therefore, a part of the chapter is also focused on biological and environmental aspects of permanent grasslands. It is not possible to incorporate all related topics in their entirety because of limited scope of the chapter. The aim of this chapter is to give general knowledge with emphasis on reciprocal coherence of mentioned issues. Detailed information can be found in cited literature.

\section{Importance of permanent grassland}

Permanent grasslands are important parts of natural landscape, as well as, element of management of agricultural land not only in the Europe territory. Grassland covers approximately $3.410^{9}$ ha, i.e. $69 \%$ of the world's agricultural area or $26 \%$ of total land area. In Europe, grasslands also cover a considerable amount of landscape. Currently they represent almost $38 \%$ of agricultural land area. Area in the Czech Republic has been expanding over last few years. At present grasslands cover over $23 \%$ of agricultural land area (Food and Agriculture Organization Statistic [FAOSTAT], 2011). 
Permanent grassland is defined as a land used permanently (for five years or more) for herbaceous forage crops, either cultivated or growing wild (FAOSTAT, 2011). Under favourable conditions, the grass species prevail in grasslands. However varied ecological conditions allow expansion of large amount of different plant species, where legumes are, for many reasons, very important. The plant composition is the result of interaction of ecological factors of placement and the methods of cultivation. The mediation of succession, such composition of natural species is created on sites that in given ecological conditions and specific way of utilization thrives the best. Throughout the years this balance is also created on newly founded stands seeded with mix of grasses and legumes.

Depending on place of origin we can discern between two basic types of permanent grasslands:

- Natural grasslands - were created without human intervention. They are situated on steppe, marshland and peat bog locality, in areas above high altitude tree-lines. Production of biomass is negatively affected by less favourable conditions of locality. These grasslands are used mostly extensively.

- Semi-natural grasslands - are situated in areas originally planted with trees. Their existence is dependent on continuous human intervention and cultivation such as grazing or/and cutting. They often have a potential for large yields and they can be used intensively. Among this group we can also find grasslands created by seeding of mix cultural grasses and species of legumes.

Permanent grasslands belong to agricultural systems with very high environmental value. They are among the most biologically active and most productive vegetation types with fast cycle of growth and high capability of transferring chemical elements in biosphere. Their importance comes from two key aspects: productive and non-productive functions.

\section{Functions of permanent grassland}

Agriculture traditionally puts emphasis mainly on productive function of permanent grasslands. They are source of both livestock fodder and plant biomass used for alternative purposes. For productive purposes, however, only a part of permanent grassland can be used. In some regions, the requirements of grass fodder are lower than the amount that permanent grasslands are able to produce. Therefore, great deal of area can remain unused. Nevertheless the grasslands that are not used for production are also very valuable parts of landscape, as they hold broad scale of so-called non-productive functions.

\subsection{Productive functions}

Production of permanent grasslands is in a close relationship with amount and quality of produced biomass. Productive function of permanent grasslands is historically connected particularly with providing fodder for livestock. In this way, permanent grasslands significantly contribute to human diet by providing fodder for livestock and thus allowing production of human foodstuff (milk and meat). It is for this reason that the research of production potential of grasslands was for the major part focused on optimizing relationship between production of fodder, its quality and productivity of animals. 
The usage of biomass for animal nutrition is still dominant way of its utilization, but in the recent period the importance of this traditional relation has been reduced. The main reasons for this can be considered reducing the quantity ruminants, especially in the countries of Central and Eastern Europe. As a result of increasing milk and meat productivity of animals, in suitable regions there is an increase of amount of fodder being produced from arable land (legume-grass mixture, maize). Because of this and other reasons (for example political and financial support for renewable energy) there has been in last 10 - 15 years significant increase in usage of biomass produced from permanent grasslands for alternative purposes (Hohenstein \& Wright, 1994; Prochnow et al., 2009a, 2009b; Rösch et al., 2009).

According to Prochnow et al. (2009b), the grassland biomass is suitable in many ways for producing energy. Currently it is used in practice as a feedstock for biogas production and as solid biofuel for combustion. Future pathways can include the production of lignocellulosic bioethanol, synthetic biofuels or synthetic natural gas. Feedstock from grassland will also be used as raw material for the bio-industry within Green Biorefineries (Kromus et al., 2006, as cited in Prochnow et al., 2009b).

If suitable management of permanent grasslands regarding productive and nonproductive functions stays the same, the change in how the final product is being used will not have a negative impact on farming of permanent grasslands. Permanent grasslands also have an important function in relation with arable land. Ruminants transfer the biomass through digestion and partially use it for their need. The remaining $35-50 \%$ of organic matter is excreted in form of excrements. Organic matter in form of farm fertilizer is then used primarily on arable land and there it is important factor contributing to its fertility. When we utilize grass biomass for energy, however, loss of organic matter is higher. Biogas fermentation can degrade cellulose to an extent of about $80 \%$ (Ress et al., 1998). Usage of biomass for direct combustion leads to $100 \%$ loss of organic matter. Energy utilization of biomass can therefore lead to reduction in return of organic matter into soil, in comparison with traditional system, where fodder is utilized by ruminants.

With reduction of return of the organic matter into the soil, there can be disruption in organic balance of the agricultural system, which can lead to number of negative consequences (reduction in fertility of the soil, increase in leaching nutrients into the underground water, increased hazard of erosion etc.). It is necessary to reduce hazards to arable lands such as these by applying effective countermeasures, for example by increasing the share of legumes in crop rotation or by growing catch crops (Brant et al., 2011). The risk is not significant in permanent grasslands. The root system of the plants creates sufficient amount of organic matter inside the soil, so it is not necessary to fertilize them organically at a regular base.

\subsection{Non-productive functions}

Permanent and semi-natural grassland are very important not only as a source of fodder, but they also play a significant role in environment (Stypiński et al., 2009). These nonproductive functions of permanent grasslands interfere in different fields such as: 
- $\quad$ Protection and stabilization of biodiversity - plant and animal genetic resources.

- Protection against erosion of soil - against both wind and water erosion.

- Water management - high infiltration of rainfalls and flood waters, maintenance of water reserves in the soil.

- Function of biological filtration - they filter considerable amount of agents that are dangerous to health (nitrates, phosphates, biocides) and they prevent them from penetrating into deeper layers of the soil and subsequently into the underground water.

- Increasing soil fertility - they create large amount of dead organic matter and they enrich the soil with humus, improving the soil structure.

- Great supply of both above-ground and underground active living matter.

- Fixation of air nitrogen - both symbiotic and non-symbiotic.

- Balancing changes in temperature and humidity of surrounding air.

- Aesthetic and landscape functions.

- Health-hygienic function - production of oxygen, capturing of gas emission, reduction in dustiness and level of noise etc.

- Social economic function - particularly in marginal regions in connection with livestock breeding, they are used as source of living for people.

Permanent grasslands are able to fulfil these and other functions, provided that correct management is applied. Underutilized and neglected permanent grasslands are able to maintain these functions only in limited amount, or they can even contribute negatively in those areas, according many literal sources (Hopkins \& Holz, 2006; Rychnovská, 1993; Rychnovská \& Parente, 1997). Absence of regular utilization and grassland management cause degradation to fallow, and consequently, establishment of high number pioneer shrubs and trees. Planning of grassland management is necessary to conserve total diversity and retain its important functions in landscape (Moog et al., 2002).

Maintains of present status of grasslands and introduction of agro-environmental programs and agreements is one of the solution for sustainable development, it means the optimal and environmentally friendly utilization of nature resources like soil, water, plants and animals communities (Stypiński et al., 2009).

\section{Primary productions and energy balance of permanent grassland}

Productivity of permanent grassland is a determinative component influencing affectivity of use of biomass, whether it involves fodder for ruminants or biomass for energy use. From the point of view of possibility of affecting productivity of permanent grasslands, it is necessary to understand that we are talking about open systems with many structures and functions, which are affected by many known and even larger number of unknown feedbacks. The site conditions (such as soil composition, supply of water) and the system of management that is being used have a huge impact on botanical composition and with it connected yield of biomass (Rychnovská \& Parente, 1997).

Primary production of permanent grasslands is traditionally expressed in yield of dry matter $\left(t_{D M} h^{-1}\right)$. Variability in yield of permanent grassland is, considering different ecological conditions and different management, very broad and can vary in range of $1-15$ (in rare cases even more) $t \mathrm{ha}^{-1}$. 
As far as energy flows in ecosystem are concerned, it is more apposite to monitor the amount of produced energy from specific area of land. Expressing primary production of stands in energy units allows considering the suitability of applied management from the point of view of expressed energy inputs and outputs in the system. To calculate these balances the energy requirements of individual applied arrangements must be known and it is also necessary to determine the amount of energy contained in biomass.

\subsection{Calorific value}

The amount of energy in biomass is possible to determine on the basis of calorimetric measurement. The principle of calorimetric determination of the volume of gross weight is based on burning down a sample in oxygen atmosphere and recording resulting increase of temperature in calorimetric system. The gross calorific value of the substance that is being burned down is counted using the following formula (1):

$$
Q=\frac{C \cdot \Delta T-Q 1}{m}
$$

Q - Gross calorific value of the sample $\left(\mathrm{J} \mathrm{g}^{-1}\right)$

$\mathrm{C}$ - Heat capacity of the calorimeter system $\left(\mathrm{J} \mathrm{K}^{-1}\right)$

$\Delta \mathrm{T}$ - Increase in temperature of the calorimeter system during a combustion experiment $(\mathrm{K})$

$\mathrm{Q}_{1}$ - Extraneous energy from combustion of the cotton thread (J)

$\mathrm{m}$ - Mass of the sample (g)

It is possible to use acquired gross calorific value to determine other parameters, such as:

- Net calorific value (calorific value of combustible substance; the weight of sample reduced by weight of ashes after burning down).

- Heating value of biomass (the usage of biomass as a fuel for direct combustion).

- The number of energetic balances when growing plants etc.

The usage of calorimetric method for studying plants has been already presented by Long (1934). The content of energy in plant material is given by the chemical composition in the plants and it can differ for individual plant species (Yajing et al., 2007). In mixed association, such as permanent grasslands, the content of energy is dependent on composition of species, but it can be changed during the vegetation (Neitzke, 2002). It depends on proportion of individual parts of plants (Sims \& Singh, 1978), on ecological or climatic conditions (Long, 1934) and on other parameters.

As far as anthropogenic aspects are concerned, frequency of mowing and dosage of nutrients are considered to be the most important factors influencing the production of permanent grasslands. When appraising the significance of those as well as other ways of management on any of the indicators (the quality of the fodder, the content of energy in the fodder etc.), it is necessary to consider mainly experiments, where the chosen type of management is being applied on long-term basis. Permanent grasslands are dynamic associations, where stabilization occurs after long-term application of applied treatments. These experiments have higher testifying value then the short term ones. 
The data presented below are results of long-term meadow experiments, where the dominant species was meadow foxtail (Alopecurus pratensis), alliance Deschampsion cespitosae. The experimental locality is situated near village Černíkovice, Czech Republic $\left(49^{\circ} 46^{\prime} 26^{\prime \prime} \mathrm{N}\right.$, $14^{\circ} 34^{\prime} 52^{\prime \prime E}$ ), on alluvial meadow in $363 \mathrm{~m}$ a.s.l. Average annual rainfall is $664 \mathrm{~mm}$, average annual temperature of locality is $7.2{ }^{\circ} \mathrm{C}$. The soil type is Gleyic Fluvisol with level of underground water in range of $0.1-0.5 \mathrm{~m}$ under the surface.

The experiment with application of various doses of nutrients was started in 1966 and it is sorted by method of randomized blocks in four replications. The area of individual plots is $15 \mathrm{~m}^{2}(3 \times 5 \mathrm{~m})$. The stand is harvested in three subsequent cutting. There are six different treatments:

- $\mathrm{N}_{0} \mathrm{P}_{0} \mathrm{~K}_{0}-$ no fertilization

- $\mathrm{N}_{0} \mathrm{P}_{40} \mathrm{~K}_{100}$ - application of $40 \mathrm{~kg} \mathrm{P} \mathrm{ha}^{-1}+100 \mathrm{~kg} \mathrm{~K} \mathrm{ha}^{-1}$ year-1 $^{-1}$

- $\quad \mathrm{N}_{50} \mathrm{P}_{40} \mathrm{~K}_{100}$ - application of $50 \mathrm{~kg} \mathrm{~N} \mathrm{ha}^{-1}+\mathrm{PK}$

- $\mathrm{N}_{100} \mathrm{P}_{40} \mathrm{~K}_{100}$ - application of $100 \mathrm{~kg} \mathrm{~N} \mathrm{ha}-1+\mathrm{PK}$

- $\mathrm{N}_{150} \mathrm{P}_{40} \mathrm{~K}_{100}$ - application of $150 \mathrm{~kg} \mathrm{~N} \mathrm{ha}^{-1}+\mathrm{PK}$

- $\mathrm{N}_{200} \mathrm{P}_{40} \mathrm{~K}_{100}$ - application of $200 \mathrm{~kg} \mathrm{~N} \mathrm{ha}^{-1}+\mathrm{PK}$

There was another experiment with different frequency of mowing found in 2001 at the same locality. The harvests are realized in May and in October for the two cuts per year treatment and in October for the one cut per year treatment. The monitored plots are not fertilized.

The samples of biomass for determination the content of energy were taken during vegetation period in years 2007 - 2009. The calorific value in the dry biomass was measured by the automatic adiabatic calorimeter system IKA C 5000 control. The calorific value was calculated according to the Czech State Standard ČSN ISO 1928 (1999), without the dissolving temperature of sulphuric acid and nitric acid correction.

Differences in calorific value in above-ground biomass of the permanent grassland according to supply of nutrients and sequence of cutting are presented in Fig. 1 and Fig. 2. Calorific value in above-ground biomass was, in average of three cuts, significantly influenced by treatment of fertilizing $(P=0.0004)$, where the lowest value $\left(16891 \mathrm{~J} \mathrm{~g}^{-1}\right)$ was recorded with the variant which was not fertilized and the highest value $\left(18143 \mathrm{~J} \mathrm{~g}^{-1}\right)$ with the variants fertilized by nitrogen. There was no proof of any significant influence of increasing the dosage of nitrogen. The content of energy in biomass differed in individual cuts $(P=0.0053)$. The highest one was in the first cut $\left(18131 \mathrm{~J} \mathrm{~g}^{-1}\right)$ and the lowest was in the third cut $\left(17237 \mathrm{~J} \mathrm{~g}^{-1}\right)$.

Although the presented results document significant effect of fertilization and cutting sequence on energy content in biomass, it is necessary to emphasize that the differences between minimal and maximal values range up to $10 \%$. This fact can be also noticed from results of another experiment in which permanent grassland that is cut once a year is compared with a different treatment cut twice a year. Significantly highest content of energy $(P=0.0003)$ in years $2007-2008$ was recorded in biomass during spring harvest $\left(18620 \mathrm{~J} \mathrm{~g}^{-1}\right)$, and lowest (18006 $\mathrm{J} \mathrm{g}^{-1}$ ) during autumn harvest of the twice cut treatment. Content of energy in biomass from treatment, which was cut once a year in autumn (18203 J g-1), did not differ from autumn harvest from treatment which was cut twice a year. 


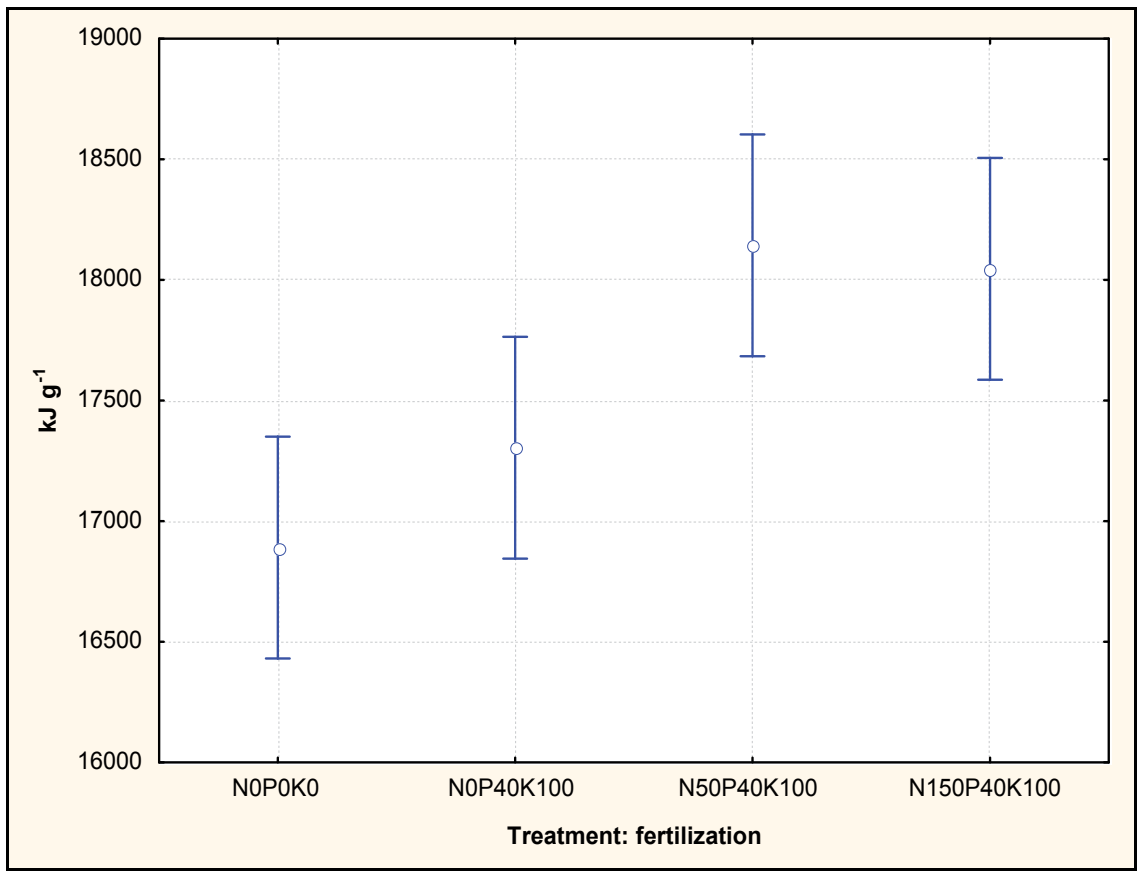

Fig. 1. The effect of fertilization on calorific value $\left(\mathrm{kJ} \mathrm{g}^{-1}\right)$ of above-ground biomass of permanent grassland, 2009, Černíkovice locality, Czech Republic

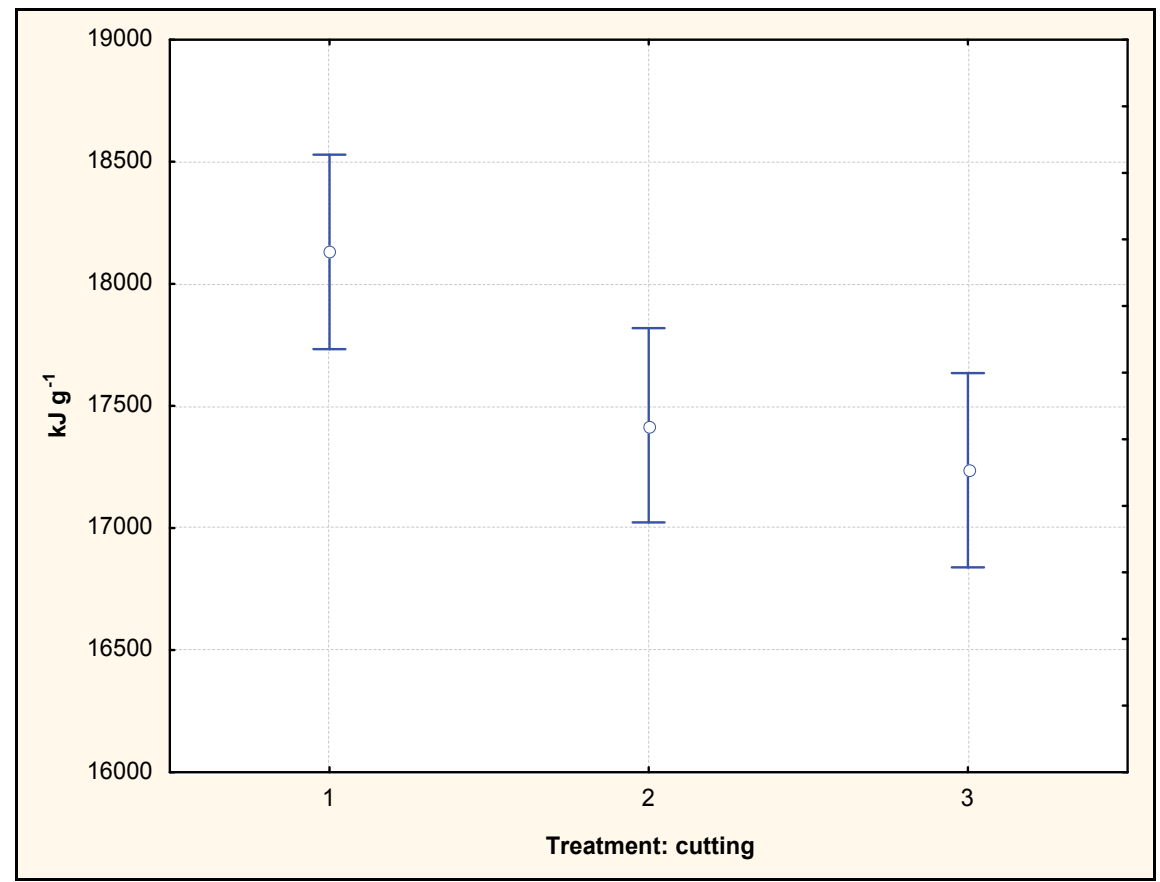

Fig. 2. The effect of cutting sequence on calorific value $\left(\mathrm{kJ} \mathrm{g}^{-1}\right)$ of above-ground biomass of permanent grassland, 2009, Černíkovice locality, Czech Republic 
A difference in energy value of plants with different supply of nutrients was already recorded by Long (1934). Neitzke (2002) detected an influence of an increase in the nutrient supply on the calorific values only in some types of grasslands. On the contrary, Úlehlová (1980) while studying content of energy of permanent grasslands with low production of biomass, did not record any differences when using fertilization. The differences among weed species (Elytrigia repens, Cirsium arvense, Chenopodium album, Amaranthus retroflexus, Echinochloa crus-galli) recorded Fuksa et al. (2006). The calorific value of dry matter ranged from $16800 \mathrm{~J} \mathrm{~g}^{-1}$ (A. retroflexus) to $18210 \mathrm{~J} \mathrm{~g}^{-1}$ (E. crus-galli).

It is possible to conclude, that the change in content of energy in harvested biomass can be caused by change in chemical composition of plants within the species as a reaction to fertilization, and also by change of species composition of the vegetation. If the fertilization in a specific experiment has a low impact on composition of species or on increase of biomass in context of plants' chemical composition, its impact will be also low as far as content of energy in plants is concerned. According to Fuksa et al. (2006) and Brant et al. (2011) it is necessary to replenish that calculation of energy produced from certain area of land is dependent primarily on yield of biomass, as content of energy in biomass has smaller variability then the yield. For precise calculation of energy balances, however, determining the content of energy in biomass is important.

\subsection{Factors affecting primary production of permanent grasslands}

Ability of yield of permanent grasslands is dependent on botanical composition, which is an outcome of interaction of stands' conditions, competitive relationships among plants and a way of stand management. Composition of stand is usually affected the most by water and nutritional regime of the locality. Other edaphic, climatic and orographic factors, similarly to biotic factors (interaction with plants, animals and microorganisms) have lower impact in relation to botanical composition.

The most important agrotechnical intervention that can be used to affect primary production of permanent grasslands is regular cutting or pasture. The absence of management usually leads to degradation of grassland. Another important and very effective factor is fertilization. Other interventions (for example changes in water regime) are applied only on small areas, or they are not very effective in affecting yield (harrowing, dragging, rolling, additional seeding etc.).

\subsubsection{The impact of cutting on primary production}

While cutting, large part of assimilation area of plants is removed. Number of cuttings, date of mowing and the height of growth that is being mowed affects not only yield and quality of harvested matter, but also the ability of plants to regenerate for further growth.

High frequency of cutting has rather negative impact on yield of biomass, especially during the first half of vegetation period. The plants that are cut regenerate from nutrients stored in their root system. In residue of leaves and stalks there is still photosynthesis going on, however, because of small assimilation area, the production of carbonaceous agents is quite low. As a result the plants grow initially very slowly. However, with larger assimilation area also increases speed of growth. The more often plants reach this period, the less biomass is 
produced during the year. The process of regeneration of growth can be significantly sped up by applying high dose of $\mathrm{N}$-fertilizer (Frame, 2000). On the other hand, short intervals between individual cuttings lead to increased quality of harvested biomass. Plants in early phase of growth have lower content of fiber and higher content of proteins and watersoluble carbohydrates. This is favourable from the point of using biomass as a fodder or while the process of biogas formation.

Table 1 presents results of experiment with varying frequency of mowing from experimental location Nicov, Czech Republic. This stand of permanent grassland is located in $880 \mathrm{~m}$ a.s.1. $\left(49^{\circ} 7^{\prime} 35.027^{\prime \prime} \mathrm{N}, 1^{\circ} 37^{\prime} 0.435^{\prime \prime} \mathrm{E}\right)$, on Loamy-sand type of soil. Long-term average of temperature is $6.0{ }^{\circ} \mathrm{C}$, and long term average of rainfalls is $819 \mathrm{~mm}$ per year. The experiment was arrangement in the block design in three replications. The area of one plot is $18 \mathrm{~m}^{2}(1.5 \times 12 \mathrm{~m})$. Factors being monitored are various doses of nitrogen $(40 \mathrm{~kg} \mathrm{~N} \mathrm{ha-1}, 80 \mathrm{~kg}$ $\mathrm{N} \mathrm{ha}^{-1}$ and variant without fertilization) and double frequency of mowing (two-cut and fourcut variant). The dose of $40 \mathrm{~kg} \mathrm{~N}^{-1}$ was applied on a one-time basis at the beginning of the vegetation period, dose of $80 \mathrm{~kg} \mathrm{~N}$ ha was divided into $40 \mathrm{~kg} \mathrm{~N} \mathrm{ha}^{-1}$ at the beginning of the vegetation period and $40 \mathrm{~kg} \mathrm{~N} \mathrm{ha}^{-1}$ after first mowing.

\begin{tabular}{llccccc}
\hline Number of cuts & $\begin{array}{c}\text { Fertilization } \\
\left(\mathbf{k g ~ h a}^{-1}\right)\end{array}$ & $\mathbf{1}^{\text {st }}$ cut & $\mathbf{2}^{\text {nd }}$ cut & $\begin{array}{c}\mathbf{3}^{\text {rd }} \text { cut } \\
\left(\mathbf{t} \mathbf{h a}^{-\mathbf{1}} \mathbf{)}\right.\end{array}$ & $\mathbf{4}^{\text {th }}$ cut & Total yield \\
\hline 2 cuts & $\mathrm{N}_{0} \mathrm{P}_{0} \mathrm{~K}_{0}$ & 3.92 & 1.97 & - & - & 5.89 \\
& $\mathrm{~N}_{40} \mathrm{P}_{0} \mathrm{~K}_{0}$ & 4.77 & 2.14 & - & - & 6.91 \\
& $\mathrm{~N}_{80} \mathrm{P}_{0} \mathrm{~K}_{0}$ & 5.41 & 2.76 & - & - & 8.17 \\
\hline 4 cuts & $\mathrm{N}_{0} \mathrm{P}_{0} \mathrm{~K}_{0}$ & 2.68 & 1.44 & 1.23 & 0.40 & 5.76 \\
& $\mathrm{~N}_{40} \mathrm{P}_{0} \mathrm{~K}_{0}$ & 2.84 & 1.48 & 1.26 & 0.34 & 5.92 \\
& $\mathrm{~N}_{80} \mathrm{P}_{0} \mathrm{~K}_{0}$ & 3.16 & 1.90 & 1.44 & 0.39 & 6.89 \\
\hline
\end{tabular}

Table 1. Effect of cutting and fertilization on biomass yields of permanent grassland $\left(t_{D M} h^{-1}\right)$, average of years 2007 - 2009, Nicov locality, Czech Republic

There was no significant yield difference between two-cut and four-cut utilization in the locality of Nicov. Increasing size of doses of nitrogen led to an increase in yield in both variants of mowing, and to higher yield when using same dose of nitrogen were recorded when using the two-cut variant. These results show that the most suitable regime for mowing should come out of conditions of locality, as well as of the anticipated level of fertilization (Table 1).

From the result's listed in the Table 2, we can clearly see that one-cut variant used in the locality of Černíkovice is not compatible with the length of growth at the stand, and this represents significant loss in yield, or more precisely in energy, when compared to the twocut variant.

Frequency of mowing also affects yield of biomass in indirect way, through changes in botanical composition of the growth. In general, frequent mowing reduces presence of highgrowing species and supports increase in share of low-growing and shade-intolerant species, including leguminous species. Positive impact of leguminous species comes from their ability to assimilate aerial nitrogen with the help of rhizobia (Soussana \& Tallec, 2010). 
Changes in botanical composition have been described by number of authors. For example Kramerger \& Gselman (1997) found that when using higher doses of N (180 kg ha-1) + PK, we can find in grasslands that are mowed often (6 times a year) more species, then in grasslands that are mowed only 2-3 times a year. Authors contribute this to competition over light between the plants. On the opposite, Zechmeister et al. (2003) describes negative correlation between richness of species variation and intensity of mowing. The highest amount of cuts that were included in the study, however, was 4 times a year. Level of fertilization was also lower.

\begin{tabular}{llccccc}
\hline $\begin{array}{c}\text { Number } \\
\text { of cuts }\end{array}$ & $\begin{array}{c}\text { Fertilization } \\
\left(\mathbf{k g ~ h a}^{-1}\right)\end{array}$ & $\begin{array}{c}\text { Yield } \\
(\mathbf{t ~ h a - 1})\end{array}$ & $\begin{array}{c}\text { Energy } \\
\text { outputs } \\
\left(\mathbf{G J ~ h a}^{-1}\right)\end{array}$ & $\begin{array}{c}\text { Energy } \\
\text { inputs } \\
\left(\mathbf{G J ~ h a}^{-1}\right)\end{array}$ & $\begin{array}{c}\text { Energy } \\
\text { gain } \\
\left(\mathbf{G J ~ h a}^{-1}\right)\end{array}$ & $\begin{array}{c}\text { Energy } \\
\text { effectiveness } \\
\left(\mathbf{G J ~ G J}^{-1}\right)\end{array}$ \\
\hline 1 cut & $\mathrm{N}_{0} \mathrm{P}_{0} \mathrm{~K}_{0}$ & 4.80 & 87.38 & 1.58 & 85.77 & 55.19 \\
2 cuts & $\mathrm{N}_{0} \mathrm{P}_{0} \mathrm{~K}_{0}$ & 7.91 & 145.39 & 2.81 & 142.58 & 51.66 \\
\hline 3 cuts & $\mathrm{N}_{0} \mathrm{P}_{0} \mathrm{~K}_{0}$ & 6.08 & 102.97 & 3.11 & 99.86 & 33.13 \\
& $\mathrm{~N}_{0} \mathrm{P}_{40} \mathrm{~K}_{100}$ & 6.53 & 115.40 & 6.55 & 108.84 & 17.61 \\
& $\mathrm{~N}_{50} \mathrm{P}_{40} \mathrm{~K}_{100}$ & 8.56 & 154.51 & 11.34 & 143.17 & 13.63 \\
& $\mathrm{~N}_{150} \mathrm{P}_{40} \mathrm{~K}_{100}$ & 10.83 & 199.24 & 20.21 & 179.03 & 9.86 \\
\hline
\end{tabular}

Table 2. Effect of cutting (average of years 2007 - 2008, data in the upper part of the table) and effect of fertilization (2009, data in the lower part of the table) on biomass yield ( $t_{\mathrm{DM}}$ ha- $\left.^{-1}\right)$ and energy balance of permanent grassland, Černíkovice locality, Czech Republic

The optimal date for first mowing is from the beginning to full earing of the predominant grasses in the sward. Earlier mowing means increase of the quality and lower yield of fodder, later mowing results in the opposite (Frame, 2000). When we utilize early mowing, we support growth mainly of lower-growth species that are little affected by defoliation. When we utilize late mowing, there is decrease in quality of overgrown sod, which is felt the most in dry areas.

Height of mowing determines how much of assimilation area and reserve material is kept. Optimal height for mowing permanent grassland's is $30-40 \mathrm{~mm}$. Lower height of mowing is more tolerable to creeping species (for example Poa pratensis, Festuca rubra, Agrostis gigantea, Alopecurus pratensis) than bunch type of grasses (Dactylis glomerata, Phleum pratense, Festuca pratensis, Lolium perenne, Arrhenatherum elatius etc.).

\subsubsection{Effect of fertilization on primary production}

Nutrients removed by harvest of permanent grasslands can be compensated for one part from soil's resources, for another part from the atmosphere (most importantly N) and also from application of fertilizers. The question of fertilizing permanent grasslands represents complex problem, which is composed of diversity and colorfulness of composition of swards in relationship to water and nutritional regime, the way sward is utilized, weather conditions, type of fertilizers, date and method of applying fertilizers etc.

Fertilizing supports development of species which have higher ability to use nutrients for creating a large amount of biomass and gain competitive advantage in this way. As a consequence plants of lower growth that reside in shade are eliminated from growth 
(Lepš, 1999). Those are usually less valuable components of grasslands. Fertilization also supports creating of new tillers and larger foliage and in general it creates more robust habitus of plants.

The effect of fertilization is usually bigger on swards that are less productive, but are composed of species which react well to fertilization. If favourable humidity conditions are present, it is possible with help of fertilization by mineral fertilizers to increase the yield by 100 to $200 \%$ as show for example Honsová et al. (2007).

Hopkins (2000) points out that at some localities, even if grasslands are based on very productive species (for example Lolium perenne and Trifolium repens), it is necessary to apply high doses of nutrients for maintaining of high yield, while original swards usually have much lower demands in this area.

Source of production stability is high diversity of species in swards, whose auto-regulative mechanisms allow alternating dominance of group of species which are best adapted to climatic conditions of the particular year.

Nitrogen is considered to be the most important nutrient for increasing yield, but its overall effect has to be considered in more broad perspective. The response of sward to nitrogen fertilization was researched in many experiments all over the Europe. Most of grasslands were mowed at the same time, doses of $\mathrm{N}$ were ranging from zero to the extreme of 600 $\mathrm{kg} \mathrm{ha}^{-1}$.The specific reaction of the sward is also dependent on other factors - the availability of water, weather of season, type of sward (content of leguminous species, density of grass shoots, the size of root system etc.), soil's characteristics, and frequency of defoliation (Hopkins, 2000).

The increase of biomass when applying $\mathrm{N}$ is usually linear $(15-25 \mathrm{~kg}$ of dry matter for $1 \mathrm{~kg}$ of $\mathrm{N}$ ) up to doses of $250-350 \mathrm{~kg} \mathrm{ha}^{-1}$. When applying higher doses of $\mathrm{N}$ (350 - $\left.450 \mathrm{~kg} \mathrm{ha}^{-1}\right)$ the increase of yield drops down to $5-15 \mathrm{~kg}$ for $1 \mathrm{~kg}$ of applied $\mathrm{N}$. Increase in yield stops at doses of $450-600 \mathrm{~kg} \mathrm{ha}^{-1}$. When using mixture of grass and white clover, the yield increases in linear fashion up to $250-300 \mathrm{~kg} \mathrm{ha}^{-1}$. The increases of biomass yield are lower, as clover gradually declines, until it disappears altogether and the grassland is then composed only of grass component (Frame, 2000; Whitehead, 1995).

Excessive input of nitrogen leads to undesired changes in vertical structure of growth, to mutual casting of shadow on leaves, to turning yellow of lower levels of sward and to reduction in photosynthesis. Natural fixation of nitrogen is stopped, unused nitrogen is leached into underground water and increased content of free nitrates in the plants appears.

Annual individual nitrogen fertilization usually leads to initial increase in mass, but after several years the production decreases again as a result of exhaustion of other nutrients (Van Der Woude et al., 1994). At some localities the application of nitrogen does not have to produce any effect, because the growth of grassland is limited by different source (Malhi et al., 2010) - usually by phosphorus or potassium. Niinemets \& Kull (2005) recorded significant increase in yield of grasslands on calcite soil even when phosphorus was applied solely. When phosphorus and calcium were applied in combination, the increase in yield was higher than when it was applied individually. 
Impact of phosphorus on yield is, due to its low mobility, visible only after several years have passed. Its usage is increased when there is sufficient humidity and low reserve of available potassium in soil and it is dependent on botanical composition of the growth. Production effectiveness of P-fertilization is in average about $5.3 \mathrm{~kg}$ of dry matter to $1 \mathrm{~kg}$ of added $\mathrm{P}$. With simultaneous application of $\mathrm{K}$ the production effectiveness increases to 22.5 $\mathrm{kg}$ of dry matter to $1 \mathrm{~kg}$ of added P (Klapp, 1956). The yield variability is usually higher then in sward that are not being fertilized, as a result of variations in cover by leguminous species. On soil with low content of $\mathrm{P}$ its influence can be supported by simultaneous $\mathrm{N}$ fertilization (Frame, 2000).

Potassium is more mobile in soil then phosphorus and plants accept it easily. Its production effectiveness is lower then effectiveness of phosphorus. Klapp (1956) lists relative increase of yield by $12.5 \%$, and it increases throughout the years, as K-fertilization is continuously applied. The biggest effect is achieved on impoverished peat and peaty soils. To achieve good effect, it is important that sufficient humidity is present. Lack of $\mathrm{K}$ can be felt during dry years and particularly on stands with very low reserve of $\mathrm{K}$ in soil. In general, with insufficient potassium nutrition there is a reduction of photosynthesis, growth is slowed down, and there is a decrease in yield and quality of fodder, regardless of any potential Nfertilizing. There is a constraint in root system and together with decrease in effectiveness of regulating transpiration of leaves, the plant are more susceptible to dry weather (Frame, 2000).

The inaccessibility of phosphorus in soil for plants is often caused by too low level of $\mathrm{pH}$. This can be improved by appropriate liming. Applying of calcium independently has only small effect on yield of biomass. It can cause only transitory mobilization of nutrients in soil, which leads to short-term increase in biomass yield. After exhausting all available nutrients, yield is reduced yet again. The increase in yield after liming varies within broad limits and is strongly dependent on placement and specific conditions (Klapp, 1956).

The effect of fertilization on above-ground biomass in permanent grassland is well visible in Fig. 3, which records long-term yields of four variants of fertilization used in experiment in Černíkovice. Yields were significantly affected by climatic conditions of the particular year. Lowest yields were always recorded in $\mathrm{N}_{0} \mathrm{P}_{0} \mathrm{~K}_{0}$ variant, which was not fertilized. Yields from areas fertilized by PK started to show differences, from unfertilized areas, after approximately 25 years of periodical fertilization. Higher yields were recorded particularly in years that were favourable to growth of leguminous species. NPK-fertilizing, in most cases, significantly increased the yield. When $200 \mathrm{~kg} \mathrm{~N}^{-1}$ was applied, higher effect was recorded, in contrast with dose of $100 \mathrm{~kg} \mathrm{~N} \mathrm{ha}^{-1}$.

In table 3 yields of biomass and production of energy of permanent grassland are shown which were evaluated from the same experiment in time period of 2007 - 2009. Total yield was significantly increasing as a result of applying nutrients: from $6.08 \mathrm{t} \mathrm{ha}^{-1}$ for nonfertilized variant to $9.67 \mathrm{t} \mathrm{ha}^{-1}$ for the variant $\mathrm{N}_{150} \mathrm{P}_{40} \mathrm{~K}_{100}$. Significant effect of fertilization was recorded during monitored time period particularly during first mowing. It was not recorded in the course of following mows. This aspect can contribute to application of dose of nitrogen which happened before first mowing, which is also visible in share of first mowing on the total yield (44-57\%) rising proportionately to the dosage of fertilizer being applied. 


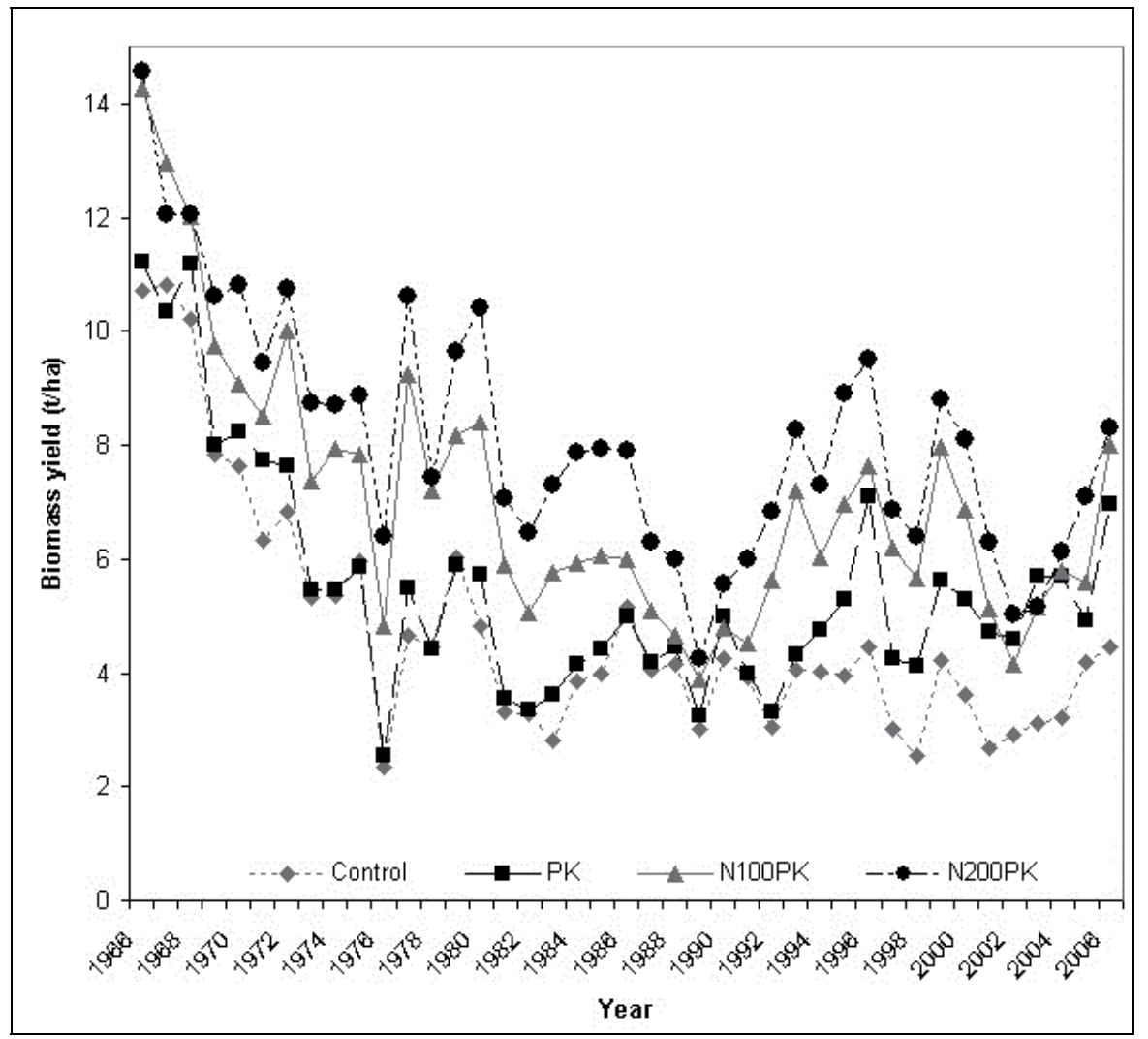

Fig. 3. Development of biomass yields $\left(t_{\mathrm{DM}}\right.$ ha $\left.^{-1}\right)$ of permanent grassland in $1967-2006$, Černíkovice locality, Czech Republic (Honsová et al., 2007)

\begin{tabular}{lcccc}
\hline $\begin{array}{c}\text { Fertilization } \\
\left.\mathbf{( k g ~ h a - 1}^{-1}\right)\end{array}$ & $\mathbf{1}^{\text {st }}$ cut & $\mathbf{2}^{\text {nd }}$ cut & $\begin{array}{c}3^{\text {rd }} \text { cut } \\
\mathbf{t ~ h a}^{-1} \mathbf{~}\end{array}$ & Total yield \\
\hline $\mathrm{N}_{0} \mathrm{P}_{0} \mathrm{~K}_{0}$ & 2.66 & 2.54 & 0.88 & 6.08 \\
$\mathrm{~N}_{0} \mathrm{P}_{40} \mathrm{~K}_{100}$ & 3.52 & 3.00 & 0.95 & 7.46 \\
$\mathrm{~N}_{50} \mathrm{P}_{40} \mathrm{~K}_{100}$ & 4.64 & 3.00 & 0.97 & 8.62 \\
$\mathrm{~N}_{150} \mathrm{P}_{40} \mathrm{~K}_{100}$ & 5.46 & 3.13 & 0.95 & 9.54 \\
\hline
\end{tabular}

Table 3. Effect of fertilization on biomass yields of permanent grassland $\left(t_{\mathrm{DM}} \mathrm{ha}^{-1}\right)$, average of years 2007 - 2009, Černíkovice locality, Czech Republic

It is particularly important how high the yield was in relationship to the total production of energy that was determined for year 2009, which means that the calculated values were increasing proportionately to the increase in level of fertilization (Table 2). Highest values for the average of all variants of fertilization were recorded during first mow (67 GJ ha-1) and the lowest during third one (16 GJ ha-1). Total production of energy reached on these grasslands in Černíkovice (102.97 - 199.24 GJ ha-1) is comparable to total production of plants grown on arable soil. For example Fuksa et al. (2006) presented data on total energy production of silage maize in range from 107.27 to $231.04 \mathrm{GJ} \mathrm{ha}^{-1}$, depending on particular 
year and the way growth was treated to improve its protection against weed. Rösch et al. (2009) set the production of energy from $66 \mathrm{GJ} \mathrm{ha}^{-1}$ (low-input grassland) to $119 \mathrm{GJ} \mathrm{ha}^{-1}$ (high-input grassland).

From the perspective of total energy balances (chapter 4.3) it is not only the total production of energy that is significant, but it is also important to consider necessary energy inputs, which are particularly high for nitrogenous fertilizers.

\subsubsection{The effect of fertilization on composition of species}

One of main factors affecting composition of species in grassland is the availability of nutrients, which is possible to significantly alter by usage of fertilizers (Hejcman et al., 2007). The most significant effect of fertilization is a direct influence on individual species, which will result in change of reciprocal abilities to compete. At the same time, indirect effect of nutrients will start, for example there will be increase in density of the sward, which leads to less light being able to penetrate into lower levels, which can provoke even more pressure to compete.

The number of species of plants has very close relationship to production of above-ground biomass (for example Hejcman et al., 2007; Oomes, 1992). On more impoverished localities, a number of low-growing species coexists. When the placement is gradually enriched by nutrients, the production of the above-ground biomass increases. At the same time, plants that are more demanding and higher are also able to spread and competition over light in the sward increases. Lower-growth species of plants disappear from grassland and only few species most capable in competition remain (Guo \& Berry, 1998).

$\mathbf{N}$-fertilization has the most profound effect in the starting period (3 - 6 years). It increases the cover of grasses (directly in proportion to the doses of $\mathrm{N}$ ), mainly higher bunch and rhizomatic species. On oligothropic soils, the low grasses are replaced by medium-grown ones. At the same time, there is a significant decrease of cover of legumes - critical level of $\mathrm{N}$ doses, which can still maintain 10 - $15 \%$ of legumes in meadows, is according to ecological conditions $50-60 \mathrm{~kg} \mathrm{ha}^{-1}$. There is also a significant reduction in cover of other dicotyledonous species, particularly the lower ones (Mrkvička et al., 2006; Whitehead, 1995).

The following period is prominent for increase in cover of rhizomatic grasses, which gradually become the main part of the sward. The speed of their spread and size of the share of the sward they have is in direct proportion to dosages of $\mathrm{N}$ being applied (Honsová et al., 2007). Rhizomatic grasses have higher capacity of reserve organs, bigger leaf area left after mowing and higher ability of vegetative reproduction. Even though they are of lower growth, they are better adapted to applications of high doses of available $\mathrm{N}$ than bunch grasses are.

$\mathrm{N}$ fertilization not only significantly affects botanical composition, but its effect is also long-term. Systematic fertilization using higher doses of N (above $100 \mathrm{~kg} \mathrm{ha}^{-1}$ ) gradually creates more simple, largely grass stands, and their grow shows higher dependence on meteorological conditions. This effect does not have to affect all localities, however, in some cases it is conditioned by adding PK-fertilization at the same time (Schellberg et al., 1999). 
Negative effect of $\mathrm{N}$-fertilization is a reduction of number of species in the sward. When the doses of nitrogen are increased, the number of species is reduced by $50-60 \%$ (Willems et al., 1993; Zechmeister et al., 2003). N does not have to be the single factor affecting number of species, however. Permanent grasslands that are rich in species and are limited by $\mathrm{N}$ have about $30-40$ species on area of $1 \mathrm{~m}^{2}$, swards limited by $\mathrm{N}$ and $\mathrm{P}$ can be even more rich in species. For example Niinemets \& Kull (2005) recorded $70-90$ species in area of $1 \mathrm{~m}^{2}$. Hejcman et al. (2007) found that many undemanding species that can spread in sward are fertilized solely by N, but when the PK-fertilization is added, they quickly start to decline.

Fertilization by phosphorus and potassium has usually smaller effect on botanical composition of the sward, but it still has mostly positive effect. Its significance is higher on soils with lower content of available $\mathrm{P}$ and $\mathrm{K}$. When PK-fertilizers are systematically applied, there is an increase in a share of legumes from average of $15 \%$ for unfertilized swards up to $20-25 \%$ (Klapp, 1956). At the same there is a decline in other dicotyledonous species (Mengel \& Steffens, 1985). PK-fertilization also slightly increases a share of lowergrowth and medium-growth grasses.

At some localities, $\mathrm{P}$ subsidiaries can negatively affect the number of species. Wassen et al. (2005) describes a case where limitation of $\mathrm{N}$ was more important then limitation of $\mathrm{P}$. Enrichment of soil by phosphorus can lead to decline in species adapted to its low accessibility. Some of the more rare species can be suppressed that way and are often replaced by the more common species.

Over fertilization by potassium leads significantly to negative effects. When extreme doses are applied and inappropriate ratio of $\mathrm{N}: \mathrm{P}: \mathrm{K}$ is used, it leads not only to decline of legumes, but later even grasses are forced out and ruderal weeds spread, such as Rumex obtusifolius etc. Shortage of $\mathrm{K}$, on the other hand, reduces the ability of plants to survive winter. Trifolium repens is particularly sensitive to its shortage and it can result in a complete disappearance from the growth (Frame, 2000).

Positive effect of $\mathrm{P}$ and $\mathrm{K}$ on the spread of legumes can be supported by suitable application of Ca. Ca itself has generally small effect on botanical composition of the growth. However when the $\mathrm{pH}$ is modified on acid soils, there can be suppression of some of the more sensitive species.

Conclusive effect of variants of fertilizing on botanical composition is shown on long-term fertilized grassland in Černíkovice. In the total evaluation of years 2007 - 2009 the variants of fertilization explained 21. $6 \%$ of data variability. Ordination diagram (Fig. 4) shows the spread of intensity of fertilization along 1 . axis (15.8 \% of variation). The difference between unfertilized variant and PK variants and the variants that used $\mathrm{N}$-fertilization is noticeable. Along the second axis there is a gradual increase in doses of applied N, which caused differences between botanical composition of $\mathrm{N}_{50} \mathrm{P}_{40} \mathrm{~K}_{100}$ and $\mathrm{N}_{100} \mathrm{P}_{40} \mathrm{~K}_{100}$ variants and the variants $\mathrm{N}_{150} \mathrm{P}_{40} \mathrm{~K}_{100}$ and $\mathrm{N}_{200} \mathrm{P}_{40} \mathrm{~K}_{100}$. Species that prospered on unfertilized and PK treatments were from monocotyledonous species, for example Luzula campestris, Agrostis capillaris and Anthoxanthum odoratum, furthermore all legumes (particularly Lathyrus pratensis), and number of other dicotyledonous species, for example Alchemilla sp. and genus Ranunculus. For variants $\mathrm{N}_{50} \mathrm{P}_{40} \mathrm{~K}_{100}$ and $\mathrm{N}_{100} \mathrm{P}_{40} \mathrm{~K}_{100}$, Holcus lanatus a Deschampsia cespitosa were dominant. For variants $\mathrm{N}_{150} \mathrm{P}_{40} \mathrm{~K}_{100}$ and $\mathrm{N}_{200} \mathrm{P}_{40} \mathrm{~K}_{100}$, high grass Alopecurus pratensis was dominant in the first place, and furthermore also Urtica dioica and Elytrigia repens. Analysis 
of redundance (RDA) has also shown conclusive effect of year on botanical composition, which has explained $3.2 \%$ of data variability.

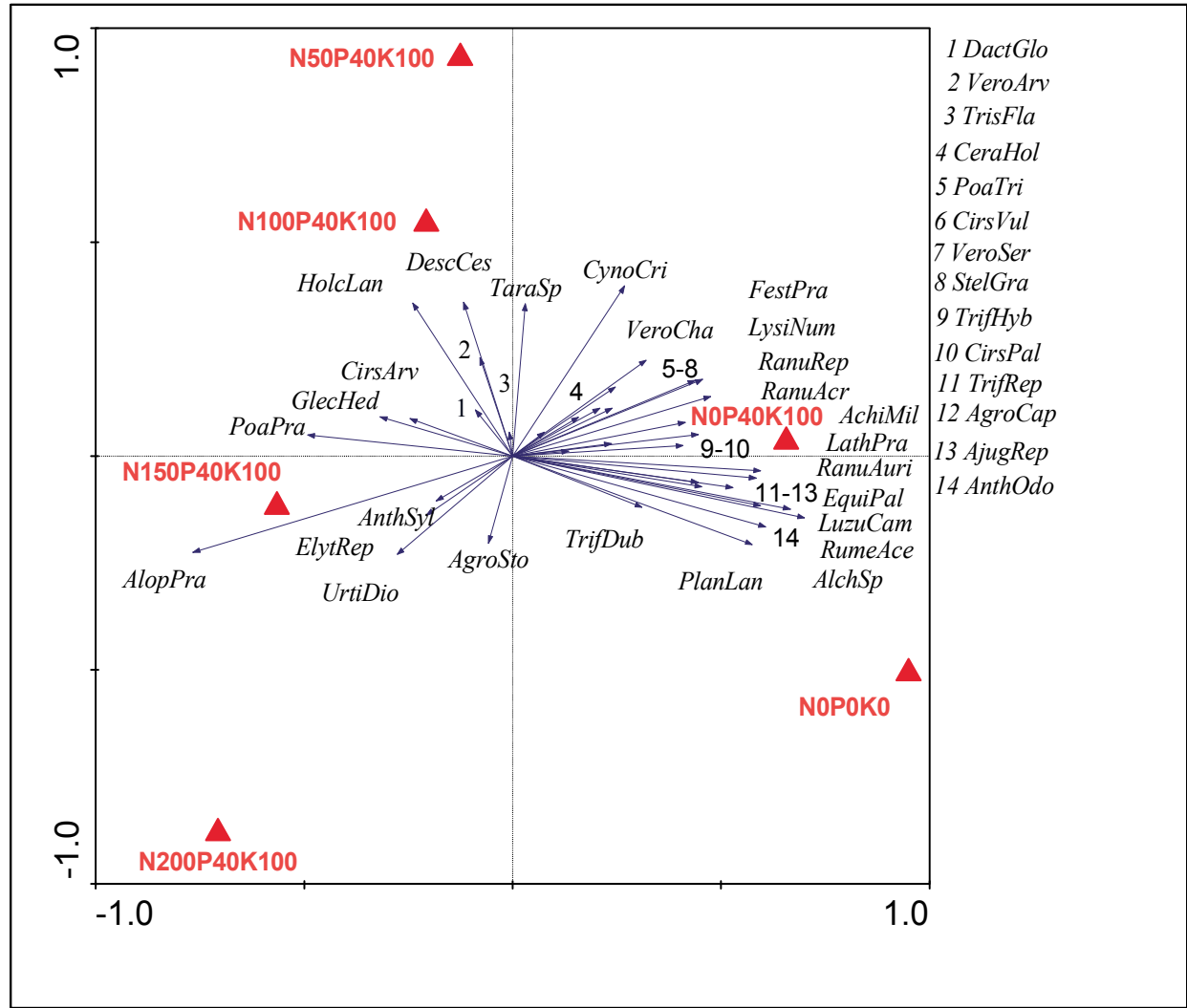

Note: Agrostis capillaris - AgroCap, Agrostis stolonifera - AgroSto, Achillea millefolium - AchiMil, Ajuga reptans - AjugRep, Alchemilla sp. - AlchSp, Alopecurus pratensis - AlopPra, Anthoxanthum odoratum AnthOdo, Anthriscus sylvestris - AnthSyl, Cerastium holosteoides - CeraHol, Cirsium arvense - CirsArv, Cirsium palustre - CirsPal, Cirsium vulgare - CirsVul, Cynosurus cristatus - CynoCri, Dactylis glomerata DactGlo, Deschampsia caespitosa - DescCes, Elytrigia repens - ElytRep, Equisetum palustre - EquiPal, Festuca pratensis - FestPra, Glechoma hederacea - GlecHed, Holcus lanatus -HolcLan, Lathyrus pratensis - LathPra, Luzula campestris - LuzuCam, Lysimachia nummularia - LysiNum, Plantago lanceolata - PlanLan, Poa pratensis - PoaPra, Poa trivialis - PoaTri, Ranunculus acris - RanuAcr, Ranunculus auricomus - RanuAuri, Ranunculus repen - RanuRep, Rumex acetosa - RumeAce, Stellaria graminea - StelGra, Taraxacum sect.

Ruderalia - TaraSp, Trifolium dubium - TrifDub, Trifolium hybridum - TrifHyb, Trifolium repens - TrifRep, Trisetum flavescens - TrisFla, Urtica dioica - UrtiDio, Veronica arvensis - VeroArv, Veronica chamaedrys VeroCha, Veronica serpyllifolia - VeroSer

Fig. 4. RDA analysis of relationship between species composition of permanent grassland and variants of long term fertilization, average of years 2007 - 2009, Černíkovice locality, Czech Republic

Suitable management of permanent grasslands can lead to increase in diversity, although this usually has negative impact on production. Biodiversity has value not only from the point of ethical and esthetical view, but it also is important for preserving species and their genotypes, as the diversity of ecosystem leads to its stability (Nösberger \& Kessler, 1997). 


\subsection{Energy balance of permanent grassland}

Energy balance of permanent grassland comes from comparison of inputs and outputs of energy. Energy outputs are divided into energy of plant production, residue of plants and irreversible energetic losses. For permanent grassland, the largest share is composed of above-ground biomass (industrially or alternatively usable biomass), as mentioned in chapter 4.2.

Input energy consists of energy of outer environment (sunlight, energy in soil, atmosphere and infrastructures of surround environment) and energy of technological inputs, which consist of direct part (energy of human work, fossil energy, other energy sources - draught animal etc.), and indirect part (energy of mechanisms, products of chemical industry, organic fertilizers, seeds etc.) (Hülsbergen et al., 2001). Additional energy can increase volume of sunlight energy that is captured in biomass (Jones, 1989).

Table 2 shows calculated energy inputs of permanent grassland with different levels of fertilization and frequency of mowing being applied, at the experimental location of Černikovice. Energy of human work, technological interventions (application of fertilizers, mowing and hay-making) and applied fertilizers were included in energy inputs. The largest share of inputs for the fertilized permanent grasslands is formed from energy in form of nitrogenous fertilizers. For grassland that is mowed three times a year, there was more then six times larger difference in the total value of energy inputs between unfertilized variant and the highest level of fertilization variant $\left(\mathrm{N}_{150} \mathrm{P}_{40} \mathrm{~K}_{100}\right)$. On the contrary, very low values were found for unfertilized grasslands that were harvested once or twice a year.

As is above-mentioned, total production of energy is dependent mainly on levels of yield reached, because the content of energy in biomass of permanent grassland has low variability. Assessment of energy balance further allows to evaluate total effectiveness of production of energy, when considering the same energy inputs into system. We calculated values of energy gain (difference between energy production and inputs of energy) and energy effectiveness (how much energy is produced from one unit of energy input) from the results of evaluation of experiments with different ways of managing grasslands in locality of Černíkovice.

From the evaluated energy balances follows that with the increase in level of fertilization, there is a significant increase of energetic gain (Table 2). For the $\mathrm{N}_{150} \mathrm{P}_{40} \mathrm{~K}_{100}$ variant the energy gain was higher by $79.17 \mathrm{GJ}^{-1}$ when compared to unfertilized variant. This difference was gained by increasing inputs from 3.11 to $20.21 \mathrm{GJ}^{-1}$, which means by 17.10 GJ ha-1.

In comparison to energy gain, highest values of energy effectiveness were reached in grassland with minimal inputs (no fertilization, low frequency of mowing). With the intensification of management (particularly fertilization), this value decreases. Energy effectiveness of crops grown on arable soil is according to findings of Hülsbergen et al. (2001) for example for potatoes 4.3, winter wheat 14.4, winter barley 9.4, spring barley 9.9 and sugar beets $11.1 \mathrm{GJ} \mathrm{GJ}^{-1}$. With the increase of additional energy inputs the energy effectiveness in permanent grasslands decreases, however it still reaches higher values in comparison with crops grown on arable soil. 
On the basis of the present results it can be concluded, that for swards with suitable botanical composition while the energy in form of fertilizers is added, it leads to adequate yield reaction and the value of energy gain reached is comparable with intensive crops on arable soil. In contrast to regular crops on arable soil, permanent grasslands reach noticeably higher levels of energy effectiveness as a result of very low energy inputs into system.

\section{Biogas production from permanent grassland}

The aim of supplying crop feedstock for biogas production is to achieve the highest possible biogas yields per area unit $\left(\mathrm{m}^{3} \mathrm{ha}^{-1}\right)$. The area biogas yield consists of the substrate biogas yield $\left(1 \mathrm{~kg}^{-1} \mathrm{ODM} ; \mathrm{ODM}\right.$ - organic dry matter) and the biomass yield $\left(\mathrm{kgODM} \mathrm{ha}^{-1}\right)$. The substrate biogas yield depends on biomass quality on one hand and on biogas technology and process of engineering on the other hand (Prochnow et al., 2009b). It is possible to affect effectiveness of production of biogas by using suitable combination of biomass yields and its quality from the standpoint of biogas production. The most significant controllable factors, which determine the potential of yield of permanent grasslands, have been already described in the previous parts of the chapter. Quantity of biomass is, however, closely connected with its quality. The factors, which affect grasslands production, therefore have an impact on its quality as well.

\subsection{Quality of biomass used for biogas production}

In general, all types of biomass (liquid manure, energy plants, bio waste, sewage sludge) can be used as substrates, as long as they contain carbohydrates, proteins, fats, cellulose, and hemicellulose as main components (Deublein \& Steinhauser, 2008). According to Amon et al. (2007), the methane production from organic substrates mainly depends on the content of nutrients (crude protein, crude fat, crude fiber, $\mathrm{N}$-free extracts), which can be degraded to $\mathrm{CH}_{4}$ and $\mathrm{CO}_{2}$. The biogas represents mainly the mixture of $\mathrm{CH}_{4}$ and $\mathrm{CO}_{2}$ with minority ratio of other gases $\left(\mathrm{N}_{2}, \mathrm{O}_{2}\right.$, etc.). Ratio of $\mathrm{CH}_{4}$ in biogas usually varied from 60 to $65 \%$ (Straka et al. 2006).

The organic matter is, the only source of utilizable energy, which was stored in it by the energy of sunlight while the plants were growing. This organic matter allows storing the energy up to the time when it is released again, in the process of its degradation while influencing of microorganisms in rumen or biogas plant.

Requirements on the biomass quality are different when crops are anaerobically digested in biogas plants compared to being fed to cattle. The digester at the biogas plant offers more time to degrade the organic substance than the rumen does. In addition, it is likely to assume that the microorganism population in the digester is different from that in the rumen (Amon et al., 2007). As with fodder for animals, chemical analysis of biomass can be considered as basic evaluation of quality, which assesses the content of individual nutrients. There is a difference in the specific methane yield of crude fat $\left(8501 \mathrm{~kg}^{-1} \mathrm{ODM}\right)$, crude protein $\left(4901 \mathrm{~kg}^{-1} \mathrm{ODM}\right)$, and carbohydrates (crude fiber and $\mathrm{N}$-free extracts: $3951 \mathrm{~kg}^{-1} \mathrm{ODM}$ ) (Karpenstein-Machan, 2005, as cited in Amon et al., 2007). The assessed content of nutrients gives no picture of how well they are degradable, which is dependent also on technological aspects of biogas transformation itself. For this reason, the chemical analyses of total content and mutual ratios of individual nutrients represent in the 
first place starting potential for following degradation. Real yield of biogas from plant biomass is then affected mainly by technological parameters of the process of degradation, from the size of input particles, parallel fermentation of various substrates, to compliance with suitable conditions for all levels of micro-bacterial degradation.

In the following sub-chapters 5.2 there are results of experiments with various types of management of permanent grasslands and the impact on yields of substrate and total production of biogas described.

\subsection{Substrate biogas yield}

Assessment of yield of biogas from biomass represents basic qualitative characteristic in this process of energy production. As mentioned before, the basic thing is content of individual nutrients. This fact leads to logical effort to theoretically calculate production of biogas from its content. Amon et al. (2007) described the methane energy value model, which estimates methane yield from the nutrient composition of energy crops in mono fermentation via regression models. This model investigates and considers the impact of the content of crude protein, crude fat, crude fiber and $\mathrm{N}$-free extracts on the methane formation. It is necessary to put a reminder here, however, that the calculations based on content of nutrients or laboratory tests of amount of yield described below, show potential degradation of biomass with ideal conditions present. As above-mentioned, real values reached depend on technological aspects of fermentation in a specific biogas plant.

Table 4 presents results of substrate biogas yield in litter per $\mathrm{kg}$ of dry matter $\left(1 \mathrm{~kg}^{-1} \mathrm{DM}\right)$ from two experimental locations (Nicov and Černíkovice) in 2009. Characteristics of locality conditions and design of these experiments are mentioned in chapters 4.1 and 4.2.

\begin{tabular}{|c|c|c|c|c|c|}
\hline Locality & $\begin{array}{c}\text { Fertilization } \\
\qquad(\mathbf{k g ~ h a - 1 )}\end{array}$ & $1^{\text {st }}$ cut & $\begin{array}{r}2^{\text {nd }} \text { cut } \\
(1\end{array}$ & 3) & $4^{\text {th }}$ cut \\
\hline \multirow[t]{6}{*}{ Nicov } & $\mathrm{N}_{0} \mathrm{P}_{0} \mathrm{~K}_{0}$ & 318 & 380 & - & - \\
\hline & $\mathrm{N}_{40} \mathrm{P}_{0} \mathrm{~K}_{0}$ & 364 & 367 & - & - \\
\hline & $\mathrm{N}_{80} \mathrm{P}_{0} \mathrm{~K}_{0}$ & 338 & 317 & - & - \\
\hline & $\mathrm{N}_{0} \mathrm{P}_{0} \mathrm{~K}_{0}$ & 445 & 331 & 407 & 503 \\
\hline & $\mathrm{N}_{40} \mathrm{P}_{0} \mathrm{~K}_{0}$ & 358 & 425 & 453 & 445 \\
\hline & $\mathrm{N}_{80} \mathrm{P}_{0} \mathrm{~K}_{0}$ & 375 & 418 & 405 & 414 \\
\hline \multirow[t]{3}{*}{ Černíkovice } & $\mathrm{N}_{0} \mathrm{P}_{0} \mathrm{~K}_{0}$ & 520 & 410 & 541 & - \\
\hline & $\mathrm{N}_{50} \mathrm{P}_{40} \mathrm{~K}_{100}$ & 545 & 484 & 483 & - \\
\hline & $\mathrm{N}_{150} \mathrm{P}_{40} \mathrm{~K}_{100}$ & 446 & 467 & 588 & - \\
\hline
\end{tabular}

Table 4. Substrate biogas yield ( $\left.1 \mathrm{~kg}^{-1} \mathrm{DM}\right)$ from permanent grassland, 2009, Nicov and Černíkovice localities, Czech Republic 
The substrate biogas yield was assessed while using laboratory batch test. The plant material was processed in fresh state, immediately after harvest of monitored grasslands. Basic homogenization and grinding of matter followed. Tested biomass was put together with inoculum in doses into fermentors that were gas-sealed. Biomass from experimental locality of Nicov was tested in 2 litres bottles in three replications for each variant. Dosage of mixed substrate was $1000 \mathrm{~g}$ (100 - $200 \mathrm{~g}$ of biomass and $800-900 \mathrm{~g}$ of inoculum). Cultivation took place in thermo box at $37^{\circ} \mathrm{C}$. Time of delay for mixed substrate in fermentors was 35 days. Biomass from experimental location of Černíkovice was tested in $120 \mathrm{ml}$ bottles in five replications for each variant. Two grams of tested biomass and $80 \mathrm{ml}$ of inoculum were dosed into fermentors. Cultivation took place in thermo box at $40{ }^{\circ} \mathrm{C}$ for a period of 49 - 50 days. Production of biogas in laboratory tests of biomass was evaluated once a day from both locations, using gas-metric burette. Besides tests of production of biogas with substrates, cultivation of inoculum itself in the same conditions was done and it was subsequently discounted from production from test bottles with substrates. In this way, net substrate production of biogas was obtained. Active mesophile anaerobic sediment from biogas plant was used as the inoculum.

Values of substrate biogas yield were in range of 317 to 5881 of biogas for kg DM (Table 4). It is clear from the presented results, that the main influence on yield of biomass had term and sequence of mowing, and the highest values were reached when earlier term and higher frequency of mowing were applied. That is in concordance with results summarized by Prochnow et al. (2009b), who found that the yield of methane in general declines as the vegetation phase proceeds. Amon et al. (2007) came to similar conclusions that substrate methane yield declines from value around $3001 \mathrm{~kg}^{-1} \mathrm{ODM}$ during stem elongation and before inflorescence, to $1711 \mathrm{~kg}-1$ ODM during flower stage.

Results in Table 4 also show that in the framework of individual experiments, higher values in yield were reached during the third and the fourth mowing. The reason for that can be the generally applicable negative relationship between quality and quantity, where increasing yield decreases degradability of substrate, because of changes in chemical composition and higher share of lower quality tissues. The yield is usually lower during the third and the fourth mowing, with higher content of leaves in harvested material. Leaves are in general considered to have higher quality and are more easily degradable than stems (Pearson \& Ison, 1997). Fertilization had no consistent effect on yield but it is possible to conclude that with strong increase in yield while fertilizing, there was also a slight decrease in yield of substrate. This difference was more apparent during earlier terms of mowing. It is therefore possible to affect quality of harvested biomass mainly by numbers and terms of mowing, and it is necessary to consider earliness and height of plants in the grassland as well.

Another influencing factors, however, has to be considered as well. The specific methane yields of grassland showed significant differences (Fig. 5) between the mountainous and the valley regions (Amon et al., 2007). A low specific methane yield (128 - $\left.2211 \mathrm{~kg}^{-1} \mathrm{ODM}\right)$ only was measured from the biomass coming from the hill site, independent of the number of cuts. The grass grown at the valley site produced $190-3921 \mathrm{~kg}^{-1} \mathrm{ODM}$. The highest specific methane yield was reached in the biomass from the second cut of the four-cut variant. The yield of biogas gained thus depends significantly on specifically varying compositions of species in permanent grasslands different locations. Grasslands always represent mixed associations of different botanical composition, from grasslands that are intense and poor in 
species, to grasslands that are quite rich in species. This can lead to different management focused on different goals, which takes into consideration environmental functions.

Barring the content of nutrients in biomass, yield of biogas can also be influenced by modification of substrate. According to Hendriks \& Zeeman (2009), pretreatment (mechanical, thermal, chemical) can be done to improve the hydrolysis yield and total methane yield. Mshandete et al. (2006) studied the effect of particle size on biogas yield from sisal fiber waste. Methane yield increased by $23 \%$, when the fibers were cut to $2 \mathrm{~mm}$ size, compared to untreated fibers.

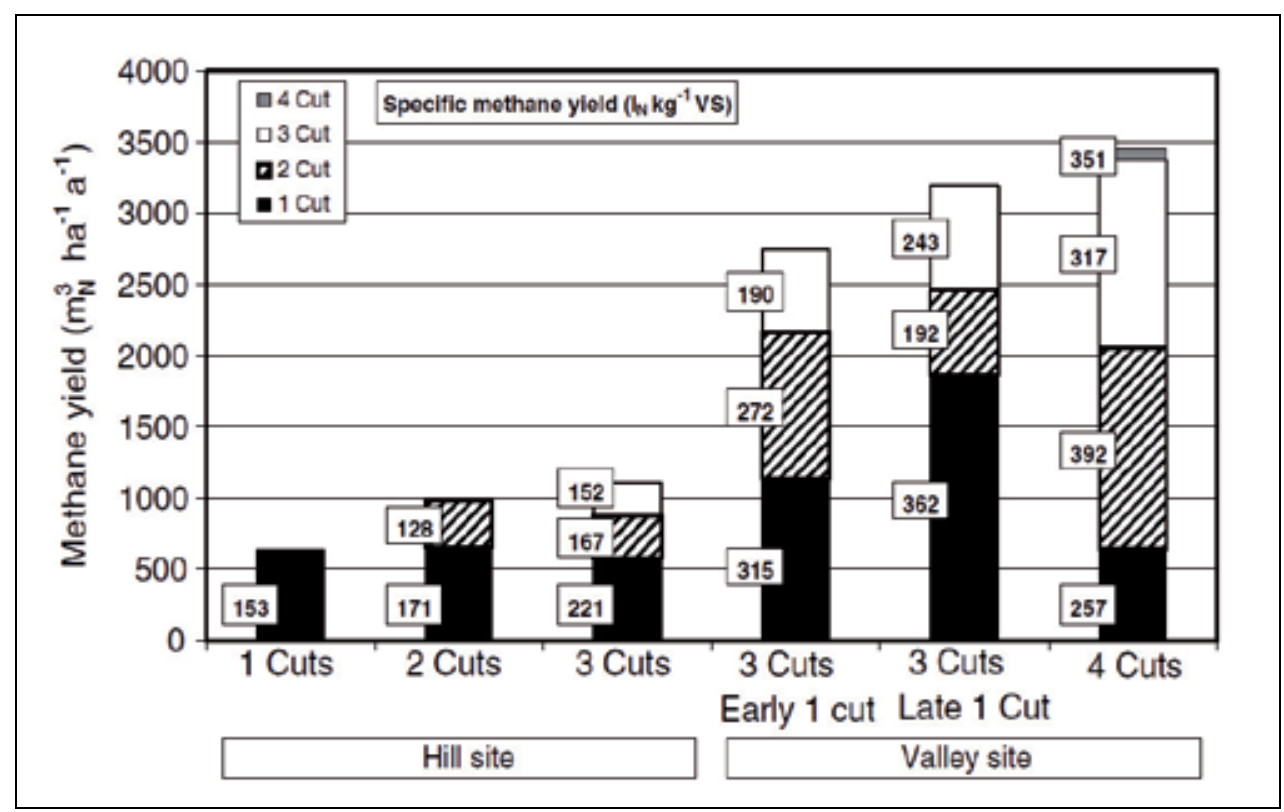

Fig. 5. Methane yield $\left(1 \mathrm{~kg}^{-1} \mathrm{ODM} ; \mathrm{m}^{3} \mathrm{ha}^{-1}\right)$ from permanent grassland at two sites (hill and valley) and under different management intensity (Amon et al., 2007)

\subsection{Area biogas yield}

The yield of biogas from one unit of area represents basic indicator for calculating economical effectiveness of the grown plants. Acceptable supply costs can be achieved at high grass yields, moderate distances of transport and favourable field conditions for machinery operation (Blokhina et al., 2011). As was noted by Deublein \& Steinhauser (2008), it is only profitable from an economic point of view, when the materials are sourced from a location within a distance of $15-20 \mathrm{~km}$.

Results shown in Fig. 6 and Fig. 7 clearly demonstrate that although the effect of fertilization on substrate biogas yield was inconsistent, suitable doses of nutrients significantly increase production of biogas per hectare. Fig 6 shows furthermore that although higher frequency of mowing increased quality of biomass (Table 4), total production of biogas per hectare was comparable to two-cut and four-cut systems. Four-cut system has higher need for energy inputs (see chapter 4.3), which means the two-cut system can be evaluated as the more suitable system in this case. 
Amon et al. (2007) found that area methane yield tends to increase with increasing number of cut and fertilization levels. The biomass yields seem to be more important factor to achieve high area methane yield. According to Gerin et al. (2008), extensity of management of permanent grasslands leads to decrease in yield of dry matter and substrate biogas yield. However, too high intensity does not necessarily have to produce satisfactory results either.

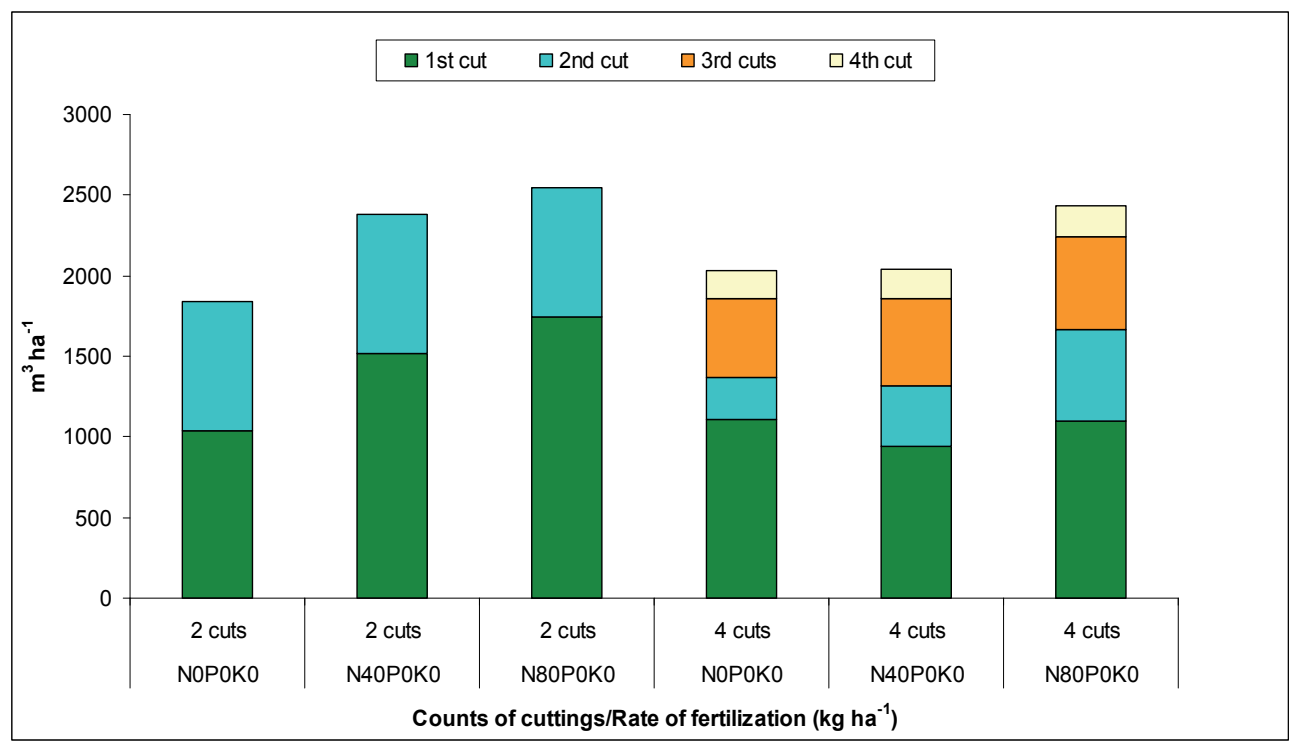

Fig. 6. Area biogas yield $\left(\mathrm{m}^{3} \mathrm{ha}^{-1}\right)$ from permanent grassland under different management intensity, 2009, Nicov locality, Czech Republic

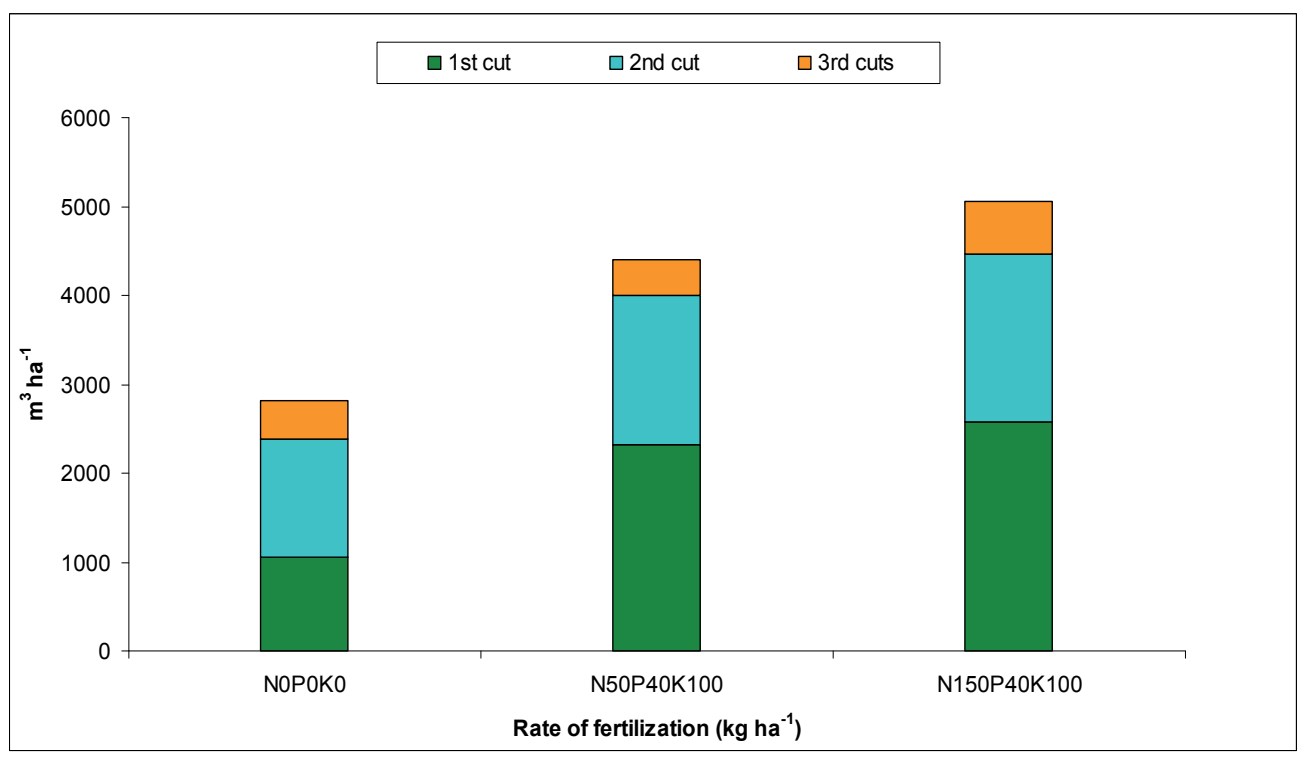

Fig. 7. Area biogas yield $\left(\mathrm{m}^{3} \mathrm{ha}^{-1}\right)$ from permanent grassland under different management intensity, 2009, Černíkovice locality, Czech Republic 
Therefore, it is possible to conclude that the basic element for determination of suitable management methods is still permanent grassland with specific composition of species, on specific locality, with respect to its environmental functions. According to variability of permanent grasslands, there is no universal optimal management for production of biomass for animals or energy use. The first and the basic step for optimizing production of biogas is a well-chosen number of mows, which will suitably utilize present vegetation period and natural fertility of locality. Terms of mows consequently must be based on planned number of mows considering earliness of sward and actual biomass yield. It is necessary to understand that frequent mows in early vegetation periods do increase substrate biogas yield $\left(1 \mathrm{~kg}^{-1} \mathrm{ODM}\right)$, but because of lower yield from higher number of mows, reduction of area biogas yield $\left(\mathrm{m}^{3} \mathrm{ha}^{-1}\right)$ can occur. This aspect of reduction in yield can be partially eliminated on grasslands with suitable composition of species by using adequate fertilization. This significantly increases yield in various regimes of harvest. At the same time, it does not significantly reduce yields of substrate.

\section{Conclusion}

Utilization of permanent grasslands for production of biogas represents a system with different final adjustment in comparison with utilization of forage for feeding purposes. The basic management of permanent grasslands abides preserved, however optimization of this process can differ from traditional use of biomass. The chapter shows that the term grassland is very wide and includes varied groups of stands. Therefore, it cannot be provided any all-purpose instructions for biogas produce from permanent grasslands. It is also necessary to point out that optimal management, which would cover both productive and non-productive functions of this vegetation, does not exist.

According cited literature and our own results, it is evident that for determination the optimal management of permanent grasslands for production of biogas it is necessary to take into consideration an influence of locality, species composition and other reciprocal biological relations. The system of biogas production from the permanent grasslands can fulfil productive as well as non-productive functions of grasslands. Considering the type of stand it is possible to modify the management towards maximization of production or strengthen their environmental value.

\section{Acknowledgment}

Research was supported by projects MSM 6046070901 and NAZV 1G58055. Publishing was supported by project Klastr Bioplyn No. 5.1 SPK02/019 financed by CzechInvest, Investment and Business Development Agency.

\section{References}

Amon, T.; Amon, B.; Kryvoruchko, V.; Machmüller, A.; Hopfner-Sixt, K.; Bodiroza, V.; Hrbek, R.; Friedel, J.; Pasch, E.; Wagentristl, H.; Schreiner, M. \& Zollitsch, W. (2007). Methane production through anaerobic digestion of variol energy crops grown in sustainable crop rotations. Bioresource Technology, Vol.98, No.17, (December 2007), pp. 3204-3212, ISSN 0960-8524 
Blokhina, Y.N.; Prochnow, A.; Plöchl, M.; Luckhaus, C. \& Heiermann, M. (2011). Concepts and profitability of biogas production from landscape management grass. Bioresource Technology, Vol.102, No.2, (January 2011), pp. 2086-2092, ISSN 0960-8524

Brant, V.; Pivec, J.; Fuksa, P.; Neckář, K.; Kocourková, D. \& Venclová, V. (2011). Biomass and energy production of catch crops in areas with deficiency of precipitation during summer period in central Bohemia. Biomass and Bioenergy, Vol.35, No.3, (March 2011), pp. 1286-1294, ISSN 0961-9534

ČSN ISO 1928 (1999). Tuhá paliva - Stanovení spalného tepla kalorimetrickou metodou v tlakové nádobě a výpočet výhřevnosti, ČNI, Prague, Czech Republic

Deublein, D. \& Steinhauser, A. (2008). : Biogas from waste and renewable resources - an introduction, WILEY-VCH Verlag GmbH Co. KGaA, ISBN 978-3-527-31841-4, Weinheim, Federal Republic of Germany

FAOSTAT (October 2011). Land use database, In: FAOSTAT, 03.10.2011, Available from: $<$ http:/ / faostat.fao.org>

Frame, J. (2000). Improved Grassland Management, Farming Press, ISBN 0-85236-543-8, Tonbridge, United Kingdom

Fuksa, P; Kocourková, D.; Hakl, J. \& Kalista, J. (2006). Influence of weed infestation on the calorific value and chemical composition of maize (Zea mays L.). Journal of Plant Diseases and Protection, Supplement, No.2, pp 823-830, ISSN 1861-4051

Gerin, P.A.; Vliegen, F. \& Jossart, J.M. (2008). Energy and $\mathrm{CO}_{2}$ balance of maize and grass as energy crops for anaerobic digestion. Bioresource Technology, Vol.99, No.7, (May 2008), pp. 2620-2627, ISSN 0960-8524

Guo, Q.; \& Berry, W.L. (1998). Species richness and biomass: Dissection of the hump-shaped relationships. Ecology, Vol.79, No.7 (October 1998), pp. 2555-2559, ISSN 0012-9658

Hejcman, M.; Klaudisová, M.; Schellberg, J. \& Honsová, D. (2007). The Rengen Grassland Experiment: plant species composition after 64 years of fertiliser application. Agriculture, Ecosystems and Environment, Vol.122, No.2, (October 2007), pp. 259-266, ISSN 0167-8809

Hendriks, A.T.W.M. \& Zeeman, G. (2009). Pretreatments to enhance the digestibility of lignocellulosic biomass. Bioresource Technology, Vol.100, No.1, (January 2009), pp. 10-18, ISSN 0960-8524

Hohenstein, W.G. \& Wright, L.L. (1994). Biomass energy production in the United States: an overview. Biomass and Bioenergy, Vol.6, No.3, pp. 161-173, ISSN 0961-9534

Honsová, D.; Hejcman, M.; Klaudisová, M.; Pavlů, V.; Kocourková D. \& Hakl J. (2007). Species composition of an alluvial meadow after 40 years of applying nitrogen, phosphorus and potassium fertilizer. Preslia, Vol.79, No.3, (March 2007), pp. 245258, ISSN 0032-7786

Hopkins, A. (2000): Herbage production, In: Grass. Its Production and Utilization, Hopkins, A. (Ed.), pp. 90-110, Blackwell Science, Ltd., ISBN 0-632-05017-9, Cornwal, United Kingdom

Hopkins, A. \& Holz, B. (2006). Grassland for agriculture and nature conservation: production, quality and multi-functionality. Agronomy Research, Vol.4, No.1, pp. 320, ISSN 1406-894X

Hülsbergen, K.-J.; Feil, B.; Biermann, S.; Rathke, G.-W.; Kalk, W.-D. \& Diepenbrock, W. (2001). A method of energy balancing in crop production and its application in a long-term fertilizer trial. Agriculture, Ecosystems and Environment, Vol.86, No.3, (September 2001), pp. 303-321, ISSN 0167-8809

Jones, M. R. (1989). Analysis of the use of energy in agriculture-Approaches and problems. Agricultural Systems, Vol.29, No.3, pp. 339-355, ISSN 0308-521X 
Klapp, E. (1956). Wiesen und Weiden. Behandlung, Verbesserung und Nutzung von Grünlandflächen. P. Parey, Berlin, Federal Republic of Germany

Kramberger, B. \& Gselman, A. (1997). The effects of cutting frequency on the yield and floristic diversity of grassland, Proceedings of Management for grassland biodiversity, $9^{\text {th }}$ of the European Grassland Federation Symposium, pp. 93-96, ISBN 83-908158-1-8, Warszawa-Łomża, Poland, May 19-23, 1997

Lepš, J. (1999). Nutrient status, disturbance and competition: an experimental test of relationships in a wet meadow. Journal of Vegetation Science, Vol.10, No.2, (April 1999), pp. 219-230, ISSN 1100-9233

Long, F.L. (1934). Application of calorimetric methods to ecolgical research. Plant Physiology, Vol.9, No.2, (April 1934), pp. 323-337, ISSN 0032-0889

Malhi, S.S.; Nyborg, M. \& Soon, Y.K. (2010). Long-term effects of balanced fertilization on grass forage yield, quality and nutrient uptake, soil organic $\mathrm{C}$ and $\mathrm{N}$, and some soil quality characteristics. Nutrient Cycling in Agroecosystems, Vol.86, No.3, (April 2010), pp. 425-438, ISSN 1385-1314

Mengel, K. \& Steffens, D. (1985). Potassium uptake of rye-grass (Lolium perenne) and red clover (Trifolium pratense) as related to root parameters. Biology and Fertility of Soils, Vol.1, No.1 (March 1985), pp. 53-58, ISSN 0178-2762

Moog, D.; Poschlod, P.; Kahmen, S. \& Schreiber, K.-F. (2002). Comparison of species composition between different grassland management treatments after 25 years. Applied Vegetation Science, Vol.5, No.1, (May 2002), pp. 99-106, ISSN 1402-2001

Mrkvička, J.; Veselá, M.; Klimeš, F. \& Kocourková, D. (2006). The changes of species richness and diversity of foxtail type stand during long-term fertilization. Scientia Agriculturae Bohemica, Vol.37, No.2, pp. 41-48, ISSN 1211-3174

Mshandete, A.; Björnsson, L.; Kivaisi, A.K.; Rubindamayugi, M.S.T. \& Mattiasson, B. (2006). Effect of particle size on biogas yield from sisal fibre waste. Renewable Energy, Vol.31, No.14, (November 2006), pp. 2385-2392, ISSN 0960-1481

Neitzke, M. (2002). Changes in energy fixation and efficiency of energy capture in aboveground biomass along an environmental gradient in calcareous grasslands. Flora, Vol.197, No.2, pp. 103-117, ISSN 0367-2530

Niinemets, Ü. \& Kull, K. (2005). Co-limitation of plant primary productivity by nitrogen and phosphorus in a species-rich wooded meadow on calcareous soils. Acta Oecologica, Vol.28, No.3, (November-December 2005), pp. 345-356, ISSN 1146-609X

Nösberger, J. \& Kessler, W. (1997). Utilisation of grassland for biodiversity, Proceedings of Management for grassland biodiversity, $9^{\text {th }}$ of the European Grassland Federation Symposium, pp. 33-42, ISBN 83-908158-1-8, Warszawa-Łomża, Poland, May 19-23, 1997

Oomes, M.J.M. (1992). Yield and species density of grassland during restoration management. Journal of Vegetation Science, Vol.3, No.2, (April 1992), pp. 271-274, ISSN 1100-9233

Pearson, C.J. \& Ison, R.L. (1997). Agronomy of grassland system, Cambridge University Press, ISBN 0-521-56889-7, Cambridge, United Kingdom

Prochnow, A.; Heiermann, M.; Plöchl, M.; Amon, T. \& Hobbs, P.J. (2009a). Bioenergy from permanent grassland - A review: 2. Combustion. Bioresource Technology, Vol.100, No.21, (November 2009), pp. 4945-4954, ISSN 0960-8524

Prochnow, A.; Heiermann, M.; Plöchl, M.; Linke, B.; Idler, C.; Amon, T. \& Hobbs, P.J. (2009b): Bioenergy from permanent grassland - A review: 1. Biogas. Bioresource Technology, Vol.100, No.21, (November 2009), pp. 4931-4944, ISSN 0960-8524

Ress, B.B.; Calvert, P.P.; Pettigrew, C.A. \& Barlaz, M.A. (1998). Testing anaerobic biodegradability of polymers in a laboratory-scale simulated landfill. Environmental Science and Technology, Vol.32, No.6, (February 1998), pp. 821-827, ISSN 0013-936X 
Rösch, C.; Skarka, J.; Raab, K. \& Stelzer, V. (2009). Energy production from grassland Assessing the sustainability of different process chains under German conditions. Biomass and Bioenergy, Vol.33, No.4, (April 2009), pp. 689-700, ISSN 0961-9534

Rychnovská, M. (1993). Functioning of grasslands in the landscape. In: Structure and functioning of seminatural meadows, Rychnovská, M. (Ed.), pp. 341-360, Academia, ISBN 0-444-98669-3, Prague, Czech Republic

Rychnovská, M. \& Parente, G. (1997). Grassland and Environment: (I) Mutual effects and (II) Agricultural aspects, Proceedings of Management for grassland biodiversity, $9^{\text {th }}$ of the European Grassland Federation Symposium, pp. 173-183, ISBN 83-908158-1-8, Warszawa-Łomża, Poland, May 19-23, 1997

Schellberg, J.; Möseler, B.M.; Kühbauch, W. \& Rademacher, I.F. (1999). Long-term effects of fertilizer on soil nutrient concentration, yield, forage quality and floristic composition of a hay meadow in the Eifel mountains, Germany. Grass and Forage Science, Vol.54, No.3, (September 1999), pp. 195-207, ISSN 0142-5242

Sims, P.L. \& Singh, J.S. (1978). The structure and function of ten Western North American grasslands: IV. Compartmental Transfers and Energy Flow within the Ecosystem. Journal of Ecology, Vol.66, No, 3 (November 1978), pp. 938-1009, ISSN 0022-0477

Straka, F.; Dohányos, M.; Zábranská, J.; Jeníček, P.; Dědek, J.; Malijevský, A.; Novák, J.; Oldřich, J. \& Kunčarová, M. (2006). Bioplyn, GAS, ISBN 80-7328-090-6, Prague, Czech Republic

Soussana, J.-F. \& Tallec, T. (2010). Can we understand and predict the regulation of biological $\mathrm{N}_{2}$ fixation in grassland ecosystems? Nutrient Cycling in Agroecosystems, Vol.88, No.2, (November 2010), pp. 197-213, ISSN 1385-1314

Stypiński, P.; Hejduk, S.; Svobodová, M.; Hakl, J. \& Rataj, D. (2009). Development, current state and changes in grassland in the past year, Proceedings of Alternative functions of grassland, 15 th of the European Grassland Federation Symposium, pp. 1-10, ISBN 978-808698-15-1, Brno, Czech Republic, September 7-9, 2009

Úlehlová, B. (1980). Contents, accumulation and release of energy in green, dead and decomposing plant materials in an upland grassland near Kameničky, Czechoslovakia. Folia Microbiologica, Vol.25, No.2, (March 1980), pp. 162-167, ISSN 0015-5632

Van Der Woude, B.J.; Pegtel, D.M. \& Bakker, J.P. (1994). Nutrient limitation after long-term nitrogen fertilizer application in cut grassland. Journal of Applied Ecology, Vol.31, No.3, (August 1994), pp. 405-412, ISSN 0021-8901

Wassen, M.J.; Venterink, H.O.; Lapshina E.D. \& Tanneberger, F. (2005). Endangered plants persist under phosphorus limitation. Nature, Vol.437, No.7058, (September 2005), pp. 547-550, ISSN 0028-0836

Whitehead, D.C. (1995). Grassland Nitrogen, CABI Publishing, ISBN 0-85198-915-2, Wallingford, United Kingdom

Willems J.H.; Peet R.K. \& Bik L. (1993). Changes in chalk-grassland structure and species richness resulting from selective nutrient additions. Journal of Vegetation Science, Vol.4, No.2, (April 1993), pp. 203-212, ISSN 1100-9233

Yajing, B.; Zhenghai, L.; Xingguo, H.; Guodong, H. \& Yankai, Z. (2007). Caloric content of plant species and its role in a Leymus chinensis steppe community of Inner Mongolia, China. Acta Ecologica Sinica, Vol.27, No.11, (November 2007), pp. 4443-4451, ISSN 1872-2032

Zechmeister, H.G.; Schmitzberger, I.; Steurer, B.; Peterseil, J. \& Wrbka, T. (2003). The influence of land-use practices and economics on plant species richness in meadows. Biological Conservation, Vol.114, No.2, (December 2003), pp. 165-177, ISSN 0006-3207 


\title{
Globalization of the Natural Gas Market on Natural Gas Prices in Electric Power Generation and Energy Development
}

\author{
Thomas J. Hammons \\ International Practices for Energy Development and Power Generation, \\ University of Glasgow, \\ Scotland, UK
}

\section{Introduction}

The world's natural gas market is rapidly global zing. Traditionally, gas supplies for electric power generation have been delivered entirely within regional markets - usually with little geographical distance between the source of gas and its ultimate combustion. However, a significant and growing fraction of world gas is traded longer distances via pipeline and, increasingly, as LNG. The rising role of LNG is interconnecting gas markets such that a single global market is emerging.

This chapter discusses in a form not referenced in the literature in a convenient form heretofore the impacts of this globalization on the power generation industry. The electricity supply industry is increasingly turning to natural gas fuelled plants. Discussed in relation to the major gas producing and gas consuming regions is demand, infrastructure, price impacts and the possible responses of the power industry.

\section{Modeling and analyzing impact of interdependency between natural gas and electricity infrastructures}

With increasing investment in natural gas powered generation technologies, limitations in gas delivery capabilities are becoming increasingly relevant to operational planning of electric power systems. Thus it is essential to model and analyze the impact of the interdependency between natural gas and electricity infrastructures. Through integrated modeling of the two infrastructures, critical energy infrastructure vulnerabilities can be identified, thereby providing useful information for future planning of the natural gas delivery system and the electric power system.

A nation's energy security and sustainability that depends primarily on its energy infrastructure's security and sustainability are of critical importance to a nation's economic competitiveness and the improvement of people's daily lives. Natural gas infrastructure and electricity infrastructure are two essential elements of the nation's energy infrastructure. 
It is reported that the majority (up to $90 \%$ ) of the electric power plants that were built in recent years and will be built in the future are fuelled by natural gas [1, 2]. By 2030, generation by natural gas is expected to increase by $230 \%$, the greatest relative increase of any generation technology [3].

Such rapid deployments have intensified the physical and economic interdependencies between natural gas and electricity infrastructures, which have introduced additional challenges for managing the security of such interdependent infrastructures. Specifically, the emergence of a large quantity of gas-fired units necessitates a more extensive gas supply and transmission infrastructure. This could greatly increase the vulnerability of gas pipeline infrastructure from the security aspect, and increase demand and thus market prices of natural gas from the economic viewpoint. There is evidence that natural gas usage for electric power in the summer may have a noticeable impact on working natural gas in storage and winter gas availability.

Conversely, the limitations of the gas delivery system become increasingly relevant to power system operations with the increased reliance on natural gas. An interruption or pressure loss in gas transmission systems could lead to a loss of multiple gas-fired electric generators that could jeopardize power system security. In the event of outages in gas transmission or power transmission systems, inconsistent control, monitoring, and curtailment procedures in the energy infrastructure could further constrain operations and may lead to cascading outages and blackouts.

The two infrastructure systems have become highly interdependent [4]. Gas market prices have a direct impact on unit commitment and economic dispatch in security-constrained power system operation. Changes in gas prices may mean the difference between using gas-fired units, or units which rely on coal or other fuels.

A framework for modeling the interdependency between natural gas and electricity infrastructures and impact of such interdependency on the economics and security of electric power system operation is necessary [5].

\subsection{Modeling the Interdependency between natural gas and electricity infrastructures}

\subsubsection{Gas network model}

Pipeline Flow: Gas pipelines are defined as either passive, for pipelines without a compressor, or active. For passive pipelines, the gas flows are determined only by the pressure difference. For active pipelines, a compressor allows the flow to exceed the pressure difference. Additionally, for active pipelines, the gas can only flow in one direction. A detailed mixed-integer-programming (MIP) based formulation can be found in [5].

Gas Contracts: Gas contracts may be modeled as interruptible, where the gas customer pays only for the amount of gas used, or take or pay, where the gas customer pays a fixed cost in advance for a specified amount of gas. In both cases, the total gas usage must be less than or equal to the contract amount. For interruptible contracts, the gas customer pays a fixed perunit price for the amount of gas used. For take-or-pay contracts, the gas customer pays a single fixed amount regardless of the gas actually used. Mathematical formulation for modeling gas contracts can be found in [5]. 


\subsubsection{Electrical network model}

The short-term operation of the electrical network can be simulated using a securityconstrained unit commitment (SCUC) model. The objective of SCUC is to determine a dayahead unit commitment (UC) for minimizing the system operating cost while meeting the prevailing constraints listed as follows:

1. Power balance

2. System spinning and operating reserve requirements

3. Minimum up/time limits, ramping up and down rate limits, start-up and shutdown characteristics of units

4. Must-on and area protection constraints

5. Fuel and multiple emission constraints

6. Transmission flow and bus voltage limits

7. Load shedding and bilateral contracts

8. Limits on state and control variables

9. Scheduled outages.

A complete model can be found in [6-8].

\subsubsection{Gas pipeline and electrical network interdependency}

The coupling constraints between the gas and electrical network are the flow conservation constraints: the total gas entering a node is equal to the sum of the gas leaving the node and the total gas withdrawal. The inclusion of the flow conservation constraints enables gas usage limits to vary as a function of gas flow limitations instead of being fixed values. The current operating limitations on gas usage can therefore be directly represented in the problem. Mathematical formulations for the gas flow conservation constraints are given in [5].

\subsubsection{Solution to the integrated gas network and electrical network model}

The addition of gas pipeline network modeling to SCUC will increase the size of the optimization problem in terms of number of variables and constraints. SCUC with gas pipeline network modeling is decomposed into two sub problems: UC and network analysis (NA). The UC problem is formulated for various types of generating units including thermal, combined-cycle, fuel switching, hydro, pumped storage, and renewable resources (wind or photovoltaic). The gas pipeline network model is incorporated as additional constraints in the UC problem for considering interdependency on gas network. A detailed MIP approach is applied to calculate the hourly unit commitment. The NA sub problem conducts security analysis based on the UC solution and coordinates with the UC problem through shift factor based method [9] or Benders decomposition [6,7].

\subsection{More realistic modeling}

As the electricity industry becomes more and more dependent on natural gas-fired generation, limits in the natural gas delivery system are becoming increasingly relevant to power system operation. 
The incorporation of natural gas network modeling is a start to comprehensively analyze the interdependency between the natural gas and electricity infrastructures. The gas network model suggested here is a very simplified model. Gas storage is not modeled; only gas usage for electric power production is considered; other non-power gas usages, such as residential and commercial, and the associated impacts are not modeled. A more detailed gas network model should be employed for a more realistic study on a practical system, for which the availability of data may be an issue. In addition, the impact of the interdependency between natural gas and electricity infrastructures mainly from the perspective of power system operation should be considered as should impact of such interdependency on gas network operation.

\section{Generation development options in United Kingdom (UK) from the aspect of natural gas availability and prices}

The tendency in West Europe to use more natural gas for heating and electrical generation could be boosted by further development in the European gas market. The considerable number of new pipeline and gas storage projects as well as constructive regulatory activities indicates that gas supply could be significantly increased.

Developing a competitive and regulated gas market supported with significant infrastructure investments and fulfilled environment requirements provide the framework to encourage increase in use of gas in the UK. From the aspect of energy resources diversity it appears that there is sufficient room for growth of CCGT and CHP plants to keep the right balance of generation mix.

The effect of gas market reforms on the power sector, particularly on generation mix in combination with industrial and heating requirements in the UK is now discussed. Optimum generation mix considers choice of fuel supply on a long-term basis via the analysis of remaining reserves and predicting market trends.

\subsection{Energy demand and supply in Europe and United Kingdom}

Annual energy demand growth projection in Europe is expected to be between 1.0 and 1.2 per cent in the next twenty years. Local electricity production, however, has a relatively low prospect for growth. It is expected that local sources will be insufficient to meet energy demand in the medium and long term. This combination of demand growth and local supply decline creates a need for a half a million billion cubic meters of new gas supplies in Europe.

Significant new supplies to Europe and UK are required and consideration has been given to pipelines from the North (Russia and Norway), East (ex Soviet countries via South East European corridor) and South (North African countries).

It is expected that gas would come from new developments in West Siberia (Yamal from 2012) and the Russian Barents Sea, pipelines through the Black Sea, the South East European (SEE) countries and over the Mediterranean Sea from Africa to Italy.

The electricity sector is one of the largest sectors of most European countries and could claim up to a half of the total capital investment. On average, electrical generation claims 
one third of countries total fuel consumption. On the other hand the total power generation of the developing world (including Asia, Latin America and Middle East) is expected to be over 60 per cent of the world's total.

From the projection of fuel inputs to power generation, coal and gas today represent about $66 \%$ of fuel inputs, and by 2030 it is expected that it will reach over $70 \%$.

\subsection{Gas market - Brief overview}

The main participants in the gas industry are suppliers, infrastructure owners, distributors and consumers. Most of the existing contracts for supply of gas to the distributors in Europe and UK are long term contracts based on steady increase in demand. The current pressure to supply local areas with gas and electricity at a new development pace requires fast response from the suppliers, which is difficult to achieve at competitive prices under the existing contract terms. Hence major changes are expected in restructuring of those contracts to reflect the dynamic changes in heat and electricity demand. The new open market would also need to adjust by providing prompt changes in price in accordance with the demand and supply.

The changes in the gas supply industry are visible in that the suppliers now tend to target more than one market. In an open market the consumers would equally have a choice of suppliers that would therefore result in a reduction and optimization of prices.

\subsection{Generation options in UK}

\subsubsection{Planning principles}

Figure 1 illustrates a relationship between the main factors in a country's economy at various levels.

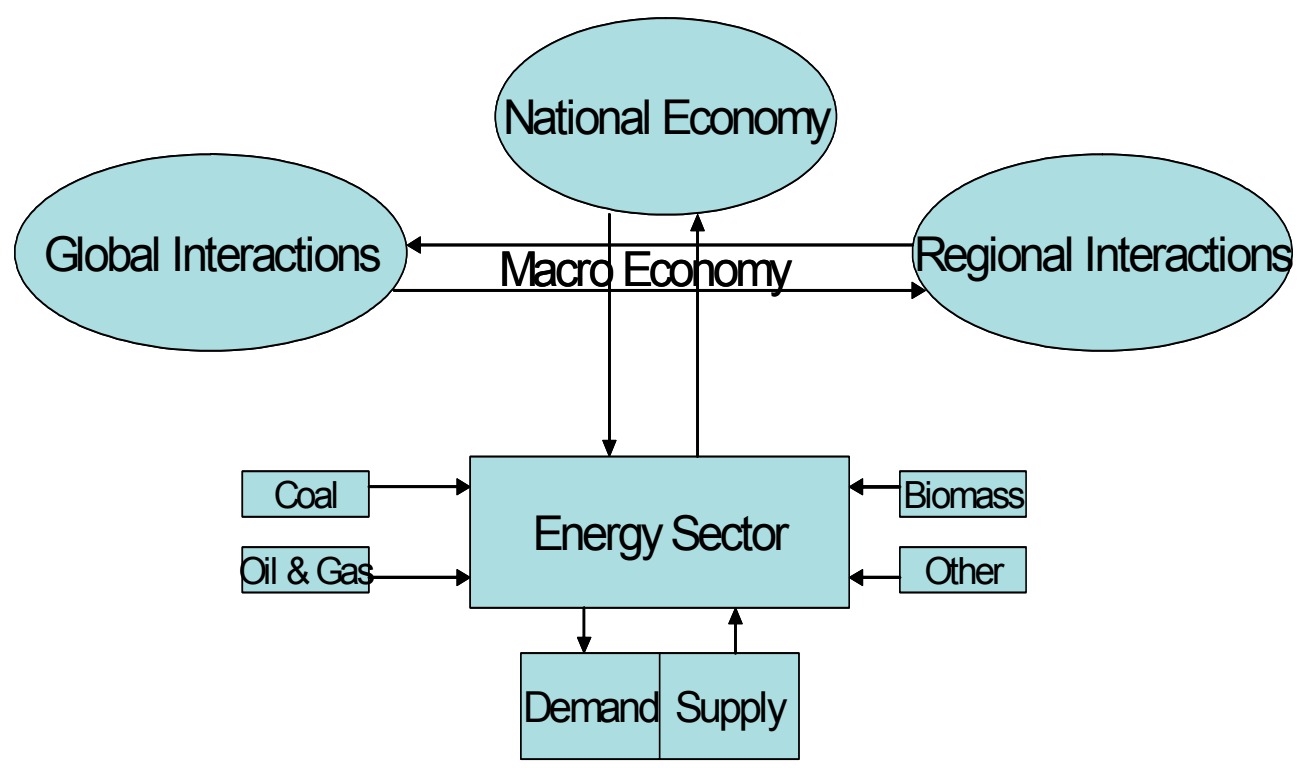

Fig. 1. Macro Economy Factors 
It is seen that a macro economy based strategy is related to national economy with strong ties with the energy sector with a strong influence and interactions at regional and global levels.

Electricity is a major sub-sector of Energy, which together with other sectors such as agriculture, transport, health and education greatly affects the national economy. Electricity is irreplaceable in many areas and plays a strong role in expansion of the sectors and therefore its development is of crucial importance for a country's economic growth.

The main generation planning principle is to provide supply to meet the predicted demand in the most economic way in accordance with the adequate security and safety standards. Integrated Resource Planning (IRP) [10] is a recognized process that identifies a mix of resources to meet the future electricity service needs of the consumers, economy and the society.

Table 1. compares the various sources of energy participating in generation in UK and Europe. There is a significant effort to increase the use of sustainable sources.

\begin{tabular}{|c|c|c|c|c|c|c|c|c|}
\hline & $\mathrm{N}$ & $\mathrm{CL}$ & $\mathrm{P}$ & $\mathrm{NG}$ & $\mathrm{H} / \mathrm{W}$ & $\mathrm{B}$ & Other & Total \\
\hline & $\%$ & $\%$ & $\%$ & $\%$ & $\%$ & $\%$ & $\%$ & '000 GWh \\
\hline UK & 22 & 34 & 2 & 37 & 2 & 1 & - & 386 \\
\hline EU & 33 & 25 & 6 & 17 & 15 & 2 & 2 & 2671 \\
\hline
\end{tabular}

N-Nuclear; CL-Coal Lignite; P-Petrol; NG-Natural Gas; H/W-Hydro/Wind; B-Biomass Source: Wikipedia; comparison of emissions from various energy sources.

Table 1. Electricity Generation in UK and Europe

Nuclear technology in the UK is likely to rise to $33 \%$ in the next $10-15$ years in accordance to governmental predictions. Consideration has also been given to use of coal and lignite with new technologies that would purify the fuel and increase the plant efficiency. Exchange of experience with countries using those technologies in Europe, such as Poland and Russia, may lead to reopening of some coal mines and result in maintaining coal's share of current electricity production in UK.

The UK is committed to reducing the emissions of greenhouse gasses (GHG) as per the Kyoto protocol. The mechanisms to import clean energy from the countries with high margins (mainly developing countries in Eastern Europe) are also on the agenda.

Future electricity generation technologies will aim at achieving clean emissions in order to reduce impact on the environment, achieve high efficiency and short lead times to minimize uncertainties and risks. CCGT as well as CHP fully comply with this requirement. CHP technology is more common in Sweden, The Netherlands, Germany and Austria due to the high demand in heat for longer winter periods.

The main advantages of the gas turbine generation are:

- $\quad$ There is more choice for location for gas power plant.

- $\quad$ Gas plants and CHP can operate in peak shaving mode due to its fast response.

- $\mathrm{CHP}$, which is capturing waste heat and reusing it in an industrial process, is considered as the most efficient type of generation. 
Conversely, the main disadvantage is that the availability and prices of gas will always be associated with risks related to disintegrated markets and political stability of the countries with the gas source as well as countries associated with gas transmission.

\subsubsection{CHP plants in UK}

Most thermal plants worldwide produce electricity with very low efficiency i.e. of the order of $33 \%$. This has prompted concerns regarding high emissions of global warming gasses due to the GHG effect with evident local, regional and likely global implications. Due to those climate change initiatives, the focus on modern electricity generation has shifted towards improving energy efficiency and reduction of pollution.

Table 2 illustrates the advantages of gas over fuel oil and coal in terms of air pollution emission.

\begin{tabular}{|c|c|c|c|c|}
\hline Fuel & $\mathrm{SO}_{2}$ & $\mathrm{NOx}$ & $\mathrm{CO}_{2}$ & $\mathrm{PM}$ \\
\hline Coal & 0.081 & 0.018 & 3.57 & 0.106 \\
\hline Oil & 0.06 & 0.017 & 3.13 & 0.004 \\
\hline Gas & none & 0.012 & 2.07 & none \\
\hline
\end{tabular}

[in mill tons/m.t.o.e of fuel]. PM-Particulate matter; $\mathrm{SO}_{2}$ sulphur dioxide; $\mathrm{CO}_{2}$ carbon dioxide; $\mathrm{NO}_{x}$ nitrogen oxide

Source: Wikipedia; comparison of emissions from various energy sources.

Table 2. Air Pollution Emission

According to environmental agencies new CHP plants in the UK can deliver cost-effective carbon savings between 4 and 6 million tonnes and up to 8 million tonnes by 2015 .

From the technical point of view they provide fast response to generate into the system, which fits nicely in the new regulated and more dynamic gas market. Gas turbines are generally more reliable than pure sustainable sources.

\subsection{UK legislation and policy}

\subsubsection{Energy review}

The UK Government's report on 'The Energy Challenge' was issued on 11 July 2006. The main objective is to meet two major long-term challenges in UK energy policy, namely (i) climate change by reducing carbon dioxide emissions and (ii) to deliver secure, clean energy at affordable prices, as UK moves to increasing dependence on imported energy.

The consultation on the new measures on gas security of supply took place from 16 October 2006 to 12 January 2007. This consultation discussed:

- the effectiveness of current gas security of supply arrangements

- their robustness as UK moves to higher dependence on gas imports over the next 10-15 years

- whether new measures are needed to strengthen them.

The document considers details on the security of gas supply and examines the extent to which the current policy framework is likely to deliver security of supply. 
It also assesses the new challenges faced as the flexible sources of gas in the UK decline and discusses views on the costs, benefits and risks of some possible adjustments to the current commercial and regulatory framework to strengthen the ability to rise to that challenge.

A number of other consultations have been launched to help address security of energy supply and climate change challenges. A selection of a few is listed below.

- $\quad$ New nuclear policy framework, October 2006

- $\quad$ Energy Efficiency Commitment April 2008-March 2011, October 2006

- Proposals on banding, and amending the Renewables Obligation, December 2006 (part 2) and January 2007 (part 1)

- Measures to reduce carbon emissions in large non-energy intensive business and public sector organizations, January 2007

- $\quad$ Energy billing and metering, February 2007

- $\quad$ Resilience of Overhead Power Line Networks, March 2007

- $\quad$ Distributed energy, A call for evidence, January 2007

- A consultation on Offshore Natural Gas Storage and Liquefied Natural Gas Import Facilities. This consultation considers the need for, and provides views on, changes to existing legislation with regard to the storage of natural gas in non-hydrocarbon features (e.g. salt caverns), the storage of natural gas in hydrocarbon features (e.g. partially depleted oil and gas fields) and the unloading of Liquefied Natural Gas (LNG) offshore.

- Offshore Natural Gas Storage and Liquefied Natural Gas Import Facilities: consultation, February 2007.

On 15 December 2006, the Department of Trade and Industry (DTI), now Department for Business, Enterprise and Regulatory Reform (BERR), issued new Guidance to power station developers to maximize the use of CHP where feasible. In issuing this Guidance the Government is signaling its strong commitment to $\mathrm{CHP}$, whilst recognizing that it is up to the market to bring forward the most competitive proposals to help ensure security of supply. The outcome of this was fed into the Energy White Paper in 2007.

\subsubsection{Energy white paper}

The White Paper, published on 23 May 2007, sets out the Government's international and domestic energy strategy to respond to these changing circumstances, address the long term energy challenges we face and deliver our four energy policy goals:

- to put UK on a path to cutting $\mathrm{CO}_{2}$ emissions by some $60 \%$ by about 2050 , with real progress by 2020

- to maintain the reliability of energy supplies

- $\quad$ to promote competitive markets in UK and beyond

- to ensure that every home is adequately and affordably heated.

It shows how the measures set out in the Energy Review Report in 2006 have been implemented, as well as those announced since, including in the Pre-Budget Report in 2006 and the Budget in 2007.

Some of the measures in this White Paper require further public consultation. Alongside the White Paper consultations on nuclear power, the Renewables Obligation and guidance on the 1965 Gas Act have been launched. 
CHP plants are currently in the focus of energy experts as the alternative to failure of meeting the targets related to sustainable energy. Total CHP generated energy in UK in 2005 was 27TWh of electricity and 51TWh of heat. The UK government predicted that just over $10 \%$ could be generated out of total predicted energy of $350 \mathrm{TWh}$ with the trend to grow up to $17 \%$ as an ultimate potential. Other countries in Europe such as Germany, report that they expect CHP plants to meet $25 \%$ of the overall demand.

\subsection{Generation development options in UK}

The advantages of gas turbines over other sources are numerous from fast response to system requirements to acceptable ecological characteristics with low $\mathrm{NO}_{x}$ and no $\mathrm{SO}_{x}$ emissions. In terms of efficiency, CCGTs are considered the best of all thermal power plants with efficiencies up to $60 \%$. Further improvements, which is the trend in the UK, is to combine the gas turbine with use of sustainable sources of energy that would reduce the emission of GHG and improve efficiency up to $80 \%$ by connection to district heating and providing heat to industrial processes.

Liberalization of the European Gas Market opens the opportunity for gas to participate in UK's generation mix in developing more CHP in addition to already implemented CCGT.

Dependence on gas imports to replace UK reserves is most likely to be both pricey and vulnerable to the loss of supply due to political instability. It is prudent to plan for such a foreseeable situation by consideration of the following.

- Build modern Nuclear to replace existing operational old stations that could provide deficit that other low $\mathrm{CO}_{2}$ technologies cannot provide.

- Allow power generation from abated emission, modern coal power stations, as well as providing incentive to utilize more coalmine methane in gas engines.

- Continue promoting 'renewable' fuels and wind, wave and solar, whilst keeping in perspective the relatively low percentage of their overall contribution.

- Minimize output from existing gas fired power stations to retard the rate of consumption of Britain's own reserves - this may mean returning to a higher percentage of power generation from coal, having "clean coal" technology.

- Adequately fund development of tidal and under sea current technologies, for predictable power generation.

- Government policy with regard to the structure of the energy markets should aim to remove the short-term price horizons in those markets that are a major bar to capital investments that depend on long tern return periods.

\section{US and Canadian liquefied natural gas}

US and Canadian gas consumers are averse to long-term physical contracts - the traditional mechanism for securing liquefied natural gas (LNG) in the world market. The US and Canadian natural gas market is wedded to spot transactions. This is partly a reaction to costly experiences unwinding long-term, reserve-based, bundled supply and transportation contracts that were well above spot prices a few decades ago, and partly a reflection of just how comfortable market participants have become in relying on the spot market whenever they need to buy or sell physical gas. 
The LNG industry, by contrast, is wedded to long-term contracts. Two drivers are responsible. First, long-term contracts with credit-worthy off-takers were necessary to underpin the large capital investments for the first several LNG projects. Second, buyers who must depend on LNG and are thereby displacing other fuels, require dedicated upstream resources; liquefaction trains and tankers for assurance the gas will be there when needed. The US and Canada (and the UK) attract supply with price, while Europe and Asia attract new supply with long-term contracts.

Flows of LNG to the US are not simply a function of the relative attractiveness of North American spot prices. The lack of US and Canadian commitment to LNG clashes with the dependency that North American countries will have on this new supply.

\subsection{Power sector need for LNG}

Power sector demand growth alone will boost the need for gas. Electricity consumption has grown at an annual average rate of $1.3 \%$ per year in the last decade. With the latest round of new power plant capacity more than $90 \%$ gas-fuelled, natural gas is serving a large and growing share of power sector demand growth. The outlook is for more with natural gas slated to serve the larger share of power plant additions ahead. Power sector use of gas added an average of 0.75 bcf per day of gas demand each year in the past decade (Figure 2).

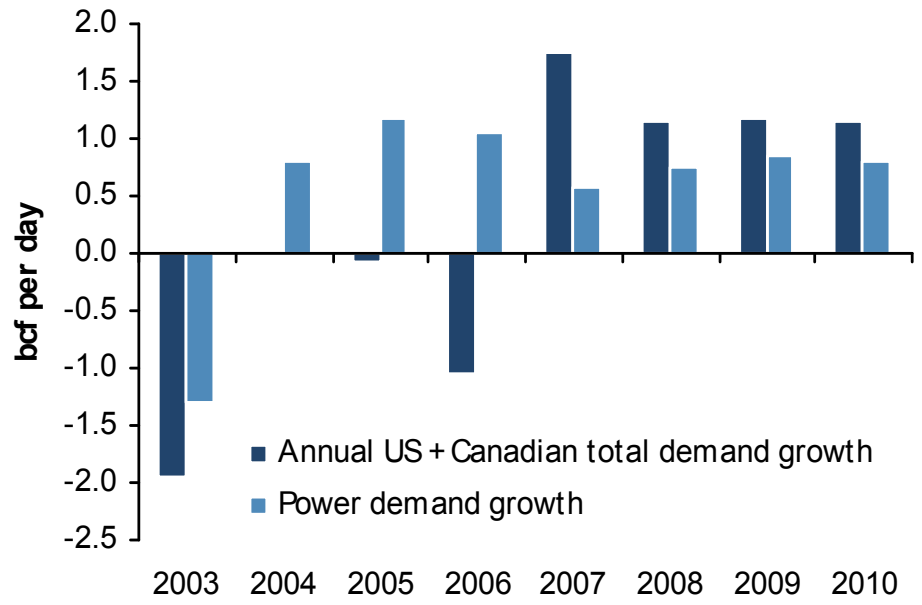

Source: EIA, Barclays Capital

Fig. 2. Gas Consumption in the Power Sector

\subsection{Global LNG supply boom}

The expected reliance of the US and Canada on LNG parallels two significant events in the LNG industry. The first is a boom in global LNG supplies. These have grown 9 bcf per day since the start of the last decade and are set to grow an additional 9 bcf per day by the end of the decade (Figure 3). The 5 bcf per day of LNG supply additions in 2008 would be the largest single year of supply additions in the industry's history. 
This boom in global LNG supply is facilitated by a second significant event - the intermediation of energy companies as supply off-takers for many new liquefaction projects. Sensing a growing global need for new LNG supply, a number of new supply projects were launched, with energy companies - rather than end-users - contracting for the new supply. There is essentially no unsold LNG supply from liquefaction projects that are under construction. Committing to LNG supply without an end-use buyer may be risky. The large, liquid US market provides a convenient destination of last resort for any supply that does not otherwise find an end-user by the time the liquefaction project comes on line.

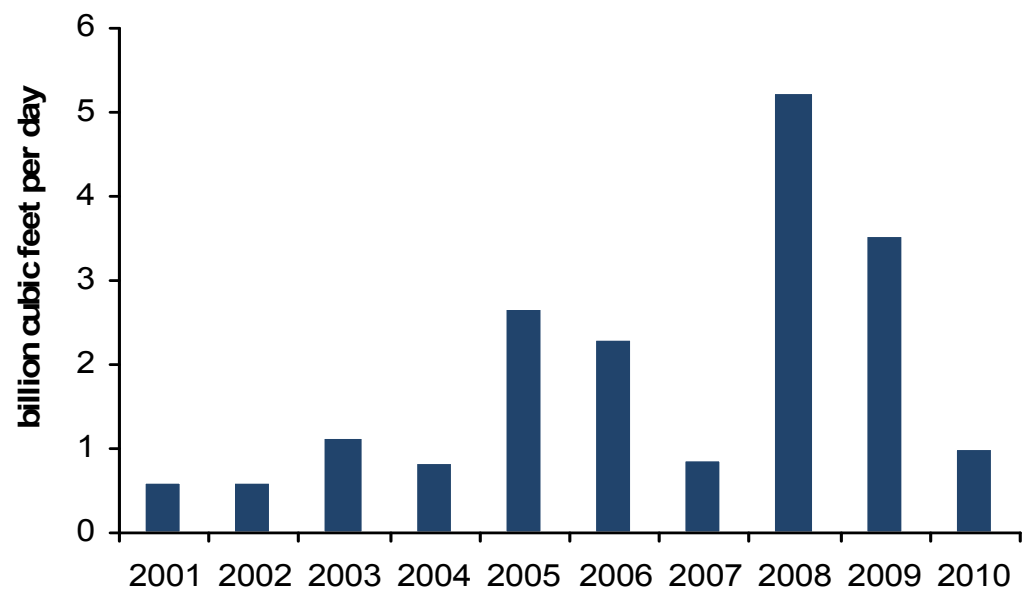

Source: EIA, Barclays Capital

Fig. 3. Global LNG Supply Growth

\subsection{Oil-indexation, Yen and Euros}

Energy company intermediaries have never intended to hold vast quantities of LNG supply for spot market sales. With global prices for natural gas remaining robust, and with strong demand growth for natural gas in non-North American markets, a growing number of new long-term contracts have allowed these energy companies to commit this LNG to end-users. These long-term end-user contracts allow the companies controlling the supply to reduce their risk, at prices that have proven to be desirable.

Beyond new, long-term LNG contracts to non-North American end-users, two additional powerful trends are driving LNG away from US shores. First, typical European and Asian long-term LNG contracts are linked to oil prices. With oil selling at an increasing premium to natural gas (Figure 4) oil-linked LNG in non-US markets carries an automatic premium to US Henry Hub at current market levels. Many countries that import LNG do not have functioning gas markets; thus, prices must be linked to another commodity, typically oil. Oil-linked LNG provides buyers and sellers an opportunity to hedge. The second trend is the strength of the yen and euro compared with the US dollar, with the dollar declining 9\% against the yen over the years (2005-2007), and falling 25\% against the Euro. 


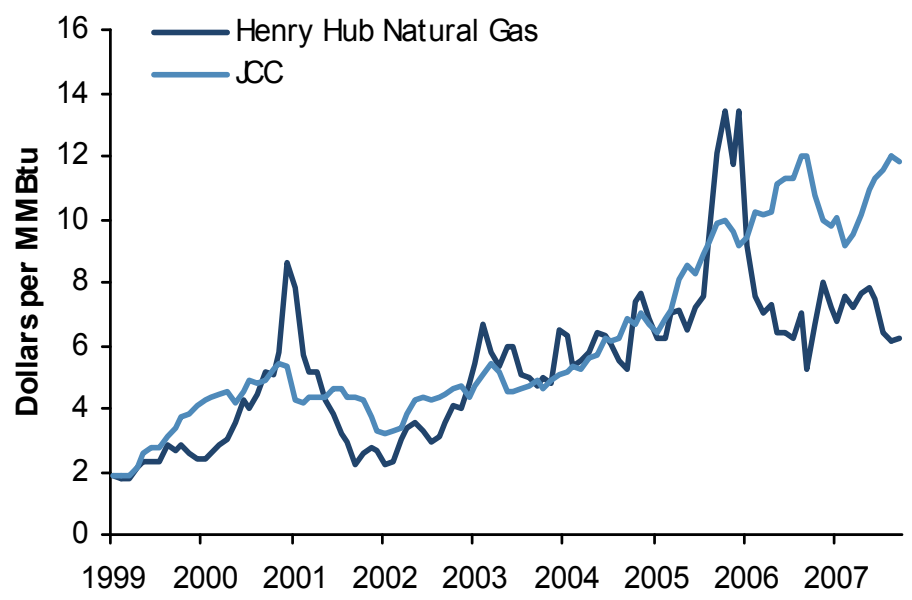

Source: EIA, Barclays Capital

Fig. 4. Growing Oil Premium to Natural Gas (Japanese Crude Cocktail (JCC) oil prices compared with US Henry Hub)

\subsection{Standby for LNG}

With US and Canadian end-users averse to long-term physical contracts for LNG the risk remains that, without committing to LNG, it may not be available if needed in the years ahead. It is unlikely that none would be available on a spot basis for a given sustained period in the years ahead, when forecast non-North American gas demand is compared with global LNG supply. Yet, there remains the risk that in any given period, LNG flows could fall to low levels, even zero, depending on events outside of North America. The US and Canada do not have control over LNG flows into their markets.

US and Canadian buyers should not rush out at this time to contract for LNG. This is because:

- Financial hedges combined with flexible, short-term physical supply offers fewer headaches for buyers and sellers.

- Some LNG contracts include marine risk (as part of force majeure); LNG tankers do not enjoy hurricanes, for example. This risk creates a challenge for some buyers.

- An energy supplier is more likely to offer a buyer portfolio gas rather than specifically LNG under a US-destined long-term physical contract.

- $\quad$ LNG is not necessarily cheaper than portfolio gas.

- If utilities continue to be judged on their purchase prices against the spot market, then a drought of LNG that pushes spot prices higher for everyone presents no inherent risk for a utility so judged.

- An increasingly smaller amount of LNG remains uncommitted. The opportunity available to sellers of Pacific LNG, for example, is a Japanese Crude Cocktail (JCC)linked price. No utilities are interested in signing oil-linked LNG contracts.

- A long-term contract represents a tremendous contractual liability of a buyer's balance sheet. 
Some utilities have a free-rider approach: let others bring the LNG to market, enjoy the downward price pressure that results, and buy it on the spot market.

\subsection{LNG imports to remain de-linked with US spot prices}

Global LNG supply growth will moderately outstrip non-North American consumption, allowing deliveries to the US to grow. Regasification capacity and shipping capacity pose no restriction to US imports. Regasification capacity, which registered substantial growth in 2008, should further outstrip available supply to fill it (Figure 5). Should economic growth boom overseas, particularly in Asia, LNG deliveries to the US would dwindle far below the amounts shown in Figure 5. Conversely, faster pace of LNG supply growth or more moderate rates of gas demand growth in the other fifteen LNG consuming countries would boost deliveries to North America.

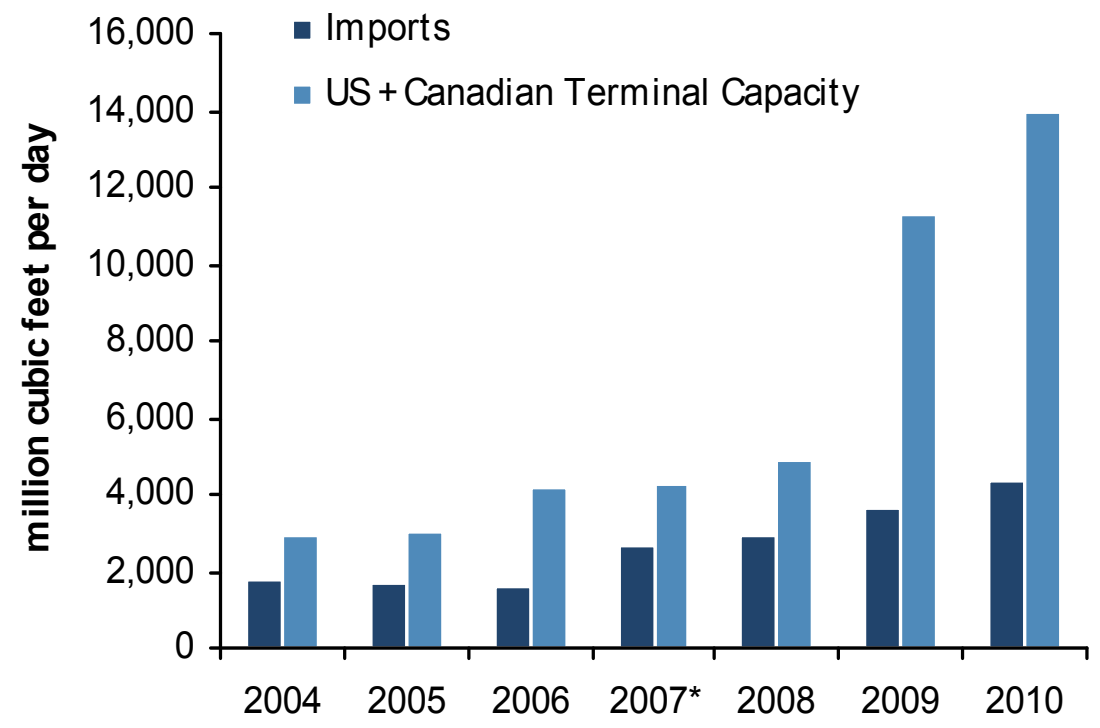

Note: *Estimated. Source: EIA, Barclays Capital

Fig. 5. US and Canadian LNG Imports versus Regasification Capacity

It is incorrect to add up all non-North American LNG supply contract volumes and assume these will not be available to the US and Canada. End-use LNG buyers contract for more supply than is needed. This allows surpluses to be marketed in the spot market. New LNG contracts offer greater flexibility to divert cargoes. The large storage market in the US provides a ready destination for surplus volumes. There have even been modest signs of interest in buyers securing LNG supply, notably in California. Thus, a growing slice of LNG supply can be marketed on a spot basis to buyers.

In competition for these supplies will be any market in need. Asian markets, which typically clear on volume and not price, have shown a penchant to out-bid these spot cargoes. European buyers have shown more price responsiveness, while the UK market operates much as the US and Canadian market, with spot pricing. 


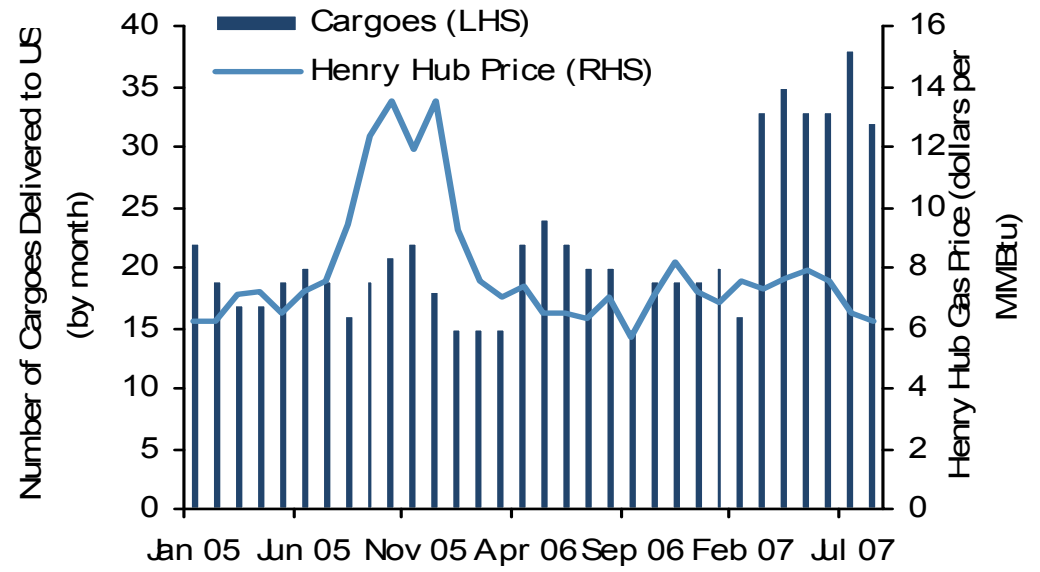

Source: EIA, NYMEX, Barclays Capital

Fig. 6. US LNG Imports versus Gas Prices (Henry Hub)

This standby method of purchasing LNG attracts it to the US at some times, and not at others. Figure 6 illustrates the historical relationship between US pricing and LNG deliveries. Spot prices are not the primary driver of flows into the US. The general trend in increased deliveries in 2007 was due to more available spot LNG supply, not stronger US prices.

With US and Canadian end-users averse to long-term physical contracts for LNG the risk remains that, without committing to LNG, it may not be available if needed in the years ahead. It is unlikely that none would be available on a spot basis for a given sustained period in the years ahead, when forecast non-North American gas demand is compared with global LNG supply. There remains the risk that in any given period, LNG flows could fall to low levels, even zero, depending on events outside of North America. The US and Canada do not have control over LNG flows into their markets.

Energy information and the New York Mercantile Exchange information is available at the websites: (i) Energy Information Administration (EIA), "International Energy Outlook 2007, www.eia.doe.gov. and (ii) New York Mercantile Exchange (NYMEX), www.nymex.com .

\section{Impact of natural gas market on power generation development in Russia}

This Section discusses the natural gas market and its impact on power generation development in Russia

A large part of natural gas consumed in Russia is used for electricity and centralized heat production. Table 3 presents gas volumes consumed in 2005 in Russia for electricity and heat production [11].

Of 397 bln $\mathrm{m}^{3}$ of natural gas used in Russia in 2005, electricity and heat generation required 243 bln $\mathrm{m}^{3}$ or $61 \%$; the remaining $39 \%$ was used by the population and other branches: metallurgy, petro-chemistry, agro-chemistry, etc. Almost the same relation in shares has been observed in recent years. 


\begin{tabular}{|l|c|}
\hline \multicolumn{1}{|c|}{ Type of final energy and generation sources } & $\begin{array}{c}\text { Gas consumption } \\
\text { mln. tce } / \text { bln.m }\end{array}$ \\
\hline Electricity supplied by fuel-fired power plants & $129 / 112$ \\
\hline Heat supplied by fuel-fired power plants & $65.9 / 57$ \\
\hline Heat supplied by industrial and residential boiler plants & $81.8 / 71$ \\
\hline $\begin{array}{l}\text { Heat supplied by boiler plants of agricultural } \\
\text { enterprises }\end{array}$ & $2.7 / 2$ \\
\hline Total: & $270.4 / 243$ \\
\hline
\end{tabular}

*tce - ton coal equivalent

Table 3. Gas Consumption for Electricity and Heat Production in Russia in 2005

Table 4 indicates the structure of fuel consumption by the generation companies of RAO "EES Rossii" in 2000-2006 for electricity and heat production. It is virtually impossible in Russia to consider separately the production of electricity and centralized heat at cogeneration plants (CPs), because almost $1 / 3$ of electricity is generated in combination with heat at thermal power plants (TPPs).

\begin{tabular}{|l|c|c|c|c|c|c|c|}
\hline & 2000 & 2001 & 2002 & 2003 & 2004 & 2005 & 2006 \\
\hline Gas, bln. $\mathrm{m}^{3}$ & 127.1 & 131.2 & 132.4 & 135.6 & 139.7 & 142.6 & 148.1 \\
\hline Fuel oil, mln. $\mathrm{t}$ & 8.5 & 7.6 & 7 & 6.8 & 53 & 49 & 6.2 \\
\hline Coal, mln. $\mathrm{t}$ & 120.1 & 109.6 & 106 & 109.3 & 101.2 & 104.4 & 109.2 \\
\hline
\end{tabular}

Source: Annual reports of RAO "EES Rossii"

Table 4. Structure of Fuel Consumption by Subsidiary Generation Companies of RAO “EES Rossii" in 2000 - 2006

Conversion of data from Table 4 to standard fuel enables the share of each resource of fuel supply to be indicated for the generation capacities. This is indicated in Figure 7.

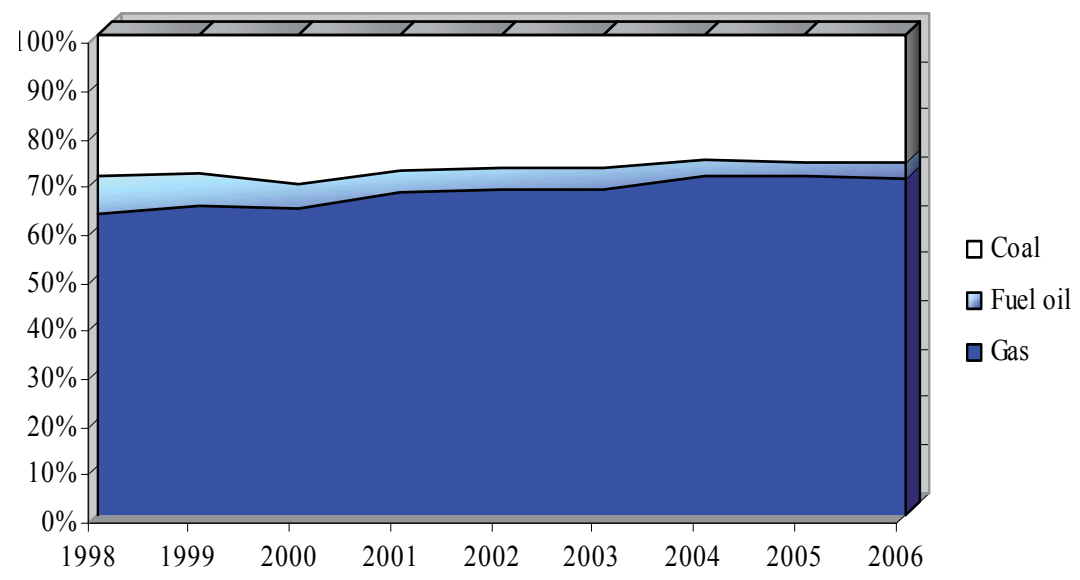

Fig. 7. Share of individual fuel resources in fuel supply for generation capacities of RAO "EES Rossii" 1998-2006 
Figure 7 shows that over these 8 years (1998-2006) the share of natural gas used for the production of electricity (and centralized heat at cogeneration plants) at thermal power plants increased from $63 \%$ to $70 \%$.

For the same period the price of gas supplied to industrial consumers and power plants increased from $\$ 10 / 1000 \mathrm{~m}^{3}$ to $\$ 51 / 1000 \mathrm{~m}^{3}$ (the last figure is for 2007). Note that the indicated prices are controlled and are several times lower than those for European countries and USA.

Such a situation for gas prices in Russia cannot last long. Prices will inevitably rise because of the following:

- The tendency of RAO "EES Rossii" to achieve equal profitability of the gas industry in the external and domestic gas markets (in 2006 the gas price in the European countries was at the level of $\left.\$ 250 / 1000 \mathrm{~m}^{3}\right)$;

- The price increase will be caused by objective necessity for Russia to move to new (with very expensive development) areas of natural gas production (the Yamal and Gydan Peninsulas, shelves of the Barents and Kara Seas). This seems to be the main reason for price increase.

The necessity to sharply increase domestic gas prices is also understood by the Government of the Russian Federation (RF). The change of wholesale domestic gas prices to year 2010 was determined on 30 November 2006. Based on different factors (depletion of the main gas fields in the current gas production areas, growth of gas demands, aging of fixed production assets, growing demands of the industry for investments, etc.) the gas price level for industry and the electric power industry in 2011 will approach $\$ 115 / 1000 \mathrm{~m}^{3}-\$ 120 / 1000$ $\mathrm{m}^{3}$. Further, the possibility for including the gas price formula (approved by the Federal Tariff Service of RF in July 2007) in long-term contracts for domestic consumers is examined at present [12]. (It will take into account primary cost of gas of a concrete gas production area in a concrete gas consumption area including the necessary charges, taxes, and dues). The average gas price calculated by this formula was about $\$ 170 / 1000 \mathrm{~m}^{3}$ in 2007. Prior to 2007 this price was hypothetic, in 10-15 years such a price will be real for the reasons mentioned above.

\subsection{Cost of primary gas for the main gas fields}

Table 5 gives values of cost of primary gas for the main gas fields of the Yamal Peninsula (Bovanenkovskoye and Kharasaveyskoye), the shelf of the Kara Sea (Leningradskoye and Rusanovskoye) and the fields of the Gydan Peninsula in the Moscow region (i.e. in the center of the European part of Russia) that were calculated at the Energy Systems Institute, Irkutsk, Russia.

The prime cost of gas for the above field (Table 3) represents the relation between the total capital and operating costs for the whole time period of infrastructure creation on the field and the total gas production for the same time period. Here the total costs are the costs for creation and operation of:

- Production and social infrastructure required for development of the considered field and later on - its exploitation;

- Systems of gas production and preparation for long-distance transportation;

- Systems of long-distance gas transportation from the field to the area of its consumption. 


\begin{tabular}{|l|c|c|c|c|c|}
\hline \multirow{2}{*}{ Field } & \multicolumn{3}{|c|}{ Prime cost components } & \multicolumn{2}{c|}{ Prime cost } \\
\cline { 2 - 6 } & Development & $\begin{array}{c}\text { Production } \\
\text { and } \\
\text { preparation }\end{array}$ & Transport & $\begin{array}{c}\text { Range of } \\
\text { possible } \\
\text { values }\end{array}$ & $\begin{array}{c}\text { Average } \\
\text { values }\end{array}$ \\
\hline $\begin{array}{l}\text { Bovanen- } \\
\text { kovskoye }\end{array}$ & $12-15$ & $30-35$ & $53-59$ & $95-109$ & 102 \\
\hline $\begin{array}{l}\text { Kharasa- } \\
\text { veyskoye }\end{array}$ & $12-15$ & $30-35$ & $54-60$ & $95-110$ & 103 \\
\hline $\begin{array}{l}\text { Lenin- } \\
\text { gradskoye }\end{array}$ & $18-20$ & $45-50$ & $60-67$ & $123-137$ & 130 \\
\hline $\begin{array}{l}\text { Rusanov- } \\
\text { skoye }\end{array}$ & $18-20$ & $45-50$ & $64-71$ & $127-141$ & 134 \\
\hline $\begin{array}{l}\text { Fields of } \\
\text { Gydan } \\
\text { Peninsula }\end{array}$ & $15-18$ & $35-40$ & $64-70$ & $114-128$ & 121 \\
\hline
\end{tabular}

Table 5. Primary Cost of Gas for the Main Fields of new Gas Production Areas in the Moscow Region, \$/1000 m

The values of primary cost of gas in Table 3 were calculated on the base of the corresponding specific capital and operating costs that are reasonable only for the present day. Correspondingly, the obtained preliminary figures for primary cost of gas of new gas production areas should be considered correct only for the current gas production. At the time of actual start of gas production from the considered fields the figures can change because of the uncertainty factor.

According to Table 5, the most probable prime cost of gas in the Moscow region could make up currently $\$ 100 / 1000 \mathrm{~m}^{3}-\mathbf{-} \$ 105 / 1000 \mathrm{~m}^{3}$ (for Yamal), $\$ 130 / 1000 \mathrm{~m}^{--} \$ 135 / 1000 \mathrm{~m}^{3}$ (for the shelf of the Kara Sea) and $\$ 128 / 1000 \mathrm{~m}^{3}$ (for the fields of the Gydan Peninsula). It can be said with reasonable confidence that the specific capital and operating costs will increase with lapse of time and hence the primary cost of gas in new gas production areas will also rise. Based on different data for the period from 2000 to 2006 the indicated specific costs increased on the whole by $70--100 \%$. Even if the growth rates of specific costs for the period to 2020 are not so high and make up about $50 \%$ with respect to those for the present day, by 2020 primary cost of gas will increase to $\$ 150 / 1000 \mathrm{~m}^{3}$ for the Yamal gas, to $200 / 1000 \mathrm{~m}^{3}$ for the Kara Sea shelf and to $\$ 180 / 1000 \mathrm{~m}^{3}$ for the Gydan Peninsula.

In the foregoing, only the prime cost is discussed. Hence, the average gas price of $\$ 170 / 1000 \mathrm{~m}^{3}$ (that was calculated by the gas price formula) can be considered quite real in 10-15 years. So much so, the gas share in new gas production areas in 15-20 years will amount to $70--75 \%$ of the total gas production in the country.

Thus, the gas price rise in the domestic market of Russia, in particular for generation companies is inevitable. This will involve an increase in price of electricity generated and correspondingly an increase in price of all types of industrial products and service industries.

There are various methods by which this process could be dampened. One is to decrease the share of a costly resource (gas) in favor of one that is more financially accessible (in this situation it is coal). In addition, the increase in diversification of the fuel mix in Russia (gas 
share is $80 \%$ of total fuel consumption) will have a positive impact on the level of Russia's energy security.

\subsection{Structure of generation capacities for Russia considering increase in involvement of coal}

Using the required data, the change in share of gas-fired thermal power plants in the structure of generation capacities for Russia due to increase in the coal share can be evaluated. The data relates to:

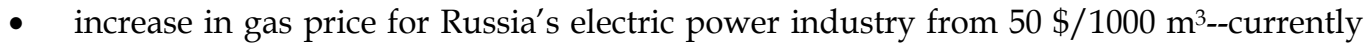
to $170 \$ / 1000 \mathrm{~m}^{3}$ in 2020

- change in relationships between coal and gas prices (in terms of standard fuel) from 1:1.1--currently up to 1:1.6-1.8 in 2020

- national electricity demand, taken on the basis of the Energy strategy of Russia up to 2020 [13]

- technical and financial constraints on replacement of worn and obsolete generation equipment and construction of new capacities

- $\quad$ specific capital investments in the construction of new generation capacities of different types (gas- and coal-fired thermal power plants, nuclear and hydro power plants) and specific operating costs for currently operating and new capacities, etc.

A technique for electric power industry development planning which accounts for its interrelations with other branches of the Fuel and Energy Complex (FEC) in Russia has been developed [14]. It is similar to the integrated resource planning approach [15, 16]. The approach is integrated planning of electric power systems and gas supply systems expansion in a market environment. Consideration is given to the practical approach of using such techniques in multi-step planning of Russia's power industry development, taking into account prospects for development of the national gas industry and bearing in mind the possible substantial rise in the price of gas used in the electric power industry.

Such multi-step modeling supposes two-level studies:

1. entire Fuel and Energy Complex of the country;

2. systems of electric power and gas supply.

At first level the territorial and production model of the national Fuel and Energy Complex (FEC) is employed to determine the main relationships between development of the fuel industries and the electric power industry, taking into consideration their interaction in the considered time horizon. Then, involving a more detailed mathematical model of electric power industry development, the prospective structure of generation capacities and their allocation are determined.

The next step assumes creation of scenarios of possible deviations in gas industry development from the basic conditions (considered at the FEC level). The scenarios are studied from the viewpoint of their impact on electric power industry development. Then, based on analysis of the studies and using alternately the models of FEC, electric power industry and gas industry, the solutions of potential electric power industry development 
that are adaptive to expected conditions of gas industry development (including changes in the gas prices within the set ranges) are determined. At the same time (at the FEC level) account is taken of the conditions for expansion of all types of generation capacities and development of all fuel industries - in terms of fuel inter-changeability and reserves.

Analysis of factors determining the structure of the generation capacities within multi-step modeling reveals that in addition to gas and coal prices themselves, the key factors for Russia (at least up to 2020) are physical capabilities of involving gas and coal in the fuel mix of the country. In turn the volumes of such involvement will largely depend on the possibilities to produce fuel resources in the country.

The volume of national coal production can be increased substantially. With the investments available and with the demand for coal, its production can reach 450-500 mln t/year or 270$300 \mathrm{mln}$ tce by 2020 [17] compared with the current production level of $300 \mathrm{mln}$ t or $180 \mathrm{mln}$ tce annually.

It is not easy to increase the volumes of gas production. Aside from the need to invest huge sums of money in the development of new gas production areas it is necessary to consider time lag. For example, it will take 12-13 years at best for the volume of gas production on Yamal to reach 240-250 bln $\mathrm{m}^{3}$ /year (this is a maximum volume) from scratch.

In 2006 the country produced 656-bln $\mathrm{m}^{3}$ of gas. Based on the estimates of the Energy Systems Institute, Irkutsk, Russia, gas production level in Russia in 2020 will be not exceed $680 \mathrm{bln} \mathrm{m}^{3}$. This is on the assumption that:

- gas production on Yamal will start in 2010 and will then grow and reach the level of 240 bln $\mathrm{m}^{3}$ /year in 2020;

- gas production at the Shtokmanovskoye field will start in 2011-2012 reaching the maximum annual production 60-80 bln $\mathrm{m}^{3}$ /year in 2020-2025;

- total volume of gas production in other new areas (the Sakhalin Island Shelf, Irkutsk region, the Sakha republic (Yakutia) and other regions) will reach 40-bln $\mathrm{m}^{3}$ in 2010 and 60-80 bln m³/year in 2015-2020.

Taking into account the above, the potential volumes of gas and coal involvement in the fuel mix of Russia, and the potential volumes of their use for production of electricity and centralized heat at co-generation plants have been compared up to 2020. The model-based studies took into consideration that all gas and coal involved in the fuel mix is consumed for two purposes:

- $\quad$ production of electricity and centralized heat;

- use by all other categories of consumers (industry, population, housing and public utilities, etc.).

The results of the comparison are presented in Table 6.

Separation of coal and gas demand for production of electricity and heat, and for other needs allows estimation of the extent to which the shares of these energy resources will be redistributed in the future. For example the demand for fuel at thermal power plants in 2020 can be met owing to 290-mln tce of gas that can be supplied by the gas industry and up to 210-mln tce of coal that can be supplied by the coal industry. 


\begin{tabular}{|c|c|}
\hline \multicolumn{2}{|c|}{ Natural gas, bln $m^{3}$} \\
\hline Potential production & up to 680 \\
\hline Own needs of the industry & 60 \\
\hline Possible import & 60 \\
\hline Possible export & 260 \\
\hline Domestic demand & 170 (except for electricity and heat production at TPP) \\
\hline Reserve* $^{*}$ & up to 250 \\
\hline Reserve in mln tce & up to 290 \\
\hline \multicolumn{2}{|c|}{ Coal, $m \ln t$} \\
\hline Potential production & up to 500 \\
\hline Possible import & 15 \\
\hline Possible export & 90 \\
\hline Domestic demand & $\begin{array}{l}80 \text { (except for the electricity and heat production } \\
\text { at TPP) }\end{array}$ \\
\hline Reserve* $^{*}$ & up to 345 \\
\hline Reserve in mln tce & up to 210 \\
\hline
\end{tabular}

*Gas and coal volumes that can be used at Thermal Power Plants

Table 6. Comparison of Possible Coal and Gas Involvement in Fuel Mix of Russia and Volumes of use for Production of Electricity and Centralized Heat (2020*

Thus, the prospective relationship between gas and coal use for production of electricity and centralized heat at cogeneration plants can make up $58 \%$ or $290 \mathrm{mln}$ tce of natural gas against $42 \%$ or $210 \mathrm{mln}$ tce of coal.

It should be noted that in 2006 the gas share neared $70 \%$. Besides, there was fuel oil in the fuel mix in 2006. For 2020 fuel oil (as a basic fuel) was not considered in the fuel mix: by that time this kind of fuel should be only used as an emergency reserve and process fuel (for example ignition of steam generators at cogeneration plants).

In summary, the gas share at thermal power plants of Russia, despite a sharp gas price rise (from $50 \$ / 1000 \mathrm{~m}^{3}$ in 2007 to $170 \$ / 1000 \mathrm{~m}^{3}$ in 2020), can be decreased only $11-12 \%$ in favor of increase in the coal share, which to some extent will enable one to mitigate the cost rise of the electricity and centralized heat produced at TPPs in the natural gas demand zone. The above can be real if future coal generation is based on clean coal, modern technologies.

\section{China: Future of natural gas coal consumption in Beijing, Guangdong and Shanghai - An assessment utilizing MARKAL}

There are many uncertainties regarding the future level of natural gas consumption in China. Using an economic optimization model MARKAL [21], drivers including the level of sulphur dioxide emissions constraints set by the government, the cost of capital, the price and available supply of natural gas, and the rate of penetration of advanced technology on both the supply and demand sides are considered. The results show that setting strict rules for $\mathrm{SO}_{2}$ emissions will be instrumental in encouraging the use of natural gas, and may also cause some reduction in $\mathrm{CO}_{2}$ emissions. Conversely, the currently differentiated cost of capital for various sectors within the Chinese economy artificially boosts the economics of 
capital-intensive coal relative to natural gas. This suggests that financial reform could be a lever for encouraging increased gas use.

Traditionally, gas supplies have been delivered entirely within regional markets - usually with little geographical distance between the source of gas and its ultimate combustion. However, a significant and growing fraction of world gas is traded longer distances via pipeline and, increasingly, as LNG. The rising role of LNG is interconnecting gas markets such that a single global market is emerging [18].

Within this increasingly integrated gas market, the role of China remains highly uncertain. Today, China's share of the global gas market is tiny; with a natural gas market that is smaller than California's [19], but the future demand for natural gas in China is potentially enormous. With an average gross domestic product (GDP) growth of $9.6 \%$ for the last twenty years (China National Bureau of Statistics, 2006) [20] and no signs of slowing down, China's demand for energy commodities-coal and oil, notably-has been expanding rapidly. With appropriate policies, natural gas could also grow rapidly.

Potential drivers for increased natural gas demand within the Chinese energy system are now examined where three regions are focused on: Beijing, Shanghai and Guangdong. This regional model reflects that natural gas sourcing and the downstream natural gas market vary greatly by region due to climatic and geographical barriers. For example, Guangdong receives no pipeline gas and is dependent on LNG imports (at present from Australia), while domestic pipelines principally supply Beijing's and Shanghai's gas demands. The major off-takers for the gas differ between regions as well. In Shanghai, for example, the industrial sector consumes almost all of the gas, while peaking power plants are major off-takers in Guangdong. The regional organization reflects the political realities of decision-making in China. While there are national policies on energy in China, most decisions that affect the usage of natural gas are made at the provincial and local level and driven by the economics and consumption patterns of each locale. A regional focus is therefore useful to model the nuances unique to each area.

In analyzing the energy systems of Beijing, Guangdong, and Shanghai, three separate, regional MARKAL models are used. Given a projected level of total energy demand services, each MARKAL model solves for a least cost optimal solution) [21] over the course of twenty years (2000-2020), utilizing a menu of technologies that is provided as an input for the models. The specific types of energy and emissions control technology are characterized by performance and cost parameters. The model solves by selecting a combination of technologies that minimizes the total system cost and meets the estimated energy demand. The goal is not necessarily to produce a firm prediction of future gas use, since key input assumptions, such as the level of demand services, are highly uncertain. Rather, such models are particularly well suited to reveal how sensitive natural gas demand is to key factors.

Some of the major factors that are likely to affect future demand for gas have been identified to include:

- $\quad$ Rate at which more efficient end-use technology is made available

- Stringency of local and regional environmental constraints

- Financial reforms that affect the cost of capital for different sectors of the economy (i.e., power, industry, residential, commercial, transportation)

- $\quad$ Pricing and availability of gas. 
The most important drivers (apart from polices that directly influence the price of natural gas relative to other fuels) that affect the consumption of natural gas are the implementation of $\mathrm{SO}_{2}$ controls in the system and financial reforms. For very tight limits on $\mathrm{SO}_{2}$ emissions, a switch to natural gas in the power and industrial sectors becomes the economically optimal alternative to other fossil fuels in many cases. When the rise in gas demand is in the industrial sector, this gas displaces oil. In the power sector, where gas competes with coal, it is much harder for gas to gain a substantial share of the market. A side benefit to $\mathrm{SO}_{2}$ emissions reduction policies is a corresponding decline in $\mathrm{CO}_{2}$ emissions of the order of 60 million tons $\mathrm{CO}_{2}$ for some locales (equivalent to about a quarter of the entire stock of Clean Development Mechanism projects in China) (UNEP, 2007) $)^{1}$.

This suggests that a leverage point for governments in developing countries like China to start addressing global concerns about climate change is through regulation of local pollutants that yield visible and immediate benefits while also fortuitously limiting growth of $\mathrm{CO}_{2}$.

As for the effects of financial policies on energy consumption, with differentiation of the cost of capital by sector as occurs in China today, the consumption of coal is particularly favored. The power sector has access to cheaper capital than other sectors within the economy, providing an incentive to build power plants with a high ratio of capital to operating costs. This arrangement favors large coal facilities, which are expensive to build and cheap to operate, over natural gas plants, which are cheap to build but expensive to operate because of the higher price of gas. While the situation is now changing due to financial reforms, it may help explain why gas has had a particularly difficult time making inroads in the power sector. This also suggests that financial reforms could have a big impact on the country's $\mathrm{CO}_{2}$ emissions.

\subsection{Methodology}

The pivotal policy driver for each of the regional model scenarios is the implementation of sulphur dioxide $\left(\mathrm{SO}_{2}\right)$ constraints upon the energy system. $\mathrm{SO}_{2}$ is used as a proxy for the full range of local pollutants -- future studies might model other pollutants more directly. Currently, data for $\mathrm{SO}_{2}$ is the most complete and accurate of all the pollutants that are monitored in China (compared to data for $\mathrm{NO}_{x}, \mathrm{PM} 10, \mathrm{PM} 2.5, \mathrm{CO}_{2}$ ).

To examine the influence of $\mathrm{SO}_{2}$ constraints, three "core" scenarios were developed. In the base case reference scenario (R), it is assumed that no changes are made to the status quo. The model operates on a least cost optimization paradigm so that it solves for the most economically favorable solution. In this situation, coal is expected to out-compete gas in all sectors due to the lower fuel cost. Some emissions control programs are already in place on the national and regional levels; the reference case scenario only includes policies that are currently implemented, as well as highly likely extensions of those policies. From this starting point, there are two main scenario developments.

\footnotetext{
${ }^{1}$ UNEP Riso Centre, Capacity Development for the Clean Development Mechanism, http://www.cdmpipeline.org
} 
Scenario " $\mathrm{P}$ " is the case in which the output $\mathrm{SO}_{2}$ emissions are reduced by $40 \%$ from the reference case and is defined as the "plausible" scenario. This scenario tests the system response if $\mathrm{SO}_{2}$ emissions are capped at a level $40 \%$ below what is currently expected in the status quo.

Scenario " $\mathrm{Ag}$ " is the case in which $\mathrm{SO}_{2}$ emissions are reduced by $75 \%$ from the baseline. This is defined as the "aggressive" scenario and is less likely to represent the future than scenario " $\mathrm{P}$ ", but is not entirely out of the question.

Having defined the core $\mathrm{SO}_{2}$ scenarios, the "More Gas" scenarios ("M") were developed. The goal of these extensions is to find out how the system would react to sensitivity parameters with a plausible $\mathrm{SO}_{2}$ constraint and more gas supply available to the region (such as might be available from a successful effort to develop international pipelines and price gas favorably). With the "MoreGas" scenarios, it is possible to determine the relative effects of gas availability and pricing as compared with the other drivers in the model.

Within each of the core scenarios, how gas demand would vary with two other factors was studied. First, the rate at which efficient, advanced end-use technology is allowed to enter the market (the "Fast" scenarios) was changed. Second, how specifying different costs of capital for each of the sectors would impact on consumption patterns (the "Diffcost" scenarios) was investigated. The factors were also combined with each other.

In all, twelve scenarios were studied. These scenarios allow four broad hypotheses to be investigate, namely:

1. Policies that constrain total $\mathrm{SO}_{2}$ emissions from the entire system lead to increased natural gas consumption.

2. The rate of technological diffusion significantly influences the amount of natural gas consumed within the system.

3. Varying the cost of capital for different sectors has an effect on energy consumption patterns.

4. Gas prices and the availability of gas are important factors in determining which sector consumes what volume of natural gas.

\subsection{Results}

\subsubsection{Constraints on $\mathrm{SO}_{2}$ emissions}

Figure 8 shows projections of natural gas consumption for the reference $(\mathrm{R})$, the plausible $(\mathrm{P}$, $40 \%$ reduction in emissions), and the aggressive ( $\mathrm{Ag}$, 75\% reduction) scenarios from 2000 to 2020 in all three areas. The estimates for consumption vary widely depending on which $\mathrm{SO}_{2}$ constraint is implemented in the system. From 2000 to 2020 in the reference base case, natural gas consumption increases by about six times in Beijing and fifty times in Shanghai. Guangdong goes from zero gas consumption to around $5 \mathrm{bcm}$. The natural gas consumed in 2020 in the aggressive scenario for all three regions is close to $50 \mathrm{bcm}$ greater than the amount consumed in the reference scenario. These results suggest that a tighter $\mathrm{SO}_{2}$ constraint leads to a higher gas demand. 


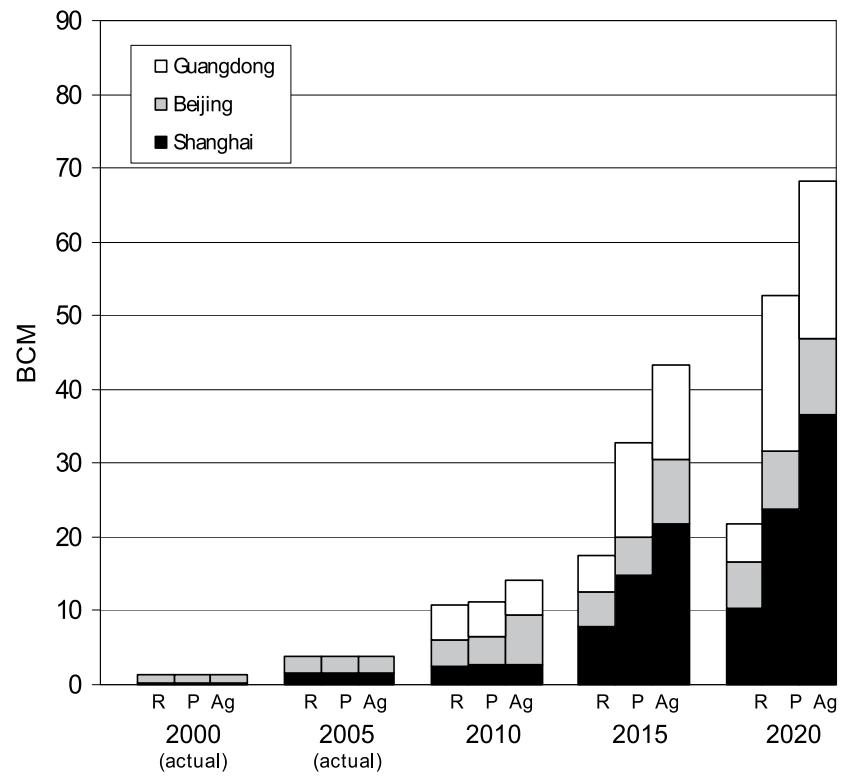

Fig. 8. Natural gas consumption for all study areas: Comparison of results for reference and $\mathrm{SO}_{2}$ constrained scenarios

\subsubsection{Effects of differing costs of capital across sectors}

This section examines effect of varying costs of capital reflective of the historical reality of the Chinese financial system (P Diffcost) and compares it with behavior under a uniform cost of capital across all sectors. For reference runs, what has been done many times in other models is replicated, which is to assume that there is a uniform discount rate across all sectors $(10 \%)$ reflecting the assumption that the cost of capital is uniform. For the scenarios that vary cost of capital, however, the actual differentiated discount rate system under which the Chinese economy has been operating is simulated by assigning different lending rates for each sector in MARKAL [22]. These different discount rates should lead to a significantly different energy system.

Coal consumption in the modest environmental constraints scenario is higher in the case of differentiated costs of capital between sectors. With their high investment and low O\&M costs, coal-fired power plants benefit disproportionately from the low cost of capital for the power sector, while gas plants with their low fixed and high O\&M costs are comparatively disadvantaged.

Taking a look at Guangdong, coal consumption is a dramatic 88\% higher under differentiated costs of capital, with natural gas consumption lower by about $40 \%$ (Figure 9). Advanced coal plants with pollution control equipment (FGD, ESP) are built at the expense of LNG-fired power plants. In fact, the situation on the ground is already evolving in this direction due to rising LNG prices in recent years.

Next, what affect that some of the scenarios may have on $\mathrm{CO}_{2}$ emissions is examined. In particular, the hypothesis that limits on $\mathrm{SO}_{2}$ could yield some reduction in $\mathrm{CO}_{2}$ due to greater use of natural gas is considered. $\mathrm{CO}_{2}$ emissions reductions in response to $\mathrm{SO}_{2}$ limits are most 
apparent in Guangdong. In the case of the aggressive scenario, about 99 million tons less of coal would be used in 2020 compared to the reference case. Figure 10 explains the carbon consequences of this fuel switch for Guangdong. Imposing a 75\% emissions cap on the $\mathrm{SO} 2$ emissions can avert about 57 million tons of carbon dioxide emissions. For comparison, 50 million tons is about a quarter of the $\mathrm{CO}_{2}$ saved by the entire stock of Clean Development Mechanisms (CDM) projects in China in 2006. It is also a quarter of Europe's Kyoto commitment [23]. While in absolute numbers these savings alone will not alter the global trajectory of climate change, they do suggest new ways of thinking about the climate issue, especially with regard to how to bring developing countries to the climate negotiation table.

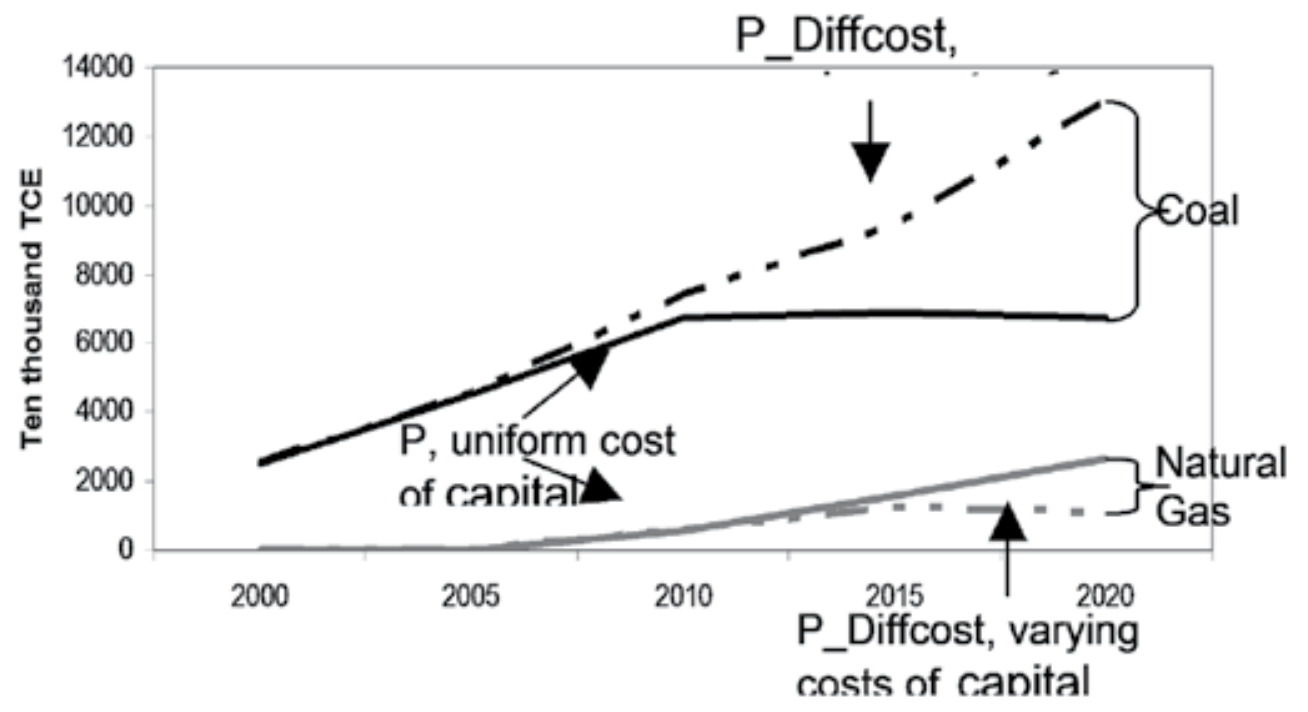

Fig. 9. Coal and Natural Gas Consumption in the Guangdong (Power Sector) 


\subsection{Implications for $\mathrm{CO}_{2}$}

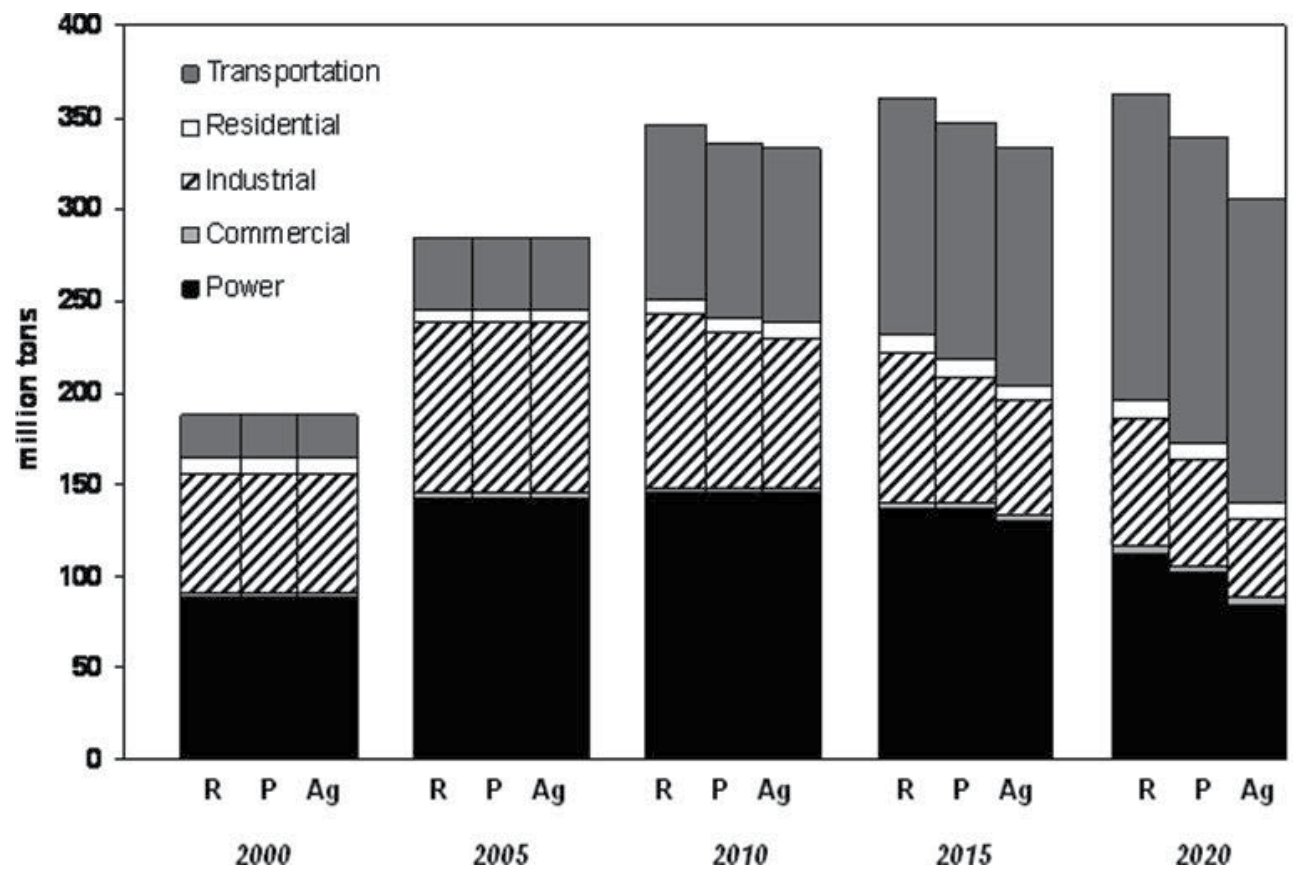

Top to bottom: Transportation; Residential; Industrial; Commercial; Power

Fig. 10. $\mathrm{CO}_{2}$ Emissions from Guangdong in the Reference, Plausible, and Aggressive Scenarios 


\subsection{Key findings}

There are five key findings on competitiveness of natural gas in China over the next two decades:

1. China is a supply-constrained environment for natural gas. Growth in gas demand in China could lead to a surge of natural gas imports, as demand is likely to far outstrip domestic supplies in certain parts of the country. This supply constraint provides an impetus for the Chinese government to seek out new supplies, such as a large international pipeline from Russia, Kazakhstan, or Turkmenistan, and more LNG regasification terminals. It should be noted, however, that such international supplies (especially via pipelines) are often challenging and time-consuming to realize.

2. Gas demand is highly dependent on financial policies. The current Chinese financial system provides extremely low costs of capital for the power sector. This makes the construction of capital-intensive coal-fired power plants especially attractive. Because coal and natural gas are in direct competition as the fuel source in most cases, this diminishes the opportunity for more natural gas combined cycle plants to be built. In Guangdong, for example, the MARKAL model would predict almost 50\% lower coal consumption by 2020 if a 10\% discount rate were applied to all sectors. While policies related to the banking system do not usually factor into considerations for planning an energy system, the study shows that this is an important aspect to consider in creating the right incentives for a sustainable energy plan.

3. The industrial sector can in some cases be more attractive for fuel switching than the power sector. The study found that looking outside of the power sector for fuel switching opportunities could prove to be a cost effective option. According to the model, a switch from coal to natural gas boilers would be cheaper than forcing a switch in power plants in the case of Shanghai where the industrial sector is currently dependent on inefficient coal boilers. Replacing an inefficient coal boiler requires much less upfront capital than converting a power plant from coal to natural gas. When there are enough boilers in the industrial sector to make a difference in emissions, this is an especially attractive alternative.

4. The fuel mix for electricity generation is unlikely to change dramatically. In all of the scenarios that were tested in the model, coal remains the dominant fuel in the energy mix. Coal is simply too cheap and abundant to leave unused (China has the world's third largest coal reserves). Aggressive sulfur reductions do shift the electricity mix somewhat towards a greater role for natural gas, but sulfur reductions can often be met more cheaply through fuel shifts in the industrial sector and by installing end-of-pipe solutions on coal plants.

5. Non-climate policies could have a large impact on carbon emissions. While China is unlikely to accept binding carbon dioxide emissions reductions targets in the near future, very large $\mathrm{CO}_{2}$ reductions might be realized as a side benefit from other policies enacted for reasons other than climate concerns. For example, in the case of China, a cap on $\mathrm{SO}_{2}$ emissions could have a significant effect on $\mathrm{CO}_{2}$ emissions by promoting the use of cleaner burning fuels and more advanced technology. An $\mathrm{SO}_{2}$ policy might be more palatable to the Chinese government than explicit $\mathrm{CO}_{2}$ regulation because it addresses immediate local concerns about air quality and health that directly affects its citizens. Such issues are much more likely to gain traction and spur change in the near term. 


\section{LNG in South America: Markets, prices and security of supply}

Markets, prices and security of supply of LNG in South America is now reviewed. Latin America has been in recent years one of the most intensive regions for natural gas and electricity development [24]. The region is very hydropower dependent (about $57 \%$ of the region's installed capacity is hydro) and the need to diversify away from heavy investments in hydropower and oil is driving many South American countries to promote use of natural gas, especially for power generation. Examples of these developments are in Brazil, Chile and Colombia. Countries of the region have great diversity in size, electrical installed capacity, electrical power demand, and electrical transmission/natural gas network characteristics (level of meshing and geographical extension). Figure 11 shows the share of hydro and thermal power and the installed capacity in some countries of the region (2003 data).

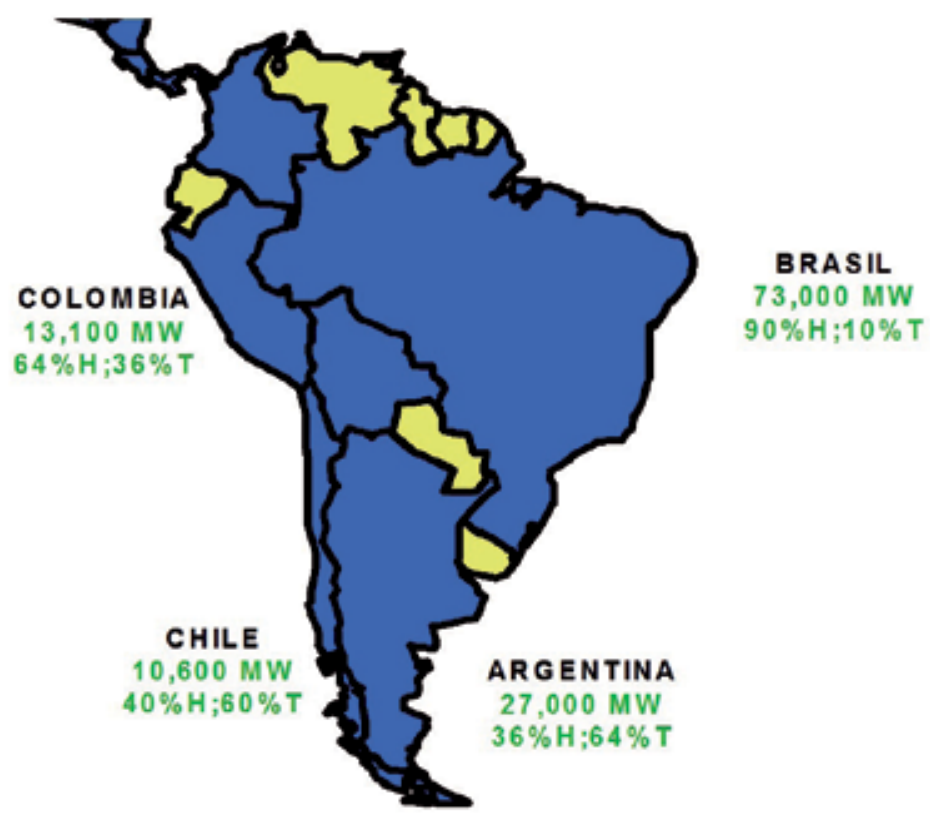

Fig. 11. South American Electricity Markets

Economic reforms have opened important sectors to private investors that were previously reserved to the State. This reform boosted the development of an infrastructure of electricity and natural gas pipelines in the region, both in each country separately and in cross-border electricity-gas interconnections.

The introduction of natural gas (NG) in the energy matrix of the countries took place in a more aggressive manner at the end of the 1990s, with construction of cross-border gas pipelines (Bolivia-Brazil, Argentina-Chile, etc) and the development of local gas production fields [24]. NG consumption for industrial and automotive use grew at quite significant rates and, in the electrical sector, the installation of gas-fired thermal generation also increased fast, representing the biggest potential market for the NG sector. Figure 12 presents an outlook of the potential demand and current gas reserves in the region. 


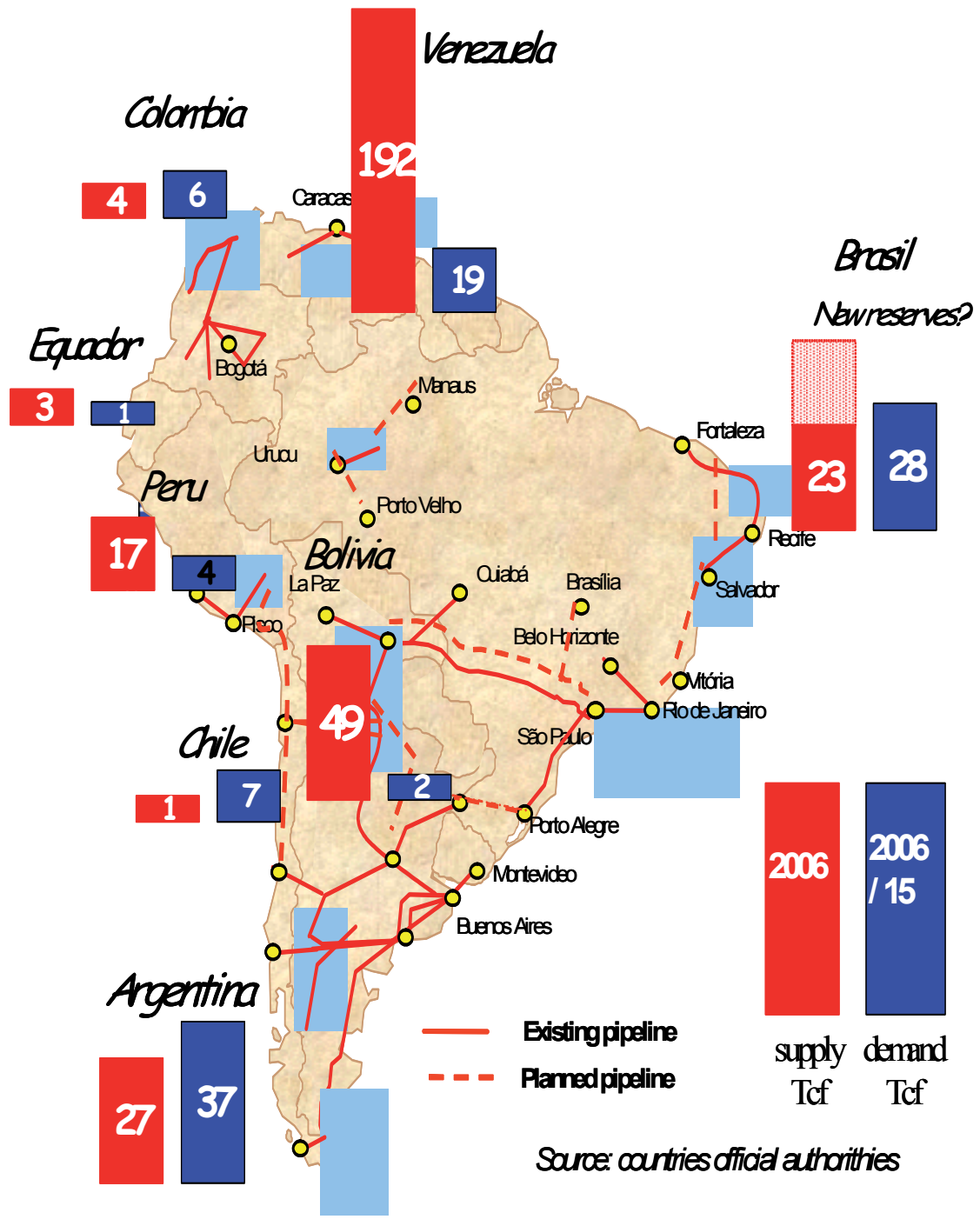

Fig. 12. Outlook of Potential Demand and Current Natural Gas Reserves in the South America Region.

While the "non-power" consumption of NG is practically constant (firm), gas consumption for thermal power plants is variable and strongly dependent on hydrological conditions. Hydro plants are able, during most of the time, to displace thermal energy production, which are then operated in complementation mode. This is achieved through hydrothermal coordination [25].

Over the period 2004-2008, Chile and Brazil decided to implement re-gasification plants to start importing LNG from 2009. Motivation for the two countries is quite similar: (i) to diversify the gas supply for the country (in case of Chile, to diversify from Argentina and in case of Brazil to diversify from Bolivia) and (ii) to create a flexible supply able to accommodate the use of gas to power generation. 


\subsection{LNG in South America: Markets, prices and security of supply}

\subsubsection{Why LNG?}

There are three main drivers behind LNG import and export in South America.

1. Gas imbalances: there are countries or sub regions with gas surpluses and others with deficits. Brazil, for example, has a growing potential natural gas market and still not enough gas production.

2. Security: in Brazil and Chile imports from neighboring countries have proven to be unreliable. and further dependence on supply from a single country is deemed to be undesirable.

3. Flexibility of gas supply: because of the hydro predominance in the region, gas-fired dispatch is very much volatile and flexibility is an attractive attribute.

\subsubsection{The markets}

LNG in South America is divided into importing countries with LNG re-gasification plants under construction (Brazil \& Chile), candidate importing countries (Argentina, Uruguay) and candidate exporting countries (Peru, Venezuela and Brazil in the future).

This means that LNG in South America is categorized into Brazil and Chile as importers. Figure 13 shows the LNG terminals. These countries are analyzed further.

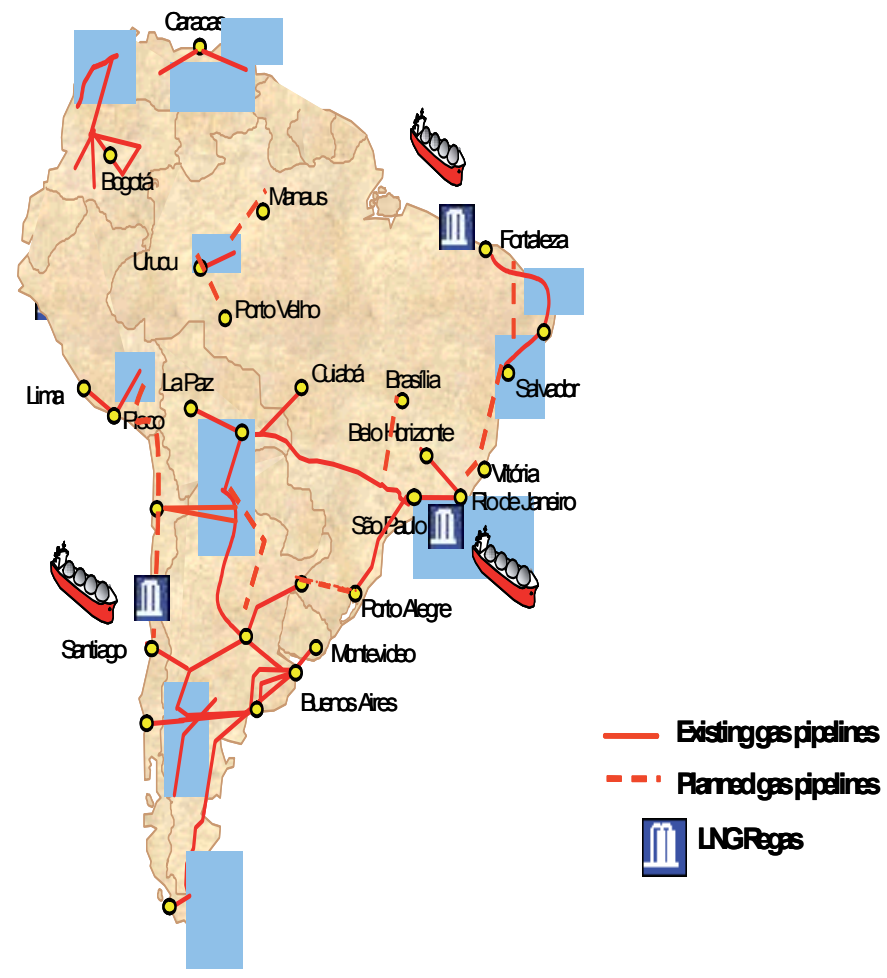

Fig. 13. South America LNG terminals 


\subsubsection{The prices}

The introduction of LNG will have several implications for the region's gas and energy markets, particularly in price benchmarks, energy security, and pipeline infrastructure.

LNG has an opportunity cost. Imported LNG could be more expensive than any regional gas supply and is likely to set a new price benchmark in almost all markets into which it is introduced. As LNG becomes more prominent in the energy mix, its link to global prices will create an inexorable pull on gas prices in previously isolated South American markets. LNG import prices in Latin America will also depend crucially on the timing of the different LNG projects.

\subsubsection{The security of supply}

The first reason for importing or exporting LNG is related to the region's natural gas balance: there are countries or sub regions with gas surpluses and others with deficits. The second reason is geopolitical and is related to energy security and the diversification of natural gas supplies and markets.

\subsection{Main challenges for LNG in Chile}

Chile has no significant local gas supply resources. The existing ones are located in the Southern part of the country, about $3,000 \mathrm{~km}$ away from the main demand centers. Chile started to import gas from Argentina in 1997. The Argentinean gas is responsible for the development of the Chilean gas industry and imports were responsible until 2004 for more than $70 \%$ of the country's gas supply, which is mostly concentrated in the central part of the country. The northern part of the country depends entirely on Argentina for their gas supply.

However, as discussed in [26], since 2004 Argentina has struggled to meet its own domestic gas needs and has started cutting exports to Chile. The total annual exports to Chile have been falling since 2005 and cuts started to be frequent and recently (2007) have reached as high as 95 percent of committed volumes on several occasions

\subsection{Main challenges for LNG in Brazil}

\subsubsection{Natural gas market in Brazil}

Ingress of NG in the Brazil energy matrix took place in a more aggressive manner at the end of the 1990s, with construction of the Bolivia-Brazil gas pipeline and development of local production fields. NG consumption for industrial and automotive use grew at quite significant rates (induced by tax benefit policies, by increase in supply and by prices) and, in the electrical sector, the installed gas thermal generation capacity also had a fast growth, so that in Brazil it accounts today for some $8000 \mathrm{MW}$. The question of natural gas supply for thermal generation has been the object of concern by the authorities ever since the conception of the new model for the Electrical Sector [27]. A recent (2006) "dispatch test" performed by Aneel (power sector regulator) in the gas thermal power plants disclosed that such concern is actually legitimate, because about $50 \%$ of the tested capacity in the South/ Southeast-Center West Regions did not manage to produce energy due to fuel deficiency. 


\subsubsection{The business model: LNG flexible supply}

The introduction of LNG is observed with interest by the electrical sector, for three main reasons: (i) to diversify gas supply sources, (ii) a contract market with shorter ranges and greater flexibility, and (iii) it is possible to build thermoelectric plants located relatively close to the major LNG delivery ports, thus avoiding investment (fixed costs) in gas pipelines.

In this manner, the final cost to the consumer of thermal energy produced from LNG may become more attractive. This is because the flexible supply of gas provided by LNG permits thermal power plants to be operated in the mode of complementing hydroelectric production and, therefore, fossil fuel is saved. As discussed in [28], the final consequence of this operation is the reduction of energy cost to the consumer ${ }^{2}$. Petrobras has announced its intention of contracting LNG to supply the Brazilian market in a flexible manner.

\subsubsection{Challenges for LNG supply}

LNG has one important characteristic: its price (as a commodity) strongly depends on how much in advance its order is placed. A LNG order placed one year in advance can normally have a fixed price, since the vendor has the possibility of contracting adequate hedges against the oscillations of the strongly uncertain and volatile international prices. On the other hand, a LNG order placed just a few weeks in advance has a price above that of usual references, associated to the opportunity cost of displacing this gas with respect to its destination market, and increased by an "urgency rate".

\subsubsection{Virtual gas storage: gas stored in hydro reservoirs}

The expectation of a LNG order for gas to be used in thermal dispatch may be frustrated by the occurrence of a more favorable hydrology than that expected. In this case, the requested natural gas would not be needed after the arrival of the liquefied gas carrier ships at the regasification stations.

\subsection{Virtual gas storage and smart electricity-gas swaps}

The introduction of flexible LNG supplies in the region can bring up several opportunities to integrate the electricity and gas markets in the region. This is because energy swaps with LNG are much more economical than the proposed point-to-point pipelines. An example of gas-electricity integration is the so-called "gas exports from Brazil to Chile without gas or pipelines". Essentially, Chile purchases $2000 \mathrm{MW}$ of electricity from Brazil, for delivery to Argentina (via the Brazil-Argentina DC link). The power from Brazil now displaces 2000 MW of gas-fired thermal generation in Argentina, which frees up $10 \mathrm{~mm}^{3} /$ day of natural gas supply, which is (finally) shipped to Chile.

\footnotetext{
${ }^{2}$ Thermal insertion in Brazil took place based on contracts for supply of inflexible gas, with 'take or pay' and 'ship or pay' clauses, which correspond to fixed payments, respectively to gas producer and to transporter. This way, the benefit of the operation and of the hydro-thermal synergy is not exploited, and the final cost of this technology becomes higher.
} 
Another example is the use of LNG against the proposed "Southern Gas Pipeline", from Venezuela to Brazil and Argentina.

In summary, the primary challenge for South American countries is to ensure sufficient capacity and investment to serve reliably their growing economies. The region has emerged as one of the most dynamic areas for natural gas and electricity developments. More recently, LNG has emerged as an attractive option. However, South America is a latecomer to the LNG business. Other regions and countries have already incorporated this external natural gas supply source in their portfolios for many years. An example of gas-electricity integration is the so-called "gas exports from Brazil to Chile without gas or pipelines". Essentially, Chile would purchase $2000 \mathrm{MW}$ of electricity from Brazil, for delivery to Argentina (via the existing 2,000 MW Brazil-Argentina DC link). The power from Brazil would displace $2000 \mathrm{MW}$ of gas-fired thermal generation in Argentina, which would free up $10 \mathrm{~mm}^{3}$ / day of natural gas supply, which would be (finally) shipped to Chile.

\section{Natural gas market dynamics and infrastructure development in South East Europe}

The status and outlook of the market dynamics and its related infrastructure in the South East Europe (SEE) is now discussed [29-32]. An important emphasis is given in the actual coalitions that will assist in the faster and more robust development of the gas sector in SEE, the existing infrastructure, the future projects that are under development or under study and the regulation that is needed in order to guide the above. The ultimate goal of these developments is the creation of a common financial market in the SEE region. Some of the most sensitive factors that have to be taken into consideration to smoothly accomplish the common market between the countries are also discussed.

SEE, during the last 5 years has demonstrated significant potential for development in the field of energy. More specifically, important projects and studies both in the electricity and gas sector have taken place. Since 2005, strategic developments in the sectors have entered a significant period where infrastructure and regulatory decisions from the SEE countries will define the energy map for the years to come.

\subsection{Context and status}

\subsubsection{Common market concept - The gas forum in Istanbul}

The countries of SEE are characterized by a low-level gas penetration. The use of power for heating is widespread in many of the region's urban areas. This has been identified as a problem in the "Framework for Development of Energy Trade in South East Europe " as power is a relatively inefficient means of providing heat, and the use of power for heat in South East Europe exacerbates energy affordability problems. From an environmental perspective, substituting gas for power for purposes of heating would result in lower greenhouse gas emissions given that the dominant form of power generation in the region is and will continue to be lignite based.

One obstacle to increased gas penetration is lack of a gas market in the region. The prevailing Russian gas monopoly has implications both for gas pricing and security of supply. Introducing competition to Russian gas through development of a gas market in the 
region would bring both price and security benefits. There is then scope for increased competition / diversification through transporting of Caspian gas across Turkey to SEE.

Recognizing the above needs, an Energy Community Treaty was created to develop a regional gas market. This Treaty is organized by the European Commission and basically requires that SEE countries undertake gas sector reforms through development of regulatory frameworks and industry unbundling with a view to increased gasification in each state and establish an integrated regional energy market and progressively ensure its integration into the European Community's Internal Energy Market.

The Istanbul Gas Forum was established to support development of a SEE Gas market and follow the implementation of the Treaty. The Gas Forum in Istanbul is to the countries of SEE what the European Gas Regulatory Forum in Madrid is to the EU countries. The aim is to facilitate development of a regional gas market and bring Caspian gas into the Balkans region, the key element being to establish a surer supply of gas for the Union. This is not only because Europe will have access to new sources from the east but because the new market will operate according to the EU's own rules reflected in the newly created energy community in SEE.

The Gas Forum in Istanbul comprises representatives of the European Commission, governments, regulators and transmission system operators of the countries of SEE, the Council of European Energy Regulators (CEER), the European Transmission System Operators (ETSO), representatives of donors, gas producing companies, and consumers. The Forum is co-chaired by the European Commission and a representative of the president in office.

The Gas Forum has created a regional plan with the following objectives:

- To implement national gas market reform in all signatory countries

- To implement international best practice in the wholesale gas markets and to facilitate cross-border trade

- To create regional and national gas markets, in part to reduce the environmental impact of existing thermal plants; and,

- To secure supplies for the region and the EU through the creation of a seamless integrated market between Vienna and Ankara.

\subsubsection{Actual situation of the gas market in SEE}

The countries of SEE are neither major natural gas producers nor consumers. Although the region does hold some fossil fuel deposits, these resources are not significant on a world scale. The gas market in the region is relatively underdeveloped considered as a whole, but this masks wide difference between the Eastern Balkans through into Turkey, and the Western Balkans through into Albania. In the Eastern Balkans and Turkey, gas use is either mature (Romania) or rapidly developing (Turkey and Bulgaria). In the Western Balkans, gas supply to Albania, Bosnia and Herzegovina, Croatia, FYROM, Montenegro, Serbia and UNMIK Kosovo is either underdeveloped or non-existent or has fallen into disuse (Montenegro and UNMIK have no gas infrastructure at all).

Natural gas is mainly used in industry and partly in power generation in the region (except in Bosnia and Herzegovina in which it is used in residential and commercial sectors and in Turkey in which it is used mostly for power generation). 
Most of the countries import natural gas only from Russia. Only Turkey has diversified their sources of supply, and only Romania, Croatia and Serbia have some domestic reserves.

In most Countries, postage stamp methodology is or is expected will be used for transmission. Tariffs are mostly determined and/or approved by Regulatory Authorities. However it is not yet clear whether such tariffs, as well as other features of third party access regimes in the region (with the exception of Romania) are suitable for the development of competition. In fact they are not used due to the lack of competitors.

While several pipelines physically link several countries, their transit rights are almost entirely attributed to long-term contracts for import from external sources. As a consequence, none of the countries has access to the other's market or facilities that may boost security of supply, like domestic production fields, storage plants and LNG terminals.

\subsubsection{Final goal: Creation of a financial common market similar to the NW Europe}

Firstly, improving the balance between energy supply and demand is crucial to improve and sustain economic development in SEE. This requires a strong legal commitment by the countries of the region towards market oriented reforms, regional integration and sustainable development, and investment security. This will offer significant advantages both in terms of improved utilization of existing supply and production capacities, but also in fostering more cooperation and integration in the region, which would result in economic growth, stability and investment.

Secondly, the security of supply of the European Union is based on diversifying supply of gas and in being politically able to counter threats to energy disruption in the European Union. By connecting this strategic area with the internal energy market, this will assist in assuring both the European Union's security of supply and that of the region.

The final goal is to achieve the fluidity level of the electricity and gas markets of NW Europe where many energy trading transactions occur each day promoting gas to gas competition and resulting to the lowest European gas prices in the wholesale gas markets such as those in UK, Holland and Belgium.

To achieve this goal the Energy Community Treaty has three operational parts:

i. The treaty will extend the application of the energy, environmental, renewable, competition and other parts of the acquis communautaire (legislation and rules decided at EU level). This will create a level playing field, though there will have to be credible, effective and policed transition dates.

ii. The treaty will create regional mechanisms that extend into the European Union to allow for deeper integration of local energy markets. This will for example mean enabling regulation allowing for accelerated infrastructure development, in particular for gas pipelines (especially new connections to the Caspian Sea and the Middle East).

iii. Given that the idea of a common energy market is central to the Energy Community, there is agreement to work toward common policies for external trade, mutual assistance and the removal of internal energy market barriers. 
The Energy Community Treaty provides that the states will:

- implement electricity and gas tariff reform plans;

- implement all necessary technical standards, such as grid codes, accounting systems and information exchange for the operation of the grid;

- implement effective third party access to infrastructure;

- create National Regulatory Authorities and transmission system operators;

- develop local solutions to pressing problems of regulation, energy poverty and social equity, and

- implement the gas and electricity directives.

\subsection{Actual infrastructure}

\subsubsection{Transmission, storage and distribution capacity}

The Natural Gas (NG) Transmission network is relatively underdeveloped in the region. The NG Transmission infrastructures are owned and operated by state companies.

Bulgaria, Croatia, Romania, Serbia and Hungary have underground storage with a total working Gas capacity of 7,500 mcm from which only Romania and Hungary have 6,000 mcm of storage working gas capacity. Turkey and Greece have LNG Terminals. Turkey has 2 LNG Terminals and Greece 1.

NG Distribution networks are relatively underdeveloped in the region. The distribution lines per capita index are significantly high in Croatia and Serbia. In all other Non-EU ECSEE Countries the distribution network is under fast development. Infrastructure in Hungary only is very well developed.

Sizeable total market is $47.5 \mathrm{bcm} /$ year in Non-EU ECSEE Countries and $103.4 \mathrm{bcm} /$ year in EU-ECSEE Countries (Italy, Hungary, Austria and Greece).

In the Non-EU ECSEE Countries, the weighted average share of gas in primary energy supply is $23.8 \%$, which is very close to that of EU Members average $(24 \%)$. Gas markets in Austria, Hungary and Italy feature high levels of per capita consumption and low expected growth rates; hence they can be regarded as mature markets. Among Non-EU ECSEE Countries the only relatively mature gas market in the region is Romania

Greek, Turkish, Serbian, Bulgarian and Croatian gas markets are expected to develop rapidly. In the remaining countries of the region gas consumption has either just started recently or is very little developed. Turkey and Romania consume $83 \%$ of the total consumption.

Natural Gas is mainly used in industry and partly in power generation in the Non-EU ECSEE and Greece. In more mature EU-ECSEE Countries consumption patterns are more mixed.

\subsubsection{Regulatory framework, market transaction and players}

Most of the countries in the region have opened theirs markets, and identifying at least some eligible threshold. 
All the countries in the region have their respective independent Regulators. Transmission System Operators (TSOs) and Distribution System Operators (DSOs) are in process of legal and managerial unbundling. Accounting unbundling is foreseen for almost all activities. Access to domestic pipelines is regulated in most of the countries in the region. However, as far as the transit network is concerned, access is in principle regulated in some countries of the region and is negotiated in others.

In most Non-EU-ECSEE Countries, postage stamp methodology is being or is expected to be used for transmission. Tariffs are mostly determined and/or approved by Regulatory Authorities. However, it is not yet clear whether such tariffs, as well as other features of Third Party Access regimes in Non-EU ECSEE countries and in Greece (with the exception of Romania), are suitable for the development of competition. In fact they are not used due to the lack of competitors.

\subsubsection{Actual technical problems for infrastructure development}

The inadequate gas infrastructure in all domains (transmission, distribution and storage) is based on the following:

- The domestic resources are limited (except Romania),

- No diversification of external supplies, including LNG,

- Non-EU ECSEE countries as well as Greece have no access to each other's markets or facilities that may boost security of supply, like domestic production fields, storage plants and LNG Terminals,

- The geology of the region where the major part of the territory in the region is covered by high mountain chains, and

- Poor experienced construction and manufacturer local companies in the gas industry (piping manufacturer, special machinery for construction etc.).

\subsection{Future development}

\subsubsection{Gas projects development}

The energy industry, represented by the International Association of Oil and Gas Producers (OGP) believes that the Caspian Region holds 6\% of the world's natural gas reserves, with $12,240 \mathrm{bcm}$, representing 178 years of gas supply at the current rate of production (148 $\mathrm{bcm} /$ year). Forecasts predict that production will double in 15 years. OGP also presented statistics and forecasts for Iran which possesses $27,500 \mathrm{bcm}$ of natural gas but which consumes slightly more than $85.5 \mathrm{bcm}$ annually which it produces. Together, Iran and Iraq could supply more than $100 \mathrm{bcm} /$ year to the export potential of the Caspian Region. Currently the gas production from the Caspian Region is between 80 and $100 \mathrm{bcm} /$ year. In comparison, the EU consumes approximately $500 \mathrm{bcm} /$ year, $55 \%$ of which is imported.

Infrastructure feasibility studies until now have dealt with four projects. The first is the Nabucco project linking Turkey with Austria via Bulgaria, Romania and Hungary. A second project is to link Bulgaria with Serbia, and a third, piloted by Edison Gas is to link Turkey with Italy passing through Greece but not Albania. In competition with this is a fourth project, piloted by the Swiss utility EGL with the intention of linking the Greek network with Italy, but this time via Albania. A fifth project, the "West Balkan connector" still in the 
study phase, will connect Greece with Slovenia via the FYROM, Serbia, Bosnia-Herzegovina and Croatia. All these projects will be examined by the World Bank and judged according to the benefits that they could offer the region

A recently announced project by the Russian Gas Giant Gazprom and ENI is the South Stream Pipeline. This pipeline will cross the Black Sea from the East (Russian Coast) to the West (Bulgarian Coast) bypassing Turkey and connect to the Bulgarian Gas Grid. From this grid it will be spit into two sub-streams: The south sub-stream will be connected to the gas grid and with use of the IGI Interconnector will bring Russian gas supplies to Italy and then to Europe. The north sub-stream will be routed to Austria via Serbia, Romania and Hungary. This last project will be in competition with the "Nabucco" project.

The List of the 10 major Gas Projects in SEE are indicated in Table 7:

\begin{tabular}{|c|c|c|c|c|c|c|}
\hline & $\begin{array}{l}\text { Planed/Proposed } \\
\text { Gas Routes }\end{array}$ & $\begin{array}{c}\text { Length } \\
(\mathbf{k m})\end{array}$ & $\begin{array}{l}\text { Capacity } \\
\text { (bcm/year) }\end{array}$ & Sponsor & $\begin{array}{l}\text { Cost } \\
(\mathrm{mill})\end{array}$ & Stage \\
\hline 1 & $\begin{array}{l}\text { South Caucasus } \\
\text { Pipeline }\end{array}$ & 960 & $7.1-22$ & BP-Statoil & $900 \$$ & $\begin{array}{c}\text { In } \\
\text { Operation }\end{array}$ \\
\hline 2 & $\begin{array}{c}\text { Turkey-Greece } \\
\text { Interconnector } \\
\text { (TGI) }\end{array}$ & 285 & $3.6-12$ & $\begin{array}{l}\text { Botas- } \\
\text { DEPA }\end{array}$ & $280 \$$ & $\begin{array}{c}\text { In } \\
\text { Operation }\end{array}$ \\
\hline 3 & $\begin{array}{l}\text { Greece-Italy } \\
\text { Interconnector } \\
\text { (IGI) }\end{array}$ & 804 & $8-12$ & $\begin{array}{l}\text { Edison- } \\
\text { DEPA }\end{array}$ & $1300 \$$ & $\begin{array}{c}\text { Advanced } \\
\text { Study } \\
(\exp 2011)\end{array}$ \\
\hline 4 & $\begin{array}{c}\text { Nabucco } \\
\text { (TR-BUL-ROM- } \\
\text { HUN-AUS) }\end{array}$ & 3400 & $25-30$ & $\begin{array}{l}\text { Botas- } \\
\text { Bulgargas } \\
\text {-MOL- } \\
\text { OMV }\end{array}$ & $4400 €$ & $\begin{array}{c}\text { Advanced } \\
\text { Study } \\
(\exp 2012)\end{array}$ \\
\hline 5 & $\begin{array}{l}\text { Hungary-Romania } \\
\text { Interconnector }\end{array}$ & 55 & $0.5-2$ & Trnasgaz & $20 \$$ & \\
\hline 6 & $\begin{array}{l}\text { Serbia-Bulgaria } \\
\text { Interconnector }\end{array}$ & 230 & 3 & $\begin{array}{c}\text { Bulgargaz } \\
\text {-NIS }\end{array}$ & & Study \\
\hline 7 & $\begin{array}{c}\text { Trans Adriatic (N) } \\
\text { (BUL-M-AL-IT) }\end{array}$ & & & EGL+ & & Study \\
\hline 8 & $\begin{array}{c}\text { Trans Adriatic (S) } \\
\text { (GR-AL-IT) }\end{array}$ & 570 & & EGL & & Study \\
\hline 9 & $\begin{array}{l}\text { Western Balcan } \\
\text { Corridor }\end{array}$ & & & $\begin{array}{c}\text { Relevant } \\
\text { Countries } \\
\text { TSO }\end{array}$ & & Study \\
\hline 10 & $\begin{array}{l}\text { South Stream } \\
\text { (RUS-BUL-GR- } \\
\text { SER-HUN-AUS }\end{array}$ & 900 & 30 & $\begin{array}{l}\text { Gazprom- } \\
\text { ENI }\end{array}$ & $1000 €$ & \\
\hline
\end{tabular}

Table 7. Major Projects in South East Europe 


\subsubsection{Regulation and liberalized market development}

Most benefits can only be achieved through a single common market, as most national markets in the region are too small.

Some of these benefits are:

- Negotiating for import supplies,

- Diversifying of gas sources,

- Ensuring security of supply through use of storage, interconnection and LNG facilities of each country,

- Exploiting economies of scale in gas transportation,

- Matching excess supply with excess demand markets in the short and long run, and

- Developing new long distance transmission infrastructure.

Consistently with the experience of the EU market opening according to the Directives 98/30/EC and 2003/55/EC, further research and regulatory effort should in particular address the following issues, with a view to ensure their necessary harmonization and their compatibility for a common market:

- Authorization and licensing regimes for existing and new transportation infrastructure,

- Technical standards and other obstacles to cross border exchanges, in comparison with the EASEE-gas process in the EU,

- Legal, fiscal and tariff barriers to cross border trade including destination clauses and other commercial restrictions,

- Independence and responsibilities of national market regulators,

- Stability, predictability and accountability of the regulatory framework,

- Regulated access to transmission, distribution and (at least in the medium term) storage and LNG facilities,

- Impact of existing and new long term contracts on competition in the region,

- Infrastructure capacity information and allocation criteria,

- Infrastructure financial viability under competitive conditions,

- Implementation of cost-reflective (preferably entry-exit) pricing mechanisms of transmission,

- Economically sound fair and non discriminatory public service obligation criteria,

- Legal and management unbundling of transmission and distribution operations,

- Criteria for release and availability of unused capacity,

- Promotion of gas consumption through environmentally consistent fiscal and regulatory policies,

- Increased cooperation and trade among ECSEE countries, and

- Promotion of measures to ensure security of supply on a non-discriminatory basis.

In summary, the actual status of the gas market in SEE has been reviewed. More specifically, emphasis on the actual coalition that assist the development of the gas market, the existing infrastructure, the future projects and the regulation that is currently set in place have been analyzed. The importance of existence of a common market to assist infrastructure development in the region has been identified. 
There is a fine geopolitical balance defined by US and Russian interests that are directly depicted from the projects under construction or study. Moreover, the provenance of funds from very different sources such as international organizations, countries, investment funds and utilities define an uneven order of priorities that might have a negative effect on overall development of the projects. Hence, there is a very delicate task submitted to all commissions, forums and boards that govern and supervise the process of development where a set of technical specifications and plans defining the projects have to be combined with a tense geopolitical situation.

\section{Conclusions}

1. As the electricity industry becomes more and more dependent on natural gas-fired generation, limits in the natural gas delivery system are becoming increasingly relevant to power system operation.

2. Dependence on gas imports to replace UK reserves for electric power generation is most likely to be both pricey and vulnerable to the loss of supply due to political instability.

3. With US and Canadian end-users adverse to long-term contracts for LNG there is risk that without committing to LNG it may not be available if needed in the future.

4. The gas share at thermal power plants of Russia, despite a sharp rise in gas price (from $50 \$ / 1000 \mathrm{~m}^{3}$ in 2007 to $170 \$ / 1000 \mathrm{~m}^{3}$ in 2020 ), can be decreased only $11-12 \%$ in favor of increase in the coal share, which to some extent will mitigate the rise in cost of electricity and centralized heat produced at Thermal Power Plants.

5. Growth in gas demand in China could lead to a surge of natural gas imports, as demand is likely to far outstrip domestic supplies in certain parts of the country. Fuel mix for electricity generation in China is unlikely to change dramatically. Non-climate policies could have a large impact on carbon emissions. Although China is unlikely to accept binding carbon dioxide emission reductions targets in near future, very large $\mathrm{CO}_{2}$ reductions might be realized as a side benefit from other policies enacted such as a cap on $\mathrm{SO}_{2}$ emissions.

6. There are opportunities for economic integration of regional gas-electricity markets in South America.

7. There are major projects under study and in operation for planned gas routes in South East Europe. The Caspian Region holds 6\% of the world's natural gas reserves and production will double in the next 15 years. There is a fine geopolitical balance defined by United Sates and Russian interests.

\section{Acknowledgement}

Contributing Authors include Raymond Johnson, (Manager Portfolio Development, Southern California Edison, CA, USA), Michael Urbina and Zuyi Li (Illinois Institute of Technology, USA), Vulkan Polimac (Polimac Ltd., Godalming, UK), George Hopley, Commodities Research and Michael Zenker, North American Gas and Power Research (Barclays Capital, San Francisco, USA), Nikolai Voropai, Victor Rabchuk, Sergey Senderov, and Natalia Pyatkova (Energy Systems Institute, Irkutsk, Russia), BinBin Jiang (Stanford University, USA), Chen Wenying (Tsinghau University, Beijing, China), Yu Yuefeng (Shanghai Jiaotong University, Shanghai, China), Zeng Lemin (Guangdong Techno- 
economic Research and Development Center, Guangzhou, China), Luiz Augusto Barroso (PSR, Rio de Janeiro, Brasil), Hugh Rudnick (Pontificia Universidad Catolica de Chile, Santiago, Chile), and Niko Iliadis (Energy Consultant, Athens, Greece).

\section{References}

[1] Z. Li, "Natural gas for generation: a solution or a problem?" IEEE Power and Energy Magazine, vol. 3, no. 4, pp. 16-21, July/August 2005.

[2] Z. Li and J. Guo, "Wisdom about age: understanding the aging electricity infrastructure," IEEE Power and Energy Magazine, vol. 4, no. 3, pp. 44-51, May/June 2006.

[3] Energy Information Administration, “International Energy Outlook 2007," available at www.eia.doe.gov.

[4] M. Shahidehpour, Y. Fu, and T. Wiedman, "Impact of natural gas infrastructure on electric power systems," Proceedings of the IEEE, vol. 93, no. 5, pp. 1042-1056, May 2005.

[5] M. Urbina and Z. Li, "A combined model for analyzing the interdependency of electrical and gas systems," Proceedings of the 39th North American Power Symposium, October 2007

[6] Y. Fu, M. Shahidehpour, and Z. Li "Security Constrained Unit Commitment with AC Constraints," IEEE Transactions on Power System, vol. 20, no 3, pp.1538-1550, August 2005.

[7] Y. Fu, M. Shahidehpour, and Z. Li, "AC contingency dispatch based on securityconstrained unit commitment," IEEE Transactions on Power System, vol. 21, no. 2, pp. 897-908, May 2006

[8] Y. Fu, M. Shahidehpour, and Z. Li, "Long-term security-constrained unit commitment: hybrid Dantzig-Wolfe decomposition and subgradient approach," IEEE Transactions on Power System, vol. 20, no. 4, pp. 2093-2106, November 2005

[9] A. Wood and B. Wollenberg, Power Generation, Operation and Control, John Wiley \& Sons, Inc, 2nd edition, 1996.

[10] Hisham Khatib; Financial and Economic Evaluation of Projects in Electricity Supply Industry, 1997.

[11] Statistical data of the Russian Committee for Statistics "Data on the use of fuel resources in 2005".

[12] Order No 156 of 05.07.2007 of the Federal Tariff Service of the RF “On the approval of the guidelines for determination of the gas wholesale price formula".

[13] Energy Strategy of Russia up to 2020 // Energeticheskaya politika. M.: FU IES Ministry for Energy of Russia, 2003. - 136 p.

[14] L.S. Belyaev, Yu.D. Kononov, A.A. Makarov. Methods and Models for Optimization of Energy Systems Development: Soviet Experience, (Review of Energy Models, No. 3, RR-76-18, 1976, pp. 22-33).

[15] J. Michel, J. Arceluz, E. Gordano et al, "IPR/DSM/LCP and Their Effect in Power System Planning" (CIGRE, 1996 Session, report 37-203, 11p.).

[16] S. Hecq, Y. Bouffioulx, P. Doulliez, Ph. Saintes, “The Integrated Planning of the Natural Gas and Electricity Systems Under Market Conditions", (2001 IEEE Porto Power Tech Conference Proceedings, September 10-13, 2001, Porto, Portugal, 4 p.). 
[17] N.I.Voropai, V.I. Rabchuk, S.M.Senderov et al. Assessment of possibilities to ensure national energy security up to 2020. Energeticheskaya politika, 2000, issue 1-2, pp.27-33.

[18] Jensen, J., 2004. The development of a global LNG market. Oxford Institute for Energy Studies NG 5

[19] U.S. Carbon Dioxide Information Analysis Center, U.S. Department of Energy (2007).

[20] China National Bureau of Statistics, 10 January 2006

[21] Noble, Ken et. al.(2005) MARKAL Training Workshop Support Notes, The Australian Bureau of Agricultural and Resource Economics, June 30, 2005.

[22] Jiang et. al "The future of natural gas vs. coal consumption in Beijing, Guangdong, and Shanghai: An assessment in MARKAL" (2007) Program on Energy and Sustainable Energy, Stanford University, Working Paper \#62

[23] Victor, D., Jaffe, A., Hayes, M. 2006. Natural Gas and Geopolitics: From 1970 to 2040. Cambridge University Press, Cambridge, U.K.

[24] IEA - South American Gas - Daring to Tap the Bounty, IEA Press, 2003.

[25] B. Bezerra, R. Kelman, L.A. Barroso, B. Flack, M.L. Latorre, N. Campodonico and M.V. Pereira. "Integrated Electricity-Gas Operations Planning in Hydrothermal Systems". Proceedings of the X Symposium of Specialists in Electric Operational and Expansion Planning, Brazil, 2006, pp. 1-7.

[26] H. Rudnick, "Electricity Generation and Transmission Expansion under Uncertainty in Natural Gas". Proceedings of IEEE 2005 PES General Meeting, San Francisco, 2005, paper 05GM1094, pp. 1-2.

[27] H. Rudnick, L.A. Barroso, C. Skerk, and A. Blanco. "South American Reform Lessons Twenty Years of Restructuring and Reform in Argentina, Brazil and Chile". IEEE Power and Energy Magazine, Vol. 3, (4) July/August 2005, pp. 49-59.

[28] L.A.Barroso, B.Flach, R.Kelman, B.Bezerra, S.Binato, J.M.Bressane, M.V.Pereira "Integrated Gas-Electricity Adequacy Planning in Brazil: Technical and Economical Aspects", Proceedings of IEEE General Meeting 2005, San Francisco, USA, Pages $866-872$.

[29] Energy Community (2005): Conclusions of 3rd Permanent High-Level Group (PHLG) Meeting 5 December 2006, Vienna.

[30] Energy Community (2005): Bottlenecks of SEE Gas Market \& Challenges, Donors Meeting.

[31] Energy Community (2006): New Gas Infrastructure Investment Regulation (NGIIR).

[32] Energy Community (2007): Implementation of the Treaty 


\title{
An Analysis of the Effect of Renewable Energies on Spanish Electricity Market Efficiency
}

\author{
Blanca Moreno ${ }^{1}$ and María Teresa García-Álvarez ${ }^{2}$ \\ ${ }^{1}$ University of Oviedo/Department of Applied Economics \\ ${ }^{2}$ University of La Coruna/Department of Economic Analysis and Business Administration \\ Spain
}

\section{Introduction}

The deployment of renewable energy is a key concept in European Union by environmental and economic reasons. This energy contributes to the securing of the objectives established by Kyoto Protocol of the United Nations Framework Convention on Climate Change (Kyoto, 11 December 1997) which entails that European Union has made the commitment to reduce their emissions by $8 \%$ during the period 2008-2012 and by at least 20\% below 1990 levels by 2020 .

In order to reduce emissions of carbon dioxide and others greenhouse gases, special strategies have been implemented to promote electricity generation from renewable within the regulatory framework of the European Union. The 2009/28/EC directive of the European Parliament on the promotion of the use of energy from renewable sources requires each member state to increase its share of renewable energies in energy mix to raise the overall share to $20 \%$ by 2020 . In Spain, the target means that renewable sources must account for at least $20 \%$ of final energy consumption by 2020 - the same as the EU average.

In Spain, the Renewable Energy Development Plan 2005-2010 -and the Renewable Energy Plan 2011-2020 which is concurrently being drafted, processed by the Industry and Energy Council of the Spanish government and the Spanish Institute for Energy Diversification and Saving-IDEA, set the policies and strategies to its deployment of renewable energies (RES). According to the first plan is expected a contribution from RES of $12.1 \%$ of primary energy consumption in 2010 and electricity generation from RES of $30.3 \%$ of gross electricity consumption. As a result of the design of policies to promote renewable energies, Spain has registered an increase in the share of electricity from RES from $17.8 \%$ in 1990 to $29.4 \%$ in 2009 as we can see in Figure 1.

The development of renewable energy industries became a way to achieve environmental objectives. Besides, provides several positive effects, mainly referred to the expected increasing in energy self-sufficiency, employment, investment and production, the improvement of opportunities of regional and local development and the creation of a domestic industry (Moreno and López, 2008). Some of those positive effects which have been quantified by Deloitte-Appa (2009) are: 
- A positive contribution of renewable energies to GDP in Spain. The increase of the industry of renewable energies in the period 2005-2008 gets a value of $55 \%$ in terms of GDP. The renewable technologies with greater impact on GDP have been wind energy, photovoltaic solar, biomass and mini-hydraulic.

- The development of the research, development and innovation activities. The high increase of some renewable production technology has entailed the creation of an important industry related to equipment and components fabrication with an innovative profile.

- The development of a fundamental concept in the environmental protection of Spain. The emissions of carbon dioxide $\left(\mathrm{CO}_{2}\right)$ are reduced in around 23,6 ton millions in the period 2005-2010.

- The increasing of employment in the renewable energy industry. The creation of employment has a value of 120.722 jobs until 2008 . The $62 \%$ of them is direct jobs and the remaining $37 \%$ is indirect employment.

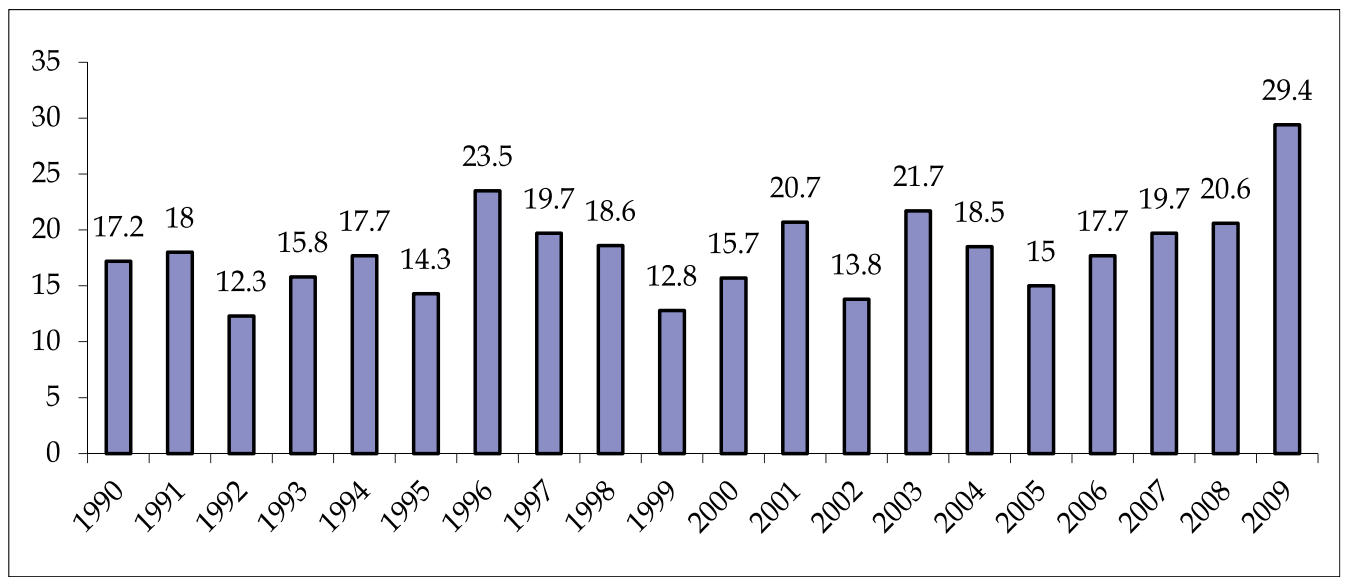

Fig. 1. Electricity generated from renewable sources, \% of gross electricity consumption. Source of data: Eurostat.

In contrast to the investment-induced positive production and employment effects, some disadvantages are associated to renewable technologies as those associated to their predictability and manageability, transportation systems, costs related to adjustments in production and their prices.

Regarding the RES-E effects on electricity prices a controversial debate has arisen. This chapter attempts to contribute to this debate.

The inclusion of electricity generation from renewable energy (RES-E) has been produced in a more liberalized electricity market. The energy market liberalization has been implemented across the European Union since 1996 (Directive 96/92/EC of the European commission concerning common rules for the internal market in electricity).

The electricity industry is progressively restructuring in order to reduce the amount of economic- productive and pricing- inefficiencies that existed in the former verticallyintegrated, state-owned monopoly regime. 
The creation on the wholesale electricity market is one of the key concepts in the Spanish electricity industry restructured process (Law 54/1997 and Law 17/2007).

Theoretically, competitive markets should lead to efficiency gains in the economy. However, the real benefits from increasing the competition are object of debate because the market's opening-up does not necessary imply market efficiency and competitive prices. It depends on the characteristics of the electricity supply and the electricity demand.

Regarding the electricity supply, the electricity generated from renewable energies is physically integrated into the wholesale electricity market and can influence electricity market efficiency and competitiveness.

These production technologies are characterized by having lower short-term marginal cost than fossil conventional Technologies (Jensen \& Skytte, 2003; Weigt, 2009). Therefore, their entrance in the electricity markets can allow the reduction of the wholesale electricity prices because they displace the marginal technology based on fossil fuel.

However, there is not clear evidence about the effect of the development of renewable energies on the final electricity prices as the development of renewable energy technologies is mainly driven by different public renewable support schemes. Most RES-E support systems are financed via the electricity market, which could increase the electricity prices.

Then, the overall effect of the RES-E on electricity prices is not clear.

Significant econometric evidence about the effect of renewables is not easy to find at country level. Traditional parametric methods require an elevated sample size for the efficient estimation of the coefficients in the models. However, the sample data regarding the introduction of renewables in the liberalized market is limited as legal opening electricity market in Spain finish in 2003. Therefore, when trying to estimate models through regression procedures a dimensionality problem arises.

As an alternative to explain the impact of RES-E on electricity prices we propose a model by using a Maximum Entropy Econometric approach.

This approach has been defined by Golan (2002) as "a sub-discipline of processing information from limited and noisy data with minimal a priori information on the datagenerating process". It has its roots in Information Theory and builds on the entropyinformation measure (Shannon 1948), the classical maximum entropy principle (Jaynes 1957a, 1957b), which was developed to recover information from underdetermined models, and the Generalized Maximum Entropy Theory (Golan et al., 1996).

We investigate its possibilities in the estimation of Spanish electricity market efficiency.

The chapter is structured in the following way: firstly, the effects of renewable energies on wholesale electricity market are studied; secondly, the main characteristics of the different mechanisms of renewable support used in the European Union are briefly described. Later, we analyze the promotion policies of this type of production technology in Spain and the consequent effects on the economy. After that, the Maximum Entropy Econometric procedure is described and finally the estimated effect of RES-E on Spanish electricity prices is presented.

Some concluding remarks complete the paper. 


\section{The effect of renewable energy on wholesale electricity market}

The electricity generated from renewable energies (RES-E) is physically integrated into the wholesale electricity market.

In wholesale electricity daily market (which sets the $89 \%$ of final electricity price in Spain), electricity generation selling companies determine, for every generation unit, the offered amount and price according to their short-term marginal cost, which is the variable cost of producing one extra unit of electricity (including the fuel, the emissions, and the operation and maintenance costs).

The supply curve is constructed according to the "merit order" of plants of different technologies in generation markets, ranking capacity from the cheapest to the most expensive (in terms of marginal costs). Plants with low marginal cost are used to cover base demand; plants with intermediate marginal cost operate in the middle of the merit generation and finally plants with high marginal cost are used to cover demand peaks. In parallel, electricity consumers establish the demanded amount.

Finally, supply and demand settle at the same marginal kWh cost of electricity. Thus, in the wholesale market all of the electricity producers get the same price according to the marginal kWh cost of electricity.

Suppose a wholesale market without RES-electricity plants (this is illustrated in Figure 2 below). The figure shows how the different types of production units typically offer electricity at different costs corresponding to their short-term marginal cost.

The production units with the lowest short-term marginal cost are nuclear plants followed by technologies based on coal and gas as combined heat and power or condensing power plants. The resulting price is the price level at which the supply and demand curves intersect.

RES-E is physically integrated into the market and will influence wholesale electricity price. These production technologies are characterized by having lower short-term marginal cost than other conventional technologies.

Therefore, their entrance in the electricity markets can allow the reduction of the wholesale electricity prices because they displace the marginal technology based on nuclear and fossil fuel. The introduction of RES-E thus changes the structure of power supply shifting the whole curve to the right and decreases marginal prices, due to the increased supply at low variable costs as we can see in Figure 3.

In addition, environmental costs related to $\mathrm{CO}_{2}$ emissions in electricity generation usually have a significant negative effect on electricity price as a $\mathrm{CO}_{2}$ emission trading scheme (ETS) exists. The substitution of conventional electricity generation by renewable energies could reduce the costs derived from environmental emissions and the electricity price.

Additional RES-E substitute electricity from fossil fuels, and thus $\mathrm{CO}_{2}$-emissions are reduced. The demand for emission reductions is lowered; as a result the $\mathrm{CO}_{2}$ price is also reduced and consequently the wholesale price for electricity decreases (Rathmann, 2007). 


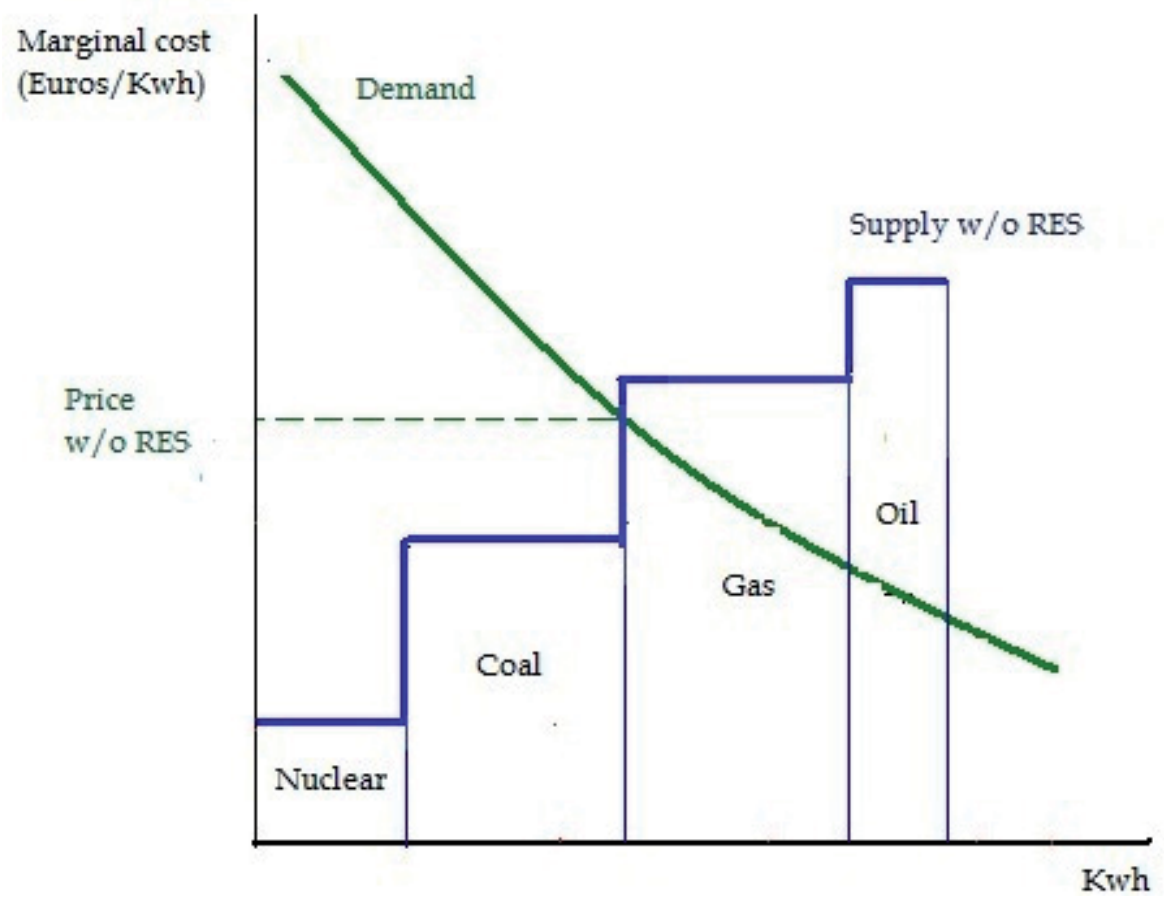

Fig. 2. Wholesale Electricity market without RES-E

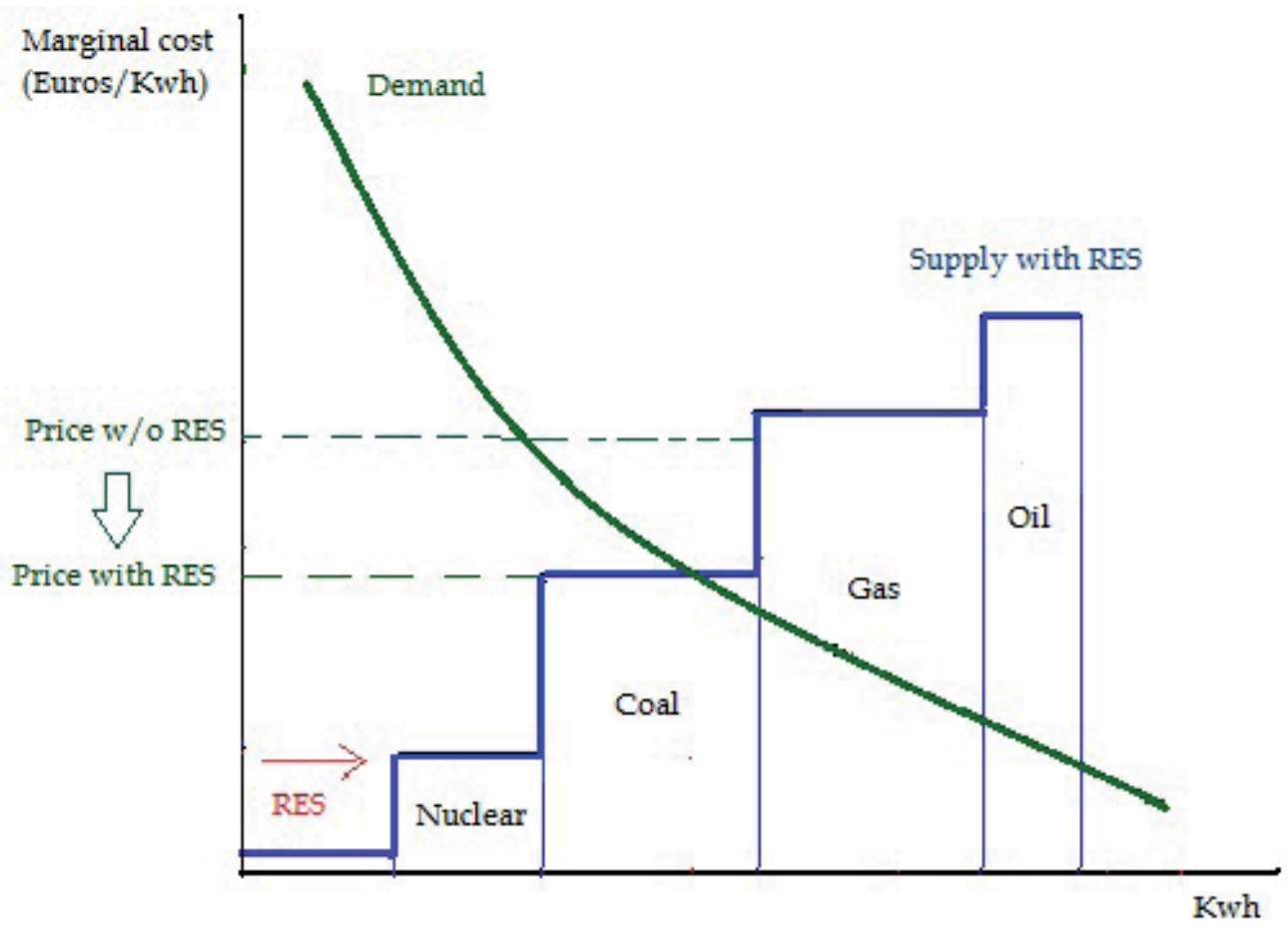

Fig. 3. Wholesale Electricity market with RES-E 
With increasing RES-E, the effect on wholesale market prices is starting to become significant in some countries, notably Denmark, Spain, and Germany (Klessmann et al., 2008, Sáenz de Miera et al., 2008). However, there is not clear evidence about the effect of the development of renewable energies entail on the final electricity prices.

A large share of RES-E power generally gives lower electricity prices, as it has been shown, reducing the profitability of investing in new electricity capacity (RES are characterised by high capital investment). If RES-E generators are exposed to market prices, it directly affects their market revenues.

In this context, the participation of the governments is necessary in the initial phase of the introduction of the new production technologies. It will allow to secure their development and to protect them from the direct competition of the conventional technologies.

Reiche \& Bechberger (2004) identify a number of success conditions for an increased use of RES: long-term planning security for investors, technology-specific remuneration for green power, strong efforts in the field of the power supply systems (grid extension, fair access to the grid, etc.) and measures to reduce local resistance against RES projects.

Therefore a higher use of renewable energies could reduce the wholesale electricity prices but as the development of RES-E is mainly driven by public renewable support schemes, which are financed via the electricity market, it could increased the final price paid by consumers.

\section{The promotion of the renewable energies in spain in the framework of the European Union}

Therefore, as the majority of renewable energy technologies are not profitable at current energy prices, their development is mainly driven by different public renewable support schemes: feed in tariffs, quota obligations, green-certificate trading, fiscal measures as tax benefits, investment grants, etc (a classification of the existing promotion strategies for renewals is provided in Haas et al., 2011).

Directive 2009/77/CE allows to each member state for the choice of mechanism of renewable energy promotion that can be better adapted to its characteristics. A revision of these measurements, in EU, shows the establishment of three types of mechanisms:

- feed-in tariffs,

- competitive auctions and

- the quotas of negotiable green certificates.

By means of the feed-in tariffs, renewable energy generators have right to sell all their production in the electricity wholesale market and to obtain, for it, a retribution based on a fixed price or in the daily price of electricity market plus an incentive that compensates the environmental value of the renewable production.

With the competitive auction systems, the regulator reserves a proportion of market for the production of renewable energy and develops the competition between generators that use these resources. Distributors have the obligation of acquiring the total of produced quantity in that reserved market. Therefore, by means of this mechanism, competition is centered on the price due to the production offers are sorted in an increasing order of prices until the proposal quantity was reached. 
The objective of the quotas of negotiable green certificates is that the produced energy from renewable sources can be converted in an integral part of the electricity market. For it, the government establishes the obligation that distributors have to acquire a certain percentage of their supply, generally that increases in the time, from renewable energy (fixed quota of electricity).

Feed in tariffs promotion support is placed in most of the European Union countries (see Table 1) with the exception of UK, Sweden, Italy, Belgium, and Poland where Quota-based systems are now in place (European Commission, 2008).

\begin{tabular}{|l|c|c|c|}
\hline & Feed-in tariffs & $\begin{array}{c}\text { Quotas of negotiable } \\
\text { green certificates }\end{array}$ & Auctions \\
\hline Austria & $\mathrm{X}$ & $\mathrm{X}$ & \\
\hline Belgium & $\mathrm{X}$ & & \\
\hline Bulgaria & $\mathrm{X}$ & & \\
\hline Chipre & $\mathrm{X}$ & & $\mathrm{X}$ (wind) \\
\hline Czech Republic & $\mathrm{X}$ & & \\
\hline Denmark & $\mathrm{X}$ & & $\mathrm{X}(>12$, except wind) \\
\hline Estonia & $\mathrm{X}$ & & \\
\hline France & $\mathrm{X}$ & $\mathrm{X}$ & \\
\hline Germany & $\mathrm{X}$ & $\mathrm{X}$ & \\
\hline Greece & $\mathrm{X}$ & & \\
\hline Hungary & $\mathrm{X}$ & $\mathrm{X}$ (wind) \\
\hline IreGeothermal & $\mathrm{X}$ (photovoltaic solar) & $\mathrm{X}$ & \\
\hline Italy & $\mathrm{X}$ & $\mathrm{X}$ & \\
\hline Latvia & $\mathrm{X}$ & $\mathrm{X}$ & \\
\hline Lithuania & $\mathrm{X}$ & $\mathrm{X}$ & \\
\hline Luxembourg & $\mathrm{X}$ & $\mathrm{X}$ & \\
\hline Malta & $\mathrm{X}$ & & \\
\hline HolGeothermal & & & \\
\hline PoGeothermal & & & \\
\hline Portugal & $\mathrm{X}$ & & \\
\hline Romania & & & \\
\hline Slovakia & & & \\
\hline Slovenia & & & \\
\hline Spain & & & \\
\hline Sweden & & & \\
\hline UK & & & \\
\hline & & & \\
\hline
\end{tabular}

Source: European Comission, 2008.

Table 1. Mechanisms of renewable energy promotion used in European Union

Therefore, the countries of European Union have introduced various support mechanisms to the renewable production technologies as there is not a consensus about which instrument is the most suitable. However, the experience shows that the development of a feed-in tariff system, that allows to guarantee an attractive profitability of the renewable installations, is effective in the promotion of the renewable energies. 
It is the case of Spain that has been characterized by introducing this mechanism from the first phases of the promotion in the renewable production technologies.The feed-in tariff ${ }^{1}$, in this country, entails two possibilities in the sale of electricity generated by renewable energies:

- $\quad$ to sell their surplus of electricity energy to a distributor where the reward will be given in the way of a feed-in tariff and it is calculated as a percentage of the medium or reference electricity tariff every year (see Table 2) or

- to sell their production surplus in the electricity production market or by means of a bilateral contract where the reward will be given by the negotiated market price, an incentive for their participation and a fixed premium.

\begin{tabular}{|c|c|c|c|c|c|c|c|c|c|c|}
\hline $\begin{array}{l}\text { Production } \\
\text { Technology }\end{array}$ & 1999 & 2000 & 2001 & 2002 & 2003 & 2004 & 2005 & 2006 & $\begin{array}{c}2007 \\
\text { R.D. } 436 \\
\end{array}$ & $\begin{array}{c}2007 \\
\text { R.D. } 661 \\
\end{array}$ \\
\hline \multicolumn{11}{|l|}{$\begin{array}{l}\text { Photovoltaic } \\
\text { solar }\end{array}$} \\
\hline$<5 \mathrm{~kW}$ & 39,6 & 39,6 & 39,6 & 39,6 & 39,6 & & & & & \\
\hline$>5 \mathrm{~kW}$ & 21,6 & 21,6 & 21,6 & 21,6 & 21,6 & & & & & \\
\hline$<=100 \mathrm{~kW}$ & & & & & & 41,441 & 42,149 & 44,038 & 44,038 & 44,038 \\
\hline $\begin{array}{l}>100 \mathrm{~kW} \text { and } \\
<=10 \mathrm{MW}\end{array}$ & & & & & & 21,621 & 21,991 & 22,976 & 22,976 & 41,75 \\
\hline $\begin{array}{l}>10 \mathrm{MW} \text { and } \\
<=50 \mathrm{Mw}\end{array}$ & & & & & & 21,621 & 21,991 & 22,976 & 22,976 & 22,976 \\
\hline Thermal solar & & & & & & 21,621 & 21,991 & 22,976 & 22,976 & 26,937 \\
\hline \multicolumn{11}{|l|}{ Wind } \\
\hline $\begin{array}{l}\text { Geothermal } \\
<=5 \mathrm{MW}\end{array}$ & 6,62 & 6,26 & 6,26 & 6,28 & 6,21 & 6,486 & 6,597 & 6,892 & 6,892 & 7,322 \\
\hline $\begin{array}{l}\text { Geothermal > } \\
5 \mathrm{MW} \text { and <= } \\
50 \mathrm{MW}\end{array}$ & & & & & & 6,486 & 6,597 & 6,892 & & \\
\hline Sea $<=5 \mathrm{MW}$ & & & & & & 6,486 & 6,597 & 6,892 & & \\
\hline Sea $>=5 \mathrm{MW}$ & & & & & & 6,486 & 6,597 & 6,892 & 6,892 & 7,8 \\
\hline \multicolumn{11}{|l|}{ Biomass } \\
\hline Energy crops & 6,5 & 6,15 & 6,15 & 6,17 & 6,85 & 6,486 & 6,597 & 6,892 & 6,892 & 15,889 \\
\hline \multicolumn{11}{|l|}{\begin{tabular}{|l|} 
Biomass from \\
agricultural \\
wastes
\end{tabular}} \\
\hline \begin{tabular}{|l} 
Biomass from \\
forestry \\
wastes
\end{tabular} & 6,73 & 6,36 & 6,36 & 6,38 & 6,49 & 6,486 & 6,597 & 6,892 & 6,892 & 6,89 \\
\hline
\end{tabular}

Source: Del Río (2008).

Table 2. Feed-in tariffs established in the Spanish electricity industry (sale option to distributor) (in hundredth part of Euro/kWh).

${ }^{1}$ The current legal framework of renewable energy in Spain is the Royal-Decree 661/2007. Later, Royal Decree 1578/2008 establishes a new tariff system for the photovoltaic solar energy. The new feed-in tariff system is based on the location of this type of plants: plants located on covers (type I) and plants located on the ground (type II). Order ITC/1723/2009 establishes an actualization of the tariffs and the premiums fixed for the renewable production technologies based on cogeneration and wastes. Likewise, the Royal Decree 1614/2010 establishes a restriction of the equivalent hours of functioning in the installations of wind production and thermal solar with right to premium and it supposes an updating of their premiums. 
By means of this new regulation, the reward of each renewable production technology is not homogenous but is given by the produced amount and the temporal horizon of each plant. Likewise, a reference premium and the upper and lower limits are established for every renewable production technology that participates in the wholesale market (see Table 3).

\begin{tabular}{|c|c|c|c|c|c|c|c|c|c|c|c|c|}
\hline $\begin{array}{l}\text { Production } \\
\text { Technology }\end{array}$ & 1999 & 2000 & 2001 & 2002 & 2003 & 2004 & 2005 & 2006 & $\begin{array}{l}2007 \\
\text { R.D. } \\
436\end{array}$ & $\begin{array}{c}2007 \\
\text { R.D. } 661 \\
\text { Reference }\end{array}$ & $\begin{array}{c}2007 \\
\text { R.D. } 661 \\
\text { Upper } \\
\text { limit }\end{array}$ & $\begin{array}{c}2007 \\
\text { R.D. } \\
661 \\
\text { Lower } \\
\text { limit }\end{array}$ \\
\hline \multicolumn{13}{|l|}{$\begin{array}{l}\text { Photovoltaic } \\
\text { solar }\end{array}$} \\
\hline$<5 \mathrm{~kW}$ & 36 & 36 & 36 & 36 & 36 & & & & & & & \\
\hline$>5 \mathrm{~kW}$ & 18 & 18 & 18 & 18 & 18 & & & & & & & \\
\hline$<=100 \mathrm{~kW}$ & & & & & & $\mathrm{a}$ & $\mathrm{a}$ & $\mathrm{a}$ & $\mathrm{a}$ & & & \\
\hline $\begin{array}{l}>100 \mathrm{~kW} \text { and } \\
<=10 \mathrm{MW}\end{array}$ & & & & & & 18,74 & 19,059 & 19,912 & 19,912 & & & \\
\hline $\begin{array}{l}>10 \mathrm{MW} \text { and } \\
<=50 \mathrm{MW}\end{array}$ & & & & & & 18,74 & 19,059 & 19,912 & 19,912 & & & \\
\hline Thermal solar & 0,03 & 0,03 & 0,03 & 12 & 12 & 18,74 & 19,059 & 19,912 & 19,912 & 25,4 & 34,397 & 25,403 \\
\hline \multicolumn{13}{|l|}{ Wind } \\
\hline $\begin{array}{l}\text { Geothermal } \\
<=5 \mathrm{MW}\end{array}$ & 3,16 & 2,87 & 2,87 & 2,89 & 2,66 & 3,603 & 3,665 & 3,829 & 3,829 & 2,929 & 8,494 & 7,127 \\
\hline $\begin{array}{l}\text { Geothermal > } \\
5 \mathrm{MW} \text { and <= } \\
50 \mathrm{MW}\end{array}$ & & & & & & 3,603 & 3,665 & 3,829 & 3,829 & & & \\
\hline Sea $<=5 \mathrm{MW}$ & & & & & & 3,603 & 3,665 & 3,829 & 3,829 & 8,43 & 16,4 & \\
\hline \multicolumn{13}{|l|}{ Sea $>=5 \mathrm{MW}$} \\
\hline \multicolumn{13}{|l|}{ Biomass } \\
\hline Energy crops & 3,04 & 2,76 & 2,76 & 2,78 & 3,32 & 3,603 & 3,655 & 3,829 & 3,829 & 11,529 & 16,63 & 15,41 \\
\hline $\begin{array}{l}\text { Biomass from } \\
\text { agricultural } \\
\text { wastes }\end{array}$ & & & & & & & & & & 8,211 & 13,31 & 12,09 \\
\hline $\begin{array}{l}\text { Biomass from } \\
\text { forestry wastes }\end{array}$ & & & & & & & & & & 8,211 & 13,31 & 12,09 \\
\hline
\end{tabular}

(a) Photovoltaic solar plants under R.D. 661 and below $100 \mathrm{~kW}$ under R.D. 436 do not have the premium option.

Source: Del Río (2008).

Table 3. Fixed premiums established in the Spanish electricity industry (sales to market) (in hundredth part of Euro/kWh).

In Spain the government support of renewable energies has suppose that Spain becomes a pioneering and leader country in the integration of renewable energies

The importance of renewable energies in Spain is observed in Figure 4. It shows the electricity generated by sources as percentage of the total in the year 2009. 


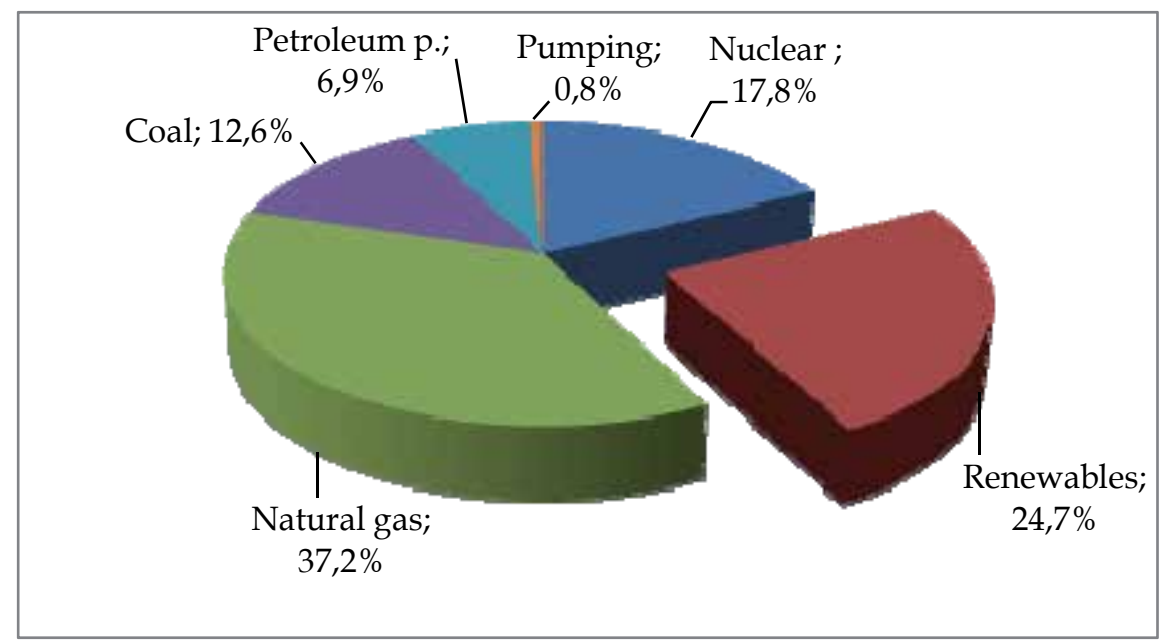

Fig. 4. Electricity generation by source (2009).

In fact, Spain is the second European country in terms of wind installed capacity and production, only behind Germany as we can see in Table 4. Spain is the fourth country in the world in terms of installed wind power after the US, Germany and China

The Spanish Renewable Energy Plan 2011-2020 processed by the Industry and Energy Council of the Spanish government and the Spanish Institute for Energy Diversification and Saving-IDEA shows that wind energy will continue to play a dominant role, accounting for $52 \%$ of renewable electricity production in 2020 (on- and offshore considered jointly).

\begin{tabular}{|c|c|c|c|c|c|c|c|c|c|}
\hline & $\mathbf{2 0 0 1}$ & $\mathbf{2 0 0 2}$ & $\mathbf{2 0 0 3}$ & $\mathbf{2 0 0 4}$ & $\mathbf{2 0 0 5}$ & $\mathbf{2 0 0 6}$ & $\mathbf{2 0 0 7}$ & $\mathbf{2 0 0 8}$ & $\mathbf{2 0 0 9}$ \\
\hline Germany & 8754 & 11994 & 14609 & 16629 & 18415 & 20622 & 22475 & 23903 & 25777 \\
\hline Spain & 3397 & 4891 & 5945 & 8317 & 10028 & 11630 & 15151 & 16740 & 19149 \\
\hline Italy & 697 & 788 & 904 & 1132 & 1718 & 2123 & 2726 & 3737 & 4185 \\
\hline France & 94 & 153 & 249 & 382 & 756 & 1737 & 2482 & 3542 & 4521 \\
\hline Sweden & 293 & 328 & 399 & 452 & 493 & 519 & 831 & 1021 & 1560 \\
\hline Unitd Kingdom & 474 & 552 & 649 & 933 & 1565 & 1961 & 2477 & 3406 & 4051 \\
\hline Portugal & 125 & 194 & 297 & 537 & 1047 & 1681 & 2150 & 2862 & 3535 \\
\hline Denmark & 2417 & 2889 & 3115 & 3125 & 3129 & 3135 & 3142 & 3166 & 3481 \\
\hline
\end{tabular}

Table 4. Installed wind energy (MW). Source: Eurobserver

\section{The impact of RES-E on electricity prices. A maximum entropy econometric estimated model}

Therefore, the increased participation of renewable energies is an important factor to explain the final electricity price in the liberalized electricity market. In this section, the effect of RES-E on electricity prices in Spain is explored by using a maximum entropy econometric model. The used data set are provided by Eurostat during the period 2003-2008 (available at the web site http://epp.eurostat.ec.europa.eu). 
Spanish electricity market liberalization has been progressively adopted since 1998 and finished 1st of July 2007.

The liberalization has the purpose of increasing efficiency of the energy sector following in a reduction of electricity prices. However, as we have seen previously RES-E affects the electricity prices in the liberalized market. We investigate this effect over the period 20032008 as legal opening electricity market in Spain finish in 2003.

Additionally, it is important to account others electricity generation technologies in empirical analysis as different technologies will result in different marginal costs and then different electricity prices. As it is showed in figure 5, generation is greatest proportion of electricity tariff costs, so the majority of variation in end-user prices should be accounted for by generation prices.

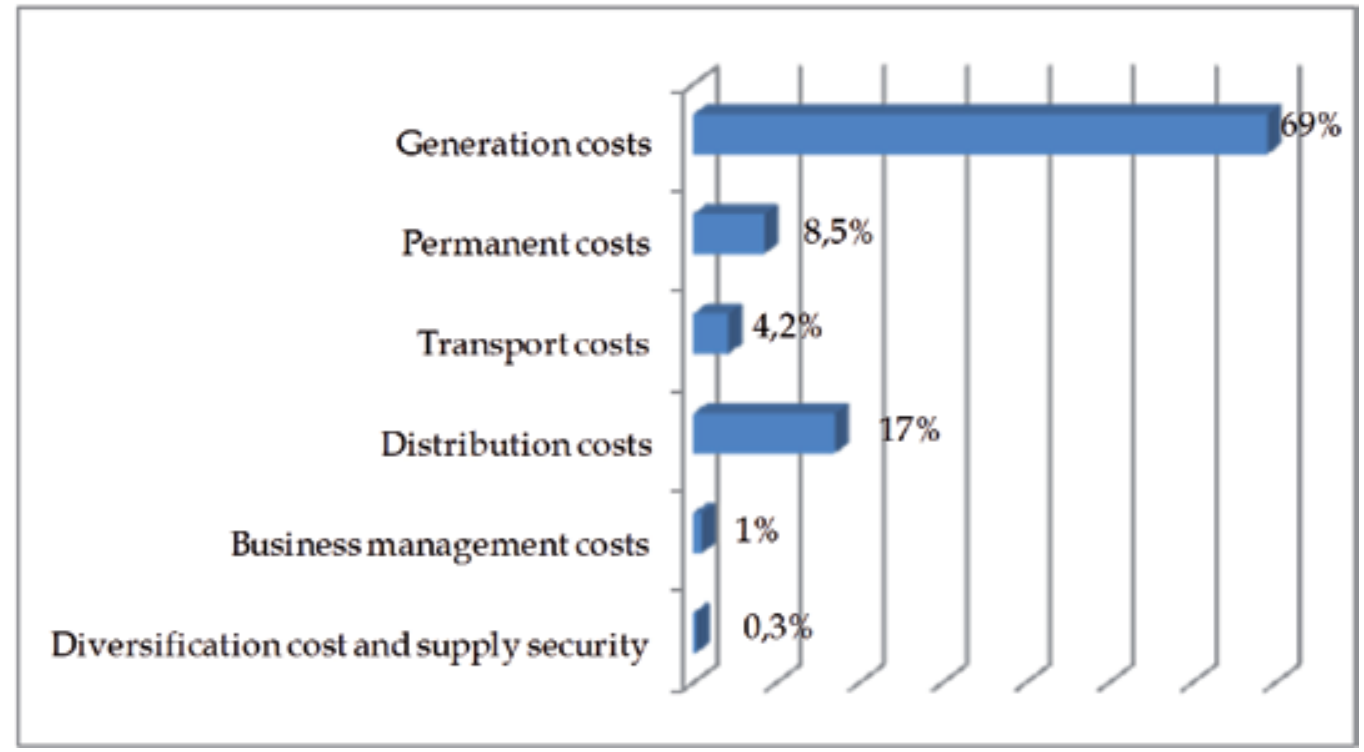

Fig. 5. Breakdown of electricity tariff costs. 2008

The goal of this section is to estimate the effect of several variables (m) related to electricity generation by RES and other sources on electricity prices $(y)$ by using data of several years (2003-2008, T=6): $y=X \beta+u$, being $X$ a matrix $\mathrm{T}_{X \mathrm{~m}}, y$ a matrix $\mathrm{T}_{X} 1, \beta$ the vector of coefficients to be estimated (vector $(\mathrm{m}+1) \times 1$, included a constant term) and $\mathrm{u}$ the vector of disturbances.

As dependent variable we use the Electricity prices for Household consumers (y). This indicator measures electricity prices charged to final consumers, which are defined as follows: Average national price in Euro per MWh without taxes applicable for the first semester of each year for medium size household consumers (Consumption Band Dc with annual consumption between 2500 and $5000 \mathrm{kWh}$ ).

The following explanatory variables $(\mathrm{m})$ related to the participation of different energies in the electricity generation and thus in the wholesale electricity market are proposed: 
- Electricity generated from renewable sources- \% Total gross electricity generation.

- Electricity generated from nuclear- \% Total gross electricity generation

- Electricity generated from natural gas- \% Total gross electricity generation

- Electricity generated from petroleum - \% Total gross electricity generation

- Electricity generated from hard coal- \% Total gross electricity generation.

Moreover, the following variables are also used:

- Greenhouse gas emissions by Energy industries as a total of Greenhouse gas emissions. The emission trading schemes affect the short-term marginal cost of energy industries, increasing the wholesale electricity prices and thus, the household electricity price. Ceteris paribus, a positive effect of this variable on electricity prices is expected.

- Gross Domestic Product per capita, GDP per capita: This variable aims to study the effect of the general economic activity on electricity prices. A positive effect of this variable on electricity prices is expected by keeping constant both known and unknown factors that may also influence the relationship between household electricity price and the GDP independent variables.

- Energy dependency: Spain has a high dependence (around 80\% levels) on imported resources such as crude oil and natural gas, therefore electricity prices are linked to such international energy commodities prices.

The estimation of $\beta$ by regression techniques requires that the number of observations was superior to the number of independent variables $(T>m)$. Nevertheless, information is limited ( $T=6$ and $m=9$-including a constant term) and when trying to estimate the electricity price models through regression procedures a dimensionality problem arises. Therefore, in a situation of limited sample data the estimation of the model by regression procedures (OLS) is not possible as the problem is undetermined or ill-posed. However, when these circumstances of small amount of information available make it unfeasible to estimate the model $y=X \beta+u$ through OLS procedures the Maximum Entropy Econometric approach allows to recover the estimates of $\beta_{1}, \beta_{2}, \ldots, \beta_{m}$ in the corresponding parameterized model without making distributional assumptions. The approach consists of developing a nonlinear inversion procedure (Golan et al. 1996) which requires the application of the tools provided by the Information Theory (Shannon, 1948; Jaynes 1957a, 1957b).

\subsection{Maximum entropy econometric approach}

Consider a regression-based method: $y=X \beta+u$ in a situation of limited sample data where $\mathrm{m}>\mathrm{T}$. A probability distribution should be used in order to represent partial and limited information regarding the individual observations so they are consistent with the observed sample data. Therefore, following Golan et al. 1996 it is possible to define an inverse general problem for recovering $\beta$ defined as: $y=X \beta+u=X P+u$, where $P:\left(p_{1}, \ldots, p_{m}\right)^{\prime}$ is a mdimensional vector of unknown terms related to the probability distribution. The main objective is to estimate a probability distribution $\mathrm{P}$ given the limited information and minimal distributional assumptions and therefore recover $\beta$ as $\hat{P}=\hat{\beta}$.

However, as the number of observations (T) is smaller than the number of independent variables $(\mathrm{m})$, in order to recover $\mathrm{P}$ by using traditional procedures of mathematical 
inversion, there is more than one vector $\mathrm{P}$ making the solution feasible. Therefore the problem is ill-posed and there is no basis for picking a particular solution vector for $\mathrm{P}$ from the feasible set. Thus, by asking for a particular set of probabilities considered as most likely, it seems reasonable to favour the one that could have been generated in the greatest number of ways given the available data.

The definition of the entropy measure $\mathrm{H}(\mathrm{P})$ and the formulation of the Entropy Maximization problem can help to estimate a unique $\mathrm{P}$ distribution since the principle of Maximum Entropy provides a basis for transforming the sample information into a probability distribution that reflects the uncertainty about the individual outcomes.

The measures of entropy $\mathrm{H}(\mathrm{P})$ quantify the uncertainty associated with a random experiment. In particular, given a random variable $\mathrm{X}$ with values $\mathrm{xi}$ and probability distribution $P=\left(p_{1}, \ldots, p_{n}\right)$ with $p_{i} \geq 0 \quad(\mathrm{i}=1 \ldots, \mathrm{n})$ and $\sum_{i=1}^{n} p_{i}=1$, Shannon's measure of entropy (Shannon 1948) is defined as: $H_{S}(P)=H_{S}\left(p_{1}, \ldots, p_{n}\right)=-\sum_{i=1}^{n} p_{i} \log p_{i}$.

The value of the entropy is maximum when all the values $x_{i}$ have the same probability (and then $\mathrm{P}$ is a uniform distribution). This situation would be justified by the Laplace Indifference Principle, according to which the uniform distribution is the most suitable representation of the knowledge when the random variable is completely unknown. Nevertheless, sometimes the ignorance of the probability distribution of $X$ is not absolute and there is some partial information on the distribution such as the mean, variance, moments or some characteristics which can be formulated as equality constraints. In such a case, it is possible to estimate the probability distribution through the application of the Maximum Entropy principle (Jaynes 1957) choosing the distribution for which the available information is just sufficient to obtain the probability assignment.

Thus, if certain values $a_{r}(\mathrm{r}=1 \ldots, \mathrm{s})$ associated with functions $g_{r}(X)$ of the values of $\mathrm{X}$ are known but its distribution is unknown, the problem consists of estimating a nonnegative distribution that fulfils the conditions $p_{i} \geq 0$ for $\mathrm{i}=1 \ldots, \mathrm{n}$ and $\sum_{i=1}^{n} p_{i}=1$, maximizing the value of the entropy.

By solving the maximization problem it is possible to obtain the estimated probabilities $\hat{P}=\left\{\hat{p}_{1}, \ldots, \hat{p}_{n}\right\}$. The maximum entropy distribution does not have a closed-form solution and therefore numerical optimization techniques must be used to compute the probabilities.

Working towards a criterion for recovering the parameters of the regression model related to electricity price in the general inverse problem $y=X \beta+u=X P+u$, if there is no evidence that a specific independent variable is more significant than others, the related probability distribution (P) would be the uniform (according to Laplace Indifference Principle). However, the principle of maximum entropy provides a basis for using the sample information in a probability distribution $\mathrm{P}$ that reflects the uncertainty about the individual independent variable. Therefore, the problem consists of estimating a nonnegative distribution $\mathrm{P}$ by 
maximizing the value of the entropy $\mathrm{H}(\mathrm{P})$ subject to the available information. By solving the optimization problem the estimated probability distribution $\hat{P}$ is obtained.

A general inverse problem $y=X \beta+u=X P+u$ it is considered where the goal is to determine the unknown and unobservable frequencies $P=\left(p_{1}, \ldots, p_{m}\right)^{\prime}$, representing the data generating process. Then, within the possible sets of probabilities fulfilling $\sum_{i=1}^{m} p_{i}=1, p_{i} \geq 0$, a single vector must be chosen. Through the application of the principle of maximum entropy $\mathrm{H}(\mathrm{P})$ is maximized under the restrictions of information consistency $y=X \beta+u$, and the adding up-normalization constraint for $P: P^{\prime} \ell=1$.

If the vector of disturbances, $\mathrm{u}$, is assumed to be a random vector with finite location and scale parameters, it is possible to represent the uncertainty about it by treating each $u_{t}(\mathrm{t}=1$, ..., T) as a finite and discrete random variable with $2 \leq J \leq \infty$ possible outcomes.

Thus, it is assumed that each $u_{t}$ is limited by an interval $\left(v_{t 1}, v_{t J}\right)$, whose probability, $\operatorname{Pr}\left(v_{t 1}<u_{t}<v_{t J}\right)$, can become as small as it is wanted. For example, for $\mathrm{J}=2$, the error can be defined as: $u_{t}=w_{t} v_{t 1}+\left(1-w_{t}\right) v_{t J}$ where each $w_{t} \in[0,1]$ is a vector of error weights. Furthermore, $J \geq 2$ can be used to assume certain characteristics of symmetry and kurtosis about the error distribution.

Because there may be different levels of uncertainty underlying each $\beta_{i}$, for more general inferential purposes, point estimates may be limiting and unrealistic. Consequently, it is possible to generalize the maximum entropy problem to permit a discrete probability distribution to be specified and obtained for each $\beta_{i}$. Rather than search for the point estimates of $\beta$, each $\beta_{i}$ is viewed as the mean value of some well defined random variable $\mathrm{z}$.

Then, for each $\beta_{i}$, it is assumed there exists a discrete probability distribution that is defined over a parameter space $\mathbb{R}^{K}$ by a set of equally distanced discrete points $z_{i}=\left[z_{1}, \ldots, z_{K}\right]^{\prime}$ with corresponding probabilities $p_{i}=\left[p_{i 1}, \ldots, p_{i K}\right]^{\prime}$ and with $K \geq 2$. Therefore: $\beta_{i}=E_{P_{i}}\left[z_{i}\right]$ or $\beta=E_{P}[z]$.

Using the Maximum entropy econometric approach, one investigates how "far" the data pull the estimates away from a state of complete ignorance (uniform distribution). In order to measure the reduction in the initial uncertainty, the information index entropy measure $R$ is defined (Golan, 1994; Soofi 1992, 1994) and where $R \in[0,1]$. Higher is the value of $R$ better is the estimated model.

Moreover, some measures are defined to evaluate the information in each one of the variables $\mathrm{i}=1,2, \ldots, \mathrm{m}$ as the normalized entropy: $S\left(\hat{p}_{i}\right)$. These variable-specific information measures reflect the relative contribution (of explaining the dependent variable) to the independent variable. Where $S\left(\hat{p}_{i}\right) \in[0,1]$, zero reflects no uncertainty while one reflects total uncertainty in the sense that $\mathrm{P}$ is uniformly distributed. 


\subsection{Maximum entropy econometric estimated model}

For the solution of the optimization the GAMS program version 21.3 (General Algebraic Modeling System) is used. This is a programming language which allows diverse optimization problems to be solved.

A general maximum entropy model with a reparametrized error is considered.

Firstly, it is necessary to establish an a priori range for the possible values that may be assumed by $\mathrm{u}$ error in the model, which may be employed to assume certain characteristics of its distribution: $V$. Since this decision is arbitrary, a support vector for the errors $(-\mathrm{v},-\mathrm{v} / 2$, $0, \mathrm{v} / 2, \mathrm{v})$ for $\mathrm{v}>0$ it is assigned. It guarantees error's symmetry around zero. The decision regarding the amplitude of the range of values which it may assume is arbitrary. According with Pukelsheim (1994) support vector v can be assessed if the variability presented on y was knonwn and it would be possible to use the three standard deviation rule as estimation for v. In fact, the proposal of Golan et al (1997) who use the sample variance of y as an estimate for $\mathrm{v}$ is used. In sample data used the variance of $y$ is 9,6 (euros/MWh) and then $v=16,15$. However, as a widening of the error bound by increasing $\mathrm{v}$ the estimated weights converge on the uniform distribution (the difference between the weights of the variables is reduced), the most reduced $v$ that makes the solution feasible $(v=18)$ is used.

Moreover, a priori range for the possible values that may be assumed by $\beta$ in the model is also established. Thus, the support space $Z$ has to be chosen, and then use the data to estimate the $\mathrm{P}$ which in turn yields $\beta$. The restrictions imposed on the parameter space through $\mathrm{Z}$ should reflect the prior knowledge about the unknown parameters. However, such knowledge is not available as the estimated models are scarce, and a variety plausible bound on $\beta$ may want to be entertained.

However, a vector support symmetrical and centered on zero is considered according with the value ranking that the independent variables may take. Moreover, as an initial approximation, a covariate matrix was calculated and negative values in $\beta$ was finding. So, $\mathrm{Z}=(-\mathrm{z}, 0, \mathrm{z})$ was considered $(\mathrm{z}>0$ which guarantees its symmetry around zero). The same $\mathrm{z}$ for all coefficients $(\mathrm{z}=0.6)$ was located. It implies to be very cautious in the interpretation of the estimated $\hat{\beta}$. As $S\left(\hat{p}_{i}\right)$ are reported and $S\left(\hat{p}_{i}\right) \cong 1$ implies $\beta_{i} \cong 0$ a natural criterion for identification of the information content of a given $x_{i}$ is just the normalized entropy.

Table 5 shows estimated weights for the electricity price $(\beta)$ under the reparameterized system.

The reported estimated coefficients for the model correspond with highest $\mathrm{R}$ obtained. The results are those obtained under the narrowest $\mathrm{V}$ vector.

The estimated information index $\mathrm{R}=0,67$ indicates a reduction of the uncertainty by using the maximization entropy approach, however, the findings yield that the variable Electricity generated from renewable energies (RES-E) have sense to explain electricity prices as $S\left(\hat{p}_{i}\right) \cong 0,38$. Electricity from RES contributes a reduce prices as negative sign is found.

Also natural gas and energy dependency contributes to explain the increasing in electricity prices. 


\begin{tabular}{|l|c|c|}
\hline \multicolumn{1}{|c|}{ Variables } & $\hat{\beta}_{i}$ & $S\left(\hat{p}_{i}\right)$ \\
\hline Electricity generated from RES & $-0,516$ & 0,383 \\
\hline Electricity generated from nuclear & 0,522 & 0,366 \\
\hline Electricity generated from natural gas & 0,503 & 0,425 \\
\hline Electricity generated from petroleum & 0,596 & 0,035 \\
\hline Electricity generated from hard coal & $-0,323$ & 0,790 \\
\hline GHG energy indutries & 0,477 & 0,496 \\
\hline GDP per capita & $-0,323$ & 0,790 \\
\hline Energy dependency & 0,598 & 0,014 \\
\hline Support vector for the errors (-v, -v $/ 2,0, \mathrm{v} / 2, \mathrm{v})$ & $\mathrm{v}=$ & 18 \\
\hline Support space for coefficients $(-\mathrm{z}, 0, \mathrm{z})$ & $\mathrm{z}=$ & 0,6 \\
\hline Estimated information index & $\mathrm{R}=$ & 0,67 \\
\hline
\end{tabular}

Table 5. Estimated Household electricity price model by Maximum entropy econometric approach

Energy dependency has also an important effect. Spain has a high rate of energy dependency due to the scant presence of primary fossil fuel deposits. That great dependence introduces some risk to energy generation related to volatility of international market prices.

\section{Conclusion}

The creation on the wholesale electricity market is one of the key concepts in the Spanish electricity industry liberalization process (Law 54/1997 and Law 17/2007). Theoretically, competitive markets should lead to efficiency gains in the economy. However, the real benefits from increasing the competition are object of debate because the market's openingup does not necessary imply market efficiency and competitive prices. It depends on the characteristics of the electricity supply and the electricity demand.

Regarding the supply side, the generation from renewable sources became an important share of the total electricity generation. Over the last years Spanish electricity generation from renewable sources (RES-E) has rapidly risen accounted for approximately $25 \%$ of total electricity generation in 2009. The largest part of the electricity generation by RES is devoted to wind power and hydro which are in the forefront accounting for over $86 \%$ of total renewable electricity ( $52 \%$ and $36 \%$ respectively). It follows by solar photovoltaic $(8 \%)$, biomass (3.2\%), municipal solid waste $(1,2 \%)$ and solar thermoelectric $(0,1 \%)$.

According to the Spanish Renewable Energy Plan 2011-2020 processed by the Industry and Energy Council of the Spanish government and the Spanish Institute for Energy Diversification and Saving-IDEA these renewable resources will meet $36 \%$ of electricity demand in 2020.

Therefore, the electricity generated from renewable energies become more integrated into the wholesale electricity market and can influence electricity market efficiency and competitiveness. 
An electricity generation technology based on renewable energies produce a least-cost merit order in the wholesale electricity market and its associated efficiency gains should also lead to lower electricity prices. However, there is not clear evidence about the effect of renewable energies on the final electricity prices.

A large share of RES-E power generally gives lower electricity prices reducing the profitability of investing in new electricity capacity. If RES-E generators are exposed to market prices, it directly affects their market revenues.

In this context, the participation of the governments is necessary in the initial phase of the introduction of the renewable electricity generation technologies for securing their development and protecting them of the direct competition that suppose the conventional technologies.

In Spain, the public support in electricity generation using renewable energies is the feed-in tariff which guarantees a price higher than that existing in the wholesale market for the renewable technology employed. This cost increment is financed by electricity tariffs.

Therefore, although large share of RES-E power generally gives lower wholesale electricity prices, a controversial debate has arisen about the RES-E effects on final electricity prices.

In order to contribute to this debate, in this chapter we propose a maximum entropy econometric model with the aim of explaining the electricity prices as a function of variables related to renewable energy sources and other electricity generation sources.

The sample data regarding the introduction of renewables in the wholesale is limited and when trying to estimate models through regression procedures a dimensionality problem arises. As an alternative to estimate the model, when a dimensionality problem arises, we propose a Maximum Entropy Econometric approach.

The obtained results show that electricity generated by reneawable energies contributes to increase final electricity prices. But also, the most important variables affecting prices is energy dependency. Spain has a high dependence (around 80\% levels) on imported resources such as crude oil and natural gas (100\%), therefore electricity prices are linked to such international energy commodities prices and introduces some risk to energy generation related to volatility of international market prices.

\section{References}

Del Río, P. (2008). Ten years of renewable electricity policies in Spain: An analysis of successive feed-in tariff reforms. Energy Policy, Vol. 36, (August, 2008), pp. (29172929), ISSN 0301-4215.

Deloitte-Appa (2009). Estudio macroeconómico del impacto de las energías renovables en la economía española, Asociación de Productores de Energía Renovable, Madrid.

European Commission (2009). Directive 2009/28/EC of the European Parliament and of the Council of 23 April 2009 on the promotion of the use of energy from renewable sources 
and amending and subsequently repealing Directives 2001/77/EC and 2003/30/EC. Official Journal of the European Union OJ L140 of the 5/6/2009 p. 16-62: 2009, Brussels.

European Commission (2008). The Support of Electricity from Renewable Energy Sources Accompanying Document to the Proposal for a Directive of the European Parliament and of the Council on the Promotion of the Use of Energy from Renewable Sources, $\operatorname{COM}(2008)$ 19, SEC(2008) 57: 2008, Brussels.

European Commission (2001). Directive 2001/77/EC of the European Parliament and the Council of 27 September 2001 on the promotion of electricity produced from renewable energy sources in the internal electricity market. L283/33-40. Official Journal of the European Union OJ L283 of the 17/10/2011, Brussels.

European Commission (1996). Directive 96/92/EC of the European Parliament and of the Council of 19 December 1996 concerning common rules for the internal market in electricity. Official Journal of the European Union OJ L27 of the 30/1/1997, Brussels.

Golan, A. (2002). Information and entropy econometrics -Editor's view. Journal of Econometrics, Vol. 107, (January, 2002), pp. (1-15), ISSN 0304-4076.

Golan, A., Judge, G. and Perloff, D. (1997). Estimation and inference with censored and ordered multinomial response data. Journal of Econometrics, Vol. 79, (July, 1997), pp 23-51. ISSN 0304-4076.

Golan, A., Judge, G. \& Miller, D. (1996). Maximum Entropy Econometrics: robust estimation with limited data, John Wiley \& Sons Ltd, ISBN 0-471-95311-3, London.

Golan, A. (1994). A multi-variable stochastic theory size distribution of firms with empirical evidence. Advances in Econometrics, Vol. 10, (December, 1994), pp (1-46), ISSN 155938-461-1.

Haas, R., Resch, G., Panzer, C., Busch, S., Ragwitz, M. \& Held, A. (2011). Efficiency and effectiveness of promotion systems for electricity generation from renewable energy sources: Lessons from EU countries. Energy, Vol. 36, (April, 2011), pp (21862193), ISSN 0360-5542.

Jaynes, E.T. (1957a). Information Theory and Statistical Mechanics I. Physics Review, Vol. 196, (December,1957), pp (620-630), ISSN 0360-5442.

Jaynes, E.T. (1957b). Information Theory and Statistical Mechanics II. Physics Review, Vol. 108, (October, 1957), pp (171-190), ISSN 0360-5442.

Jensen, S. \& Skytte, K. (2003). Simultaneous attainment of energy goals by means of green certificates and emission permits. Energy Policy, Vol. 31, (January, 2003), pp. (63-71), ISSN 0301-4215.

Klessmann, C., Nabe, C. \& Burges, K. (2008). Pros and cons of exposing renewables to electricity market risks. A comparison of the market integration approaches in Germany, Spain, and the UK. Energy Policy, Vol. 36, (October, 2008), pp (36463661), ISSN 0301-4215

Moreno, B. \& López, A.J. (2008). The effects of renewable energy on employment. The case of Asturias (Spain). Renewable E Sustainable Energy Reviews, Vol. 12, (April, 2008), pp. (732-751), ISSN 1364-0321.

Pukelsheim, F. (1994). The three sigma rule. The American Statician, Vol. 48, (May, 1994), pp 88-91, ISSN 0003-1305. 
Rathmann, M. (2007). Do support systems for RES-E reduce EU-ETS-driven electricity prices?. Energy Policy, Vol. 35, (January, 2007) pp (342-349), ISSN 0301-4215.

Reiche, D. \& Bechberger, M. (2004). Policy differences in the promotion of renewable energies in the EU member states. Energy Policy, Vol. 32, (May, 2004), pp. (843-849), ISSN 0301-4215.

Sáenz de Miera, G., del Río P. \& Vizcaíno, I. (2008). Analysing the impact of renewable electricity support schemes on power prices: The case of wind electricity in Spain. Energy Policy , Vol. 36, (September, 2008), pp (3345-3359), ISSN 0301-4215.

Shannon, C.E. (1948). A Mathematical Theory of Communication. Bell System Technology Journal, Vol. 27, (1948), pp (379-423).

Soofi, E.S. (1994). Capturing the intangible concept of information. Journal of the American Statistical Association, Vol. 89, (July, 1994), pp 1243-1254, ISSN 0163-6804..

Soofi, E.S. (1992). A generalizable formulation of conditional logit with diagnostics. Journal of the American Statistical Association, Vol. 89, (December, 1992), pp (1243-1254), ISSN 0162-1459.

Spanish Government (2010). Royal-Decree 1614/2010, concerning the regulation and modification and change of various aspects relative to electricity production activity from solar and wind technologies. Madrid.

Spanish Government (2009). Order ITC/1723/2009, concerning the revision of access tolls from 1 th January 2009 and the tariffs and feed-inn of various installations of the special regime. Madrid.

Spanish Government (2008). Royal-Decree 1578/2008, on the payment for the electric production activity from solar photovoltaic technology. Madrid.

Spanish Government (2007). Royal-Decree 661/2007, which regulates the production of electricity under a special regime applicable to electricity produced from renewable energy sources. Madrid.

Spanish Government (2007). Law 17/2007 of the 4 of July amending the Law 54/1997, of the 27 of November related to electricity sector to adapt it to Directive 2003/54/CE of the European Parliament and of the Council of 26 June 2003 concerning common rules for the internal market in electricity. Madrid.

Spanish Government (2004). Royal-Decree 436/2004, establishing the methodology for the updating and systematization of the legal and economic regime for electric power production in the special regime. Madrid.

Spanish Government (1997). Law 54/1997 of the 27 of November concerning rules for the Electricity Sector. Official Journal of the Spanish Government. Madrid.

Spanish Government (1990). National Energetic Plan 1990-2000.Madrid,

Spanish Ministry of Industry, Tourism and Trade and Institute for Energy Diversification and Energy Saving (IDEA) (2012). Spanish Renewable Energy Action Plan for 20112020. IDEA, Madrid

Spanish Ministry of Industry, Tourism and Trade and Institute for Energy Diversification and Energy Saving (IDEA) (2005). Spanish Renewable Energy Plan 2005-2010. IDEA, Madrid.

United Nations Framework Convention on Climate Change (2007). Kyoto Protocol. Japan. 
Weigt, H. (2009). Germany's wind energy: The potential for fossil capacity replacement and cost saving. Applied Energy, Vol. 86, (October, 2009), pp (1857-1863), ISSN 03062619. 


\title{
Modernization and Intensification of Nitric Acid Plants
}

\author{
Marcin Wilk et al.* \\ Instytut Nawozów Sztucznych, Puławy \\ Poland
}

\section{Introduction}

Nitric acid plants both in AZOTY Tarnów and ANWIL SA in Włocławek are dual pressure plants which means that ammonia oxidation and heat recovery take place under a low pressure whereas absorption under a high pressure. Nevertheless, there are important differences between them in regard to pressure and construction solutions applied and the level of their exploitation. A number of design solutions were implemented which aimed at removal of equipment damage, as well as exchange of machines and equipment and provision of plant continuous operation before 2000. Most of these works were performed by companies themselves, however Fertilizers Research Institute (Instytut Nawozów Sztucznych) participated in realization of some of them. After 2000 the increase of nitric acid plant capacity in the above mentioned Works became necessary. The scope of tasks to be undertaken, the realization of which was necessary to increase plant capacity in the above mentioned Works was to be defined in the first stage. This project was realized in cooperation with Fertilizers Research Institute. Some of the accomplished tasks which allowed for the achievement of stated objectives are presented below.

\section{Nitric acid plant $0.5 / 1.5 \mathrm{MPa}, 700 \mathrm{~T} \mathrm{HNO}_{3} / \mathrm{d}$ in AZOTY Tarnów}

\subsection{Plant description}

Process design of nitric acid plant of a nominal production capacity - $700 \mathrm{t} \mathrm{HNO}_{3} / \mathrm{d}$ for Zakłady Azotowe SA in Tarnów-Mościce was prepared by Fertilizers Research Institute and Prosynchem in Gliwice in 19851). The pressure applied that is $0.5 \mathrm{MPa}$ in ammonia oxidation unit and $1.5 \mathrm{MPa}$ in absorption unit provided energy self-sufficiency of this plant and, $\mathrm{NO}_{x}$ content in outlet gases below $200 \mathrm{ppm}$ and allowed for the nitric acid production with the concentration of $65 \%$ by weight.

The plant called Dual Pressure Nitric Acid Plant, presented on Fig. 1 was started in 1992. During Start-up a number of changes were introduced 3,4$)$ which improved its operation

\footnotetext{
*Andrzej Kruszewski², Marcin Potempa ${ }^{2}$, Romuald Jancewicz ${ }^{3}$, Jacek Mendelewski

Paweł Sławiński ${ }^{3}$, Marek Inger ${ }^{1}$ and Jan Nieścioruk ${ }^{1}$

${ }^{1}$ Instytut Nawozów Sztucznych, Puławy, Poland

2AZOTY Tarnów, Poland

${ }^{3}$ ANWIL SA, Wtoctawek, Poland
} 
efficiency and made it safer both for staff and environment. No significant technological errors were found with guarantee parameters and production capacity confirmed during Start-up.

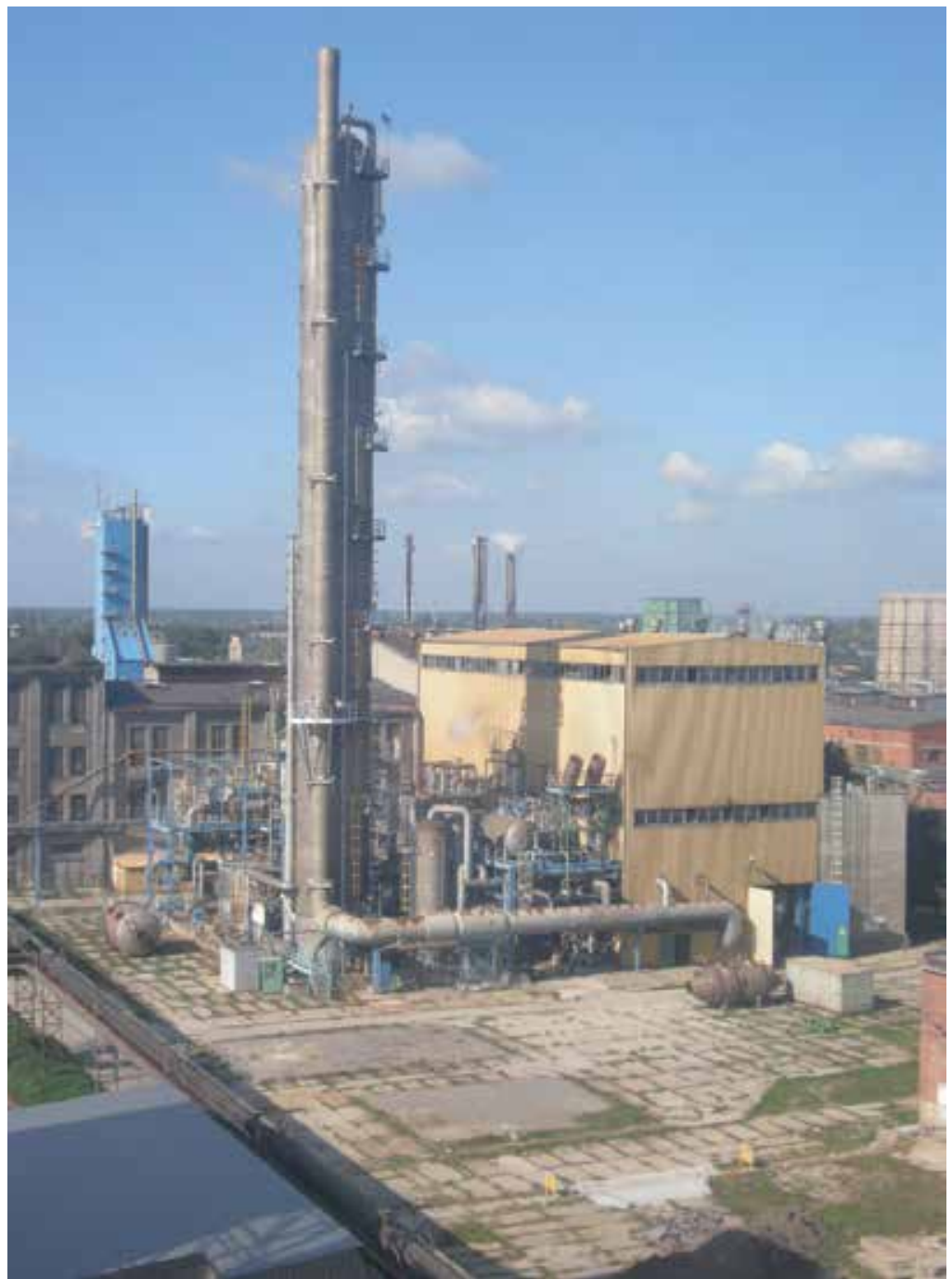

Fig. 1. Nitric acid plant in AZOTY Tarnów

\subsection{Plant modernization stages}

The first modernization stage included actions aimed at improvement of plant stability and reliability with a nominal load as well as optimization of heat use. The below mentioned actions were undertaken to achieve these goals:

- Additional low pressure heater (E14) of tail gases was built-up,

- $\quad$ The construction of tube pack in high pressure tail gases heater (E9)5) was changed,

- Construction changes were introduced to air heater E1,

- Maintenance and changes in turbine set, 
During the second stage of modernization, works aiming at gradual intensification of the plant (increase of plant capacity) by removal of bottlenecks and further improvement of stability and reliability were performed. More actions than in the first stage were undertaken to achieve this objective including:

- Improvement of heat exchange in a low pressure condenser E8 and high pressure condenser E10, by the change of buffles and the change of tube pack6),

- Improvement of mist elimination efficiency and vortex breaker in separator V87),

- Engineering analysis of Dual Pressure Nitric Acid Plant at load of $900 \mathrm{t} \mathrm{HNO}_{3} / \mathrm{d}^{8)}$, the result of which was determination of plant operation parameters and specification of any changes to be introduced into units, that may limit plant operation at such load,

- Control system modernization and intelligent controllers built-up which provide stable operation at high load,

- $\quad$ Economizer E7 modernization - increased efficiency of heat exchange,

- $\quad$ Start-up of double stage Tapproge system for a continuous tube cleaning of the steam turbine condenser,

- Engineering analysis of Dual Pressure Nitric Acid Plant at the load of $950 \mathrm{t} \mathrm{HNO}_{3} / \mathrm{d}^{9}$ ), containing operation conditions at this load,

\subsection{Results of plant modernization}

Due to works performed in the first stage the possibility of nitric acid production on design level with a simultaneous energy consumption improvement was obtained and the number of plant stays was limited.

During the second stage mass and heat balances for the load of 900 and $950 \mathrm{t} \mathrm{HNO}_{3} / \mathrm{d}$ were prepared within engineering analysis and operation parameters of particular plant units at the above mentioned loads were specified. This analysis was possible with modernization works performed by AZOTY Tarnów. Some of them include:

- $\quad$ Filtration area enlargement and the use of a different filtration material,

- Gradual filtration area enlargement of $\mathrm{NH}_{3}$ - air filter and flow resistance lowering,

- Limitation of air II content for whitening of nitric acid solution to minimum value which guarantees "proper " whitening (the removal of dissolved nitrous oxides), which enabled us to direct additional air to ammonia oxidation unit,

- Modernization of pump systems which feed boiler system and construction changes of demister in boiler drum, due to which water separation from wet steam was improved and quality of the overheated steam directed to steam turbine powering turbine set was also improved,

- Separator modernization of nitric acid mist from tail gases after absorption column which improved its operation and limited corrosion of tail gases heater E14.

Research on optimization - the adjustment of catalytic packages for increasing technical nitric acid production in the following platinum campaign was conducted during works over plant intensification.

As the result of modernization discussed above daily production capacity of the plant and the level of its exploitation were increased, as presented on Fig. 2 and 3. Moreover, modernization and strengthening of catalytic baskets were performed, which allowed for built-up of the catalyst for a high temperature $\mathrm{N}_{2} \mathrm{O}$ decomposition within JI project. 


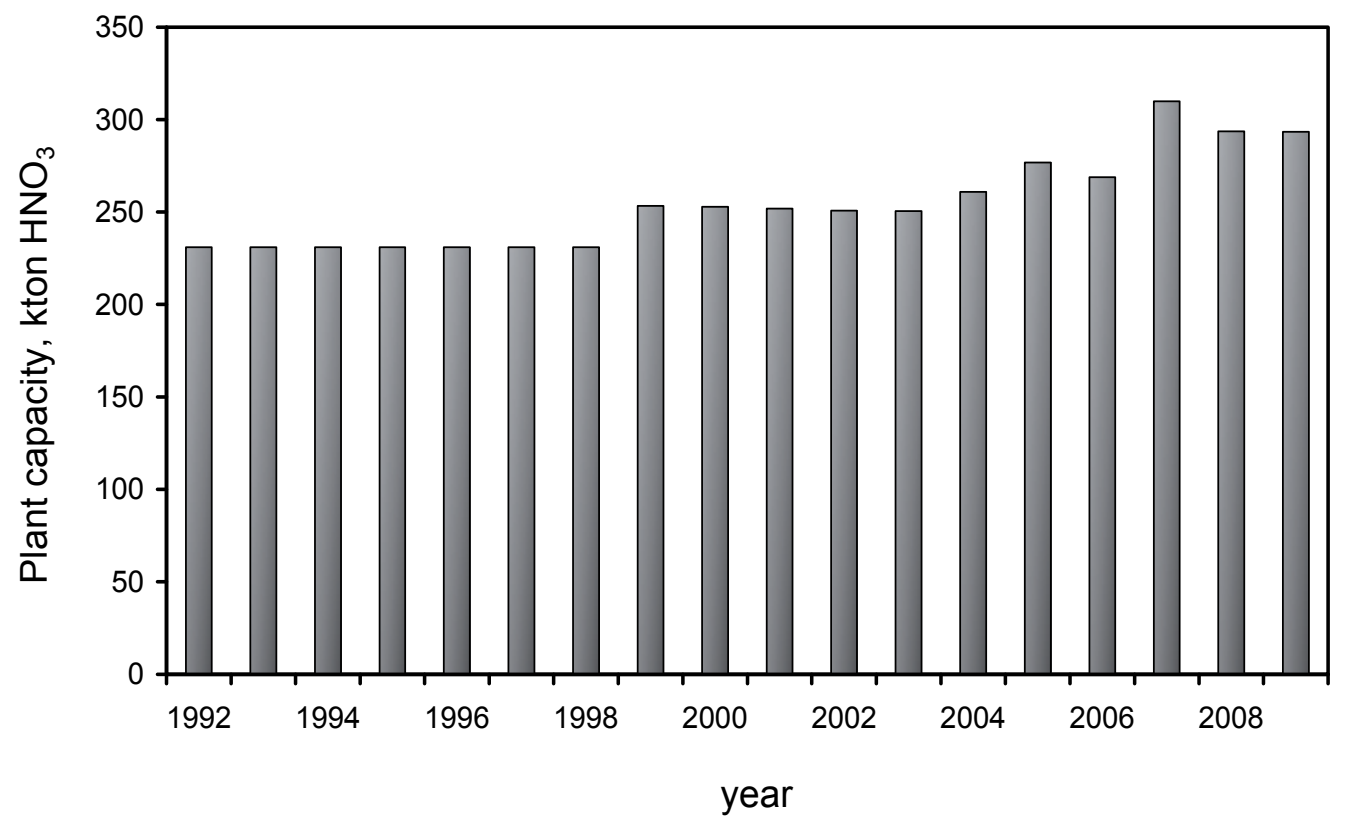

Fig. 2. A change of annual capacity as a result of modernization

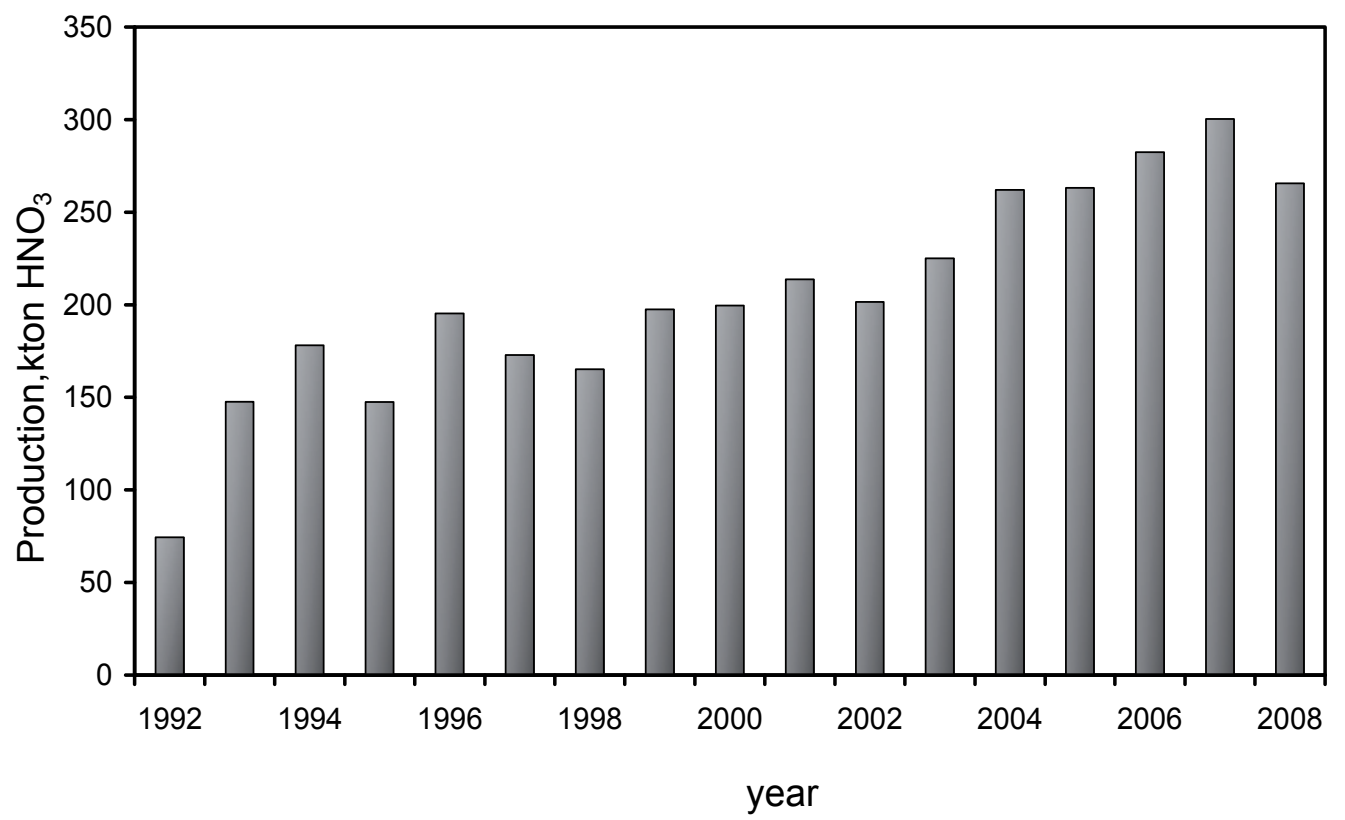

Fig. 3. Annual production of nitric acid in AZOTY Tarnów 


\section{Nitric acid plant 0.35/0.9 Mpa, $900 \mathrm{t} \mathrm{HNO}_{3} / \mathrm{d}$, ANWIL SA in Włocławek}

\subsection{Plant description}

Nitric acid plant in ANWIL SA was built according to the project of French company Societe Chimique de la Grande Paroisse in 1968. It consists of two trains of a nominal value of $900 \mathrm{t}$ $\mathrm{HNO}_{3} / \mathrm{d}$ each. In the 70's it was the first dual pressure plant in Poland. The solutions applied provided energy self-sufficiency of the plant but with the NOx content in tail gases of 400 ppm and $\mathrm{NHO}_{3}$ concentration in solution of $56.5 \%$ by weight.

The plant presented on Fig. 4 was started in 1971-1972. During start-up in the 70's nominal production capacity was obtained and the most important exploitation problems were eliminated.

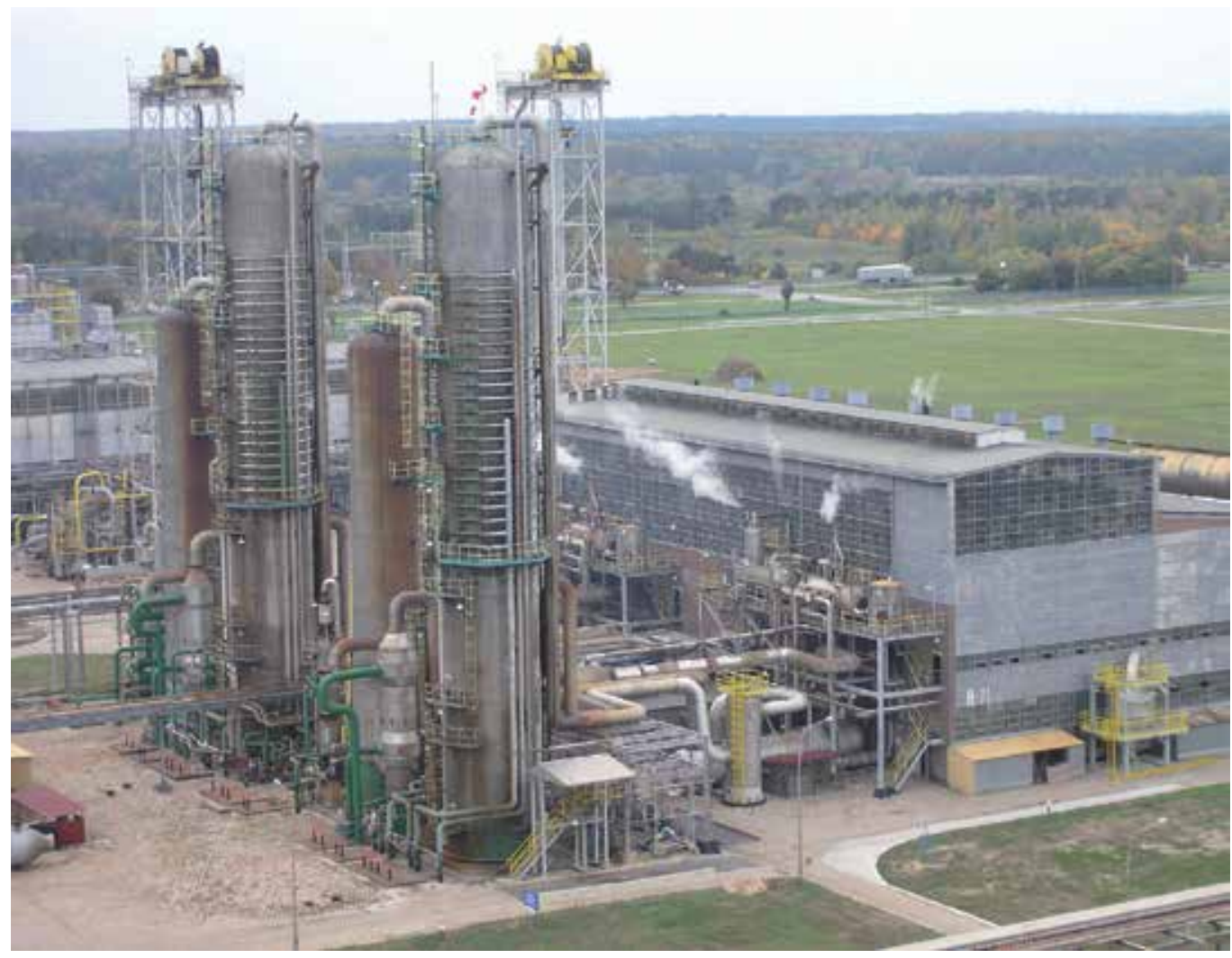

Fig. 4. Nitric acid plant in ANWIL SA 


\subsection{Plant modernization stages}

No significant modernization works were performed in 1980-2000 due to a poor economic trend. The main objective was to provide continuous operation of the plant which contributed to decrease of the number of plant stays from 25 in 1980 to 7 in 2000.

Actions aiming at modernization and intensification of the plant have been undertaken since 2000. Some worn out equipment was replaced and due to actions undertaken exchange of one of the most important apparatus that is a high pressure tail gases heater E2211 became unnecessary. The results of analysis ${ }^{11,12}$ ) of operation conditions of this apparatus indicated the necessity of application of condensate drops separation from tail gases after absorption column. Furthermore, periodical controls of wall thickens of this apparatus were performed, as well as maintenance of thinned or damaged tubes by placing rolled steel tubes 2RE10 inside and washing process optimization of nitrous gases compressor and continual controls of dehydrating nozzles permeability.

The preparation of mass and heat balance by Fertilizers Research Institute for the load of $1100 \mathrm{t} \mathrm{HNO}_{3} / \mathrm{d}(122 \%)$ and specification of the changes to be introduced into loop, limiting production capacity, were the next stages of modernization process. A number of actions were undertaken by ANWIL SA based on the results of above mentioned works and their own observations, the realization of which was the condition for the increase of the production capacity. They included mainly:

- the application of selective $\mathrm{NO}_{x}$ reduction,

- the increase of turbine sets energy efficiency,

- $\quad$ the increase of $\mathrm{NH}_{3}$-air relation,

- the modernization of condenser E220914),

- the modernization of boiler system and whitening column D 220515),

- the modernization of ammonia oxidation reactors by special catalytic baskets, modernization of feeding system and hydrogen and $\mathrm{NH}_{3}$-air distribution ${ }^{16)}$.

\subsection{Results of plant modernization}

The solutions applied concerning failure frequency of nitrous gases heater E2211 resulted in operation time prolonging of this apparatus. The amount of condensate introduced earlier with tail gases to the separator was significantly reduced due to separator built-up Fig. 5 . The modernization of the other technologically important apparatus -condenser E2209 consisted of a different distribution of cooling water, its degassing system in the upper bottom of the sieve and different method of tube fixing in the sieve bottom. A significant reduction of condenser corrosivity is envisaged to be the result of this modernization.

The application of selective $\mathrm{NO}_{x}$ reduction and the modernization of boiler system and whitening column as well as the increase of $\mathrm{NH}_{3}$-air relation allowed for an increased plant load due to decreased pressure in absorption loop and directing larger amount of air for ammonia oxidation process. Boiler system modernization consisted mainly of the use of circulation pump of a higher efficiency and the change of circulation tube system. During whitening column modernization hydraulics of liquids and gases flow was improved due to tray and weir modernization, which allowed for the $40 \%$ reduction of the air necessary for nitric acid whitening. 


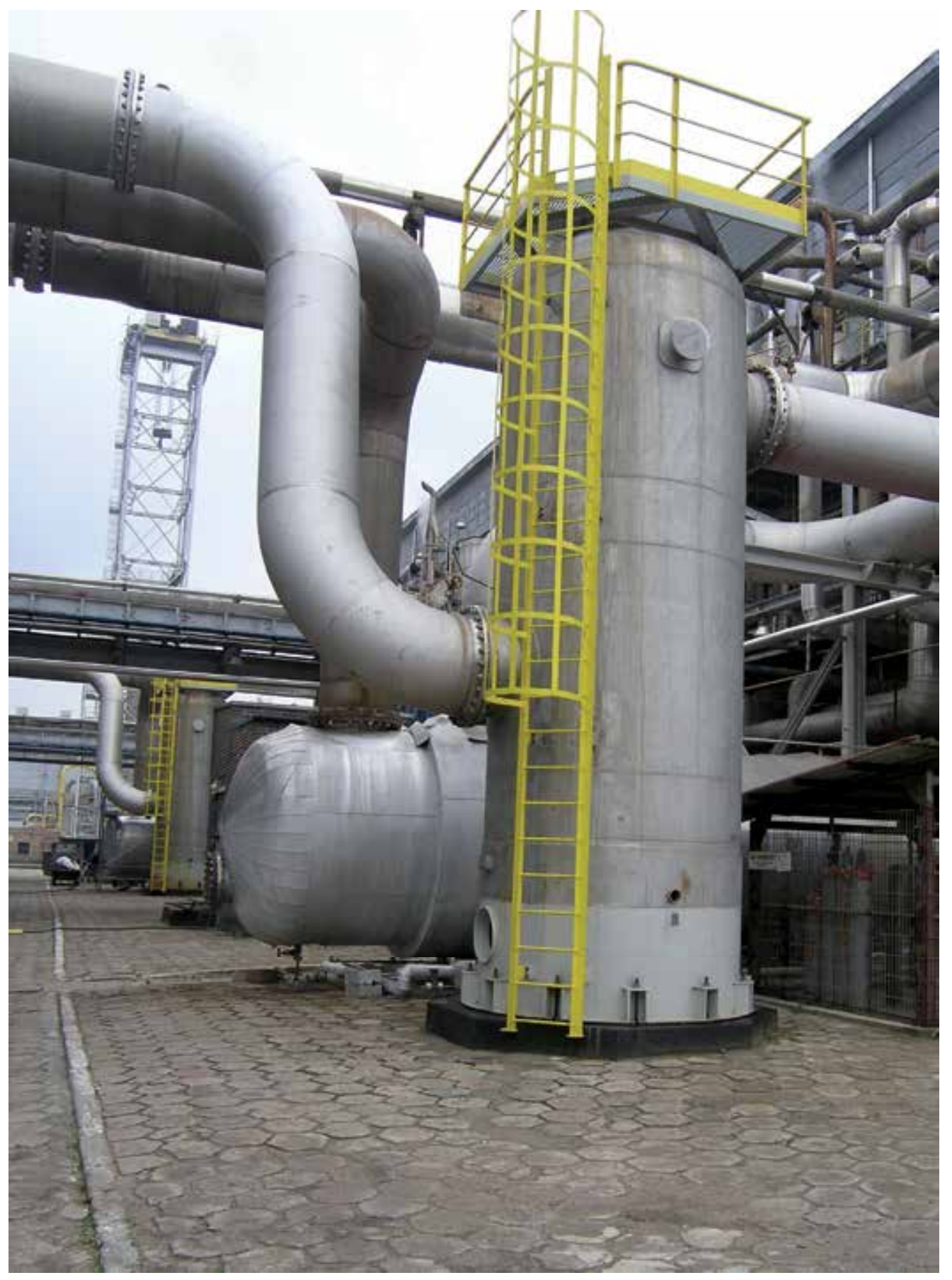

Fig. 5. Condensate separator from tail gases 
After additional modernization of turbine set rotors (adjusted shapes of blades and the application of a different method of fixing blades to the rotor disks) the increase of the plant load up to $122 \%$ and even up to $125 \%$ temporarily became possible with a co-existent energy efficiency improvement. The results of modernization discussed here are presented on Fig. 6 and 7.

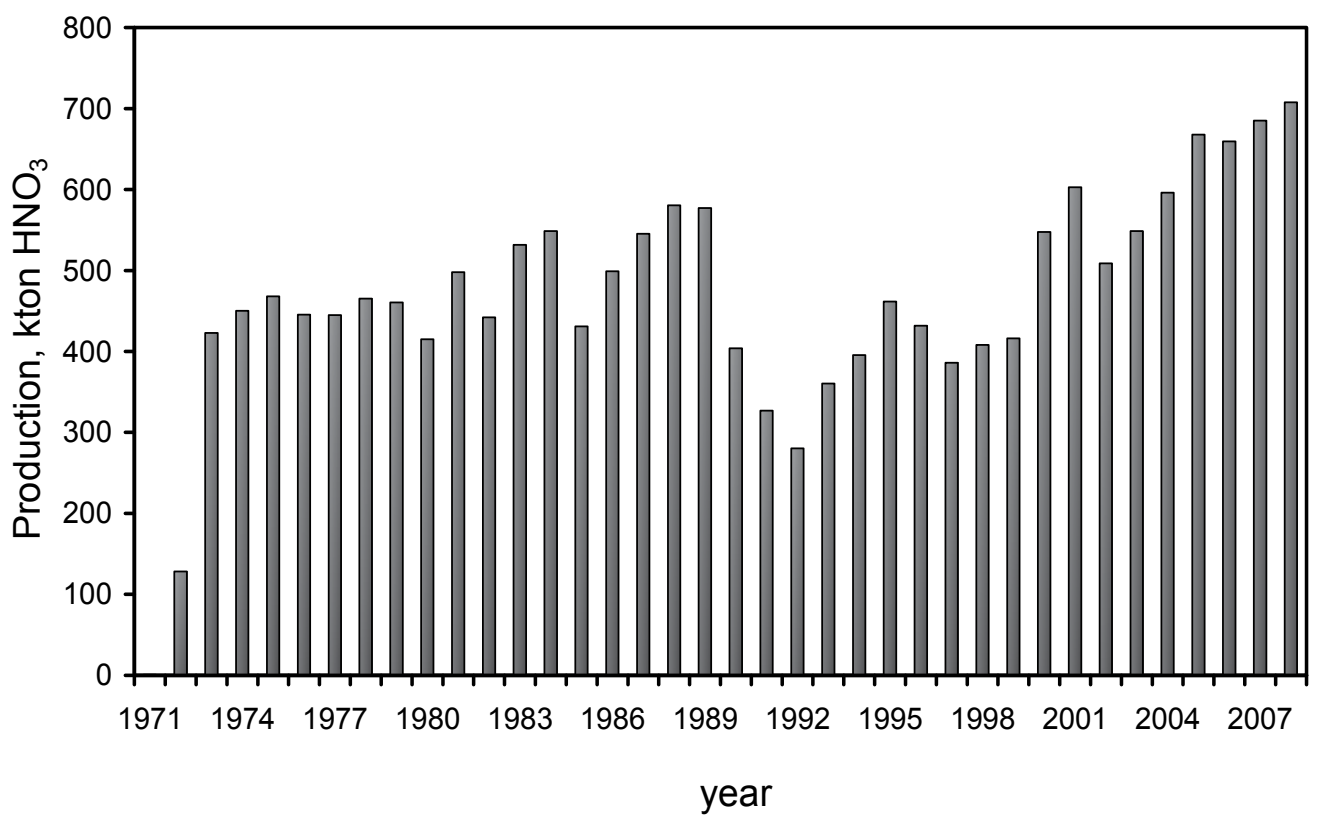

Fig. 6. Annual production of nitric acid in ANWIL SA 


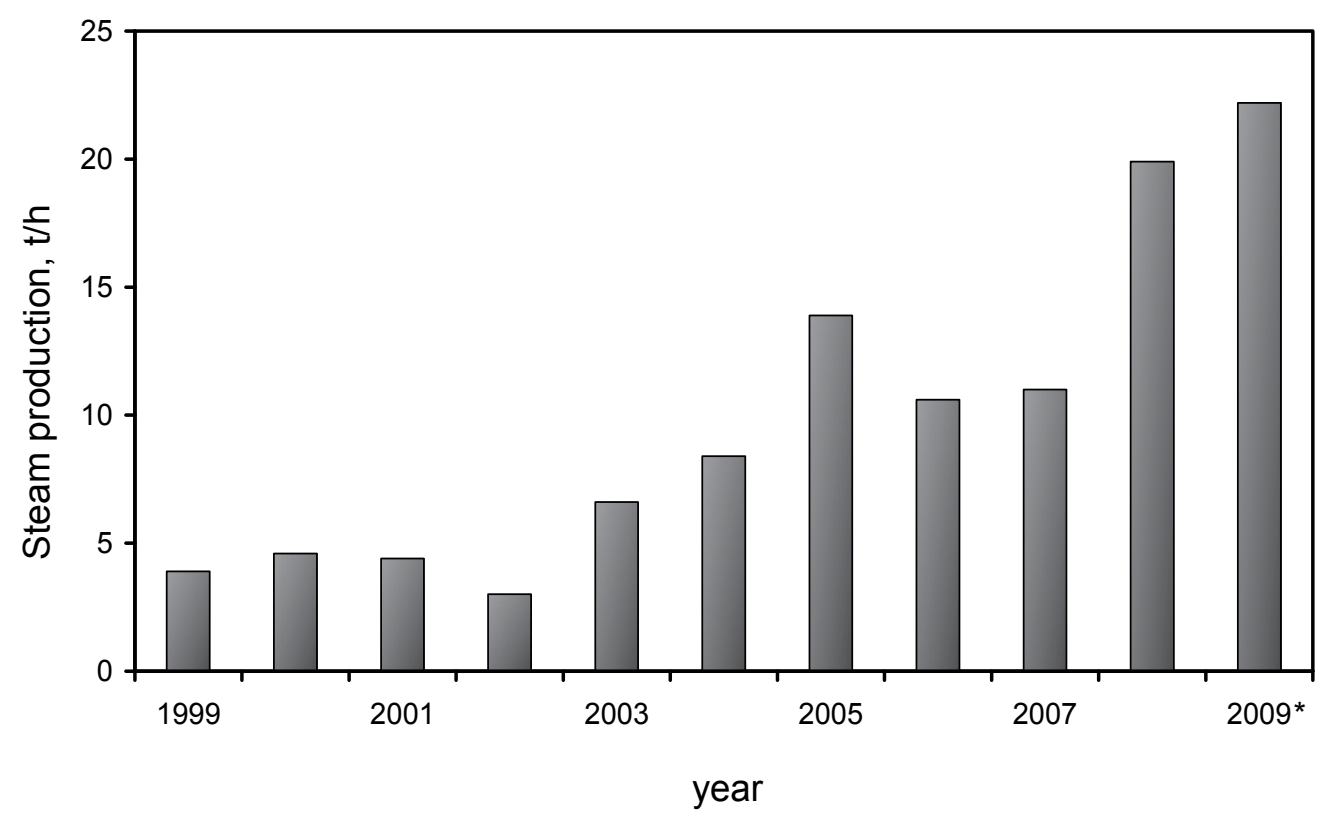

Fig. 7. Generation increase in steam carried away to the plant system

The modernization of ammonia oxidation reactors consisted mainly of built-up of special catalytic baskets, which were delivered by Johnson Matthey. This allowed for the installation of the catalyst for a high temperature nitrous oxide decomposition within JI project. The catalyst developed by Fertilizers Research Institute was applied in one of the plant trains. The modernization of $\mathrm{NH}_{3}$-air and hydrogen distribution made the plant safer during start-up and protected catalytic gauzes (of PtRh-Pd alloy) against contamination and damage.

\section{Summary}

Nitric acid plants modernization performed by AZOTY Tarnów and ANWIL SA Włocławek increased stability and reliability of these plants and improved their energy efficiency. The possibility of significant intensification of production capacity and exploitation level was achieved. A nominal production capacity was increased up to $130 \%$ in AZOTY Tarnów and up to $125 \%$ in ANWIL SA.

\section{References}

[1] M. Wilk, K. Kozłowski, J. Nieścioruk, Przem. Chem., 1988, t. 67, 10, 464.

[2] W. Janicki, A. Laska, K. Bronikowski, K. Kozłowski, J. Nieścioruk, M. Wilk, Projekt procesowy, Gliwice, 1985.

[3] L. Gniadek, A. Kruszewski, R. Świtalski, Pr. nauk. Inst. Technol. Nieorg. PWr nr 39, Seria: Konf. nr 21, 3.

[4] K. Kozłowski, Pr. nauk. Inst. Technol. Nieorg. PWr nr 39, Seria: Konf. nr 21, 11.

[5] M. Wilk, J. Nieścioruk, Projekt INS, Puławy, 1998.

[6] M. Wilk, J. Nieścioruk, Sprawozdanie INS, nr 2819, Puławy, 2003. 
[7] M. Wilk, J. Nieścioruk, Projekt INS, Puławy, 2003.

[8] M. Wilk, J. Nieścioruk, M. Inger, E. Rój, Sprawozdanie INS, nr 3009, Puławy, 2005.

[9] M. Wilk, J. Nieścioruk, M. Inger, E. Rój, Sprawozdanie INS, nr 3190, Puławy, 2007.

[10] $\mathrm{N}_{2} \mathrm{O}$ abatement project at nitric acid plant of ZAT, Poland, nr 0091, 2006.

[11] J. Nieścioruk, M. Wilk, E. Rój, Sprawozdanie INS, nr 2997, Puławy, 2005.

[12] J. Nieścioruk, M. Wilk, E. Rój, Sprawozdanie INS, nr 3000, Puławy, 2005.

[13] M. Wilk, M. Inger, J. Nieścioruk, Sprawozdanie INS, nr 3008, Puławy, 2006.

[14] J. Nieścioruk, E. Rój, M. Wilk, Sprawozdanie INS, nr 3178, Puławy, 2007.

[15] J. Nieścioruk, M. Wilk, M. Inger, Sprawozdanie INS, nr 3276, Puławy, 2008.

[16] J. Nieścioruk, M. Wilk, E. Rój, Sprawozdanie INS, nr 3275, Puławy, 2008.

[17] $\mathrm{N}_{2} \mathrm{O}$ emissions reduction project at Zakłady Azotowe Anwil SA, 2006.

[18] M. Wilk, M. Inger, J. Kruk, A. Gołębiowski, R. Jancewicz, B. Szczepaniak, Przem. Chem., 2009, t. $88,6,730$. 


\title{
Optimal Design of an Hybrid Wind-Diesel System with Compressed Air Energy Storage for Canadian Remote Areas
}

\author{
Younes Rafic ${ }^{1}$, Basbous Tammam ${ }^{2}$ and Ilinca Adrian ${ }^{3}$ \\ ${ }^{1}$ Lebanese University, Faculty of Engineering, Beirut, \\ ${ }^{2}$ LREE, University of Quebec in Chicoutimi, Chicoutimi, \\ ${ }^{3}$ LREE, Quebec University in Rimouski, Rimouski, \\ ${ }^{1}$ Lebanon \\ 2,3Canada
}

\section{Introduction}

\subsection{Context}

Most of the remote and isolated communities or technical installations (communication relays, meteorological systems, tourist facilities, farms, etc.) which are not connected to national electric distribution grids rely on Diesel engines to generate electricity [1]. Dieselgenerated electricity is more expensive in itself than large electric production plants (gas, hydro, nuclear, wind) and, on top of that, should be added the transport and environmental cost associated with this type of energy.

In Canada, approximately 200,000 people live in more than 300 remote communities (Yukon, TNO, Nunavut, islands) and are using Diesel-generated electricity, responsible for the emission of 1.2 million tons of greenhouse gases (GHG) annually [2]. In Quebec province, there are over 14,000 subscribers distributed in about forty communities not connected to the main grid. Each community constitutes an autonomous network that uses Diesel generators.

In Quebec, the total production of Diesel power generating units is approximately $300 \mathrm{GWh}$ per year. In the mean time, the exploitation of the Diesel generators is extremely expensive due to the oil price increase and transportation costs. Indeed, as the fuel should be delivered to remote locations, some of them reachable only during summer periods by barge, the cost of electricity produced by Diesel generators reached in 2007 more than 50 cent/kWh in some communities, while the price for selling the electricity is established, as in the rest of Quebec, at approximately 6 cent/kWh [3].

The deficit is spread among all Quebec population as the total consumption of the autonomous grids is far from being negligible. In 2004, the autonomous networks represented $144 \mathrm{MW}$ of installed power, and the consumption was established at $300 \mathrm{GWh}$. Hydro-Quebec, the provincial utility, estimated at approximately 133 millions CAD\$ the annual loss, resulting from the difference between the Diesel electricity production cost and the uniform selling price of electricity [3]. 
Moreover, the electricity production by the Diesel is ineffective, presents significant environmental risks (spilling), contaminates the local air and largely contributes to GHG emission. In all, we estimate at 140,000 tons annual GHG emission resulting from the use of Diesel generators for the subscribers of the autonomous networks in Quebec. This is equivalent to GHG emitted by 35,000 cars during one year.

The Diesel power generating units, while requiring relatively little investment, are generally expensive to exploit and maintain, particularly when are functioning regularly at partial load [4]. The use of Diesel power generators under weak operating factors accelerates wear increases fuel consumption [5]. Therefore, the use of hybrid systems, which combine renewable sources and Diesel generators, allows reducing the total Diesel consumption, improving the operation cost and environmental benefits.

\subsection{Wind-Diesel systems}

Among all renewable energies, the wind energy experiences the fastest growing rate, at more than $30 \%$ annually for the last 5 years $[7,8]$. Presently, wind energy offers cost effective solutions for isolated grids when coupled with Diesel generators. The "Wind-Diesel hybrid system" (WDS) represent a technique of generation of electrical energy by using in parallel one or several wind turbines with one or several Diesel groups. This approach is at present used in Nordic communities in Yukon [9], Nunavut [10] and in Alaska [11].

The "penetration rate" is used in reference to the rated capacity of the installed wind turbines compared to the maximum and minimum loads. A strict definition of a "low-penetration" system is one when the maximum rated capacity of the wind component of the system does not exceed the minimum load of the community. In practical terms however, a lowpenetration system is one where the wind turbines are sized so as not to interfere with the Diesel generators' ability to set the voltage and frequency on the grid. In effect, the windgenerated electricity is "seen" by the Diesel plant as a negative load to the overall system. It is important to note however that because such a system needs to be designed for the peak capacity of the wind generator it will typically operate with an average annual output of 20$35 \%$ of its rated power, such that while low-penetration systems will have noticeable fuel and emissions savings they will be fairly minor $[12,2]$. In many cases it is likely that similar savings could be achieved through energy efficiency upgrades for similar capital costs.

A "high-penetration" system without storage [13], as illustrated in Figure 1, is one where the output from the wind generators frequently exceeds the maximum load for extended periods of time (10 min to several hours), such that the Diesel generators can be shut off completely when there is significant wind. The variation of wind and Diesel-generated power according to the wind speed and considering a constant load is illustrated at Figure 2. The Diesel generators therefore are required only during periods of low winds and/or to meet peak demands. The advantage of such systems are that very significant fuel savings can be achieved reducing import and storage costs, but also will extend the life and servicing frequency of the Diesel generators as they will log less hours. Such systems can also benefit from economies of scale for construction and maintenance, but require much more significant and expensive control systems $[14,15]$ to regulate the grid frequency and voltage while the Diesel generators are turned off. A dump load is required during periods when the power from the wind turbines exceeds the demand in order to maintain system frequency and voltage [11]. 


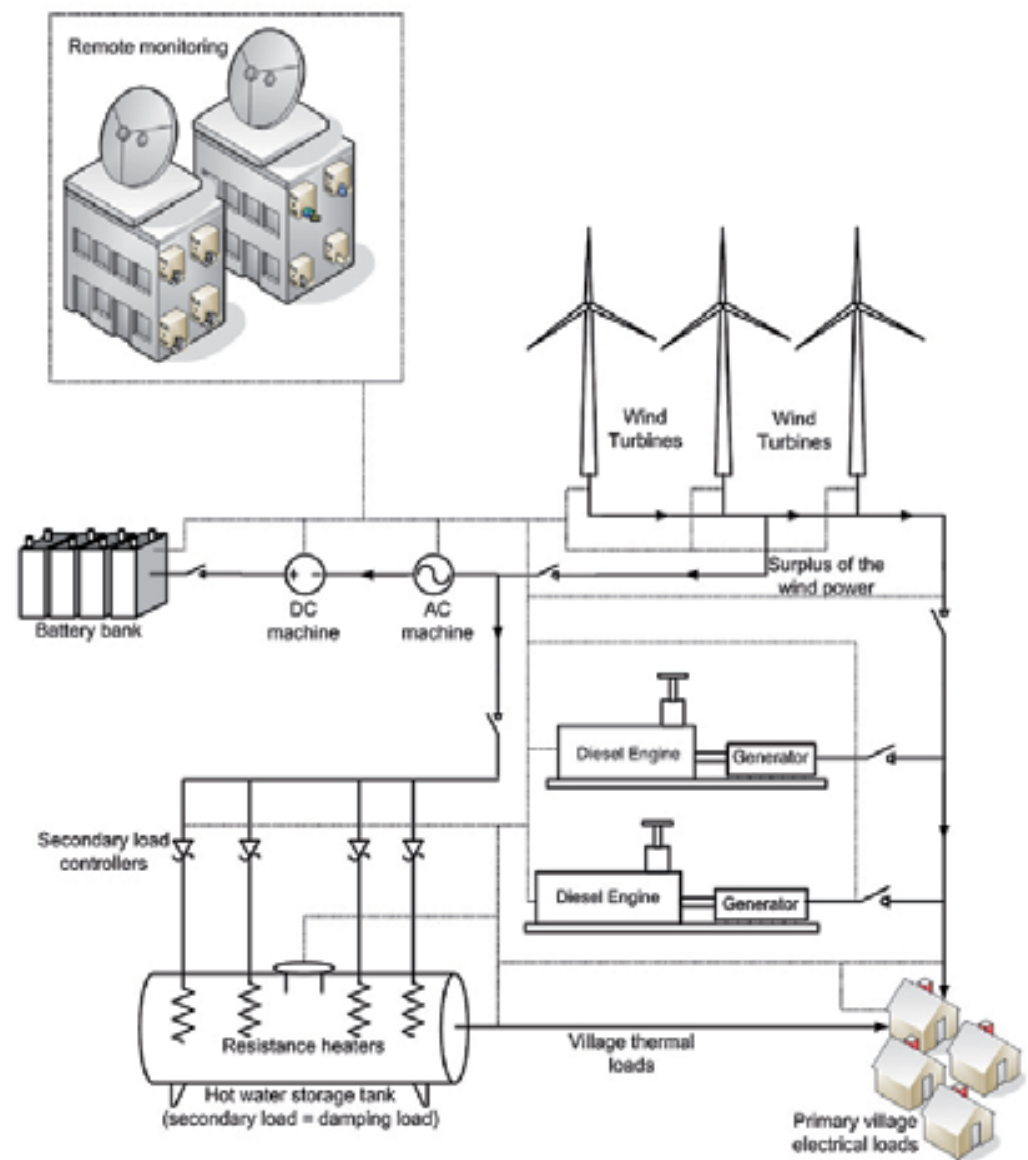

Fig. 1. Wind -Diesel system with dump load.

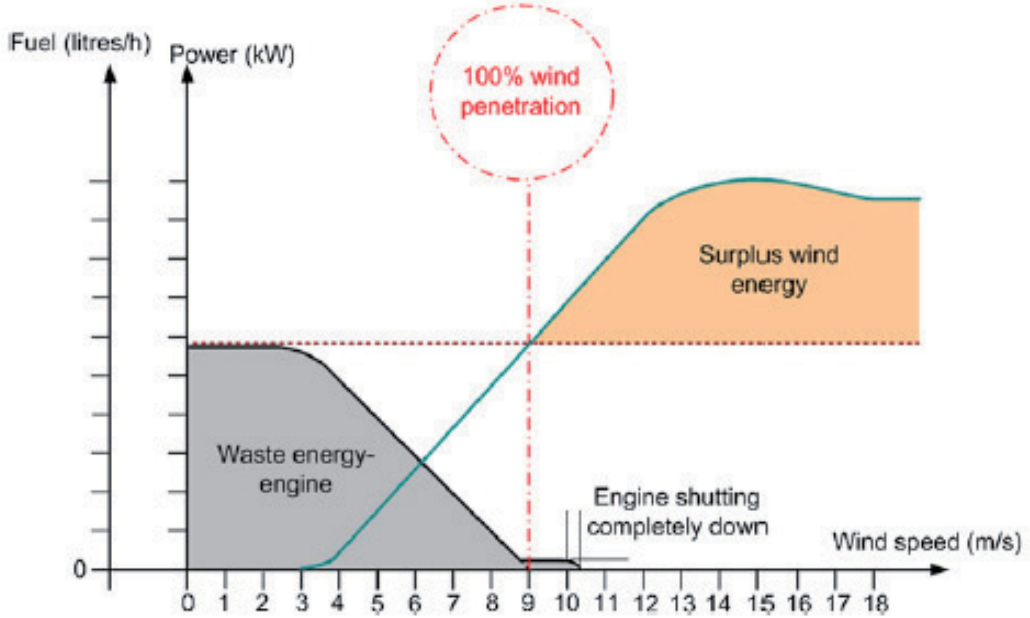

Fig. 2. Variation of wind and diesel power with wind speed for a high-penetration WDS [16]. 
A medium-penetration system refers to a system in between the low- and highpenetration configurations. A medium-penetration system will have periods of time when the wind-generated electricity dominates the Diesel-generated electricity and may also be able to meet the system load for brief periods of time (30 s - $5 \mathrm{~min})$. When wind speeds are high and/or the community demand is very low, the Diesel generators may not be required at all, but are not shut off, rather they are left to idle to be able to respond quickly to load demands. A medium-penetration system is potentially subjected to both the benefits and the drawbacks of low- and high penetration configurations. Beyond a certain penetration, the obligation to maintain idle the Diesel at any time, generally around $25-30 \%$ of its nominal output power, forces the system to function at a very inefficient regime. Indeed, for low- and medium-penetration systems, the Diesel consumes, even without load, approximately $50 \%$ of the fuel at nominal power output. These systems are easier to implant but their economic and environmental benefits are marginal [12]. The use of high-penetration systems allows the stop of the thermal groups, ideally as soon as the wind power equals the instantaneous charge, to maximize the fuel savings. However, considering the Diesel starting time as well as the instantaneous charge and wind speed fluctuations, the thermal production must be available (Diesel group to minimal regime) from the moment when the over-production passes under a threshold, named power reserve, considered as security to answer to the instantaneous requested power. The value of this reserve should be chosen so that it insures the reliability of the system and has a direct effect on the fuel consumption and the exploitation and maintenance costs of the Diesel generators. In other words, the Diesels must still idle to compensate for a sudden wind power decrease under the level of the charge and a greater the value of the power reserve leads to longer periods of time during which the Diesels are functioning at inefficient regimes.

During time intervals when the excess of wind energy over the charge is considerable the Diesel engine must still be maintained on standby so that it can quickly respond to a wind speed reduction (reduce the time of starting up and consequent heating of the engine). This is an important source of over consumption because the engine could turn during hours without supplying any useful energy. Assuming optimum exploitation conditions $[17,2]$ the use of energy storage with wind-Diesel systems can lead to better economic and environmental results, allows reduction of the overall cost of energy supply and increase the wind energy penetration rate (i.e., the proportion of wind energy as the total energy consumption on an annual basis) [2].

Presently, the excess wind energy is stored either as thermal potential (hot water), an inefficient way to store electricity as it cannot be transformed back in electricity when needed or in batteries which are expensive, difficult to recycle, a source of pollution (leadacid) and limited in power and lifecycle. The fuel cells propose a viable alternative but due to their technical complexity, their prohibitive price and their weak efficiency, their appreciation in the market is still in an early phase. The required storage system should be easily adaptable to the hybrid system, available in real time and offer smooth power fluctuations. For this reason we examine the use of compressed air energy storage (CAES) with the wind-Diesel hybrid system (WDCAS), illustrated in Figure 3. The energy storage in the form of compressed air (CAES) is adaptable for the two sources of electricity production (wind energy and Diesel). Moreover, the CAES is an interesting solution to the 
problem of strong stochastic fluctuations of the wind power because it offers a high efficiency conversion (60-70\% for a complete charge-discharge cycle), uses conventional materials which are easy to recycle and is able to make an almost unlimited number of cycles $[18,19]$.The compressed air energy storage can more specifically, be used to overcharge the Diesel engines and ensure maximum efficiency over all functioning regimes. In this paper we analyze the technical and economical performances of a Diesel engine overcharged with compressed produced from wind energy surpluses. However, the advantage of a hybrid system compared to a wind alone system, depends on many fundamental factors: the form and the type of the load, the regime and speed of the wind, the cost and the availability of energy, the relative cost of the wind machine, the storage system and other efficiency determining factors [20]. The capital cost of the wind turbine and the CAES system is considerably damped by the reduction of the operating costs of Diesel generators [21,22].

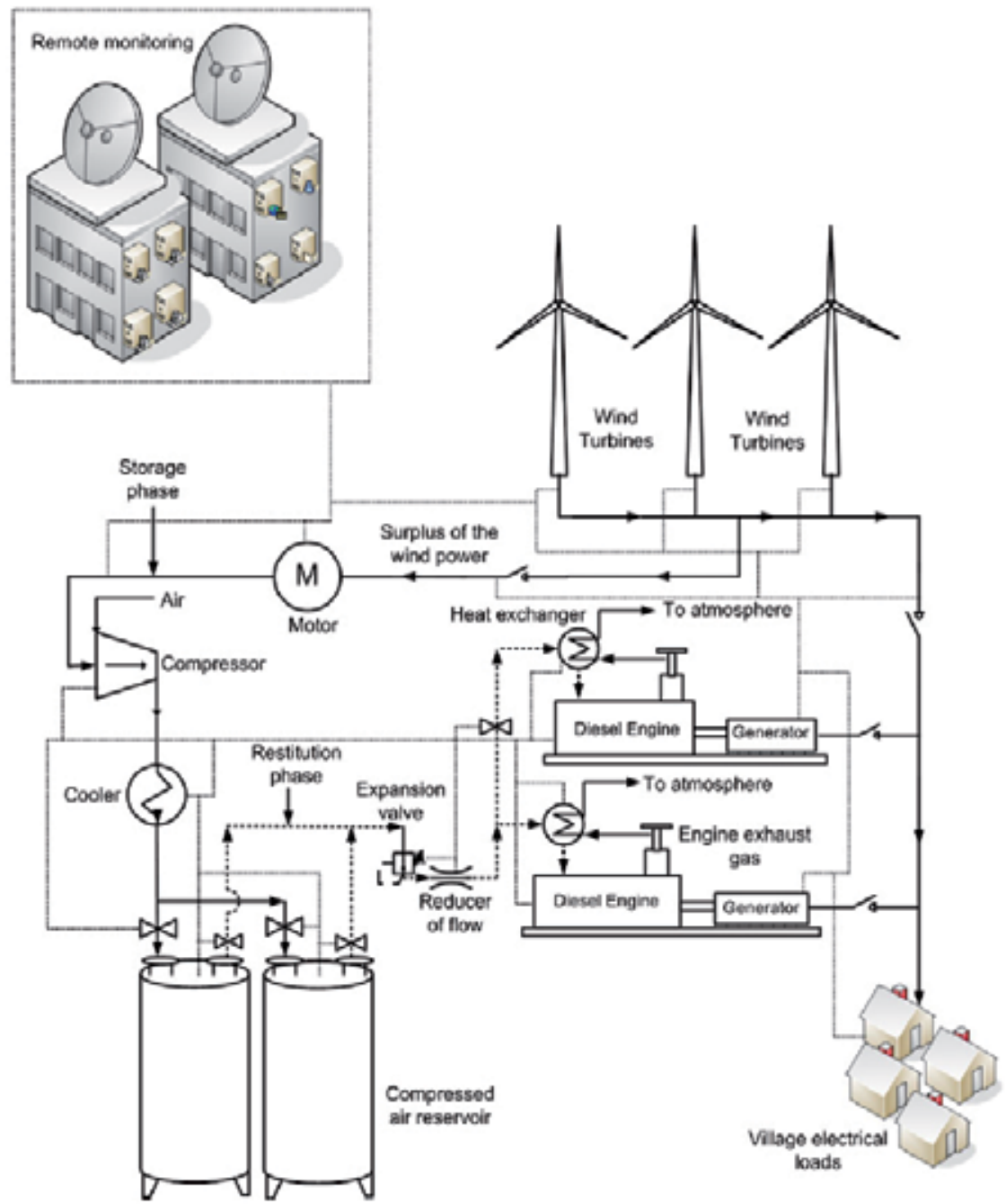

Fig. 3. Wind-Diesel system with compressed air energy storage 


\section{Suggested concept}

\subsection{Wind Diesel system with compressed air storage (WDCAS)}

The proposed system, (WDCAS) combined with the Diesel engine supercharge, will increase of the rate of penetration of the wind energy (RPWE). The supercharging is a process which consists of a preliminary compression with an objective to raise the intake air density of engines to increase their specific power (power by swept volume) $[23,24]$. During periods of strong wind, the surplus of the wind power (when wind power penetration rate defined as quotient between the wind-generated power and the charge is greater than 1 e WPPR $>1$ ) is used to compress the air via a compressor and store it. The compressed air then serves to turbo-charge the Diesel engine with a dual advantage of increasing its power and decreasing the fuel consumption. The Diesel generator works during the periods of low wind velocity, when the wind power is not sufficient for the load.

The WDCAS has a very important commercial potential for remote areas as it is based on the use of Diesel generators already in place. It is conceived like the adaptation of the existing engines at the level of the intake system, the addition of a wind power station and an air compression and storage system. The lack of information on the economics, as well as on performances and reliability data of such systems is currently the main barrier to the acceptance of wind energy deployment in the remote areas. This project intends to answer some of these interrogations. Using information available $[4,6,25]$, and performance analysis $[23,26]$, we estimate that on a site with appreciable wind potential, the return on investment (ROI) for such installation is between 2 and 5 years, subject to the costs of fuel transport. For sites accessible only by helicopters the ROI can be less than a year [17]. This analysis does not take into account the raising prices of fuel, nor GHG credit which only tend to reduce the ROI [27].

\subsection{Possible techniques for making advantage of CAES to increase Diesel engine efficiency}

Among different techniques investigated, two of them were selected for being compatible with a simple adjustment of existing Diesel Power system without heavy investments:

\section{Technique 1: admission of the compressed air at the compressor inlet}

The indicated efficiency of a Diesel engine follows a quadratic variation function of Airto-Fuel ratio, as shown in Figure 4. The idea is therefore to use the CAES to increase the pressure at the intake of the compressor, as shown in Figure 5, mainly at high loads, when there is a lack of air. This would increase the air flow admitted by the engine and increase therefore the Air-to-Fuel ratio to bring it artificially to its optimal value witch is around 53.

\section{Technique 2: admission of the compressed air at the engine inlet}

The idea is to remove the turbocharger and connect directly the CAES to the inlet of the engine, as shown in Figure 6 . The benefit would be increasing the scavenging work to make it contributing to the provided power, in addition to the ability to increase the Air-to-Fuel ratio as in the previous technique. 


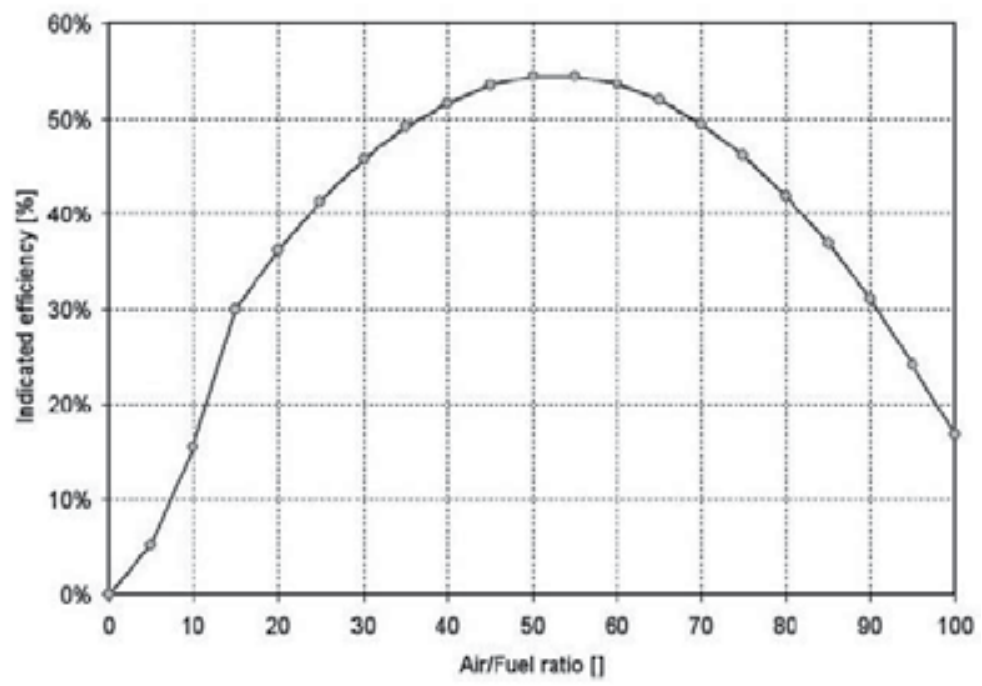

Fig. 4. Variation of indicated efficiency with the air/fuel ratio [39]

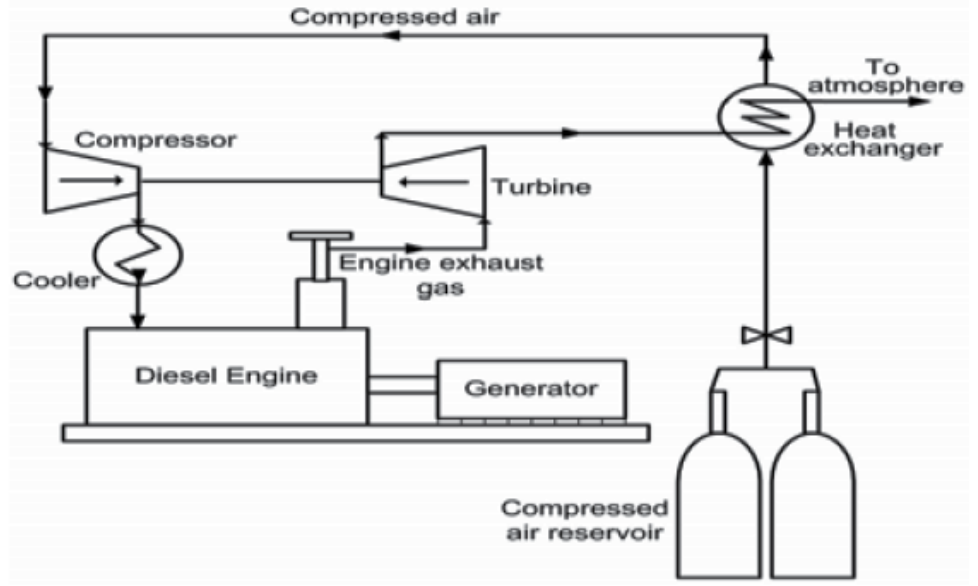

Fig. 5. Admission of CAES at the compressor intake.

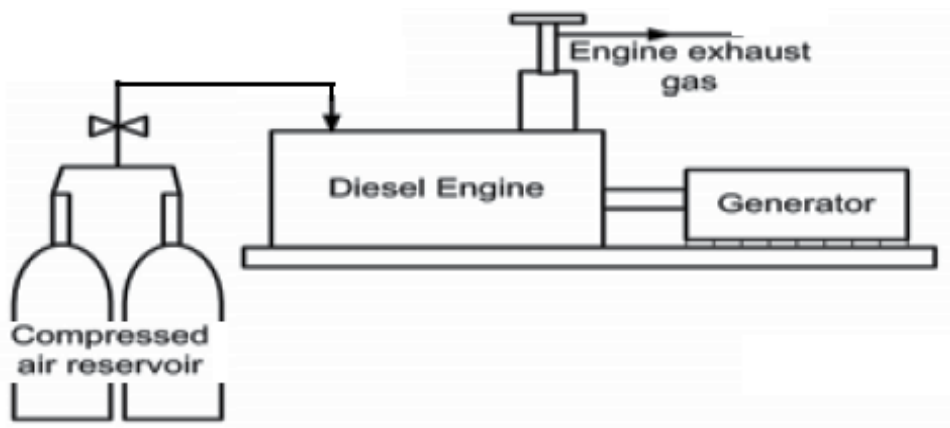

Fig. 6. Admission of CAES at the engine intake 


\section{Fuel economy evaluation by numerical analysis}

\subsection{Mathematical modeling}

Technique 1

\begin{tabular}{|c|c|c|c|}
\hline State variable & $\begin{array}{c}\text { Can be expressed as a } \\
\text { function of }\end{array}$ & Type & Reference \\
\hline$p_{1}$ & $\left(p_{0}, Q_{\text {comp }}\right)$ & $\begin{array}{c}\text { Thermodynamic } \\
\text { equation }\end{array}$ & \\
\hline$T_{1}$ & $\left(p_{o}, T_{o}, p_{1}\right)$ & $\begin{array}{c}\text { Thermodynamic } \\
\text { equation }\end{array}$ & [37] \\
\hline$p_{2}$ & $\left(Q_{\text {comp }}, p_{1}, T_{1}, N_{\text {comp }}\right)$ & $\begin{array}{c}\text { Thermodynamic } \\
\text { equation }\end{array}$ & [37] \\
\hline$T_{2}$ & $\left(Q_{\text {comp }}, p_{1}, T_{1}, N_{\text {comp }}\right)$ & $\begin{array}{c}\text { Thermodynamic } \\
\text { equation }\end{array}$ & [37] \\
\hline$p_{3}$ & $\left(Q_{\text {comp }}, p_{2}\right)$ & $\begin{array}{c}\text { Thermodynamic } \\
\text { equation }\end{array}$ & [37] \\
\hline$T_{3}$ & $\left(Q_{\text {comp }}, p_{2}, T_{2}\right)$ & Empirical model & {$[37]$} \\
\hline$Q_{\text {comp }}$ & $\left(p_{2}, p_{3}, N_{\text {comp }}\right)$ & Cartography & {$[30]$} \\
\hline$\eta_{\text {comp }}$ & $\left(p_{2}, p_{3}, N_{\text {comp }}\right)$ & Cartography & {$[30]$} \\
\hline$P_{\text {comp }}$ & $\left(Q_{\text {comp }}, p_{2}, T_{2}, p_{3}, \eta_{\text {comp }}\right)$ & $\begin{array}{c}\text { Thermodynamic } \\
\text { equation }\end{array}$ & {$[30]$} \\
\hline$Q_{\text {int }}$ & $\left(p_{3}, T_{3}, \eta_{v o l}\right)$ & $\begin{array}{c}\text { Thermodynamic } \\
\text { equation }\end{array}$ & [37] \\
\hline$\eta_{v o l}$ & $N_{\text {eng }}$ & Empirical model & {$[37,39]$} \\
\hline$T_{4}$ & $\left(T_{3}, Q_{\text {int }}, Q_{f u e l}\right)$ & Empirical model & {$[37]$} \\
\hline$P_{\text {out }}$ & $\left(Q_{\text {fuel }}, \eta_{\text {ind }}, P_{\text {fric }}\right)$ & $\begin{array}{c}\text { Thermodynamic } \\
\text { equation }\end{array}$ & {$[37]$} \\
\hline$P_{\text {fric }}$ & $N_{\text {eng }}$ & Empirical model & {$[45]$} \\
\hline$\eta_{\text {ind }}$ & $\left(Q_{\text {int }}, Q_{\text {fuel }}\right)$ & Empirical model & {$[37,39,40]$} \\
\hline$Q_{e x h}$ & $\left(Q_{\text {int }}, Q_{\text {fuel }}\right)$ & $\begin{array}{c}\text { Thermodynamic } \\
\text { equation }\end{array}$ & {$[37]$} \\
\hline$Q_{\text {turb }}$ & $\left(p_{4}, p_{5}, N_{t u r b}\right)$ & Cartography & {$[30]$} \\
\hline$\eta_{\text {turb }}$ & $\left(p_{4}, p_{5}, N_{\text {turb }}\right)$ & Cartography & [30] \\
\hline$P_{\text {turb }}$ & $\left(Q_{t u r b}, p_{4}, T_{4}, p_{5}, \eta_{t u r b}\right)$ & $\begin{array}{c}\text { Thermodynamic } \\
\text { equation }\end{array}$ & [30] \\
\hline
\end{tabular}

The numerical resolution of the problem consists in finding the roots of the state variables which ensures the equilibrium of the system. 


\section{For an operation without CAES}

The unknown variables are $\left(Q_{\text {int }}, Q_{\text {fuel }}, N_{\text {comp }}, p_{3}, p_{4}\right)$ and the equilibrium equations are the following:

- balance equation of the crankshaft:

The power supplied by the engine must be equal to the resistant power:

$$
P_{\text {out }}=P_{\text {load }}
$$

- balance equation of the turbocharger torque

The torque supplied by the turbine must be equal to the necessary torque to drive the compressor:

$$
P_{\text {comp }}=P_{\text {turb }}
$$

- balance equation of the turbocharger speed

The speed of the turbine and the compressor are equal:

$$
N_{\text {comp }}=N_{\text {turb }}
$$

- $\quad$ intake aire continuity

$$
Q_{\text {comp }}=Q_{\text {int }}
$$

- $\quad$ exhaust air continuity

$$
Q_{\text {turb }}=Q_{\text {exh }}
$$

\section{For an operation with CAES}

The unknown variables are $\left(Q_{\text {int }}, Q_{\text {fuel }}, N_{\text {comp }}, p_{0}, p_{3}, p_{4}\right)$ and the equilibrium equations are the same as previous five equations in addition to the sixth following equation:

- Optimal Air-to-Fuel ratio

$$
\frac{Q_{\text {int }}}{Q_{\text {fuel }}}=53
$$

\section{Technique 2}

Main equations are issued from the mass and heat conservation as well as the ideal gas assumptions $[6,13]$. The application of the first law or thermodynamics and the perfect gas law to the control volume results in the differential equation 1 [13] that drives all the thermodynamic transformations.

$$
d(m \cdot u)=-P \cdot d V+d q_{\text {walls }}+d q_{\mathrm{comb}}+h_{T} \cdot d m_{\mathrm{int}}+h_{\text {ech }} \cdot d m_{\mathrm{exh}}+h_{\text {fuel }} \cdot d m_{\text {fuel }}
$$




\begin{tabular}{|l|c|c|c|}
\hline State variable & $\begin{array}{c}\text { Can be expressed as a } \\
\text { function of }\end{array}$ & Type & Reference \\
\hline$u$ & $\left(T, x_{i}\right)$ & Thermodynamic tables & {$[54]$} \\
\hline$h$ & $\left(T, x_{i}\right)$ & Thermodynamic tables & {$[54]$} \\
\hline$V$ & $\theta$ & Kinematic equation & {$[56,57]$} \\
\hline$d q_{\text {walls }}$ & $\left(T_{\text {gas }}, T_{\text {walls }}, N_{\text {eng }}\right)$ & Empirical model & {$[55]$} \\
\hline$d q_{\text {comb }}$ & $\left(\theta, \theta_{0}, \theta_{\text {delay }}\right)$ & Empirical model & {$[56,57]$} \\
\hline$\theta_{\text {delay }}$ & $\left(T_{\text {gas }}, P_{\text {gas }}, N_{\text {eng }}\right)$ & Chemical model & {$[56,57]$} \\
\hline$d m$ & $\left(P_{\text {in }}, P_{\text {out }}, T_{\text {in }}, A\right)$ & Thermodynamic model & {$[56,57]$} \\
\hline
\end{tabular}

\subsection{Results and analysis}

\section{Technique 1}

We suppose in this numerical application that the used engine possesses a capacity of 51 and turns at a regime of 1500 rotations per minute. Thus, the results obtained by the optimization are presented in Figures. 9-11. In conventional operation, the ratio air/fuel decreases with the load to reach in full load at the neighborhood of the stoichiometry as shown in Figure 9. For any requested torque lower than $120 \mathrm{Nm}$, we obtain an Air-toFuel ratio higher than 53, which means that there is no provision of the use of compressed air. Once the torque exceeds $120 \mathrm{~N} \mathrm{~m}$, the turbocharger cannot ensure the quantity of necessary air to have an optimal air/fuel ratio. The engine then works in the zone of interest of operation with compressed air. Figure 10 shows the necessary inlet pressure of the compressor to operate the engine at its maximum efficiency thanks to the compressed air. Indeed, in the absence of CAES, the inlet pressure of the compressor is constant and equal to 1 bar, which is shown by the red curve ("Without Compressed Air"). The CAES allows feeding of the compressor at a chosen pressure to achieve the exact necessary air flow for maximum performance (efficiency). In our case, this pressure varies between 1 bar at very low regimes and 2.6 bars at full load. An adapted strategy for checking the valve relaxation of compressed air would achieve that balance. Finally, Figure 11 shows the reduction in fuel consumption which is brought about by the compressed air. This reduction in fuel consumption grows with the load to peak to $50 \%$ fuel saving at $800 \mathrm{Nm}$ 


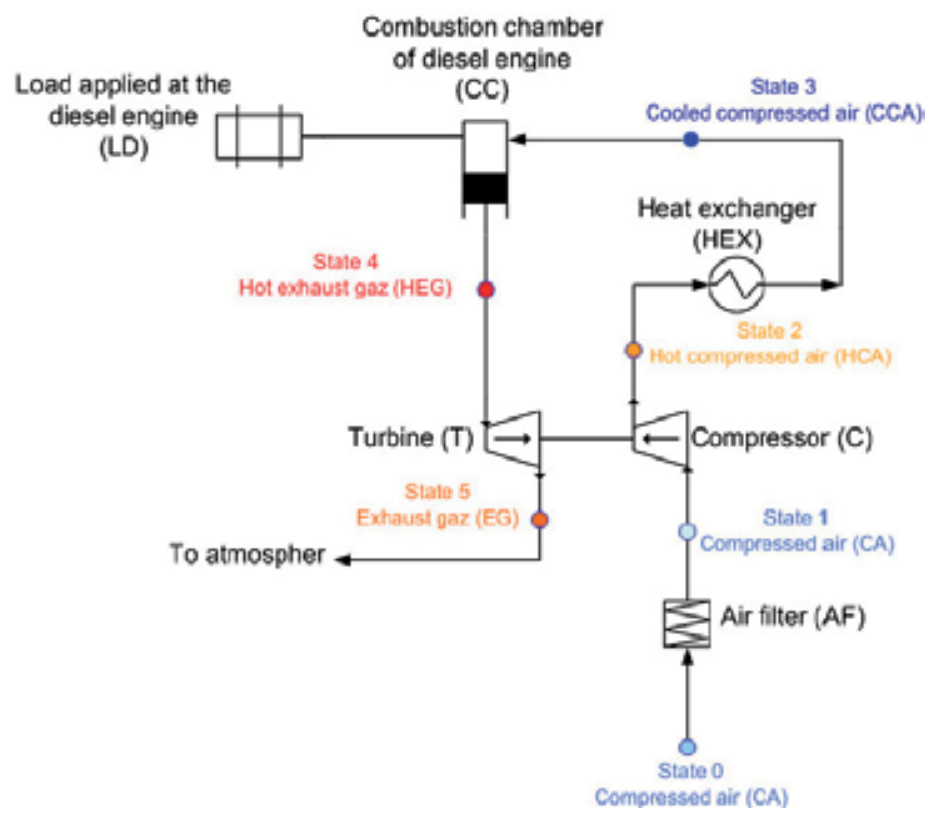

Fig. 7. Schema of Diesel engine main components

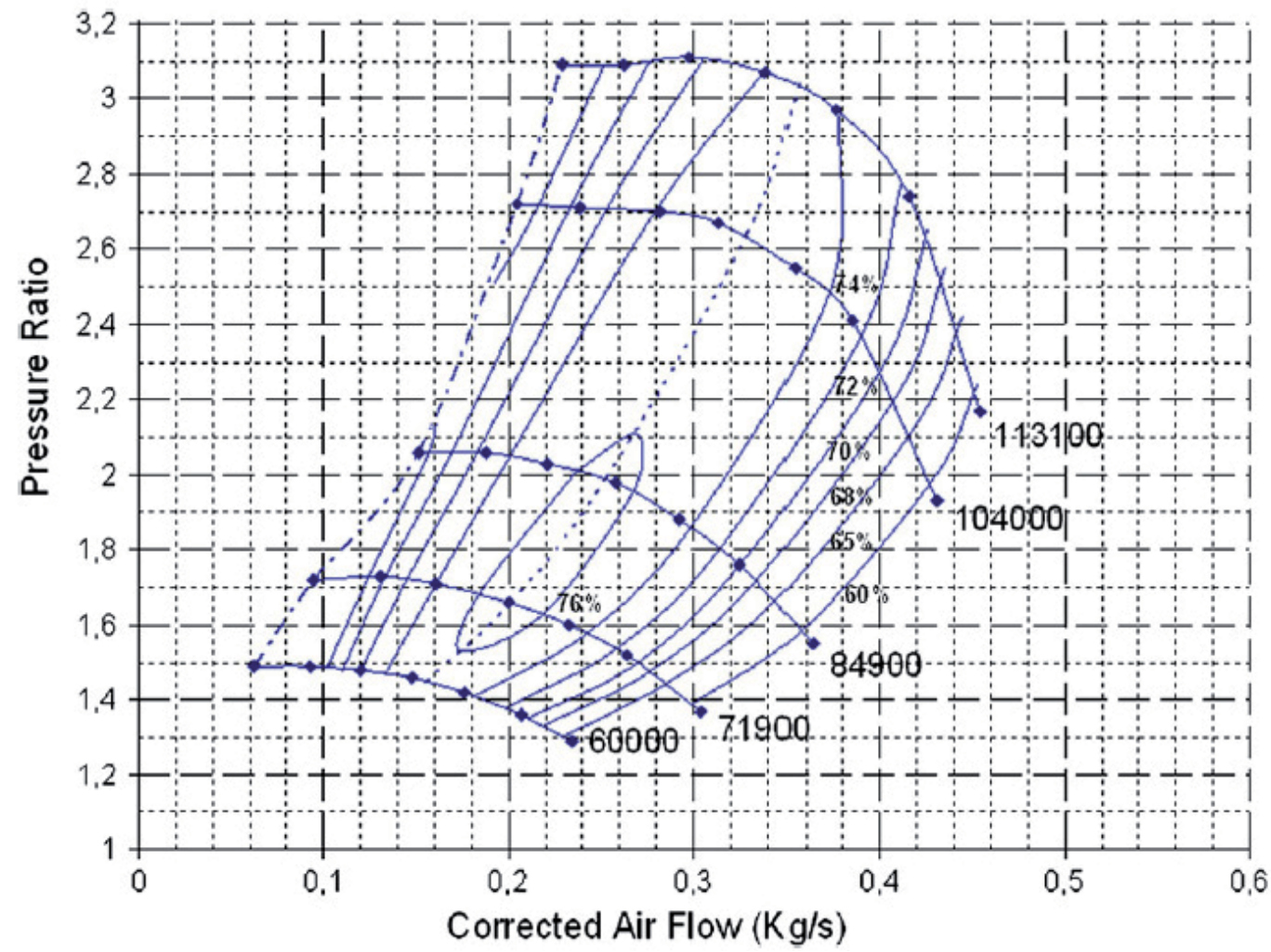

Fig. 8. Variation Characteristic curves of the compressor given by the manufacturer [30]. 


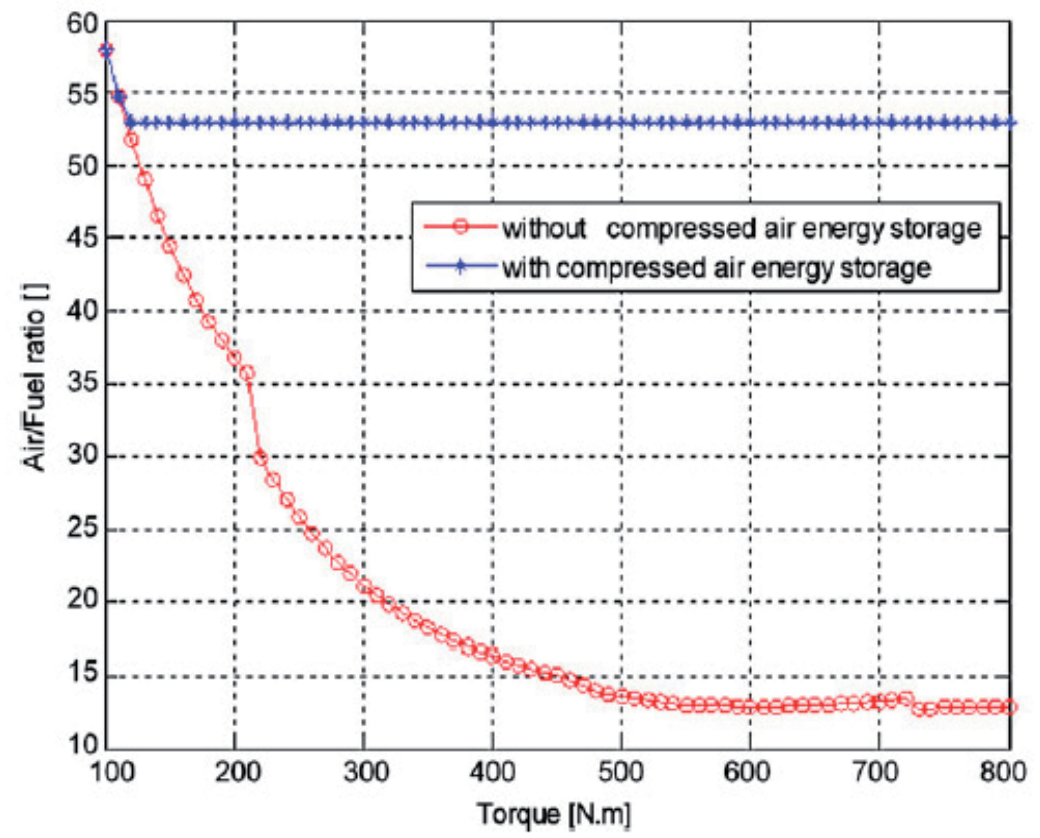

Fig. 9. Comparison of the (air/fuel) ratio.

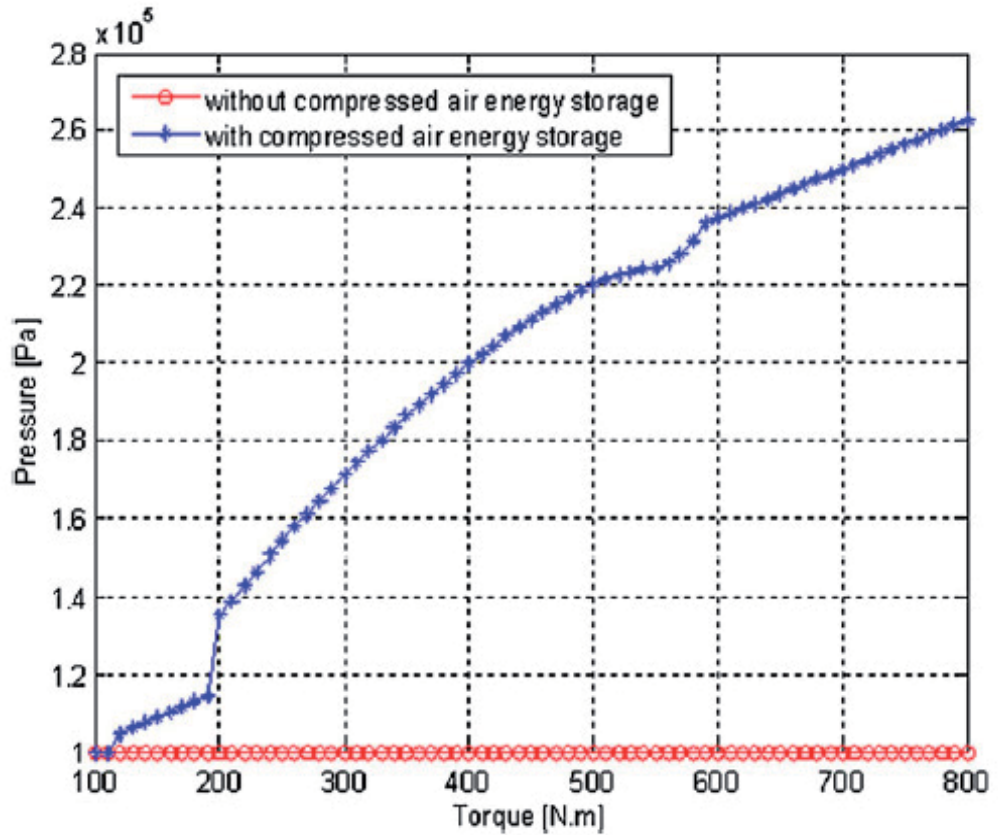

Fig. 10. Comparison of the pressure at compressor inlet.. 


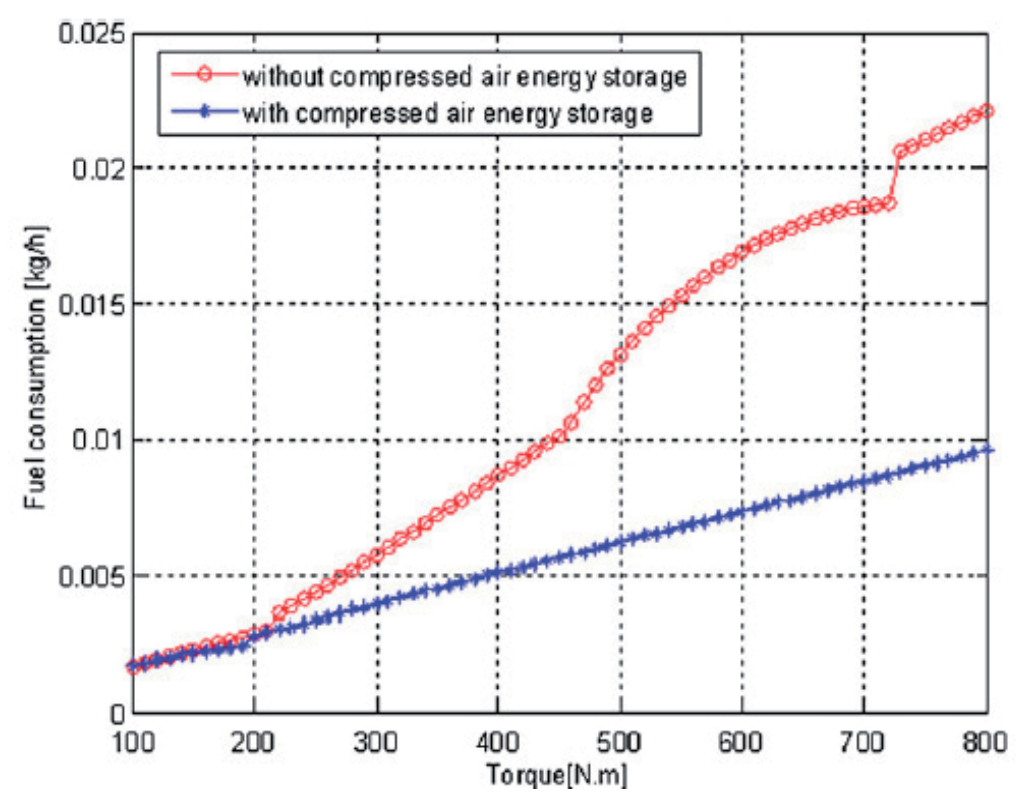

Fig. 11. Comparison of the fuel consumption.

\section{Technique 2}

In our study, we have chosen to focus on three operating modes to study the impact of injection advance:

- Turbocharged mode with compressed air cooling;

- $\quad$ CAES charged mode with an intake temperature of $25^{\circ} \mathrm{C}$;

- $\quad$ CAES charged mode with an intake temperature of $-50^{\circ} \mathrm{C}$.

For the CAES charged mode temperatures, we know that a temperature drop will inevitably occur when expanding the CAES from storage pressure to intake pressure. However, it is possible to heat the intake air before admitting it using engine's cooling system or exhaust temperature recovery. We have chosen not to work below intake temperature of $-50^{\circ} \mathrm{C}$ because it is the range of minimum external temperature that can be met in northern areas. Below this temperature, we need to investigate if the Diesel engine remains operational which exceeds the purpose of this study. These operating modes are not the only ones to be studied, but they were chosen to increase our understanding of the Diesel engine behavior regarding intake and exhaust conditions.

\section{Detailed parametric study at BMEP $=10$ bars}

In order to understand its behavior, we will provide a complete analysis of the variation of the thermodynamic cycle and its efficiency, depending on the control parameters (intake pressure, intake temperature, exhaust pressure and injection advance) for a fixed load corresponding to a BMEP of 10 bars. Figure 13 illustrates the effect of intake pressure and exhaust pressure on specific fuel consumption of the engine at a BMEP of 10 bars for a fixed intake temperature of $298 \mathrm{~K}$ and a fixed injection advance of 6 degrees. As we can observe, increasing intake pressure and reducing exhaust pressure highly reduces fuel consumption. 


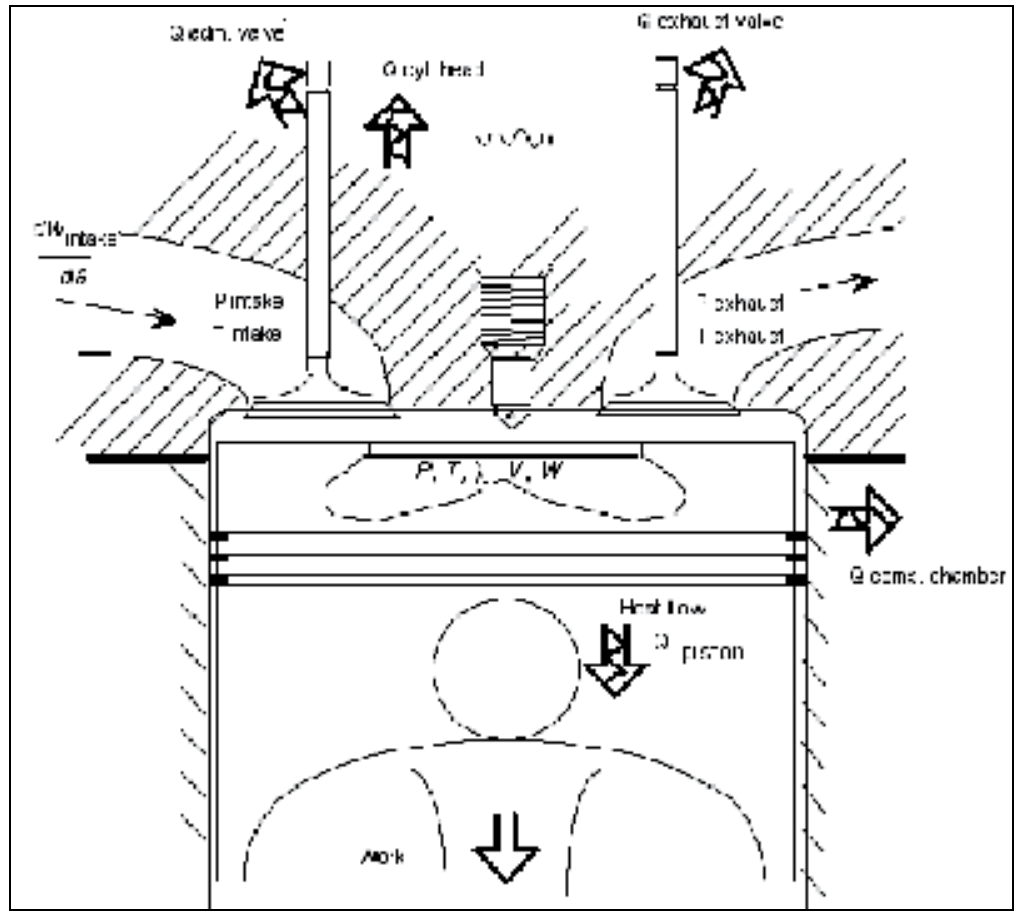

Fig. 12. Direct injection Diesel engine simplified thermodynamic model.

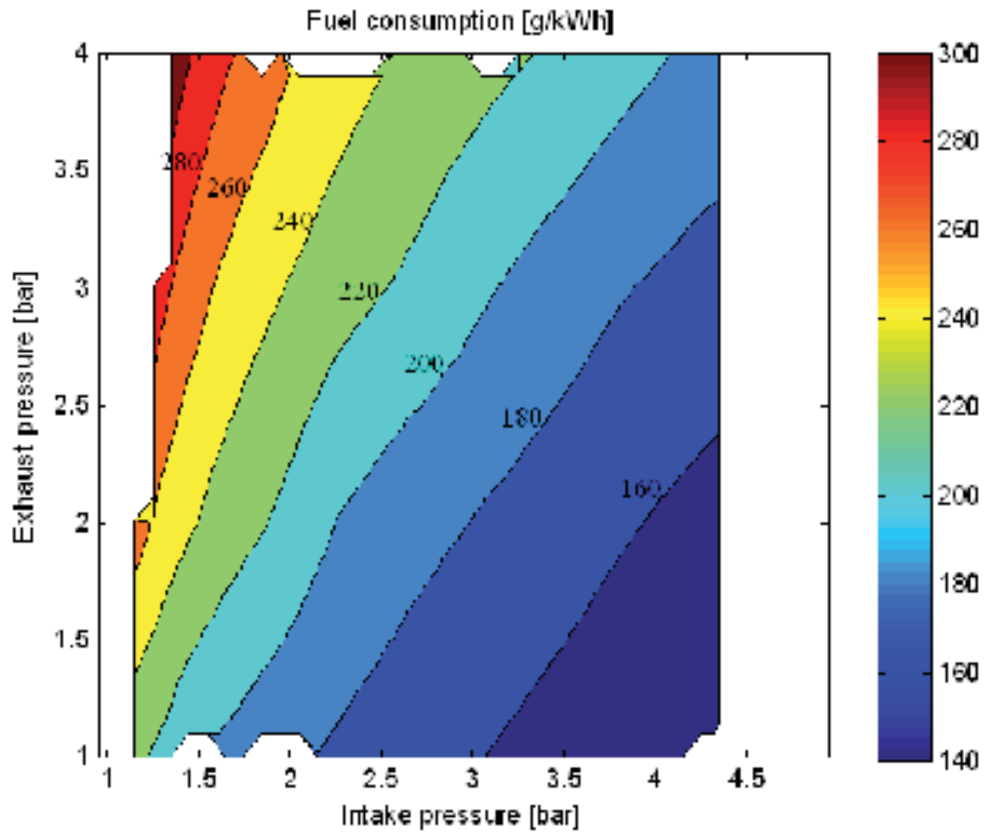

Fig. 13. Fuel consumption as a function of intake and exhaust pressures, for a fixed intake temperature of $25^{\circ} \mathrm{C}$ at $\mathrm{BMEP}=10$ bars 
We present some qualitative explanations for this improvement, which will be completed with data in the rest of this paragraph. Actually, two main reasons are behind the fuel consumption reduction when the intake pressure is increased and exhaust pressure decreased:

- The scavenging work, called also "the low pressure cycle work", increases and turns out to be positive (motor). That is added to the work provided by the high pressure cycle and reduces fuel consumption. In a classic turbocharged Diesel, intake pressure is slightly lower than exhaust pressure; the scavenging work is slightly negative and requires more fuel for the same total work of the thermodynamic cycle.

- The high-pressure cycle efficiency increases with pneumatic hybridization thanks to higher fresh air quantity. This improvement is mainly due to lower thermal losses, due to the reduction of combustion temperature resulting from less fuel burned from one side, and higher air density (therefore higher calorific capacity) from the other side.

As mentioned before, the maximum pressure allowed in the cylinder limits the amount of intake pressure. Figure 14 shows the variation of the maximum cylinder pressure as a function of the intake and exhaust pressures. We observe the maximum cylinder pressure is almost not affected by exhaust pressure but varies linearly with intake pressure with a high slope of about 40 to 1 . With a 4 bars intake pressure, the maximum cylinder pressure reaches already 180 bar.

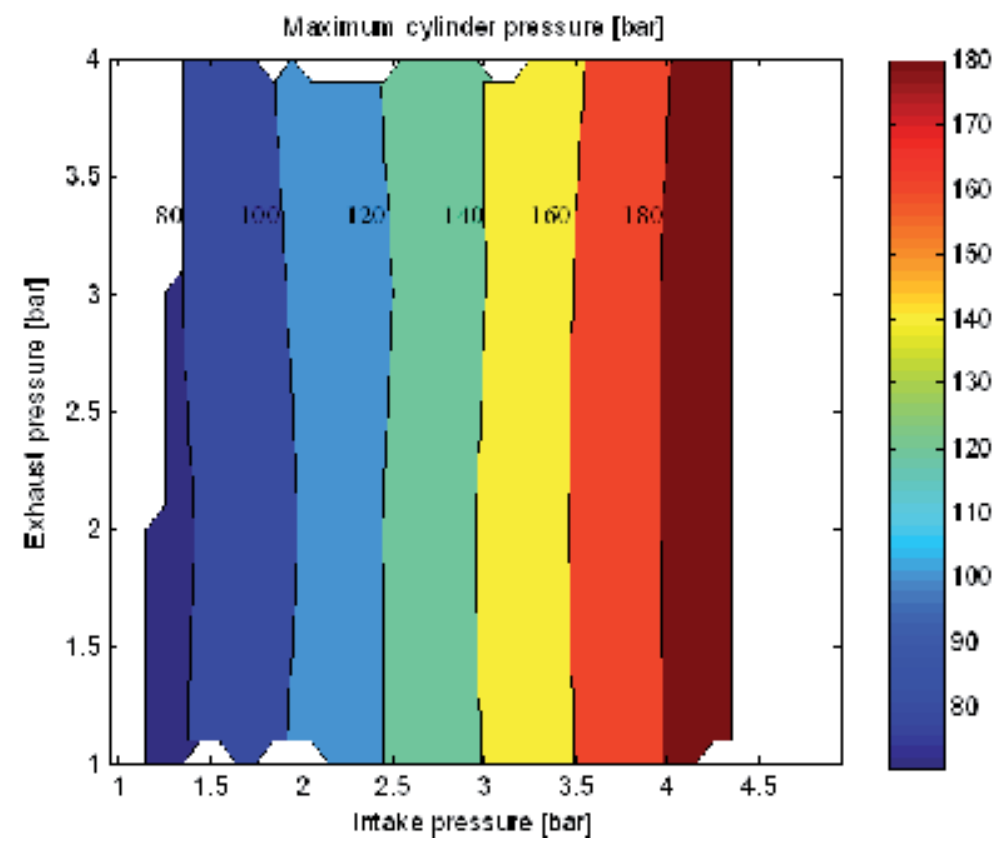

Fig. 14. Maximum gas pressure variation with intake and exhaust pressures, for a fixed intake temperature of $25^{\circ} \mathrm{C}$, at $\mathrm{BMEP}=10$ bars

The second potential limitation that we have investigated is the exhaust temperature. Actually, exhaust valve has a threshold in terms of gas temperature not to be exceeded. As we can observe in Figure 15, the exhaust temperature is lower when intake pressure is 
increased or exhaust pressure is decreased. Therefore, exhaust temperature will not limit the pneumatic hybridization.

After the analysis of the effect of intake and exhaust pressures for a fixed intake temperature and fixed injection advance, we illustrate (Figure 16) the effect of intake temperature and pressure on fuel consumption, for a fixed exhaust pressure of 1 bar and a fixed injection advance of 6 degrees. Fixing exhaust pressure to 1 bar assumes that the turbocharger is already by-passed. Fuel consumption is reduces as intake temperature lowers. As will be shown later with additional data, reducing intake temperature for the same intake pressure will reduce heat losses as well and improve cycle efficiency because the global gas temperature is lower (higher air density and lower initial cycle temperature).

Regarding maximum cylinder pressure, we observe in Figure 17 that reducing the intake temperature for the same intake pressure increases the maximum cylinder pressure. This is due to higher air quantity admitted. Therefore the maximum intake pressure we can reach is lower for low intake temperature. For example, at $-50^{\circ} \mathrm{C}$ intake temperature, the maximum cylinder pressure reaches 180 bars for an intake pressure of 3.2 bars, which is 0.8 bars lower than the limitation at $+25^{\circ} \mathrm{C}$ intake temperature.

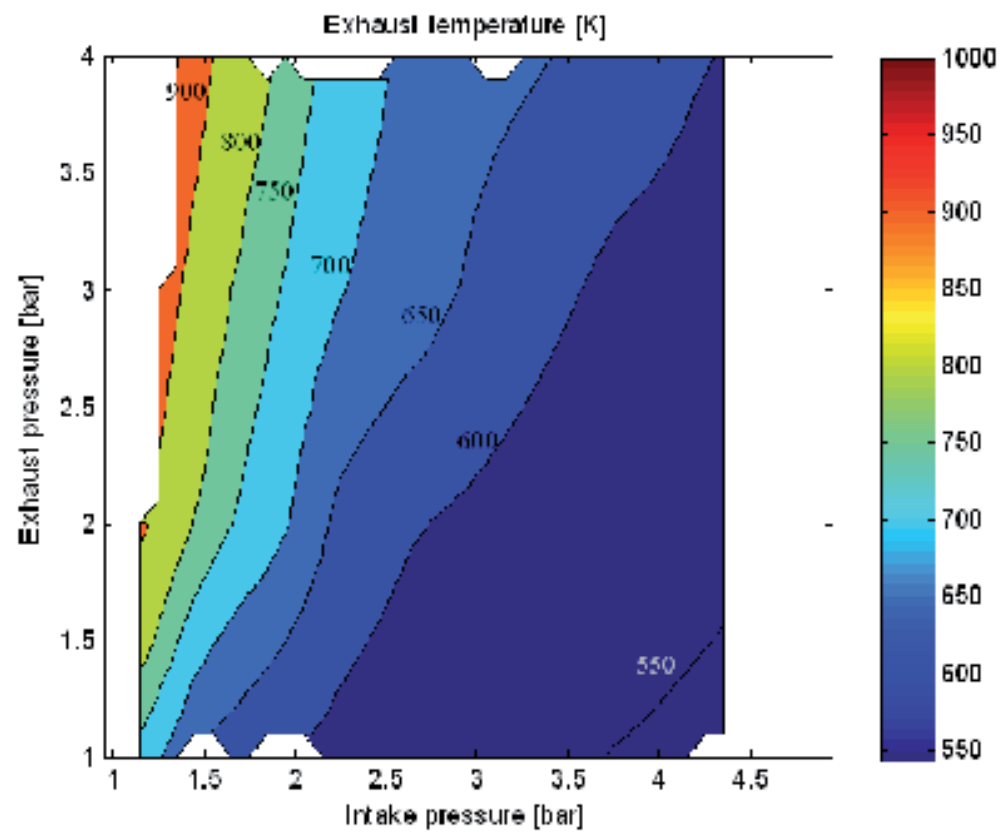

Fig. 15. Exhaust gas temperature function of intake and exhaust pressures, for a fixed intake temperature of $25^{\circ} \mathrm{C}$, at $\mathrm{BMEP}=10$ bars 


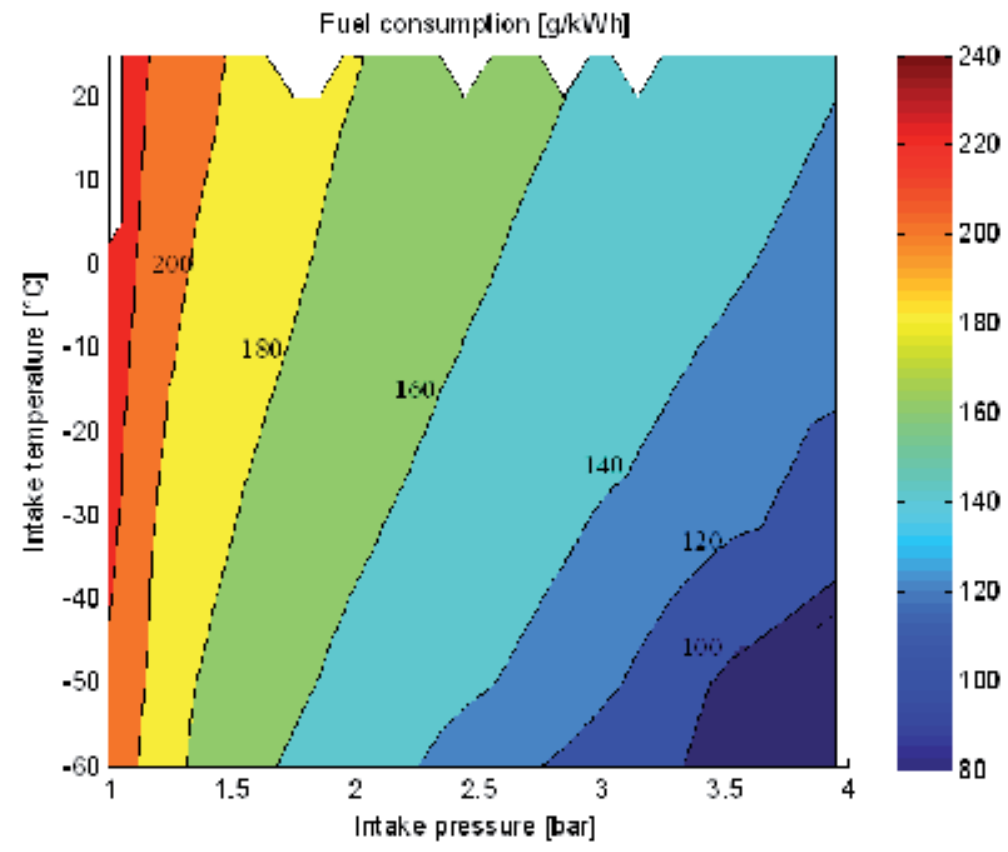

Fig. 16. Fuel consumption as a function of intake pressure and temperature, for a fixed exhaust pressure of 1 bar, at BMEP $=10$ bars

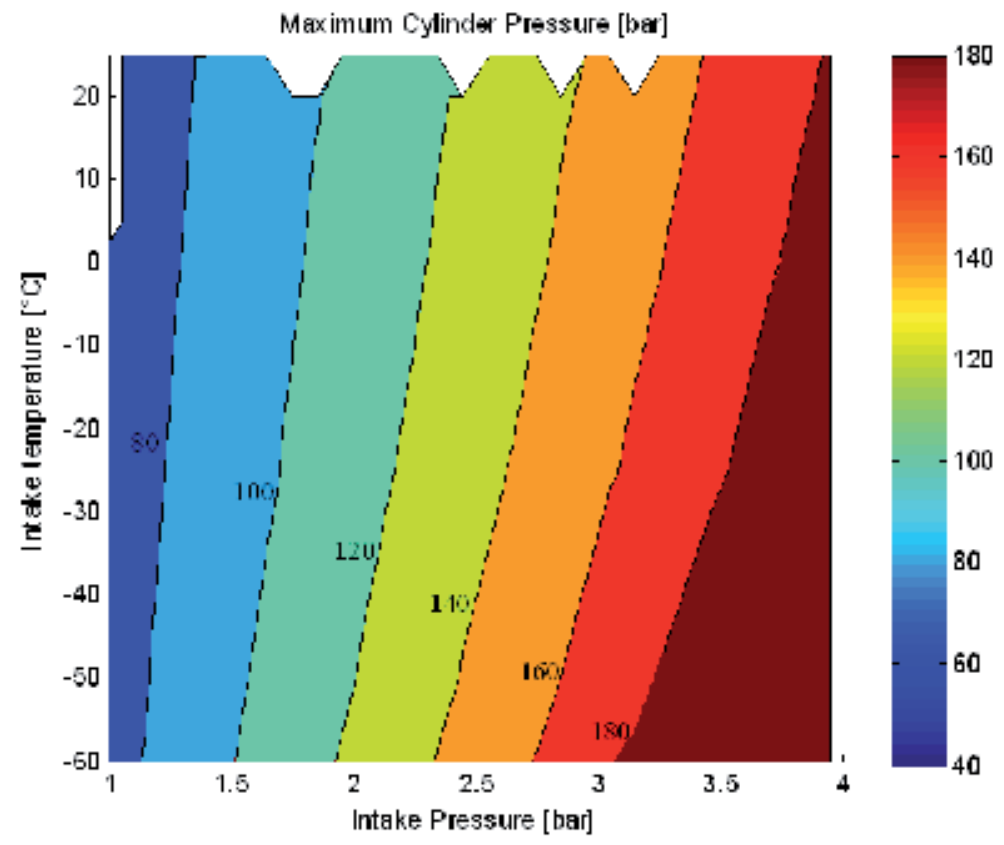

Fig. 17. Maximum gas pressure function of intake pressure and temperature, for a fixed exhaust pressure of 1 bar, at $\mathrm{BMEP}=10$ bars 
The last parameter studied is the Injection Advance (IA) which is responsible of Start of Combustion (SOC) angle. Actually, there is an optimal advance that reduces the fuel consumption to a minimum, for every condition of intake pressure, intake temperature and exhaust pressure. The reasons are:

- The Auto-Ignition Delay (AID) depends of the intake conditions and so does the SOC because it is simply equal to the difference between the IA and the AID. It is important to have a SOC angle nearly before the Top Dead Center (TDC) in order to have good cycle efficiency.

- The thermal loss depends of the intake temperature and pressure and the cylinder pressure profile changes consequently. To have optimal cycle efficiency, the SOC needs to be adjusted around its nominal value.

For the simplification of the study, the AID was not modeled and the effect of the SOC angle is directly studied and set to its optimal value. Figure 18 illustrates the effect of SOC angle on fuel consumption, for the three chosen operating points. We observe that the optimal SOC angle for turbocharged mode is 6 degrees, for CAES charged at $25^{\circ} \mathrm{C}$ mode is 7 degrees and for CAES charged at $-50^{\circ} \mathrm{C}$ mode, is 9 degrees. It is important to note that increasing injection advance to reduce fuel consumption, increases the maximum cylinder pressure, and therefore decreases the maximum intake pressure. In that case, the fuel consumption may increase instead of decreasing, but the global efficiency is better because less compressed air is consumed.

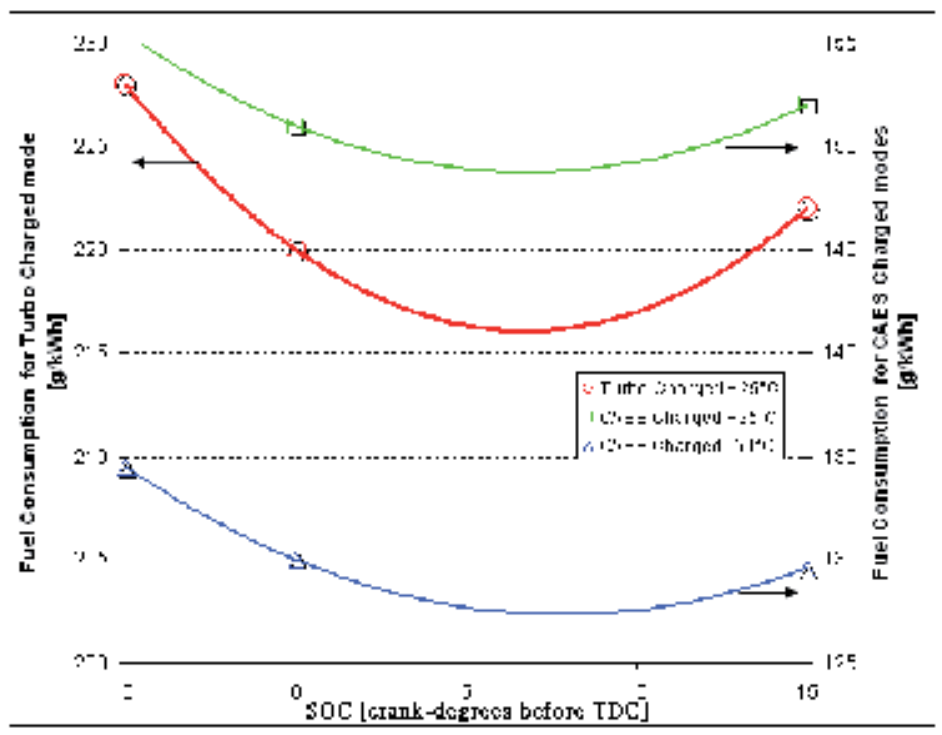

Fig. 18. Effect of SOC angle on fuel consumption, at BMEP = 10 bars, for different charging modes

The thermodynamic cycles of the chosen operating points are illustrated in Figures 19 and 17. All three operating modes are working at optimal SOC angles and therefore optimal IA.

Figure 19 illustrates the P-V diagram plotted in a logarithmic scale. It is interesting to analyze the low-pressure cycle called also the scavenging cycle. We notice that the pneumatic work witch is the area of the scavenging cycle is near zero for turbo-charged 
mode and positive for CAES charged modes. We also notice that the scavenging work in $\mathrm{CAES}+25^{\circ} \mathrm{C}$ is slightly higher than the one in CAES $-50^{\circ} \mathrm{C}$ because intake pressure is higher.

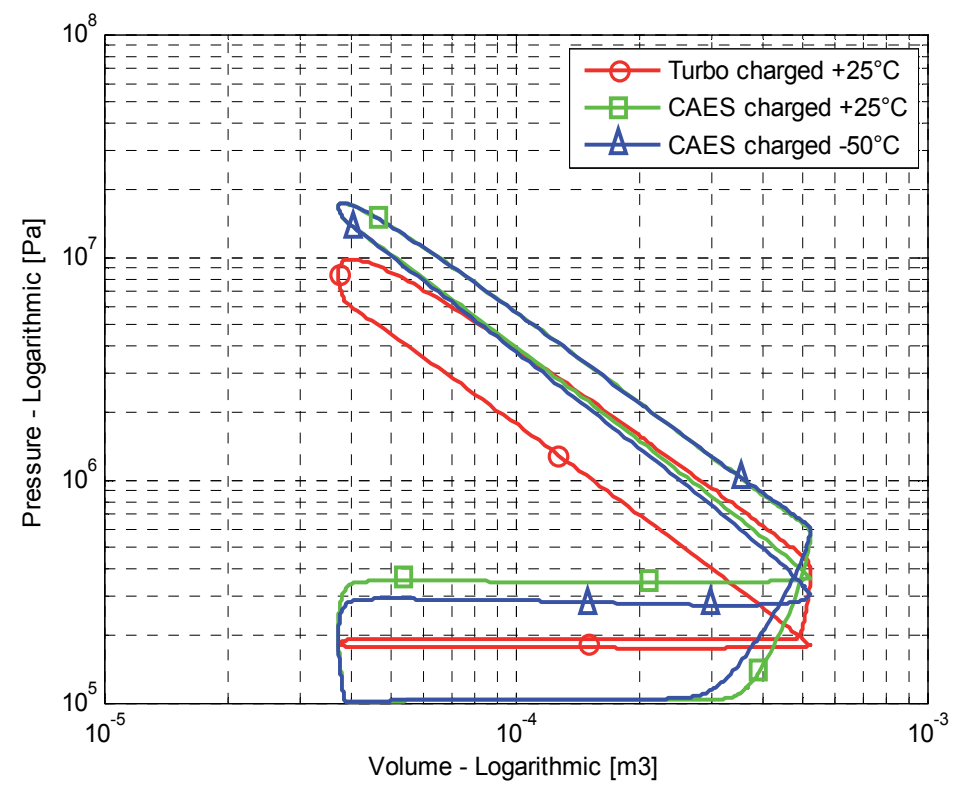

Fig. 19. $\log \mathrm{P}-\log \mathrm{V}$ diagrams at $\mathrm{BMEP}=10$ bars, for different charging modes

We notice in Figure 20 the high increase of the maximum cylinder pressure when moving from turbocharged mode to CAES charged mode.

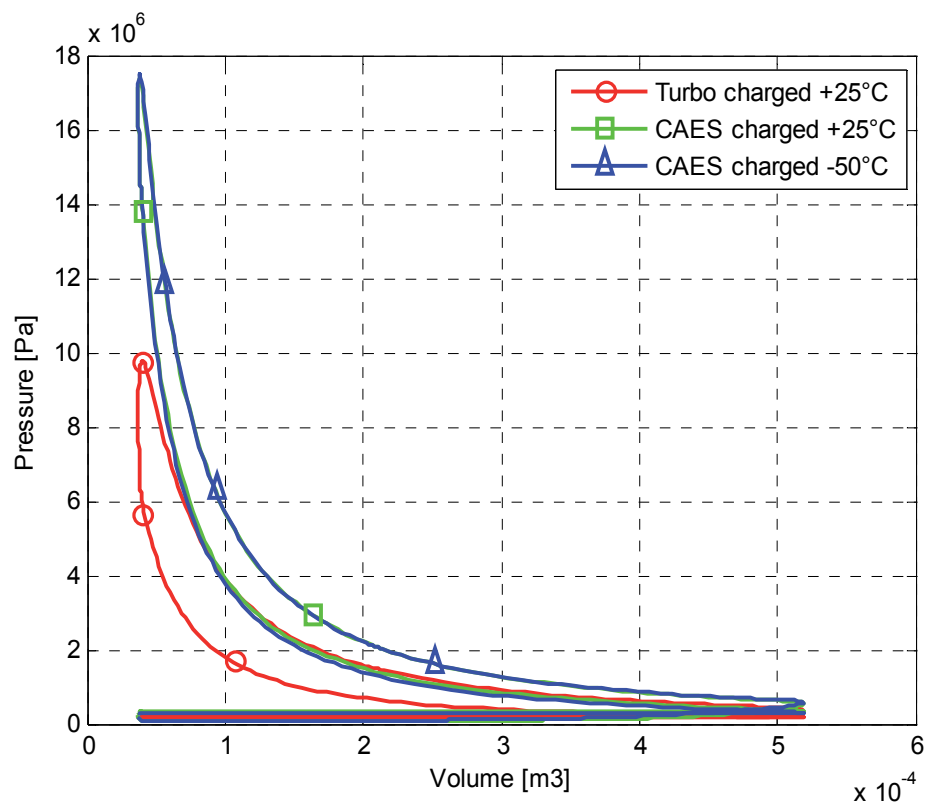

Fig. 20. $\mathrm{P}-\mathrm{V}$ diagram at $\mathrm{BMEP}=10$ bars, for different charging modes 
Figure 21 and 22 illustrate respectively the T- $\theta$ diagram and heat exchange through boundaries for the three modes. We can see in Figure 21 that a significant decrease in gas temperature is obtained when moving from turbocharged mode to CAES $-50^{\circ} \mathrm{C}$ mode passing by CAES $+25^{\circ} \mathrm{C}$ charging mode. This temperature decrease is a result of the three following reasons:

1. The higher air density resulting from the higher intake pressure and/or the lower intake temperature, leads to higher calorific capacity of the in-cylinder gas and therefore lower temperature rise for a certain heat energy released by the combustion.

2. Lower heat release resulting from lower quantity of burned fuel that reduces temperature rise for CAES $25^{\circ} \mathrm{C}$ and CAES $-50^{\circ} \mathrm{C}$;

3. Intake air temperature is $75^{\circ} \mathrm{C}$ lower for CAES $-50^{\circ} \mathrm{C}$ that is responsible for lower average gas temperature of this operating mode compared to CAES $25^{\circ} \mathrm{C}$.

In Figure 22, negative flow means the gas is loosing energy through boundary and positive flow means the gas is earning energy from boundary. For turbocharged mode, the flow is positive only during intake because gas temperature at this time is lower than boundaries' temperatures. During combustion, expansion and exhaust phases, the heat flow is negative causing significant loss in energy. As for the CAES charged mode at $25^{\circ} \mathrm{C}$, we observe that heat loss decreases significantly comparing to turbocharged mode but the flow is still negative. In CAES charged mode at $-50^{\circ} \mathrm{C}$, the overall heat flow is positive therefore the system is not loosing energy, on the contrary, it is recovering thermal energy from the engine. Of course, this assumes that the engine is hot and that the CAES charged mode at $-50^{\circ} \mathrm{C}$ occurs occasionally, after a certain time of working under standard turbocharged mode. The thermal inertia of the Diesel engine defines the minimal and maximal working time of turbocharged mode and CAES mode respectively in order to make this hypothesis valid. In case the time of operating with CAES charged mode at $-50^{\circ} \mathrm{C}$ exceeds a certain limit, the heat flow will stabilize to meet a global value near zero which will increase the fuel consumption by a small amount.

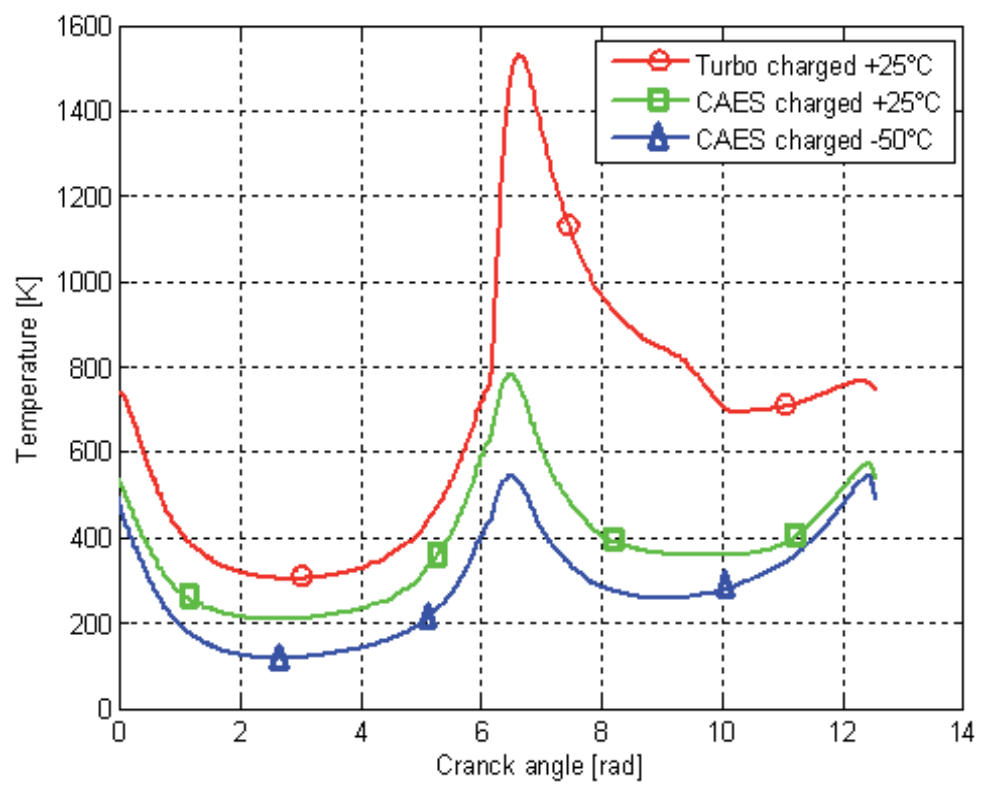

Fig. 21. $\mathrm{T}-\theta$ diagram at $\mathrm{BMEP}=10$ bars, for different charging modes 


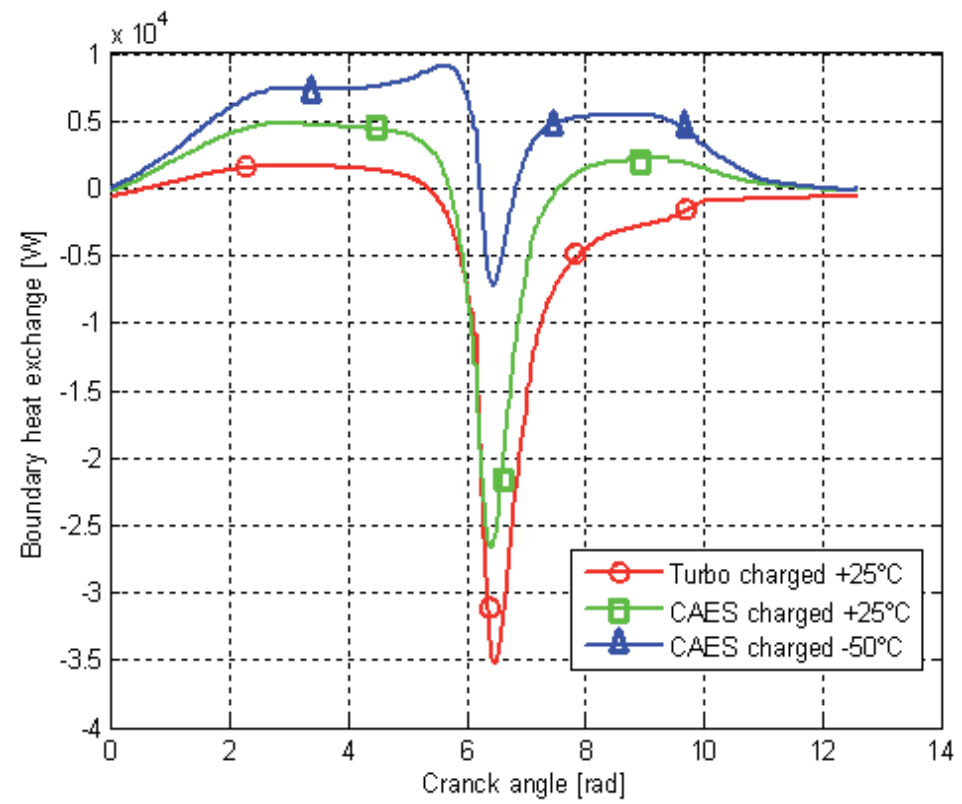

Fig. 22. Heat flow through boundary, for different charging modes, at BMEP $=10$ bars

As a synthesis of this complete study around the operating point of BMEP 10 bars, Figure 23 illustrates the reasons for fuel economy brought by CAES charged modes compared to turbocharged mode. We observe that $65 \%$ of the fuel consumption reduction from turbocharged mode at $+25^{\circ} \mathrm{C}$ to CAES charged mode at $+25^{\circ} \mathrm{C}$ is caused by direct pneumatic power production and $35 \%$ is caused by heat loss reduction. The heat loss reduction constitutes the only reason for the improvement from CAES charged $+25^{\circ} \mathrm{C}$ to CAES charged $-50^{\circ} \mathrm{C}$ mode, as the pneumatic contribution is higher in $\mathrm{CAES}+25^{\circ} \mathrm{C}$ mode due to higher intake pressure.

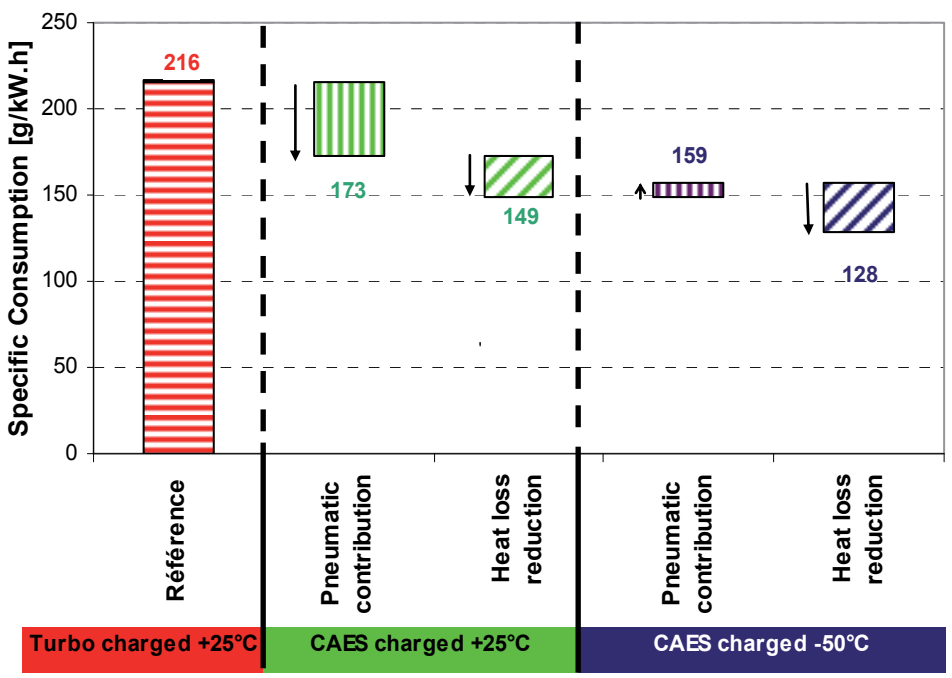

Fig. 23. Explanation of consumption change from a charging mode to another, at $\mathrm{BMEP}=10$ bars 


\section{Optimization result at different loads}

In this section, we will compare different charging modes on different criteria, for different operating points, after optimization. The charging modes considered are:

- $\quad$ CAES Charged mode at $50^{\circ} \mathrm{C}$;

- $\quad$ CAES charged mode at $25^{\circ} \mathrm{C}$;

- $\quad$ CAES charged mode at $0^{\circ} \mathrm{C}$;

- $\quad$ CAES Charged mode at $-50^{\circ} \mathrm{C}$;

- Turbo charged mode at $25^{\circ} \mathrm{C}$.

All CAES charged modes are operating at maximum allowable intake pressure, that is intake pressure for witch maximum gas pressure during thermodynamic cycle reaches 180 bars and at an exhaust pressure of 1 bar, while turbocharged mode operates at an intake pressure and exhaust pressure both dependant on BMEP but almost equal. All operating points are set with an optimal injection advance, the one that maximizes the cycle efficiency, even if the intake allowed pressure has to be decreased. As mentioned before, the variation of intake pressure and exhaust pressure as a function of BMEP for a turbocharged engine depends on the design of the turbocharger. We have taken here an example provided by a previous simulation [1] conducted on a Diesel engine.

Figure 24 illustrates the intake pressure and the injection advance at every operating point simulated. We can see that for higher loads the allowable intake pressure lowers; we can also see that a lower intake temperature will reduce the allowable intake pressure.

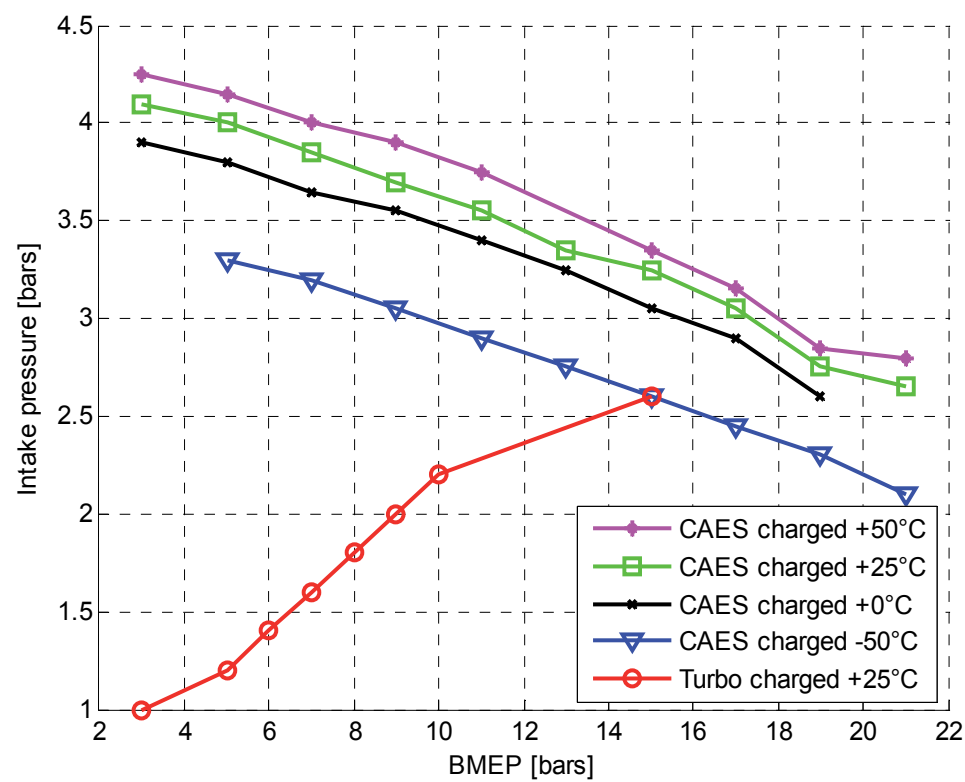

Fig. 24. Intake maximum pressure for different charging modes, function of engine load

These intake pressures make the maximum gas pressure during Diesel cycle reach 180 bars, as shown in Figure 25, while in turbocharged mode, maximal pressure is significantly lower. 


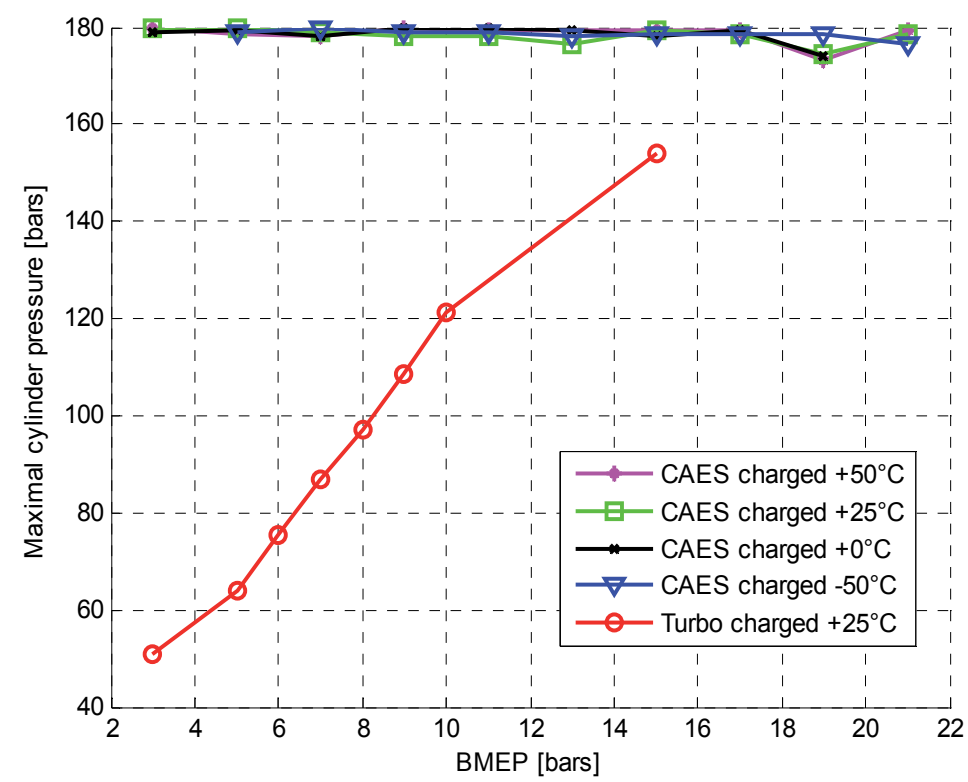

Fig. 25. Maximum cylinder pressure for different charging modes, function of engine load

When comparing fuel consumption of CAES charged mode with turbocharged mode, we observe in Figure 26 that at lower loads, the reduction is higher. That is due to the more important absolute pneumatic power as intake pressure is higher, relatively to the total power of the engine. We notice also that better fuel economy for lower intake temperature for the same reasons as described in the previous paragraph.

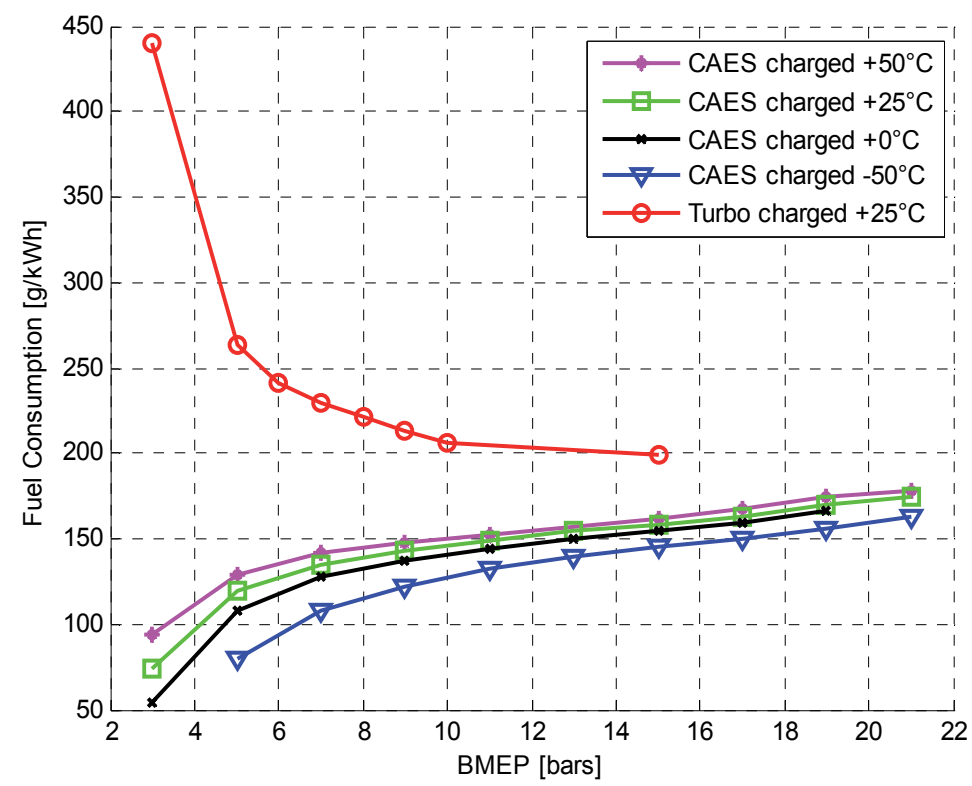

Fig. 26. Fuel specific consumption for different charging modes, function of engine load 
Finally, the air consumption is one important criterion as the storage tank volume depends on it. Figure 27 shows that air consumption increases at low loads and also at low temperature because filling is better. In order to optimize the use of stored air, another criterion is necessary. We have calculated and illustrated in Figure 28, the fuel economy per kilogram of air consumed. This criterion has to be maximized in order to get the maximum advantage of stored air. As we can notice at Figure 28, it is more interesting to use CAES charged mode at low and very low loads. We can also see that even if it has positive effect on fuel consumption, very low intake air temperature is less suitable when considering consumed air quantity.

In case the storage pressure is higher than the intake temperature, it is needed therefore to expand it before introducing it into the engine intake. A temperature drop will probably accompany this expansion. In that case, we recommend heating the air after its expansion, using a free of charge source as the engine cooling system or an exhaust gas exchanger.

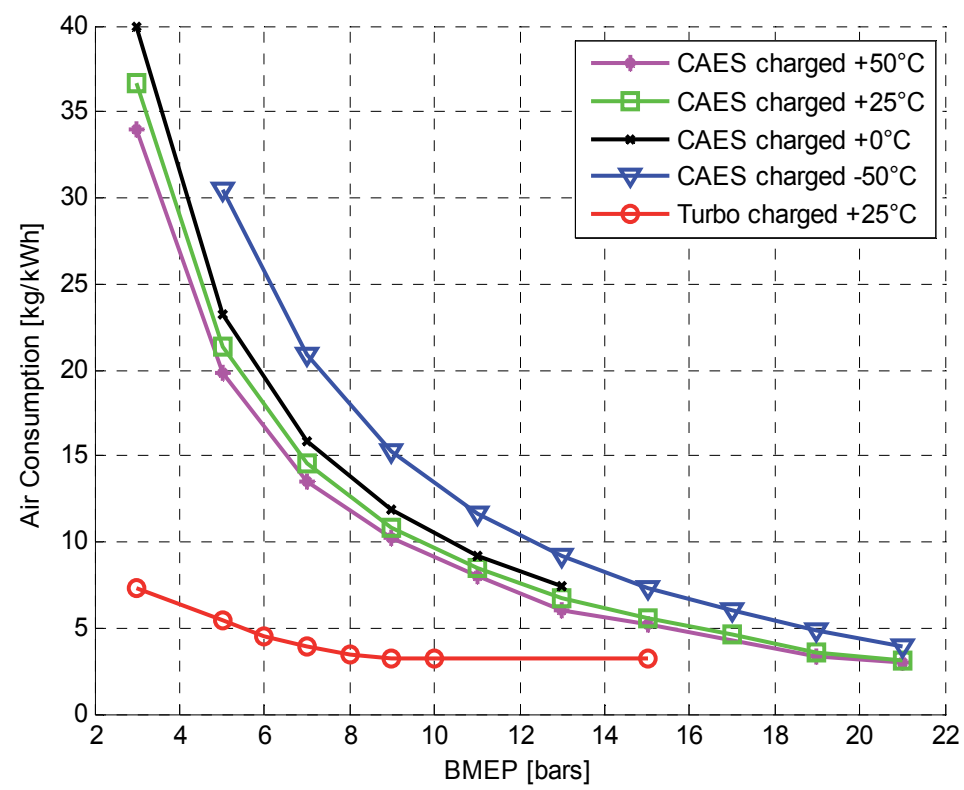

Fig. 27. Air specific consumption for different charging modes, function of engine load 


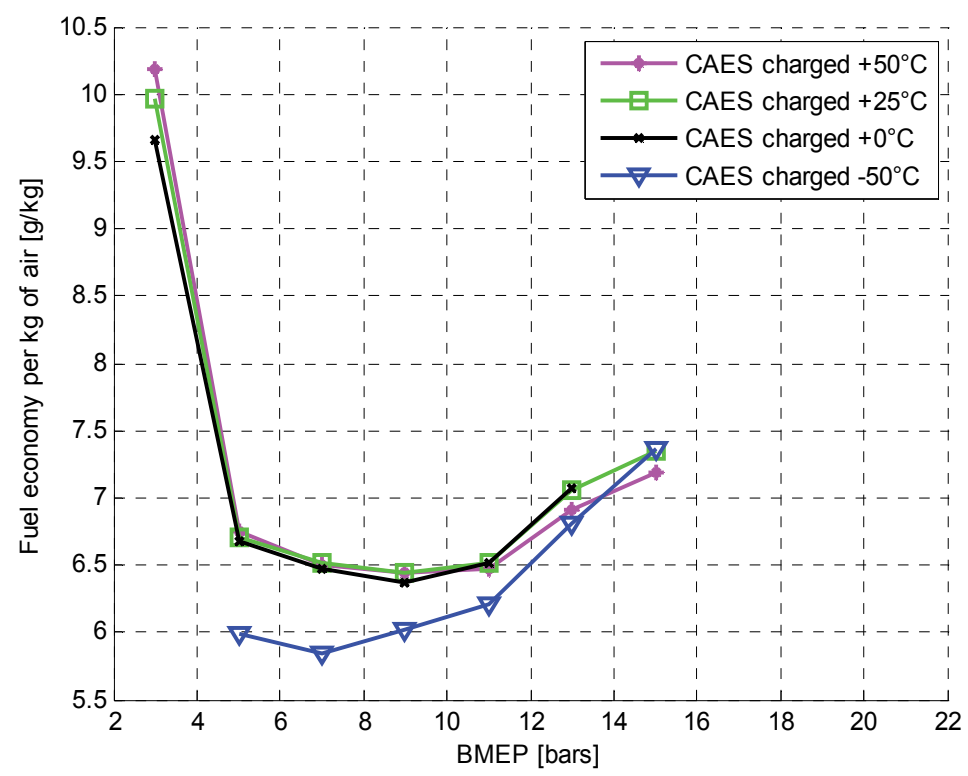

Fig. 28. Fuel economy per kilogram of air consumed, for different CAES charging modes, function of engine load

\section{General conclusion and auto-critique}

This document is a milestone study to demonstrate the interest around the WDCAS in portraying its potential to reduce fuel consumption and increase the efficiency of the diesel engine. We demonstrated that we can expect savings which can reach $50 \%$. However, physical limits can jeopardise the achievement to this level of economy. Among these limits, we quote mainly those due to the permeability limit of the intake valves if a sound blocking takes place. Most, if the supercharging pressure is important Furthermore, some models used, were the object of validation in previous publications. In the case of our present study, we extrapolate the use of these models in zones beyond those in which they were validated. Among these models, the most important one being the engine performance (efficiency) according to the Air-to-Fuel ratio and which proposes appropriate sizing and representation of the gain in consumption that we forecasted. It is therefore necessary to either verify their validation in these conditions, or substitute more physical models (example: simulation of the thermodynamic cycle instead of using a polynomial model). 
However, it has been demonstrated that when the intake pressure increases of 1 bar, maximal cylinder gas pressure increases about 40 bars. Considering that this maximal cylinder gas pressure needs to stay below a certain threshold for reliability reasons, the intake pressure is limited to 4 bars for the low loads and 3 bars for the high loads, as shown in Figure 14. This is a very big problem because that means that we have two options:

- The storage pressure is around four bars, witch means the volume needed to have significant fuel economy would be very high

- $\quad$ The storage pressure is high enough to have acceptable volume, but the air is expanded before the intake.

- If the expansion happens through an orifice, a very high temperature drop occurs; the gas looses its entropy, and the global efficiency (energy discharged/energy stored) would be very low.

- If the expansion happens through an air motor or air turbine, then it would be more efficient to expand the air until atmospheric pressure without any pneumatic Hybridization of the Diesel engine.

Other concepts of pneumatic hybrid Diesel engine are being studied to solve this problem.

\section{Nomenclature}

$\begin{array}{ll}p & \text { Pressure } \\ T & \text { Temperature } \\ u & \text { Internal energy } \\ h & \text { Enthalpy } \\ \theta & \text { Crank angle } \\ V & \text { Volume } \\ Q & \text { Flow } \\ q & \text { Heat } \\ P & \text { Power } \\ \eta & \text { Efficiency } \\ N & \text { Rotational speed } \\ x & \text { Faction } \\ m & \text { Mass } \\ A & \text { Area }\end{array}$

\section{References}

[1] Liu W, Gu S, Qiu D. Techno-economic assessment for off-grid hybrid generation systems and the application prospects in China.

http://www.worldenergy.org/wecgeis/publications/.

[2] Weis TM, Ilinca A. The utility of energy storage to improve the economics of windeDiesel power plants in Canada. Renewable Energy 2008;33(7):1544e57. 
[3] La stratégie énergétique du Québec 2006e2015. L'énergie pour construire le Québec de demain. http://www.mrnf.gouv.qc.ca/energie/eolien.

[4] Hunter R, Elliot G. WindeDiesel systems e a guide to the technology and its implementation. Cambridge (UK): Cambridge University Press; 1994.

[5] Forcione A. Système jumelé éolien-Diesel aux Îles-de-la-Madeleine (Cap-aux-Meules) e Établissement de la VAN optimale. Institut de Recherche, Hydro-Québec, Février; 2004.

[6] HOMER v2.0 e the optimisation model for distributed power. NREL. www.nrel.org.

[7] Ibrahim H, Ilinca A, Perron J. Solutions actuelles pour une meilleure gestion et intégration de la ressource éolienne. CSME/SCGM Forum 2008 at Ottawa. The Canadian Society for Mechanical Engineering, 5e8 June 2008.

[8] ACÉÉ. Association canadienne de l'énergie éolienne. http:/ / www.canwea.com.

[9] Maisson JF. Wind power development in sub-arctic conditions with severe rime icing. In: Presented at the circumpolar climate change summit and exposition, Whitehorse, Yukon; 2001.

[10] www.nunavutpower.com.

[11] Reeves B. Kotzebue electric association wind projects. In: Proceedingsof NREL/AWEA 2002 windeDiesel workshop, Anchorage, Alaska, USA, 2002.

[12] Singh V. Blending wind and solar into the Diesel generator market. Renewable Energy Policy Project (REPP) research report, Winter 2001, No. 12, Washington, C.

[13] Reid R. Application de l'éolien en réseaux non reliés. Liaison ÉnergieFrancophonie,N_35/2e Trimestre; 1997.

[14] Jean Y, Nouaili A, Viarouge P, Saulnier B, Reid R. Développement d'un système JEDHPSS représentatif d'un village typique des réseaux non relies. Rapport IREQ94-169-C; 1994.

[15] Gagnon R, Nouaili A, Jean Y, Viarouge P. Mise à jour des outils de modélisation et de simulation du Jumelage Éolien-Diesel à Haute Pénétration Sans Stockage et rédaction du devis de fabrication de la charge de lissage. Rapport IREQ-97- 124-C; 1997.

[16] www.danvest.com.

[17] Ilinca A, Chaumel JL. Implantation d'une centrale éolienne comme source d'énergie d'appoint pour des stations de télécommunications. Colloque international sur l'énergie éolienne et les sites isolées, Îles de la Madeleine; 2005.

[18] Ibrahim H, Ilinca A, Perron J. Energy storage systems e characteristics and comparisons. Renewable \& Sustainable Energy Reviews 2008;12(5):1221-50.

[19] Ibrahim H, Ilinca A, Perron J. Comparison and analysis of different energy storage techniques based on their performance index. IEEE Canada, Electrical Power Conference 2007, "Renewable and alternative energy resources", EPC2007, Montreal, Canada, October 25-26, 2007.

[20] Belhamed M, Moussa S, Kaabeche A. Production d'électricité au moyen d'un système hybride éolien-photovoltaïque-Diesel. Revue Énergies Renouvelables: Zones Arides; 2002:49-54. 
[21] Kaldellis JK, Vlachos GTh, Kavadias KA. Optimum sizing basic-principles of a combined photovoltaic windeDiesel hybrid system for isolated consumers. In: Proceedings of EuroSun 2002 international conference, Paper W141, Bologna, Italy, 2002.

[22] Bowen AJ, Cowie M, Zakay N. The performance of a remote wind-Diesel power system. Renewable Energy 2001;22(4):429-45.

[23] Ibrahim H, Younès R, Ilinca A. Optimal conception of a hybrid generator of electricity. CANCAM02007 ETS-39, Toronto, Canada. p. 358-9.

[24] Ibrahim $H$, Younès R, Ilinca A, Perron J. Investigation des générateurs hybrides d'électricité de type éolien-air comprimé. Colloque international des energies renouvelables E5, 04e05 mai 2007, Oujda MAROC.

[25] Robb D. Making a CAES for wind energy storage. North American Wind Power, June 2005.

[26] Ibrahim H, Ilinca A, Perron J. Moteur Diesel suralimenté, bases et calculs, cycles réel, théorique et thermodynamique. Rapport interne, UQAR-UQAC, LREE-02; Novembre 2006.

[27] Ibrahim H, Ilinca A, Younès R, Perron J, Basbous T. Study of a hybrid wind-Diesel system with compressed air energy storage. IEEE Canada, electrical power conference 2007, "Renewable and alternative energy resources", EPC2007, Montreal, Canada, October 25e26, 2007.

[28] Ibrahim H, Younès R, Ilinca A, Dimitrova M, Perron J. Study and design of a hybrid wind-Diesel-compressed air energy storage system for remote areas; Applied Energy 2010;87(5):1749e62.

[29] Basbous T. Étude de faisabilité d'un jumelage éolien-Diesel avec stockage ; d'énergie sous forme d'air comprimé. Mémoire de Maîtrise en ingénierie,Université du Québec à Rimouski, Août 2008.

[30] Garrett engine boosting systems. http:/ /www.egarrett.com/.;

[31] Lallemand A. Modélisation d'un groupe turbocompresseur de suralimentation; de moteur alternatif. Entropie 1983;111

[32] Parois A. Suralimentation par turbocompresseur. Techniques de l'ingénieur. Fascicule 1990;2631.

[33] Gissinger G, Le Fort-Piat N. Contrôle-Commande de la voiture. Hermes \&Lavoisier; 2002.

[34] Dovifaaz X. Modélisation et commande d'un moteur Diesel en vue de la réduction de ses émissions. Thèse de doctorat, École Centrale de Lyon, France; 2001.

[35] Younes R, Ouladsine M, Noura H. Optimisation du débit d'air dans le Diesel suralimenté. Bordeaux, France: Congrès International Francophone d'Automatique,CIFA; 2006.

[36] Jensen JP, Kristensen AF, Sorenson SC, Hendricks E. Mean value modelling of a small turbocharged Diesel engine. SAE Technical paper, n_910070; 1991.

[37] Younes R. Élaboration d'un modèle de connaissance du moteur Diesel avec turbocompresseur à géométrie variable en vue de l'optimisation de ses émissions. Thèse de doctorat, École Centrale de Lyon, France; 1993. 
[38] Kao M, Moskwa JJ. Turbocharged Diesel engine modeling for nonlinear engine control and state estimation. Journal of Dynamic Systems, Measurement, and Control 1995;117(1):20-30.

[39] Hendricks E. Continuous identification of a four stroke SI engine. In: Proc. Of the American control conference; 1990. p. 1876-81.

[40] Setoklosa H, Ferenc M, Osaba J, Osuch W. Evaluation of the dynamic response of a medium speed Diesel engine in generator set applied as stand-by power source for nuclear plants. In: CIMAC 87 in Warschau, 17th international congress on combustion engines; 1987.

[41] Hendrickes E. Mean value modeling of a small turbocharged Diesel engines. SAE paper n_910070; 1991.

[42] Younes R. Modélisation du turbocompresseur de suralimentation en régime stationnaire et instationnaire. DEA, École Centrale de Lyon, Ecully, France; 18 septembre 1989.

[43] Duyme V. Récupération énergétique à l'échappement d'un moteur de véhicule industriel par une turbine à gaz entraînant les auxiliaires, Simulation $d u$ fonctionnement et optimisation du système. Thèse de doctorat, INSA, Villeurbanne, France; 19 Février 1990.

[44] Ledger JD, Walmsley S. Computation and simulation of a turbocharged Diesel engine operation under transient load conditions. SAE paper $n \_71077 ; 1977$.

[45] Heywood JB. Internal combustion engine fundamentals. 2nd ed. New York:McGrawHill; 1988. 950p.

[46] Millington BW, Hartles ER. Frictional losses in Diesel engine. SAE Transactions 1968;680590:2390e410.

[47] Winterbone DE, Tennant DWH. The variation of friction and combustion rates during Diesel engine transients. SAE paper; 1981, n_810339, 4p.

[48] Furuhama S, Sasaki S. New device for measurement of piston frictional forces in small engines. SAE Transactions 1983;831284:39-50.

[49] Yokooku K, Nagoa A, Oda H. Development of Mazda fuel-efficient concept car.SAE Transactions ;841309:295-307.

[50] Guichaoua JL, Magnien JF, Perrin H, Constants B. Frottement et temperature du film d'huile entre piston, segments et chemise d'un moteur Diesel. Journées internationales sur le moteur Diesel d'application. SIA École Centrale de Lyon, 13e14 mai 1984. p. 131-53.

[51] Gish RE, Mc-Cullough JD, Retzloff JB, Mueller H. Determination of engine friction. SAE Transactions 1958;66(9):649e-67.

[52] Omran R, Younes, Champoussin JC. Optimal control of Diesel engines: applications and methods. In: 3rd international conference on advances in vehicle control and safety, Argentina, 2007.

[53] Omran R, Younes, Champoussin JC. Optimization, genetic algorithm for dynamic calibration of engine's actuators. SAE paper, n_2007-01-1079.

[54] JANAF Thermochemical Tables, third edition, (1985)

[55] Woschni, G., 1967, A universally applicable equation for the instantaneous heat transfer coefficient in the internal combustion engine, SAE, 670931. 
[56] Stone, R., 1999, Introduction to internal combustion engines, Department of Engineering Science, University of Oxford

[57] Heywood, J.B., 1988, Internal Combustion Engine Fundamentals, New York, McGraw Hill. 



\section{Edited by Arzu Sencan Sahin}

This book includes solar energy, wind energy, hybrid systems, biofuels, energy management and efficiency, optimization of renewable energy systems and much more.

Subsequently, the book presents the physical and technical principles of promising ways of utilizing renewable energies. The authors provide the important data and parameter sets for the major possibilities of renewable energies utilization which allow an economic and environmental assessment. Such an assessment enables us to judge the chances and limits of the multiple options utilizing renewable energy sources. It will provide useful insights in the modeling and optimization of different renewable systems. The primary target audience for the book includes students, researchers, and people working on renewable energy systems.

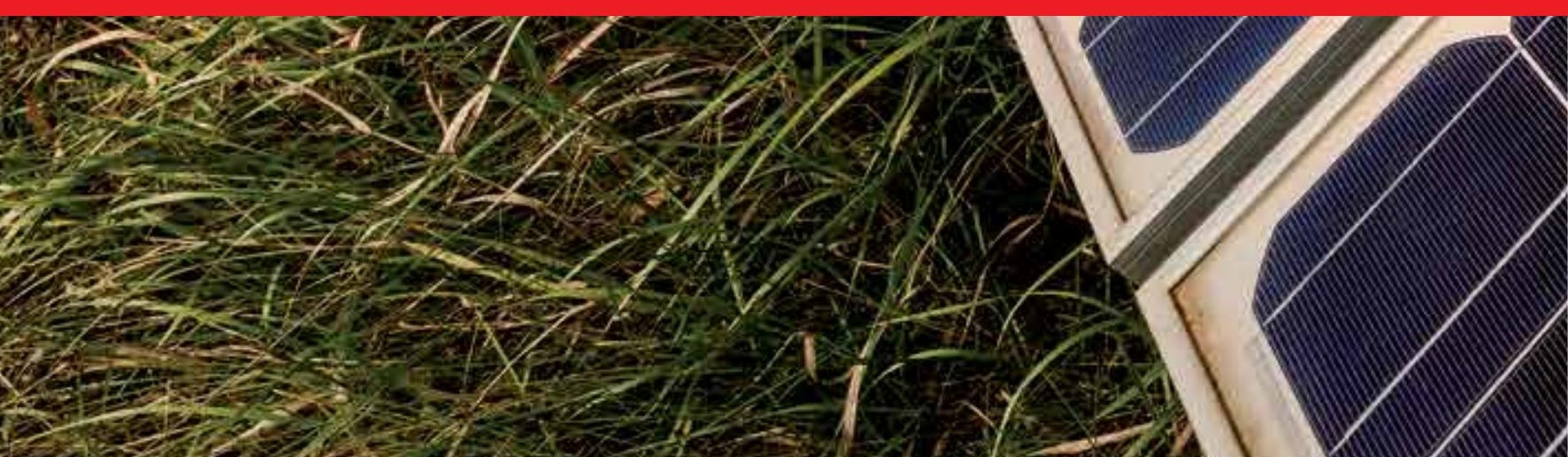

